INSTITUTO DE PESQUISAS ENERGÉTICAS E NUCLEARES

Autarquia associada à Universidade de São Paulo

\title{
ESTRUTURA DE SERVIÇOS DO CONHECIMENTO EM PARQUES CIENTÍFICOS E TECNOLÓGICOS - INCREMENTANDO A RELAÇÃO EMPRESA - UNIVERSIDADE - CENTROS DE PESQUISA
}

\author{
ADRIANA BRAZ VENDRAMINI BICCA MAGALHÃES
}

Tese apresentada como parte dos requisitos para obtenção do Grau de Doutor em Ciências na Área de Tecnologia Nuclear - Aplicações.

Orientadora:

Dra. Désirée Moraes Zouain

São Paulo 
Às minhas queridas, avó Helena (in memoriam), mamãe ; e filhas Ariadne e Adèle. 


\section{Agradecimentos}

Agradeço à Professora Désirée Moraes Zouain pelo sempre presente estímulo, inabalável confiança e constante apoio e orientação.

Agradeço ao IPEN o apoio que sempre recebi para desenvolver este trabalho.

Agradeço aos Professores Roberto Rogero, Guilherme Ary Plonsky e José Octávio Armani Paschoal pela atenção e colaboração nos momentos em que foi necessário.

Agradeço à Dra. Conceição Vedovello, experiente profissional do tema, que com suas colaborações prestimosas, agregaram enorme valor ao processo de desenvolvimento deste trabalho.

Agradeço aos meus colegas do IPEN, Rodolfo, Willy, Adriano, Iraídes, Kátia, Roberto e Rolim, que acompanharam e apoiaram no tempo, o desenvolvimento desta pesquisa.

Por fim, agradeço à minha família e amigos(as), em especial a minha amiga Rosangily Correia, que me apoiaram e carinhosamente compreenderam os movimentos de altos e baixos, que envolveram meu espírito, do início ao fim dessa jornada. 


\section{ESTRUTURA DE SERVIÇOS DO CONHECIMENTO EM PARQUES CIENTÍFICOS E TECNOLÓGICOS - INCREMENTANDO A RELAÇÃO EMPRESA - UNIVERSIDADE - CENTROS DE PESQUISA}

\section{Adriana Braz Vendramini Bicca Magalhães}

\section{RESUMO}

Esta pesquisa propõe um modelo de Estrutura de Serviços do Conhecimento aplicável aos Parques Científicos e Tecnológicos e direcionados às micro, pequenas e médias empresas, de maneira a otimizar a relação empresa universidade - centros de pesquisa. A idéia surgiu a partir de leituras e estudos relativos aos parques científicos e tecnológicos e à observação de uma lacuna do conhecimento: não estavam disponíveis trabalhos acadêmicos que modelassem estruturas de serviços de apoio à relação empresa - universidade - centros de pesquisa em Parques Científicos e Tecnológicos. A metodologia utilizada na pesquisa foi: estudos exploratórios complementados por pesquisa ação. Foram determinadas cinco dimensões de análise (serviços do conhecimento, desenvolvimento de negócios, serviços comuns, expansão de área, e imagem/visibilidade); com base nas dimensões definidas foi elaborado o instrumento de pesquisa e aplicado na forma de e-survey; o questionário foi respondido por gestores de Parques Científicos e Tecnológicos de diversos países (Espanha, Itália, Portugal, Alemanha, Reino Unido, China, Brasil, Turquia e Uruguai). Alguns dos parques estudados, europeus, foram visitados (o que complementou a última fase da pesquisa-ação). Após apresentação, análise e discussão dos resultados, foi formulado o modelo conceitual de estrutura de serviços do conhecimento para Parques Científicos e Tecnológicos. Durante a etapa de formulação do modelo, uma breve discussão sobre a importância do conhecimento e do atendimento das necessidades do cliente, implicou na inclusão de uma interface-cliente no modelo final. 


\title{
KNOWLEDGE SERVICES IN SCIENCE \& TECHNOLOGY - IMPROVING THE UNIVERSITYIRESEARCH CENTRE-COMPANY RELATIONSHIP
}

\author{
Adriana Braz Vendramini Bicca Magalhães
}

\begin{abstract}
This research proposes a conceptual model for Knowledge Services Structure applicable to Science \& Technology Parks (STP) and targeted to micro, small and medium enterprises, in order to improve the business - university - research centers relationship. The idea emerged from exploratory studies on STP and the observation of a knowledge gap on this subject: academic studies that have proposed support services structures to link companies - university - research centers in STP were not available. The study methodology is composed by: exploratory studies complemented by action research. Five aspects of analysis (knowledge services, business development, ordinary/ S\&T infrastructure services, expansion of area, and image / visibility) were chosen; a questionnaire based on the these aspects were elaborated and applied by e-mail (e-survey), using as data-base the IASP associated members for the selection of potential respondents. The questionnaire was answered by STP managers from different countries (Spain, Italy, Portugal, Germany, United Kingdom, China, Brazil, Turkey and Uruguay) and, for a deeper and better answers understanding, presential interviews were conducted in certain European STP. After presentation, analysis and discussion of the results, a conceptual model of knowledge service structure for STP has been made, using as basis the Technology Park of Sao Paulo structure. During the formulation of the conceptual model stage, a brief discussion on the importance of knowing and meet the customer needs meant on the inclusion of a customer-interface in the final model.
\end{abstract}




\section{SUMÁRIO}

1. INTRODUÇÃO 1

2. OBJETIVOS E CONTRIBUIÇÕES ORIGINAIS 5

3 REVISÃO DA LITERATURA E FUNDAMENTAÇÃO TEÓRICA 7

3.1 Intensificação da Globalização e valorização do Conhecimento 7

3.2 Parques Científicos e Tecnológicos $\quad 14$

3.3 Evolução dos modelos de parques científicos e tecnológicos - 17 perspectivas

4. METODOLOGIA DA PESQUISA 31

4.1 Método da pesquisa 31

$4.2 \mathrm{O}$ Instrumento de pesquisa 33

5. RESULTADOS

5.1 Consolidação dos resultados da pesquisa 38

5.1.1 Respostas das questões fechadas 38

5.1.1.1 Questões de abertura 38

5.1.2 Respostas das questões abertas $\quad 46$

5.1.3 Caracterização dos respondentes $\quad 70$

5.1.4 Observações pessoais 138

6. ANÁLISE E DISCUSSÃO DOS RESULTADOS 148

6.1 Análise e discussão dos resultados das questões fechadas e 149 abertas

6.2 Análise e discussão dos resultados das observações in loco 162

6.3 Identificação e análise das práticas de sucesso 164

6.4 A identificação dos fatores críticos de sucesso relacionados aos 173 serviços do conhecimento

7. FORMULAÇÃO DO MODELO CONCEITUAL 188

7.1 Detalhamento dos grupos de serviços e dos serviços propostos no 195 modelo

8. DISCUSSÃO E LIMITAÇÕES DO MODELO CONCEITUAL 201

8.1 IASP General Survey 2006/2007 versus Magalhães e-survey 201

8.2 Questionamento do modelo desenvolvido na opinião de Vedovello 206

9. CONCLUSÕES E RECOMENDAÇÕES 210

APÊNDICE A - O instrumento de pesquisa $\quad 217$ 
APÊNDICE B - Siglário

REFERÊNCIAS BIBLIOGRÁFICAS 


\section{INTRODUÇÃO}

A intensificação do processo de globalização da economia ocorrida nas últimas décadas é discutida no meio acadêmico desde os anos 80 , sendo que um dos aspectos mais enfocados nos estudos desse processo se refere às suas características e conseqüências nas dinâmicas dos atores sociais. As principais características apontadas são o movimento de liberalização e desregulação dos mercados e o advento das tecnologias da informação e comunicação. As conseqüências mais significativas são o estabelecimento de uma nova dinâmica tecnológica e econômica onde o conhecimento se torna o ativo principal da competitividade empresarial, paralelo ao surgimento de novas formas de organização e interação entre as empresas, agentes públicos e centros produtores de conhecimento e formação de pessoas, e rápidas mudanças nas estruturas de pesquisa, produção e comercialização.

Uma das formas de organização e cooperação entre empresas são os chamados 'habitats de inovação', que se pode definir como ambientes favoráveis ao desenvolvimento contínuo de inovações, como é o caso dos Parques Científicos e Tecnológicos (PCT) cujo movimento foi iniciado nas décadas de 1960 e 1970 e tem suas origens na Universidade de Stanford (Califórnia Estados Unidos) com a experiência conhecida como o "Vale do Silício". Esta experiência influenciou uma série de modelos mundiais de criação de espaços privilegiados e estimulantes ao desenvolvimento da relação entre universidades, centros de pesquisa e empresas privadas, com o objetivo de desenvolver negócios inovadores, evitar a evasão de cérebros, apoiar o desenvolvimento regional, entre outras ações de caráter econômico e imobiliário (ZOUAIN e PLONSKY, 2006).

\footnotetext{
1 "Habitats de inovação são ambientes propícios ao desenvolvimento contínuo de inovações tecnológicas. Os habitats constituem espaços de aprendizagem coletiva, intercâmbio de conhecimentos e práticas produtivas, de interação entre os diversos agentes de inovação: empresas, instituições de pesquisa, agentes governamentais, incubadoras de empresas, parques tecnológicos,...", Grupo de Estudos em Habitats de Inovação - GEHI, sítio do CNPq, endereço eletrônico $\quad$ http://dgp.cnpq.br/buscaoperacional/detalhegrupo.jsp?grupo=0067602QJTOALV Acesso 10/2/2009.
} 
Ainda, considerada a necessidade de se utilizar mais as chamadas infraestruturas científico-tecnológicas, enquanto elementos fomentadores do desenvolvimento econômico, sobretudo frente à crescente busca pela competitividade das organizações, esse movimento vem se expandindo no mundo, observando-se uma aceleração na década de 1990, sobretudo nas chamadas economias em desenvolvimento ou emergentes (ZOUAIN - 2003).

As definições mais comuns de Parque Científico e Tecnológico são as apresentadas por três associações internacionais de parques científicos, a International Association of Science Parks (IASP), a Association of University Research Parks (AURP) e a United Kingdom Science Park Association (UKSPA); e em nível nacional pela Associação Nacional de Entidades Promotoras de Empreendimentos de Tecnologias Avançadas (ANPROTEC). A IASP é a mais importante Associação que agrega parques tecnológicos e outros modelos de ambientes de inovação no mundo, contando, atualmente, com 356 membros, mais de 200.000 empresas inseridas no contexto dos seus associados, estando estes em 71 países (IASP, 2008) ${ }^{2}$.

A definição de PCT pode mudar ao longo do tempo. Como KIRK e CATTS (2004) afirmam, os modelos de PCT continuam a evoluir e se modificar como entidades físicas e organizacionais e como "forja" do desenvolvimento econômico de base tecnológica e elo para formação de negócios e programas de apoio empresariais. É conhecido que o papel, ou as funções dos PCT apresentam um desafio, porque não há dois similares; suas metas e seus objetivos variam de acordo com os parceiros envolvidos, com a balança de poder e influência entre eles e o ambiente econômico local ${ }^{3}$.

Assim, atualmente, os modelos de PCT representam uma complexa articulação de vários fatores que agregam valor e que buscam incrementar sua capacidade de agir como um instrumento único de apoio ao desenvolvimento sócio-econômico sustentável. Nestes modelos, os principais fatores são: a governança e a gestão, a criação de conhecimento (os laços com universidades, institutos de pesquisa públicos e privados - laços formais e informais), o valor

\footnotetext{
${ }^{2}$ IASP at a glance, disponível no sítio da IASP, endereço eletrônico www.iasp.ws. Acesso em $17 / 7 / 2008$.

${ }^{3}$ Science and Technology Park Scoping Study, Kirk e Catts, 2004; disponível no endereço eletrônico http://www.nzte.govt.nz/common/files/ science-tech-scoping.pdf. Acesso em 01/7/2008.
} 
agregado dos serviços, espaços de qualidade oferecidos pelo PCT (ambiente adequado para a atração de empresas), a criação de empresas (start-ups, spinoffs, de universidades ou de inventores independentes, ou de outras empresas, bem como seus resultados de P\&D), a influência territorial (no desenvolvimento regional de políticas públicas), e a atuação em rede (networking).

Cada PCT define os seus objetivos e o caminho para alcançá-los, levando em consideração as partes interessadas, as autoridades locais, a economia local e regional, a sustentabilidade e o ambiente, o equilíbrio de poder, entre outros aspectos. No entanto, há uma meta que parece comum a todos os PCT: atrair e manter agrupadas (movimentos de cluster $^{4}$ ) novas e inovadoras empresas e reforçar a base econômica local e regional. Parte da execução dessa tarefa pelos Parques Científicos e Tecnológicos, é realizada por meio do fornecimento de serviços do conhecimento às micro, pequenas e médias empresas de base tecnológica instaladas no parque, ao mesmo tempo em que fortalece a relação entre as empresas, universidades e centros de pesquisa.

O objetivo deste trabalho é propor uma estrutura de serviços do conhecimento para ser utilizada pelos Parques Científicos e Tecnológicos em benefício das micro, pequenas e médias empresas de base tecnológica instaladas, fortalecendo a relação entre as empresas, as universidades e os centros de pesquisa.

O texto é apresentado em nove capítulos, a saber:

1 - Introdução

2 - Objetivos e contribuições originais

3 - Revisão da literatura e fundamentação teórica

4 - Metodologia da pesquisa

5 - Resultados

\footnotetext{
${ }^{4}$ Um cluster é um grupo de empresas e instituições associadas, geograficamente próximas; e interconectadas por afinidades e complementaridades. Definição baseada em Porter (1998) e Gerolamo et alli (2008).
} 
6 - Análise e discussão dos resultados

7 - Formulação do modelo conceitual

8 - Discussão e limitações do modelo conceitual

9 - Conclusões e recomendações 


\section{OBJETIVO E CONTRIBUIÇÕES ORIGINAIS}

\section{Objetivo da Pesquisa}

Identificar e compreender os fatores críticos de sucesso $^{1}$ em iniciativas nacionais e internacionais caracterizadas como parques científicos e tecnológicos no que tange as suas estruturas de serviços do conhecimento em apoio às micro, pequenas e médias empresas de base tecnológica, visando otimizar a relação empresa - universidade - centros de pesquisa, no contexto desses ambientes de inovação.

\section{Contribuições Originais}

A originalidade do trabalho pode ser caracterizada pelo preenchimento da lacuna do conhecimento, visto que não estão disponíveis trabalhos acadêmicos que modelem estruturas de serviços de apoio à relação empresa-universidade-centros de pesquisa em Parques Tecnológicos.

\section{A questão da pesquisa é a seguinte:}

Como devem ser estruturados os serviços de apoio a empresas de base tecnológica que possam otimizar a relação universidade - centros de pesquisa empresas, em 'habitats de inovação', particularmente em parques tecnológicos ?

\footnotetext{
${ }^{1}$ Para tanto adotamos a seguinte definição de fatores críticos de sucesso (FCS): "são, para qualquer negócio, o número limitado de áreas nas quais os resultados, se forem satisfatórios, irão assegurar um desempenho competitivo de sucesso para a organização. Eles são as poucas áreas chave em que 'as coisas tem que andar bem para o negócio prosperar. Se os resultados nessas áreas não forem adequados, os esforços da organização para o período ficarão abaixo do desejado" (MILANI,1998 apud ROCKART, 1979). Os FCS não devem ser confundidos com os objetivos ou com as estratégias da organização. Os objetivos definem o que a organização deseja alcançar e as estratégias definem como alcançar os objetivos. Os FCS são os meios que garantem a realização dos objetivos (MILANI, 1998 apud ROCKART, CRESCENZI, 1984). Informação disponível no endereço eletrônico http://ms161u13.u-3mrs.fr/memoires/AngeloMilani.pdf Acesso em 15/2/2009.
} 


\section{REVISÃO DA LITERATURA E FUNDAMENTAÇÃO TEÓRICA}

Os aspectos relacionados à revisão da literatura e à fundamentação teórica são apresentados neste capítulo, em três tópicos relacionados aos pressupostos desta pesquisa; a saber:

3.1 Intensificação da Globalização e valorização do Conhecimento

3.2 Parques Científicos e Tecnológicos

3.3 Evolução dos modelos de parques científicos e tecnológicos - perspectivas

\subsection{Intensificação da Globalização e valorização do Conhecimento}

A intensificação do processo de globalização da economia ocorrido nas últimas décadas é discutida no meio acadêmico desde os anos 80. ZOUAIN (2003), ao discorrer sobre os aspectos do processo de globalização, aponta alguns elementos de consenso no que se refere às características desse movimento e de suas conseqüências nas dinâmicas dos atores sociais.

Segundo a autora, as principais características desse processo são o movimento de liberalização e desregulação dos mercados e o advento das tecnologias de informação e comunicação (TIC). Quanto à suas conseqüências marcantes, se pode citar o estabelecimento de uma nova dinâmica tecnológica e econômica, em nível internacional, onde o conhecimento torna-se um ativo primordial para o incremento da competitividade, ao mesmo tempo em que emergem novas formas de organização e interação entre as empresas e rápidas mudanças nas estruturas de pesquisa, produção e comercialização.

De fato, CASSIOLATO\&LASTRES (1999) consideram que as questões de liberalização de mercados e as TIC evidenciam uma mudança de paradigma; este cenário de ruptura quanto à extensão dos contatos e de trocas de informações possíveis entre os atores, individuais e coletivos, enfatiza a correlação da competitividade das empresas e nações à sua capacidade inovativa.

Um texto conjunto do SEBRAE-ABIPTI-CNPq (2003) corrobora essas colocações, dizendo que, nesse contexto, as indústrias tecnologicamente 
maduras foram rejuvenescidas, ao mesmo tempo em que emergiram outras novas (TIC) e que se tornaram a base do rápido desenvolvimento tecnológico da produção e do comércio internacionais; a intensificação da competição entre empresas e países, sobretudo a partir dos anos 90, evidencia a importância da inovação para a competitividade; ou melhor, a capacidade de rapidamente gerar, introduzir e difundir inovações passa a ser vista como instrumento central da estratégia competitiva.

Sendo assim, a intensificação do processo da globalização, ou do mercado global, adiciona no contexto da competitividade das empresas, uma maior procura por produtos e serviços de alta qualidade e intensivos em conhecimento e inovação (ZOUAIN, 2003).

O conhecimento configura-se como elemento básico para a competitividade, ao que se somam as novas formas de organização e interação entre organizações de diversos tipos, facilitando mudanças mais rápidas nas estruturas de pesquisa, produção e comercialização das empresas. (CASSIOLATO\&LASTRES, 1999 e ZOUAIN, 2003). Cita-se, com relação a este tema, CRUZ (2001): "Mais do que nunca, hoje, o conhecimento tornou-se a verdadeira riqueza das nações: aquelas que forem capazes de gerá-lo e aplicá-lo com mais desenvoltura serão as que terão oportunidade de desenvolver-se econômica e socialmente".

Nesse contexto em que o 'recurso' conhecimento cresce em importância quando comparado com outros recursos econômicos tradicionais, tais como capital financeiro, mão de obra de baixo custo e localização geográfica, a gestão da inovação e do conhecimento se tornam uma necessidade para as organizações que pretendem ser ou manter-se competitivas (TERRA, 2000; e PORTER, 1898).

SPENDER\&MARR $\left(2005^{1}\right)$ afirmam que o conhecimento se tornou o principal elemento estratégico de uma empresa e que a economia é hoje muito mais intensiva em conhecimento do que já foi; tais fatos trazem implicações tanto no modo como produtos e serviços são produzidos quanto à maneira como são vendidos; a natureza da vantagem competitiva em mercados globalizados e

\footnotetext{
${ }^{1}$ Tradução livre do artigo "The epistemology of knowledge and the knowkedge process cycle: beyound the "objectivist" vs "interpretivist" de Roy WILIAMS, citando SPENDER\&MARR (2005), publicado no JOURNAL OF KNOWLEDGE MANAGEMENT, Vol. 12, no. 4, 2008, pp. 72-85, Q Emerald Group Publishing Limited.
} 
saturados, nos quais a diferenciação e a inovação se tornam críticas, e nos quais as ferramentas de gestão focadas no custo não provem aos gestores a adequada informação.

Sendo assim, se pode dizer que a intensificação do processo de globalização teve como conseqüência a impressão de uma nova dinâmica tecnológica e econômica internacional, onde o conhecimento é o ativo primordial de competição; e onde emergem novas formas de organização e interação entre as empresas e rápidas mudanças nas estruturas de pesquisa, produção e comercialização.

Assim, surgem novas demandas e desafios para promoção, geração e difusão do conhecimento como base para a competitividade empresarial e o crescimento econômico, uma "maior demanda por produtos e serviços de alta qualidade e intensivos em conhecimento e inovação" (ZOUAIN, 2003).

Para ZOUAIN (2003), é necessária a discussão do papel das empresas, das nações e das regiões no contexto da competitividade; e o desenvolvimento e o impacto da inovação (ou dos sistemas de inovação) no desenvolvimento desses atores.

A discussão desses papéis é evidenciada no livro de PORTER (1989) "A Vantagem Competitiva das Nações", onde é destacado o papel das Nações para a competitividade industrial e o desenvolvimento econômico; nele o autor estabelece uma teoria segundo a qual a "vantagem competitiva das Nações" é representada na figura de "diamante" em que estão contidos os atributos (determinantes) que compõem o ambiente competitivo das empresas/Nação, atuando de forma sistêmica.

Os atributos ou determinantes são: a Estratégia, estrutura e rivalidade das empresas, que representam as condições nacionais que determinam a forma pela qual as empresas são criadas, organizadas e dirigidas, mais a natureza da rivalidade interna; as Condições de fatores, que representam a posição do país nos fatores de produção necessários à competição em determinadas indústrias; as Condições de demanda, que se referem à natureza da demanda interna para os produtos ou serviços da indústria; e as Indústrias correlatas e de apoio, que se referem à presença ou ausência, no país, de indústrias abastecedoras e indústrias correlatas que sejam internacionalmente competitivas. 
PORTER (1989) afirma que os atributos, ou determinantes, atuam individualmente e como um sistema, criando um contexto no qual as empresas de um país surgem e competem. O autor complementa a dinâmica desse conceito apresentando as quatro etapas que impulsionam o desenvolvimento competitivo das economias das nações. As três primeiras etapas (Fatores, Investimento e Inovação) representam o avanço da economia, a quarta etapa (Riqueza) representa o declínio e a estagnação.

Baseada nesse modelo, ZOUAIN (2003) conclui que "na economia impulsionada pela inovação, é possível observar-se um maior número de grupos ou segmentos de empresas capazes de competir, tendo em vista uma conjunção de determinantes" que apresentam vantagens sobre o ponto de vista da prosperidade econômica. A autora ainda destaca a importância do "papel do governo e suas estratégias e ações na economia impulsionada pela inovação".

PORTER (1989), na construção de sua teoria da vantagem competitiva das nações, versando sobre as determinantes da vantagem nacional, ou elementos de sua figura metafórica de 'diamante', coloca que "em todos os níveis, o governo pode melhorar ou piorar a vantagem nacional"; e sugere que as políticas governamentais sejam precedidas do exame cuidadoso das influências passíveis no sistema de determinantes, pois elas (as políticas) podem tanto enfraquecer como fortalecer a vantagem competitiva nacional.

Quanto à aplicabilidade de sua teoria, o autor complementa: "embora meu estudo seja feito em termos de países, é importante explicar a concentração geográfica das indústrias dentro das nações. A política governamental em nível estadual e municipal tem papel importante na formação da vantagem nacional."

No entanto, no contexto da 'globalização de mercado', ZOUAIN (2003) contrapõe a visão de PORTER (1989) à visão de OHMAE (1996), que confere maior importância ao papel dos estados-regiões vis-a-vis os estados-nações.

OHMAE (1996) ressalta as oportunidades criadas pelos estadosregiões quando as mesmas são tratadas como portas de entrada para a economia global, podendo trazer benefícios para as nações e suas populações.

"Onde existe a prosperidade, sua base é regional. E quando uma região próspera, sua boa fortuna espalha-se pelos territórios adjacentes dentro e fora da federação política a que pertence. O progresso econômico dentro e ao 
redor de Bangcoc, por exemplo, levou os investidores a explorar opções em outros pontos da Tailândia. O mesmo poder-se ia dizer de São Paulo - se o governo central brasileiro aprender a tratá-la como um genuíno Estado-região e permitir que se integre a economia global. Caso o faça, ao menos uma região no Brasil poderia aderir à Organização de Cooperação e Desenvolvimento Econômico ( $\left.O C D E^{2}\right)$ "; essa ação poderia levar o Brasil a elevar-se à condição de país candidato a membro da OCDE, como o são hoje o Chile, a Estônia, Israel, a Rússia e a Eslovênia. Hoje o status do Brasil para a OCDE, em conjunto com a China, a Índia, a Indonésia e a África do Sul, é de país engajando-se à organização ${ }^{3}$. "Caso não o faça - devido a preocupações com o mínimo público ou ao medo de que o equilíbrio entre as regiões seja sacrificado - o país como um todo poderá até sair da lista das economias recém-industrializadas" (OHMAE, 1996).

ZOUAIN (2003) correlaciona as colocações de OHMAE (1996) e NAISBITT (1984), apontando para a formação de uniões regionais (alianças econômicas), para a economia baseada num mercado global, para a revolução das comunicações, para a disseminação dos sistemas democráticos, para a fragmentação das grandes empresas em confederações de pequenas empresas e empreendedores.

NAISBITT (1994) em seu livro "Paradoxo Global" diz que as mudanças que vem ocorrendo nas últimas décadas encerram paradoxos, sendo que o paradoxo mais representativo dessas transformações é o fato de que "quanto maior a economia mundial, mais poderosos são os seus protagonistas menores". Segundo o autor, quanto mais globalizada a economia mundial se tornar, mais componentes da sociedade se tornam universais, aqueles que permanecem 'tribais' ganham valor e poder. E complementa "quanto mais universais nos tornamos, mais tribalmente agimos. O que, no paradoxo global, também significa partes menores e em maior número".

\footnotetext{
${ }^{2}$ A OCDE é uma organização internacional e intergovernamental que agrupa os países mais industrializados da economia do mercado; os representantes dos países membros se reúnem para trocar informações e definir políticas com o objetivo de maximizar o crescimento econômico e o desenvolvimento dos países membros. Informação disponível no sítio da Controladoria Geral da União, endereço eletrônico http://www.cgu.gov.br/ocde/sobre/index.asp Acesso em 10/02/2009.

${ }^{3}$ Informações disponíveis no sítio da OCDE, endereço eletrônico http://www.oecd.org/countries list/0,3351, en 338731083384443011111 1,00.html Acesso em 10/02/2009.
} 
Para ZOUAIN (2003) "as tendências apontam para uma capacidade cada vez maior das empresas de pequeno e médio porte (atuando em redes e confederações) de competir no mercado, por serem mais inovadoras e ágeis do que as empresas" de maior porte. Na opinião da autora, "a cooperação, as alianças estratégicas, e a atuação em redes, facilitadas pela revolução nas telecomunicações e nos sistemas de informações, são as soluções encontradas pelas empresas que, ao invés de buscarem estratégias de crescimento, procuram redes de unidades de negócios de menor porte, que possam suplantar as dificuldades e barreiras burocráticas".

As colocações de autores corroboram e complementam esse conjunto de idéias. Num texto conjunto do SEBRAE-ABIPTI-CNPq (2003), a formação de redes de inovação é apresentada como característica dos anos 80 nos países avançados, tendo seu modelo influenciado a estratégia competitiva industrial.

PLONSKY (1999) destaca o papel da cooperação apresentando a como "eixo estruturante para a sustentabilidade contemporânea, como contraponto à competição"; destaca a cooperação como um dos elementos fundamentais da estratégia das organizações e do desenvolvimento institucional.

Se pode dizer que as 'redes de inovação' buscam oferecer respostas às novas demandas e desafios para promoção, geração e difusão do conhecimento como base para a competitividade empresarial e o crescimento econômico.

Dentre os mecanismos utilizados nas 'redes de inovação' estão os sistemas e formas de cooperação que visam o estabelecimento de relações profícuas e duradouras entre as universidades e instituições de pesquisa com o setor empresarial.

Uma das formas de cooperação são os 'habitats de inovação'. No glossário de termos da ANPROTEC-SEBRAE (2002), são apresentadas duas definições para o termo 'habitats de inovação':

(1) "Espaço relacional em que a aprendizagem coletiva ocorre mediante a transferência de know how, imitação de práticas gerenciais de sucesso comprovado e implementação de inovações tecnológicas no processo de produção. Nesse ambiente é intenso o intercâmbio entre os diversos agentes de inovação: empresas, instituições de pesquisa e agências governamentais"; e 
(2) "Ambiente que congrega fatores favoráveis ao processo de inovação contínua" Um exemplo de habitat de inovação são os Parques Científicos e Tecnológicos (PCT).

Atualmente, a importância dos 'protagonistas menores', micro, pequenas e médias empresas (PME), no contexto da economia global é visivelmente confirmada, para citar alguns exemplos: nos Estados Unidos da América (EUA) elas representam 99\% das empresas, empregando cerca de 65 milhões de pessoas e seus negócios equivalem entre $40 \%$ e $50 \%$ do PIB nacional e em vários setores elas são responsáveis pela condução da inovação e da competição $^{4}$; nos 25 Estados-Membros da União Européia (UE) existem cerca de 23 milhões de PME que representam 99\% do total de empresas da UE e empregam aproximadamente 75 milhões de pessoas ${ }^{5}$; na China 42 milhões de PME produzem $60 \%$ do PIB e $50 \%$ das receitas fiscais, criam $75 \%$ do total de novos postos de trabalho e são responsáveis por $65 \%$ das patentes ${ }^{6}$; e no Brasil as micro e pequenas empresas (PME) representam 98\% das empresas, 67\% das ocupações e $20 \%$ do PIB $^{7}$.

Sendo o conhecimento o combustível da inovação e esta última a chave da competitividade no contexto da economia global, é fato que o conhecimento é de fundamental importância para as micro, pequenas e médias empresas, que são hoje os 'atores' mais significativos da economia global e regional.

Em se tratando de PME de base tecnológica instaladas em Parques Científicos e Tecnológicos (PCT) a importância do conhecimento é ainda mais crítica para o seu desempenho; para começar, as PME que se instalam em PCT buscam esses ambientes em função da proximidade com as Universidades e/ou com os Centros de Pesquisa, a fim de obterem benefícios para o desenvolvimento do seu produto ou serviço inovador; da concepção e do desenvolvimento do

\footnotetext{
4 Tradução livre de informações disponíveis no sítio da Comunidade Européia, endereço eletrônico http://ec.europa.eu/enterprise/enterprise policy/sme definition/index en.htm. Acesso em 20/12/2008.

${ }^{5}$ Informação do documento "A nova definição de PME" publicado pela Comissão Européia e disponível no endereço eletrônico http://ec.europa.eu/enterprise/enterprise policy/sme definition/ sme user guide pt.pdf Acesso em 22/7/2008.

6 Informação da Comissão Européia disponível no endereço eletrônico http://www.egovmonitor.com/node/ 12201. Acesso 20/07/2008.

${ }^{7}$ Informação disponível no sítio do SEBRAE, endereço eletrônico http://www.sebrae.com.br/customizado/ sebrae/institucional/quem-somos/sebrae-um-agente-de-desenvolvimento Acesso em 20/07/2008.
} 
produto ou serviço inovador à introdução no mercado, existe um 'mar' a navegar e o trajeto dessa navegação está relacionado ao conhecimento, que pode ser apoiado por políticas públicas direcionadas a esse fim e por ações diretas do PCT e/ou conjugadas com os parceiros envolvidos. O diálogo da empresa com a universidade e/ou com os centros de pesquisa é fundamental nesse processo; e não é simples. Daí a necessidade de se estabelecer um modelo de estrutura de serviços do conhecimento $^{8}$ a ser utilizada pelos PCT em apoio às micro, pequenas e médias empresas de base tecnológica visando otimizar a relação empresa - universidade - centros de pesquisa.

\subsection{Parques Científicos e Tecnológicos}

Conforme foi visto no capítulo de introdução, os PCT surgiram na década de 1960 e 1970 na Universidade de Stanford, tendo a experiência da conhecida como "Vale do Silício" influenciado uma série de modelos mundiais de criação desses tipos de espaços privilegiados que tem por objetivo, entre outros, desenvolver negócios inovadores e apoiar o desenvolvimento regional. As definições mais comuns de Parques Científicos e Tecnológicos, são apresentadas na tabela 3.2.1 baseada em ZOUAIN (2003).

\footnotetext{
${ }^{8}$ No interesse deste estudo considera-se o termo "serviços do conhecimento", aplicado aos Parques Científicos e Tecnológicos (PCT), como os serviços, ações e atividades que proporcionam às empresas instaladas ou associadas aos PCT acesso ao conhecimento sem fronteiras, ações de compartilhamento e disseminação do conhecimento, ações de proteção à propriedade intelectual e comercialização de tecnologia e ações que proporcionam o desenvolvimento tecnológico e a inovação e prospecção tecnológica; no âmbito da gestão dos negócios e pelo apoio ao desenvolvimento do plano de negócios e pelas ações de melhoria da gestão dos negócios os serviços do conhecimento são definidos pelo apoio ao desenvolvimento do plano de negócios e pelas ações de melhoria da gestão do negócio; como suporte ao bom desempenho do acesso ao conhecimento consideram-se como fundamentais a provisão de serviços comuns, infra-estrutura adequada e disponibilidade para a expansão dos negócios.
} 
TABELA 3.2.1 - Principais definições adotadas para Parques Científicos e Tecnológicos

\begin{tabular}{|c|l|}
\hline Fonte & \multicolumn{1}{|c|}{ Definição } \\
\hline $\begin{array}{l}\text { ANPROTEC } \\
\text { (a) Complexo industrial de base científico-tecnológica planejado, de caráter } \\
\text { formal, concentrado e cooperativo, que agrega empresas cuja produção se } \\
\text { baseia em pesquisa tecnológica desenvolvida em centros de P\&D vinculados ao } \\
\text { Parque; }\end{array}$
\end{tabular}

(b) Empreendimento promotor da cultura da inovação, da competitividade, do aumento da capacitação empresarial fundamentado na transferência de conhecimento e tecnologia, com o objetivo de incrementar a produção de riqueza.

IASP ${ }^{10} \quad$ "Um Parque Científico é uma organização gerida por profissionais especializados cujo principal objetivo é o de aumentar a riqueza de sua comunidade através da promoção da cultura da inovação e da competitividade das empresas e dos seus associados com base no conhecimento instituições. Para permitir que esses objetivos sejam atingidos, um PCT estimula e gere o fluxo de conhecimento e tecnologia entre universidades, instituições de Pesquisa e Desenvolvimento (P\&D), empresas e mercados; o que facilita a criação e o crescimento de empresas baseadas na inovação por meio de processos de incubação e de spinoffs; e oferece outros serviços de valor agregado, juntamente com espaços e instalações de alta qualidade".

AURP 11 A definição da AURP engloba parques científicos e incubadoras tecnológicas, considerando-os como:

- Áreas e prédios, existentes ou planejados, projetados, principalmente, para instalações de pesquisa e desenvolvimento, públicas e privadas, para empresas baseadas em ciência e alta tecnologia, e para serviços de apoio;

- Possuem um contrato e/ou são de propriedade e mantêm um relacionamento operacional com uma ou mais universidades ou outras instituições de educação superior e pesquisa científica;

- Têm uma função de promoção de pesquisa e desenvolvimento, por meio da universidade em parceria com a indústria, assessorando no crescimento de novos negócios, e promovendo desenvolvimento econômico;

- Têm uma função de auxiliar a transferência de tecnologia e práticas de negócios entre a universidade e os arrendatários.

O parque ou a incubadora podem ser entidades para fins lucrativos ou sem fins lucrativos, de propriedade, total ou parcial, da universidade ou de uma entidade relacionada à universidade. Alternativamente, o parque ou a incubadora podem ser de propriedade de uma entidade não-universitária, mas que tem contrato ou uma relação formal com a universidade, incluindo "joint venture" ou "cooperative venture" entre um parque científico privado e a universidade.

UKSPA $^{12} \quad$ Um Parque Científico é uma iniciativa de apoio aos negócios e de transferência de tecnologia que:

- Encoraja e apóia os negócios baseados em conhecimento, promovendo seu crescimento;

- Provê um ambiente onde negócios grandes e internacionais podem desenvolver interações específicas e próximas com um centro de criação de conhecimento, para seu mútuo benefício;

- Tem uma ligação formal e operacional com centros de criação de conhecimento tais como universidades, institutos de educação superior e organizações de pesquisa.

\footnotetext{
${ }^{9}$ Glossário Dinâmico de Termos na Área de Tecnópolis, Parques Tecnológicos e Incubadoras de Empresas, ANPROTEC, Brasília, setembro de 2002

${ }^{10}$ Tradução livre de informação da IASP - International Association of Science Parks, disponível no endereço eletrônico http://www.iasp.ws/publico/index.jsp?enl=2. Acesso em 20/07/2008.

11 Tradução livre de informação do sítio da Association of University Research Parks - AURP, disponível no endereço eletrônico http://www.aurp.net/about/whatis.cfm. Acesso em 20/07/2008.

12 Tradução livre de informação disponível da UKSPA - United Kingdom Science Park Association, disponível no endereço eletrônico http://www.ukspa.org.uk/. Acesso em 20/07/2008.
} 
A IASP é a mais importante Associação que agrega parques tecnológicos e outros modelos de ambientes de inovação no mundo, contando, atualmente, com 356 membros, mais de 200.000 empresas inseridas no contexto dos seus associados, estando estes em 71 países (IASP, 2008) ${ }^{13}$.

Neste estudo se utiliza a terminologia Parque Científico e Tecnológico (PCT) e se adota a definição da IASP, por ser a de maior alcance.

A definição de PCT pode mudar ao longo do tempo, como KIRK e CATTS (2004) afirmam, os modelos de PCTs continuam a evoluir e se modificar como entidades físicas e organizacionais e como "forja" do desenvolvimento econômico de base tecnológica e elo para formação de negócios e programas de apoio empresariais. É conhecido que o papel, ou as funções dos PCTs apresentam um desafio, porque não há dois similares, suas metas e seus objetivos variam de acordo com os parceiros envolvidos, com a balança de poder e influência entre eles e o ambiente econômico local ${ }^{14}$.

Assim, atualmente os modelos dos PCTs, representam uma complexa interação de vários fatores que agregam valor e que buscam incrementar sua capacidade de agir como um instrumento único de desenvolvimento econômico. Nestes modelos, os principais fatores são: a governança e a gestão, a criação de conhecimento (os laços com universidades, institutos de pesquisa públicos e privados - laços formais e informais), o valor agregado dos serviços, espaços de qualidade oferecidos pelo PCT (ambiente adequado para a atração de empresas), a criação de empresas (start-ups, spin-offs, de universidades ou de inventores independentes, ou de outras empresas, bem como seus resultados de P\&D), a influência territorial (no desenvolvimento regional de políticas públicas), e o trabalho em rede (networking).

Uma representação desse modelo é apresentada na figura de SANZ, em 2003, denominada "O PCT Cebola" (The Science and Technology Park 'Onion') e reproduzida na Figura 3.2.1, onde as camadas do seu bulbo representam os fatores interagindo num $\mathrm{PCT}^{15}$.

\footnotetext{
13 IASP. IASP at a glance. Disponível no endereço eletrônico www.iasp.ws. Acesso em: 17/07/2008.

${ }^{14}$ Conforme Science and Technology Park Scoping Study, elaborado por Kirk e Catts em 2004; e disponível no endereço eletrônico http://www.nzte.govt.nz/common/files/ science-tech-scoping.pdf. Acesso em 01/7/2008.

${ }^{15}$ Conforme Science and Technology Park Scoping Study, elaborado por Kirk e Catts em 2004; e disponível no endereço eletrônico http://www.nzte.govt.nz/common/files/science-tech-scoping.pdf. Acesso em 01/7/2008.
} 


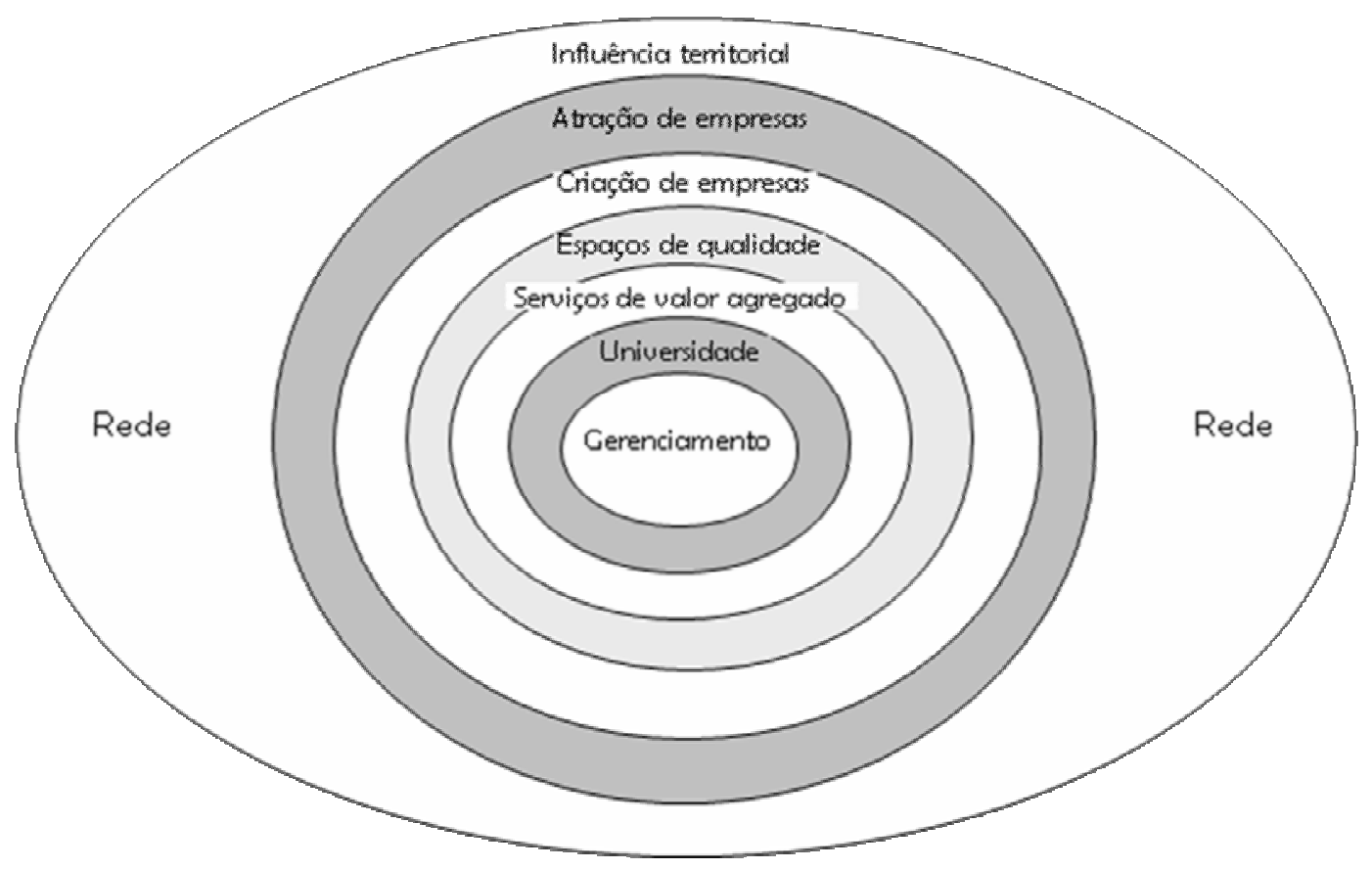

FIGURA 3.2.1 $1^{16}$ - Parque Científico e Tecnológico "Cebola"

Cada PCT define os seus objetivos e o caminho para alcançá-los, levando em consideração as partes interessadas, as autoridades locais, a economia local e regional, a sustentabilidade e o ambiente, o equilíbrio de poder, entre outros. No entanto, há uma meta que parece comum a todos os PCT: atrair e manter agrupadas (cluster) novas empresas de base tecnológica e reforçar a base econômica local e regional.

\subsection{Evolução dos modelos de parques científicos e tecnológicos - perspectivas}

Estudos recentes sobre a evolução dos modelos de parques tecnológicos apontam para uma "terceira geração" desses modelos, a saber: o relatório Third Generation Science Parks ${ }^{17}$ produzido pelo Manchester Science Park (MSP); e o relatório Characteristics and Trends in North American Research Parks $^{18}$ produzido pelo instituto Battelle em parceria com a Association of University Research Parks (AURP).

\footnotetext{
${ }^{16}$ Fonte: Apresentação de Luis Sanz, Diretor Geral da IASP, nov. de 2003 apud pg. 16 de Kirk e Catts (2004) 17 Third Generation Science Parks redigido pelo Professor John Allen e produzido em 2007 pelo Machester Science Park do Reino Unido, disponível no endereço eletrônico http://www.manchestersciencepark.co. uk/cms image depository/Full size images/MSP Third Generation Brochure.pdf Acesso em 10/12/2008. ${ }^{18}$ Characteristics and Trends in North American Research Parks - 21 century directions, produzido em outubro de 2007 pelo Battelle Technology Partnership Practice e pela Association of University Research Parks, disponível no endereço eletrônico http://www.aurp.net/more/ FinalBattelle.pdf Acesso em 10/12/2008.
} 
O relatório produzido pelo MSP é produto de um workshop de cenários realizado a fim de determinar quais as características e objetivos de futuro que um parque científico e tecnológico "maduro e bem sucedido" deveria ter para ser considerado um PCT de terceira geração.

Nele estão indicados os principais fatores chave, comuns e críticos a um parque científico e tecnológico, quais sejam: ser um ator global com raízes locais; ter uma parcela da comunidade preocupada com as pessoas e o meio ambiente; ser um ambiente propício para os negócios e uma oportunidade para investimento; ser um elemento essencial da atividade da universidade; fazer parte de inúmeras redes de relacionamento (networks); e ter o foco voltado para as necessidades das micro, pequenas e médias empresas de base tecnológica instaladas no parque.

Segundo o relatório do MSP, um Parque Científico e Tecnológico de Terceira Geração tem como características o seguinte: está conectado e envolvido na aplicação de políticas de inovação regionais e nacionais; tem estratégias de gestão de alta qualidade; emprega chefes executivos de primeira linha (top-quality) com qualidades de liderança e habilidade de se relacionar de forma positiva com todos os setores que interagem regularmente com o parque; é financeiramente sustentável, tendo proporção crescente de investimentos do setor privado; compreende a estrutura física e o ambiente do parque como uma construção de apoio ao processo de inovação, interação e criatividade - não como um fim em si mesmo; tem um relacionamento ativo, efetivo e diverso com a universidade; está conectado e atua em rede em todos os níveis (networking); e finalmente, tem o foco no desenvolvimento das micro, pequenas e médias empresas instaladas, adicionando valor aos negócios, interpretando oportunidades e conseqüências para os negócios, apoiando o crescimento dos negócios das empresas e sua atratividade para investidores potenciais, mantendo um relacionamento de proximidade, entendimento e confiança.

Por fim, o relatório do MSP indica uma série de ações necessárias para que um Parque Científico Tecnológico atinja o sucesso: pensar globalmente; integrar o parque nos planos de desenvolvimento da região; indicar um conselho e engajar um gestor sênior para que definam a estratégia de longo prazo com 
objetivos claros; agir baseado no fato de que um parque científico é um "portão de entrada" e não um "destino"; gerir o parque de modo a otimizar as situações inesperadas (serendipity); gerir o parque como um negócio sustentável e planejar o uso de parte do ganho para prover serviços às micro, pequenas e médias empresas instaladas ou ao apoio à incubação; desenvolver a infra-estrutura do parque de forma que seja atrativa e ambientalmente sustentável; desenvolver um forte relacionamento de "mão dupla" com a Universidade associada; construir ativas redes de relacionamento (networks) de todos os tipos e em todos os níveis, medindo sua eficiência; estabelecer um entendimento com as necessidades de cada instalado e prover acesso a redes de relacionamento (networks) e serviços que possam ajudá-los em seus negócios, especialmente serviços de aconselhamento e suporte comercial; e por fim, oferecer instalações para incubação tanto direta como indiretamente, assegurando que a "graduação" da incubadora seja um processo suave e positivo.

O relatório produzido pelo instituto Battelle em parceria com a AURP apresenta uma avaliação dos parques científicos dos Estados Unidos e Canadá, realizada por meio de pesquisa com diretores de parques que forneceram dados e informações que permitiram medir o impacto econômico dos parques científicos. A pesquisa indica que os parques científicos e tecnológicos estão emergindo como uma forte fonte ao empreendedorismo, talento e competitividade para a economia das regiões, estados e nações; dados apontam que cerca de 300.000 mil trabalhadores na América do Norte atuam em parques científicos e que cada um desses empregos gera aproximadamente 2,57 empregos na economia.

Segundo o relatório da Battelle/AURP, os parques científicos e tecnológicos se tornaram um elemento chave das infra-estruturas que suportam o crescimento da atual 'economia do conhecimento'. Os parques científicos e tecnológicos provêem localizações nas quais pesquisadores e empresas operam em forte proximidade, num ambiente que fomenta a colaboração, a inovação, promove o desenvolvimento, a transferência e comercialização de tecnologia.

O referido relatório indica que os PCTs de hoje diferem do modelo que emergiu na década de 60, que eram geralmente desenvolvidos em áreas vagas e próximas a uma universidade ou a outra instituição de pesquisa e proviam um atrativo conjunto de instalações do campus (campus-like setting); estes parques 
eram focados em operações de recrutamento de empresas primeiramente grandes e baseadas em tecnologia; mas na realidade, as empresas que se alocavam nos parques eram geralmente poucas, senão nenhuma, com laços reais com a universidade. Na década de 90 os parques científicos começaram a buscar formas de se tornarem mais atrativos às empresas de tecnologia, muitos procuraram atrair instalações de P\&D que pudessem ancorar o parque e atrair outras empresas, também começaram a prover espaços para incubação e construir espaços multiusuários (multitenant) para acomodar empreendedores menores e empresas start-up.

O relatório do Battelle/AURP informa que hoje os parques científicos se tornaram direcionadores chave para o desenvolvimento regional e aponta os "achados chave" (key findings) do estudo sobre os parque científicos de hoje: se importam menos com o recrutamento e mais com o apoio à incubação e ao empreendedorismo a fim de aumentar sua base futura de instalados; estão mais suscetíveis ao direcionamento para áreas específicas de desenvolvimento tecnológico e clusters industriais; estão sendo mais vistos como uma expressão do compromisso com o desenvolvimento econômico; e utilizam vários mecanismos para fomentar o relacionamento entre a universidade e a indústria, sendo que a mais efetiva é a parceria para o desenvolvimento.

Abordando a questão dos parques científicos e tecnológicos do futuro, o relatório do Battelle/AURP indica que um novo modelo de uso misto do campus estrategicamente planejado para expansões está surgindo, ele inclui espaços para o uso acadêmico e industrial. Este uso misto de desenvolvimento do campus está sendo desenhado para criar um ambiente inovador com uma livre e constante troca de informações entre os pesquisadores acadêmicos e seus parceiros da indústria.

Quanto aos fatores chave destes desenvolvimentos de uso misto do campus, o relatório indica ainda: espaço substancial para o crescimento significante de futuras pesquisas; planejamento de instalações multiusuários (multitenant) para abrigar pesquisadores e empresas; habitação e outras amenidades atrativas para os jovens estudantes, pós-docs, e estudantes graduados; e opções flexíveis de desenvolvimento, algumas dirigidas pelas universidades e outras dirigidas pelos desenvolvedores. 
Outras constatações apontadas no relatório Battelle/AURP para os parques científicos do futuro são: amenidades como um importante diferencial; desenvolvimento de parques científicos em áreas urbanas como um componente de planos de revitalização de vizinhanças; desenvolvimento de parques científicos para alavancar os ativos das organizações de P\&D não universitárias; maior ênfase ao desenvolvimento sustentável e ao design; e importância crescente das parcerias internacionais.

O referido relatório indica que os parques científicos são um importante componente da infra-estrutura de inovação necessária para apoiar a hoje 'economia do conhecimento', tanto quanto estradas, pontes e ferrovias foram críticas na economia industrial do passado.

Por fim, em se referindo aos "desafios chave" para os Parques Científicos do Século 21, o estudo indica serem os seguintes: ultrapassagem das barreiras culturais entre a academia e as comunidades de negócios e facilitação de verdadeiras parcerias; financiamento e apoio para a comercialização da propriedade intelectual; atração e retenção de talentos; especulação e "onda" (surge) de desenvolvimento de espaços; colaboração entre empresas e com outros parceiros; seguro e segurança; continuidade do apoio financeiro; revitalização da comunidade urbana; desempenho e responsabilidade; e serviços de valor agregado aos instalados (tenants).

Algumas experiências de parques científicos e tecnológicos analisadas pelos relatórios citados (Machester Science Park e Instituto Battelle) e a experiência do Research Triangle Park estão apresentadas na Tabela 3.3.1, onde são disponibilizadas informações referentes à infra-estrutura e aos serviços do conhecimento disponibilizados pelos PCTs às PMEs instaladas. 
TABELA 3.3.1 - Infra-estrutura e Serviços do Conhecimento disponibilizados às PMEs

\begin{tabular}{|c|c|}
\hline Do Parque Tecnológico & Da Infra-estrutura e Dos serviços do conhecimento \\
\hline $\begin{array}{l}\text { Mjärdevi Science Park } \\
\text { Localizado em Linköping, na } \\
\text { Suécia. } \\
\text { Tem atualmente } 230 \text { empresas } \\
\text { instaladas que empregam cerca de } \\
5800 \text { pessoas. } \\
\text { Endereço eletrônico: } \\
\text { http://www.mjardevi.se/opencms/ms } \\
\text { p/en/index.html }\end{array}$ & $\begin{array}{l}\text { Disponibiliza laboratórios para testes, Centro de } \\
\text { conferências, Centro de esportes, Dentista, Cabeleireiro, } \\
\text { Restaurantes, Correio, Secretaria eletrônica, etc... } \\
\text { Serviços profissionais oferecidos incluem: Escritório } \\
\text { advogados e de patentes, guarda de livros } \\
\text { (bookkeepers), auditores. } \\
\text { Apoio a processos de internacionalização; e programas } \\
\text { educacionais. } \\
\text { Rede de relacionamentos (Growlink) - Rede de apoio } \\
\text { para novas empresas - acesso a financiamento, } \\
\text { empreendedorismo e desenvolvimento empresarial, } \\
\text { formação profissional, orientadores. } \\
\text { Incubadora LiU Empreendedorismo e Desenvolvimento } \\
\text { (LEAD) - Espaços e serviços de apoio a empresas star- } \\
\text { up em ambiente profícuo, objetiva diminuir o prazo entre } \\
\text { o desenvolvimento da idéia e a colocação do } \\
\text { produto/serviço no mercado. } \\
\text { Rivstart/Flying Start - Programa de seis meses } \\
\text { direcionado a novos empreendedores. } \\
\text { Entrada (Soft Landing) para novos estabelecimentos na } \\
\text { Suécia - Agilização no processo de criação de novas } \\
\text { empresas estrangeiras em estágio de desenvolvimento, } \\
\text { suporte profissional, cooperação com agentes públicos e } \\
\text { privados, apoio profissional. } \\
\text { Redes profissionais (Professional Networks) - } \\
\text { 1) Mjärdevi Company Group - Capítulo local da Câmara } \\
\text { de Comércio da Suécia Oriente especialmente dedicado } \\
\text { às empresas instaladas no parque. } \\
\text { 2) Desenvolvimento de Pequenos Negócios em Linköping } \\
\text { (Small Business Development in Linköping - SMIL) - } \\
\text { Rede de tecnologia e de empresas baseadas no } \\
\text { conhecimento. } \\
\text { 3) BioMedley - Rede de base regional para } \\
\text { pesquisadores e empresas. }\end{array}$ \\
\hline
\end{tabular}

${ }^{19}$ Tradução livre de informações disponíveis no sítio Mjärdevi Science Park, endereço eletrônico http://www. mjardevi.se/opencms/msp/en/index.html. Acesso em 20/12/2008. 
TABELA 3.3.1 - Infra-estrutura e Serviços do Conhecimento disponibilizados às PMEs

\begin{tabular}{|c|c|}
\hline Do Parque Tecnológico & Da Infra-estrutura e Dos serviços do conhecimento \\
\hline $\begin{array}{l}\text { University of Twente Science } \\
\text { Park } \\
\text { Localizado em Enschede, na } \\
\text { Holanda. } \\
\text { Tem cerca de } 200 \text { empresas } \\
\text { instaladas que empregam cerca de } \\
4000 \text { pessoas. } \\
\text { Dispõe de } 85000 \mathrm{~m}^{2} \text {, dos quais } \\
6500 \mathrm{~m}^{2} \text { está disponível para } \\
\text { locação e } 30000 \mathrm{~m}^{2} \text { está em } \\
\text { desenvolvimento. } \\
\text { Endereço eletrônico: } \\
\text { http://www.sciencepark.nl/en/ut/ }\end{array}$ & $\begin{array}{l}\text { Com o Kennispark, a Universidade de Twente busca } \\
\text { desenvolver negócios intensivos em conhecimento por } \\
\text { meio da promoção de atividades de geração e de } \\
\text { transferência do conhecimento, incitando iniciativas que } \\
\text { colocam o trabalho científico a serviço da indústria, } \\
\text { mantendo o foco nessa ligação ciência-indústria. } \\
\text { Oferece espaços em local que agrega valor aos } \\
\text { negócios, escritórios e centros de serviços de negócios, } \\
\text { infra-estrutura de qualidade, conexões de transporte } \\
\text { público (incluindo uma estação de trem exclusiva), } \\
\text { parque de configuração planejada com áreas verdes e } \\
\text { objetos de arte, tem adjacente o Estádio de Futebol Arke } \\
\text { (Arke Stadium), centros comerciais e um estacionamento } \\
\text { com capacidade para } 2000 \text { automóveis. }\end{array}$ \\
\hline $\begin{array}{l}\text { Oulu Technology Park } \\
\text { Localizado em Oulu, na Finlândia. } \\
\text { Impulsionado por empresas } \\
\text { (company-driven) } \\
\text { Tem cerca de } 850 \text { empresas } \\
\text { instaladas e emprega cerca de } \\
18500 \text { pessoas } \\
\text { Endereço eletrônico: } \\
\text { http://www.technopolis.fi/index.php? } \\
\underline{94}\end{array}$ & $\begin{array}{l}\text { Disponibiliza instalações adaptáveis e de alta qualidade. } \\
\text { Propõe serviços de negócios (business services) com o } \\
\text { objetivo diminuir o custo e aumentar a eficiência das } \\
\text { empresas em suas operações; e serviços de } \\
\text { desenvolvimento (development services) com o objetivo } \\
\text { de ajudar as empresas a aumentar sua competitividade e } \\
\text { obter os recursos necessários para ter sucesso nos } \\
\text { mercados internacionais. } \\
\text { Programas regionais para atração de clientes, } \\
\text { incubadora, serviços de desenvolvimento de negócios, } \\
\text { serviços de consultoria para centros tecnológicos e } \\
\text { serviços de planejamento e treinamento. } \\
\text { Alguns serviços são oferecidos por empresas que } \\
\text { operam nas instalações do parque, tais como: serviços } \\
\text { de assessoria legal, contabilidade, patentes, tradução e } \\
\text { comunicação. } \\
\text { O parque possui uma rede de parceiros para provisão de } \\
\text { serviços em diversas áreas e especialidades, a rede } \\
\text { inclui somente as empresas avaliadas como de qualidade } \\
\text { e confiáveis. } \\
\text { Programas de Desenvolvimento de Negócios - atua com } \\
\text { parceiros públicos e privados do sistema de inovação a } \\
\text { fim de identificar e avaliar idéias de negócios com } \\
\text { potencial de crescimento global; trabalha diretamente } \\
\text { com os times de empreendedores para melhorar e } \\
\text { acelerar a evolução de seus negócios; e utiliza uma série } \\
\text { de serviços, como: personal sparring, orientação, } \\
\text { formação de empreendedores, coaching, programas de } \\
\text { networking, a fim de apoiar as empresas start-up a } \\
\text { tornarem se maduras e competitivas. } \\
\text { Acelerar a entrada no Mercado internacional - atua } \\
\text { próximo a uma variedade de parceiros domésticos e }\end{array}$ \\
\hline
\end{tabular}

${ }^{20}$ Tradução livre de informações disponíveis no sítio Business \& Science Park Eschede, endereço eletrônico http://www.sciencepark.nl/en/ut/. Acesso em 20/12/2008.

${ }^{21}$ Tradução livre de informações disponíveis no sítio Technopolis, endereço eletrônico http://www.technopolis filindex.php?94. Acesso em 20/12/2008.

${ }^{22}$ Tradução livre de informação disponível no sítio Virtual Finland, endereço eletrônico http://virtual.finland.fil netcomm/news/showarticle.asp?intNWSAID=54541. Acesso em 20/12/2008. 
TABELA 3.3.1 - Infra-estrutura e Serviços do Conhecimento disponibilizados às PMEs

\begin{tabular}{|c|c|}
\hline Do Parque Tecnológico & Da Infra-estrutura e Dos serviços do conhecimento \\
\hline & $\begin{array}{l}\text { internacionais a fim de facilitar o crescimento das } \\
\text { empresas e o estabelecimento estratégico em mercados } \\
\text { internacionais. } \\
\text { A Consultoria Technopolis é a unidade responsável pela } \\
\text { cooperação internacional e pela transferência de } \\
\text { tecnologia para outros países; seu objetivo é ajudar as } \\
\text { empresas a evitar erros e acelerar o crescimento regional } \\
\text { com a ajuda dos Parques Científicos e Tecnológicos e } \\
\text { das incubadoras de negócios. }\end{array}$ \\
\hline $\begin{array}{l}\text { Kista Science } \text { City }^{23} \\
\text { Localizado em Kista, na Suécia. } \\
\text { Tem cerca de } 500 \text { empresas } \\
\text { instaladas e emprega } \\
\text { aproximadamente } 20000 \text { pessoas. } \\
\text { Endereço eletrônico: } \\
\text { http://www.kista.com/adimo4/Site/ki } \\
\text { sta/web/default.aspx } \\
\text { O Kista Science City é um dos } \\
\text { clusters líderes na área de } \\
\text { Tecnologia de Informação e } \\
\text { Comunicação. }\end{array}$ & $\begin{array}{l}\text { Oferece instalações e serviços, tais como: } \\
\text { Incubadora de negócios - Kista-based technology } \\
\text { incubator Stockholm Innovation \& Growth - STING - } \\
\text { prove aconselhamento em negócios, programas de } \\
\text { suporte ao processo de negócios subdividido em quatro } \\
\text { programas: Startup, Business Lab, Business Accelerator } \\
\text { e Go Global. Cada um desses programas tem o foco no } \\
\text { desenvolvimento individual e no desenvolvimento } \\
\text { internacional do negócio. } \\
\text { Redes de Negócios e projetos para crescimento - Kista } \\
\text { Science City é caracterizado pela próxima colaboração } \\
\text { entre a comunidade de negócios, a academia e atores do } \\
\text { setor público; o parque procura identificar, facilitar e } \\
\text { fortalecer a colaboração, apoiar, criar e estimular redes } \\
\text { de contatos e espaços para encontros entre os atores da } \\
\text { região. } \\
\text { Projetos - Juntamente com as redes, uma série de } \\
\text { projetos é executada no âmbito do parque; tais projetos } \\
\text { reunem os atores da academia e do setor de negócios, } \\
\text { buscando criar as melhores condições possíveis para o } \\
\text { crescimento não somente do Kista Science City mas } \\
\text { também da região de Estocolmo. } \\
\text { Ambiente de pesquisa de classe mundial; e educação de } \\
\text { qualidade - Duas fortes universidades e a alta } \\
\text { concentração de pesquisadores atuando na área de } \\
\text { Tecnologia da Informação e da Comunicação, fazem do } \\
\text { Kista Science City um cluster único de pesquisa e } \\
\text { desenvolvimento, que tem como resultado um forte } \\
\text { crescimento em inovações, patentes e novos negócios. } \\
\text { Ensino Superior na area de TIC - Fertilização cruzada } \\
\text { entre universidades, a comunidade de pesquisa e a } \\
\text { indústrias - e Pesquisa em negócios. }\end{array}$ \\
\hline
\end{tabular}

${ }^{23}$ Tradução livre de informações disponíveis no sítio Kista Science City, endereço eletrônico http://www.kista. com/adimo4/Site/kista/web/default.aspx. Acesso em 20/12/2008. 
TABELA 3.3.1 - Infra-estrutura e Serviços do Conhecimento disponibilizados às PMEs

\begin{tabular}{|c|c|}
\hline Do Parque Tecnológico & Da Infra-estrutura e Dos serviços do conhecimento \\
\hline $\begin{array}{l}\text { Research Triangle Park - RTP }{ }^{24} \\
\text { Localizado em Raleigh-Durham-Cary } \\
\text { CSA (Combined Statistical Area) na } \\
\text { costa leste dos Estados Unidos, no } \\
\text { Estado da Carolina do Norte. } \\
\text { Tem cerca de } 170 \text { empresas } \\
\text { instaladas e emprega } \\
\text { aproximadamente } 40000 \text { pessoas. } \\
\text { Endereço eletrônico: } \\
\text { http://www.rtp.org/main/index.php?p } \\
\mathrm{id}=183 \& s e c=1 \\
\text { O RTP é um dos mais antigos e } \\
\text { maiores parques científicos e } \\
\text { tecnológicos da América do Norte; } \\
\text { foi criado em } 1959 \text { e está localizado } \\
\text { entre Durhman, Chapel Hill e } \\
\text { Raleigh, onde estão sediadas três } \\
\text { universidades de pesquisa de } \\
\text { primeira linha. }\end{array}$ & $\begin{array}{l}\text { O Park Research Center é uma de quatro incubadoras } \\
\text { que dispõe de } 13 \text { prédios que oferecem espaços para } \\
\text { locação de escritórios e laboratórios, as instalações são } \\
\text { compartilhadas e flexíveis, projetadas para prover spin- } \\
\text { outs universitários e empresas start-up. O Park } \\
\text { Research Center também oferece } 5000 \mathrm{~m}^{2} \text { de espaços } \\
\text { flexíveis para atender necessidades de treinamento e de } \\
\text { desenvolvimento profissional. } \\
\text { A Owners \& Tenants Association (O\&T) é uma } \\
\text { associação que se reúne trimestralmente para debater } \\
\text { questões de interesse dos proprietários e dos instalados } \\
\text { no parque; a O\&T atua como voz de consenso da } \\
\text { comunidade do Parque e mantém amenidades como } \\
\text { trilhas para caminhada, campos de jogos, etc... } \\
\text { Programas e eventos @rtp são oferecidos aos } \\
\text { empregadores e empregados } \\
\text { Dispõe de instalações para recreação - cerca de } 25 \text { km } \\
\text { de pistas e trilhas para caminhada, } 12 \text { quadras de vôlei e } \\
4 \text { de softball. } \\
\text { Rede de Parceiros - cooperação contínua entre governo, } \\
\text { academia e negócios, entre outros, a fim de facilitar e } \\
\text { catalizar iniciativas que possam agregar valor aos ativos } \\
\text { do conhecimento e estimular a inovação e a mudança na } \\
\text { economia. } \\
\text { O Triangle Area Research Directors Council (TARDC) é } \\
\text { um grupo informal de líderes científicos advindo de } \\
\text { organizações de pesquisa da área do Research Triangle } \\
\text { da Carolina do Norte, que se encontra mensalmente para } \\
\text { discutir assuntos de interesse e alto impacto na } \\
\text { comunidade de pesquisa. } \\
\text { Para encorajar o diálogo e a colaboração entre os } \\
\text { membros da comunidade do Research Triangle Park, foi } \\
\text { desenvolvido o wikiRTP a fim de prover um fórum sobre } \\
\text { assuntos relacionados ao RTP. } \\
\text { O Briefing Center@rtp é uma fonte de informações online } \\
\text { sobre o RTP e da região de Pesquisa do Triângulo } \\
\text { (Triangle Region). }\end{array}$ \\
\hline
\end{tabular}

Como mencionado anteriormente, de acordo com o relatório Battelle/AURP ${ }^{25}$, cada vez mais os PCT estão centrando suas ações em incubação e desenvolvimento das PME de base tecnológica. Um exemplo é o Purdue Research Park, criado em 1961, que é gerido e de propriedade da

\footnotetext{
${ }^{24}$ Tradução livre de informações disponíveis na apresentação Competing in the Global Economy - setembro de 2008 do sítio do Research Triangle Park, endereço eletrônico http://www.rtp.org/files/Fact\%20Sheets/over view presentation.pdf; e no sítio do Research Triangle Park, endereço eletrônico http://www.rtp.org/main/ index.php?pid $=183 \&$ sec $=1$. Acesso em 20/12/2008

${ }^{25}$ Characteristics and Trends in North American Research Parks - 21 century directions, produzido em outubro de 2007 pelo Battelle Technology Partnership Practice e pela Association of University Research Parks, disponível no endereço eletrônico http://www.aurp.net/more/ FinalBattelle.pdf Acesso em 10/12/2008.
} 
Fundação de Pesquisa Purdue, que nos anos 1990 passou a focar pesadamente em incubação e desenvolvimento de negócios. Seu sucesso veio a partir da utilização de um edifício multiusuário (multitenant) que já estava construído no parque, apoiado por uma variedade de programas de aceleração de negócios também geridos pela Fundação de Pesquisa, por programas de passagem (Gateways) para o desenvolvimento empreendedor; e pela aplicação de recursos financeiros a fundo perdido (Trash Fund) para pesquisa de precomercialização. Ao investir os seus fundos e financiados por meio do programa estatal Parque de Tecnologia Certificado (Certified Technology Park), o Purdue quintuplicou a área do parque e construiu uma nova incubadora e um segundo edifício multiusuário, aumentando o espaço dedicado a novas PME para mais de $200.000 \mathrm{~m}^{2}$.

Além disso, o relatório afirma que os PCT estão obtendo sucesso na incubação novas PME, aproximadamente 800 empresas foram graduadas nas incubadoras dos PCT nos últimos 5 anos, sendo que cerca de 25\% dessas empresas permaneceram nos PCT, menos de $10 \%$ deixaram a região e somente $13 \%$ fracassaram.

Em se referindo aos serviços prestados pelos PCT, o relatório Battelle/AURP aponta que os PCT oferecem uma série de serviços de negócios para as empresas instaladas, como se pode observar na Tabela 3.3.2 apresentada seguir.

TABELA 3.3.2 26 - Perfil do serviços oferecidos pelos PCT Norte Americanos

\begin{tabular}{|l|c|c|}
\hline Serviços oferecidos pelos PCT Norte Americanos & $\begin{array}{c}\text { Número de PCT que } \\
\text { oferecem os serviços }\end{array}$ & $\begin{array}{c}\text { Percentual sobre } \\
\text { o total de PCT }\end{array}$ \\
\hline $\begin{array}{l}\text { Apoio para o acesso a fundos do Estado ou } \\
\text { outros programas públicos }\end{array}$ & 94 \\
\hline $\begin{array}{l}\text { Provisão ou ligação para obtenção de fundos de } \\
\text { capital }\end{array}$ & 87 & $76 \%$ \\
\hline Planejamento de Negócios & 77 & $68 \%$ \\
\hline $\begin{array}{l}\text { Aconselhamento em Marketing e Estratégia de } \\
\text { Vendas }\end{array}$ & 70 & $64 \%$ \\
\hline Avaliação de Tecnologia e de Mercado & 69 & $45 \%$ \\
\hline $\begin{array}{l}\text { Apoio em assuntos relacionados a Recursos } \\
\text { Humanos }\end{array}$ & 48 & $38 \%$ \\
\hline $\begin{array}{l}\text { Provisão financeira para 'prova de conceito' } \\
\text { (provide proof-of-concept funding) }\end{array}$ & 40 & \\
\hline
\end{tabular}

26 Tabela baseada na Table ES-1 Profile of a Typical North American Research Park do relatório Battelle/AURP, Characteristics and Trends in North American Research Parks - 21 century directions, produzido em outubro de 2007 pelo Battelle Technology Partnership Practice e pela Association of University Research Parks, disponível no endereço eletrônico http://www.aurp.net/more/ FinalBattelle.pdf Acesso em 10/12/2008. 
Em se referindo aos serviços e amenidades (amenities) oferecidos pelos PCT às empresas instaladas, o relatório Battelle/AURP aponta ainda para os serviços da universidade, incluindo espaços recreativos, cuidados de animais, movimentação de materiais perigosos, serviços de biblioteca, serviços de transporte, estacionamento e status de 'profissional' adjunto (adjunct faculty) junto à universidade. Quanto às incubadoras, $68 \%$ dos PCT tem uma ou mais situadas no parque e estão essencialmente voltadas ao atendimento das necessidades da universidade, spin-offs e criação de empresas. A incubadora apoia o processo empresarial, contribuindo para aumentar a taxa de sobrevivência das empresa inovadoras em sua fase inicial.

Já o relatório do Manchester Science Park (MSP) ${ }^{27}$ indica que a gestão pró-ativa dos PCT, que compreende um bom entendimento do que são os negócios das PME nele instalados; Ihes oferece as competências adequadas, o aconselhamento e a rede de oportunidades, inclusive o acesso a investimentos necessários. Além disso, o PCT reconhece que as necessidades e o nível de aconselhamento necessário às PME muda na medida em que a empresa amadurece.

Segundo o relatório, os PCT bem sucedidos reconhecem que a principal deficiência das PME de base tecnológica está na falta do entendimento e das habilidades comerciais necessárias para a gestão bem sucedida do negócio, por parte do empreendedor. Para atender essa necessidade, os PCT oferecem uma série de suportes e aconselhamento, como por exemplo, cursos relacionados à venda dos produtos ou serviços.

Conforme o relatório do MSP, o apoio oferecido pelos PCT aos novos empreendedores é considerado importante pelos investidores, há um interesse crescente por parte deles nesses pequenos negócios de base tecnológica, como por exemplo os business angels, que se conectam aos PCT mais bem sucedidos a fim de identificar quais as empresas promissoras para investismento. Os capitalistas de risco estão dispostos a adquirir participações nessas empresas e

27 Third Generation Science Parks redigido pelo Professor John Allen e produzido em 2007 pelo Machester Science Park do Reino Unido, disponível no endereço eletrônico http://www.manchestersciencepark.co.uk/ cms image depository/Full size images/MSP Third Generation Brochure.pdf Acesso em 10/12/2008. 
reconhecem que a experiência dos gestores dos PCT pode ajudá-los a identificar as PME que estão de fato preparadas para receber investimento.

Outra observação do relatório do MSP sobre os PCT de $3^{a}$ geração, é a de que eles buscam se antecipar e compreender os estágios iniciais de formação e do crescimento das PME, sendo assim, eles incorporam uma incubadora ou tem acesso a uma incubadora da região; e se preocupam em tornar a transição da empresa, da incubadora para o parque, um processo suave e positivo.

Em nível nacional, a ANPROTEC apresentou em 2008 o estudo "Parques Tecnológicos Brasileiros - Estudo, Análise e Proposições ${ }^{28 "}$, realizado em parceria com a Agência Brasileira de Desenvolvimento Industrial (ABDI), onde foi proposta uma taxonomia para a área de parques científicos e tecnológicos no Brasil; e indicados alguns elementos de políticas públicas em apoio aos PCTs brasileiros. Os dados mais relevantes desse estudo estão apresentados no documento denominado Portfólio Executivo ${ }^{29}$, que contém informações sobre o movimento de parques no Brasil.

O estudo da ANPROTEC parte do princípio de que as PMEs instaladas nos parques tecnológicos são as empresas intensivas em tecnologia que são a base da chamada 'sociedade do conhecimento' e que propulsionam os demais setores da economia; diz então haver a necessidade de organização e sistematização da área de parques tecnológicos que permitam uma visão sistêmica e integrada das ações e dos atores (governo e sociedade) a fim de se obter melhores resultados para as empresas e para a economia nacional/regional.

A Figura 3.3.1 representa a taxonomia desenvolvida e proposta pela ANPROTEC; nele se observa dois eixos básicos, a Base de Ciência e Tecnologia, que considera os parâmetros, indicadores e características do Parque Tecnológico e do entorno, que dizem respeito à base de conhecimentos existente na região; e a Base Empresarial, que representa os fatores relacionados à densidade de empresas inovadoras e à cultura de empreendedorismo e inovação

\footnotetext{
28 “Parques Tecnológicos Brasileiros - Estudo, Análise e Proposições", Versão para distribuição no XVIII Seminário Nacional de Parques Tecnológicos e Incubadoras de Empresas, realizado de 22 a 26 de setembro de 2008 em Aracaju, Sergipe.

29 "Portfólio de Parques Tecnológicos no Brasil" - Versão de Trabalho, ANPROTEC, dez/2008, disponível no endereço eletrônico http://www.anprotec.org.br/ArquivosDin/portfolio completo resol media pdf 28.pdf Acesso em 10/12/2008.
} 
da região. Para se avaliar a Base de C\&T e a Base Empresarial de um Parque Tecnológico são utilizados indicadores que permitem estabelecer o Nível de Relevância da base de C\&T e da base empresarial de um Parque Tecnológico e da região onde ele está localizado.

Na taxonomia proposta pela ANPROTEC, o Nível de Relevância é a escala de graduação entre os dois eixos básicos, que são: Relevância Nacional/Mundial, Relevância Regional e Relevância Local. Por fim, a taxonomia apresenta quatro categorias para classificação dos Parques Tecnológicos: Parque Tecnológico Consolidado, Parque CIENTífICO-tecnológico, Parque EMPRESARIAL-tecnológico, e Parque Tecnológico emergente.

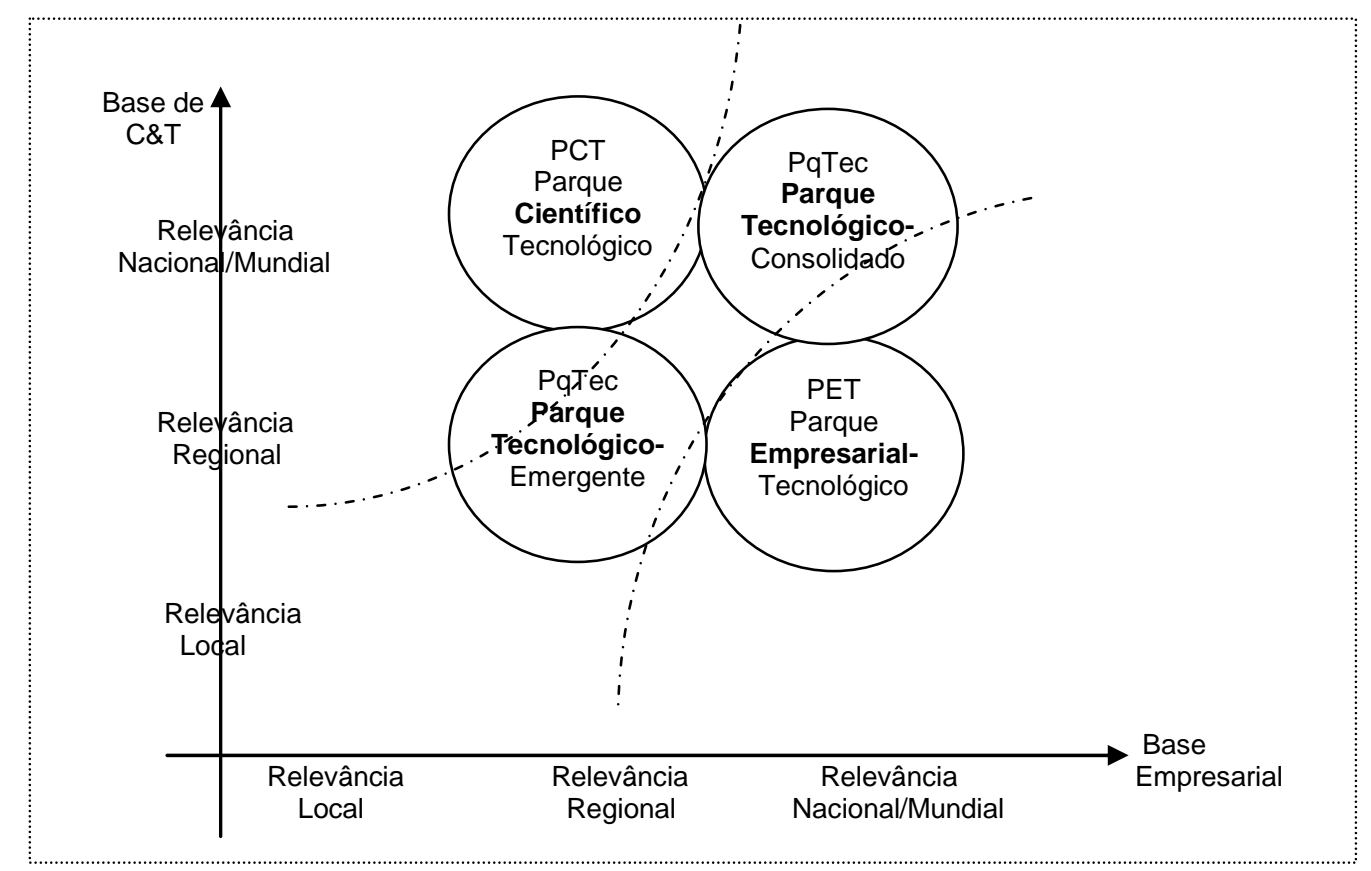

FIGURA 3.3.1 $1^{30}$ - Taxonomia proposta pela ANPROTEC/ABDI

Além da taxonomia proposta, a ANPROTEC sugere políticas públicas para a área de parques tecnológicos em três níveis de abrangência (definição de princípios, declarações e diretrizes; definição do arcabouço jurídico; e a criação do Sistema Nacional de Parques Tecnológicos e Incubadoras - SINAPTI); e dois programas de apoio (programa de apoio a parques tecnológicos e programa de apoio a empresas instaladas em parques) englobando três linhas de apoio para

\footnotetext{
${ }^{30}$ Fonte: figura disponível na página 10 do documento "Parques Tecnológicos Brasileiros - Estudo, Análise e Proposições", Versão para distribuição no XVIII Seminário Nacional de Parques Tecnológicos e Incubadoras de Empresas, realizado de 22 a 26 de setembro de 2008 em Aracaju, Sergipe.
} 
cada programa. As linhas de apoio do programa de apoio a empresas instaladas sugeridas são: linha de apoio para a pesquisa, desenvolvimento e inovação; linha de apoio para infra-estrutura predial e laboratorial de empresas de parques tecnológicos; e linha de apoio para estímulo ao investimento privado.

O Portfólio Executivo ${ }^{31}$ da ANPROTEC apresenta uma série de informações relacionadas aos 74 parques científicos e tecnológicos existentes hoje do Brasil, sendo que 25 deles estão operantes, 17 em fase de implantação e 32 em fase de projeto. No Estado de São Paulo há 4 parques em operação, dois em fase de implantação e 10 fase de projeto, sendo o Parque Tecnológico de São Paulo um deles.

Esta pesquisadora observou que nos últimos anos há um movimento de apoio aos parques tecnológicos no Estado de São Paulo, que pode ser exemplificado por algumas iniciativas como por exemplo: a criação do Sistema Paulista de Parques Tecnológicos - SPTec (decreto $n^{0} 50.504$ de fevereiro de 2006) que tem por objetivo fomentar, impulsionar e apoiar as iniciativas de criação e implantação de parques; a criação Programa de Apoio aos Parques Tecnológicos - Pró-Parques (assinado em 16/12/2008 pelo governador José Serra), que concede incentivos fiscais a empresas inovadoras que se instalarem em parques tecnológicos do SPTec; o protocolo de intenções da Prefeitura de São Paulo para a criação e implantação do Parque Tecnológico de São Paulo na Zona Oeste de São Paulo, no bairro do Jaguaré e de outro na Zona leste da cidade; e o objetivo do Estado de São Paulo de ter 10 parques tecnológicos implantados até 2010.

\footnotetext{
31 "Portfólio de Parques Tecnológicos no Brasil" - Versão de Trabalho, ANPROTEC, dez/2008, disponível no endereço eletrônico http://www.anprotec.org.br/ArquivosDin/portfolio completo resol media pdf 28.pdf Acesso em 10/12/2008.
} 


\section{METODOLOGIA DA PESQUISA}

Neste capítulo são expostos os detalhes relacionados à metodologia utilizada, expondo métodos e instrumentos da pesquisa. Esta pesquisa tem caráter exploratório, principalmente devido à inovação do tema (serviços baseados no conhecimento que podem ser prestados pelos Parques Tecnológicos às Micro Pequenas e Médias Empresas de base tecnológica) e ao limitado conjunto de informações de caráter científico sobre o tema, disponíveis na literatura. Com relação ao envolvimento do pesquisador, a pesquisa se caracteriza na concepção da estratégia de pesquisa-ação, conforme será apresentado no decorrer do capítulo.

\subsection{Método da pesquisa}

Pelas características do trabalho desenvolvido nesta tese, e para embasar o método de pesquisa selecionado, aborda-se, a seguir GIL (1999) nas questões relacionadas à pesquisa exploratória e à razão de sua utilização para estudar determinados fenômenos sociais.

Segundo GIL (pg. 42, 1999) o objetivo fundamental de uma pesquisa é descobrir respostas para problemas por meio do emprego de procedimentos científicos; no caso da pesquisa social, pode então ser definida como o processo que, por meio da utilização de metodologia científica, viabiliza a obtenção de novos conhecimentos no âmbito da realidade social.

No contexto da pesquisa social, GIL (1999) apresenta, entre outros, o que ele denomina os "níveis da pesquisa", que estão relacionados aos objetivos específicos de cada pesquisa, sendo que um deles é a pesquisa exploratória.

GIL (pg. 43, 1999) define pesquisa exploratória como aquela que tem por principal finalidade "desenvolver, esclarecer e modificar conceitos e idéias, tendo em vista a formulação de problemas mais precisos ou hipóteses pesquisáveis para estudos posteriores."

Ainda se referindo aos estudos exploratórios, GIL (pg. 43, 1999) explica que as pesquisas exploratórias são realizadas com o propósito de oferecer uma 
visão geral sobre um determinado fato; são pesquisas realizadas, sobretudo, quando o tema escolhido é pouco explorado e, portanto, se torna difícil formular hipóteses precisas e operacionalizáveis sobre eles.

Por fim e acerca das pesquisas exploratórias, o autor (GIL, pg. 43, 1999) diz se tratarem por vezes de primeira etapa de uma investigação mais ampla; no caso de temas genéricos, se torna necessário esclarecer e delimitar, revisar a literatura, discutir com especialistas, entre outros procedimentos; assim sendo, o produto final passa a ser um problema mais esclarecido, passível de investigação mediante procedimentos mais sistematizados.

À luz do objetivo desta pesquisa e das definições e considerações deliberadas por GIL (1999), a escolha pela metodologia exploratória, indica uma escolha privilegiada para a obtenção de resultados mais significativos para a pesquisa.

Sendo assim, no contexto dessa pesquisa foram realizados estudos exploratórios a partir das seguintes ações: (1) pesquisa bibliográfica e em páginas da internet, relacionadas ao tema da sociedade do conhecimento; (2) pesquisa bibliográfica e em páginas da internet, a fim de realizar um levantamento internacional sobre a conceituação de Parques Tecnológicos e outros habitats de inovação; (3) pesquisa bibliográfica e em páginas da internet, de Parques Tecnológicos no mundo, de maneira a identificar e coletar informações, tais como: data da criação; país em que está estabelecido; nome do parque científico tecnológico; localização e áreas ocupadas; sistema de gestão e gerenciamento; serviços convencionais; serviços do conhecimento e de apoio a Inovação nas empresas, entre outras; e identificação e pesquisa bibliográfica em páginas da internet de associações de Parques Tecnológicos no Mundo, objetivando, de maneira ampla obter experiência e conhecimento sobre Parques Tecnológicos no mundo no contexto da sociedade do conhecimento. 


\subsection{0 instrumento de pesquisa}

O instrumento de pesquisa, composto de 38 questões fechadas e 22 questões abertas, foi enviado por e-mail a 454 membros da International Association of Science Parks (IASP); diversos PCT, de diferentes países, responderam o questionário (e-survey), a saber: Espanha, Itália, Portugal, Alemanha, Reino Unido, China, Brasil, Turquia e Uruguai. Porém, das respostas recebidas, foram consideradas completas e com qualidade suficiente para a realização do presente estudo, aquelas apresentadas na Tabela 5.1 do capítulo 5 que apresenta os resultados desta pesquisa.

Para o desenvolvimento do instrumento de pesquisa aplicado às experiências selecionadas, foram definidas as dimensões analisadas na pesquisa de campo. São cinco as dimensões propostas, a saber: (1) os serviços baseados no conhecimento oferecidos pelo Parque Tecnológico: o apoio à elaboração de projetos; a informação tecnológica, a inovação na gestão do negócio, os serviços tecnológicos, a demonstração de tecnologia e treinamento; a propriedade intelectual e a comercialização de tecnologia; (2) os serviços relacionados à gestão de negócio oferecidos pelo Parque Tecnológico às empresas instaladas no Parque; (3) os serviços comuns oferecidos pelo Parque Tecnológico: serviços comuns disponíveis; acessibilidade aos serviços comuns, a utilização dos serviços comuns; (4) a possibilidade de expansão física no Parque Tecnológico: área prevista para construção de prédios; a área já construída e áreas ocupadas; e os projetos futuros de construção de prédios; e (5) os aspectos relacionados à imagem do Parque Tecnológico: características do local e do entorno; as características dos parceiros; e o prestígio do empreendimento. Na Figura 4.1 são apresentadas as dimensões e sub-dimensões utilizadas na pesquisa. 


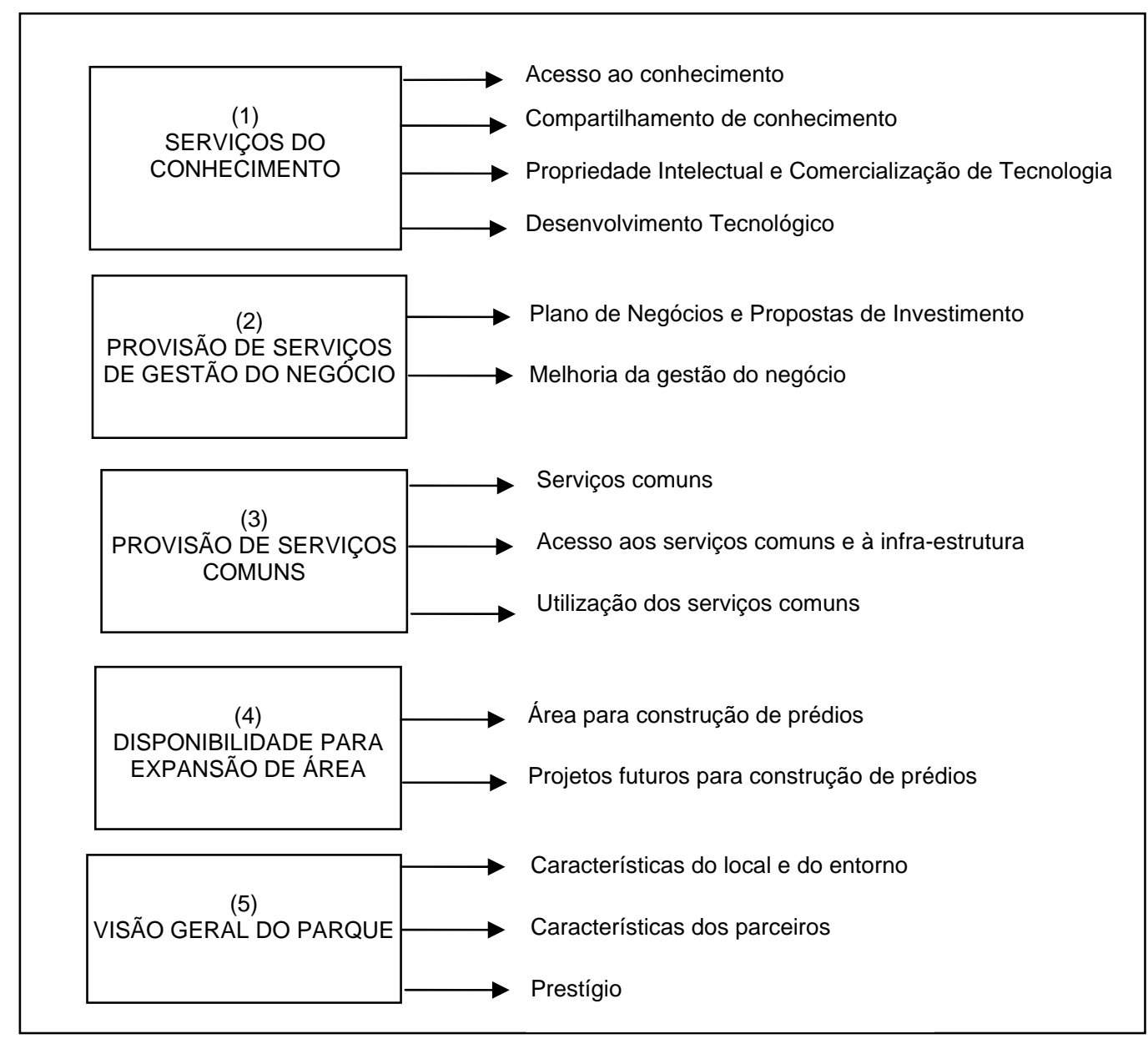

Figura 4.1 - Dimensões consideradas na pesquisa

Com base nas dimensões definidas, foi desenvolvido o instrumento de pesquisa, apresentado no APÊNDICE A e que foi elaborado em duas versões: português e inglês.

Trata-se o instrumento de pesquisa, de um questionário semi estruturado, aplicado por correio eletrônico (e_survey) e enviado a cada um dos componentes da amostra intencional, composta de membros da IASP (International Association of Science Parks).

As questões fechadas foram apresentadas como afirmações e a graduação de medição utilizada foi a escala de Likert de cinco pontos, por permitir aos respondentes indicarem o grau de concordância ou discordância com as declarações propostas. As cinco graduações utilizadas foram as seguintes: Concordo Totalmente 
(CT), Concordo Parcialmente (CP), Neutro (N), Discordo Parcialmente (DP) e Discordo Totalmente.

A escala de Likert foi criada em 1932 por Rensis Likert, a fim de medir os níveis de aceitação e aprovação dos indivíduos, resultado de suas experiências e influências sociais. Esse tipo de escala requer que os entrevistados indiquem seu grau de concordância ou discordância com as informações que estão sendo avaliadas $^{1}$.

O instrumento de pesquisa (questionário) foi revisado por três avaliadores; a saber: Dra. Conceição Vedovello da FAPESP (São Paulo - Brasil); Dr. Selwyn Seymour da Edinburgh University School of Management \& Economics (Edimburgo Escócia); e o Engenheiro Ajax Magalhães Pedrosa, Diretor de Operações da empresa multinacional Alcatel. As revisões foram realizadas no período compreendido entre os meses de fevereiro e junho de 2006; a versão em português foi revisada cinco vezes e a versão em inglês foi revisada oito vezes.

\footnotetext{
${ }^{1}$ Informação disponível no endereço eletrônico http://www.benchmarkingbrasil.com.br/bench/meto dologia/ likert.htm. Acesso em 03/03/2008.
} 


\section{5 - RESULTADOS}

Como citado anteriormente, o questionário (Anexo 1), foi enviado por e-mail aos responsáveis de parques tecnológicos e associados na IASP (International Association of Science Parks). Os dados dos respondentes do e-survey estão relacionados na Tabela 5.1.

\begin{tabular}{|c|c|c|c|c|}
\hline \multicolumn{5}{|c|}{ TABELA 5.1 - Dados cadastrais dos respondentes do e-survey } \\
\hline Id. & País & $\begin{array}{l}\text { Nome / e-mail do } \\
\text { respondente }\end{array}$ & Função do respondente & Nome / sítio internet do PCT \\
\hline 1 & Espanha & $\begin{array}{l}\text { Sonia Palomo das Neves / } \\
\text { spalomo@pta.es }\end{array}$ & $\begin{array}{l}\text { Responsable de } \\
\text { Transferencia de Tecnología } \\
\text { del PTA }\end{array}$ & $\begin{array}{l}\text { Parque Tecnológico de Andalucía } \\
\text { S.A. / www.pta.es }\end{array}$ \\
\hline 2 & Itália & $\begin{array}{l}\text { Alessandro Zampagna / } \\
\text { a.zampagna@centuria-rit.com }\end{array}$ & General Manager & Centuria RIT / www.centuria.com \\
\hline 3 & Brasil & $\begin{array}{l}\text { Paulo Tadeu Leite Arantes / } \\
\text { paulo@ufv.br }\end{array}$ & $\begin{array}{l}\text { Diretor Executivo do } \\
\text { CENTEV/UFV }\end{array}$ & $\begin{array}{l}\text { Parque Tecnológico de Viçosa - } \\
\text { PTV / www.centev.ufv.br }\end{array}$ \\
\hline 4 & Brasil & $\begin{array}{l}\text { Eduardo Grizendi / } \\
\text { egrizendi@inova.unicamp.br }\end{array}$ & $\begin{array}{l}\text { Diretor de Apoio a } \\
\text { Incubadoras e Parques } \\
\text { Tecnológicos }\end{array}$ & $\begin{array}{l}\text { Parque Tecnológico de Campinas } \\
\text { / www.inova.unicamp/parque }\end{array}$ \\
\hline 5 & China & Alfred Yu / alfred.yu@hkstp.org & Marketing \& Admission & $\begin{array}{l}\text { Hong Kong Science \& Technology } \\
\text { Parks Corporation /www.hkstp.org }\end{array}$ \\
\hline 6 & Portugal & $\begin{array}{l}\text { Patricia Lencastre / patricia. } \\
\text { lancastre@madeiratecnopolo.pt }\end{array}$ & $\begin{array}{l}\text { Image and Communication } \\
\text { Office }\end{array}$ & $\begin{array}{l}\text { Pólo Científico da Madeira / } \\
\text { www.madeiratecnopolo.pt }\end{array}$ \\
\hline 7 & Brasil & $\begin{array}{l}\text { Ricardo Melo Bastos / } \\
\text { bastos@pucrs.br }\end{array}$ & $\begin{array}{l}\text { Diretor da Agência de } \\
\text { Gestão Tecnológica }\end{array}$ & $\begin{array}{l}\text { Parque Cient. e Tecn. da PUCRS } \\
\text { - TECNOPUC / www.pucrs.br/agt }\end{array}$ \\
\hline 8 & Alemanha & $\begin{array}{l}\text { Dr Werner Willms / w.willms@ig- } \\
\text { technologiepark.de }\end{array}$ & $\begin{array}{l}\text { Managing Director "Interest } \\
\text { Group Technology Park } \\
\text { Bremen" }\end{array}$ & $\begin{array}{l}\text { Technologiepark Bremen / } \\
\text { www.technologiepark-bremen.de }\end{array}$ \\
\hline 9 & Uruguai & $\begin{array}{l}\text { Alfredo Belo / } \\
\text { abelo@datalink.com.uy }\end{array}$ & Project Manager & $\begin{array}{l}\text { Polo Tecnológico de Pando / } \\
\text { www.polotecnologico.fq.edu.uy }\end{array}$ \\
\hline 10 & Alemanha & $\begin{array}{l}\text { Marion Kronabel / } \\
\text { marion.kronabel@heildelberg.de }\end{array}$ & Deputy Managing Director & $\begin{array}{l}\text { Technologiepark Heildelberg / } \\
\text { www.technologiepark-hd.de }\end{array}$ \\
\hline 11 & Itália & $\begin{array}{l}\text { Marco di Cápua / } \\
\text { marco.dicapua@tecnoparco.it }\end{array}$ & Project Development & $\begin{array}{l}\text { Parco Tecnologico Padano / } \\
\text { www.tecnoparco.org/ }\end{array}$ \\
\hline 12 & Turquia & $\begin{array}{l}\text { Mesut Kose / mesut.kose@irc- } \\
\text { anatolia.org.tr }\end{array}$ & $\begin{array}{l}\text { General Manager (IRC- } \\
\text { Anatolia Project) }\end{array}$ & $\begin{array}{l}\text { Metu-Technolopolis / } \\
\text { www.metutech.metu.edu.tr }\end{array}$ \\
\hline 13 & Itália & $\begin{array}{l}\text { Gabriele Gatti / } \\
\text { gabriele.gatti@area.trieste.it }\end{array}$ & $\begin{array}{l}\text { Director Marketing \& } \\
\text { International Relations }\end{array}$ & $\begin{array}{l}\text { AREA Science Park / } \\
\text { www.area.trieste.it }\end{array}$ \\
\hline 14 & Turquia & $\begin{array}{l}\text { Hanzade Saricicek / } \\
\text { havci@cyberpark.com.tr }\end{array}$ & $\begin{array}{l}\text { Institutional Development } \\
\text { Manager }\end{array}$ & $\begin{array}{l}\text { Ankara Cyberpark / } \\
\text { www.cyberpark.tr }\end{array}$ \\
\hline 15 & $\begin{array}{l}\text { Reino } \\
\text { Unido }\end{array}$ & $\begin{array}{l}\text { Dr. Malcom Parry / } \\
\text { malcolm@ozymal.demon.co.uk }\end{array}$ & Director and CEO & $\begin{array}{l}\text { The Surrey Research Park / } \\
\text { www.surrey-research-park.com }\end{array}$ \\
\hline
\end{tabular}




\subsection{Consolidação dos resultados da pesquisa}

Os resultados da pesquisa são apresentados nos seguintes tópicos: respostas das questões fechadas, respostas das questões abertas, caracterização dos respondentes e observações pessoais a partir do resultado da interação desta pesquisadora com os respondentes nas experiências visitadas.

\subsubsection{Respostas das questões fechadas}

\subsubsection{Questões de abertura}

As duas primeiras questões do instrumento de pesquisa estão enquadradas na categoria da dimensão dos serviços do conhecimento, porém não vinculadas a nenhuma subdimensão. São questões de abertura e tem como objetivo verificar se os parques são provedores de serviços do conhecimento e como oferecem esses serviços.

\begin{tabular}{|l|c|c|}
\hline \multicolumn{1}{|c|}{$1^{\text {a }}$ Questão } & Sim & Não \\
\hline O Parque oferece serviços do conhecimento às $\mathrm{PME}^{1}$ ? & $100 \%$ & - \\
\hline
\end{tabular}

Todos os Parques da amostra se categorizaram como provedores de serviços do conhecimento.

\begin{tabular}{|l|c|c|c|}
\hline \multicolumn{1}{|c|}{$2^{\text {a }}$ Questão } & Internamente & Terceirizando & Uma mistura de ambos \\
\hline $\begin{array}{l}\text { Se sim, como o Parque oferece os serviços } \\
\text { do conhecimento às PME: }\end{array}$ & $7 \%$ & $7 \%$ & $86 \%$ \\
\hline
\end{tabular}

Na maioria dos PCT (86\%) os serviços do conhecimento são oferecidos tanto pelo próprio Parque como por meio de contratação externa.

\subsubsection{Questões fechadas vinculadas a dimensões e subdimensões da pesquisa}

Na Tabela 5.2 são apresentados os resultados das questões fechadas; eles se referem aos dados quantitativos do e-survey realizada por dimensão e sub-dimensão considerados nesta pesquisa.

\footnotetext{
${ }^{1}$ Considerando não haver um critério único universalmente aceito para definir PME, adotamos para fins desta pesquisa os critérios utilizados pelo SEBRAE que utiliza tanto a receita bruta anual, conforme definido no Estatuto da Micro e Pequena Empresa, de 1999 (microempresa com receita bruta anual igual ou inferior a R\$433.755,14 e empresa de pequeno porte com receita bruta anual superior a $R \$ 433.755,14$ ou inferior a $R \$ 2.133 .222,00$ ); como o conceito de funcionários nas empresas (microempresa na indústria e construção com até 19 funcionários e microempresa no comércio e serviços com até nove funcionários; pequena empresa na indústria e construção com 20 a 99 funcionários e no comércio e serviços com 10 a 49 funcionários). Informações disponíveis no endereço eletrônico http://www.sebrae.com.br/customizado/estudos-e-pesquisas/bia-97-criterio -paraclassificacao-das-empresas/. Acesso em 30/01/2008.
} 

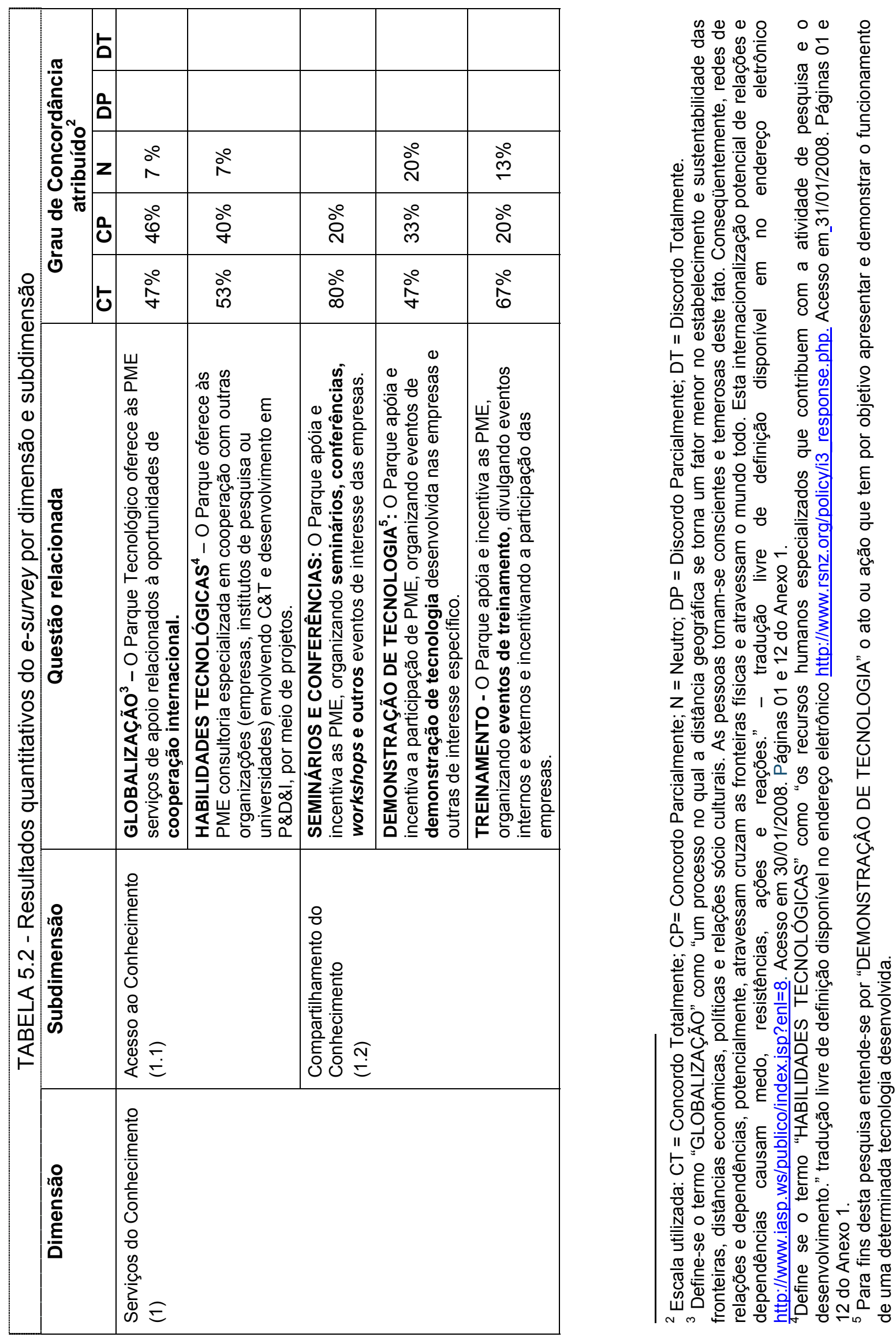


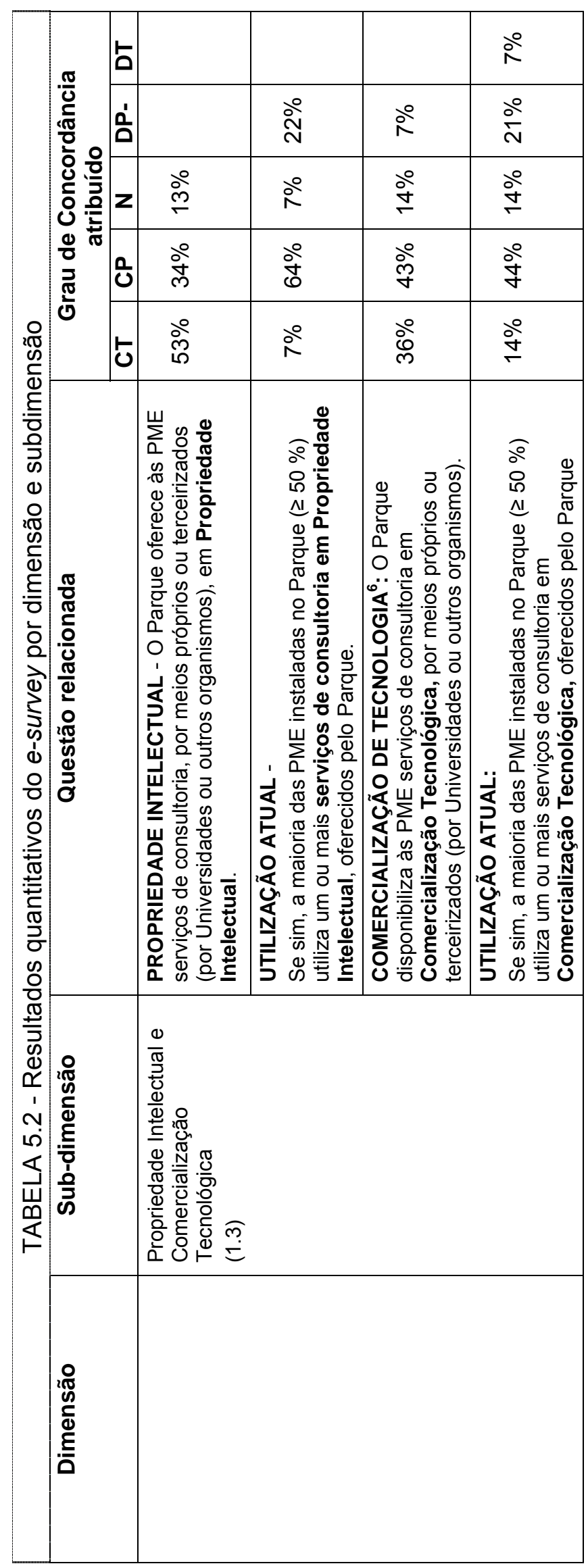

$\frac{1}{0}$

๑

힌 뜬

$\stackrel{0}{\circ} \stackrel{0}{\circ}$

ब.

$\therefore 0$

응

응

은은 은

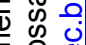

등 응

등응 음

융

ठ 힝

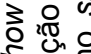

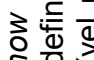

₹

잉

융

뜐ำ

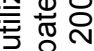

용ํㅆ

옿응

흥믕

。준

일

응흥

잉

잉요용

으음

삔흠

웡

ư

文。

से

엉음

峁㐫

0

을 웡융

Ф 중 문

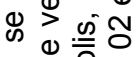

凹 쥰 융

造 


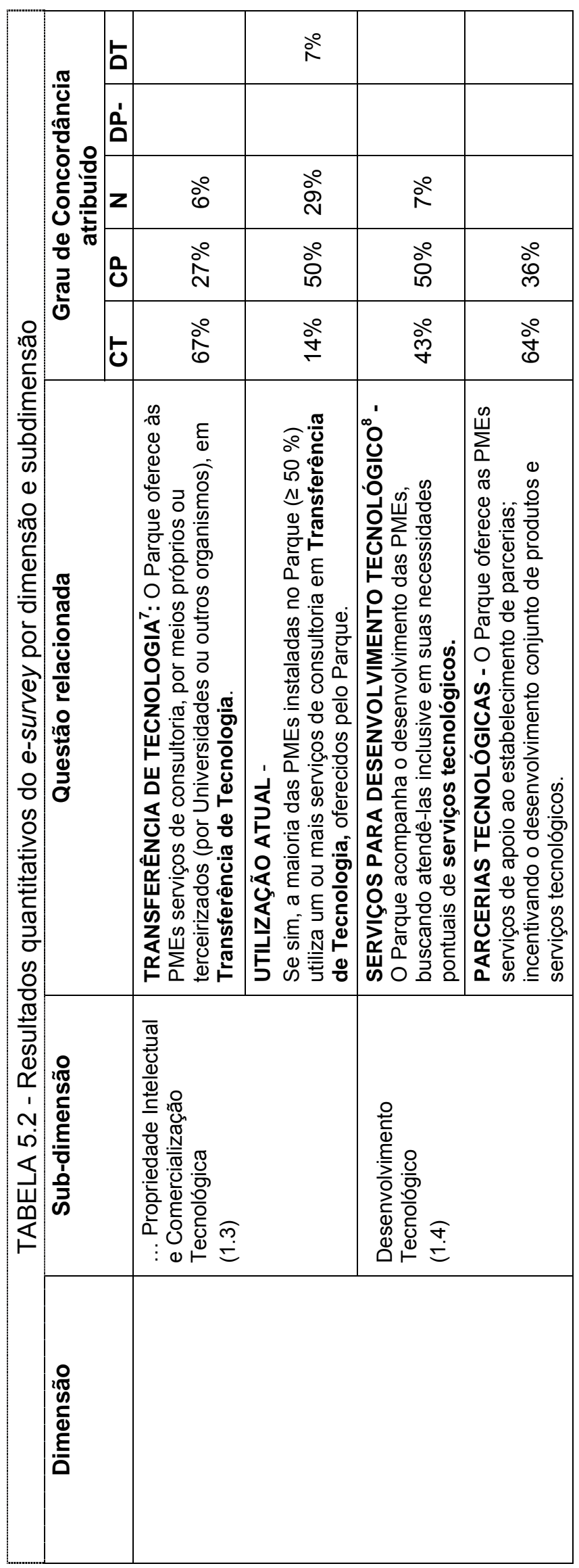

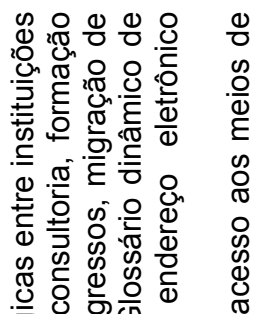

엉

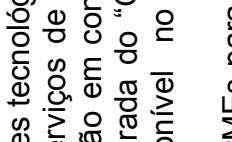

क्ये

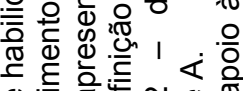

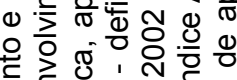

ह

d 는 는 응

다에

ช

응묘

穾 ه

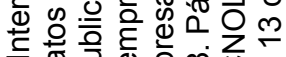

뜡 응 है 윰

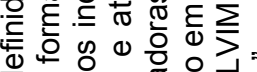

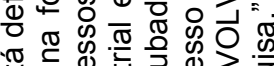
要

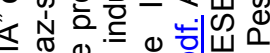
তิ ए

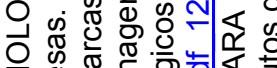

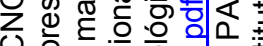
ய है की की 은

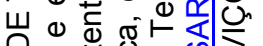

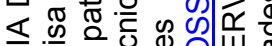

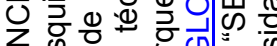
凹

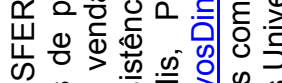
选造

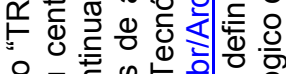

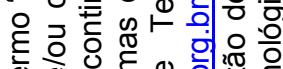

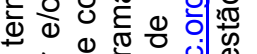

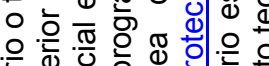

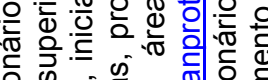
을

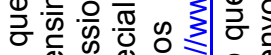

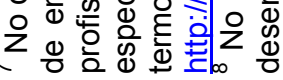




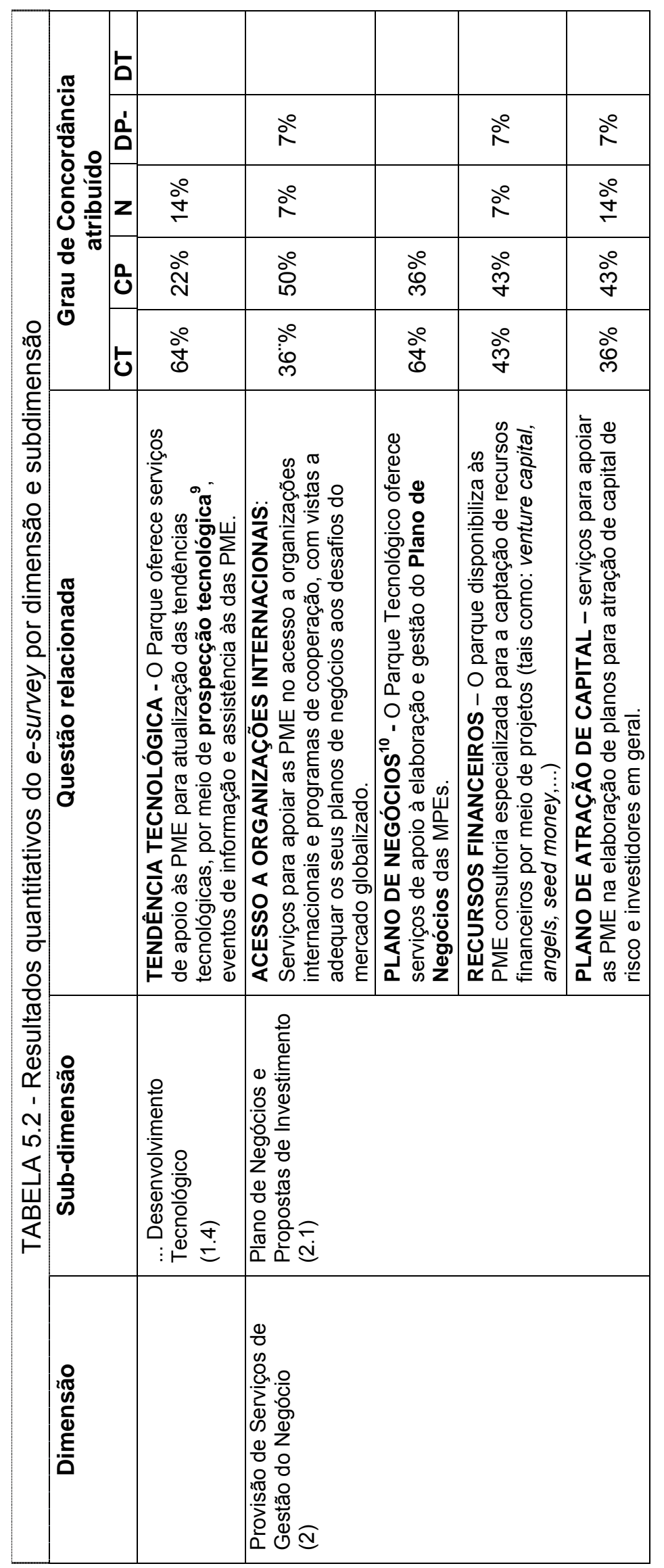

흉

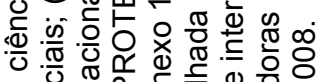

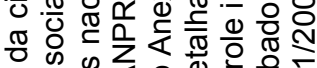

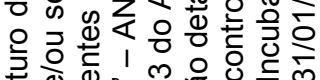

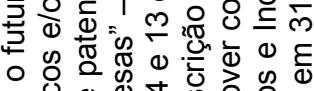

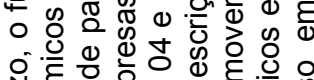
N

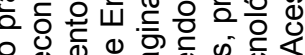

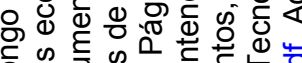

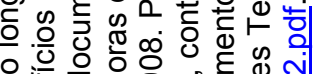

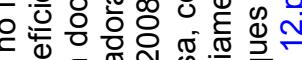

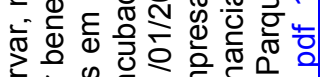

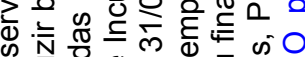
응 긍 을

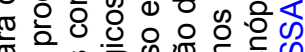
ब (1) 娄 0

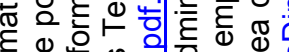
Ф क ⿻ 丨 o

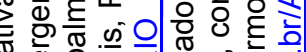
बै 응 ब ๙.

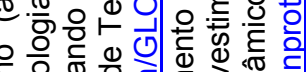

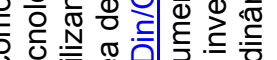

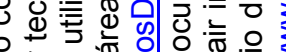

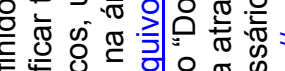

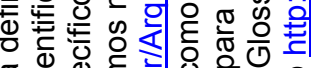

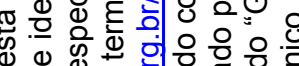

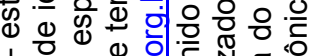

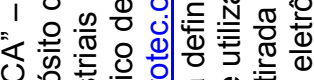
을

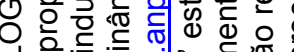

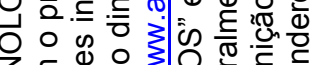

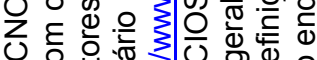
世 80000

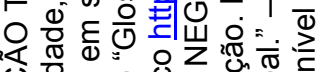
我 U.

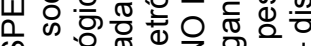

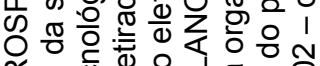

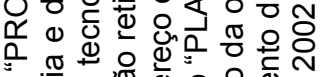
○

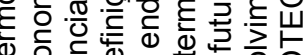
屯 :

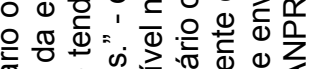

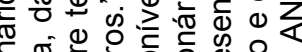

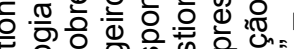
क्ष

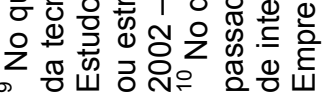



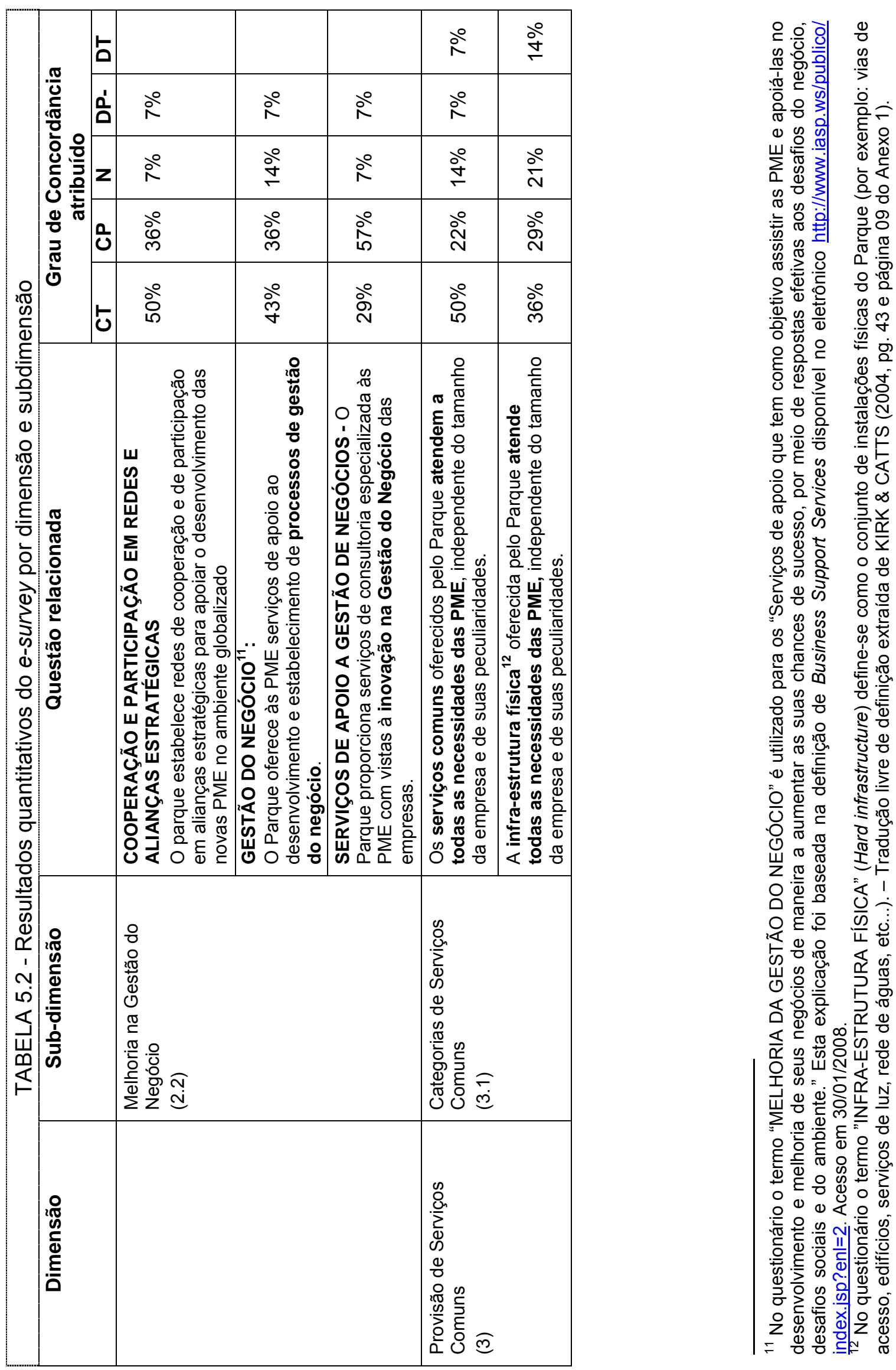


\begin{tabular}{|c|c|c|c|c|c|c|c|c|c|c|}
\hline & & 5 & $\stackrel{\circ}{\wedge}$ & $\stackrel{\stackrel{\circ}{\square}}{\leftarrow}$ & & $\stackrel{\circ}{\wedge}$ & $\stackrel{\circ}{\stackrel{0}{ }}$ & & & $\stackrel{\circ}{\stackrel{0}{ }}$ \\
\hline & 兽 & $\hat{0}$ & & & $\stackrel{\circ}{\stackrel{0}{\alpha}}$ & & & & & \\
\hline & 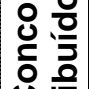 & $\mathbf{z}$ & 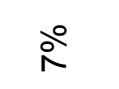 & $\stackrel{\stackrel{\circ}{\square}}{\square}$ & 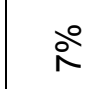 & $\stackrel{\circ}{\stackrel{\circ}{\sim}}$ & $\stackrel{\circ}{\stackrel{\circ}{\square}}$ & & $\stackrel{\circ}{\wedge}$ & 今े \\
\hline & $\frac{\pi}{0}$ & 0 & ○े & సे & ○े & $\begin{array}{l}\text { ¿े } \\
\text { ळे }\end{array}$ & ৯े & $\stackrel{\circ}{\grave{N}}$ & $\stackrel{\stackrel{\circ}{+}}{\leftarrow}$ & $\stackrel{\circ}{\grave{N}}$ \\
\hline i্ & $\overline{0}$ & $\overline{0}$ & $\begin{array}{l}\stackrel{0}{\hat{i}} \\
\text { in }\end{array}$ & ○े & לे̊ & $\stackrel{\text { ڤे }}{\text { ஸे }}$ & $\begin{array}{l}\stackrel{0}{\hat{n}} \\
\text { bे }\end{array}$ & ○े & ○̊ & ஓें \\
\hline 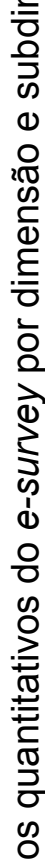 & 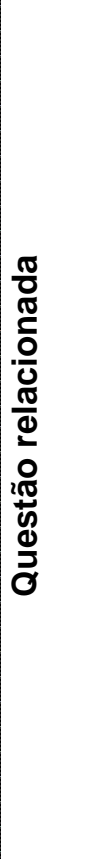 & & 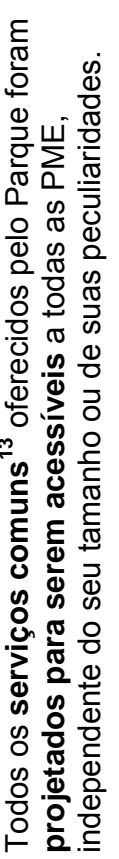 & 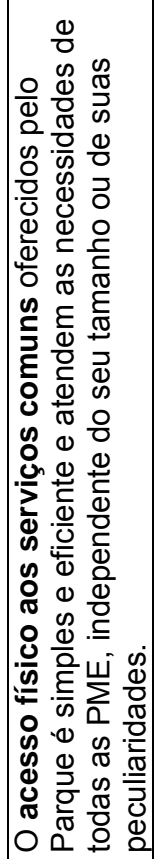 & 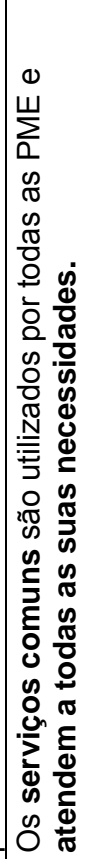 & 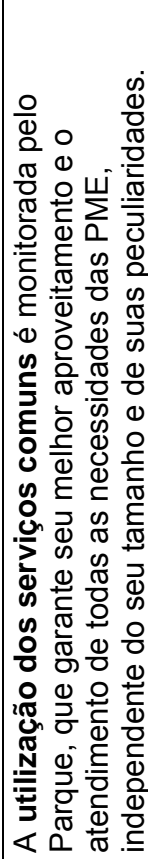 & 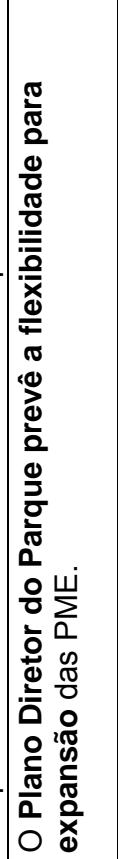 & 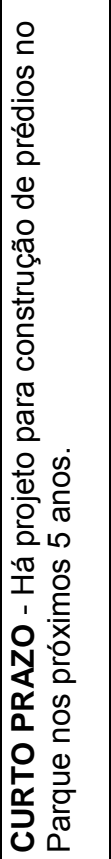 & 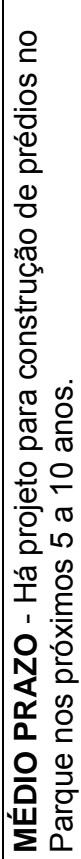 & 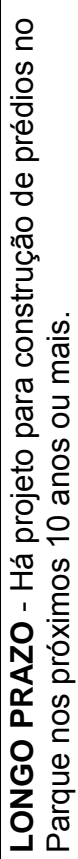 \\
\hline 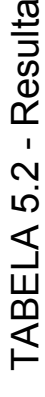 & 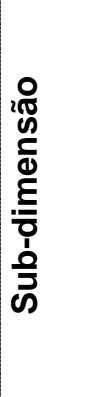 & & 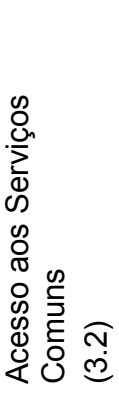 & & 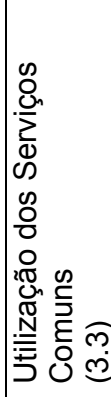 & & 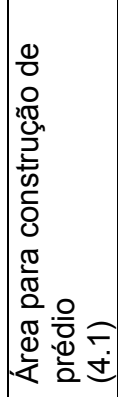 & 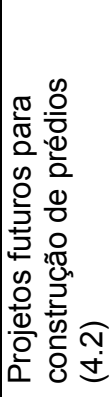 & & \\
\hline & 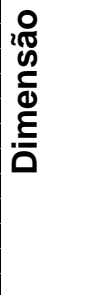 & & & & & & 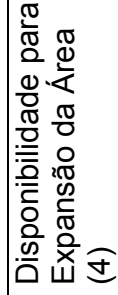 & & & \\
\hline
\end{tabular}

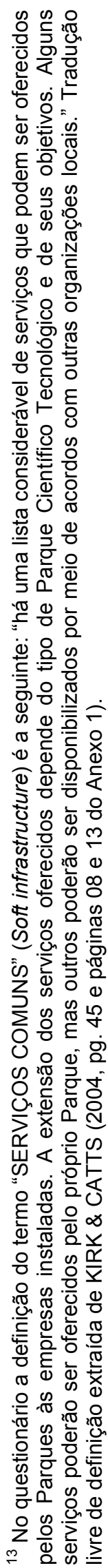




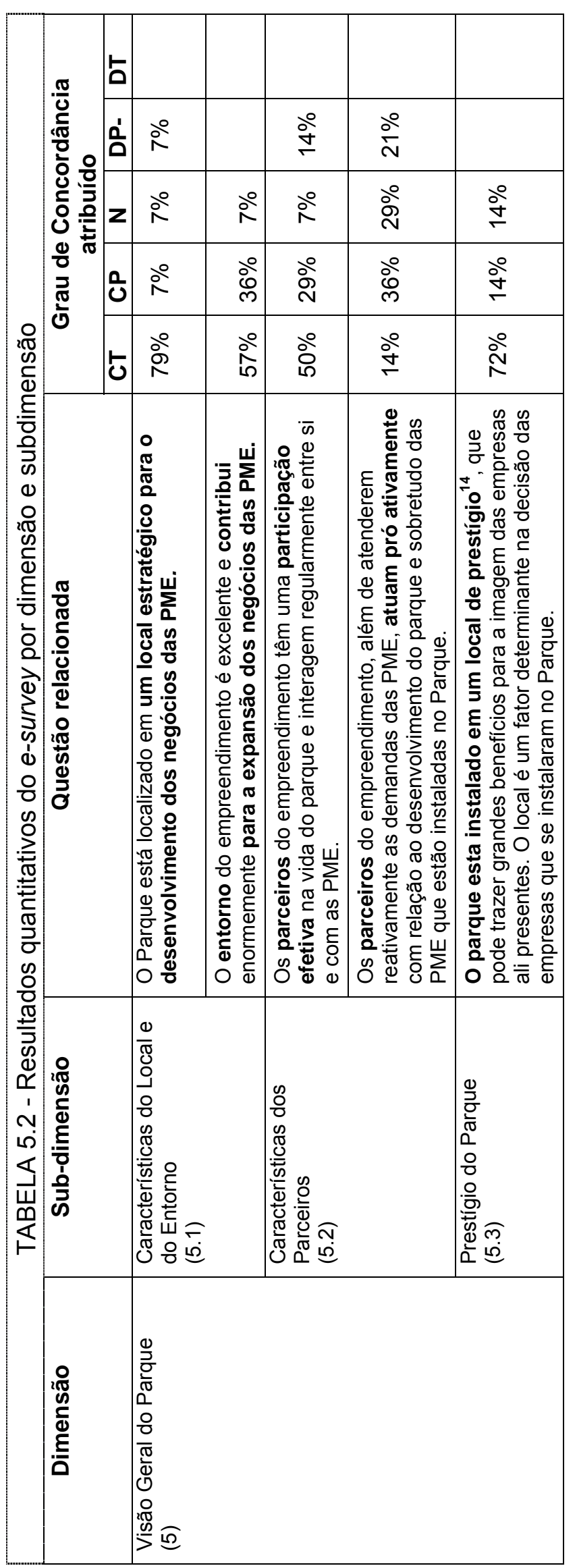

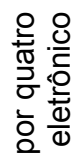

을 원

ᄋ

응 잉

등 융

ㄷㅇㅇ

응

늘

告

क 후

은 운

용

要 经

ड

$\varepsilon \otimes$

용

으을

要

유 $\frac{\pi}{\pi}$

중 0

远

ญ

ํㅓㄹ 토

क

है

0

을 은

造

䨔

응잉

용

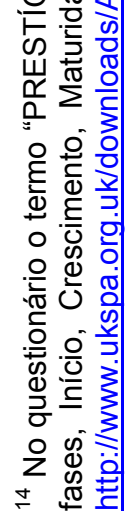




\subsubsection{Respostas das questões abertas}

Na Tabela 5.3 estão apresentados os resultados das questões abertas, eles se referem aos dados qualitativos do e-survey realizado por dimensão e subdimensão considerados nesta pesquisa. 


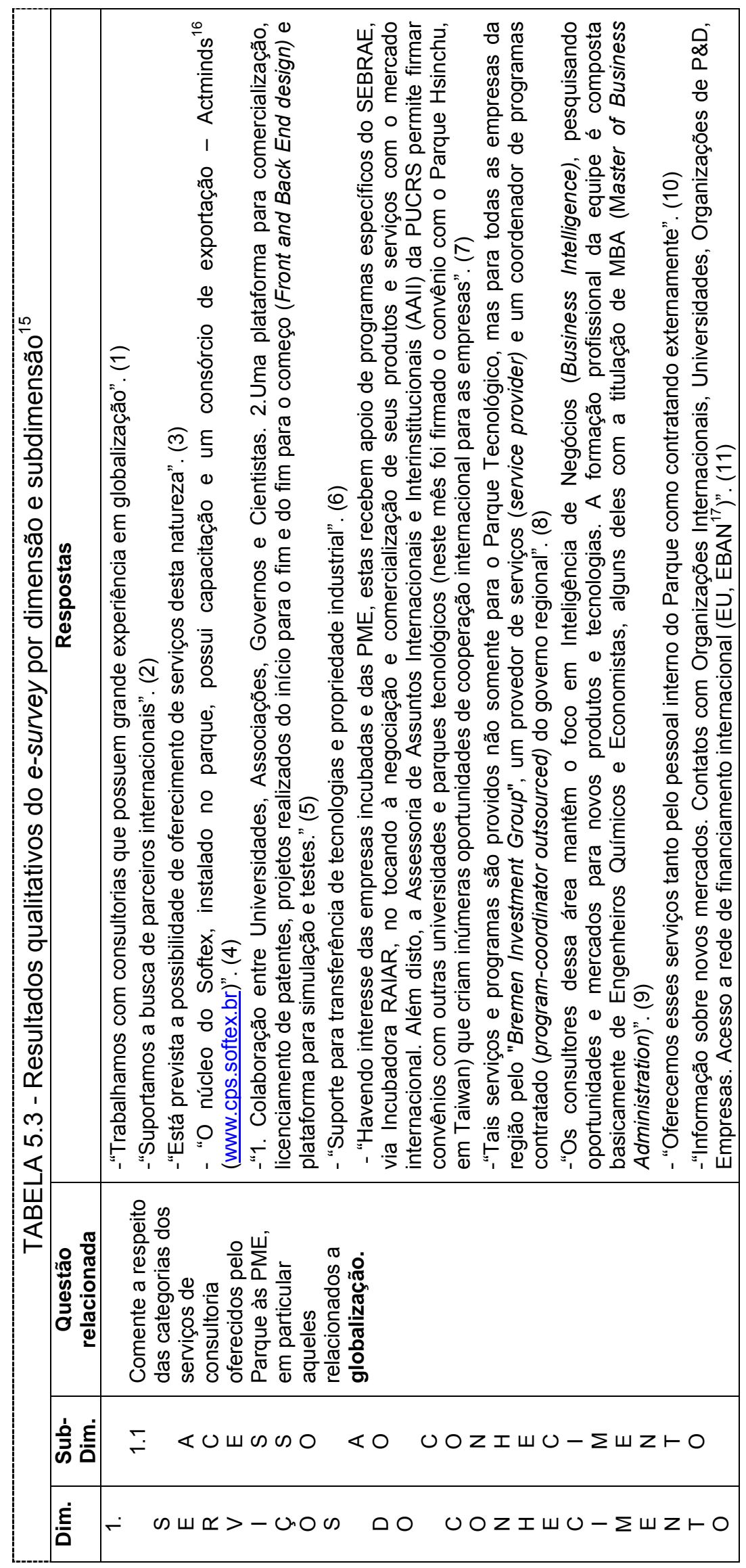

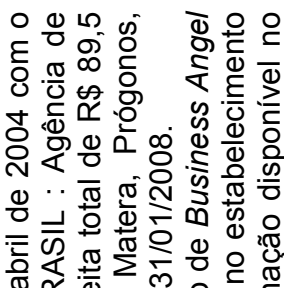

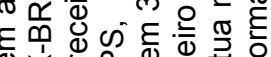

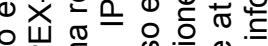

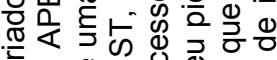
엉

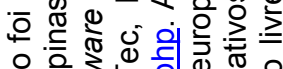

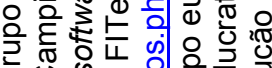
б0 0 \% ஸि

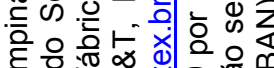
๘்

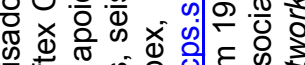
亏气

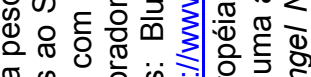
需蛋

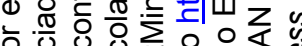

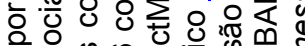

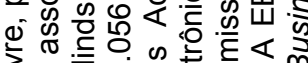

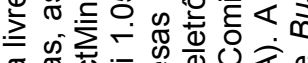
ब.

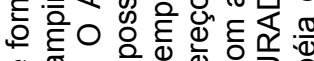

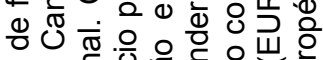
is

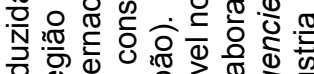
它

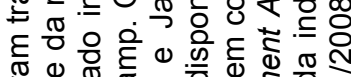

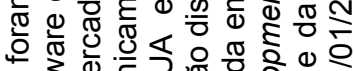

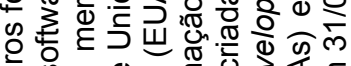

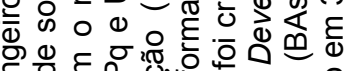

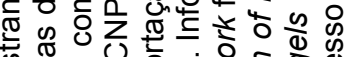
क क्ष

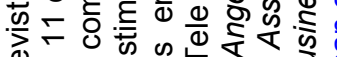
인 00

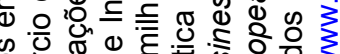
\% 过

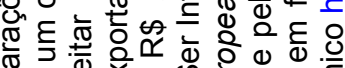
元.

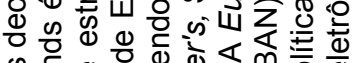
क

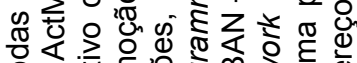

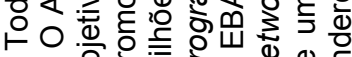




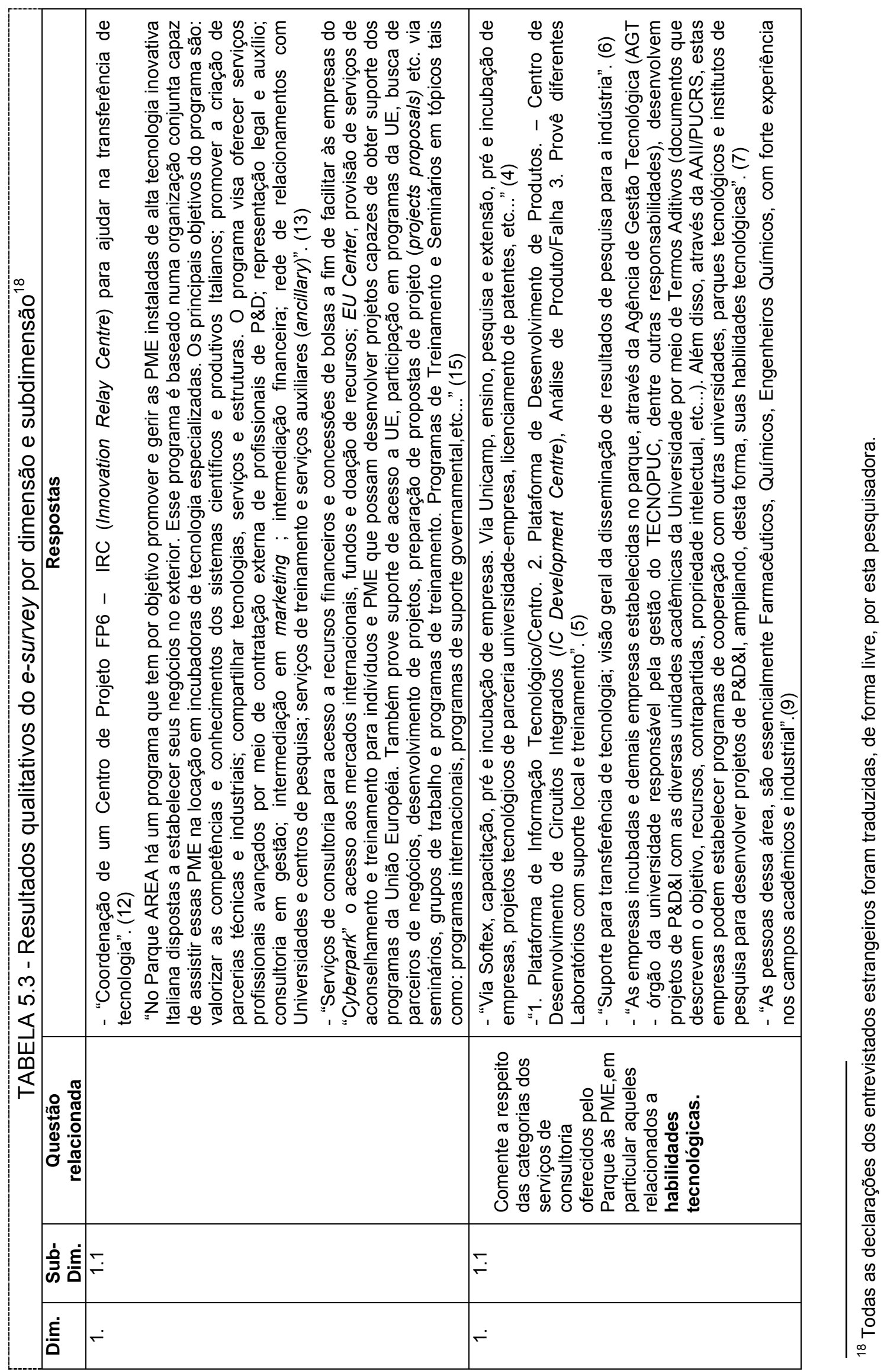




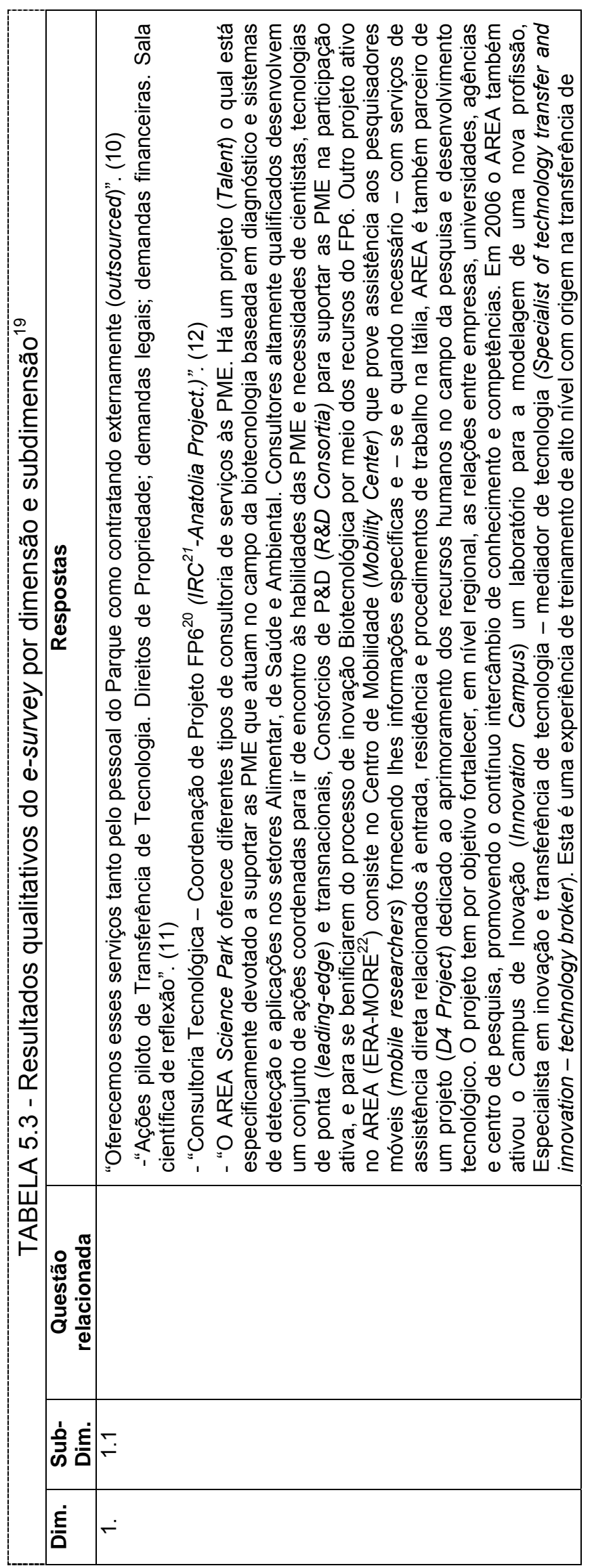

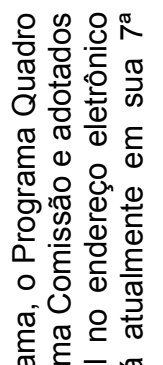

중 $\frac{1}{5} \bar{\Phi}$

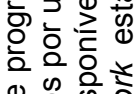

응 융 응 훙

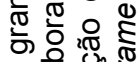

들 $\frac{0}{0}$

웡

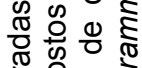

후응 항

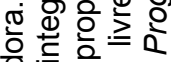

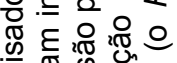

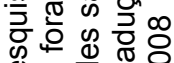

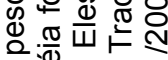

䨢 응

元 $\frac{0}{4} m$

¿워용

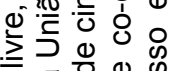

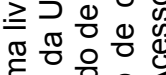

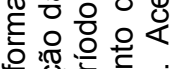

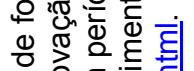

is.

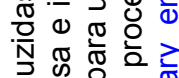

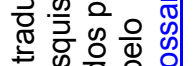

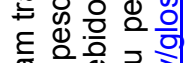

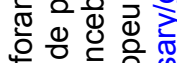

이의

ब.

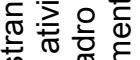

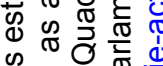

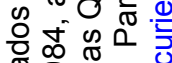

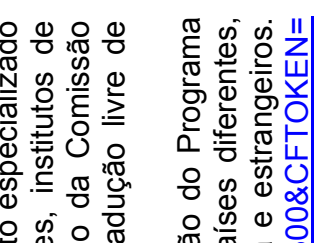

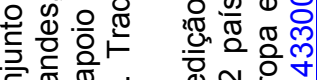

ठํำ

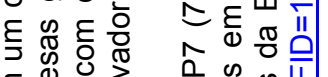

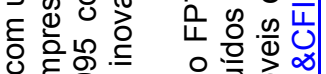

बाँ

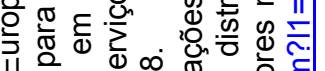

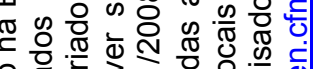

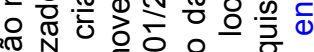

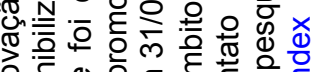

ว 厄.

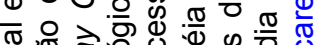

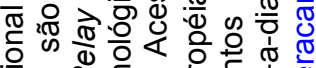

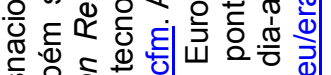

कृ

ฮั

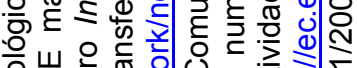

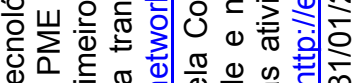

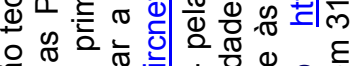

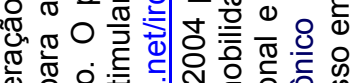

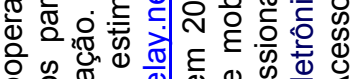

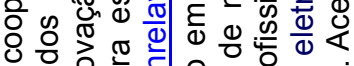
๘

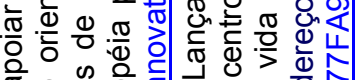

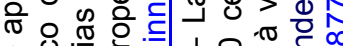
๑.

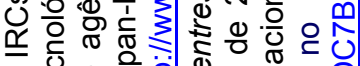
\% ఖ

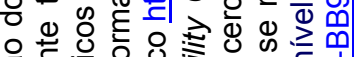

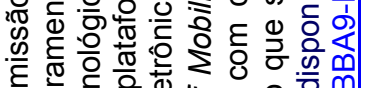

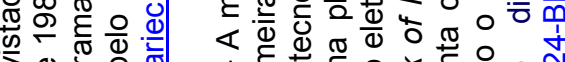

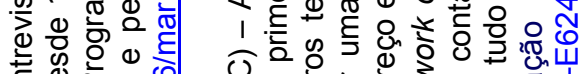

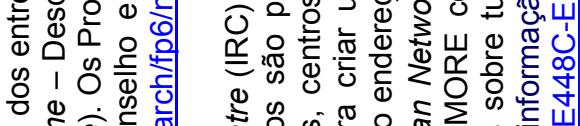

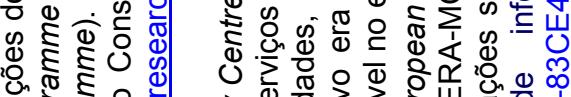

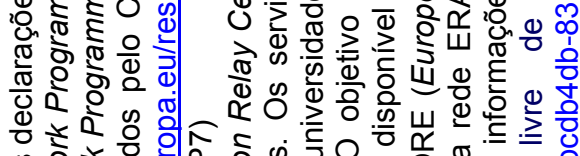

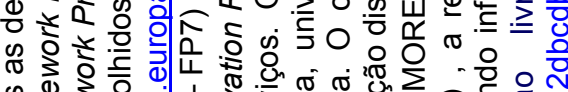

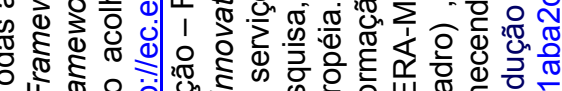

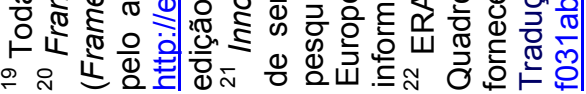




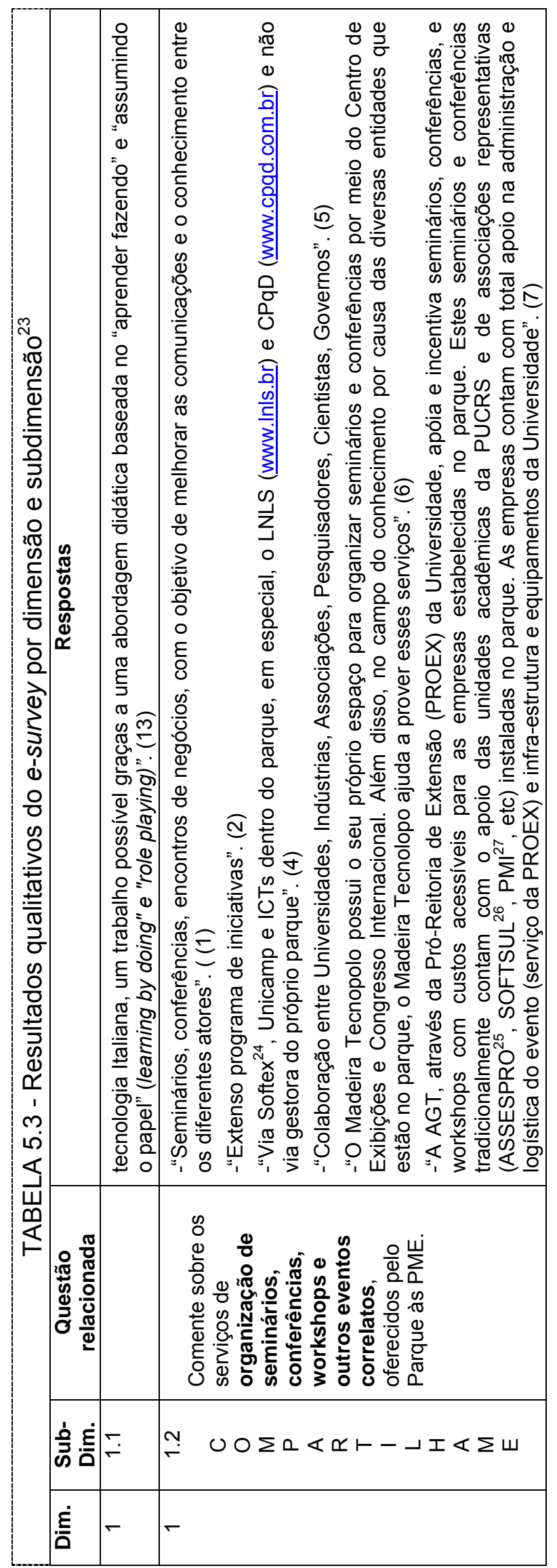

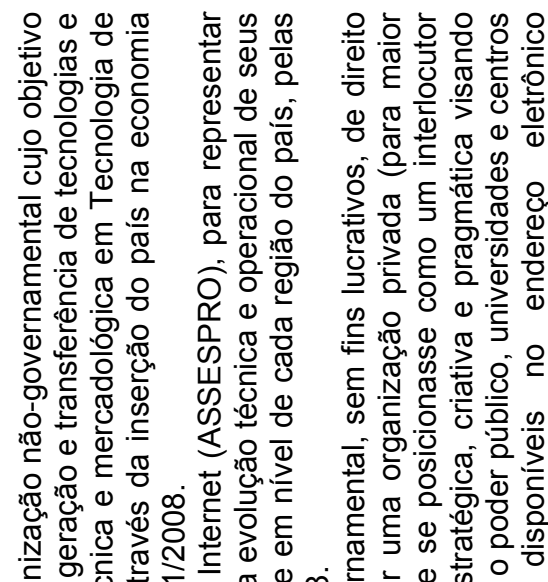

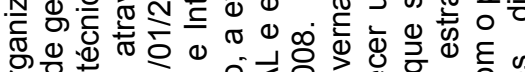

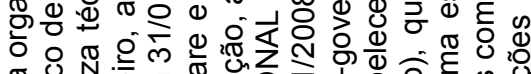

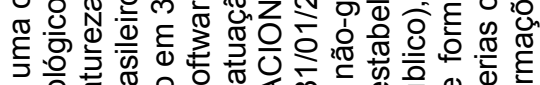

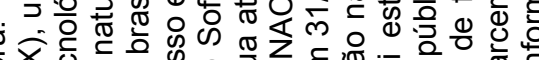

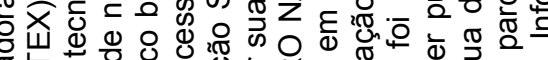

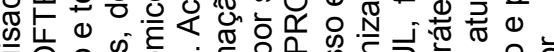

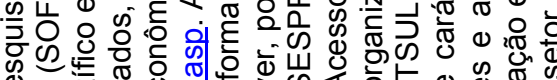

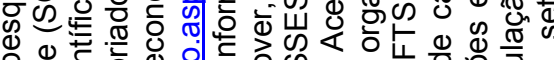

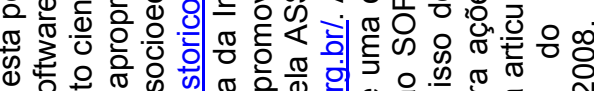

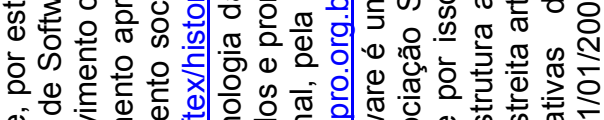
बं

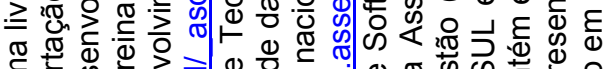

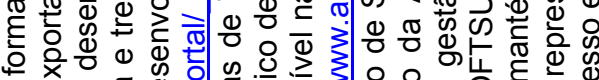

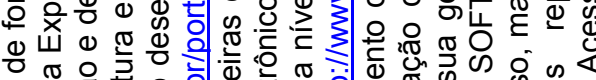

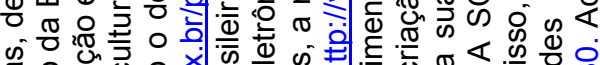

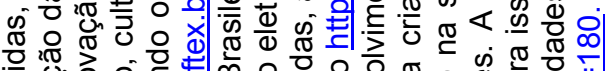

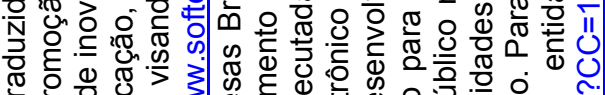

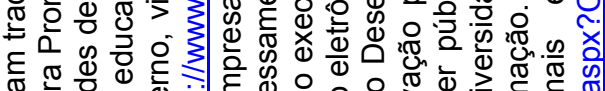

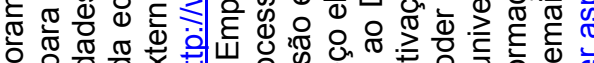

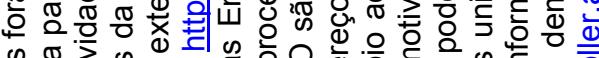

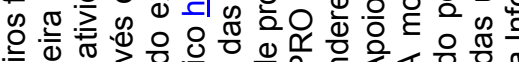

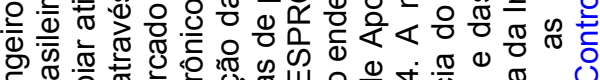

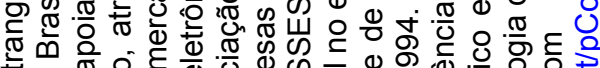
\% i)

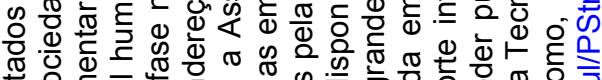

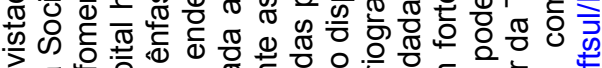

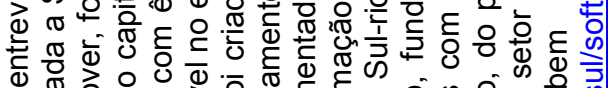

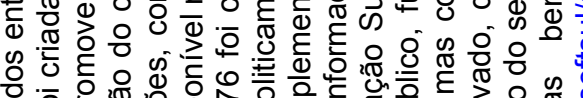

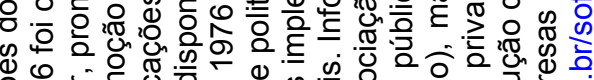

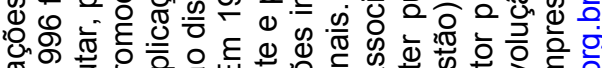

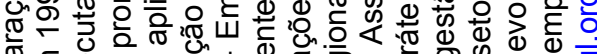

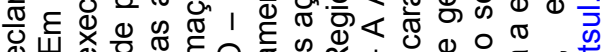

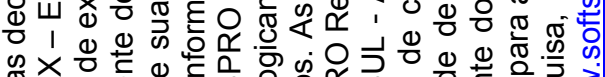

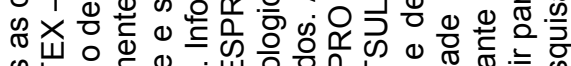
先吉 


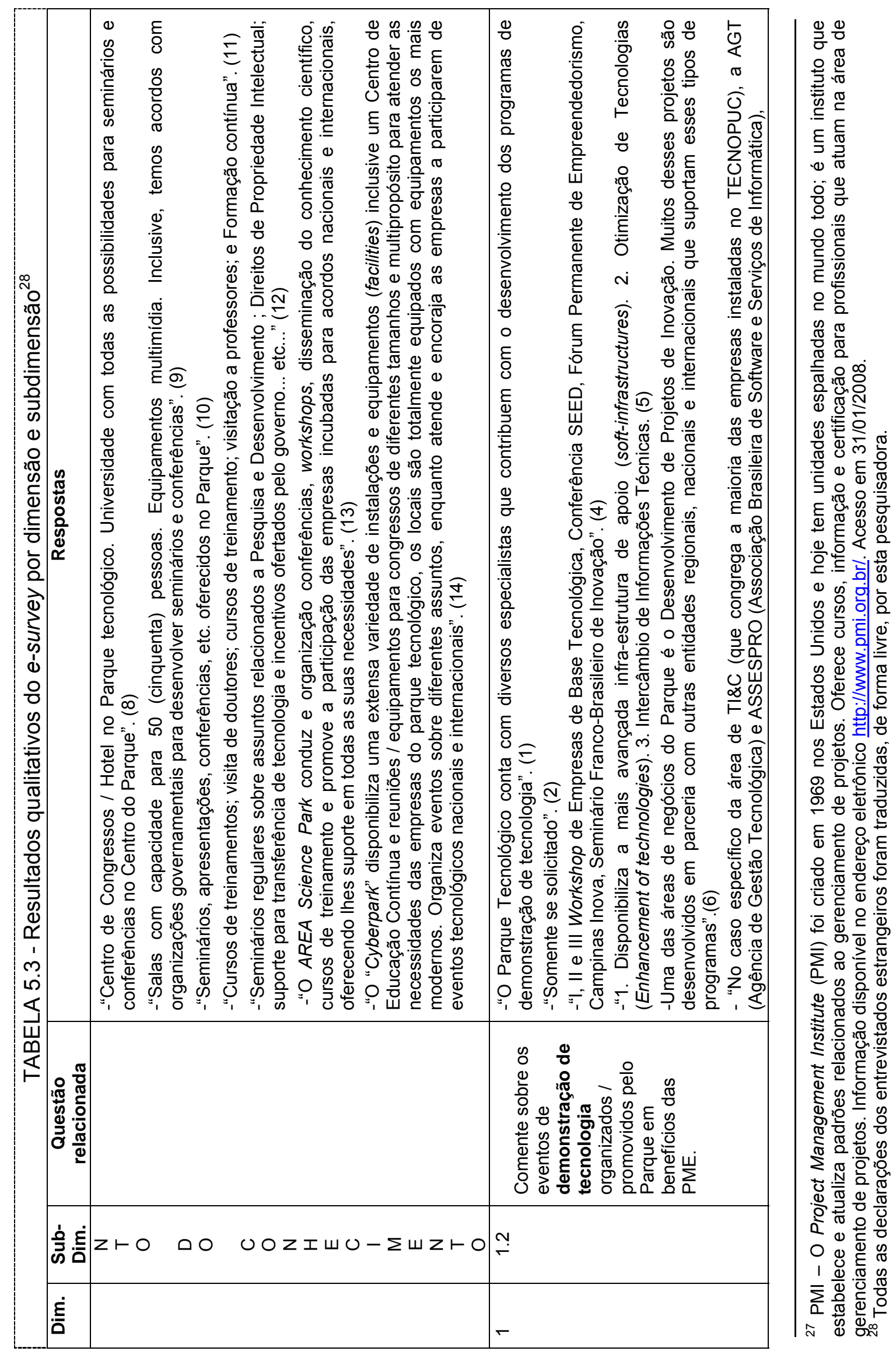




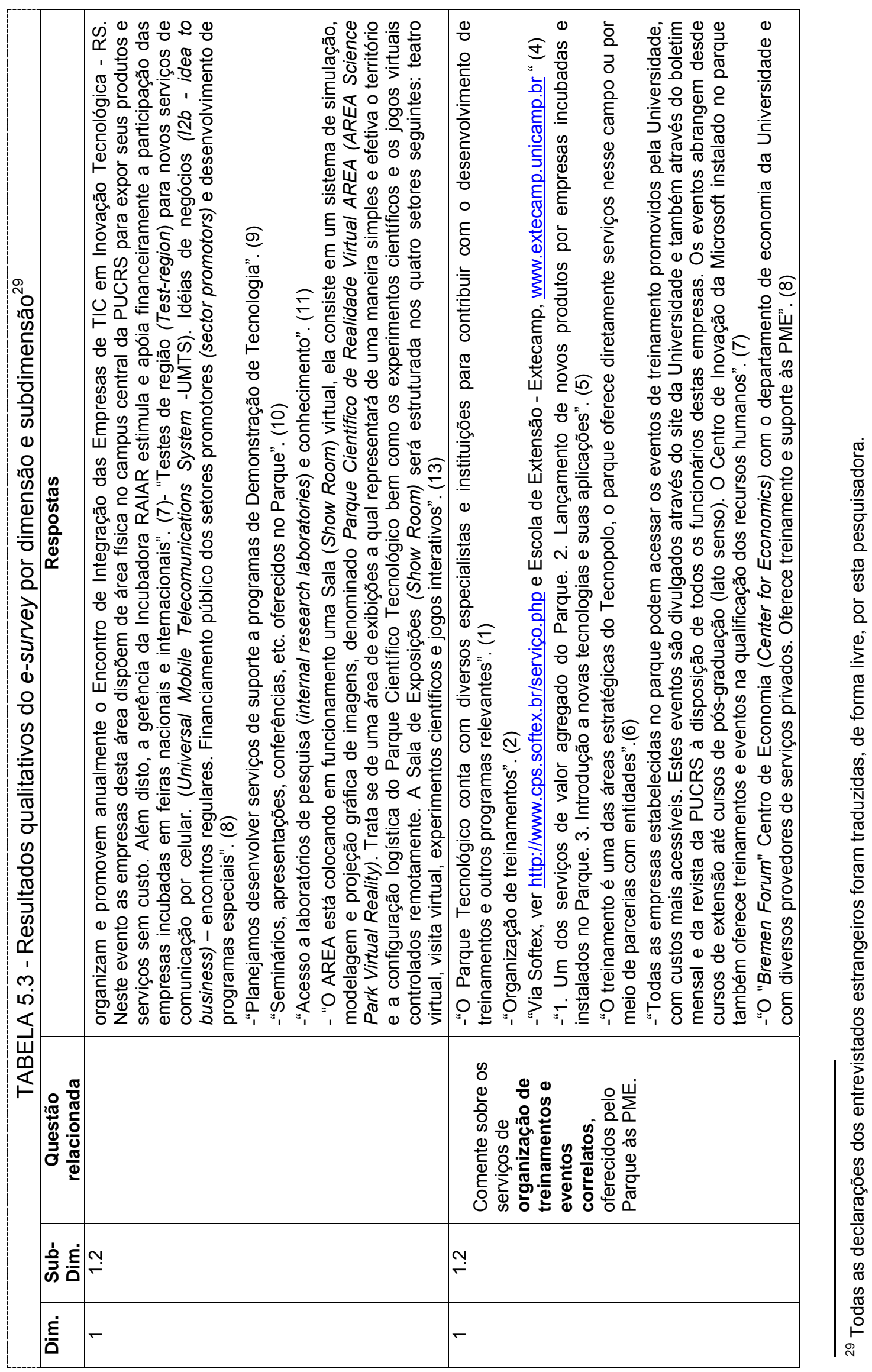




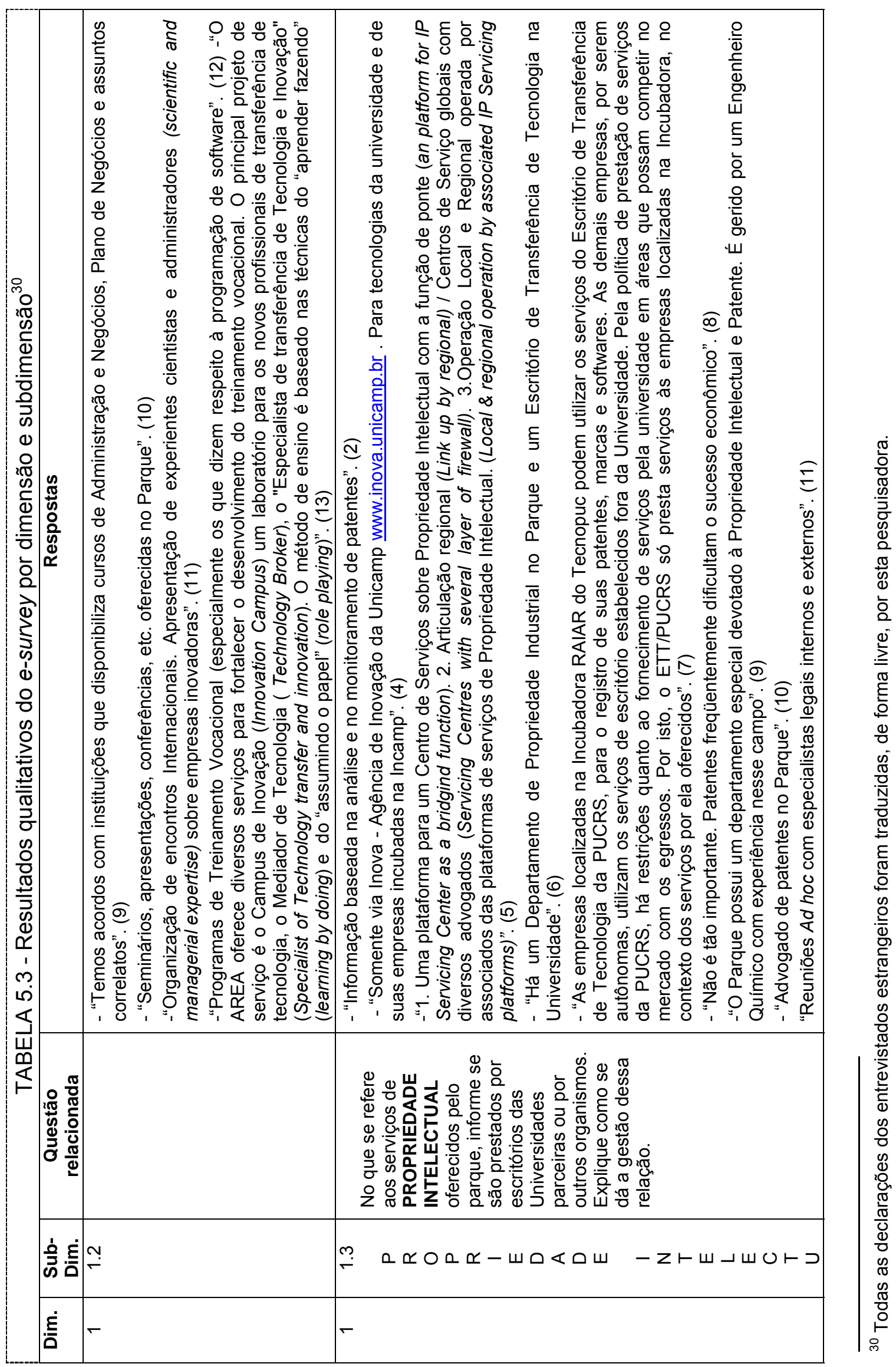




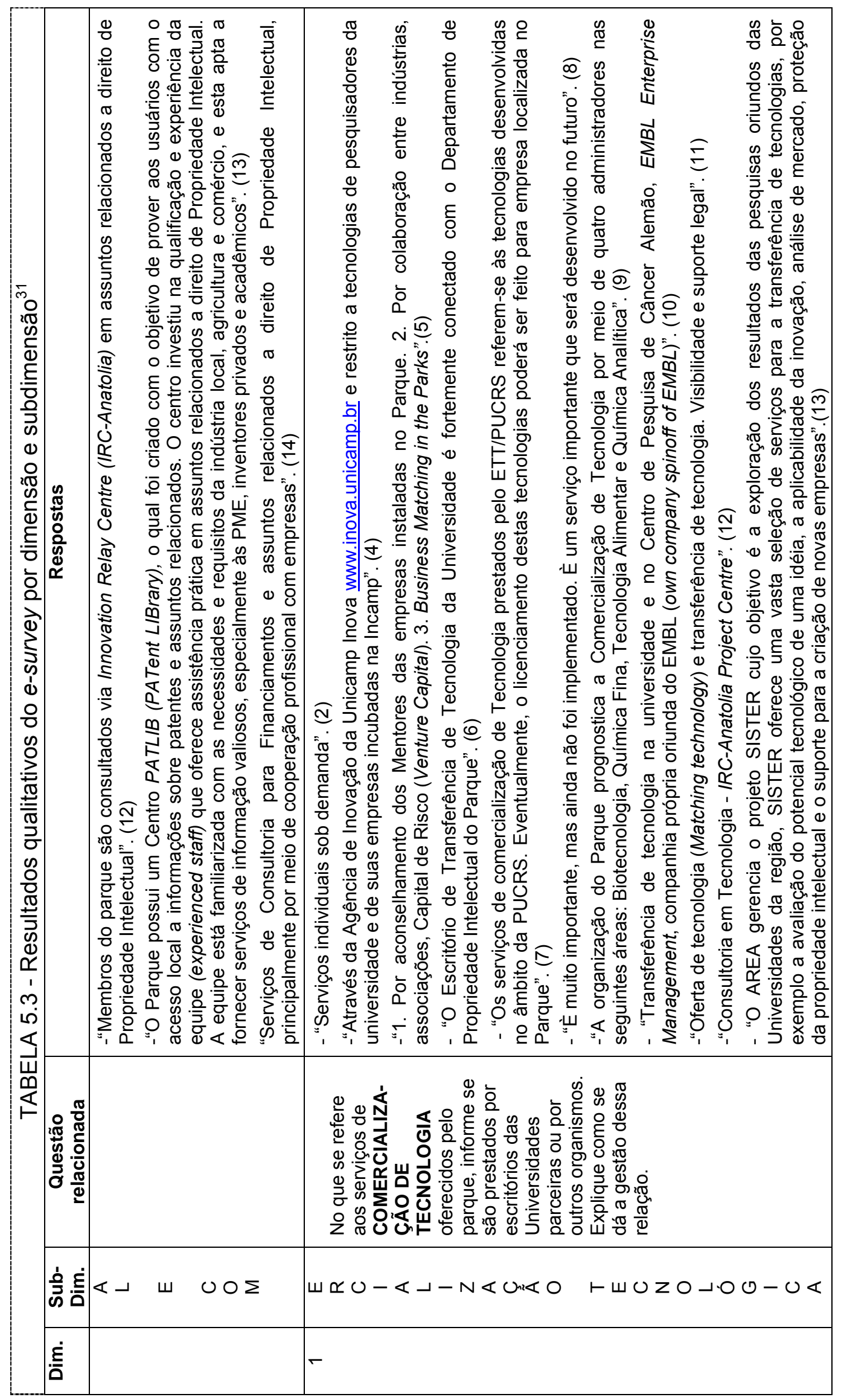

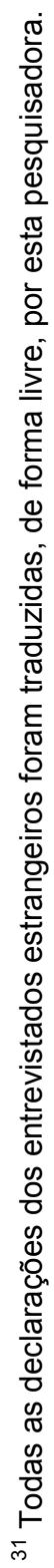




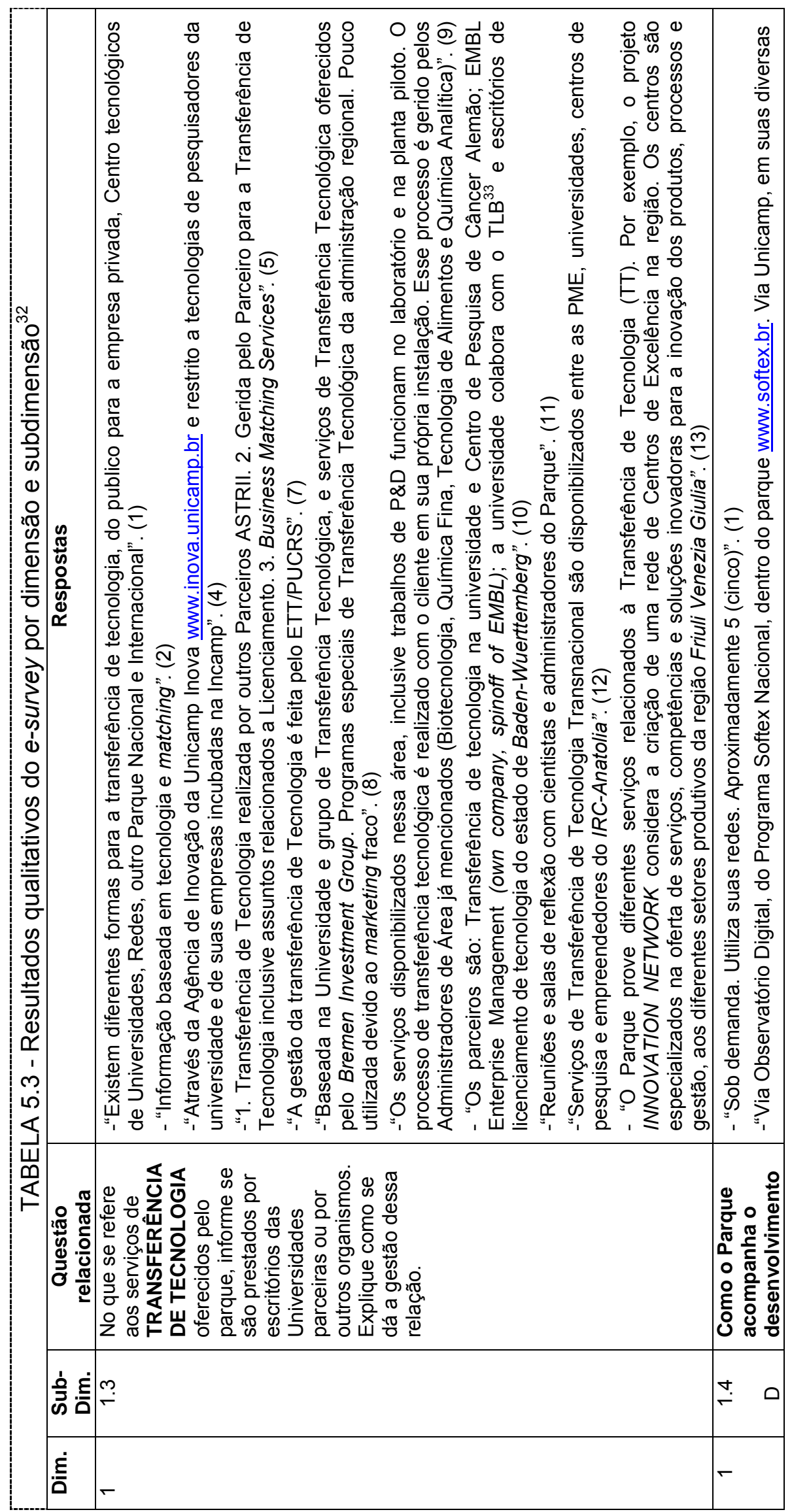

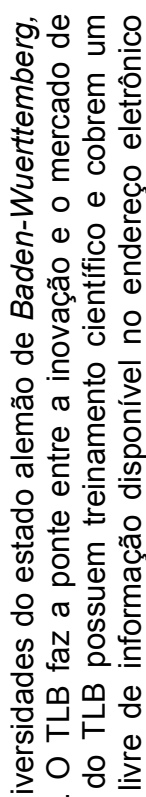

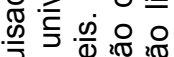

可 90.

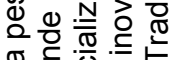

要迹㐘

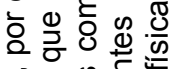

ब.

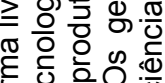

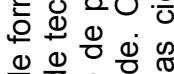

is 운 융 $\frac{\pi}{0}$

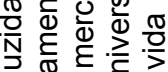

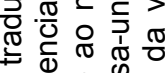

$\varepsilon$.

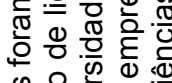

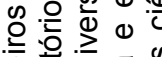

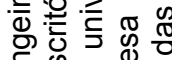

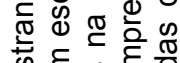

क्ष

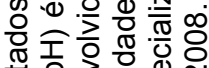

क्षे

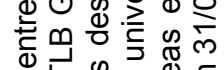

ڤै

की

吕N.

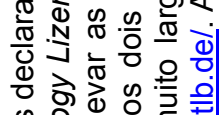

융응 응

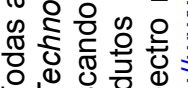

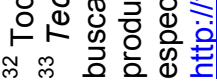




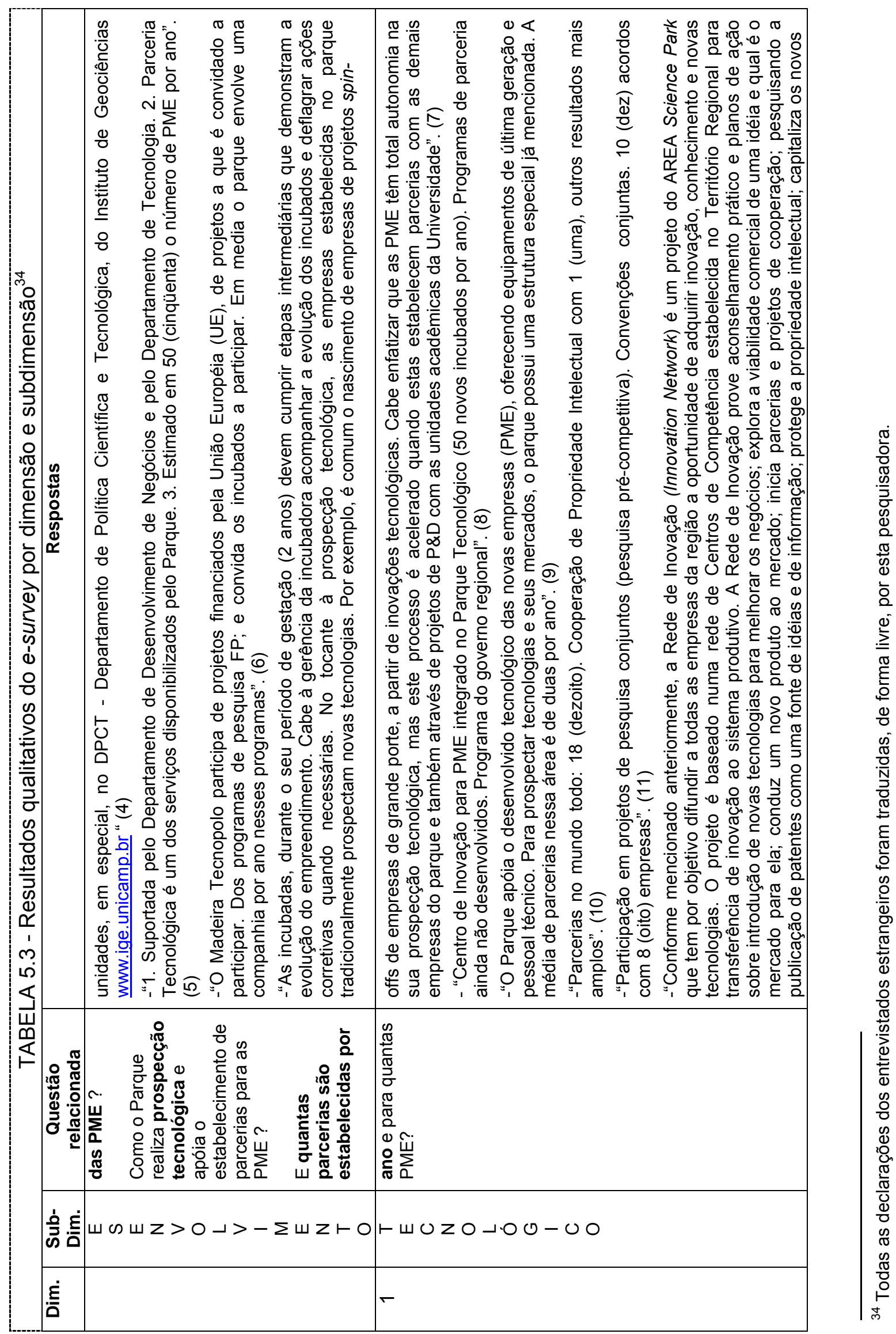




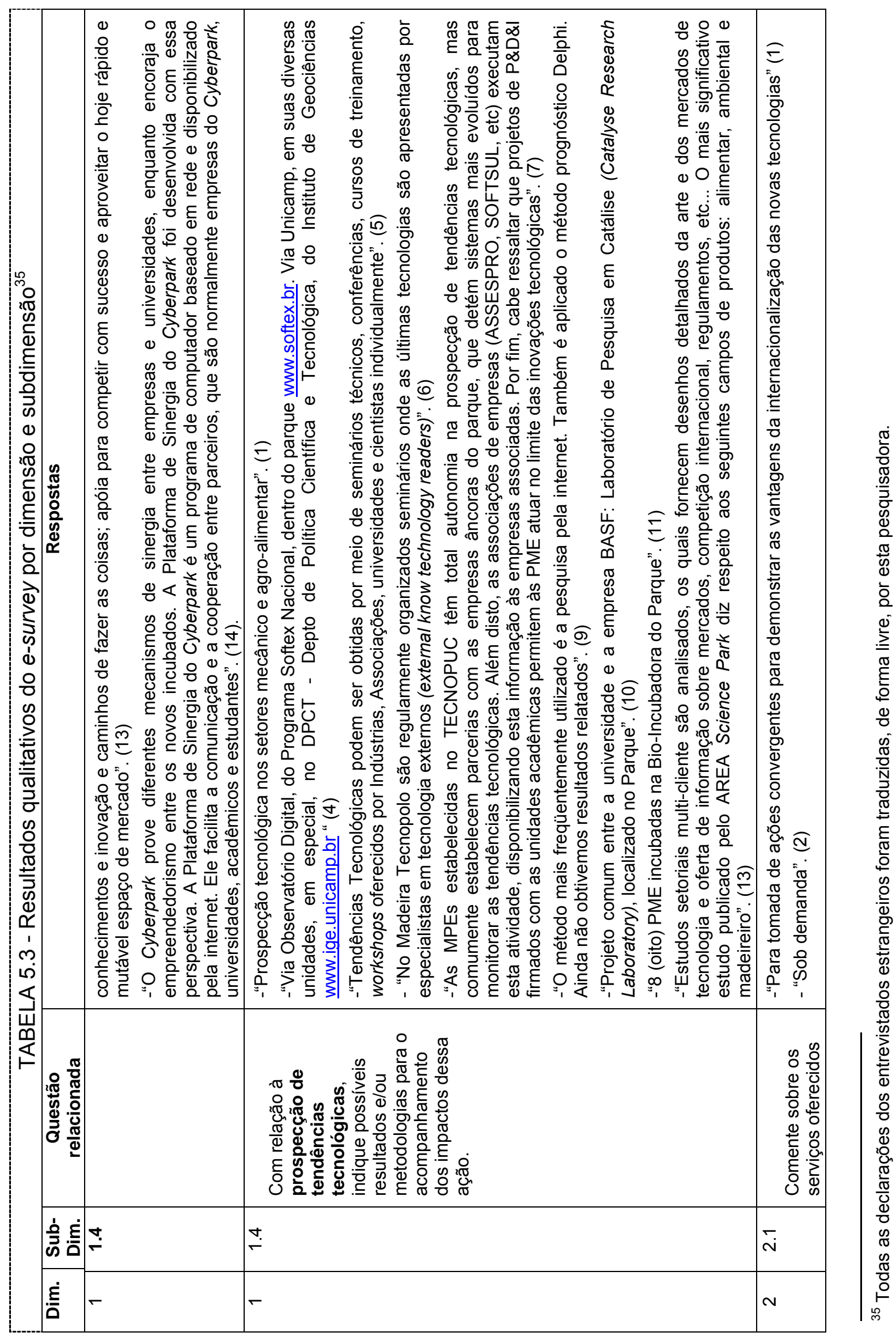




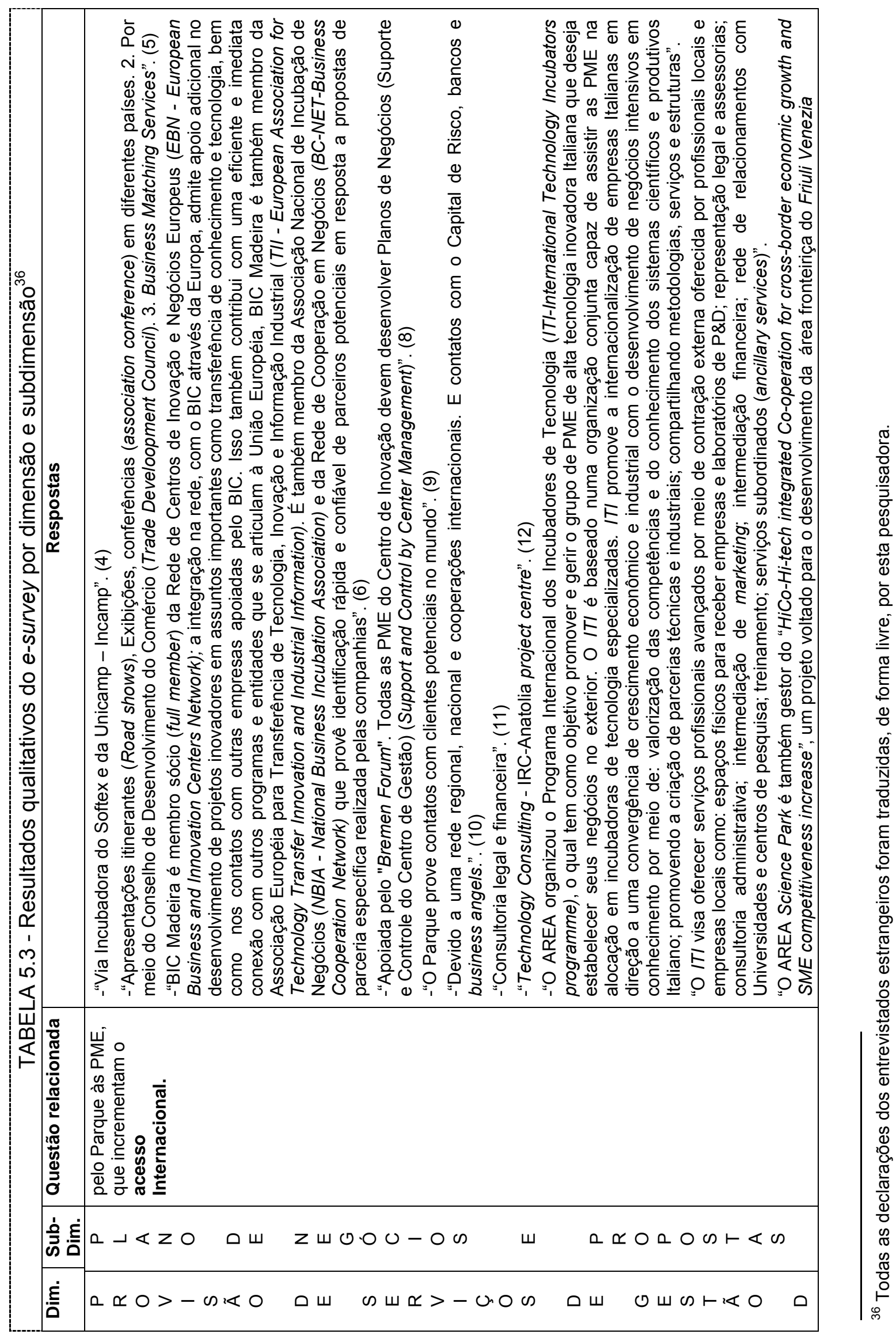




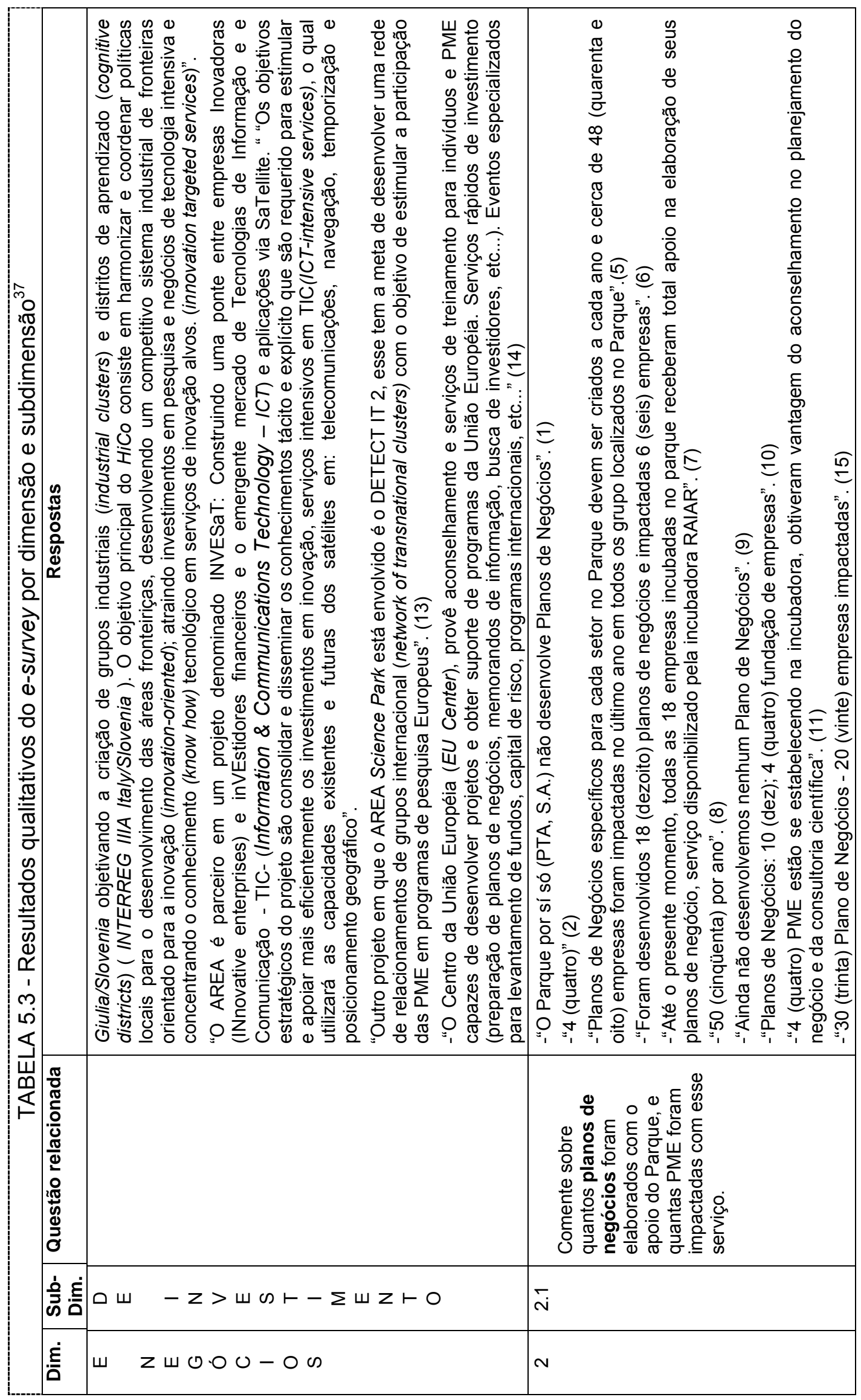

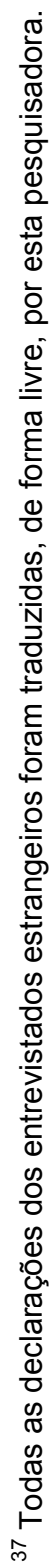




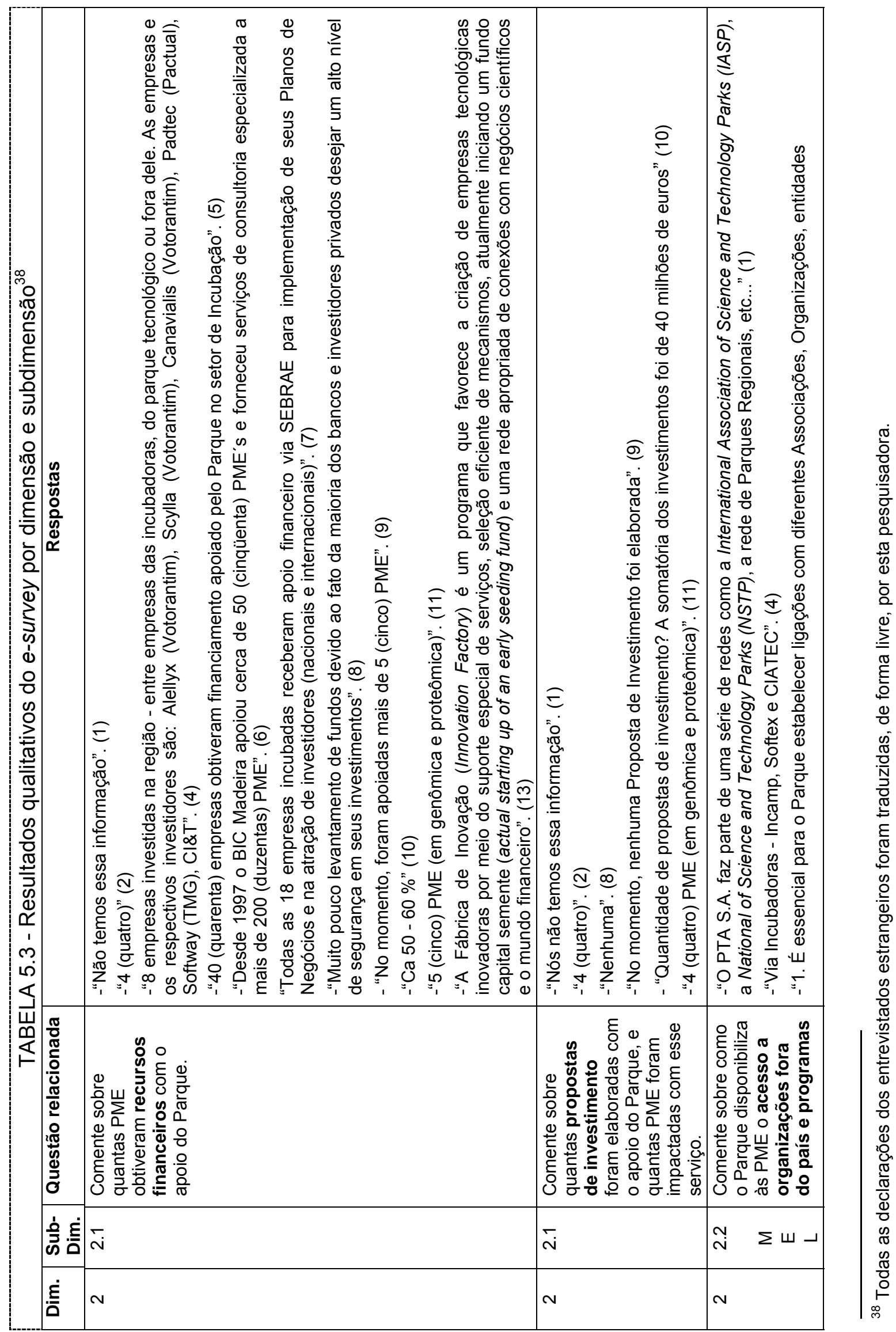




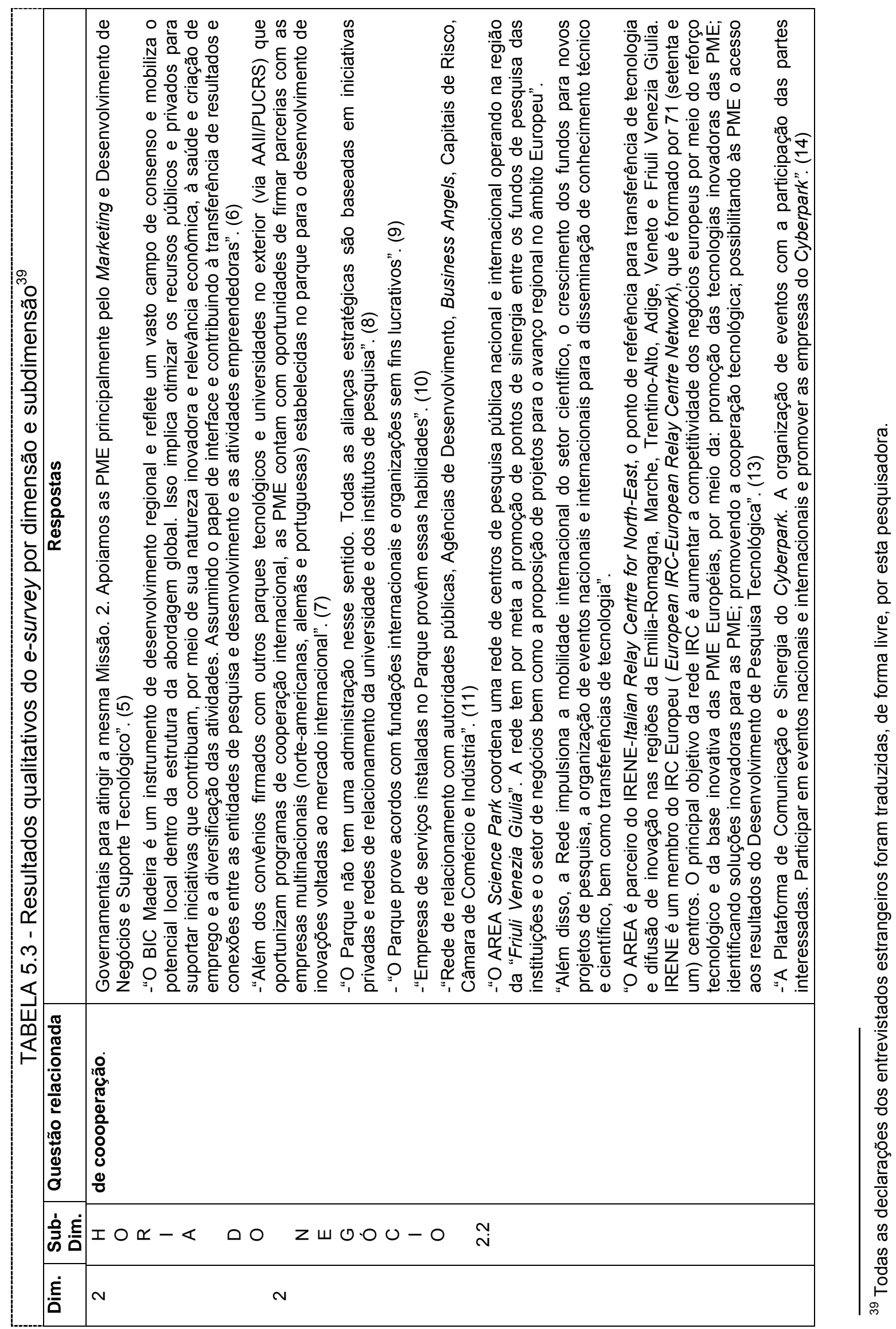




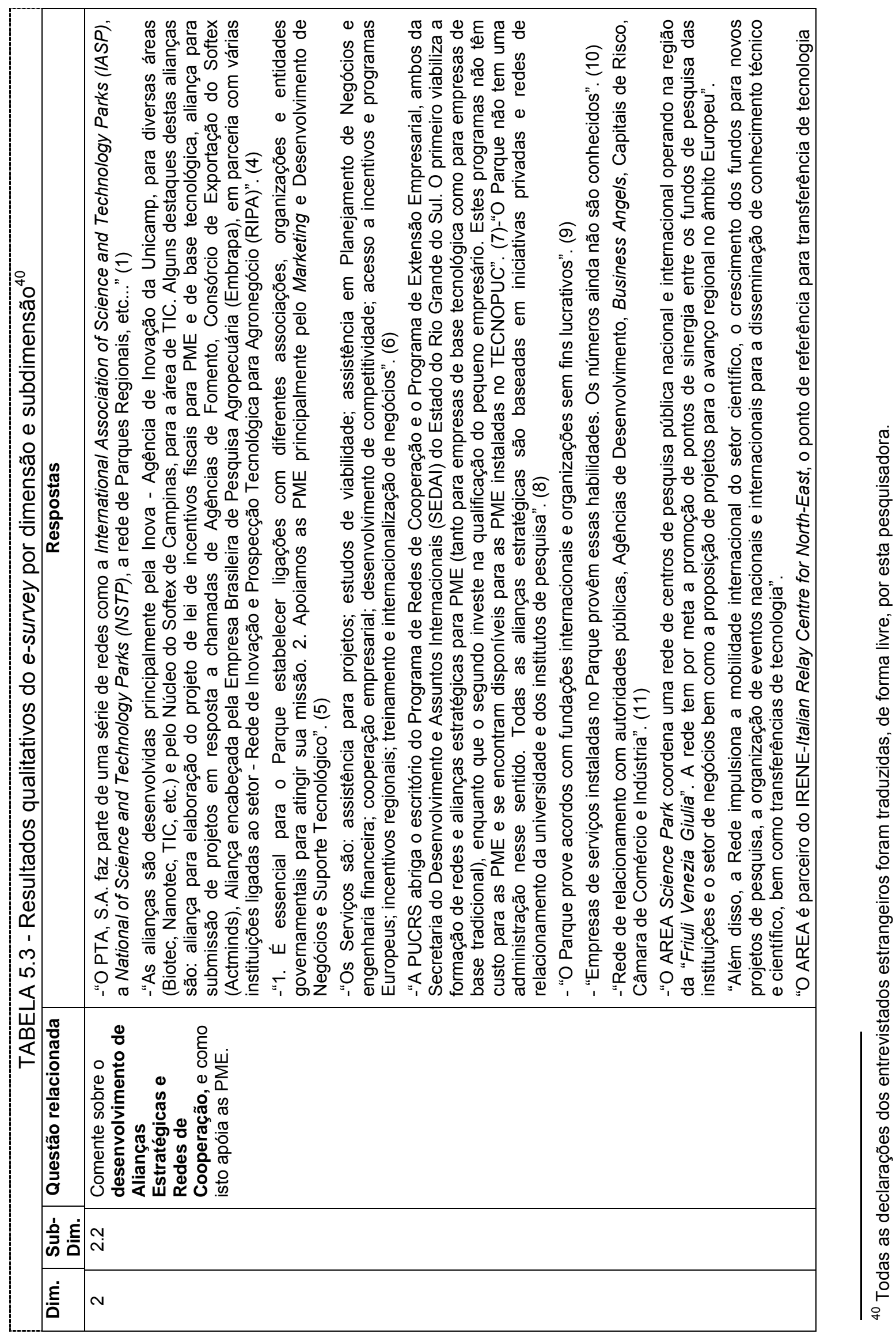




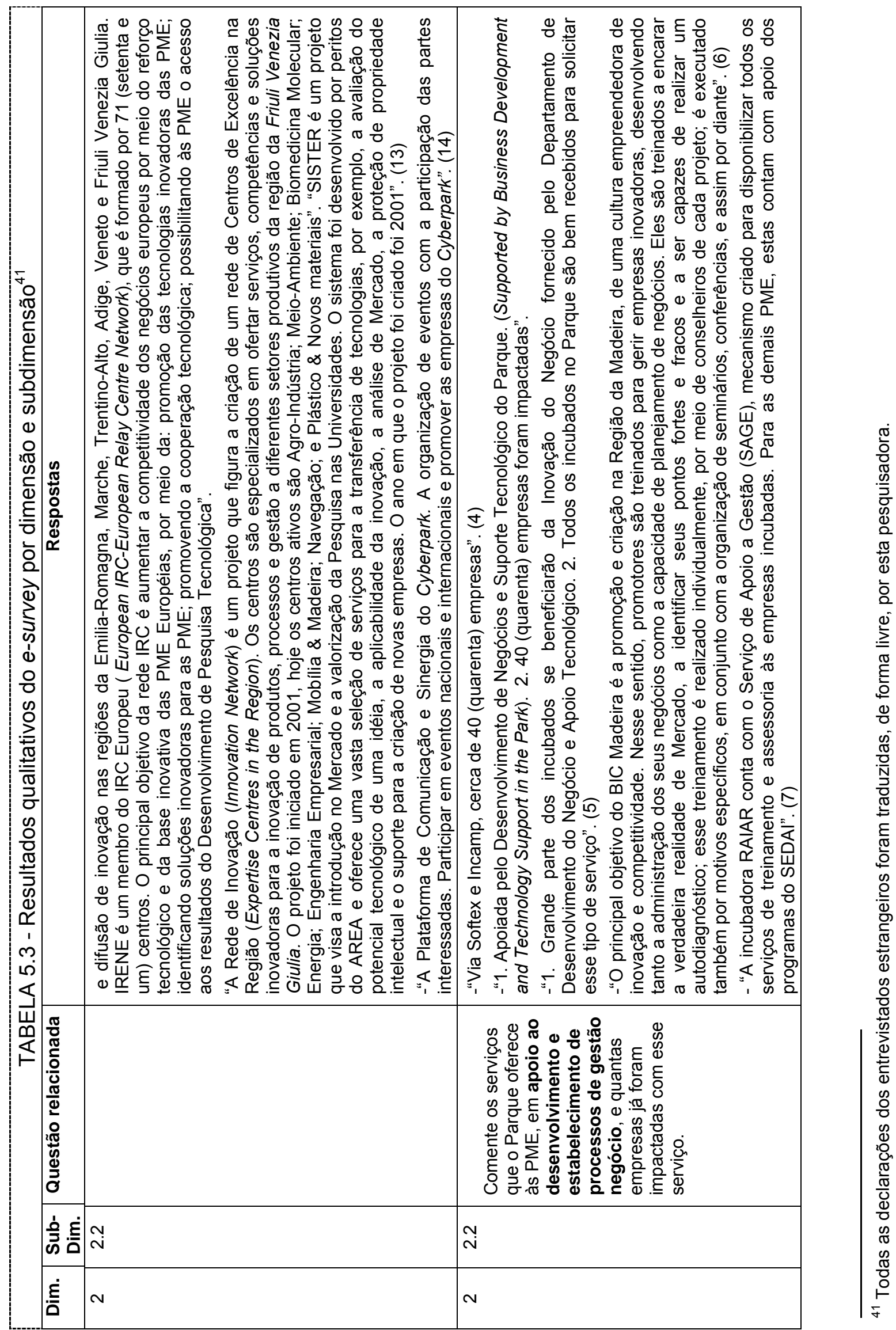




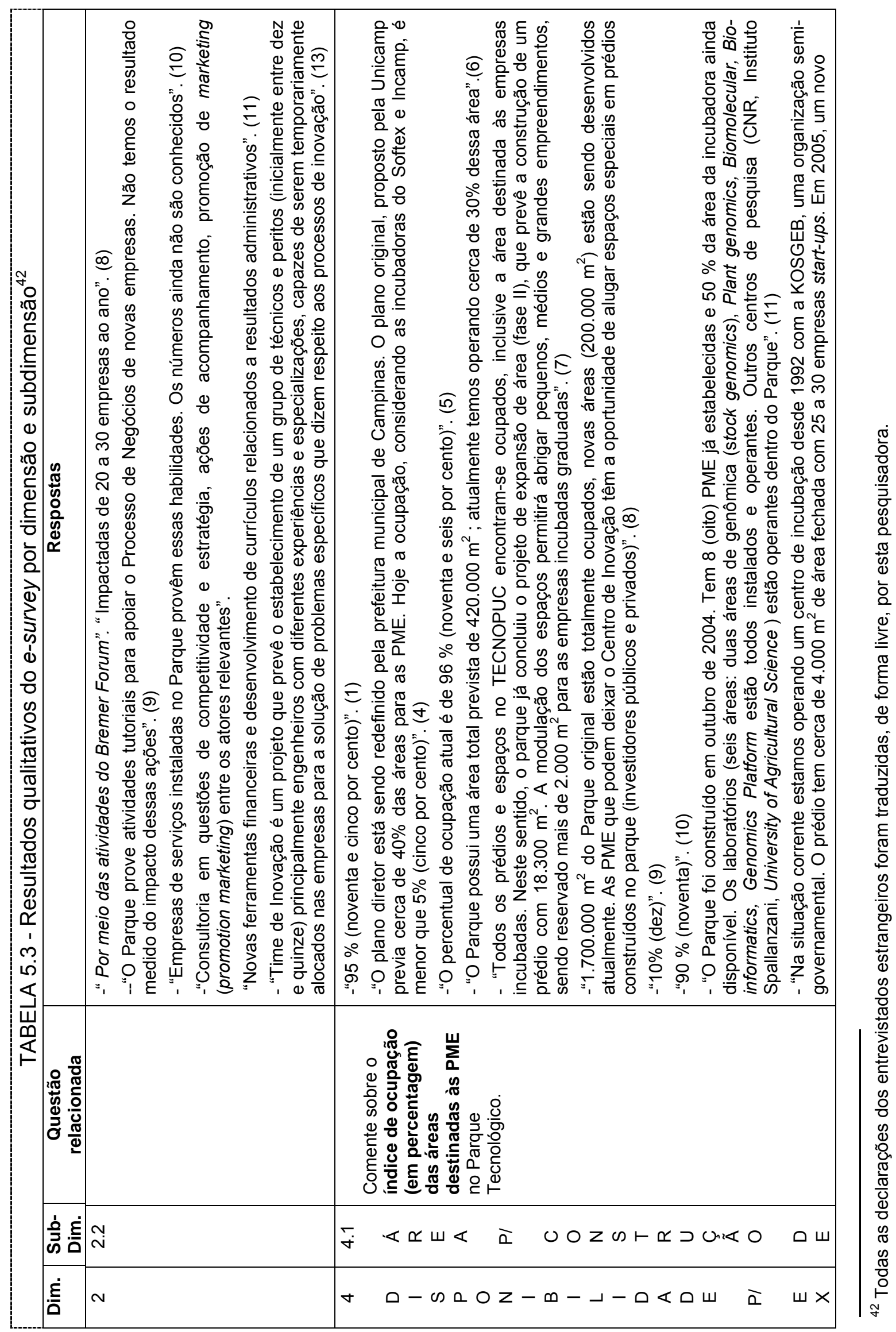




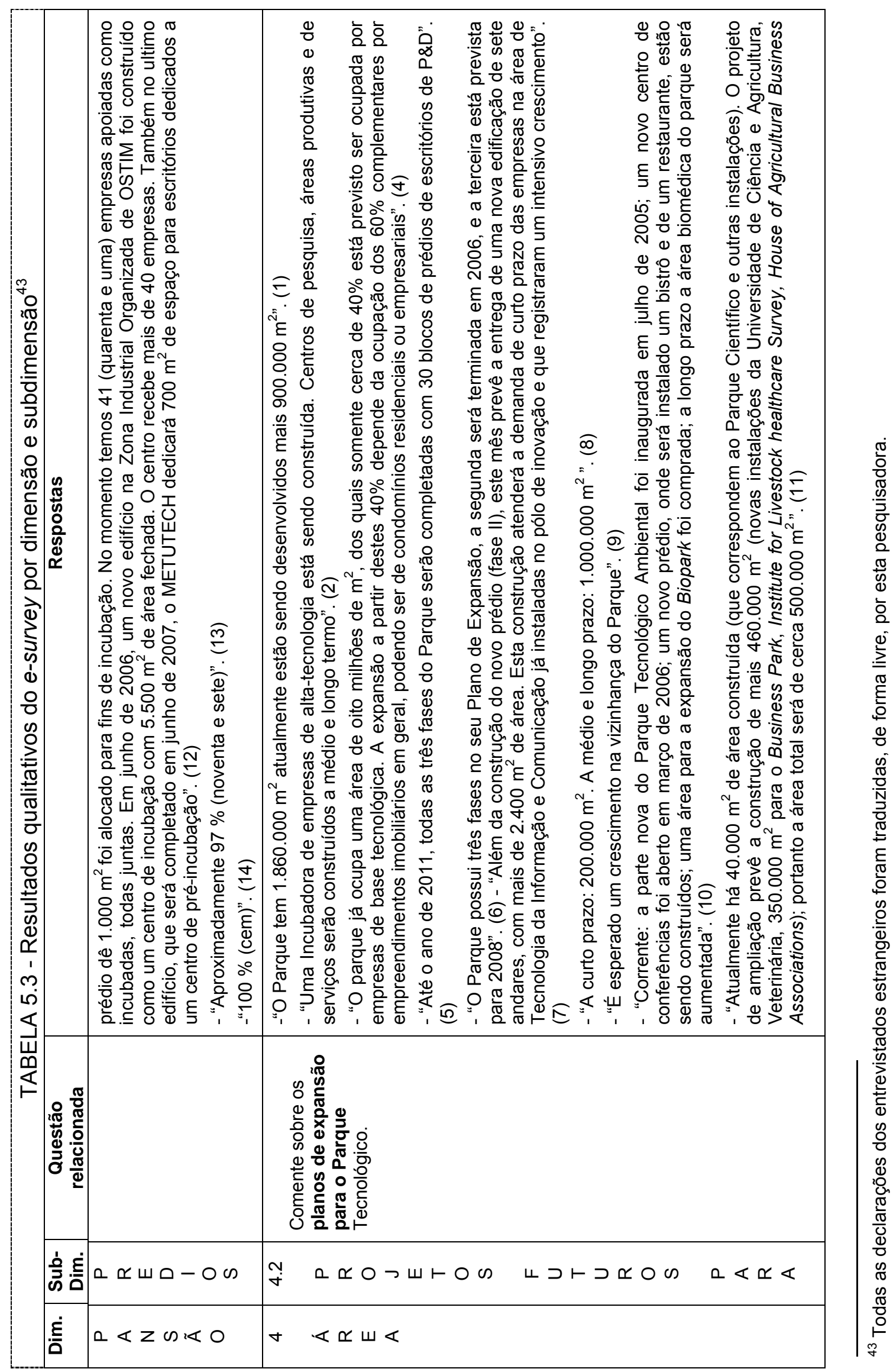




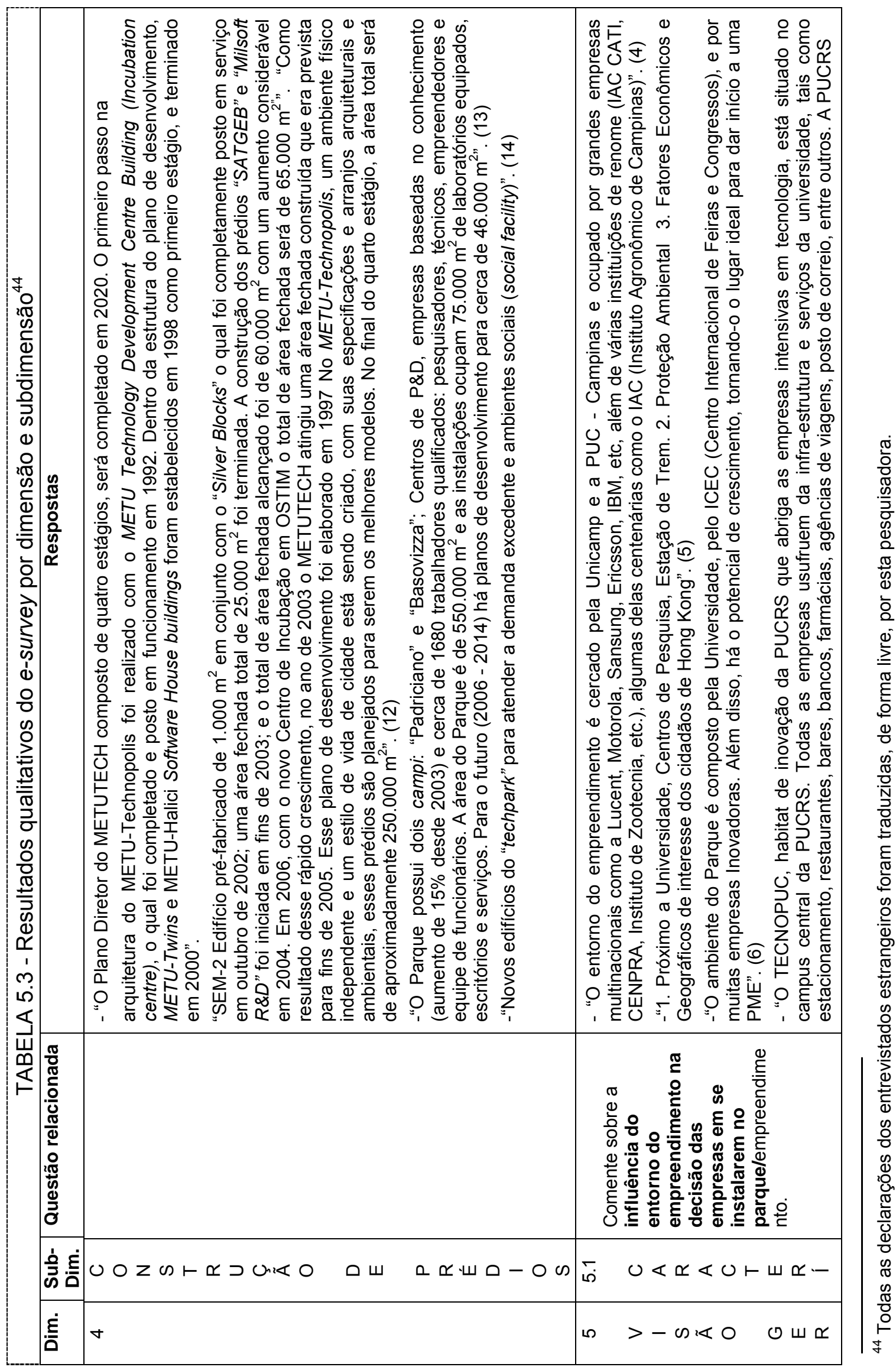




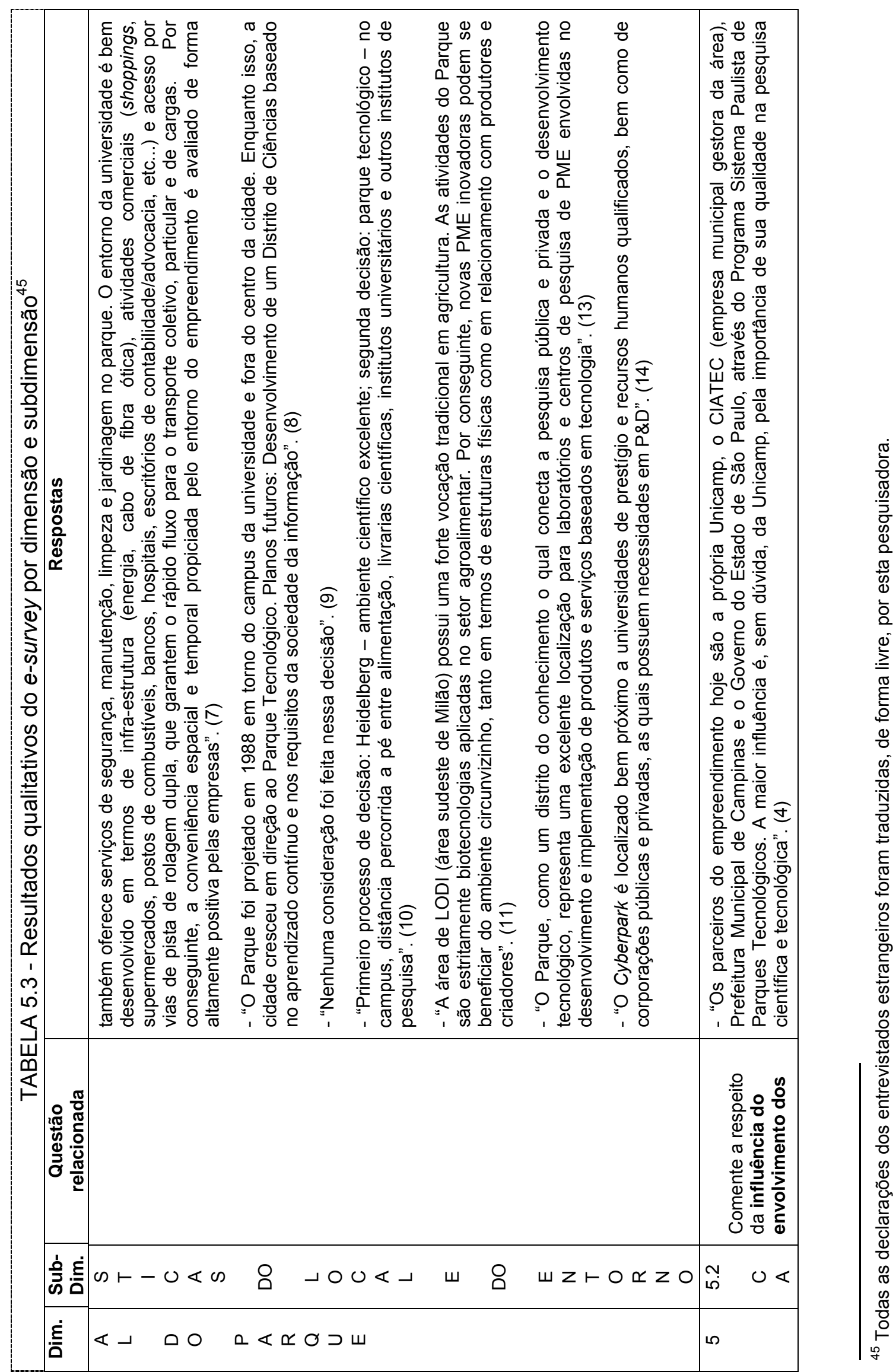




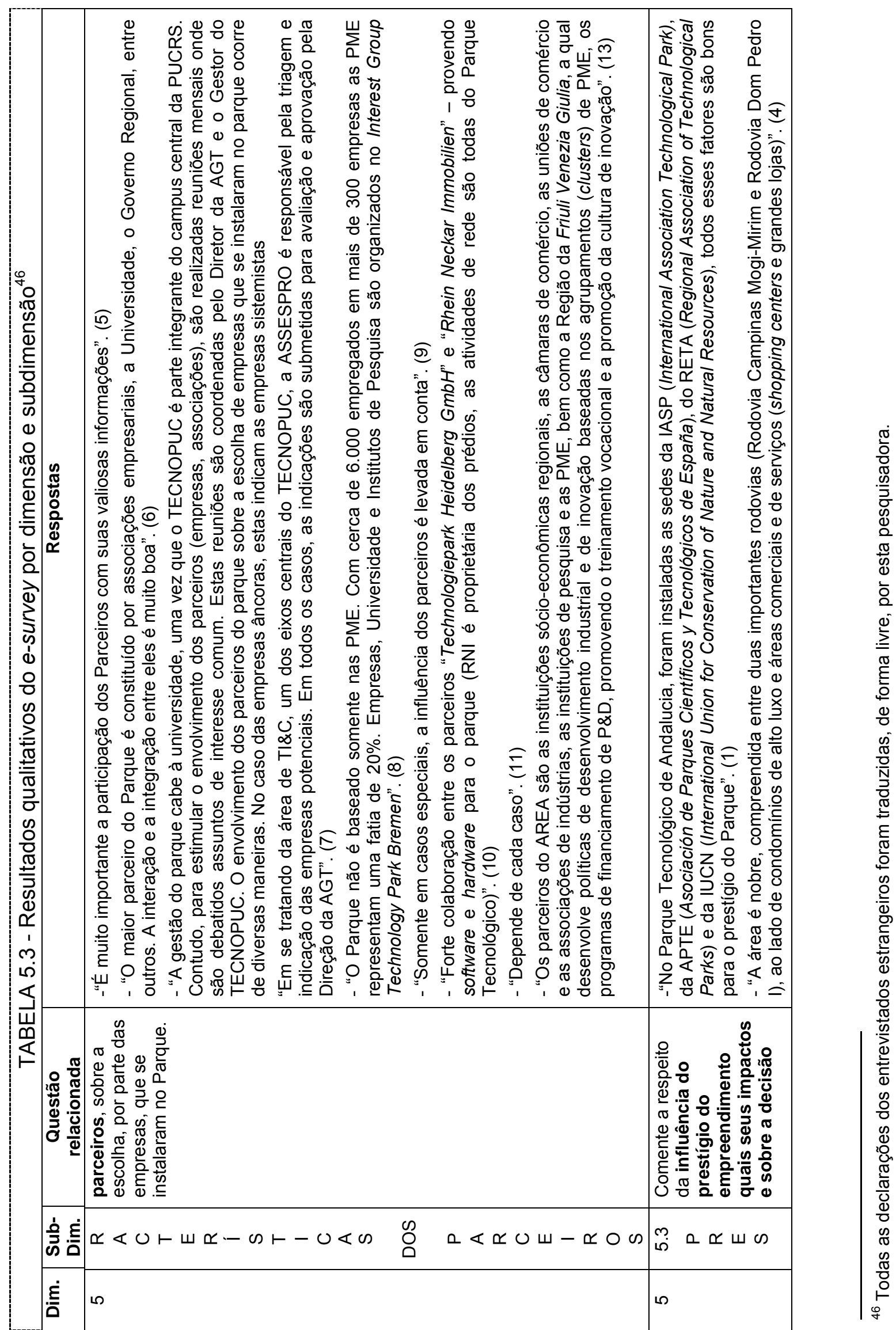




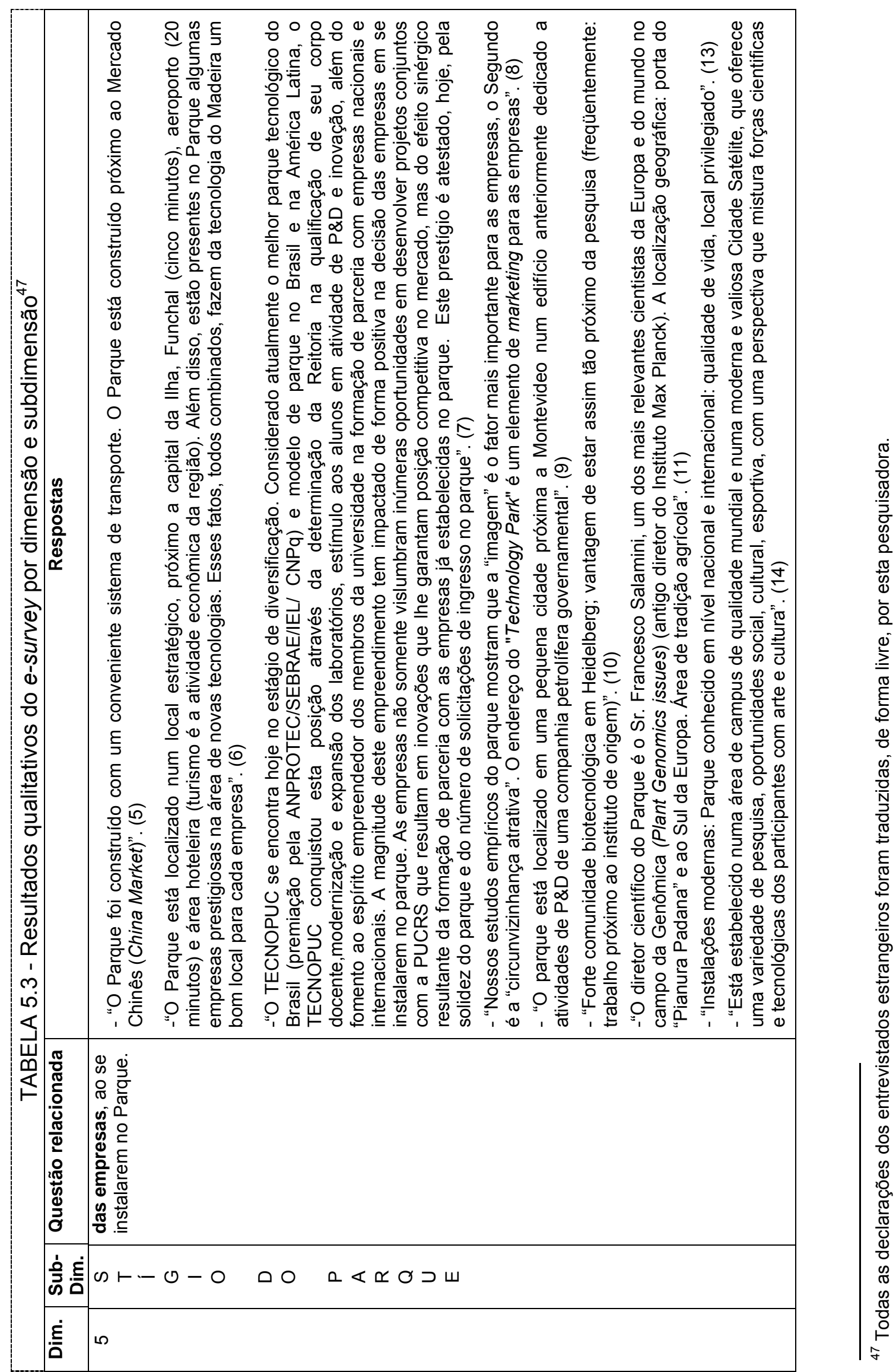




\subsubsection{Caracterização dos respondentes}

\subsubsection{Parque Tecnológico de Andalucia S.A. (PTA)}

Por se tratar de PCT visitado, a caracterização do PTA será comentada no item 5.1.4 referente às observações pessoais resultantes da interação com o pessoal do parque.

O Parque Tecnológico de Andalucia S.A. (PTA) está localizado em Campanillas na cidade de Málaga, na região de Andalucia, Espanha, foi criado em 1988, ano em que se formalizou um acordo entre a junta de Andalucia e a cidade de Málaga para a sua criação; foi inaugurado oficialmente em dezembro de 1992. Em setembro de 1995 o PTA firmou um acordo com a IASP para fixar sua Sede no PTA $^{48}$. A figura 5.1 apresenta a região da Andalucia e a Tabela 5.4 mostra alguns dados da região.
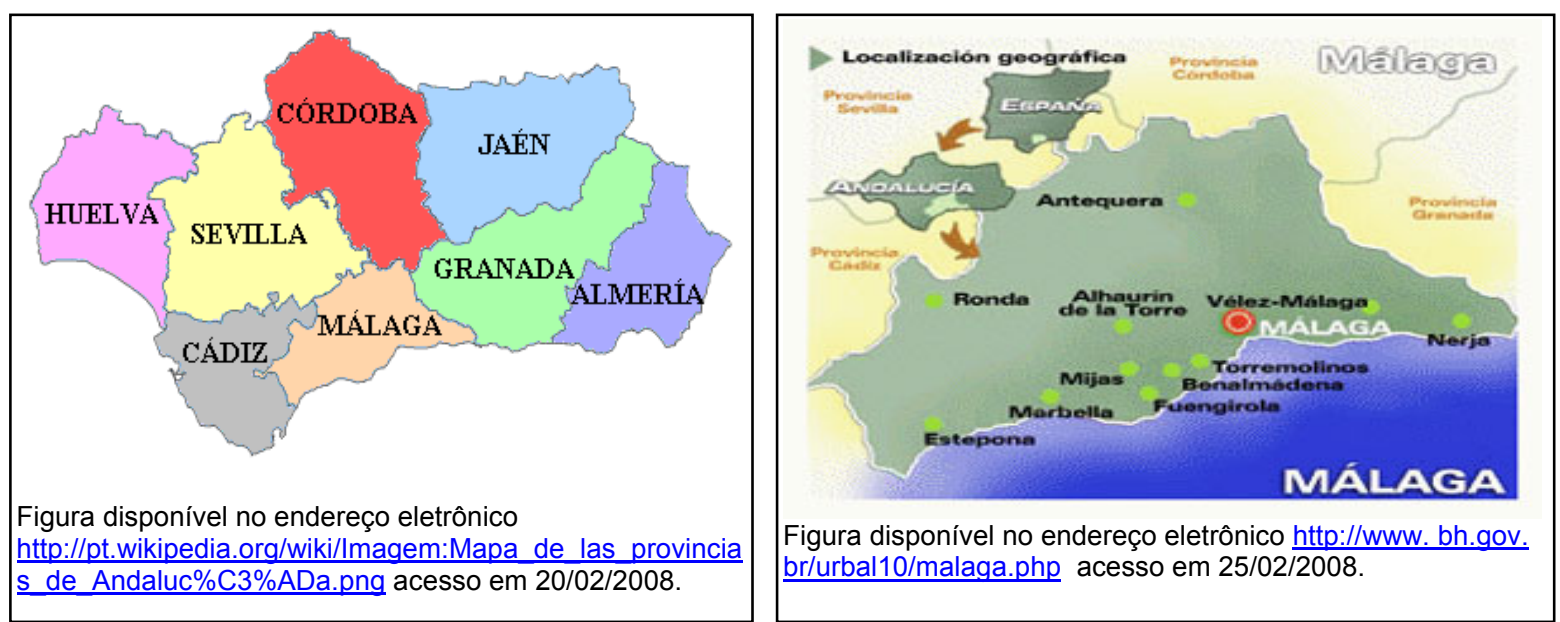

FIGURA 5.1 - Região de Andalucia

\begin{tabular}{|r|l|}
\hline \multicolumn{3}{|c|}{ TABELA 5.4 - Dados da região de Andalucia ${ }^{49}$} \\
\hline Residentes em 2006: & 8.059 .431 \\
Percentual de residentes estrangeiros em 2006: & 6,3 \\
Densidade populacional: & $92,12 \mathrm{hab} / \mathrm{km}^{2}$ \\
Superfície: & $398.25 \mathrm{~km}^{2}$ \\
Produto Interno Bruto em 2004: & 115.273 .571 milhares de euros \\
Renda disponível Bruta por habitante em 2004: & 10.171 euros \\
Taxa de atividade feminina em 2006: & $35,36 \%$ \\
Taxa de desemprego em 2006: & $12,68 \%$ \\
\hline
\end{tabular}

\footnotetext{
${ }^{48}$ Tradução livre de informações disponíveis no endereço eletrônico http://www.idisc.net/en/ Publication.267. html. Acesso em 25/02/2008.

49 Informações disponíveis no endereço eletrônico http://www.juntadeandalucia.es/institutodeestadistica/ 28Febrero/Indicadores1980-2006/index.htm. Acesso em 25/02/2008.
} 
A região de Andalucia é composta de oito províncias: Almeria (635.850 habitantes, 102 municípios), Cádis (1.194.062 habitantes, 44 municípios), Córdoba (788.287 habitantes, 75 municípios), Granada (876.184 habitantes, 168 municípios), Huelva (492.174 habitantes, 79 municípios), Jaén (662.751 habitantes, 97 municípios), Málaga (1.491.287 habitantes, 100 municípios) e Sevilha (1.835.077 habitantes, 105 municípios); sua capital é a cidade de Sevilha ${ }^{50}$.

A Andalucia é rica em recursos minerais como carvão, chumbo, cobre, ferro, quartzo, prata, mármore e também exporta sal a partir de Cádiz e Huelva. Os recursos pesqueiros estão quase esgotados e a indústria está pouco desenvolvida, com exceção do turismo, que é a mais rentável. A região é, sobretudo, forte na produção de azeite ( $70 \%$ do total espanhol), arroz, frutas, trigo, plantas industriais e na produção de gado. $\mathrm{O}$ comércio está muito desenvolvido e ocupa mais de $50 \%$ da população ativa ${ }^{51}$.

A cidade de Málaga tem uma população de 560.631 habitantes, uma superfície de $398.250 \mathrm{~m}^{2}$ e a densidade populacional de $1408 \mathrm{hab} / \mathrm{km}^{2}$;2. o PTA fica na zona situada no vale do Rio Guadalhorce que têm facilidade de acesso às demais regiões do país, graças às novas comunicações viárias Este-Oeste país. Neste local, se instalam cada vez mais empresas dedicadas às atividades industriais e de serviços, que contribuem na criação de uma boa infra-estrutura industrial ${ }^{53}$.

A cidade possui uma jovem e dinâmica Universidade com mais de 40.000 alunos, 20 faculdades e Centros de Ensino Superior, entre os quais se destacam as dedicadas às Tecnologias da Informação e da Produção, isso permite dispor de um grande potencial de mão de obra especializada ${ }^{54}$.

\footnotetext{
50 Informações disponíveis no endereço eletrônico http://pt.wikipedia.org/wiki/Andaluzia\#Economia. Acesso em 20/01/2008.

51 Informações disponíveis no endereço eletrônico http://pt.wikipedia.org/wiki/Andaluzia. Acesso em $21 / 01 / 2008$.

52 Informações disponíveis no endereço eletrônico http://pt.wikipedia.org/wiki/M\%C3\%A1laga. Acesso em 25/01/2008.

53 Tradução livre de informações disponíveis no endereço eletrônico http://www.pta.es/. Acesso em 25/01/2008.

54 Idem.
} 
O aeroporto da cidade de Málaga tem conexões diretas com toda a Europa, América e algumas cidades de outros Continentes (mais de 12 milhões de passageiros no ano de 2004). O porto turístico e comercial representa uma vantagem para as empresas que tem interesse nos mercados mediterrâneos e norte-africanos. Próximo à cidade se encontra o porto de containers de Algeciras, que é o maior porto da Espanha. ${ }^{55}$ A Figura 5.2 representa a localização do Parque Tecnológico de Andalucia.
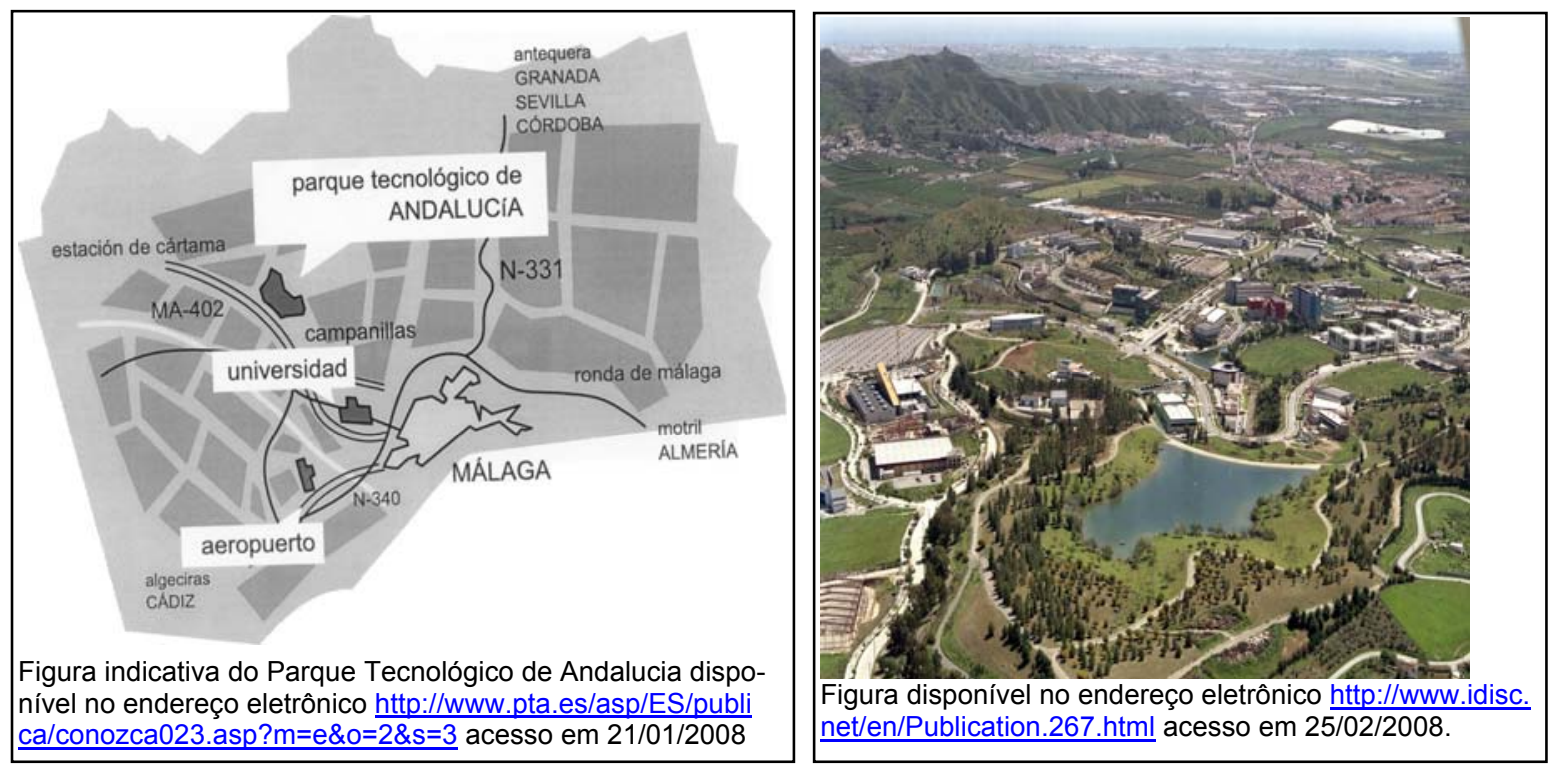

FIGURA 5.2 - Localização do Parque Tecnológico de Andalucia

O PTA está bem localizado do ponto de vista estratégico; a treze quilômetros do centro da cidade de Málaga, a sete quilômetros do campus universitário e a seis quilômetros do Aeroporto Internacional de Málaga ${ }^{56}$. O parque se propõe como um lugar de alta qualidade para a instalação de PME e de grandes empresas, inovadoras e dedicadas a produção, aos serviços avançados e a pesquisa e desenvolvimento.

O PTA oferece aos instalados no parque os seguintes serviços: áreas com jardins e áreas de lazer, serviços médicos, creche, hotel, segurança controlada por câmeras, centro de formação ocupacional, água tratada para uso industrial, subestação própria de energia elétrica, central fotovoltaica, ponto de concentração

\footnotetext{
55 Tradução livre de informações disponíveis no endereço eletrônico http://www.pta.es/. Acesso em 25/01/2008.

${ }^{56}$ Tradução livre de informação contida na apresentação Parque Tecnológico de Andalucia - um modelo de desarollo empresarial continuo, autora Sonia Palomo, disponível no endereço eletrônico http://www.idisc.net len/Publication. 267. html. Acesso em 25/02/2008.
} 
de resíduos, heliporto, serviços de telecomunicações, etc... ${ }^{57}$ Ele oferece serviços de qualidade a um custo comparativamente baixo; por exemplo, o custo de manutenção e conservação das instalações e zonas de serviços comuns é de 0,15 centavos de euro por metro quadrado ${ }^{58}$.

O PTA possui em seu espaço físico todas as estruturas necessárias para apoiar o modelo de desenvolvimento empresarial contínuo; preincubadoras (Edifício de La Universidad de Málaga, CADE - Centro de Apoio al Desarrollo Empresarial), incubadora (Edifício de La Incubadora de empresas BICEURONOVA), escritórios e plantas industriais com todos os serviços disponíveis, que são oferecidos geralmente em regime de aluguel às empresas que se instalam no PTA (Centro de empresas - NIDO, Edifício de Módulos Tecnológicos, Edifício Premier, Edifícios Possibilia, Edificios - Apex Málaga Business Park), edifícios de uso múltiplo tanto para escritórios como para plantas industriais (Edifícios de contenedores, Centro Tecnológico de Industrias Auxiliares); e propostas para aquisição de terreno no PTA (se oferece a compra de uma parcela, com direito de uso da superfície por 75 anos $)^{59}$.

A Universidade de Málaga desenvolve no Parque Tecnológico de Andalucia uma estreita cooperação com o mundo empresarial, dispondo de um edifício, no PTA, onde estão instalados grupos de pesquisa que trabalham em conjunto com as empresas. No mesmo edifício está o escritório de transferência tecnológica - OTRI (Oficina de Transferência de Resultados de Investigatión) e empresas que contam com a participação da Universidade ${ }^{60}$. Estão instalados no PTA cinco centros tecnológicos:

- O AT4 Wireless (Centro de Tecnologia das Comunicações S.A.), que é uma empresa de soluções tecnológicas relacionadas a medidas e ensaios, engenharia e assistência técnica, aplicações e sistemas ${ }^{61}$;

\footnotetext{
${ }^{57}$ Tradução livre de informação contida na apresentação Parque Tecnológico de Andalucia - um modelo de desarollo empresarial continuo, autora Sonia Palomo, disponível no endereço eletrônico http://www.idisc.net len/Publication. 267. html. Acesso em 25/02/2008.

58 Idem.

${ }^{59}$ Idem.

60 Idem.

61 Tradução livre de informação disponível no endereço eletrônico http://www.at4wireless.com/ Acesso em 28/02/2008
} 
- O CITIC (Centro Andaluz de Innovación y Tecnologias de La Información y lãs Comunicaciones), que é um centro de inovação, criado em março de 2002, como fundação privada sem fins lucrativos, composto de um patronato de 37 entidades líderes e representativas do setor de TIC andaluz ${ }^{62}$;

- O INDYCEE, S.L. (Instituto de Investigatión, Desarrollo y Control de Calidad em La Edificación), que foi promovido pelo PTA e pelo Colégio Oficial de Aparejadores y Arquitectos Técnicos de Málaga e que iniciou suas atividades em 1993. É uma entidade de caráter técnico científico, que tem por finalidade o fomento, o desenvolvimento e a pesquisa de materiais, sistemas e elementos construtivos, que revertam em uma melhor qualidade na edificação ${ }^{63}$;

- O FORMAN (Centro de Formación en Comunicaciones y Tecnologías de la Información), que foi criado e promovido pela Junta de Andalucía e pelo Ayuntamiento de Málaga; que foi concebido para formar profissionais nas novas tecnologias ${ }^{64}$; e

- O Instituto Europeu da Alimentação Mediterrânea (Instituto de la Alimentación Mediterrânea), que foi criado por iniciativa do Conselho de Agricultura e Pesca da Junta de Andalucía e colocado em funcionamento pela Empresa Pública para el Desarrollo Agrario y Pesquero de Andalucía (D.A.P.); têm como objetivo geral, dar impulso à competitividade e qualidade das empresas agroalimentares da Bacia do Mediterrâneo, se constituindo num elemento dinamizador dos intercâmbios e atividades de cooperação na região, difundindo aspectos qualitativos da dieta mediterrânea e sua repercussão na melhora da qualidade de vida e da saúde ${ }^{65}$.

Também estão instalados no PTA três centros de difusão e transferência de tecnologia:

- O CESEAND - IRC (Centro de Enlace de Andalucía), que faz parte da rede européia de centros de conexão para a informação, criado no âmbito do programa inovação da União Européia. O CESEAND É formado pelo Instituto de Fomento

\footnotetext{
62 Tradução livre de informação disponível no endereço eletrônico http://www.citic.es/index.php? option=com content\&task=view\&id=18\& Itemid=81. Acesso em 03/03/2008.

${ }^{63}$ Tradução livre de informação disponível no endereço eletrônico http://www.pta.es/asp/includes/publica/ general. asp? codH=8\&m=d\&o=8\&n=311\&len=ES. Acesso em 02/03/2008.

${ }^{64}$ Tradução livre de informação disponível no endereço eletrônico http://www.forman.es/cms/index.php/presen tacion/elcentro. Acesso em 02/03/2008.

${ }^{65}$ Tradução livre de informação disponível no endereço eletrônico http://www.pta.es/asp/includes /publica/general. $a s p$ ? codH=8\&m=d\&o=8\&n=415\&len=ES. Acesso em 03/03/2008.
} 
de Andalucía (IFA), pela dirección general de universidades e investigación de la Junta de Andalucía e pelo Instituto Andaluz de Tecnología (IAT). Seu objetivo é prestar serviços de consultoria tecnológica, assessorar projetos de P\&D; assessorar a transferência de tecnologia transnacional; e buscar sócios para projetos $^{66}$;

- O Instituto Andaluz de Tecnologia, que é uma fundação privada reconhecida como de interesse público pela Junta de Andalucia (BOJA, 26 de Junio de 1990; BOE, 4 de Agosto de 1990), que atua com o objetivo de melhorar a capacidade competitiva das empresas e organizações, facilitando sua adaptação às mudanças tecnológicas e impulsionando os processos de inovação e de melhoria contínua, mediante a prestação de serviços técnicos avançados ${ }^{67}$; e a

A ASIT (Asociación al Servicio de la Investigación y la Tecnología), que é uma associação privada sem fins lucrativos instalada no PTA que, desde 1989, desenha e gere projetos relacionados com o desenvolvimento tecnológico e local ${ }^{68}$.

Estão instaladas no PTA mais de 406 empresas dos setores de telecomunicações, eletrônica, informática, serviços avançados, meio ambiente, etc.... Desde a criação do PTA já foram investidos 590 milhões de euro, sendo 480 milhões advindos da iniciativa privada ${ }^{69}$.

A distribuição das pessoas que atuam no PTA pode ser observada na Tabela 5.5.

\footnotetext{
66 Tradução livre de informação disponível no endereço eletrônico http://www.pta.es/asp/includes /publica/general.asp? codH=8\&m=d\&o=8\&n=342\&len=ES. Acesso em 02/03/2008.

67 Tradução livre de informação disponível no endereço eletrônico http://www.pta.es/asp/includes/publica/ general. asp?codH=8\&m=d\&o=8\&n=359\&len=ES. Acesso em 03/03/2008.

68 Tradução livre de informação contida na apresentação Parque Tecnológico de Andalucia - um modelo de desarrollo empresarial continuo, autora Sonia Palomo, disponível no endereço eletrônico http://www.pucp. edu.pe/conferencia/iaspla2007/etc/sonia palomo 1.pdf Acesso em 25/02/2008.

${ }^{69}$ Idem.
} 
TABELA 5.5 - Pessoas por setor de atividade no PTA (percentuais em 2006)

\begin{tabular}{|r|c|}
\hline Setor de atividade & Pessoal por setor em 2006 (\%) \\
\hline Agroalimentos e biotecnologia & $6 \%$ \\
\hline Centros tecnológicos e de I+D & $5 \%$ \\
\hline Comercial & $5 \%$ \\
\hline Eletrônica, informática e telecomunicações & $39 \%$ \\
\hline Energia e meio ambiente & $9 \%$ \\
\hline Formação e recursos humanos & $5 \%$ \\
\hline Industrial & $10 \%$ \\
\hline Medicina e saúde & $10 \%$ \\
\hline Outros & $11 \%$ \\
\hline
\end{tabular}

\subsubsection{Centuria - Romagna Innovazione Tecnologia (Centuria-RIT)}

Por se tratar de PCT visitado, a caracterização do PTA será comentada no item 5.1.4 referente às observações pessoais resultantes da interação com o pessoal do parque.

O Centuria-RIT atua na região da Emilia Romanha, possui quatro milhões de habitantes em 22 mil km² ; e é uma das vinte regiões em que se divide a Itália. A Itália tem uma população de 57 milhões de habitantes, seu PIB é de 1.351.794 milhões de euros, seu PIB per capita é de 23.715 euros, têm cerca de 22 milhões de pessoas ocupadas e aproximadamente 550.000 empresas manufatureiras, uma taxa de desemprego de $8 \%$ e exporta 24.307 milhões de euros ao ano ${ }^{70}$.

A região da Emilia Romanha tem longa história de pioneirismo e influência política. No século XII, Bologna sediou a primeira universidade do mundo ocidental (1088). A Figura 5.3 representa a região da Emília Romanha e a Tabela 5.6 apresenta alguns dados sobre a região.

\footnotetext{
${ }^{70}$ Informações da apresentação "Evolução dos Distritos Industriais na Itália”, autor: Sergio Campodall'Orto Politecnico Innovazione - Politécnico de Milão, disponível no endereço eletrônico http://portal.crie. coppe.ufrj.br/portal/data/documents/storedDocuments/\%7B93787CAE-E94C-45C7-992B-9403F6F40836\%7D/ \%7BA2893148-FC13-48D6-BC3B-2D2814CF5B73\%7D/Evolucao Distritos.pdf. Acesso em 20/02/2008
} 

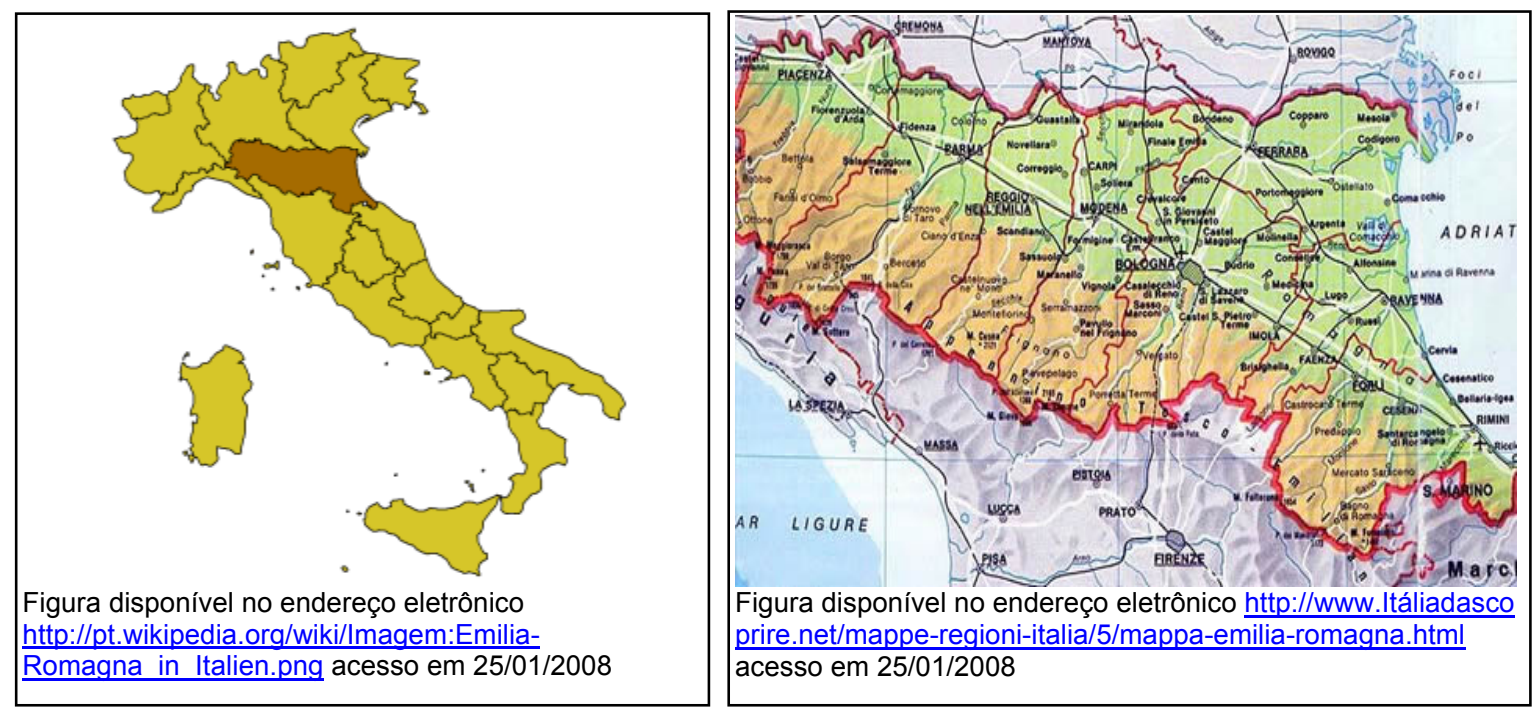

FIGURA 5.3 - Região da Emília Romanha

\begin{tabular}{|r|l|}
\hline \multicolumn{3}{|c|}{ TABELA 5.6 - Dados da região da Emilia Romanha ${ }^{71}$} \\
\hline Residentes em 31.12.2006: & 4.223 .264 \\
\hline Mulheres residentes em 31.12.2006: & 2.168 .358 \\
\hline Número de famílias em 31.12.2006: & 1.844 .228 \\
\hline Estrangeiros residentes em 31.12.2006: & 317.888 \\
\hline Percentual de residentes estrangeiros em & $7,5 \%$ \\
\hline 31/12/2006: & \\
\hline Densidade populacional em 31.12.2006: & 191 habitantes por km² \\
\hline Superfície em 31/12/2006: & $200.211 .734 \mathrm{~m}^{2}$ \\
\hline Superfície agrícola utilizada (ano 2005): & $102.991 .600 \mathrm{~m}^{2}$ \\
\hline Numero de comunas: & 341 \\
\hline Produto Interno Bruto em 2006: & 128.795 milhões de euros \\
\hline Produto Interno Bruto por habitante em 2006: & 30.626 euros \\
\hline Taxa de atividade feminina (média 2006): & $44,2 \%$ \\
\hline Taxa de desemprego (média 2006): & $3,4 \%$ \\
\hline Número de empresas (média 2005): & 379.044 \\
\hline Número de empresas agrícolas (ano 2005): & 81.323 \\
\hline and &
\end{tabular}

A economia da região é composta de uma grande quantidade de pequenas e médias empresas. São 430.000 empresas (quase uma para cada dez habitantes), das quais $47 \%$ empregam menos de 20 pessoas $^{72}$. Aos conjuntos de

71 Informações disponíveis no endereço eletrônico http://www.regione.emilia-romagna.it/wcm/statistica/ index.htm. Acesso em 22/02/2008.

${ }^{72}$ Informação do artigo "A Emilia-Romagna e o Capital Social" de autoria de José Monir Nasser do Instituto Paraná de Desenvolvimento, disponível no endereço eletrônico www.ipd.org.br/cursos/modulo15.htm. Acesso em 05/01/2008. 
pequenos concorrentes, se dá o nome, na Itália, de distritos industriais (distretti industriali), ou sistemas autônomos de produção local ${ }^{73}$.

Os distritos industriais italianos começaram a ser estudados na década de 70 , havia uma dificuldade entre os economistas em explicar a capacidade superior da empresa italiana em competir em escala mundial ${ }^{74}$. Os distritos industriais italianos estão localizados no nordeste-centro do país, em regiões como Emília Romanha, Vêneto, Trentino-Alto-Adige, Friuli Venezia Giulia, Toscana, Marche e Umbria, relativamente próximos ao triângulo industrial de Gênova, Turim e Milão; e difundiram-se rapidamente nas décadas de 60 e $70^{75}$.

Pode se observar nos distritos industriais uma forte interação das firmas e do mercado com o ambiente onde se inserem por meio de mecanismos específicos de regulação, tanto formais como informais ${ }^{76}$. Podemos dizer que os distritos industriais são clusters ${ }^{77}$.

A Emília Romanha é uma economia industrial de alto desempenho, é a segunda maior região pecuarista da Itália, uma importante produtora de vinhos e um centro de pesca ${ }^{78}$.

Este alto desempenho da economia regional pode ser demonstrado por meio de: empreendimentos produzindo bens de renome internacional, como o queijo Parmigiano-Reggiano (parmesão), o presunto de Parma, o Aceto Balsâmico

\footnotetext{
${ }^{73}$ Informação do artigo "A Emilia-Romagna e o Capital Social" de autoria de José Monir Nasser do Instituto Paraná de Desenvolvimento, disponivel no endereço eletrônico www.ipd.org.br/cursos/modulo15.htm. Acesso em 05/01/2008.

${ }^{74}$ Informações da apresentação "Evolução dos Distritos Industriais na Itália", autor: Sergio Campodall'Orto, Politécnico de Milão, disponível no endereço eletrônico http://portal.crie.coppe.ufri.br/portal/data/documents/ storedDocuments/\%7B 93787CAE-E94C-45C7-992B-9403F6F40836\%7 D/\%7BA2893148-FC13-48D6-BC3B2D2814CF5B73\%7D/Evolucao Distritos.pdf. Acesso em 20/02/2008.

${ }^{75}$ Informação do artigo "Repensar a industrialização a partir do desenvolvimento local sustentável", autor: Sergio Schneider, Departamento de Sociologia e do Programa de Pós-Graduação em Desenvolvimento Rural da Universidade Federal do Rio Grande do Sul, disponível no endereço eletrônico http://www.scielo.br/scielo. php?script=sciarttext\&pid=S010269092000000200013\&lng=in\&nrm=iso\&tlng=in. Acesso em 20/02/2008. 16 Informações da apresentação "Evolução dos Distritos Industriais na Itália", autor: Sergio Campodall'Orto Politecnico Innovazione - Politécnico de Milão, disponível no endereço eletrônico http://portal.crie.coppe.ufri. br/portal/data/documents/storedDocuments/\%7B93787CAE-E94C-45C7-992B-9403F6F40836\%7D/\%7BA 2893148 FC13-48D6-BC3B-2D2814CF5B73\%7D/Evolucao Distritos.pdf. Acesso em 20/02/2008.

${ }^{77}$ Considera-se para fins desta pesquisa a definição do SEBRAE para CLUSTERS, a saber: "Empresas e/ou instituições que interagem entre si, gerando e capturando sinergias, com potencial de atingir crescimento contínuo superior à uma simples aglomeração econômica, geograficamente próximas e pertencentes a um setor específico." Informação disponível no endereço eletrônico http://www.sebrae.com.br/customizado/ inovacao/conceitos/glossario. Acesso em 20/01/2008.

${ }_{18}$ Informação do artigo "A Emilia-Romagna e o Capital Social" de autoria de José Monir Nasser do Instituto Paraná de Desenvolvimento, disponível no endereço eletrônico www.ipd.org.br/cursos/modulo15.htm. Acesso em 05/01/2008.
} 
de Modena, o vinho Lambrusco, a Ferrari, a Lamborghini e a Ducati, todas marcas correlacionadas com qualidade e liderança no mundo, além de associadas à cultura produtiva da região ${ }^{79}$.

Além do bom desempenho econômico, a Emilia Romagna tem um dos maiores níveis de qualidade de vida da Itália. A taxa de mortalidade infantil é de 6,8 por 1.000 nascidos vivos (contra 9,9 para o país). Bolonha é a cidade mais rica da Itália, Parma é a quinta, Ravenna é a oitava, Modena é a nona e Reggio Emilia a décima primeira. A longevidade dos habitantes da região é maior que a da Itália e a criminalidade é a menor do centro-norte da Itália ${ }^{80}$.

O Centuria-RIT é um parque da região da Emilia Romanha que tem por objetivo aumentar a competitividade do território e das empresas locais por meio da inovação no setor agroindustrial e manufatureiro ${ }^{81}$. Ele é resultado da fusão entre dois consórcios de sociedades, o "Centuria" e o "RIT- Romagna Innovation et Technologie".

O Centúria, constituído em Cesena ${ }^{82}$ em 1994, nasceu como um consórcio de sociedades formado por empresas do setor agroindustrial (produção de frutas e hortaliças, empresas do setor avícola, açucareiro, de congelados, de sementes e tecnologias relacionadas a manufatura, logística, máquinas agrícolas, irrigação, softwares dedicados, etc.). O RIT foi constituído em Faenza ${ }^{83}$ em 2001 por um grupo de empreendedores do setor manufatureiro (mecânica, alimentar, automação, eletrônica, bens instrumentais, etc).

Após cerca de dois anos de intensa colaboração, caracterizada por iniciativas comuns e pelo intercâmbio de pessoal, o Centuria e o RIT iniciaram

\footnotetext{
${ }^{79}$ Informação do artigo "A Emilia-Romagna e o Capital Social" de autoria de José Monir Nasser do Instituto Paraná de Desenvolvimento, disponível no endereço eletrônico www.ipd.org.br/cursos/modulo15.htm. Acesso em 05/01/2008.

80 idem

81 Tradução livre de informação contida em apresentação fornecida pelo Sr. Francesco Beccari do CentúriaRIT em maio de 2007 (arquivo Centuria Rit General EN020082004.ppt).

${ }^{82}$ Cesena é uma comuna italiana da região da Emília-Romanha, província de Forlì-Cesena, com 93.066 habitantes. Estende-se por uma área de $249,47 \mathrm{~km}^{2}$, tendo uma densidade populacional de $373,05 \mathrm{hab} / \mathrm{km}^{2}$. A província de Forlì-Cesena é uma província italiana da região de Emília-Romanha com 362.218 habitantes, densidade de $152 \mathrm{hab} / \mathrm{km}^{2}$. Está dividida em 30 comunas, sendo a capital Forlì. Informações disponíveis no endereço eletrônico http://pt.wikipedia.org/wiki/Cesena. Acesso em 10/01/2008

83 Faenza é uma comuna italiana da região da Emília-Romanha, província de Ravenna, com 53.369 habitantes. Estende-se por uma área de $215 \mathrm{~km}^{2}$, tendo uma densidade populacional de $248 \mathrm{hab} / \mathrm{km}^{2}$. A província de Ravenna é uma província italiana da região de Emília-Romanha com 350.879 habitantes, densidade de 189 hab/km². Está dividida em 18 comunas, sendo a capital Ravenna. Informações disponíveis no endereço eletrônico http://pt.wikipedia.org/wiki/Faenza. Acesso em 10/01/2008.
} 
uma fusão social que foi completada em abril de 2003 com a constituição de uma sociedade única denominada "Centuria RIT - Romagna Innovation Technologie Associés Cons. a r.l." (responsabilità limitata).

A missão estatutária do Centúria-RIT é favorecer o desenvolvimento das empresas associadas e do território romagnolo por meio da inovação tecnológica e da organização nos setores manufatureiro e agroindustrial, encorajando a troca de idéias, a transferência tecnológica e a produção de conhecimento; e se colocando como ponto de encontro e de estímulo entre as instituições, o empreendedorismo e a pesquisa. ${ }^{84}$

As ações do Centúria-RIT estão principalmente voltadas a: otimizar o fluxo de informações qualificadas sobre o tema da inovação, seja selecionando e drenando do ambiente externo ao local, seja favorecendo o diálogo entre os diversos atores do sistema local; aumentar a capacidade local de investimento tecnológico; e estimular a realização de sinergia profícua entre os sujeitos locais em uma ótica integrada e interdisciplinar ${ }^{85}$.

As atividades do Centúria-RIT são principalmente focalizadas sobre as empresas e instituições a ele associados, sua estratégia se articula através de duas principais áreas de atividade: Informação e Network; e Projetos e Consultoria.

A área de atividade de Informação e Network corresponde à fase de criação do processo de inovação. O objetivo é "criar a oportunidade" para a geração do projeto inovador. Isso ocorre principalmente maximizando o fluxo de informações sobre novas tecnologias, processos, mercados, em direção às empresas associadas e ao território. A informação é hoje um bem disponível, tanto que o problema é geralmente gerir a quantidade e diversidade de informações. Todavia, as empresas recebem a maioria das informações e estímulos concernentes à inovação principalmente de fontes próximas e partes interessadas: fornecedores, clientes, concorrentes, revistas especializadas.

\footnotetext{
84 Tradução livre de informação contida no documento "Bilancio Sociale 2006" disponível no endereço eletrônico http://www.centuria-rit.com/centuria/shared/res/companies/-3529329303360169978/attach/BS2006 PDF. Acesso em 15/01/2008.

${ }^{85}$ Idem.
} 
O Centúria-RIT seleciona as informações das diversas fontes, mesmo aquelas distantes das empresas, as elabora e as fornece aos sócios de uma forma mais utilizável. O parque organiza encontros com especialistas de diversas áreas, de pesquisadores a técnicos de empresas, para o desenvolvimento de relações em vários níveis: entre os associados, entre os associados e os territórios, entre os associados, o território e centros de competência extraterritoriais ${ }^{86}$.

A outra área de atividade do parque é Projetos e Consultoria, este corresponde à fase de execução do processo de inovação. O objetivo é o de concretizar a oportunidade de inovação, por meio de projetos e consultoria específica.

Isto acontece assistindo de tempos em tempos os atores (empresas, centros de pesquisa, associações, instituições) envolvidos em um projeto, por meio de vários serviços, entre eles: elaboração e gestão do projeto; busca de parceria; busca de financiamento; transferência tecnológica; gestão de ativos intangíveis; estudo e análise; plano de negócios; assistência a novas empresas (neo-impreditoria) $)^{87}$.

Outra característica do Centúria-RIT é agir seja ao nível individual da empresa, principalmente associada, seja ao nível do território. Tanto na ação de "Informação e Network" quanto na ação de "Projetos e Consultoria", as providências podem ser dirigidas diretamente a uma empresa individual, como a uma filial, uma área geográfica, ou um grupo de empresas.

O parque não possui laboratórios ou incubadora e adotou como modelo o que eles denominaram "modelo leve" (soft model) ou "solução leve" (soft solution), basicamente significa atuar oferecendo serviços e não infra-estrutura.

\footnotetext{
${ }^{86}$ Tradução livre de informação contida no documento "Bilancio Sociale 2006" disponível no endereço eletrônico http://www.centuria-rit.com/centuria/shared/res/companies/-3529329303360169978/attach/BS2006 PDF. Acesso em 15/01/2008

${ }^{87}$ Idem.
} 


\subsubsection{Parque Tecnológico de Viçosa (PTV)}

O PTV fica na cidade de Viçosa, no estado de Minas Gerais. Viçosa está situada na região da Zona da Mata, entre as Serras da Mantiqueira, do Caparaó e da Piedade. Encontra-se a uma altitude de $649 \mathrm{~m}$, limita-se ao norte com os municípios de Teixeiras e Guaraciaba, ao sul com Paula Cândido e Coimbra, a leste com Cajuri e São Miguel do Anta e a oeste com Porto Firme. O município é servido pelas rodovias BR 120 , MG 280 e MG $356^{88}$.

A cidade tem tradição educadora e possui longa e permanente convivência com estrangeiros, em função da construção da estrada de ferro, da Escola e da Universidade; na década de 1920 foram construídos os primeiros edifícios e galpões da Universidade Federal de Viçosa (originaria da Escola Superior de Agricultura e Veterinária - ESAV), a Escola Agrícola Arthur Bernardes, o Colégio de Viçosa, a Escola Normal, entre outros.

Cerca de $50 \%$ da população são estudantes, o que confere à população um comportamento diferenciado. O município tem uma área total de $300,15 \mathrm{~km}^{2} \mathrm{e}$ uma população de 64.850 habitantes, o produto interno bruto (PIB) é de $R \$$ 234.272.000 e o PIB por habitante é de $\mathrm{R} \$ 3600^{89}$.

A idéia de construir um parque tecnológico em Viçosa surgiu em 1996, ano em que o Conselho Universitário da Universidade Federal de Viçosa (UFV) aprovou o Regimento da Incubadora de Empresas de Base Tecnológica; e que uma pesquisa constatou haver interesse por parte de algumas empresas de se instalar num parque tecnológico em Viçosa. No ano de 2001, por meio da assinatura de um protocolo de interesses entre a UFV, a Prefeitura do Município de Viçosa e o Governo de Minas Gerais, a implantação do Parque Tecnológico de Viçosa foi iniciada ${ }^{90}$.

O local destinado ao PTV é a antiga Divisão Agrícola Arthur Bernardes, exFundação Centro Brasileiro de Infância e Adolescência (CBIA) que estava cedida para a Prefeitura Municipal de Viçosa e que passou a ser incorporada pela UFV,

\footnotetext{
88 Informação disponível no endereço eletrônico http://www.vicosa.mg.gov.br/?area=conteudo\&secao=2 Acesso em 01/03/2008.

${ }^{89}$ Informações disponíveis no endereço eletrônico http://www.vicosa.mg.gov.br/conteudo/vicosaemnumeros .htm. Acesso em 01/03/2008.

${ }^{90}$ Informação disponível no endereço eletrônico http://www.centev.ufv.br/br/parque/historico.php?linguaid=1 Acesso em 01/03/2008.
} 
ou seja, um imóvel com 2.140.000 $\mathrm{m}^{2}$ de área, cerca de $6.000 \mathrm{~m}^{2}$ em edificações e 70 funcionários lotados.

Ainda em 2001, por meio de um edital da Fundação de Amparo a Pesquisa do Estado de Minas Gerais (FAPEMIG) para apoio à implantação de parques tecnológicos no estado de Minas Gerais, a UFV recebeu recursos da ordem de R\$ 150 mil para elaborar levantamentos, projetos de engenharia, de arquitetura, de urbanismo, ambientais e os estudos de viabilidade técnica e econômica de seu parque, que foram concluídos no final de $2003^{91}$.

O objetivo do PTV é ser um vetor de indução do desenvolvimento local e regional por meio da atração e fixação de novos empreendimentos de base tecnológica; criar condições físicas e institucionais que facilitem e promovam a transferência de informações, experiências e conhecimentos gerados na UFV para o setor produtivo, aproximando, assim, a universidade à empresa através da geração contínua de spin-offs; desmistificar o saber científico; aumentar a consciência da população a respeito da importância de se preservar o meio ambiente; e oferecer condições para o desenvolvimento de atividades relacionadas com o empreendedorismo social, em paralelo com as atividades empresariais $^{92}$.

O projeto do Parque Tecnológico de Viçosa tem as seguintes características: um sistema viário interno que permite várias conexões com as vias que cruzam a área; a implantação de um Centro de Estudos Ambientais, cuja missão é gerenciar as atividades de lazer visando a formação de uma maior consciência ambiental da população; a implantação de um Museu Interativo de Ciência e Tecnologia para proporcionar uma socialização do conhecimento; o desenvolvimento de projetos sociais que propiciarão às empresas que ali se instalarem oportunidades de interação com as comunidades de seu entorno ${ }^{93}$. A Figura 5.4 apresenta o projeto urbanístico do PTV.

\footnotetext{
${ }^{91}$ Informação disponível no endereço eletrônico http://www.centev.ufv.br/br/parque/historico.php?linguaid=1 Acesso em 01/03/2008.

${ }_{93}$ Idem.

93 Idem.
} 


\section{plano urbanístico}

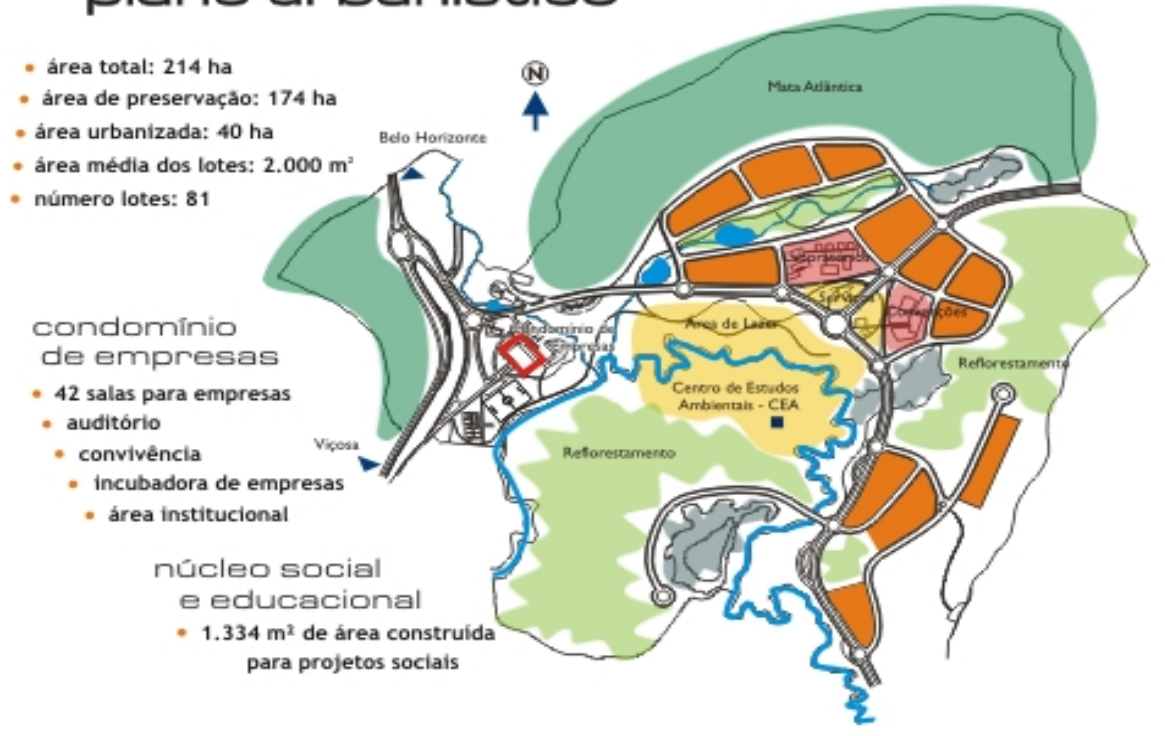

Figura disponível no endereço eletrônico http://www.centev.ufv.br/br/parque/projeto.php?linguaid=1 acesso em 01/3/2008

FIGURA 5.4 - Projeto urbanístico do PTV

\subsubsection{Parque Tecnológico de Campinas}

O Parque Tecnológico de Campinas fica no Município de Campinas que

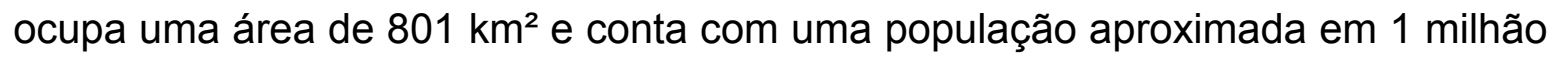
de habitantes, distribuída por quatro distritos (Joaquim Egídio, Sousas, Barão Geraldo, e Nova Aparecida) e centenas de bairros. O vigor econômico e social, trazido em especial pela ampliação de sua população trabalhadora, tem permitido à Campinas constituir-se como um dos pólos da região metropolitana de São Paulo, formada por 19 cidades e uma população estimada em 2,33 milhões de habitantes $(6,31 \% \text { da população do Estado })^{94}$. A Tabela 5.7 apresenta alguns dados econômicos e sociais da cidade de Campinas.

TABELA 5.7 - Dados Econômicos e Sociais da cidade de Campinas

Produto Interno Bruto (PIB)*: R\$ 14.716.830.000,00 (2004)

Renda Per Capita*:R\$ 14.262,00 (2004)

Índice de Desenvolvimento Humano (IDH): 0,852 (PNUD - 2000)

Principais Atividades Econômicas: indústria, comércio, construção civil, serviços e tecnologia.

Índice de Analfabetismo: 4,6 \%

Aeroporto: Aeroporto Internacional de Viracopos

Inf. disponível no end. eletrônico http://www.suapesquisa.com/cidadesbrasileiras/cidadecampinas.htm. Acesso 01/03/2008.

\footnotetext{
94 Informação disponível no endereço eletrônico http://www.campinas.sp.gov.br/campinas/campinas/origens/. Acesso em 01/03/2008.
} 
Remontam aos anos 70 as iniciativas para a implantação do Parque Científico e Tecnológico de Campinas, inclusive a destinação de uma área de $7.000 .000 \mathrm{~m}^{2}$, formada por áreas públicas e propriedades particulares, destinada a implantação de empresas e instituições de base tecnológica. Desde então, essa área, delimitada por dois vetores dinâmicos de ocupação de Campinas, as Rodovias D. Pedro I e Campinas/Mogi-Mirim, vem sendo ocupada por indústrias e atividades de serviços de âmbito regional ${ }^{95}$.

Ao longo do seu processo de desenvolvimento, Campinas consolidou condições de liderança no país na localização de instituições, empresas e atividades baseadas no desenvolvimento científico e na inovação. Campinas tem uma vocação muito forte na área de tecnologia da informação. Durante as décadas de 1980 e 1990, quase todos os investimentos privados nessa área feitos no país ocorreram nessa região, entre eles: a Nortel, o Centro de Pesquisas da Eriksson, a Motorola, a Lucent ${ }^{96}$. A Figura 5.5 representa o mapa de localização da área do Parque Tecnológico de Campinas no município.

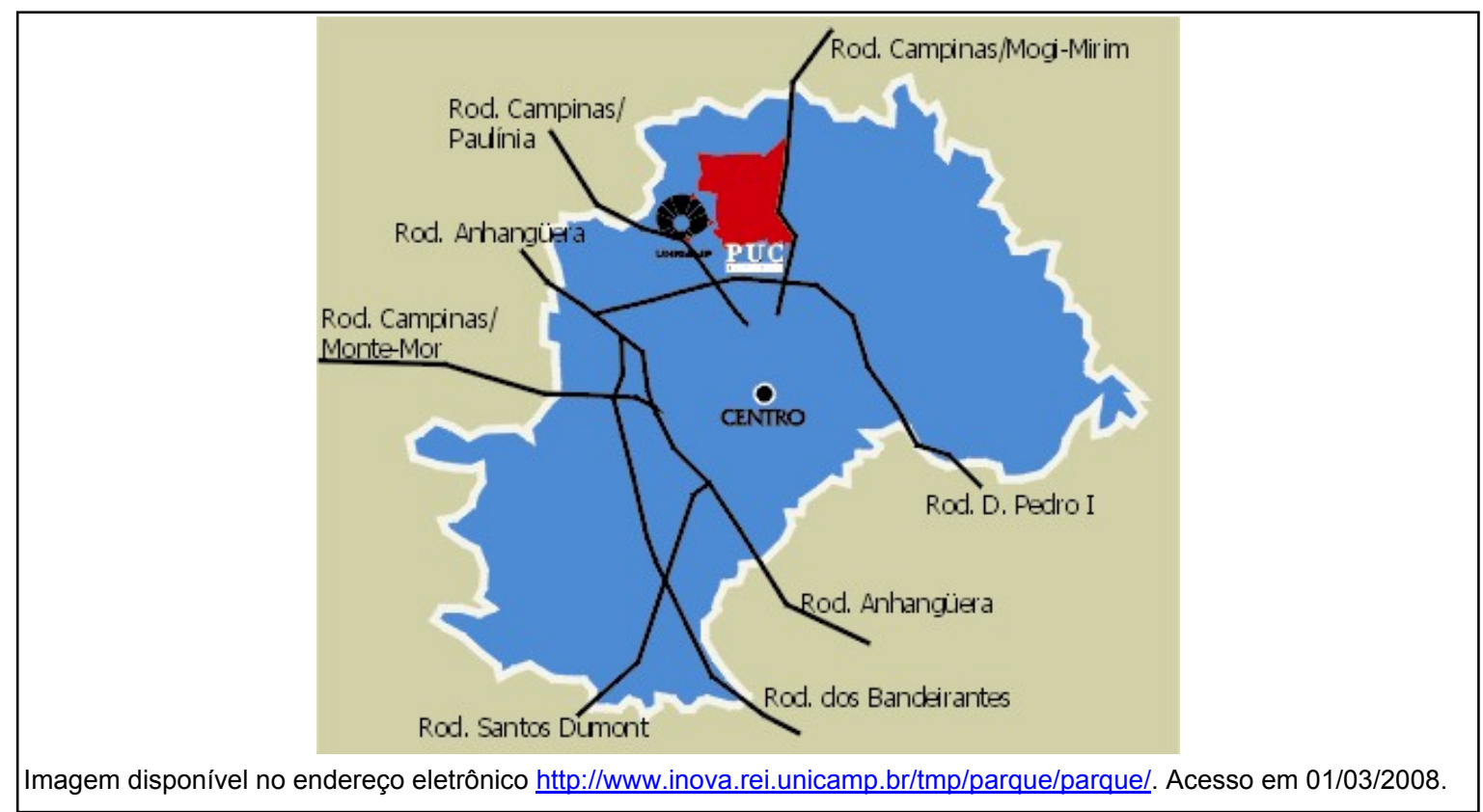

FIGURA 5.5 - Localização do Parque Tecnológico de Campinas

\footnotetext{
${ }^{95}$ Informação disponível no endereço eletrônico http://www.inova.rei.unicamp.br/tmp/parque/parque/. Acesso em 01/03/2008.

${ }_{96}$ Idem.
} 
Empresas novas na área de biotecnologia, intensivas em pesquisa e desenvolvimento, como Alellyx e Scilla, se instalaram na região. Apesar de ser ainda pequeno o número de empresas nessa área, o um interesse do capital de risco em investir no ramo de biotecnologia, abre uma possibilidade de ação nessa área. Além de tecnologia da comunicação e biotecnologia, há outros setores emergentes que poderão integrar o Parque Tecnológico ${ }^{97}$.

As empresas e instituições de P\&D existentes em Campinas e também aquelas residentes no Parque Científico e Tecnológico de Campinas concentram suas atividades nas seguintes áreas de competência: tecnologia da informação e da comunicação - TIC, telecomunicações, laser e óptica, material eletrônico, química, e biotecnologia.

No ano de 2003 a UNICAMP em parceria com a Prefeitura de Campinas e com apoio financeiro da FINEP e da Secretaria de Ciência e Tecnologia do Estado de São Paulo, deu início ao Plano de Expansão do Parque Científico e Tecnológico de Campinas. O Plano de Expansão do Parque é coordenado pela Agência de Inovação da UNICAMP e pretende atrair indústrias baseadas em pesquisa ou atividades de pesquisa e desenvolvimento que queiram se beneficiar da massa crítica existente na Universidade ${ }^{98}$.

\subsubsection{Hong Kong Science \& Technology Parks Corporation (HKSTP)}

O Hong Kong Science \& Technology Parks Corporation foi fundado em 7 de Maio de 2001 pelo Governo da Região Administrativa Especial de Hong Kong, como um órgão estatutário. O HKSTP vem conduzindo a transformação de Hong Kong num pólo regional de tecnologia nos ramos da: eletrônica, tecnologia da informação e telecomunicações, biotecnologia e engenharia de precisão ${ }^{99}$.

O projeto de construção do parque foi dividido em três fases, a primeira fase foi completada e inaugurada em 2004; a finalização da fase dois está programada para 2008 com os primeiros dois prédios já construídos em 2007, ao

\footnotetext{
${ }^{97}$ Informação disponível no endereço eletrônico http://www.inova.rei.unicamp.br/tmp/parque/parque/. Acesso em 01/03/2008.

${ }_{98}$ Informação disponível no endereço eletrônico http://www.inova.rei.unicamp.br/tmp/parque/parque/. Acesso em 01/03/2008.

99 Tradução livre de informações disponíveis no Hong Kong Science and Technology Parks Corporation Annual Report 2006/2007 disponível no endereço eletrônico http://www.hkstp.org/HKSTPC/annualReport. jsp?lan=en. Acesso em 05/03/2008.
} 
final da fase três o parque terá uma área total construída de $330.000 \mathrm{~m}^{2} 100$. A Figura 5.6 representa as três fases do projeto de construção do HKSTP e a Figura 5.7 apresenta a localização do HKSTP.

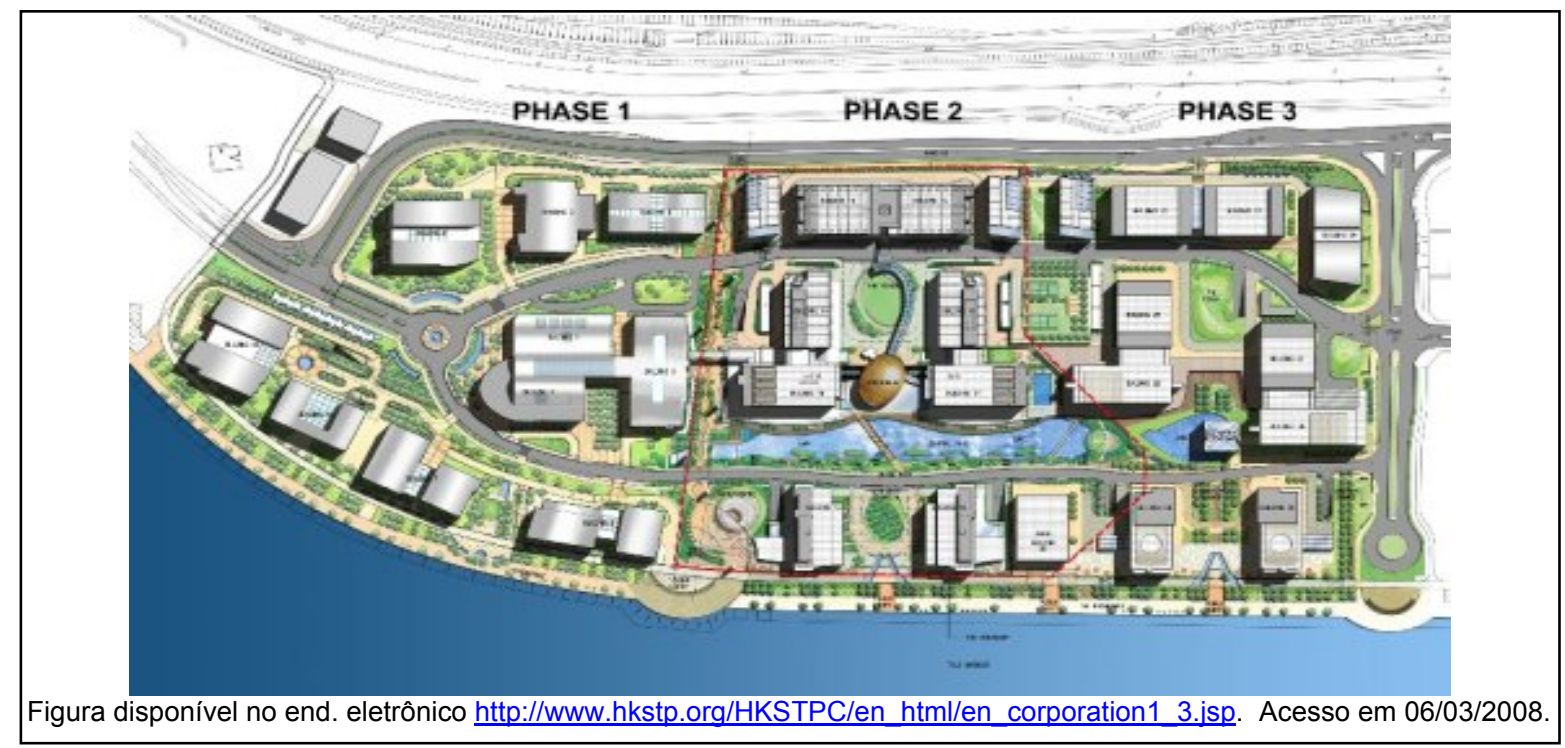

FIGURA 5.6 - Fases do projeto do Hong Kong Science \& Technology Park

\footnotetext{
${ }^{100}$ Tradução livre de informações disponíveis no endereço eletrônico http://www.hkstp.org/HKSTPC/en html// en corporation1 3.jsp. Acesso em 05/03/2008.
} 


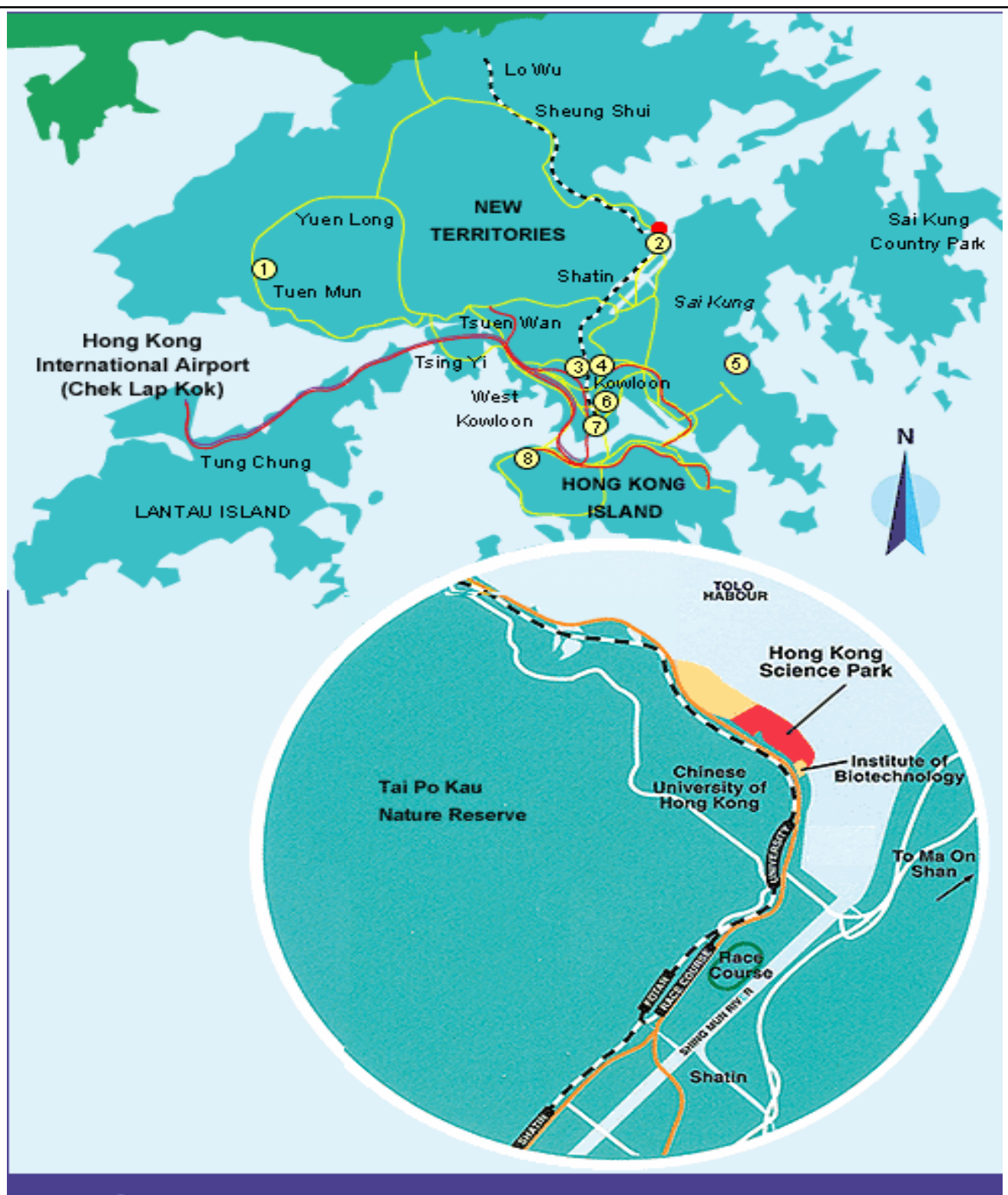

\section{LEGEND}

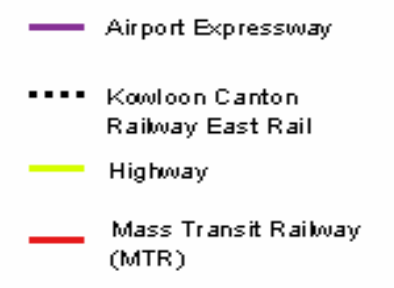

(1) Lingnan U niversity

(2) The Chinese U niversity of Hong Kong

(3) City University of Hong Kong

(4) Hong Kong Baptist University

(5) Hong Kong Universityof Science and Technology

(6) The Open University of Hong Kong

(7) The Hong Kong Pobytechinc University

(8) The University of Hong Kong

Imagem disponível no endereço eletrônico http://www.hkstp.org/HKSTPC/en html/en corporation1 2.jsp Acesso em 05/03/2008.

FIGURA 5.7 - Localização do Hong Kong Science \& Technology Park 
O HKSTP oferece uma série de instalações e serviços às empresas em suas várias fases de desenvolvimento, tais como: o InnoCentre no Kowloon Tong, que foi aberto para operação no final de 2006 e que tem como função apoiar o desenvolvimento de empresas da área de design; o Centro de Apoio ao Desenvolvimento da Informação e Comunicação em Hong Kong; o Laboratório de Testes para Comunicação sem Fio Wireless (WCTL); o Centro de Apoio ao Desenvolvimento em Fotônica; Programas de incubação e apoio a start-ups incluindo o Programa de Incubação de Negócios (Incu-Tech); Programa de Incubação em Design; e Programa STEP (Small Technology/Design Incubation Programme); atendimento às necessidades tecnológicas ou habilidades especiais necessárias às empresas; suporte técnico e de engenharia para aplicações em atividades de P\&D aos instalados no HKSTP e às empresas de Hong Kong ${ }^{101}$.

O parque HKSTP dispõe de diversas salas multipropósito, tais como: sala de apresentações; sete salas de reunião; sala de áudio visual com equipamentos para vídeo conferência; área interna e fechada de $900 \mathrm{~m}^{2}$ para exibições. As diversas salas de conferência e reunião são equipadas com áudio visual para apresentações, reuniões e eventos ${ }^{102}$.

O Centro de Negócios do Parque está localizado próximo a área de exibições e as salas de reunião; e oferece uma série de serviços que atendem as necessidades básicas dos visitantes e convidados, tais como: telefones, faxes, computadores, etc... ${ }^{103}$

Para assegurar que todos os convidados e visitantes se beneficiem de tecnologia de classe mundial, o parque provê uma série de serviços relacionados a tecnologia da informação, tais como: intranet e internet, equipamento de vídeo conferencia com conexões ISDN BRI, quiosque de informação, PC Smart Card, wireless LAN, informações LCD e monitores e mostradores de Plasma ${ }^{104}$.

\footnotetext{
101 Tradução livre de informações disponíveis no Hong Kong Science and Technology Parks Corporation Annual Report 2006/2007 disponivel no endereço eletrônico http://www.hkstp.org/HKSTPC/annual Report.jsp?lan=en. Acesso em 05/03/2008.

${ }_{102}$ Tradução livre de informação disponível no endereço eletrônico http://www.hkstp.org/HKSTPC/en html/ corporation1 6.jsp. Acesso em 05/03/2008.

${ }^{103}$ Idem.
${ }^{104}$ Idem.
} 
O Parque oferece apartamentos mobiliados e com serviços incluídos para empresas instaladas, a área de cada apartamento varia de $65 \mathrm{~m}^{2}$ a $176 \mathrm{~m}^{2} \mathrm{e}$ possui sala, cozinha aberta completa e um quarto com suíte. Ainda oferece serviços de arrumação semanal, acesso a internet, loja de conveniência 24 horas, e serviço de delivery para alimentação. Além disso, o parque dispõe de um fitness center e de uma área de recreação, serviços de transporte, ônibus e estacionamento para veículos ${ }^{105}$. O HKSTP possui um time de profissionais no local que compõem o staff na administração dos serviços oferecidos pelo Parque e orientados aos clientes.

\subsubsection{Madeira Tecnopólo - Pólo Científico e Tecnológico da Madeira}

O Madeira Tecnopólo está localizado na ilha da Madeira, na cidade de Funchal, que é o principal centro urbano e porto da ilha; situa-se na costa sul e dista cerca de $660 \mathrm{~km}$ da costa africana, $980 \mathrm{~km}$ de Lisboa, $400 \mathrm{~km}$ da Gran Canaria, e $880 \mathrm{~km}$ da llha de Santa Maria, a mais próxima do arquipélago dos Açores $^{106}$. A população da ilha é de cerca de 260 mil habitantes, a maioria de nacionalidade portuguesa. O Funchal conta com cerca de metade dos habitantes da ilha. Mais de metade da população concentra-se em apenas $7 \%$ da área da ilha, em especial na costa sul ${ }^{107}$.

A Madeira é uma Região Autônoma da República Portuguesa, com órgãos de governo próprios, dotados de autonomia, legislativa e executiva, gozando plenamente dos direitos da integração de Portugal na União Européia (UE). Está numa posição geoestratégica no espaço Euro-Atlântico, é uma plataforma para os mercados Africanos, Sul Americanos e uma porta de entrada para a Europa; é região autônoma de Portugal e beneficia de direitos acrescidos no quadro da União Européia, devido ao fato de ser considerada região ultraperiférica (tratado de Amsterdã, artigo 227) ${ }^{108}$.

\footnotetext{
105 Tradução livre de informação disponível no endereço eletrônico http://www.hkstp.org/HKSTPC/en html/ corporation1 6.jsp. Acesso em 05/03/2008.

${ }^{106}$ Informação disponível no endereço eletrônico http://pt.wikipedia.org/wiki//lha da Madeira. Acesso em 06/03/2008.

107 Idem.

${ }^{108}$ Informação disponível no endereço eletrônico http://www.madeiratecnopolo.pt/index.php?option=com content\&task=view\&id=28\&ltemid=38\&lang=pt\#. Acesso em 05/03/2008.
} 
O Madeira Tecnopólo é um dos primeiros parques científicos mundiais francos do mundo e está situado a dois quilômetros do centro da cidade de Funchal e da zona hoteleira, junto a um nó rodoviário que liga ao aeroporto e a outras importantes vias rápidas. É servido por diversos e freqüentes percursos ônibus e paradas de taxis, possuindo estacionamento para automóveis, ônibus e área VIP ${ }^{109}$. A Figura 5.8 representa a localização do Madeira Tecnopólo.

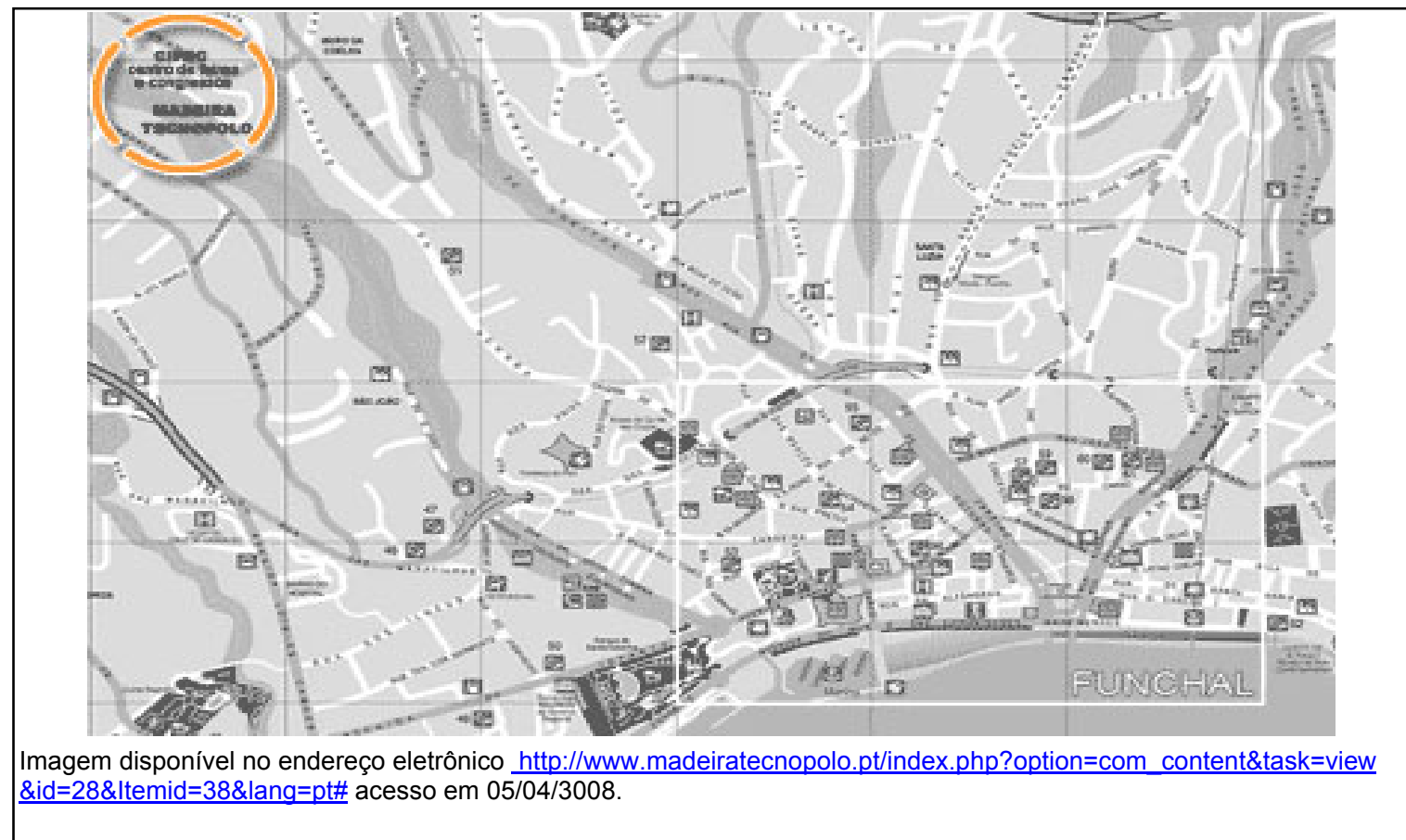

FIGURA 5.8 - Localização do Madeira Tecnopólo

O Madeira Tecnopólo, assume-se como um Centro de Competências, num espaço físico que está em constante atualização, perseguindo o objetivo de aproveitar e depois transmitir, as vantagens que advêm das relações estabelecidas: no Espaço do Madeira Tecnopólo, no espaço do Madeira Tecnopolo com a Região Autônoma da Madeira; e no Madeira Tecnopólo com Entidades Internacionais ${ }^{110}$. O Madeira Tecnopólo assume como prioritárias duas áreas de negócio: Desenvolvimento de projetos e Centro Internacional de Feiras e Congressos. Suas áreas estratégicas de atuação são: Inovação, Novas Tecnologias de Informação e Comunicação (NTIC), Desenvolvimento Sustentável,

\footnotetext{
109 Informação disponível no endereço eletrônico http://www.madeiratecnopolo.pt/index.php?option=com content\&task=view\&id=27\&ltemid=37\&lang=pt. Acesso em 06/03/2008. 
Ambiente, Educação / Formação avançada/e-Learning e Sociedade de Informação ${ }^{111}$.

O parque Madeira Tecnopólo oferece aos instalados no parque serviços de apoio, consultoria e execução de processos e procedimentos relativos às áreas de: Investigação e Desenvolvimento Tecnológico (IDT); concepção e desenvolvimento de produtos e serviços relativos à Sociedade de Informação; Tecnologias da Informação e Comunicação; Telecomunicações; Desenvolvimento Sustentável; difusão e utilização de tecnologias avançadas; Promoção e Difusão da Inovação; Internacionalização; e Ensino e Formação do Potencial Humano. O parque também realiza atividades de apoio à: Gestão e Articulação da Investigação e Desenvolvimento Tecnológico Regional e da sua inserção; Tecnologias de Informação e Comunicação; Telecomunicações; Desenvolvimento Sustentável; Inovação, Qualidade; Internacionalização; e Exposições, Congressos, Seminários e Incentivos ${ }^{112}$.

Além de diversas empresas, estão instalados no parque o Centro de Empresas e Inovação da Madeira (CEIM), a Agência Regional de Energia e Ambiente (AREAM), o Núcleo Estratégico para a Sociedade de Informação (NESI); e a Associação Portuguesa de Parques de Ciência e Tecnologia (TecParques) $^{113}$.

Fazem ainda parte do parque as seguintes instalações: um Centro de Congressos com onze salas e auditórios, dentre eles um auditório com 750 lugares; e um Centro de Feiras com $5.000 \mathrm{~m}^{2}$ de área para exposições, distribuídas por dois pavilhões contíguos e complementares, que possibilitam a construção de até 300 módulos de $9 \mathrm{~m}^{2}{ }^{114}$. As paredes móveis e as galerias técnicas situadas sob os pavilhões que facilitam ligações elétricas, água, esgoto, telecomunicações e internet, conferindo ao Centro de Congressos e ao Centro de Feiras uma grande mobilidade e adaptabilidade na prestação de serviços.

\footnotetext{
111 Informação disponível no endereço eletrônico http://www.madeiratecnopolo.pt/index.php?option=com cont ent\&task=view\&id=27\&ltemid=37\&lang=pt. Acesso em 06/03/2008.

${ }^{112}$ Informação disponível no endereço eletrônico http://www.madeiratecnopolo.pt/index.php?option=com cont ent\&task=view\&id=70\&ltemid=90\&lang=pt acesso em 06/03/2008.

${ }^{113}$ Informação disponível no endereço eletrônico http://www.madeiratecnopolo.pt/index.php?option=com cont ent\&task=view\&id=68\&ltemid=88\&lang=pt. Acesso em 05/03/2008.

${ }^{114}$ Idem.
} 
O Plano de expansão do Madeira Tecnopólo prevê uma área total de 42 Hectares, distribuídos por áreas como a Universidade, o Centro Internacional de Feiras e Congressos, a Incubadora de Empresas, as Empresas de Investigação Tecnológica, as Áreas Comerciais. A Figura 5.9 representa o plano de Expansão ${ }^{115}$.

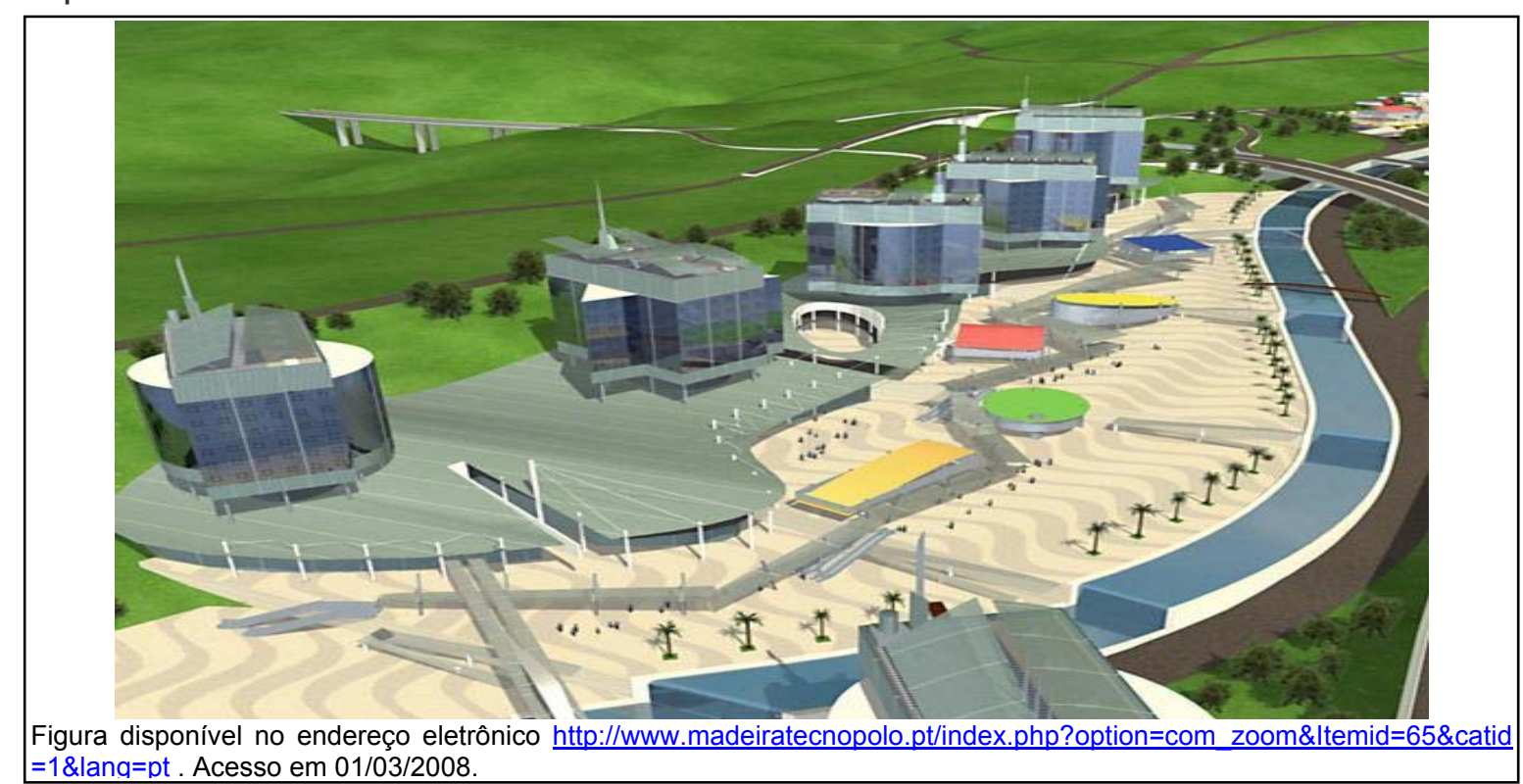

FIGURA 5.9 - Plano de Expansão do Madeira Tecnopólo

\subsubsection{Parque Científico e Tecnológico da PUCRS - TECNOPUC}

O Parque Tecnológico TECNOPUC fica na cidade de Porto Alegre, capital do estado do Rio Grande do Sul. Porto Alegre é localizada junto ao rio Guaíba, no extremo sul do país; ocupa uma área de $496,827 \mathrm{~km}^{2}$, sua população é de 1.440.939 habitantes e sua densidade demográfica é de 2.905 habitantes por $\mathrm{km}^{2116}$. É uma região com boa infra-estrutura de ciência e tecnologia, possui quatro universidades com mais de 130.000 estudantes, e oferece uma série de laboratórios técnicos e científicos, além de outros laboratórios de órgãos governamentais ${ }^{117}$ A tabela 5.8 apresenta alguns dados econômicos e sociais da cidade de Porto Alegre.

\footnotetext{
115 Informação disponível no endereço eletrônico http://www.madeiratecnopolo.pt/index.php?option=com con tent\&task=view\&id=29\&ltemid=39\&lang=pt. Acesso em 05/03/2008.

${ }^{116}$ Informação disponível no endereço eletrônico http://www.suapesquisa.com/cidadesbrasileiras/cidade porto alegre.htm. Acesso em 01/03/2008.

117 Informação disponível no endereço eletrônico http://www.pucrs.br/agt/tecnopuc/. Acesso em 05/03/2008.
} 


\begin{tabular}{|l|}
\hline TABELA 5.8 - Dados Econômicos e Sociais da cidade de Porto Alegre \\
\hline Produto Interno Bruto (PIB): R\$15.944.201.000,00 (2004) \\
Renda Per Capita: R\$ 11.257,00 (2004) \\
Principais Atividades Econômicas: indústria, comércio, serviços e construção civil. \\
Índice de Desenvolvimento Humano (IDH): 0,865 (PNUD - 2000) \\
\hline Informação disponível no endereço eletrônico http://www.suapesquisa.com/cidadesbrasileiras/cidade porto alegre.htm. \\
Acesso em 01/03/2008. \\
\hline
\end{tabular}

O TECNOPUC foi criado por iniciativa da Pontifícia Universidade Católica do Rio Grande do Sul (PUCRS) que criou em 1999 a Agência de Gestão Tecnológica e Propriedade Intelectual da PUCRS (AGT) a fim de viabilizar a relação com as empresas e instituições sociais, ampliando parcerias e adquirindo experiência para finalmente propor a criação do parque ${ }^{118}$.

A PUCRS que acolhe mais de 32.000 estudantes, 1.800 professores e 1.200 funcionários, cedeu $54.000 \mathrm{~m}^{2}$ dos seus $700.000 \mathrm{~m}^{2}$ de área total para o TECNOPUC, que tem como missão "criar uma comunidade de pesquisa e inovação transdisciplinar por meio da colaboração entre academia, empresas e governo visando aumentar a competitividade dos seus atores e melhorar a qualidade de vida de suas comunidades"119. A Figura 5.10 apresenta a localização do TECNOPUC no campus da PUCRS e a Figura 5.11 representa as instalações do parque.

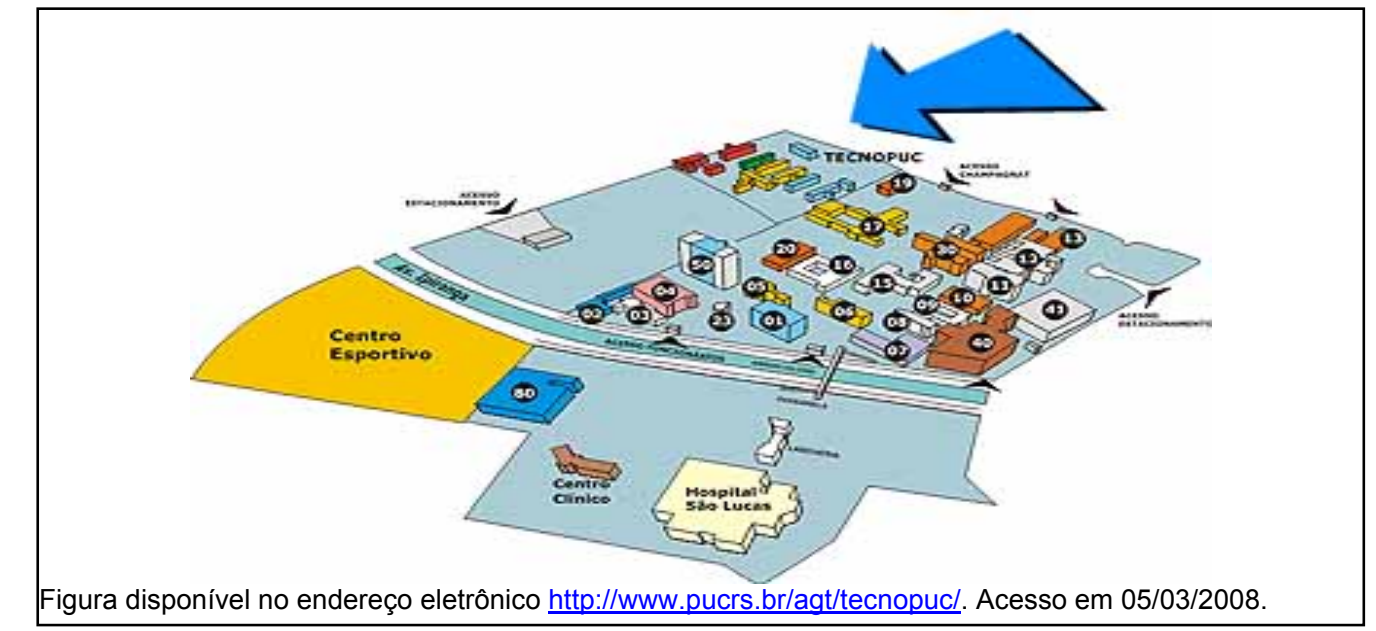

FIGURA 5.10 - Localização do TECNOPUC no campus da PUCRS

\footnotetext{
${ }_{111}^{118}$ Informação disponível no endereço eletrônico http://www.pucrs.br/agt/tecnopuc/. Acesso em 05/03/2008. 


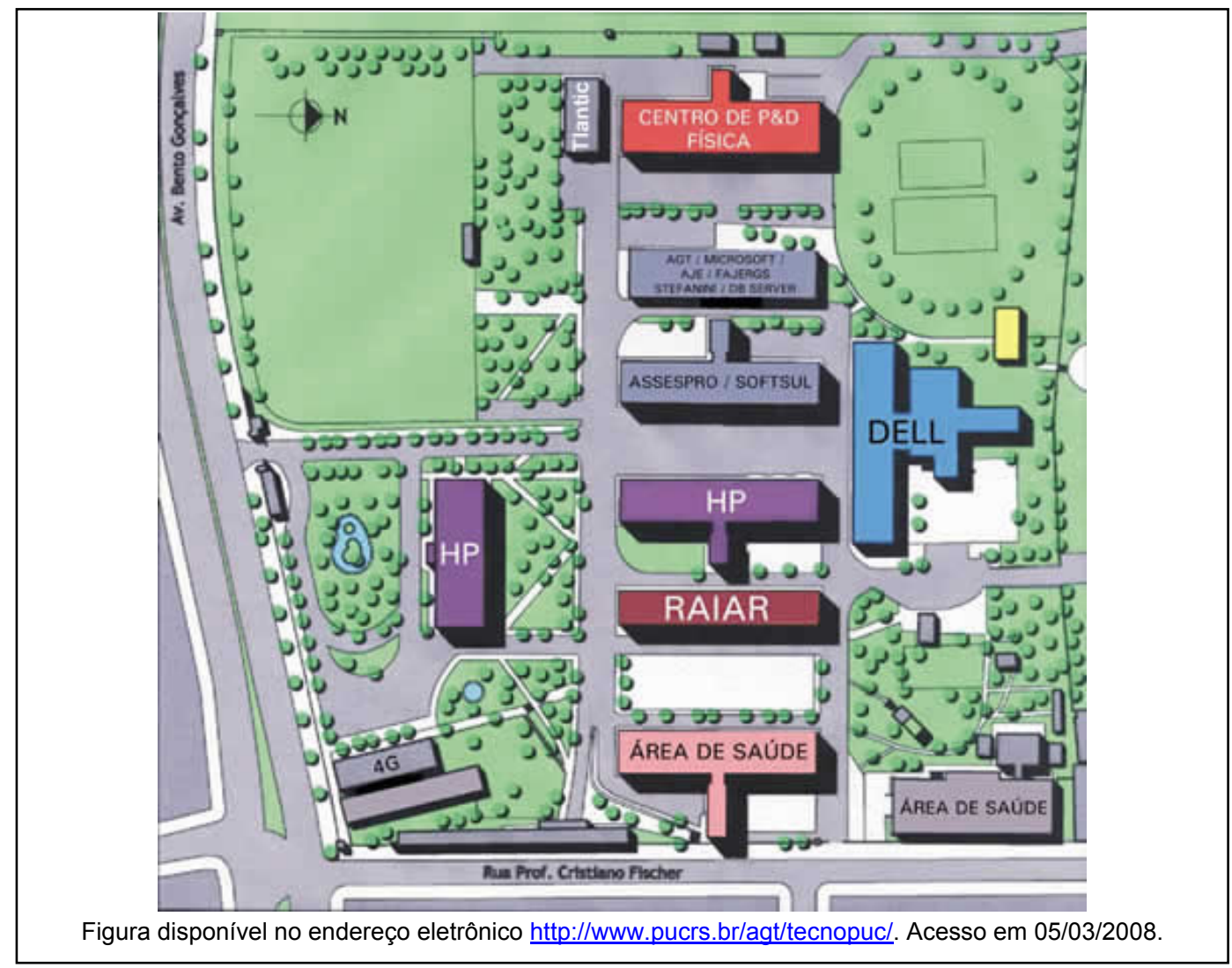

FIGURA 5.11 - Instalações do TECNOPUC

As áreas de atuação do TECNOPUC foram definidas em função da competência acadêmica da PUCRS (grupos de pesquisa científica e tecnológica e cursos de pós-graduação) associada às necessidades da sociedade, o que resultou num parque tecnológico multitemático, com foco em três áreas: Tecnologia da Informação e Comunicação; Energia e Física Aplicada; e Ciências Biológicas, da Saúde e Biotecnologia ${ }^{120}$.

São objetivos do TECNOPUC: atrair empresas de P\&D para trabalhar em parceria com a Universidade; estimular a criação e o desenvolvimento de novas empresas de base tecnológica; trazer projetos de pesquisa e desenvolvimento tecnológico em geral; incentivar a inovação e a interação empresas-Universidade; criar uma sinergia positiva entre o meio acadêmico e o empresarial; e agir de

\footnotetext{
${ }^{120}$ Informações disponível no endereço eletrônico http://www.pucrs.br/agt/tecnopuc/. Acesso em 05/03/2008.
} 
forma coordenada com a esfera governamental, em especial no âmbito do Projeto Porto Alegre Tecnópole ${ }^{121}$ - PAT $^{122}$.

A administração do TECNOPUC é realizada pela AGT que possui um comitê gestor para assuntos operacionais composto pelo: Pró-Reitor de Extensão (PROEX), Pró-Reitor de Administração e Finanças (PROAF), Pró-Reitor de Pesquisa e Pós-Graduação (PRPPG), Coordenador da Procuradoria Jurídica (PROJUR) e pelo Diretor da AGT. O conselho administrativo traça as diretrizes do Parque, bem como avalia seu desempenho periodicamente.

A equipe do TECNOPUC é composta de quatro profissionais: um da Direção, dois na Administração e um na Gestão de Relacionamento. Aos instalados no TECNOPUC são disponibilizados serviços diversos tais como: correio, bancos, biblioteca, parque esportivo, centro de convenções, unidade de ensino a distância, restaurantes e bares, hospital São Lucas, Museu de Ciência e Tecnologia, Laboratórios científicos e tecnológicos.

Além disso, o TECNOPUC disponibiliza aos instalados no parque e na sua Incubadora RAIAR, parte da infra-estrutura e dos serviços da PUCRS, como: o Escritório de Transferência de Tecnologia (ETT); o Laboratório Especializado em Eletro-Eletrônica (LABELO); o Centro de Microscopia e Microanálises; o CEPUC Centro de Eventos da PUCRS; a Biblioteca Central; o Hospital São Lucas da PUCRS; o Instituto de Pesquisas Biomédicas; a editora EDIPUCRS; o Museu de Ciências e Tecnologia da PUCRS; a PUCRS Virtual Educação a Distância; e o laboratório do Projeto GENOMA.

\subsubsection{Technologiepark Bremen (BremenTechnology Park)}

O Technologiepark Bremen está instalado na cidade de Bremen, que fica ao norte da Alemanha, situada às margens do rio Weser. Bremen têm uma população de 547.000 habitantes e uma densidade populacional de 325,38 pessoas $/ \mathrm{km}^{2}$; é uma das duas cidades pertencentes ao estado de Bremen, a outra

\footnotetext{
121 Informações disponível no endereço eletrônico http://www.pucrs.br/agt/tecnopuc/. Acesso em 05/03/2008.

122 O PAT foi criado em 1995 por iniciativa de representantes do Governo Municipal, Estadual e Federal em conjunto com representantes do setor empresarial, do meio acadêmico e dos trabalhadores. Em 1996 foram identificadas as regiões de potencial tecnológico da RMPA - REPOTs. Estas regiões definiram territórios de atuação estratégica do PAT, gerando um conjunto de ações, entre elas a constituição de diversas incubadoras de base tecnológica, programas de transferência de tecnologia nas universidades, projetos e implantação de parques tecnológicos. Informação disponível no endereço eletrônico http://www.tecnopole.palegre.com.br/ Default.asp?proj= 57\&secao=122\&m1=5369. Acesso em 05/03/2008.
} 
é Bremerhaven ${ }^{123}$. Bremen é uma cidade de tradições marítimas; o porto da cidade tem um volume de carga de cerca de 52 milhões de toneladas (em 2004), constituindo se um importante fator para a economia local ${ }^{124}$.

Altos padrões tecnológicos são fixados em Bremen nos domínios da produção, da marinha e de engenharia eletrônica. No ramos da comunicação e tecnologia da informação Bremen tem se posicionado bem. Outras áreas promissoras são a de engenharia de micro-sistemas, engenharia ambiental, o setor de saúde, tecnologia alimentar e da biotecnologia. Bremen conta com uma boa infra-estrutura de pesquisa, com quatro institutos de ensino superior e cerca de 50 institutos de pesquisa ${ }^{125}$.

Uma importante área de especialização em Bremen é a tecnologia aeroespacial, empresas inovadoras como a EADS Space Transportation ou OHBSystem $A G$, empresa líder na Europa na construção de pequenos satélites, e os centros de investigação, como o Centro de Tecnologia Espacial Aplicada e Microgravitação (ZARM) estão sediados em Bremen ${ }^{126}$.

Criado a mais de 15 anos em torno da Universidade de Bremen, com doze faculdades, 23.000 estudantes e 1.950 professores, o Technologiepark Bremen tem mais de 320 empresas de alta tecnologia instaladas no parque e 6200 trabalhadores numa área de aproximadamente $700.000 \mathrm{~m}^{2}$. O parque atua nas seguintes áreas: tecnologia da informação e comunicação, aeroespacial, logística, materiais, engenharia da produção e micro-sistemas, tecnologia de sensores e nanotecnologia ${ }^{127}$.

No Technologiepark Bremen estão instalados 20 institutos de pesquisa com um total de aproximadamente 1000 empregados. São eles: Instituto Fraunhofer para Pesquisa Aplicada de Materiais; Instituto para Ciência dos Materiais; Instituto Max Planck para Microbiologia Marinha; ZARM-Fallturm-Betriebsgesellschaft $\mathrm{mbH}$

\footnotetext{
${ }^{123}$ Informações disponíveis no endereço eletrônico http://pt.wikipedia.org/wiki/Bremen. Acesso em 05/03/2008.

124 Tradução livre de informação disponível no endereço eletrônico http://www.euroffice-services.eu/index. php?id=168. Acesso em 05/03/2008.

${ }^{125}$ Id Tradução livre de informação disponível no endereço eletrônico http://www.euroffice-services.eu/index. php?id=168. Acesso em 05/03/2008.

${ }^{126}$ Idem.

127 Tradução livre de informação disponível no endereço eletrônico http://www.technologiepark-bremen.de/en/ tp ueber den park. Acesso em 05/03/2008.
} 
(Drop Tower); Centro de Tecnologia da Informação; Centro para Tecnologia da Informação e Comunicação; Centro para Sistemas de Diagnósticos Médicos e Visualização; Instituto Bremen para Tecnologias Aplicadas da Radiação; Instituto Bremen de Tecnologia Industrial Aplicada e Ciência Aplicada ao Trabalho; Instituto para Transporte e Logística Marítima; Centro de Pesquisa Tecnológica Ambiental e Centro para Genética Humana ${ }^{128}$.

As áreas oferecidas às empresas para instalação de escritórios ou instalações industriais são disponibilizadas na base de compra ou aluguel por meio da BIG Bremen (Bremer Investitions-Gesellschaft $\mathrm{mbH}$ ) - Economic Development que é uma agência central da cidade de Bremen em matérias relacionadas ao desenvolvimento de negócios na região. A Figura 5.12 representa a localização do Parque e a Figura 5.13 dá uma visão área do Technologiepark Bremen.

Figura disponível no endereço eletrônico http://www.technologiepark-bremen.de/en/tp anfahrt. Acesso em 05/03/2008.

FIGURA 5.12 - Localização do Technologiepark Bremen

\footnotetext{
${ }^{128}$ Tradução livre de informação disponível no endereço eletrônico http://www.technologiepark-bremen.de/en/ tp ueber den park. Acesso em 05/03/2008.
} 


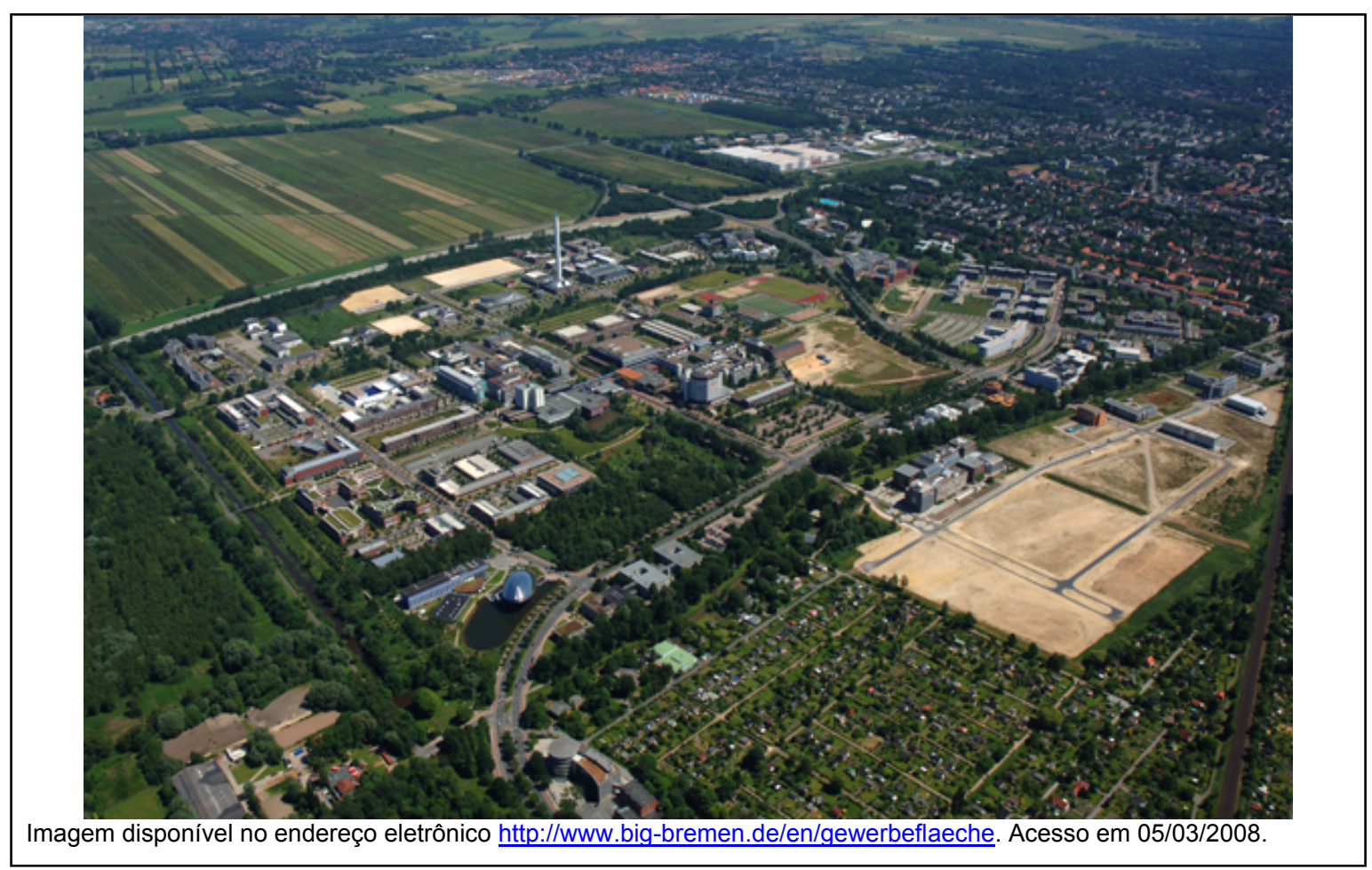

FIGURA 5.13 - Foto aérea do Technologiepark Bremen

\subsubsection{Pólo Tecnológico de Pando (PTP)}

O Pólo Tecnológico de Pando foi criado na Faculdade de Química (FQ) em 2001, está localizado nas proximidades da zona industrial da cidade de Pando, no município de Canelones, Uruguai; a população da cidade é de 24.000 habitantes $^{129}$. O pólo fica a 15 quilômetros do aeroporto Internacional de Carrasco e a 37 quilômetros de Montevideo, que tem uma população de 1.269.648 habitantes e é a capital do país ${ }^{130}$.

A criação do pólo faz parte da política da Universidade da República do Uruguai de promover a incorporação do conhecimento na produção de bens e serviços a fim de colaborar com a geração de emprego e riqueza. Para isto o Pólo Tecnológico de Pando se propõe a promover a inovação nas empresas por meio de atividades de P\&D compartilhadas entre o pólo e as empresas, trabalhando

\footnotetext{
${ }^{129}$ Informação disponível no endereço eletrônico http://pt.wikipedia.org/wiki/Pando (Uruguai). Acesso 05/03/2008.

130 Tradução livre de informação disponível no endereço eletrônico http://www.polotecnologico.fq.edu.uy/. Acesso em 05/03/2008.
} 
conjuntamente com os seguintes atores: governo, empresários, organizações de sociedade civil e organismos de cooperação internacional ${ }^{131}$.

O Pólo Tecnológico de Pando está voltado para o setor químico e biotecnológico, em particular orientado para a indústria farmacêutica e alimentícia; tem como meta colaborar na geração de um ambiente inovador na indústria e nos serviços a ela relacionados. A Figura 5.14 representa a localização e o endereço do pólo.

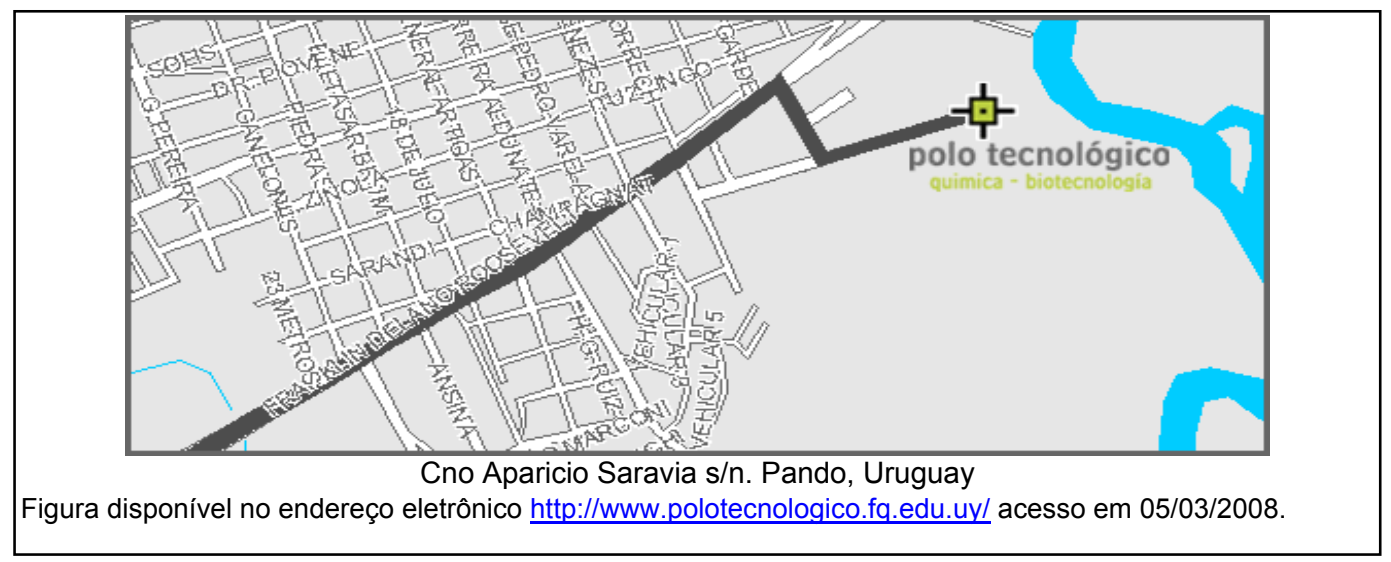

FIGURA 5.14 - Localização do Pólo Tecnológico de Pando

O Pólo permite às empresas se iniciarem numa estratégia sustentada de pesquisa para a inovação sem necessidade de investimentos significativos em instalações e equipamentos; ele funciona como uma incubadora de departamentos de P\&D para empresas já existentes, utilizando o modelo de consórcios, funciona também como provedor permanente de P\&D e serviços tecnológicos para outras empresas e instituições que não optam por formarem consórcios com o PTP ${ }^{132}$.

O Pólo Tecnológico de Pando é dirigido por uma Comissão Diretiva (CDP) composta por: 2 representantes do consórcio CESTI (Consorcio de Estrategía Tecnológica e Innovación) entre a Fundaquim (Fundação sem fins lucrativos da Faculdade de Química da Universidade da República do Uruguai) e a Urutec (empresa de consultoria privada e especializada em gestão e transferência tecnológica - Uruguay Tecnológico); 2 representantes do DEPTEQ (Departamento

\footnotetext{
131 Tradução livre de informação disponível no endereço eletrônico http://www.polotecnologico.fq.edu.uyl. Acesso em 05/03/2008. 
Tecnológica da Faculdade de Química); e 1 diretor do pólo tecnológico de Pando ${ }^{133}$.

Seu edifício principal tem $4.000 \mathrm{~m}^{2}$ e conta com 15 instalações de laboratórios químicos que ocupam uma área de $1200 \mathrm{~m}^{2}$, uma área para plantas piloto, espaço para escritórios onde funcionam projetos de empresas incubadas, sala de seminários e áreas para uso industrial ${ }^{134}$. A Figura 5.15 mostra uma foto do parque.

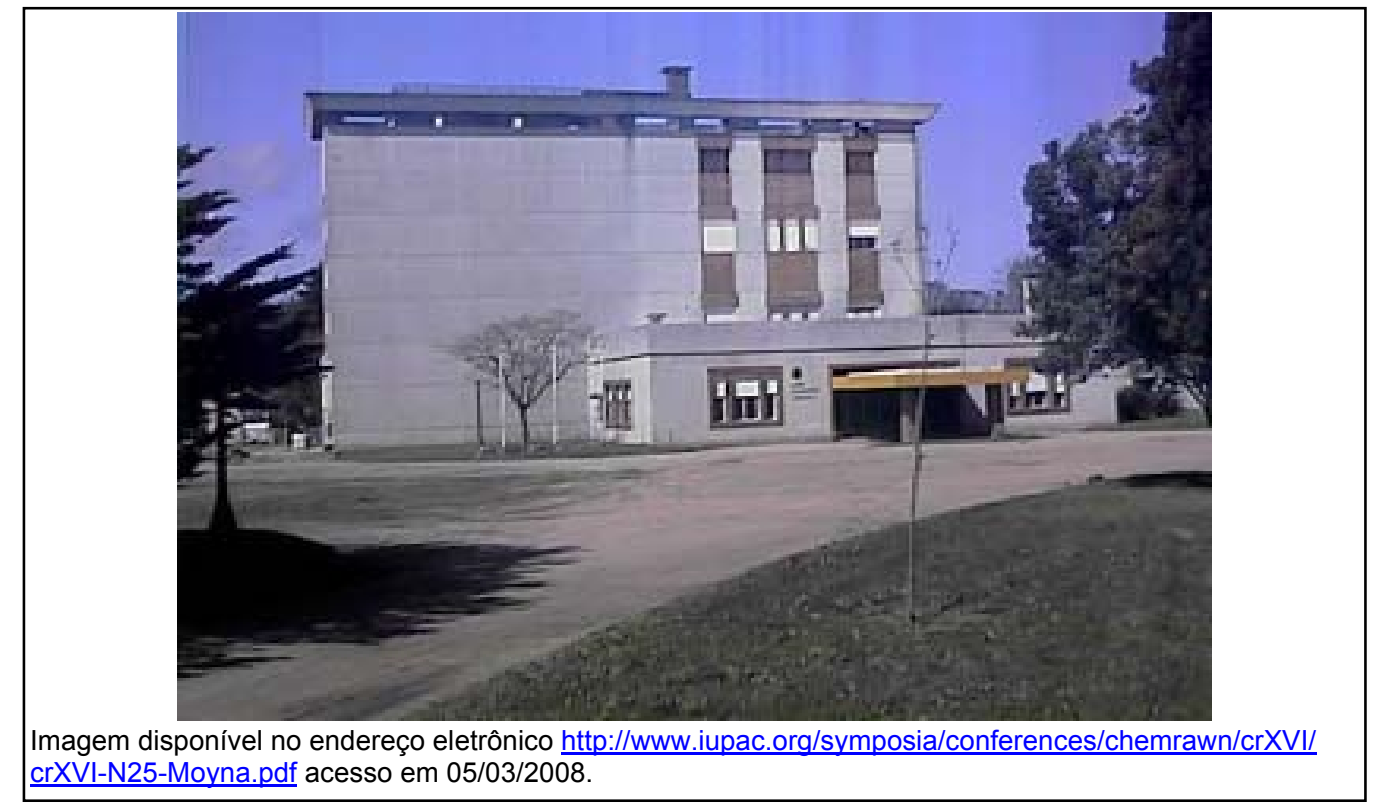

FIGURA 5.15 - Pólo Tecnológico de Pando

As plataformas tecnológicas disponíveis no pólo são: Química analítica/estrutural (ESI Q Tof-MS ; HPLC-MS/MS ; GC-MS, NMR, Absorção Atômica, Polarimetría de alta resolução, Cristalografía de Raios X); Análise Físico química (Determinação do tamanho e carga elétrica de partículas em materiais coloidais, análise de dissolução in-vitro de drogas; análise da estabilidade térmica); Ensaios Biofarmacêuticos (Biodisponibilidade e Bioequivalência); Purificação e caracterização de proteínas; síntese e caracterização de peptídeos; produção e caracterização de anticorpos poli e monoclonais; extração supercrítica;

\footnotetext{
133 Tradução livre de informação disponível no endereço eletrônico http://www.polotecnologico.fq.edu.uy/. Acesso em 05/03/2008.

134 Idem.
} 
síntese orgânica (reatores de 25 L, 100 L y 400L); e sistema de transesterificação e caracterização de graxas e óleos ${ }^{135}$.

Como serviços tecnológicos o Pólo Tecnológico Pando disponibiliza: atividades de P\&D conjuntas por meio de contrato; serviços analíticos de alta tecnologia, incluindo desenho de laboratórios analíticos; Química Fina (síntese orgânica a pedido em escalas piloto e produtiva); Capacitação de pessoal adaptada aos requisitos das empresas; Assessoria integral em assuntos de propriedade intelectual; Assessoria em Inteligência Competitiva (vigília tecnológica e de mercado) $)^{136}$.

O pólo tecnológico oferece ainda aos instalados serviços de: provisão local, acesso aos laboratórios de pesquisa e plantas piloto, apoio científico dos pesquisadores, capacitação em negócios e o correspondente apoio por meio de organizações, central de comunicações telefônicas e de fax, conexão direta por fibra ótica a rede acadêmica CLARA (internet 2), sala de reuniões e de vídeo conferencias, prédio com segurança 24 horas, gerador de energia; equipamento de segurança e serviço de assistência médica.

No Pólo Tecnológico de Pando há um Centro de Inteligência Competitiva (C.I.C.) que tem como função prestar serviços de informação e busca para a comunidade acadêmica e empresarial em três áreas principais para o desenvolvimento tecnológico do Uruguai: Indústria Farmacêutica, Biotecnologia e Alimentação; áreas que representam uma importante fonte para as atividades de P\&D no país. Os serviços oferecidos pelo C.I.C. são contratados formalmente, a fim de assegurar a confiabilidade da informação assim como sua confidencialidade, são eles: busca de informação tecnológica; vigilância tecnológica e busca de oportunidades de negócios; e assessoramento no uso da informação.

\footnotetext{
135 Informações disponíveis no endereço eletrônico http://www.polotecnologico.fq.edu.uyl. Acesso em $10 / 03 / 2008$.

136 Idem.
} 


\subsubsection{Technologiepark Heildelberg (Heildelberg Technology Park)}

O Technologiepark Heildelberg está localizado na cidade Heidelberg, que é uma cidade da Alemanha, situada no vale do rio Neckar, no noroeste do estado de Baden-Württemberg, na Alemanha. É a quinta maior cidade deste estado (seguida de Stuttgart, Mannheim, Karlsruhe e Freiburg im Breisgau), contando com 142993 habitantes em 2005. Heidelberg é uma cidade independente (kreisfreie Stadt) ou distrito urbano (Stadtkreis), ou seja, possui estatuto de distrito (Kreis) ${ }^{137}$.

O parque foi fundado em 1986 pela cidade de Heidelberg, o Technologiepark Heildelberg, é o primeiro parque dedicado a biologia na Alemanha, está localizado nas imediações da Ruprecht-Karls-University, com 11 empresas e $6.000 \mathrm{~m}^{2}$ de laboratórios e espaços para escritórios ${ }^{138}$.

O Heidelberg Technology Park é um parque científico que faz parte do campus da Universidade de Ruprecht-Karls; cobrindo uma área de $50.000 \mathrm{~m}^{2}$ com mais de 70 empresas residentes e aproximadamente 1.300 empregados, é um cluster biotecnológico da região metropolitana de Rhein-Neckar ${ }^{139}$. A Figura 5.16 representa a localização do Technologiepark Heildelberg.

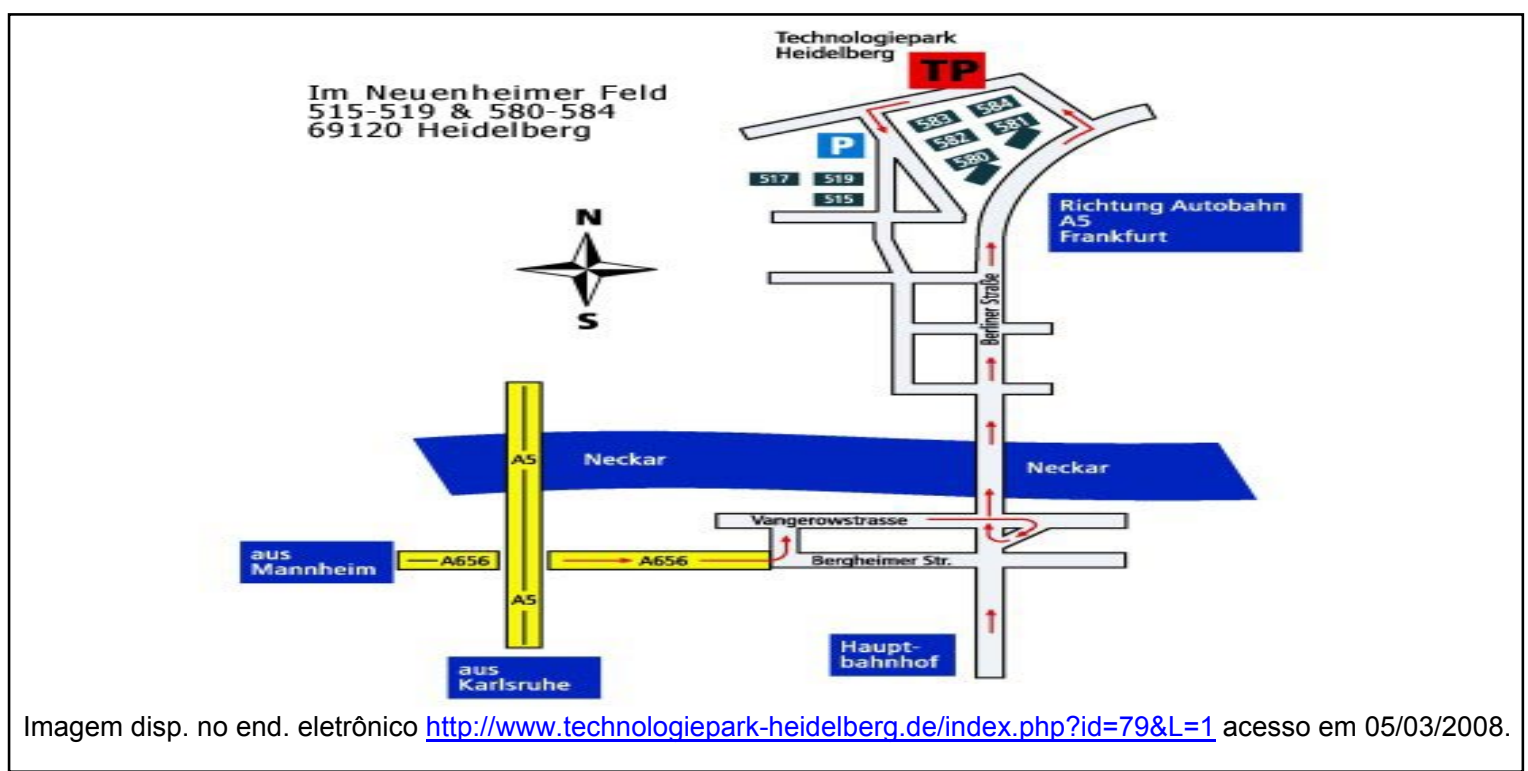

FIGURA 5.16 - Localização do Technologiepark Heidelberg

\footnotetext{
137 Informações disponíveis no endereço eletrônico http://pt.wikipedia.org/wiki/Heidelberg. Acesso em 10/03/2008.

${ }_{138}$ Informações disponiveis no endereço eletrônico http://www.technologiepark-heidelberg.de/index.php?id= $3 \& \mathrm{~L}=1$. Acesso em 10/03/2008.

${ }^{139} \mathrm{Idem}$.
} 
Faz parte do entorno do Technologiepark Heildelberg importantes organizações relacionadas às ciências da vida, tais como a Heidelberg University e centros de pesquisa de renome, como o Laboratório Europeu de Biologia Molecular (EMBL), o Centro de Pesquisa Alemão sobre o Câncer (DKFZ), o Centro de Biologia Molecular (ZMBH) assim como o Centro de Bioquímica da Universidade de Heildelberg (BZH) e o Instituto Max Planck para Pesquisa Médica e Biologia Celular ${ }^{140}$.

O Technologiepark Heidelberg $\mathrm{GmbH}$ promove o desenvolvimento tecnológico por meio de serviços de suporte e por trabalho conjunto com as empresas e institutos de pesquisa. A cidade de Heidelberg e a Câmara de Comércio e Indústria de Rhein-Neckar são parceiras do parque. O Technologiepark Heidelberg $\mathrm{GmbH}$, como empresa operadora do parque tecnológico, é o contato central para os incubados e membros associados. A RN Immobilienmanagement $\mathrm{GmbH}$ Rhein-Neckar é a proprietária dos edifícios do parque e está envolvida nos assuntos relacionados a aluguel dos espaços ${ }^{141}$.

As instalações do Technologiepark Heidelberg estão localizadas em diversos locais da cidade Heidelberg e estão divididas por áreas de especialização. O Heidelberg Technology Park BioPark possui sua sede central em Im Neuenheimer Feld. As Ciências da vida são o foco de atividade nesse local. Centros de pesquisa de renome e empresas pequenas e grandes na área de biotecnologia estão ali instaladas, bem como o departamento de ciência alemão mais antigo da universidade. $O$ endereço oferece serviços de interesse do setor e da indústria, entre eles estão os serviços de secretaria e de marketing, compras centralizadas, capital de risco, advogado de patentes, um moderno centro de conferências, berçário, um bistrô e um restaurante, entre outros serviços ${ }^{142}$.

Não muito longe deste endereço, o BioPark possui uma outra instalação em Czernyring; ali a pesquisa biotecnológica e as ciências da vida também são o foco,

\footnotetext{
140 Informação disponível no endereço eletrônico http://www.technologiepark-heidelberg.de/index.php?id= $2 \& L=1$. Acesso em 05/03/2008.

${ }^{141}$ Idem.

142 Tradução livre de informações disponíveis no endereço eletrônico http://www.technologieparkheidelberg.de/ index.php?id=5\&L=1. Acesso em 05/03/2008.
} 
porém a produção, pesquisa e o desenvolvimento são mais orientados para a indústria farmacêutica ${ }^{143}$.

Outro endereço é o do Heidelberg Technology Park UmweltPark, fundado em 2005 nos antigos edifícios 'Heinsteinwerke' em Heildelberg, que está localizado em Wieblinger Weg. Todas as atividades ali são baseadas no desenvolvimento e pesquisas relacionadas à tecnologia ambiental e de negócios ${ }^{144}$.

O "Centro Start-up para mulheres empreendedoras" oferece às mulheres suporte para criação de empresas e projetos start-up. O Centro está baseado no endereço Hans-Bunte-Straße 8-10, 69123 Heidelberg, foi fundado pela cidade de Heildelberg e pelo Departamento Federal para Indústria e Negócios do Estado de Baden-Wuerttemberg - Initiative for Start-ups and Business Transfer (ifex) com o apoio do Fundo Social Europeu. O Technologiepark Heidelberg $\mathrm{GmbH}$ é o responsável pela condução do projeto ${ }^{145}$.

Os serviços oferecidos pelo Technologiepark Heildelberg para a comunidade biotecnológica instalada no parque são os seguintes: informações e apoio para participação em programas de suporte regionais, nacionais e internacionais; cursos de treinamento científicos e de negócios, seminários e conferências; disponibilização do Technologiepark Heildelberg Conference Center (TPCC) para cursos e apresentações; biblioteca; e informações sobre o mercado de trabalho, produtos e serviços em empresas de biotecnologia ${ }^{146}$.

\subsubsection{Parco Tecnológico Padano (PTP)}

Por se tratar de PCT visitado, a caracterização do PTP será comentada no item 5.1.4 referente às observações pessoais resultantes da interação com o pessoal do parque.

O PTP fica na comuna de Lodi, capital da província italiana de Lodi, localizada na região de Lombardia. A província de Lodi tem cerca de 195.474 habitantes e densidade populacional de 249 hab $/ \mathrm{km}^{2}$. Está dividida em 61

\footnotetext{
${ }^{143}$ Tradução livre de informações disponíveis no endereço eletrônico http://www.technologiepark-heidelberg. de/ index.php?id=5\&L=1. Acesso em 05/03/2008.

$\frac{144}{14 d e m . ~}$

145 Idem.

${ }^{146}$ Tradução livre de informações disponíveis no endereço eletrônico http://www.technologiepark-heidelberg. de/index.php?id=30\&L=1. Acesso em 06/03/2008.
} 
comunas, sendo a capital Lodi, que tem 43.000 habitantes. Lodi faz fronteira a norte com a província de Milão, a este com a província de Cremona, a sul com a região da Emília-Romanha (província de Piacenza) e a oeste com a província de Pavia ${ }^{147}$.

A Lombardia é a região administrativa mais populosa da Itália, com cerca de cerca de 9,4 milhões de habitantes e $23.854 \mathrm{~km}^{2}$ de área, densidade populacional de $249 \mathrm{hab} / \mathrm{km}^{2}$; sua capital é Milão. Tem limites ao norte com a Suíça, a oeste com o Piemonte, a leste com Vêneto e com Trentino-Alto-Adige, e ao sul com a Emília-Romagna. É considerada como uma região muito industrializada, imagem que nasceu durante a revolução industrial e do pósguerra; a região é considerada uma das mais ricas da Itália ${ }^{148}$. A Figura 5.17 representa a região da Lombardia.

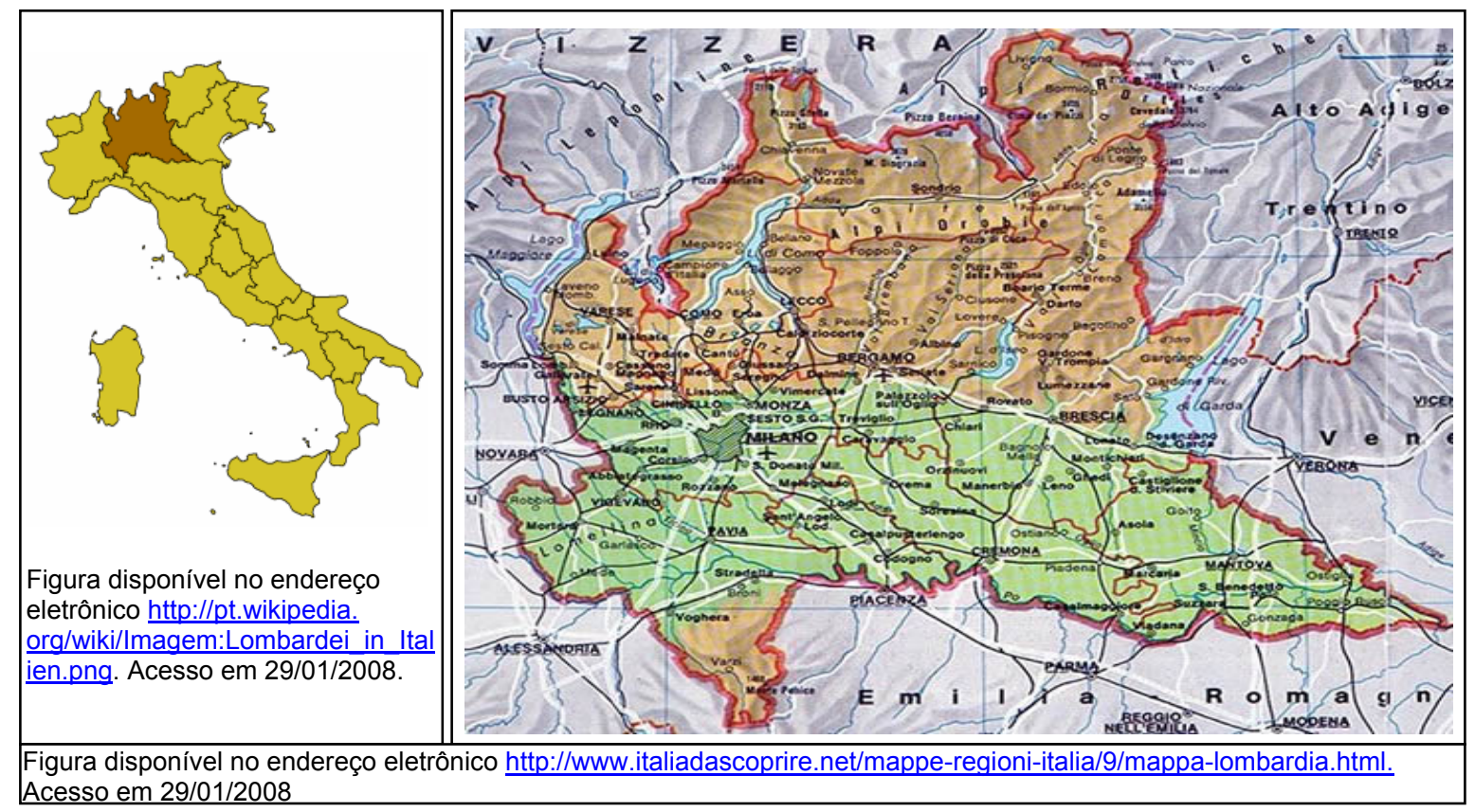

FIGURA 5.17 - Região da Lombardia

A economia da Lombardia é caracterizada por uma grande variedade de setores nas quais ela se desenvolveu. Desde os setores tradicionais como a agricultura e a criação, à indústria pesada e leve; o setor de serviços se

\footnotetext{
147 Tradução livre de informação disponível no endereço eletrônico http://www.tecnoparco.org/Default.aspx? tabid=1276. Acesso em 28/01/2008. 
desenvolveu fortemente nos últimos anos. A agricultura lombarda foi a base do desenvolvimento econômico da região; ela foi a primeira a ser investida de processos de mecanização e de reestruturação ${ }^{149}$.

A mecanização, graças a utilização de maquinários sempre mais complexos, trouxe um incremento da produção agrícola enquanto o território se reestruturava, por meio da construção e modernização de canais e outras ações permitiram o melhoramento da qualidade da produção agrícola. A agricultura da região está sobretudo na produção de cereais (milho, soja e trigo), hortaliças, frutas (pera e melão) e vinho. A produção de forragem é muito desenvolvida e constitui a base do desenvolvimento da criação de bois e suínos ${ }^{150}$.

A indústria se desenvolve em diversos setores, particularmente no metal mecânico, eletrônico, siderúrgico, têxtil, químico e petroquímico, farmacêutico, alimentar, editorial, calçadista e de móveis. Milão é a província que cobre mais de $40 \%$ das empresas da indústria lombarda. É grande o peso do setor de serviços no comércio e nas finanças. Em Milão está a sede da Bolsa Italiana que é uma das principais praças financeiras européias; e a Feira de Milão, que é o maior espaço de exposição da Europa ${ }^{151}$. A Tabela 5.9 apresenta alguns dados da região da Lombardia.

\begin{tabular}{|r|l|}
\hline TABELA 5.9 - Dados da Região da Lombardia ${ }^{152}$ \\
\hline Residentes em 31.12.2006: & 9.545 .441 \\
\hline Mulheres residentes em 31.12.2006: & 4.658 .175 \\
\hline Número de famílias em 31.12.2006: & 4.072 .207 \\
\hline Estrangeiros residentes em 31.12.2006: & 728.647 \\
\hline Percentual de residentes estrangeiros em 31/12/2006: & $7 \%$ \\
\hline Densidade populacional em 31.12.2006: & 400 habitantes por km $^{2}$ \\
\hline Superfície em 31/12/2006: & $23863 \mathrm{~km}^{2}$ \\
\hline Numero de comunas: & 1546 \\
\hline Produto Interno Bruto em 2005: & $296.282,2$ milhões de euros \\
\hline Produto Interno Bruto por habitante em 2005: & $31.405,50$ euros \\
\hline Taxa de atividade feminina (média 2006): & $59,4 \%$ \\
\hline Taxa de desemprego (média 2006): & $3,7 \%$ \\
\hline Número de empresas (ativas e registradas) em 31/12/2006: & 808.519 \\
\hline
\end{tabular}

149 Tradução livre de informação disponível no endereço eletrônico http://www.italiadascoprire.net/italia/ lombardia/9/economia.html. Acesso em 29/01/2008.

150 Idem.

151 Idem.

152 Informações disponíveis no endereço eletrônico http://www.ring.lombardia.it/asrnew/index.html. Acesso em $28 / 02 / 2008$. 


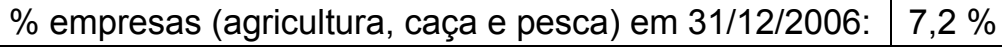

Fundado em 2000, o Parco Tecnológico Padano tem um papel articulador junto com o Center of Excellence for the Agro-Food Biotechnologies fortemente suportado em Lodi pela região da Lombardia, instituições locais e pela Universidade de Milão.

O Parque está a 0,4 quilômetros da Universidade de Milão e a 25 quilômetros do Aeroporto Internacional Milan Linate ${ }^{153}$. Na Figura 5.18 está apresentada a localização esquemática do Parque Tecnológico Padano, situado na Via Einstein, localizada na área denominada Cascina Codazza Lodi.

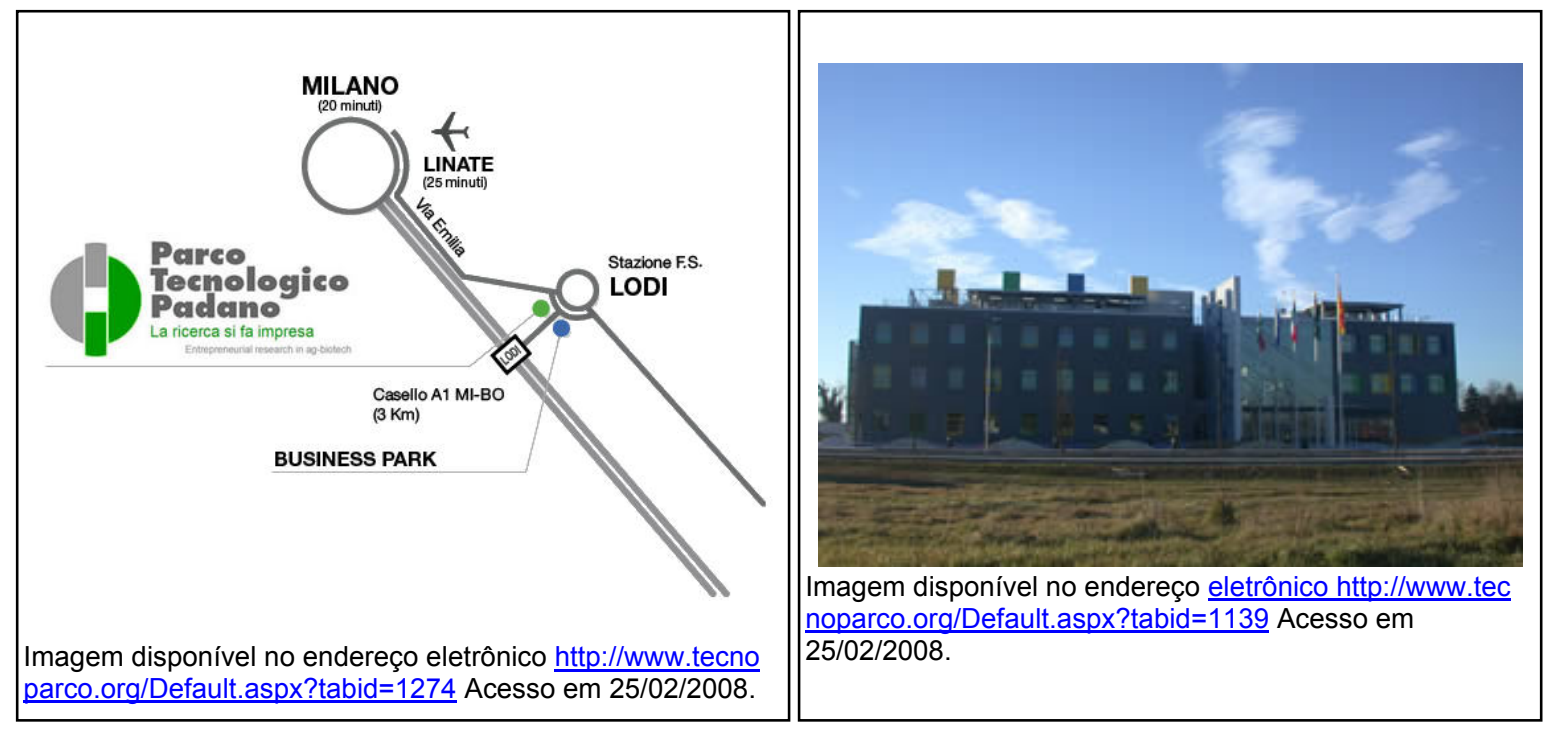

FIGURA 5.18 - Localização do Parco Tecnológico Padano

O Parque está localizado na entrada da cidade de Lodi, cidade edificada por Federico Barbarosa em 1158 as margens do rio Adda, numa área delimitada de um lado pelo encontro com a auto-estrada "del Sole" e do outro por uma estrada que atravessa o canal Muzza e que é proveniente da antiga Laus Pompeia construída na época dos romanos, em 89 a.C e da qual ainda restam traços arqueológicos $^{154}$.

A província de Lodi ocupa uma área de 782 quilômetros quadrados, seu desenvolvimento econômico está orientado ao setor agro-alimentar, em particular

\footnotetext{
153 Tradução livre de informação disponível no endereço eletrônico http://www.tecnoparco.org/Default.aspx? tabid=1276. Acesso em 28/01/2008.

${ }^{154}$ Tradução livre de informações disponíveis no endereço eletrônico http://www.provincia.lodi.it/02 Ente02. asp? IDCategoria=733. Acesso em 28/01/2008.
} 
a área de transformação, trabalho e venda de produtos de origem agrícola, graças a presença, entre outros, de 2500 quilômetros de cursos d'água. Lodi é um importante centro italiano para a agricultura e a criação, tanto que constitui um pólo de nível europeu no setor zootécnico. ${ }^{155}$

O Parco Tecnologico Padano (PTP) é líder regional no desenvolvimento de agrobiotecnologia, é o motor do cluster Lodi e mantém juntos os atores do setor agrobiotecnológico, O PTP traz consigo a Universidade de Milão, em especial as faculdades de Medicina Veterinária e de Ciências da Agricultura; laboratórios de pesquisa públicos e privados; uma incubadora de empresas e um parque de negócios (business park) ${ }^{156}$.

A missão do PTP é "construir uma rede comercial orientada pela pesquisa em agrobiotecnologia que: vá de encontro com as necessidades regionais; realizar pesquisa de alta qualidade para suportar o desenvolvimento regional; e criar startups e spin-offs oferecendo o conhecimento, as instalações e os serviços da incubadora; tudo isso em estreita colaboração com as associações dos fazendeiros ${ }^{157}$.

As unidades do PTP são: O Research Center for Livestock, Agriculture and Foodstuff Technological Development; a Faculdade de Medicina Veterinária Hospital Veterinário; o Center for Training in Animal Husbandry; I.S.U. - Institute for Student Services; a Casa da Agricultura (Transferência de Tecnologia); e o Institute for Livestock Health Survey ${ }^{158}$.

O Parco Tecnologico Padano oferece serviços às empresas e aos pesquisadores, em particular: salão de convenções com capacidade para 200 pessoas; espaço e instalações para serviços de restauração; espaços comuns equipados; instalações e administração de rede; serviços científicos baseados no uso da Plataforma de Genômica do parque (Piattaforma Genomica del PTP PGP); serviços científicos de acesso ao conhecimento tecnológico do CERSA

\footnotetext{
155 Tradução livre de informações disponíveis no endereço eletrônico http://www.provincia.lodi.it/02 Ente02. asp?IDCategoria=733. Acesso em 28/01/2008.

${ }^{156}$ Tradução livre de informações disponíveis no documento de apresentação do parque "The Cluster - your key to Southern Europe", fornecido por ocasião da visita ao PTP.

${ }^{157}$ Idem.
} 
(Centro Ricerche e Studi Agroalimentari); e serviços de consultoria, tais como: serviços de Propriedade Intelectual, Plano de Negócios, Relações Públicas, Gestão de Projetos ${ }^{159}$.

As atividades de pesquisa são conduzidas por uma divisão específica - o CERSA - que gere os recursos internos de pesquisa do parque. A missão do CERSA, conduzida pelo Professor Francesco Salamini, anterior Diretor do Instituto Max Plankt (Alemão) é: "realizar a pesquisa inovadora em genômica e diversidade genética para descobrir traços que produzam colheitas e gados mais saudáveis. Uma Unidade de Cooperação Internacional ajuda a disseminar os resultados e construir parcerias $^{160}$.

As Unidades de Pesquisa que operam junto com o CERSA são: Livestock Genomics 1, Livestock Genomics 2, Plant Genomics, Bioinformatics, Genomic Platform, Molecular and Cellular Biology. Os projetos de pesquisa em andamento têm o foco em: molecular breeding, resistência patogênica, segurança alimentar, biodiversidade e traçabilidade ${ }^{161}$.

O Parco Tecnologico Padano promove o desenvolvimento regional por meio da criação de start-ups e spin-offs, oferecendo conhecimento, instalações e serviços. Além disso, próximo ao PTP e a sua incubadora de $2.000 \mathrm{~m}^{2}$ há uma Parque de Negócios de $350.000 \mathrm{~m}^{2}$ disponível às empresas de biotecnologia e de agro-alimentares. As empresas que se estabelecem na área recebem incentivos fiscais e acesso direto aos serviços e instalações do cluster. Idéias e empresas são selecionadas para a Incubadora e para o Parque de Negócios baseadas em sua criatividade tecnológica e compatibilidade com a missão do PTP ${ }^{162}$.

\subsubsection{Metu Technopolis (METUTECH)}

O METUTECH fica localizado na cidade de Ankara, capital da Turquia. Ankara localiza-se no centro da Anatólia (região do sudoeste da Ásia), na parte asiática do país, está a 850 metros de altitude e tem cerca de 3,9 milhões

\footnotetext{
159 Tradução livre de informações disponíveis no documento de apresentação do parque "Services - all that's needed is here", fornecido por ocasião da visita ao PTP.

${ }^{160}$ Tradução livre de informações disponíveis no documento de apresentação do parque "Research - our path to the future", fornecido por ocasião da visita ao PTP.

${ }^{161}$ Idem.

162 Tradução livre de informações disponíveis no documento de apresentação do parque "Enterprises - a bridge from research to business", fornecido por ocasião da visita ao PTP.
} 
dehabitantes, incluindo oito distritos que estão sobre a administração da cidade. $A$ cidade de Ankara é a segunda maior cidade da Turquia (a primeira é Istambul), é também o centro do Governo da Turquia e local das embaixadas dos países estrangeiros $^{163}$. A Figura 5.19 representa a localização da cidade de Ankara no mapa da Turquia.

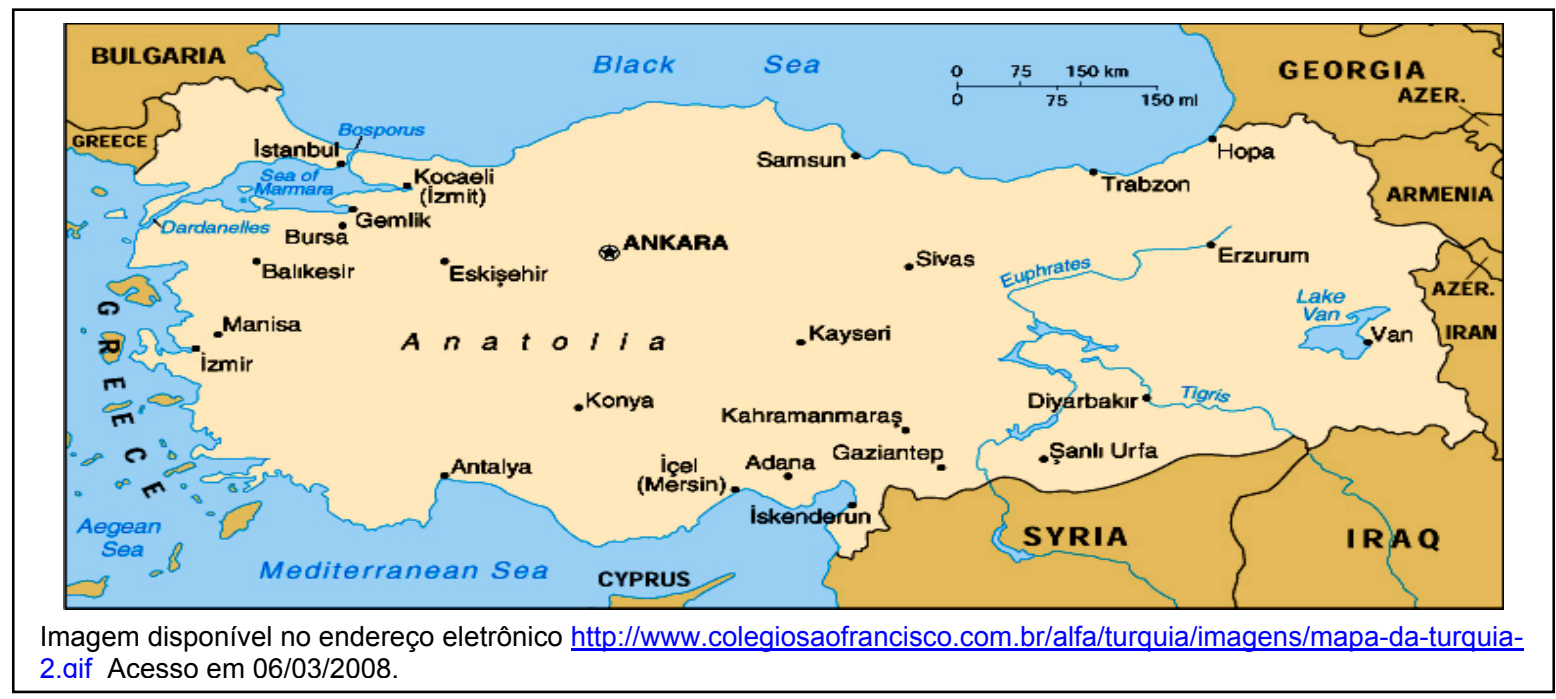

FIGURA 5.19 - Localização de Ankara no mapa da Turquia

A cidade de Ankara está localizada num ponto estratégico para o comércio regional, próxima a rede de rodovias e ferrovias ${ }^{164}$. O principal aeroporto de Ankara é o Esenboğa International Airport e está localizado a noroeste da cidade. O terminal de ônibus Ankara Intercity é um ponto importante da rede de ônibus que cobre todos os bairros da cidade. A central ferroviária Ankara Garı da Turkish State Railways é um importante elemento da rede de transportes que conecta as regiões este e oeste do país. Uma linha de alta velocidade está prevista para operar o percurso entre Ankara e Istambul em 2009. Ankara possui uma rede de trens urbanos e duas linhas de metro, outras três linhas de metrô estão sendo construídas $^{165}$.

A cidade é conhecida por abrigar diversas universidades de renome, tais como: Ankara University, Atılım University, Başkent University, Bilkent University,

\footnotetext{
${ }^{163}$ Informação disponível no endereço eletrônico http://en.wikipedia.org/wiki/Ankara. Acesso em 06/03/2008.

164 Idem.

165 Idem.
} 
Çankaya University, Gazi University, Hacettepe University, Middle East Technical University, TOBB University of Economics and Technology, entre outras ${ }^{166}$.

Os estudos para a construção do primeiro parque científico da Turquia, o METUTECH, começaram em 1987. Os principais objetivos do METUTECH são: aumentar a colaboração internacional e os contatos para estabelecimento de parcerias; apoiar o empreendedorismo e a inovação; apoiar a pesquisa e o desenvolvimento tecnológico regional e ser um dos elementos de sustentação do desenvolvimento regional; instigar e manter a colaboração universidade-empresa; apoiar a transformação da infra-estrutura de pesquisa universitária e a acumulação de informações em valor econômico por meio de spin-offs; preparar o ambiente adequado para a transferência tecnológica e para o investimento estrangeiro direto; criar empregos para recursos humanos qualificados; e promover a universidade baseada em start-ups e spin-offs ${ }^{167}$.

Para gerir o METUTECH foi fundada em 1991 a Teknopark Inc., cujos acionistas eram a Fundação para o Desenvolvimento da Universidade Técnica do Meio Oeste, a Câmara de Indústria e Comércio de Ankara, as empresas Bleda Co, EBÝ Co, e a Ortadođu Yazýlým Co.; e a Universidade Técnica do Meio Oeste ${ }^{168}$.

O primeiro passo no desenvolvimento do METUTECH foi a construção de um centro de incubação com $4.840 \mathrm{~m}^{2}$ fechados de área, o Centro de Desenvolvimento Tecnológico METU-SMIDO, criado em cooperação com a Small and Medium Size Industry Development Organization (SMIDO) em 1991 com o objetivo principal de estabelecer centros de incubação para o desenvolvimento de tecnologias $^{169}$.

Em 1996, o estudo de viabilidade conduzido por um consórcio internacional apoiado pelo Banco Mundial e o TTDF (Turkish Technology Development Foundation) criou o METUTECH, parque científico em Ankara com suas vantagens de poder de pesquisa e potencial de cooperação com a indústria e boa

\footnotetext{
${ }^{166}$ Informação disponível no endereço eletrônico http://en.wikipedia.org/wiki/Ankara. Acesso em 06/03/2008.

167 Tradução livre de informações disponíveis no endereço eletrônico http://www.metutech.metu.edu.tr/ english/teknokent/genel.php. Acesso em 06/03/2008.

168 Idem.
} 
localização ${ }^{170}$. O campus do METU é localizado na Autoestrada Ankara-Eskisehir na região oeste do centro da cidade. A entrada principal do METUTECH fica no portão A-7 da Bilkent Way e está a cerca de 8 quilômetros do centro da cidade pela Eskisehir Highway. A Figura 5.20 representa a localização esquemática do METUTECH.

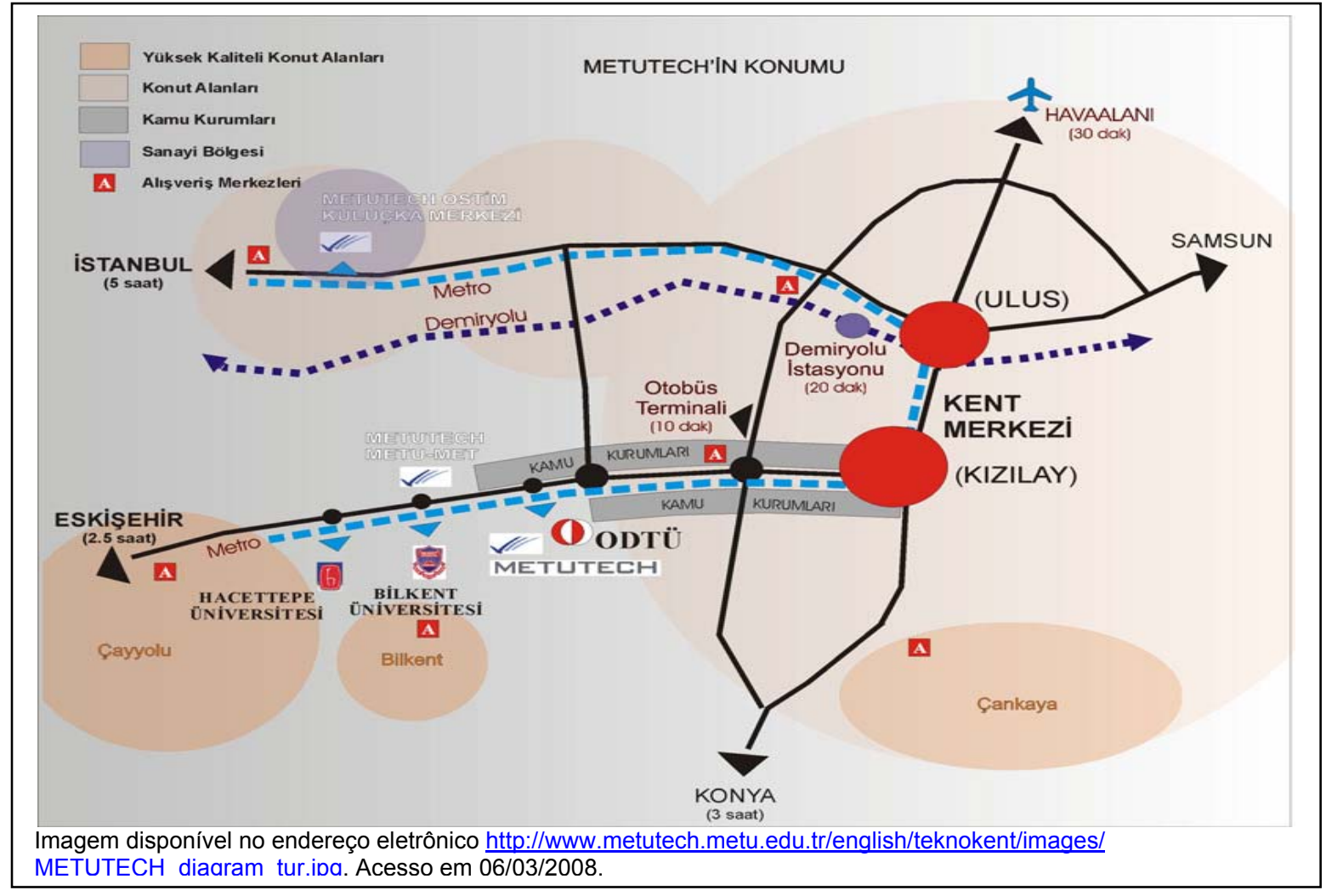

FIGURA 5.20 - Localização do METUTECH

O primeiro edifício construído por meio modelo Build-Operate-Transfer ${ }^{171}$ foi o METU-Halýcý Software House com uma área fechada de $4.850 \mathrm{~m}^{2}$ dos quais $3.700 \mathrm{~m}^{2}$ são espaços dedicados a escritórios. O edifício abriga escritórios de 25 $\mathrm{m}^{2}$ e uma área de $900 \mathrm{~m}^{2}$ com salas de reunião e salas de aula ${ }^{172}$. O METUTwins Building é um edifício de serviços de $7.000 \mathrm{~m}^{2}$ de área fechada, das quais

\footnotetext{
170 Tradução livre de informações disponíveis no endereço eletrônico http://www.metutech.metu.edu.tr/ english/teknokent/genel.php. Acesso em 06/03/2008.

171 Entende se por modelo Build-OperateTransfer o seguinte: quando uma empresa contrata com um parceiro offshore a construção de serviços compartilhados ou de um centro de desenvolvimento offshore; e o opera por um período fixo de tempo. As organizações o fazem com a expectativa de que parceiro offshore possa iniciar as operações e alcançar a estabilidade operacional do sistema mais rápido do que poderia ser realizado apenas com esforços internos. Tradução livre de definição disponível no endereço eletrônico http://www. sourcingmag.com/dictionary/Build-Operate-Transfer_model-25.htm Acesso 06/03/2008.

${ }_{172}$ Tradução livre de informações disponíveis no endereço eletrônico http://www.metutech.metu.edu.tr/english lteknokent/genel.php. Acesso em 06/03/2008.
} 
$4.800 \mathrm{~m}^{2}$ são dedicados a escritórios de $42 \mathrm{~m}^{2}$ e $450 \mathrm{~m}^{2}$, respectivamente, as unidades de $450 \mathrm{~m}^{2}$ foram projetadas para serem independentes. Oferecem serviços a 33 empresas, contém ainda um restaurante que serve aproximadamente 120 pessoas e uma sala de conferência para 100 pessoas ${ }^{173}$.

O edifício METU-Silver Blocks possui uma área fechada de $8.650 \mathrm{~m}^{2} \mathrm{com}$ espaços para escritórios desde $540 \mathrm{~m}^{2}$ podendo ser expandidas por meio de designs flexíveis; conta também com um restaurante que serve 120 pessoas. 0 Silicon Blocks contém uma área fechada de aproximadamente $11.000 \mathrm{~m}^{2} \mathrm{com}$ um restaurante, um café-bar e um salas de reunião com vários equipamentos. Além disso, uma empresa está construindo um edifício com $6.600 \mathrm{~m}^{2}$ de área fechada, o The R\&D Building of Milsoft $A D^{174}$.

O maior projeto do período 2004-2005 é o SATGEB, um cluster da indústria aeroespacial. As empresas do cluster têm acordos de colaboração com o Departamento de Engenharia Aeroespacial da Universidade Técnica do Meio Oeste. O SATGEB construído em $40.000 \mathrm{~m}^{2}$ de área é composto de quatro edifícios de P\&D e um edifício comum. O "Common Building" tem $2.000 \mathrm{~m}^{2}$, projetado com o objetivo de oferecer uma área de serviços comum para 800 pessoas; tais serviços incluem cafeteria, cozinha, salas VIP e escritórios administrativos ${ }^{175}$.

O desenvolvimento do METUTECH é contínuo e já atingiu aproximadamente $60.000 \mathrm{~m}^{2}$ de área fechada; novos investimentos estão em andamento para construção de mais espaços para escritórios e áreas de P\&D no parque. Mais de 90\% das empresas residentes do METUTECH são PME e 60\% delas são especializadas em Tecnologia da Informação e Comunicação; 25\% atuam em eletrônica; $15 \%$ são de outros setores como aeroespacial, meio ambiente, biotecnologia, nanotecnologia, materiais avançados, etc... ${ }^{176} \mathrm{~A}$ Figura 5.21 apresenta uma figura esquemática da planta do METUTECH e a tabela 5.10

\footnotetext{
173 Tradução livre de informações disponíveis no endereço eletrônico http://www.metutech.metu.edu.tr/ english/teknokent/genel.php. Acesso em 06/03/2008.

174 Idem.

175 Idem

176 Idem
} 
apresenta o resumo dos edifícios e áreas em operação no METUTECH até o momento.

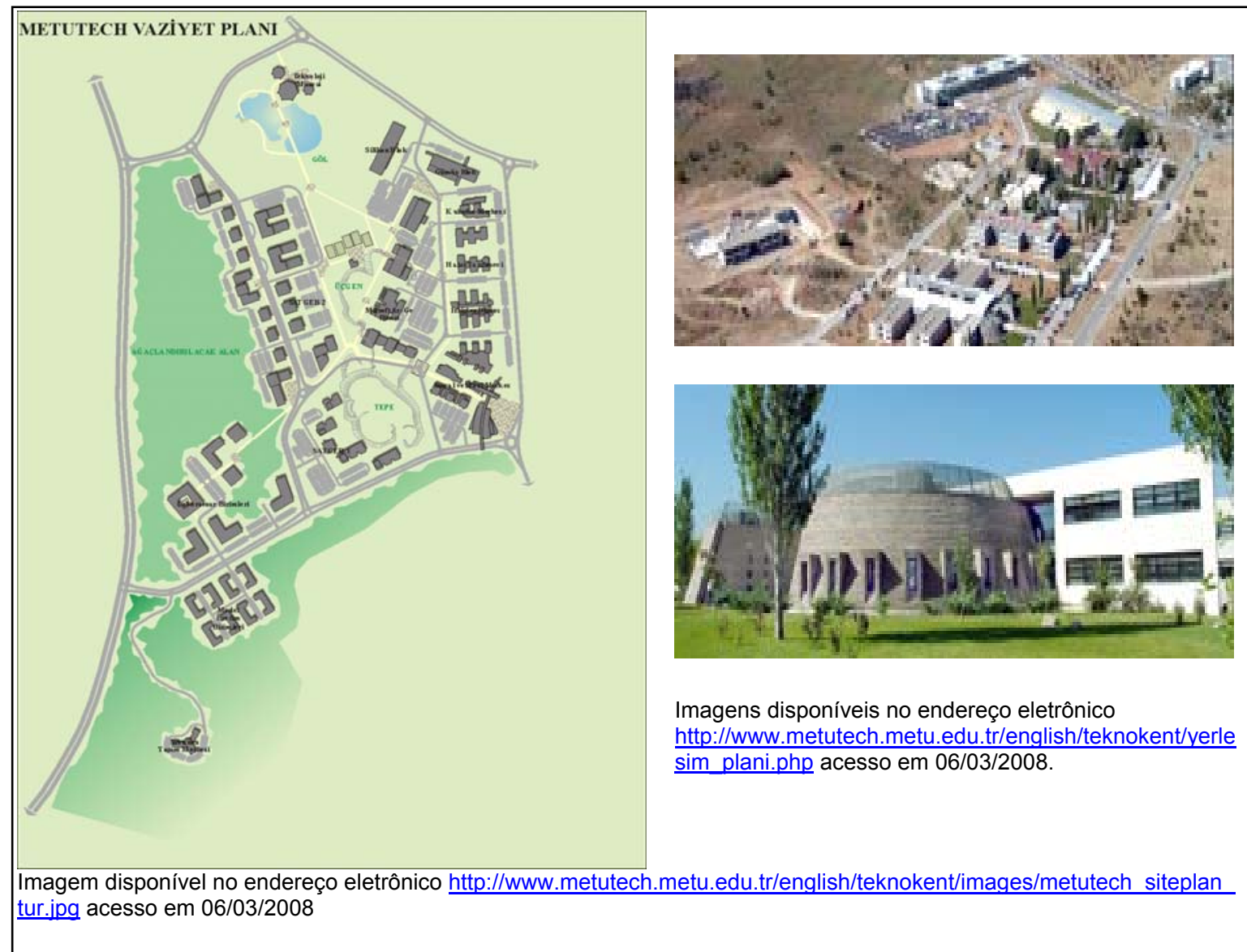

FIGURA 5.21 - Planta do METUTECH

\begin{tabular}{|c|c|c|c|c|}
\hline \multicolumn{5}{|c|}{ TABELA 5.10 - Edifícios em funcionamento no METUTECH } \\
\hline Edifício & $\begin{array}{c}\text { Ano de } \\
\text { Funcionamento }\end{array}$ & $\begin{array}{c}\text { Área } \\
\text { estrutural }\end{array}$ & $\begin{array}{c}\text { Área para } \\
\text { escritórios }\end{array}$ & $\begin{array}{c}\text { Empresas } \\
\text { instaladas }\end{array}$ \\
\hline TEKMER & 1992 & 3500 & 2000 & 31 \\
\hline METU-Twins & 2000 & 7000 & 4800 & 31 \\
\hline Halıcl Software House & 2000 & 4840 & 3700 & 10 \\
\hline Silver Blocks & 2002 & 8700 & 6000 & 31 \\
\hline Silicon Block & 2004 & 11000 & 7300 & 41 \\
\hline Milsoft R\&D Building & 2005 & 6600 & 3250 & 1 \\
\hline Aselsan (SATGEB) & 2005 & 4400 & 2400 & 1 \\
\hline Havelsan (SATGEB) & 2004 & 4670 & 2700 & 1 \\
\hline TAI (SATGEB) & 2004 & 2250 & 1150 & 1 \\
\hline
\end{tabular}

177 Informações da tabela estão disponíveis no endereço eletrônico http://www.metutech.metu.edu.tr/english/ teknokent/binalar.php. Acesso em 06/03/2008. 


\begin{tabular}{|c|c|c|c|c|}
\hline TUSAŞ (SATGEB) & 2004 & 1800 & 1050 & 1 \\
\hline Common Building (SATGEB) & 2004 & 2250 & 200 & - \\
\hline
\end{tabular}

No que se refere a transferência de tecnologia os instalados no parque contam com o IRC-Anatolia, consórcio criado em 2004 com o objetivo de desenvolver uma estrutura organizacional para promover a transferência dos resultados das pesquisas e tecnologias de acordo com as necessidades da estrutura industrial das regiões da Anatolia Sudoeste, Meio e Oeste da Turquia. O IRC-Anatolia cobre quase metade da Turquia, desde a região central até as margens do Mar Negro, e desde a costa do Mediterrâneo até a região sudoeste. Em resumo, o objetivo do IRC-Anatolia é desenvolver alianças de negócios de aproveitamento mútuo e ajudar as PME a encontrarem parceiros tecnológicos e fornecedores adequados, é também uma ponte para os programas de P\&D europeus e para a região da Anatólia ${ }^{178}$.

O METUTECH provê aos instalados serviços tais como: programas de treinamento, serviços de consultoria e outros serviços de valor agregado. Os programas de treinamento correspondem a $75 \%$ dos serviços executados; já a consultoria de serviços em marketing internacional, transferência de tecnologia, Direitos de Propriedade Intelectual, aconselhamento legal internacional e aquisição de fundos representam 15\%; os demais $10 \%$ referem se a outras categorias de serviços, como: eventos, viagens, serviços de restauração, etc... ${ }^{179}$ Os serviços de gerenciamento local fornecidos pelo METUTECH incluem a manutenção dos equipamentos e instalações, os serviços de telecomunicação, a segurança, a manutenção dos jardins, etc... As empresas instaladas no METUTECH podem ter acesso a estrutura universitária do METU que conta com cerca de 2.500 acadêmicos e 20.000 estudantes, além de 15 centros de pesquisa e cerca de 150 laboratórios ${ }^{180}$.

Também são disponibilizados pelo Technology Development Regions Law aos instalados no parque, incentivos para atividades de pesquisa e desenvolvimento; oportunidades de provisão de fundos pelas instituições

\footnotetext{
${ }^{178}$ Tradução livre de informações disponíveis no endereço eletrônico http://www.metutech.metu.edu.tr/ english/teknokent/genel.php. Acesso em 06/03/2008.

179 Idem.

180 Idem.
} 
TEKMER, TIDEB e TTGV; e serviços financeiros oferecidos pelo METUTECH. O pessoal das empresas instaladas no parque podem se beneficiar das atividades sociais e culturais disponibilizadas ao pessoal da universidade METU, inclusive bancos, lojas, restaurantes, centro de convenções e cultura, livraria, piscinas, lavanderia, ginásio, etc... ${ }^{181}$

\subsubsection{AREA Science Park}

Por se tratar de PCT visitado, a caracterização do AREA Science Park será comentada no item 5.1.4 referente às observações pessoais resultantes da interação com o pessoal do parque.

O AREA Science Park fica localizado nas imediações da cidade de Trieste, na região italiana do Friuli-Venezia Giulia. A Região do Friuli-Venezia Giulia está situada ao norte da Itália e se divide em quatro províncias: Pordenone, Udine, Gorizia e Trieste; é uma região que tem $7.845 \mathrm{~km}^{2}$ e 1,2 milhões de habitantes. A antiga capital do Friuli é Údine; a atual capital é Trieste. ${ }^{182}$. A Figura 5.22 representa a região do Friuli Venezia Giulia no mapa da Itália e a Tabela 5.11 apresenta alguns dados da região.

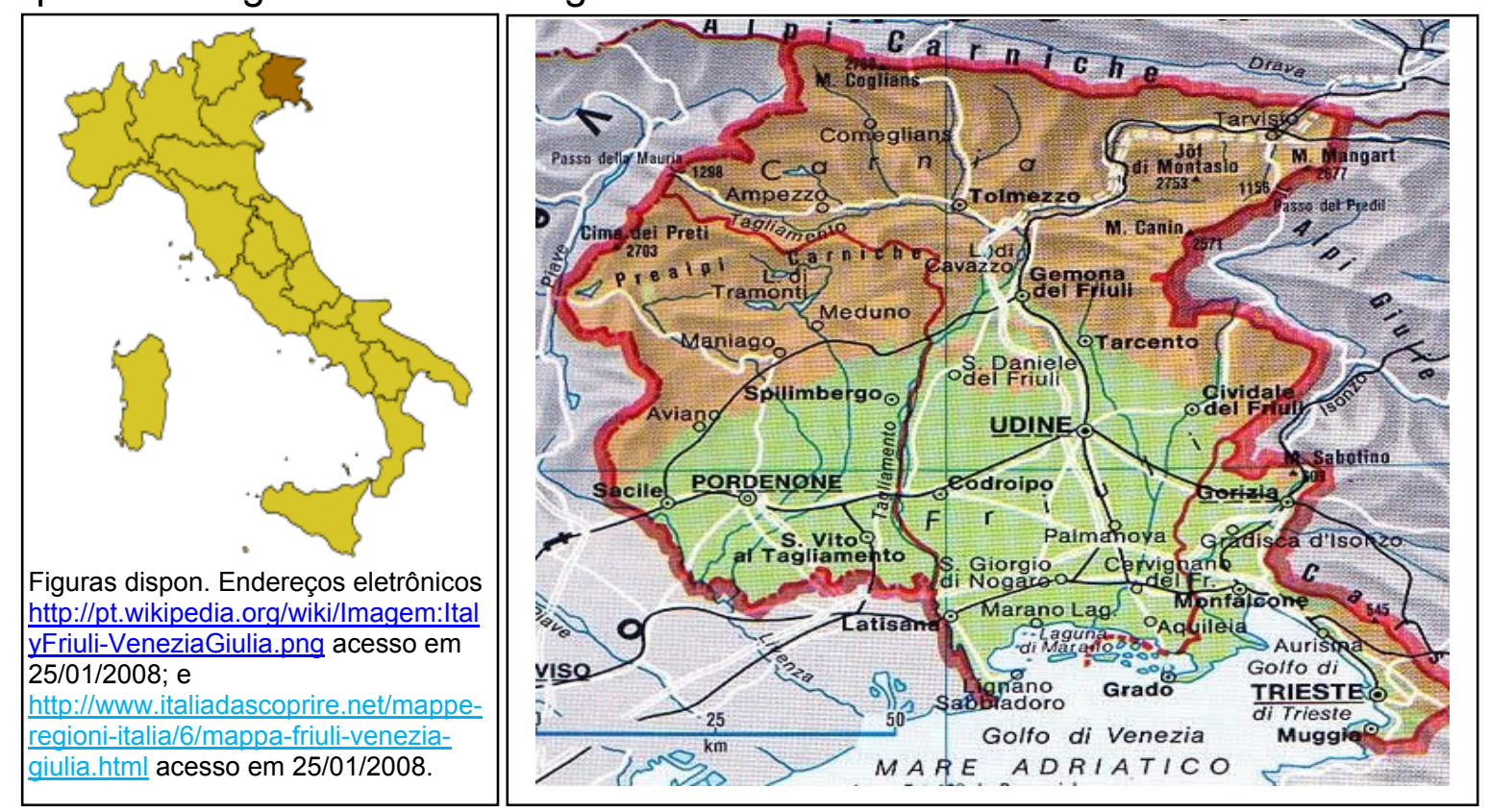

FIGURA 5.22 - Região do Friuli-Venezia Giulia

\footnotetext{
${ }^{181}$ Tradução livre de informações disponiveis no endereço eletrônico http://www.metutech.metu.edu.tr/ english/teknokent/genel.php. Acesso em 06/03/2008.

${ }^{182}$ Informações disponíveis no endereço eletrônico http://pt.wikipedia.org/wiki/Friuli-Venezia Giulia. Acesso em 24/01/2008
} 


\begin{tabular}{|r|l|}
\hline TABELA 5.11 - Dados da região da Friuli-Venezia Giulia \\
\hline Residentes em 31/12/2005: & 1.210 .903 \\
\hline Mulheres residentes em 31.12.2005: & 624.580 \\
\hline Número de famílias em 31.12.2006: & 1.204 .718 \\
\hline Estrangeiros residentes em 31.12.2005: & 65.341 \\
\hline Percentual de residentes estrangeiros em 31/12/2005: & 5,4 \\
\hline Densidade populacional: & $154,1 \mathrm{hab} / \mathrm{km}^{2}$ \\
\hline Superfície: & $7.840 .13 \mathrm{~km}^{2}$ \\
\hline Superfície agrícola utilizada (ano 2003): & $218.812 \mathrm{~km}^{2}$ \\
\hline Numero de comunas: & 219 \\
\hline Produto Interno Bruto em 2005: & 31.988 milhões de euros \\
\hline Produto Interno Bruto por habitante em 2005: & $26.000-28.400$ euros \\
\hline Taxa de atividade feminina (média 2005): & $45,3 \%$ \\
\hline Taxa de desemprego (média 2005): & $4,1 \%$ \\
\hline Número de empresas (média 2004): & 371.190 \\
\hline
\end{tabular}

Em grande parte do território da região do Friuli-Venezia Giulia se fala, além do italiano, a língua friulana. Estão presentes também minorias de língua vêneta na parte ocidental, de língua alemã no Val Canale, na fronteira com a Áustria; e de língua eslovena no Vale do Torre e do Natisone ${ }^{184}$. Até a metade do ano 1900 a região do Friuli-Venezia Giulia se caracterizou como uma terra profundamente rural e pobre, o que provocou uma imigração contínua em direção a países tais como os Estados Unidos, Canadá, Argentina e Australia ${ }^{185}$.

O desenvolvimento se iniciou nos anos 60 e levou à criação de um forte tecido de pequenas industrias e empresas artesanais que são a base do desenvolvimento do nordeste italiano; um grande impulso ao desenvolvimento industrial foi dado com a criação dos distritos industriais, entre os quais o "triangolo della sedia", parte sul oriental da província de Udine (Manzano, San Giovanni al Natisone e Corno di Rosazzo) dedicada à produção de cadeiras; o conhecido presunto "di San Daniele del Friuli" e o distrito de móveis da província de Pordenone (Brugnera). Também em Pordenone são produzidos eletrodomésticos pela empresa Zanussi que foi adquirida pela suiça Electrolux. ${ }^{186}$

\footnotetext{
183 Informações disponíveis no endereço eletrônico http://www.regione.fvg.it/istituzionale/cifre/cifre.htm. Acesso em 25/01/2008.

184 Informações disponíveis no endereço eletrônico http://pt.wikipedia.org/wiki/Friuli-Venezia Giulia. Acesso em 24/01/2008.

185 Tradução livre de informação disponível no endereço eletrônico http://www.italiadascoprire.net/italia/ friulivenezia-giulia/6/economia.html. Acesso em 24/01/2008.

${ }^{186}$ Idem.
} 
A agricultura não tem mais a importância que teve no passado, mas em dimensões reduzidas ela é setor de ponta e de alta tecnologia da qual se obtém vinhos que concorrem com os mais nobres do catálogo nacional, queijos de renome, entre outros ${ }^{187}$. A indústria pesada, anteriormente presente na capital friulana (aços Bertoli SAFAU), foi transferida para o interior Udines (aços ABS di Cargnacco) ou para mais longe da capital (aços Danieli di Buttrio e Pittini di Osoppo). Na província de Udine, sobretudo no interior, o setor de serviços tem forte presença, representando cerca de dois terços da ocupação total. ${ }^{188}$

A província de Trieste tem 240.000 habitantes, densidade de 1.132 hab/km². Está dividida em seis comunas, sendo a capital Trieste. Se estende ao longo de 30 quilômetros, fazendo fronteira a este com a Eslovénia e a sudoeste com o Golfo de Trieste (no Mar Adriático) ${ }^{189}$.

O AREA Science Park nasceu nos fins dos anos 70 (lei n. 546/77) sob os auspícios de organismos locais e da região da Friuli-Venezia-Giulia; e com o objetivo de criar uma estrutura que favorecesse os contatos e o desenvolvimento comum da ciência e das empresas ${ }^{190}$.

A tarefa de gerir e promover o parque foi instituída ao "Consórcio obbligatorio per l'impianto, La gestione e lo sviluppo dell'area di ricerca scientifica e tecnológica della provincia de Trieste", por meio do D.P.R. (Decreto Presidente della Regione) de 6 de março de 1978 n. $102^{191}$.

No decorrer dos anos o consórcio desenvolveu o parque científico tecnológico, com a progressiva instalação de numerosos laboratórios públicos e privados; e com a instalação de alguns institutos de pesquisa internacionais entre os quais: o Centro Internacional para Engenharia Genética e Biotecnologia (International Center for Genetic Engineering and Biotecnology - ICGEB) iniciado em 1988 sob a égide da UNIDO e hoje completamente autônomo; o Síncroton

\footnotetext{
187 Tradução livre de informação disponível no endereço eletrônico http://www.italiadascoprire.net/italia/ friulivenezia-giulia/6/economia.html. Acesso em 24/01/2008.

188 Idem.

189 Informações disponíveis no endereço eletrônico http://pt.wikipedia.org/wiki/Prov\%C3\%ADncia de Trieste. Acesso em 24/01/2008.

190 Tradução livre de informações retiradas de documento "Bilancio Sociale 2005" disponível no endereço eletrônico http://www.area.trieste.it/opencms/export/area/it/area e/ente nazionale/Bilancio sociale/AREA BilancioSociale2005.pdf. Acesso em 20/01/2008. ${ }^{191}$ Idem.
} 
Spa, para a realização da máquina de luz de síncroton em 1986; e o Centro Internacional de Ciência (International Center of Science - ICS) ${ }^{192}$.

O forte desenvolvimento do parque nos anos 80 e 90 e o relevo científico que ele foi assumindo, fez com que em setembro de 1999 o consórcio se tornasse um organismo de pesquisa nacional, assumindo a importância de "polo scientifico e tecnologico del Friuli Venezia Giulia e delle sue relazioni con l'estero"; o nome do consórcio foi mudado para "Consorzio per l'area di ricerca scientífica e tecnológica de Trieste ${ }^{193}$.

Novas tarefas foram acrescentadas ao consórcio, tais como: convocar anualmente uma conferência dos organismos de pesquisa nacionais e internacionais que recebessem contribuições do estado e que tivessem sede na região; e valorizar o desenvolvimento pré-competitivo e a transferência tecnológica dos resultados da pesquisa desenvolvida em sua rede científica ${ }^{194}$. Nos anos seguintes, ao lado das atividades tradicionais de desenvolvimento do parque, progrediu a atividade de transferência tecnológica e de suporte a empresas de toda a região; o papel de coordenação das instituições científicas do território se reforçou e foram ampliadas as relações com o exterior e a participação em programas de pesquisa européia, com o envolvimento de todo o parque científico ${ }^{195}$.

Em 2004, foi confiado ao consórcio a coordenação dos organismos de pesquisa da região, com protocolo assinado por dois ministérios, Ministério da Universidade e da Pesquisa - MIUR (Ministero dell'Università e de la Ricerca) e Ministério de Negócios Estrangeiros - MAE (Ministero degli Afare Esteri) da região da Friuli Venezia Giulia. Foi, então, atribuído à região da Friuli Venezia Giulia o Distrito Nacional de Biomedicina Molecular e atribuído ao Parque, por meio de sua controlada CBM (Centro de Biomedicina Molecolare), a administração do Distrito. A lei 43 de 31 de março de 2005 torna o AREA Science Park um dos principais

\footnotetext{
192 Tradução livre de informações retiradas de documento "Bilancio Sociale 2005" disponível no endereço eletrônico http://www.area.trieste.it/opencms/export/area/it/area e/ente nazionale/Bilancio sociale/AREA BilancioSociale2005.pdf. Acesso em 20/01/2008.

${ }^{193}$ Idem.

${ }_{194}^{194}$ Idem.

195 Idem.
} 
organismos de pesquisa de relevo nacional ${ }^{196}$. A Figura 5.23 apresenta a localização esquemática do AREA Science Park e a Figura 5.24 mostra uma foto aérea da localização do parque.

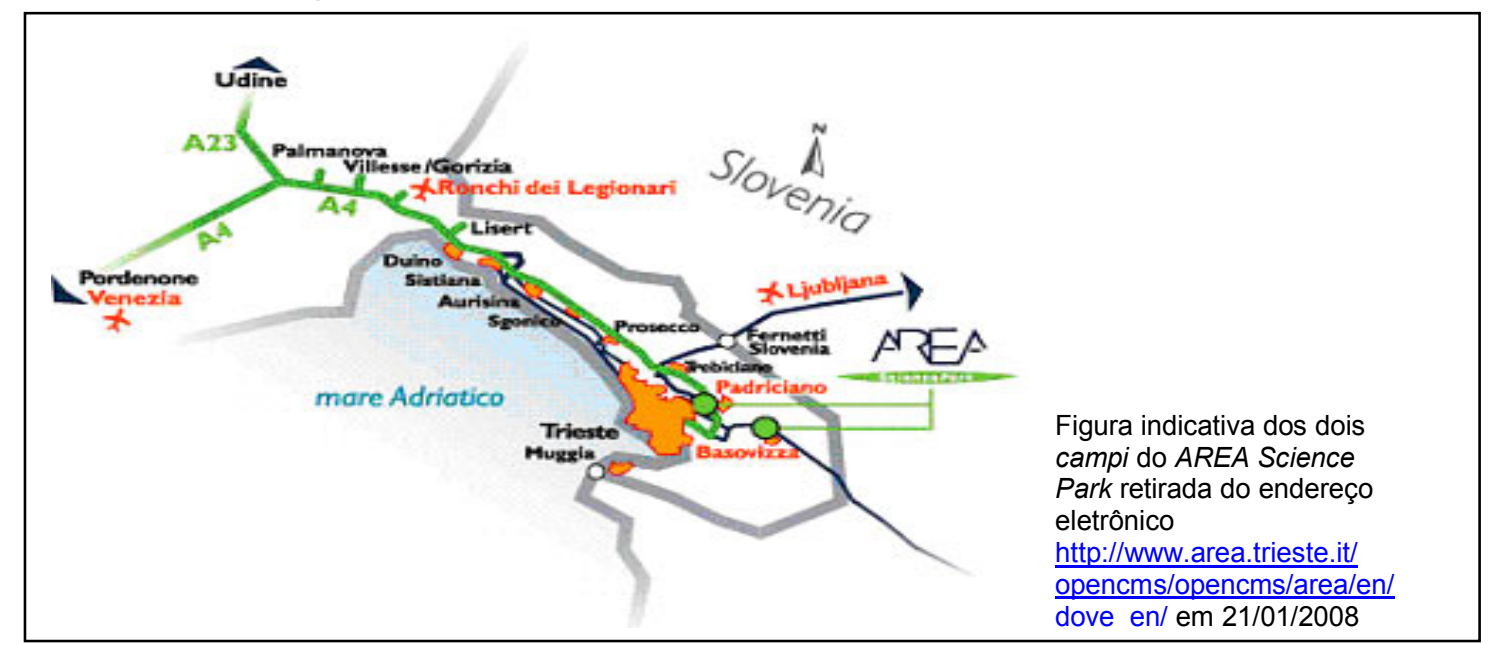

FIGURA 5.23 - Localização esquemática do AREA Science Park

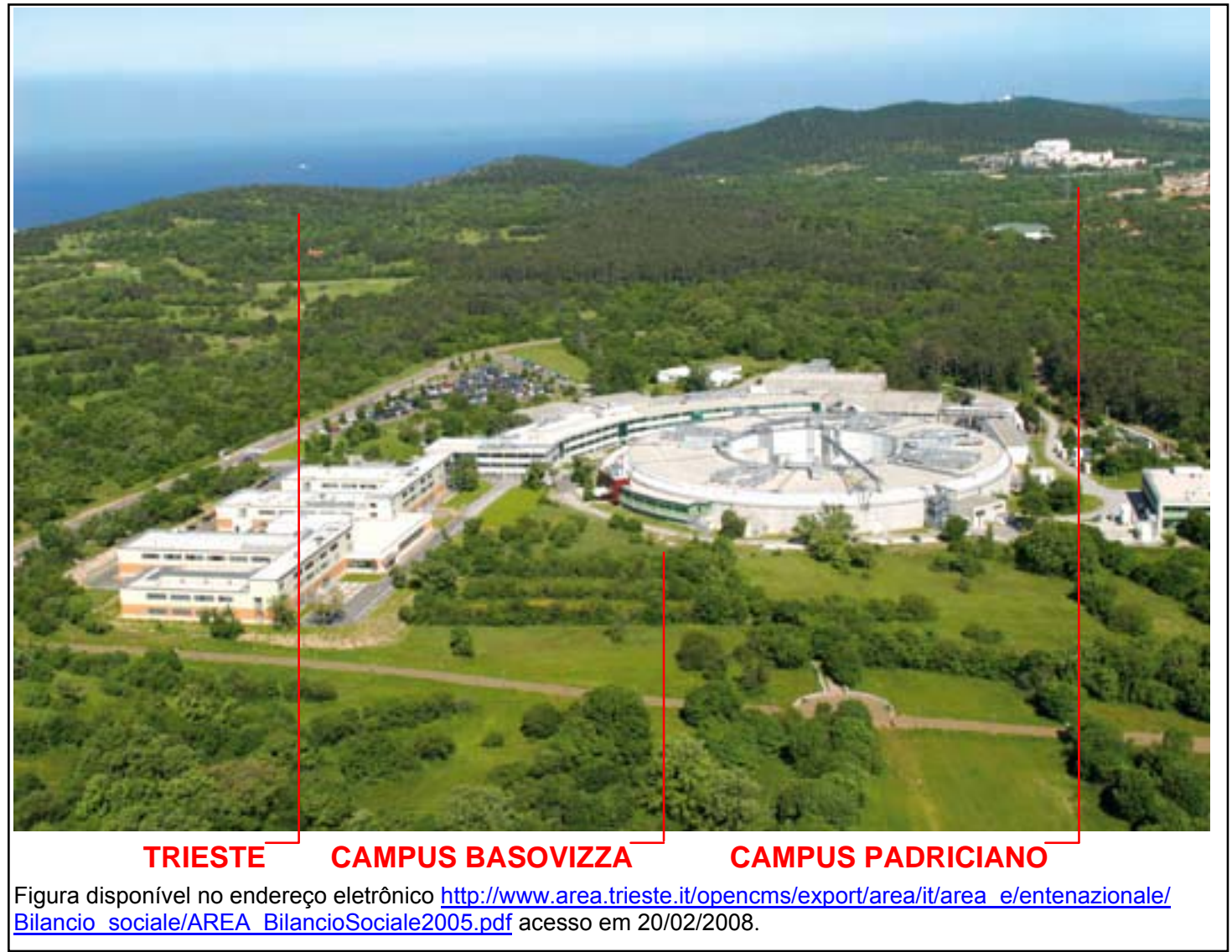

FIGURA 5.24 - Foto aérea da localização do AREA Science Park

\footnotetext{
${ }^{196}$ Tradução livre de informações retiradas de documento "Bilancio Sociale 2005" disponível no endereço eletrônico http://www.area.trieste.it/opencms/export/area/it/area e/ente nazionale/Bilancio sociale/AREA BilancioSociale2005.pdf. Acesso em 20/01/2008.
} 
O AREA Science Park possui dois campi (vide Figura 5.24), um em Padriciano e outro em Basovizza; ambos cobrem uma área total de $550.000 \mathrm{~m}^{2}$ de superfície no platô de Karst que cerca Trieste. O parque está a 10 quilômetros do centro de cidade, próximos às auto-estradas que levam a Veneza, a Milão e a Turin (pela estrada A4), a Udine e a Áustria (pela estrada A23) e a Eslovênia ${ }^{197}$.

A visão do AREA Science Park é desenvolver um sistema nacional e internacional de relações para contribuir à realização de uma rede estruturada de centros de excelência (punti eccellenza); e ser uma referência regional, nacional e internacional para transferência tecnológica e elaboração de estratégia para a inovação. A missão do parque é aumentar a competitividade e a atratividade do território mediante o apoio ao desenvolvimento empreendedor; e a difusão de produtos, processos e métodos inovadores de conhecimento e competência notáveis ${ }^{198}$.

A partir da análise da cultura organizacional da entidade realizada em 2006, foram identificados os valores organizacionais que norteiam as ações do AREA Science Park, que são: confiança, respeito, trabalho de grupo, meritocracia, transparência e correttezza (atitude e ação corretas) ${ }^{199}$. Na tabela 5.12 estão apresentados os recursos humanos atuando no parque em 31 de dezembro de 2006.

\begin{tabular}{|c|c|c|c|c|c|c|}
\hline \multirow[b]{2}{*}{ Perfil Profissional } & \multicolumn{2}{|c|}{ Tempo indeterminado } & \multicolumn{2}{|c|}{ Tempo determinado } & \multicolumn{2}{|c|}{ Total 2006} \\
\hline & Homem & Mulher & Homem & Mulher & Homem & Mulher \\
\hline Diretor Geral & & & 1 & & 1 & 0 \\
\hline DirigenteTecnólogo & 1 & & 1 & & 2 & 0 \\
\hline Primo Tecnólogo & 1 & 1 & 1 & & 2 & 1 \\
\hline Tecnólogo & 4 & 3 & 1 & 1 & 5 & 4 \\
\hline Dirigente Administrativo & 2 & 2 & & & 2 & 2 \\
\hline Colaborador T.E.R. & 8 & 1 & & 1 & 8 & 2 \\
\hline Funcionário Administrativo & 2 & 8 & 1 & 3 & 3 & 11 \\
\hline Colaborador Administrativo & & 9 & & 9 & 0 & 18 \\
\hline Operador Técnico & 4 & & & & 4 & 0 \\
\hline Operador Administrativo & 2 & 2 & & 2 & 2 & 4 \\
\hline
\end{tabular}

197 Tradução livre de informação disponível no endereço eletrônico http://www.area.trieste.it/opencms/ opencms/area/it/dove/index.html. Acesso em 26/01/2008.

${ }^{198}$ Tradução livre de informação disponível no endereço eletrônico http://www.area.trieste.it/opencms/export/ area/it/area e/ente nazionale/Bilancio sociale/AREA BilancioSociale2006 Relazione.pdf. Acesso em $26 / 01 / 2008$

${ }_{200}$ Idem.

200 Idem. 


\begin{tabular}{|l|l|l|l|l|l|l|}
\hline \multirow{2}{*}{ TOTAL } & 24 & 26 & 5 & 16 & 29 & 42 \\
\cline { 2 - 7 } & \multicolumn{2}{|c|}{50} & \multicolumn{2}{|c|}{21} & \multicolumn{2}{c|}{71} \\
\hline
\end{tabular}

Atualmente o parque científico hospeda 84 empresas e centros de pesquisa. Os centros, empresas e laboratórios presentes no parque atuam nos seguintes setores: Ambiental; Ciências da vida - biotecnologia e diagnóstico, química, bioquímica e tecnologias biomédicas; Eletrônica, informática e telecomunicações - eletrônica e automação industrial; informática e sistemas multimídia, telecomunicações; Física e materiais - física, aeroespacial e novos materiais, laboratório de luz Síncotron Elettra; e Serviços qualificados (servizi qualificati $^{201}$.

Os dois campi (Padriciano e Basovizza) dispõem atualmente de uma estrutura de superfície útil de $74.680 \mathrm{~m}^{2}$, distribuídas entre Padriciano $\left(30.380 \mathrm{~m}^{2}\right)$ e Basovizza (44.300 $\mathrm{m}^{2}$ dos quais 28.000 pertencem ao laboratório de luz Síncroton Elettra e $16.300 \mathrm{~m}^{2}$ ao AREA Science Park). O parque oferece aos instalados serviços como: estrutura para congressos e atividades didáticas, serviços comuns e serviços tecnológicos ${ }^{202}$.

As principais atividades relacionadas a serviços do conhecimento e desenvolvidas pelo AREA Science Park são: transferência de tecnologia, valorização da pesquisa, patentes, investimento em inovação, parcerias e rede internacional, formação, mobilidade, divulgação científica e estudos de setores ${ }^{203}$. O parque também promove e gerencia uma série de projetos que atendem os interesses dos instalados e dos interessados em se instalar no parque. A Tabela 5.13 apresenta os projetos em andamento no AREA Science Park e uma breve descrição deles.

\footnotetext{
${ }^{201}$ Tradução livre de informação disponível no endereço eletrônico http://www.area.trieste.it/opencms/export/ area/it/area e/ente nazionale/Bilancio sociale/AREA BilancioSociale2006 Relazione.pdf. Acesso em $26 / 01 / 2008$.

202 Idem.

${ }^{203}$ Informação disponível no endereço eletrônico http://www.area.trieste.it/opencms/opencms/area/it/mappa sitol. Acesso em 05/03/2008.
} 
TABELA 5.13 - Projetos em funcionamento no AREA Science Park ${ }^{204}$

Start-up of the Isontino area - se trata da proposição de estratégias de inovação para negócios localizados na Província de Gorizia. É um projeto direcionado para negócios baseados na província de Gorizia e resultado da colaboração entre o AREA; o Consórcio Industrial para o Desenvolvimento Industrial da Municipalidade de Monfalcone; a Província de Gorizia, a Sociedade Isontina para o Desenvolvimento; e a União Manufatureira da Província da Gorizia.

Com base no conhecimento econômico e fabril da região e nos resultados de uma pesquisa "porta a porta", foi possível obter um acurado retrato das necessidades dos negócios individuais no que diz respeito à inovação. O projeto (Animazione Isontina) oferece: apoio ao desenvolvimento de estratégias inovadoras para as empresas baseadas na província de Gorizia; facilitação na colaboração entre pesquisa e negócios, encorajando o "hábito da inovação"; promoção do uso de documentos e informação sobre patentes como um pré-requisito para projetos de inovação; construção do caminho para o estabelecimento de Centro de Competência especializado em transferência de habilidades e tecnologia para negócios em dois importantes setores da área Isontina: subcontratação naval e navegação de lazer. A administração do projeto recebeu fundos no valor de 225.000 euros, dos quais 100.000 euros foram dedicados a ações de inovação nas empresas beneficiadas, que contribuíram com a alocação de 25.000 euros.

Start-up of the Pordenone Province - se trata de um projeto voltado para negócios na área de Pordenone, tem como objetivo aumentar a competitividade dos negócios por meio da promoção de novos projetos baseados em idéias prontas para implementação. O Projeto (Animazione Pordenone) oferece: suporte a desenvolvimento de produto, processo e estratégias de gestão inovadoras; assistência especializada e suporte econômico durante a fase start-up do projeto.

Os seguintes serviços são oferecidos sem custo algum aos solicitantes: analise dos requisitos de inovação e identificação de estratégias potenciais; recuperação de patentes e documentos de informação; identificação das necessidades técnicas e científicas; desenho do esboço do projeto. $O$ projeto também realiza as seguintes atividades: planejamento e estudos de soluções inovadoras; analyses de viabilidade técnica e econômica; pesquisa e desenvolvimento de contatos com autoridades nacionais e internacionais; desenvolvimento, experimentação e validação de protótipos.

Inicialmente o projeto tinha como objetivo apoiar no mínimo 20 projetos inovadores para um valor médio de 5.000 euros cada um, sendo que $25 \%$ dos projetos seriam pagos pelos beneficiários. Os parceiros do projetos são: o AREA Science Park, o Polo Tecnologico de Pordenone (Pordenone Technology Centre), a Região do Friuli-Venezia Giulia; a Câmara de Comércio de Pordenone; a União Industrial da Província de Pordenone; e a Municipalidade da Provincia de Pordenone.

BINASP (Bio-Nanotechnology European Infrastructure in AREA Science Park)- se trata de um projeto complexo que envolve infraestrutura tecnológica e de pesquisa. Está ligado ao setor de biotecnologias integradas e promove o desenvolvimento de um Distrito Tecnológico de Biomedicina Molecular em nível Europeu. O BINASP foi iniciado em 2005 e seu funcionamento está previsto para cinco anos.

Tem como objetivo criar instalações de excelência para o desenvolvimento de atividades de pesquisa, testes e treinamentos especializados nos campos da biotecnologia e nanotecnologia integradas.

O projeto levará à criação de uma série de laboratórios especializados para grupos multidisciplinares de pesquisa e para grupos de trabalho de ação atuando na exploração economica dos resultados das pesquisas. Os laboratórios serão localizados na area nova e especialmente dedicada do Distrito Tecnológico de Biomedicina Molecular.

\footnotetext{
204 Tradução livre de Informações disponíveis no endereço eletrônico http://www.area.trieste.it/opencms/ opencms/area/en/attivita en/progetti az en/index.html e nos links associados aos projetos. Acesso em 05/03/2008.
} 
TABELA 5.13 - Projetos em funcionamento no AREA Science Park

Molecular Biomedicine Cluster - O projeto é gerido pelo AREA Science Park junto com o ENFAP (Ente Nazionale Formazione Addestramento Professionale) baseado na Gorizia, o ENFAP Trieste e o CBM (Consórcio de Biomedicina Molecular). As atividades do projeto são dirigidas aos empreendedores e empregados de PME e empresas maiores, está relacionado ao Objetivo regional 2 da área da Friuli-Venezia Giulia, que opera no setor biomédico.

Trata se de um plano de treinamento desenhado para suportar o processo de treinamento para o aprimoramento de recursos humanos e o desenvolvimento de cooperação com o cluster regional de bio-nano-tecnologia, com referência particular aos serviços avançados de cuidados com a saúde. O plano de treinamento está dividido em 13 módulos separados de cursos rápidos. Os cursos cobrem três áreas distintas: Habilidades de Gestão e Administração; Habilidade Técnicas e Científicas; e Habilidades básicas e Intersetoriais (cross-sector).

D4 Project - o projeto D4 foi fundado pelo Escritório Central para o Trabalho, Treinamento, Universidades e Pesquisa na Região Autônoma do Friuli-Venezia Giulia, junto com o Programa Operacional Regional, Objetivo 3, 2000-2006, prioridade D, medida D4, dedicado ao "aprimoramento dos recursos humanos nos setores da pesquisa e desenvolvimento tecnológico." O AREA Science Park é o líder do grupo; objetivo do projeto D4 é consolidar, em nível regional, a parceria entre negócios, universidades e centros de pesquisa; promovendo a troca contínua de habilidades e competências, a mobilidade de idéias e pesquisadores, a junção e a sinergia que envolve à implantação de projetos de pesquisa inovadores, e o desenvolvimento e transferência de tecnologia.

O projeto D4 oferece vários caminhos para a promoção e obtenção pesquisadores visitantes e de bolsas de pesquisa. O projeto também realiza análise de desempenho da região do Friuli-Venezia Giulia em termos de inovação e pesquisa, utilizando ferramentas quantitativas (EIS - European Innovation Scoreboard ${ }^{205}$ ) projetadas para oferecer uma visão geral da situação da inovação.

ERA-MORE (European Network of Mobility Centres) - o projeto ERA-MORE é o produto de uma iniciativa conjunta entre a Comissão Européia e os países participantes do $6^{\circ}$ Programa Quadro (6th EU Research Framework Programme). A rede é composta por cerca de 200 centros de mobilidade distribuídos na Europa. O objetivo da iniciativa é oferecer assistência aos pesquisadores móveis (em trânsito) e a encorajar a troca de informação e boas práticas em gestão de mobilidade entre aqueles que já operam o sistema.

Os Centros de Mobilidade oferecem aos pesquisadores móveis uma série de informações relevantes, por meio da preparação de pacotes de informação e pela publicação de dados úteis no Portal de Mobilidade Italiano e no Portal de Mobilidade dos Pesquisadores Europeus. Os Centros de Mobilidade organizam encontros individuais, bem como informações e dias de treinamento focados nos melhores caminhos para encorajar a mobilidade.

O Centro de Mobilidade do AREA Science Park está operando desde março de 2005 e oferece aos pesquisadores assistência sobre procedimentos para entrada e residência na Itália, assim como informações referents a oportunidades de pesquisa e de trabalho na Itália.

DOMOTICA FVG Project - Domotica (ou automação residencial) lida com as aplicações da tecnologia e soluções em automação para residências privadas com o objetivo de aumentar a qualidade de vida, reduzindo o consumo de energia, aumentando os níveis de segurança, renovando os aparelhos de monitoração e gerindo os equipamentos residênciais (controle e gestão). A idéia básica é a de que a luta para competir no setor mobiliário será ganha pelas empresas que não só aplicam tecnologia em seus produtos como integram melhor as diferentes

205 O EIS (European Innovation Scoreboard) é um instrumento desenvolvido por iniciativa da Comissão Européia, sobre a égide da Estratégia de Lisboa, criado para avaliar e comparar o desempenho inovativo dos Estados Membros da Comunidade Européia. Tradução livre de informação disponível no endereço eletrônico http://www.proinno-europe.eu/doc/EIS2006 final.pdf Acesso em 10/3/2008. 
TABELA 5.13 - Projetos em funcionamento no AREA Science Park

tecnologias de forma a alcançar melhores resultados que seus concorrentes.

A estratégia implica a transferência de soluções de automação residenciais (eletrônicas, óticas, telemáticas, de redução do consumo de energia, novos materiais, micro e nanotecnologias, etc...) à indústrias com visão de inovação de produtos e processos. Pesquisadores e designers poderão examinar e escolher as propostas e o projeto a ser implantado e supervisionado desde o início do desenvolvimento até a distribuição. Os parceiros do projeto são: o AREA Science Park, o Friuli Innovazione, a empresa Agemont, o Polo Tecnologico di Pordenone, com a colaboração da Fundação Rino Snaidero Scientific. As linhas de desenvolvimento do projeto: rede de cooperação para a inovação no território.

O projeto Domotica FVG pretende criar uma rede de cooperação para pesquisa e desenvolvimento no campo da prototipação de soluções em automação residencial. Tais soluções podem eventualmente ser produzidas em massa e comercializadas, graças à manufatura industrial. Os projetos tem o foco em cinco areas de desenvolvimento - conexões com ou sem fio em espaços restritos, materiais inovadores - incluindo produtos de micro e nanotecnologia, sistemas de iluminação, soluções de energia e de economia de energia e novos métodos de gestão de negócios.

FIRM (Formazione per gli Imprenditori Regionali e i Manager - Training for Owners and Managers in the Region) - Em um ambiente econômico regido pela competição e pela globalização, o principal desafio dos negócios é a inovação: em processos, produtos e na organização. A Região Autônoma do Friuli-Venezia Giulia está comprometida a perseguir uma estratégia maior de inovação e tem, durante anos, considerado as necessidades de crescimento e de competitividade local dos negócios da comunidade. A Região decidiu implantar um programa integrado de provisão de serviços de informação, orientação, assistência em treinamento para proprietários, administradores e líderes de projetos de PME da região, com o objetivo de promover a cultura empresarial, que é a chave do crescimento econômico e social.

O resultado deste conpromisso é o projeto FIRM, coordenado pela AREA Science Park e pelos parceiros ARPA Consortium, En.A.I.P. Friuli Venezia Giulia, IAL Friuli Venezia Giulia, IRES Institute for Economic and Social Research in Friuli Venezia Giulia, Boston MIT Entrepreneurship Center, Skillab s.r.l. - Human Resource Enhancement centre, Politecnico di Torino, University of Trieste, University of Udine. Seu objetivo, baseado numa rede de helpdesks, é atingir o máximo do público alvo da região. Desta forma, os proprietários e gestores das empresas da região serão orientados sobre a aprendizagem a partir de uma análise das necessidades e das competências, levado à sala de treinamento e, finalmente, a um apoio individual.

Análise dos requisitos de treinamentos - Os helpdesks fornecerão às empresas os detalhes sobre o programa FIRM e aceitarão inscrições para os cursos de treinamento. O serviço prestado inclui recepção e uma análise das necessidades empresa, com vista à oferta de formação específica adaptada para atender necessidades individuais. O serviço é inteiramente financiado a por fundos da Região e está sujeito às regras relativas aos auxílios estatais.

Treinamento - Os cursos são subidividos em quatro tópicos principais e requerem uma participação mínima de cinco pessoas. Todos os cursos ocorrem na Região, em lugar identificado como resposta às necessidades do solicitante. Todas as atividades do curso podem ser personalizadas para atender os requisitos e as condições da ajuda estatal.

Os cursos disponíveis no momento são os seguintes: cursos relacionados a FINANÇAS E RECURSOS HUMANOS (Responsabilidade corporativa e regras para financiamento, Controle de gestão e técnicas de orçamento, Financiando o crescimento da empresa, Gerindo e planejamento o crescimento em PME, Gestão de recursos humanos e motivação, Relatório de capital intelectual); cursos relacionados à INOVAÇÃO (Avaliação e gestão de projetos de investimento em inovação, Estratégias de inovação para PME); cursos relacionados à ORGANIZAÇÃO E PRODUÇÃ̃O (Continuidade empresarial e Transição Generacional, Produção enxuta: eliminação dos resíduos no processo de produção e melhoria da logística, Capitalizando o potencial inexplorado de negócios por meio de iniciativas spin-off, Melhor organização para maior 
TABELA 5.13 - Projetos em funcionamento no AREA Science Park

competitividade nos mercados internacionais, Gestão de Projetos, Gestão da cadeia de suprimentos); MERCADO E INTERNACIONALIZAÇÃO (Planejamento e Estratégias de mercado, Internalização do mercado, Mercado Internacional, Investindo na Chindia). Orientação individual proprietários e gestores que participaram de um ou mais cursos de treinamento no quadro do programa, podem solicitor orientação individual. O serviço é financiado por fundo regional e sujeito a regras de regulação para ajuda estatal.

HiCo (Hi-tech Integrated Cooperation) - O projeto HiCo promove o desenvolvimento técnico e econômico nas fronteiras da região do Friuli-Venezia Giulia com a Slovenia (região do HiCo) , o objetivo é aumentar a convergência do crescimento industrial por meio do apoio a iniciativas de pesquisa científica e ações de desenvolvimento tecnológico. O Projeto é promovido e coordenado pelo AREA Science Park em colaboração com os órgãos regionais de desenvolvimento econômico SVILUPPO ITALIA FVG e EZIT Trieste. A parceria Slovena é particularmente significante, contanto com mais de 20 participantes (serviços de $P \& D$, agências regionais de desenvolvimento, Centro de Negócios e Inovação, municipalidades), trabalhando em estreita sinergia com o AREA no âmbito de iniciativas semelhantes e em curso na Slovenia; e com o objetivo de promover a inovação tecnológica dos negócios e reforando clusters e redes de negócios. O projeto HiCo tem como objetivos: reforçar as habilidades e especialização tecnológicas, científicas e dos sistemas produtivos na área do projeto (região $\mathrm{HiCo}$ ), promover o estabelecimento de parcerias industriais e científicas; implementar e testar em campo estruturas fronteiriças para iniciar atividades orientadas para a tecnologia e a inovação; criar metodologias, estruturas de promoção e serviços para atrair investimentos da indústria.

Hepatocyte Genomics - Este projeto se destina a estabelecer a genômica funcional do tecido hepático normal e das lesões hepáticas mais freqüentes. Patrocinado e coordenado pelo AREA Science Park, o projeto foi aprovado em 2002 pelo Ministério da Pesquisa e das Universidades, qualificado para o FISR (fundo especial adicional para pesquisa) 2001, voltado para projetos de importância estratégica.

O ponto forte da pesquisa é a cooperação entre as algumas partes envolvidas para o desenvolvimento do Distrito Tecnológico de Biomedicina Molecular, especialmente o grupo, coordenado e gerido pelo AREA Science Park, do CSF - Centre for the Study of Liver Diseases of the Fund for Liver Diseases, o ICGEB (International Centre for Genetic Engineering and Biotechnology) e os centros de pesquisa da Universidade de Trieste.

Imprenderò - o projeto Imprenderò é administrado por um consórcio de 19 parceiros, promovido e fundado pela Região Autônoma da Friuli-Venezia Giulia por meio do Fundo Social Europeu no quadro do Programa Operacional, Objetivo 3, 2000-2006, prioridade D, Medida D3 e Prioridade E, Medida E1. O projeto tem por objetivo disseminar e promover a cultura de empresa, reforçando-a como um elemento indispensável para o desenvolvimento econômico e social. O projeto está direcionado a pesquisadores, doutorandos e graduados interessados em estabelecer negócios ou a colaborar e atuar em empresas interessadas em promover spin-offs.

Nesse projeto o AREA Science Park: realiza consultorias individuais provendo informações; orienta e audita habilidades para o estabelecimento de negócios; assiste a fase de desenvolvimento do plano de negócios e sua implementação, por meio de suporte e aconselhamento; cria um sistema integrado de seminários que provêem informações e treinamento nos principais tópicos relacionados a spin-offs. Uma série de seminários gratuitos nos tópicos relacionados a empresas são realizados no Centro de Conferências do AREA.

Os resultados do projeto até o momento são os seguintes: 283 horas de orientação para negócios; 35 seminários em tópicos relacionados a empresas e gestão; 1.250 horas de assistência técnica individual; 112 pessoas utilizaram o serviço de assistência técnica individual; e 24 empresas foram criadas com o apoio do projeto Imprenderò.

Innovation Campus - o campus de inovação é uma iniciativa que tem por objetivo oferecer treinamento contínuo e suporte a encontros e workshops para operadores nacionais e internacionais e agências do setor. O projeto provê cursos de educação superior, estudos 
TABELA 5.13 - Projetos em funcionamento no AREA Science Park

especializados, consultoria em temas relacionados a projetos e transferência de tecnologia. $\mathrm{O}$ novo perfil profissional que o primeiro curso superior do programa visa criar é o "technology broker - especializado em transferência de tecnologia e inovação". Este perfil está fortemente orientado para a demanda por inovação, com atenção particular ao desenvolvimento de: habilidade de se colocar apropriadamente ao empreendedor ou gestor da empresa e interpretar corretamente a demanda de inovação; habilidade em identificar as melhores oportunidades, mais desejáveis para o negócio, no campo da pesquisa; abilidade de acompanhar "pesquisa" e "empresa" durante o desenvolvimento de produtos e processos. O projeto é gerido pelo AREA Science Park em parceria com o Milan MIP-Politecnico (Instituto Tecnológico especializado em Gestão e Engenharia Industrial), o qual transmite sua experiência, obtida por meio do escritório de transferência de tecnologia (TTO - Technology Transfer Office).O Innovation Campus é patrocinado pelo Instituto de Promoção Industrial (IPI) e pela Camere di Commercio d'Italia (UNIONCAMERE). É também suportada pelo Convegno permanente dei Direttori Amministrativi e dirigenti delle Università italiane (CODAU); pelo Diffusione Informazioni Normativa Tecnica (DINTEC); e pela IASP.

Innovation factory - Fábrica de Inovação é uma iniciativa do AREA Science Park criada para dar suporte e assistência na criação de novos negócios inovadores. Esta dirigida a pesquisadores e grupos de pesquisa que pretendam implementer seus próprios projetos spin-offs; e a empreendedores interessados em fazer parte na criação de novas empresas à luz de pesquisas realizadas em colaboração com instituições de pesquisa do parque.

Innovation Factory oferece serviços de incubação de negócios com unidades especialmente equipadas; oferece assistência na avaliação dos conceitos de empreendimento tecnológico, e posições comercial, jurídica e econômica; oferece também apoio financeiro com a possibilidade de financiamento sob a forma de capital semente.

Mais precisamente, a Innovation Factory oferece: treinamento econômico, financeiro e gerencial; treinamento específico sob demanda; um business coach para atuar como tutor empresarial; ajuda na identificação de fontes de recursos.

Consultores e pessoal qualificado são também disponibizados para aconselhar em: aplicações e desenvolvimento de produtos; serviços de proteção de propriedade intelectual; validação de tecnologia e de desempenho; analise de mercado e controles.

Innovation Network - Rede de Inovação é um projeto do AREA Science Park apoiado pela Região do Friuli-Venezia Giulia que foi estabelecido dentro da região como uma estrutura de serviços para negócios, dedicado a transferir experiência e tecnologia obtida no mundo da pesquisa e estimular o estabelecimento de projetos de inovação.

A estrutura da rede é constituida em torno de Centros de Competência ativos nas areas de interesse comum, como meioambiente, energia e eficiencia produtiva, ou especializada em setores produtos típicos da região do Friuli-Venezia Giulia, como madeira e mobiliário, agroindústria e construção de barcos para navegação e lazer.

Cada link dessa rede de inovação prove negócios envolvidos com a especialidade, habilidades específicas e serviços necessários para o desenvolvimento inovador de produtos, processos e gestão. Os centros de competência atualmente em operação são: agroindústria; meioambiente; construção de barcos e navios; madeira e mobiliário; energia; negócios e engenharia; plásticos e novos materiais; e biomedicina molecular.

IRC - Irene (Italian Relay Centre North East) é um ponto central de transferência tecnológica transnacional e difusão das habilidades de inovação nas regiões da Emilia Romagna, Marche, Veneto, Trentino-Alto Adige e Friuli Venezia Giulia.O IRENE foi fundado em parceria com o programa de inovação européia e é um dos links da rede européia de Centros de Inovação existentes em 33 países.

As operações regionais do AREA no âmbito do projeto IRENE incluem: assistência à indústria na definição de necessidades tecnológicas; promoção de idéias inovadoras em nível Europeu e por 
TABELA 5.13 - Projetos em funcionamento no AREA Science Park

meio da Rede Centros de Inovação (IRC), identificação de parceiros para a aquisição de tecnologias; promoção da assinatura de acordos transnacionais de transferência tecnológica; apoio a projetos de pesquisa e de desenvolvimento tecnológico no âmbito do quadro dos programas de pesquisa e inovação da União Européia.

ITI - International Technology Incubators - o projeto ITI tem por objetivo promover, gerir e hospedar o grupo de PME inovadores italianas hi-tech ao mesmo tempo em que expandem seus negócios para o exterior. O projeto é baseado na organização conjunta de suporte à essas PME em incubadoras tecnológicas especializadas.

O modelo de negócios consiste na promoção e internacionalização de empresas italianas pela combinação de crescimento econômico e industrial com o desenvolvimento dos negócios com um alto nível de conhecimento. As principais questões do projeto são: reforçar as competências e conhecimentos dos sistemas científicos e produtivos italianos; promover a criação de parcerias técnicas e industriais; compartilhar metodologias, serviços e estruturas.

O projeto ITI oferece serviços profissionais avançados por meio de subcontratação (outsourcing system) de profissionais locais ou empresas locais para realizar: avaliação de áreas apropriadas para receber empresas e laboratórios de P\&D; apoio e representação legal; consultoria em gestão; intermediação de marketing; intermediação financeira; redes com Universidades e Centros de Pesquisa; treinamento; serviços auxiliares.

NANOLAB - Nanosized Cancer Polymarker Biochip - NANOLAB é um projeto voltado para o design e desenvolvimento de protótipos nanosized e de sensores para combater o câncer. $O$ projeto foi aprovado em 2005 pelo Ministério da Pesquisa e Universidades e qualificado para o FIRB (Fundo para Investimento em Pesquisa Básica). O projeto implica a criação de um Laboratório Molecular, Bioestrutural e Nanomaterial Modelo.

O projeto de pesquisa no AREA Science Park é parte de um programa externo envolvendo oito parceiros públicos e parceiros italiano privados, coordenado pelo Applicazione Biotechnologie in Oncologia $(A B O)$ que está baseado no Vega Science Park.

O projeto NANOLAB foi iniciado em 2006 e envolve a criação de um centro de excelência no AREA Science Park, onde modelos moleculares e computacionais serão desenvolvido e biochips serão projetados.

Nanotechnology for Biomedicine - o projeto entitulado "Aplicação de Nanotecnologia para Biomedicina -- liberação controlada de drogas in situ e diagnóstico precoce de câncer - tem a missão de criar um laboratório interdisciplinar em ciências da vida (medicina, biologia e farmácia) e ciências exatas (física e química), com o objetivo de trabalhar na aplicação de nanotecnologia e técnicas relativas de nanomanufatura para o campo biomédico (e especialmente no diagnóstico precoce de câncer).

O projeto foi aprovado em 2005 como parte do Acordo State/Regional Framework em pesquisa científica. É coordenado e gerido pelo AREA, com o envolvimento do Scarl - Consortium for Molecular Biomedicine (CBM).

O objetivo principal do projeto é a criação de dispositivos inovadores, como sistema de liberação de drogas baseados em nanocarriers interativos e "micro labs-on-chip", que podem ser controlados remotamente e são capazes de captar e transmitir dados, realizando um papel interativo no tratamento e no corpo do paciente.

Novaregio - é um projeto internacional que tem por objetivo tornar o Friuli-Venezia Giulia uma das Regiões Inovadoras da Europa. Por meio de uma análise comparativa, no âmbito da Europeu, das melhores e mais efetivas políticas e estratégias regionais e governamentais direcionadas à inovação. O projeto está apto a indicar os melhores caminhos a seguir para adotar tais práticas a nível local.

O projeto Novaregio traz consigo oito parceiros de sete países Europeus (Austria, Grécia, Itália, Espanha, Eslovênia, Suécia e Hungria) hábeis na promoção da inovação e nos link-ups com instituições influentes operando junto com o governo regional e suporte a inovação. Novaregio também atua junto a duas significativas redes Européias: a CEI - Central European Initiative (com 
TABELA 5.13 - Projetos em funcionamento no AREA Science Park 17 estados membros); e a CPMR - Conference of Peripheral Maritime Regions of Europe (representando 140 áreas periféricas e marítimas da Europa).Os objetivos do projeto são: elaborar um plano de ações para a coordenação de políticas de inovação; criar um centro Europeu virtual para a publicação online e junção de conhecimento em matéria de políticas de inovação; produzir uma análise comparativa das melhores e mais efetivas políticas e estratégias dos governos regionais, referentes à inovação em nível Europeu, para que elas possam ser adotadas em nível local; fazer um manual de benchmarking contendo exemplos políticas de financiamento da inovação regional e promover a difusão de 10 casos de boas práticas na Europa, escolhidas de 25 exemplos de sucesso; encorajar organizações regionais a adotarem as instruções sugeridas no manual.

Novimpresa Project - criado em 1997, o projeto Novimpresa é uma iniciativa do AREA Science Park criado para promover a difusão da inovação das PME da região do Friuli-Venezia Giulia. O projeto é resultado da necessidade de tornar acessível aos negócios da região do Friuli-Venezia Giulia o acesso ao conhecimento e habilidades desenvolvidas nas áreas próximas a duas universidades, aos Centros de Excelência científica e ao AREA Science Park.

O AREA oferece suporte de alta qualidade aos empreendedores locais e pode ajudá-los no desenvolvimento de produtos, processos e gestão inovadores. O projeto Novimpresa está concentrado nas seguintes estratégias básicas de ação: ação intensiva na região por meio de pesquisas porta-a-porta; forte colaboração com os órgãos de pesquisa e instituições com o objetivo de desenvolver uma rede de competências na região do Friuli-Venezia Giulia; transferência de habilidades e expertise de vários setores e contextos; desenvolvimento de colaboração entre negócios e compartilhamento de necessidades de inovação.

$\mathrm{O}$ projeto atua com um mix de instrumentos inovadores, services e expertise disponível para negócios; isto permitiu até o momento os seguintes resultados: contato com 1071 empreendimentos; visita a 493 deles; 500 ações efetivas de inovação em 26 setores estudados.

As atividades do projeto Novimpresa foram cofundadas pela União Européia por meio do Fundo de Desenvolvimento Regional Europeu (FESR), pelo Estado Italiano, pela região do FriuliVenezia-Giulia e pelo AREA Science Park.

Fuel cell project - o projeto Célula Combustível criado pelo AREA Science Park pretende criar um research-to-business "energy channel" na região do Friuli Venezia Giulia, com particular enfase no desenvolvimento de células a combustível, um setor promissor relacionado a economia do hidrogênio. AREA está executando uma série de atividades nos campos da pesquisa, industrialização e produção de células combustíveis em colaboração com instituições científicas de alto desempenho nessa área.

Innovative Business Networks - Redes de Negócios Inovadores é um projeto que tem por ojetivo aumentar o perfil da região. Ele consiste em dois subprojetos, ambos voltados para o desenvolvimento high-tech, negócios inovadores nos campos respectivos da tecnologia da informação e comunicação (TIC) na indústria espacial e nas aplicações em biotecnologia.

INVESAT- Construindo a ponte entre empresas inovadoras e investidores financeiros em mercados emergentes de TIC e aplicações em Satélites - o projeto diz respeito ao estudo e identificação de incubação e técnicas de desenvolvimento para negócios high-tech do setor TIC para aplicações em satélites. O projeto foi aceito pelo fundo europeu em janeiro de 2006 como parte do programa da União Européia "Inovação empreendedora: rede de atores chave e usuários FP6-2004-INNOV-6"

DETECT-IT 2 - Desenvolvendo uma rede transnacional de clusters para beneficiar PME orientadas a propostas FP6 e FP7 - é um projeto suportado e com o envolvimento de grupos de PME nos programas quadro europeus 6 o e 70 de P\&D no setor de biotecnologia como parte do programa europeu "Stepping up Economic and Technological Intelligence - FP6-2004-INNOV-5". 
TABELA 5.13 - Projetos em funcionamento no AREA Science Park

Sister - Liaison Office - O Escritório de Ligação SISTER é um projeto do AREA dedicado a aumentar a pesquisa na região do Friuli Venezia Giulia. Graças à colaboração com instituições regionais de pesquisa e de fundos provenientes da região do Friuli-Venezia Giulia, o AREA implementou um sistema permanente de transferência dos resultados da pesquisa da região para negócios.

O Sister - Liaison Office elaborou e testou um novo processo que representa um caminho efetivo para organizer os procedimentos e services requeridos para transferir os resultados da pesquisa para o mercado. Os serviços oferecidos pelo Sister - Liaison Office são disponibilizados sem custos a todos os pesquisadores da região do Friuli-Venezia Giulia. Um das atividades promovidas pelo Sister - Liaison Office foi a elaboração de um mapa das competências existentes nas instituições de pesquisa da região que são aplicáveis à indústria, com o objetivo de incentivar a transferência de tecnologia para os negócios.

Até o momento os resultados obtidos pelo Sister - Liason Office foram os seguintes: 153 pesquisadores contatados, 183 resultados de pesquisa identificados, 322 atividades de aprimoramento iniciadas, 30 patentes registradas na Itália, 18 patentes registradas no exterior.

Scounting - o Scounting - serviços de inovação para empresas - é um projeto desenvolvido pelo AREA Science Park para oferecer novas oportunidades de inovação às empresas pertencentes a Associação Manufetureira de Trieste, um parceiro do AREA para o desenvolvimento da inovação. A iniciativa pretende fortalecer a competitividade das empresas estimulando novos projetos baseado em idéias que ainda não tenham sido colocadas em prática.

Em particular, o projeto suporta o estágio inicial mais crítico de cada projeto, apoiando a transferência de tecnologia, e provendo assistência de especialista e de suporte financeiro. $O$ projeto foi iniciado em 2006 e suporta o desenvolvimento de planos de inovação no que se refere aos produtos, processos e gestão. Especificamente, o AREA provÊ seu conhecimento e recursos disponíveis às empresas enquanto a Câmara de Comércio de Trieste provê os fundos necessários.

Ainda, são oferecidos os seguintes serviços gratuitos: acesso às necessidades para inovação; definição das estratégias potenciais; coleta de patentes e de informação documental; identificação das técnicas e hailidades científicas mais apropriadas; elaboração de planos de projeto. Um número limitado de projetos de inovação pode receber também fundos para executar as seguintes atividades: estudo e design de soluções inovadoras; identificação de habilidades relevantes; contatos e relações nacionais e/ou internacionais; analise de viabilidade técnica e econômica; desenvolvimento e teste experimental de protótipos.

Support Project - O AREA Science Park participa no suporte ao projeto, fundado pelo programa Leonardo da Vinci da União Européia. O objetivo do projeto é criar, checar e difundir programas de treinamento e instrumentos de incentivo à introdução, em PME, de metodologias e ferramentas (como a $\mathrm{TRIZ}^{206}$ ) que podem apoiar a adoção de estratégias ecologicamente sustentáveis de inovação. O AREA atua definindo estrutura e lay-out dos materiais de treinamento criados no âmbito do projeto. Outros parceiros do projeto são: a Universidade de Leoben na Austria; a Creax da Bélgica; o Instituto Fraunhofer da Alemanha; o Joanneum Research - Austria e a Universidade de Maribor - Slovenia.

206 TRIZ (Teoriya Resheniya Izobretatelskikh Zadatch) significa "teoria para solução de problemas de inventores" ou "Teoria da solução inventiva de problemas", desenvolvida pelo pesquisador e engenheiro soviético Genrich Altshuller e seus colegas em 1946, tendo evoluído desde então. Hoje é uma metodologia, uma ferramenta, uma base de conhecimentos, para a geração de idéias e soluções inovadoras na solução de problemas. Tradução livres de informação disponível no endereço eletrônico http://en.wikipedia.org/wiki/TRIZ Acesso em 15/03/2008. 
TABELA 5.13 - Projetos em funcionamento no AREA Science Park

Talent Scout - O objetivo do projeto Talent Scout é integrar os clusters de negócios Europeus e os centros de pesquisa líderes da Europa com PME inovadoras no setor das Ciências da Vida. O projeto promove a participação de PME envolvidas no setor da biotecnologia e em setores complementares, em Integrated Projects (IPs) e Networks of Excellence (NoEs) criadas pela Comissão Européia. O projeto Talent Scout utiliza uma disseminada rede de institutos científicos, centros de pesquisa e inovação e organismos de apoio de nove diferentes países Europeus (inclusive os dois maiores IRC da Europa - o Germany's Zenith e o Greece's Help Forward).

As estruturas de pesquisa e as PME do projeto Talent Scout estão divididas em duas categorias:

"R\&D Performers" (que são aqueles envolvidos na pesquisa, e desenvolvimento de service e produto); e os "End Users" (que são os centros de análise bioquímica, clínica e ambiental; os fornecedores de equipamentos e de materiais; os serviços de engenharia clínica, veterinária, alimentar; os de serviços de diagnóstico ambiental e alimentar, etc...)

$\mathrm{O}$ projeto Talent Scout atua com PME operando nos seguintes setores: agroalimentar; médico e veterinário; químico e farmacêutico.

Talents - Desde abril de 2005 o AREA Science Park promove um programa de mobilidade regional denominado International Fellowships Programme "Talents". O projeto Talents busca estimular o potencial científico da região por meio do aumento do capital de recursos humanos qualificados e pela troca de conhecimento. $O$ projeto busca anunciar periodicamente parcerias de mobilidade (mobility fellowships) criadas por varios organismos para a seleção de jovens e experientes pesquisadores com alto nível de habilidade científica.

O Talents procura criar uma rede regional de inovação que poderá aumentar a cooperação entre o mundo da pesquisa e o da indústria. Pretende também promover a transferência de conhecimentos inovadores provenientes das pesquisas, dos centros de transferência tecnológica, dos centros de inovação e das universidades, para o sistema produtivo da região.

As características essenciais das atividades de pesquisa cobertas pelo projeto são aquelas interdisciplinares, multidisciplinares, originais e inovadoras. Atenção especial é oferecida a atividades de pesquisa de longo termo na região, as quais devem continuam além da duração da pesquisa fellowship anunciada. Ao mesmo tempo, o potencial de estabelecer redes de excelência úteis e estáveis em áreas científicas específicas, é uma prioridade do projeto.

\subsubsection{Ankara Cyberpark}

Assim como o METUTECH (descrito no item 5.1.3.12), o Ankara Cyberpark está localizado na cidade de Ankara, capital da Turquia. O Ankara Cyberpark é um parque científico tecnológico estabelecido em parceria com a Universidade de Bilkent, uma universidade privada da Turquia, afiliada ao Grupo Bilkent, composto por várias empresas de software e de pesquisa e desenvolvimento. A Universidade Bilkent cedeu uma área de $558.000 \mathrm{~m}^{2}$ na área oeste de seu campus para o Ankara Cyberpark; a localização do parque é também próxima a duas outras Universidades, a METU e a Hacettepe ${ }^{207}$.

207 Tradução livre de informação disponivel no endereço eletrônico http://www.cyberpark.com.tr/eng/ default.asp?id=3 acesso em 05/03/2008. 
O parque foi fundado em 2001 e anunciado como zona de desenvolvimento tecnológico em 2002; está prevista no parque a construção de $200.000 \mathrm{~m}^{2}$ de área fechada para escritórios, indústrias e armazéns; até o momento foram construídos nove edifícios perfazendo uma área total fechada de $50.000 \mathrm{~m}^{2}$ com 162 empresas já instaladas (dados de 2006) ${ }^{208}$. A Figura 5.25 apresenta a localização esquemática do Ankara Cyberpark.

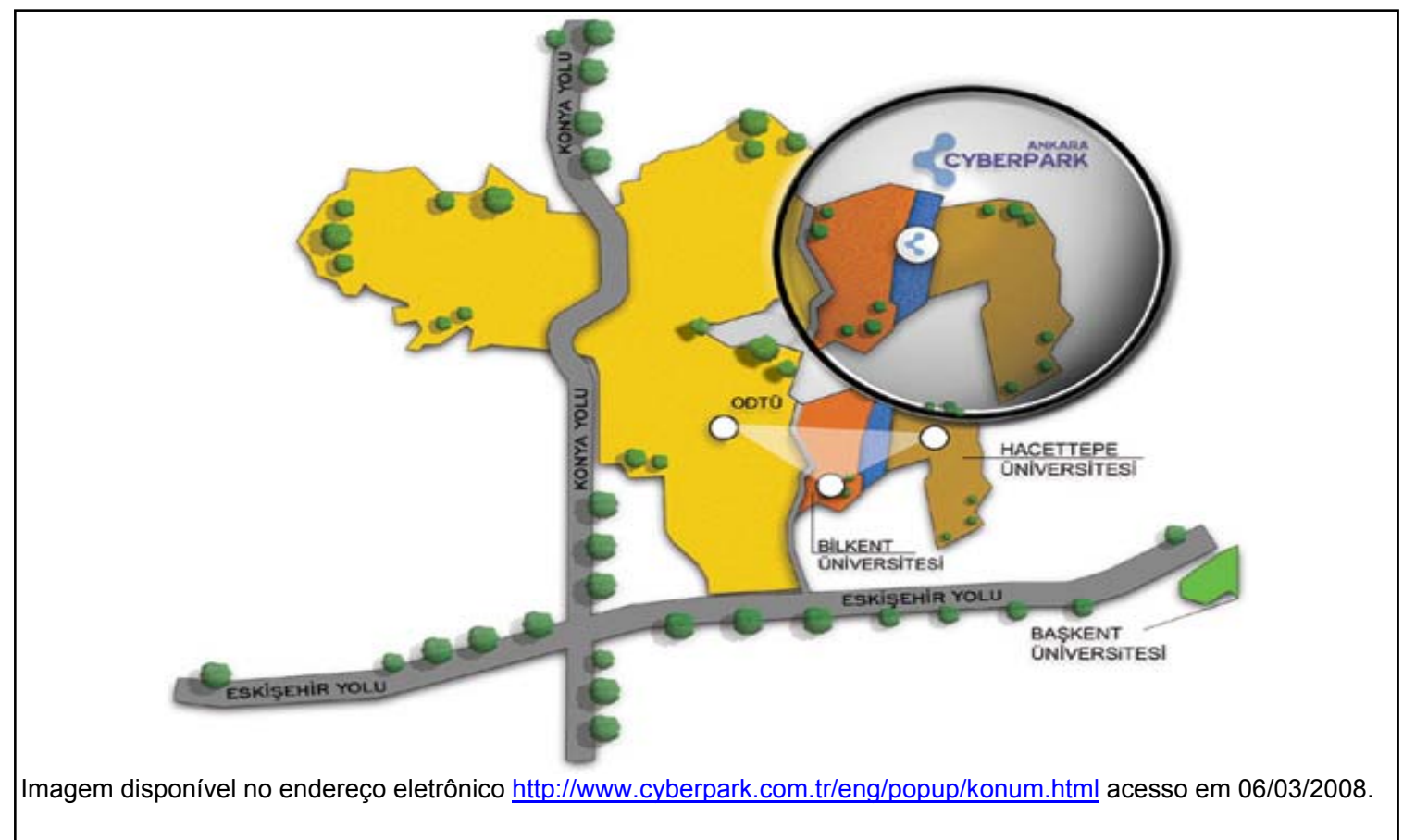

FIGURA 5.25 - Localização do Ankara Cyberpark

O Ankara Cyberpark disponibiliza às empresas espaço para se instalarem no parque; e oferece aos instalados serviços tais como: infraestrutura adequada; serviços de limpeza; segurança; manutenção, reparo e serviços de jardinagem; extintores de incêndio; serviços médicos; correio, seguros, aconselhamento e treinamento; serviços de informação e tecnologia; serviços financeiros; conferências, congressos e oportunidades de apresentação; agência de viagens, restaurantes, shopping centers, etc... ${ }^{209}$

O Ankara Cyberpark também oferece o seguinte: um Centro de Incubação, construído em parceria com a Turkish Technology Development Foundation

\footnotetext{
208 Tradução livre de informação disponível no endereço eletrônico http://www.cyberpark.com.tr/eng/default. asp? id=3 acesso em 05/03/2008.

${ }^{209}$ Tradução livre de informações disponíveis no endereço eletrônico http://www.cyberpark.com.tr/eng/default. asp?id=4 acesso em 08/03/2008.
} 
(TTGV), com a Small and Medium Industry Development Organization (SMIDO) e com a Universidade Bilkent; consultoria para acesso a recursos financeiros e bolsas; O EU Center, criado para prover aconselhamento e serviços de treinamento para pessoas ou PME que queiram desenvolver projetos capazes de obter suporte de programas da União Européia; consultoria para acesso a capital de risco; o Life-Long Education Center, que é uma área compartilhada dentro da Universidade Bilkent que provê serviços educacionais especialmente na área de Tecnologia da Informação, para novos graduados, adultos e membros do Cyberpark; e a Sala de Exibições e Congressos, que é uma área compartilhada composta por diversas salas de reuniões e de exibição de tamanhos variados e um Centro de Conferência com capacidade para 100 pessoas $^{210}$. A Figura 5.26 apresenta algumas edificações do Ankara Cyberpark.

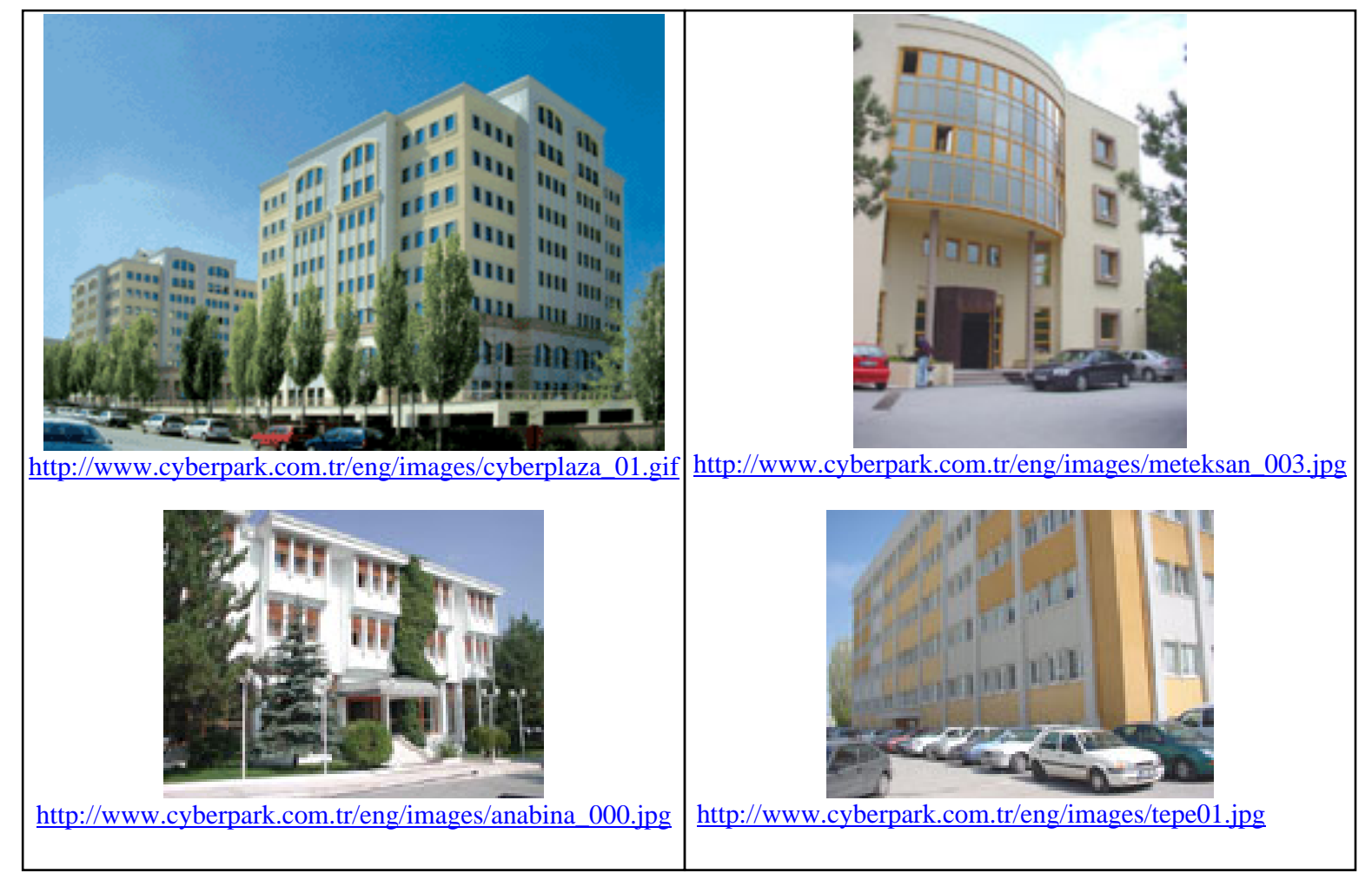

FIGURA 5.26 - Alguns edifícios do Ankara Cyberpark

\subsubsection{O Surrey Research Park}

O Surrey Research Park está localizado no distrito de Guildford, capital (county town) do condado (shire county) de Surrey, Inglaterra. É também sede do

\footnotetext{
${ }^{210}$ Tradução livre de informações disponíveis no endereço eletrônico http://www.cyberpark.com.tr/eng/default. asp?id=4 acesso em 08/03/2008.
} 
bairro (borough) de Guildford; e centro administrativo da região Sudoeste da Inglaterra. O distrito está situado a cerca de $50 \mathrm{~km}$ de Londres e têm raízes saxônicas; a cidade cresceu em importância a partir de 978 quando foi sede da casa da moeda (Royal Mint); e prosperou também à partir da construção da Wey Navigation and Basingstoke Canal Guildford, centro da rede fluvial da região ${ }^{211}$.

Guildford é uma cidade de cerca de 67.000 habitantes de bom desempenho comercial; em 2006, na lista anual do periódico Financial Times teve quatro empresas do distrito (Vodafone, Mitsubishi, Electronic Arts e Colgate-Palmolive) citadas entre as 500 maiores empresas globais (Top 500 Global Companies); outras empresas de destaque em Guildford são: a empresa de jogos Lionhead Studios, a Surrey Satellite, a Dennis Specialist Vehicules (fabricante de ônibus e carros de bombeiros) e a Automotive Technik (construtor de veículos militares) ${ }^{212}$.

Desenvolvido pela Universidade de Surrey (UniS) em uma área de 283.300 $\mathrm{m}^{2}$ próxima ao campi de Guildford, o Surrey Research Park foi fundado em março de 2000 e está localizado na região Sudeste do Reino Unido e oferece espaços e ambiente de trabalho propício ao desenvolvimento de pesquisa e desenvolvimento tecnológico em diversas áreas, contando atualmente com cerca de 110 empresas instaladas $^{213}$. A Figura 5.27 apresenta a localização esquemática da cidade de Guildford como elemento do condado de Surrey. A Figura 5.28 mostra a localização esquemática do Surrey Research Park no distrito de Guildford.

\footnotetext{
211 Tradução livre de informações disponíveis no endereço eletrônico http://en.wikipedia.org/wiki/Guildford. Acesso em 10/03/2008.

${ }^{212}$ Tradução livre de informações disponíveis no endereço eletrônico http://en.wikipedia.org/wiki/Guildford\#cite note-ft500-40. Acesso em 10/03/2008

${ }^{213}$ Tradução livre de informações disponíveis no endereço eletrônico http://www.surrey-research-park.com/ overview.php. Acesso em 10/03/2008.
} 


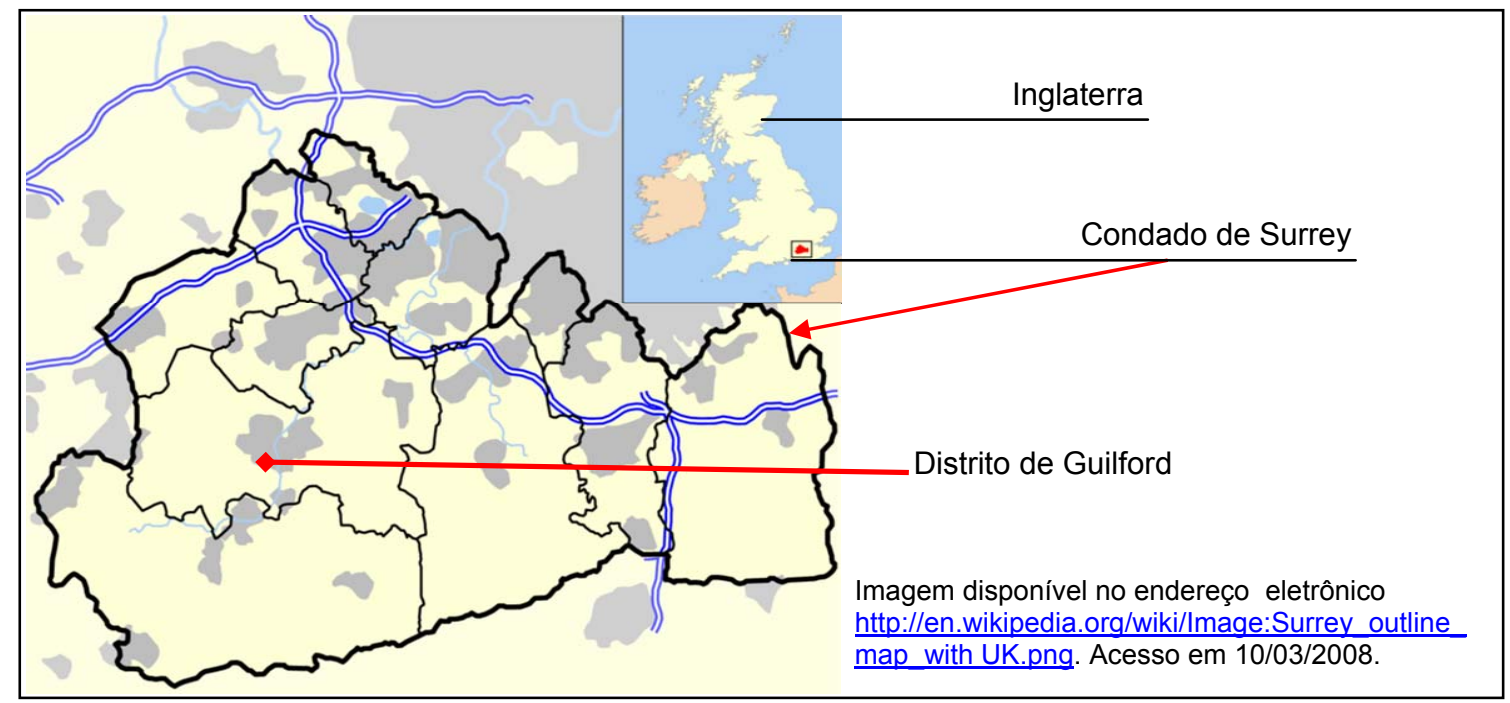

FIGURA 5.27 - Localização do distrito de Guildford no condado de Surrey

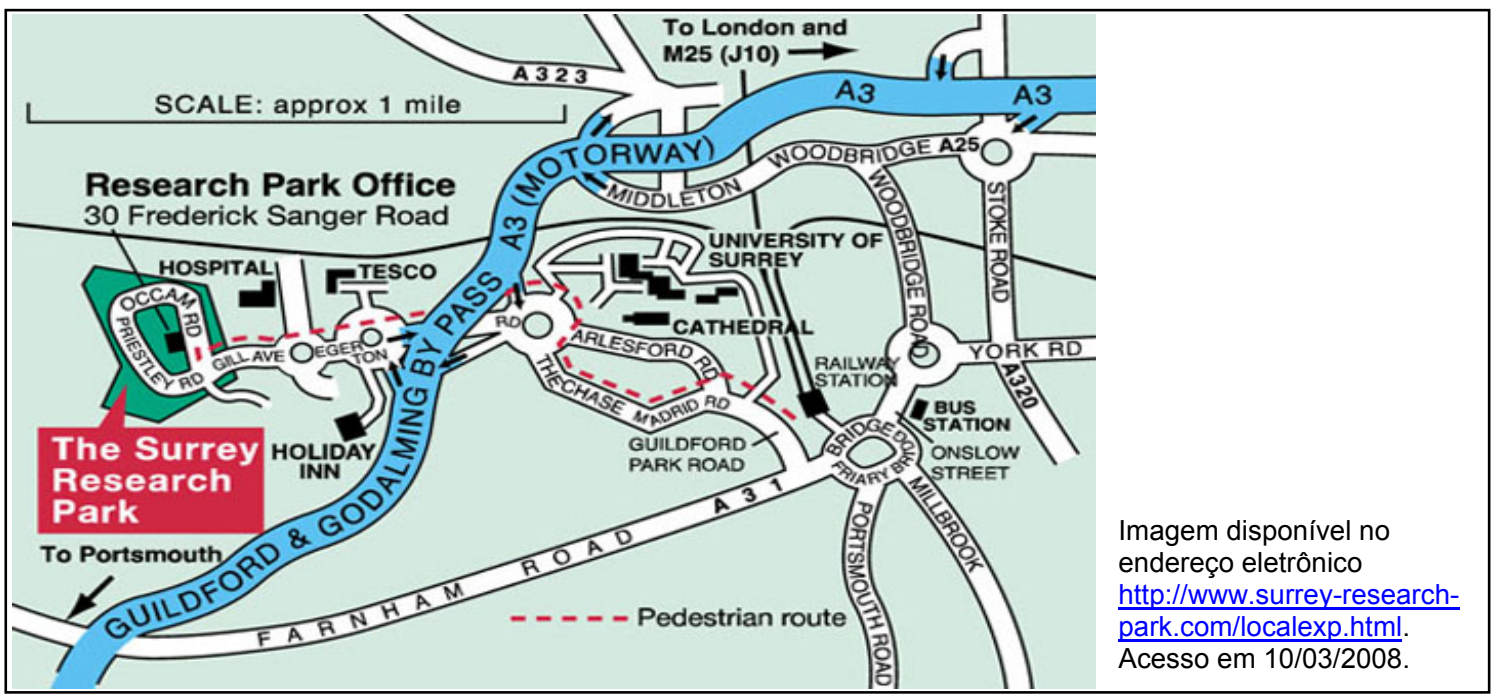

FIGURA 5.28 - Localização do Surrey Research Park

O Surrey Research Park está a 1,2 quilômetros do centro da cidade de Guilford, a principal linha de serviço ferroviário da cidade faz o trajeto de Guilford a Londres e aos terminais Eurostar para os diversos destinos do continente Europeu. A 35 minutos do parque estão os aeroportos de Heatrow e Gatwick; e a 800 metros do parque está a rodovia A3 que dá acesso às auto-estradas nacionais ${ }^{214}$.

\footnotetext{
${ }^{214}$ Tradução livre de informações disponíveis no endereço eletrônico http://www.surrey-research-park.com/ comms.html acesso em 10/03/2008.
} 
As empresas instaladas no parque atuam em diversos setores como: tecnologias da informação e comunicação, tecnologia telefônica móvel, desenvolvimento de software; biomedicina e biotecnologia. A equipe que administra o Surrey Research Park é composta por nove funcionários (dados de 2006), incluindo recepcionistas. Essa equipe é apoiada por um Grupo de Gestão e Administração do Parque que se reúne regularmente para aprovar investimentos e estratégias de desenvolvimento de longo prazo. A Figura 5.29 apresenta uma vista aérea do Surrey Research Park.

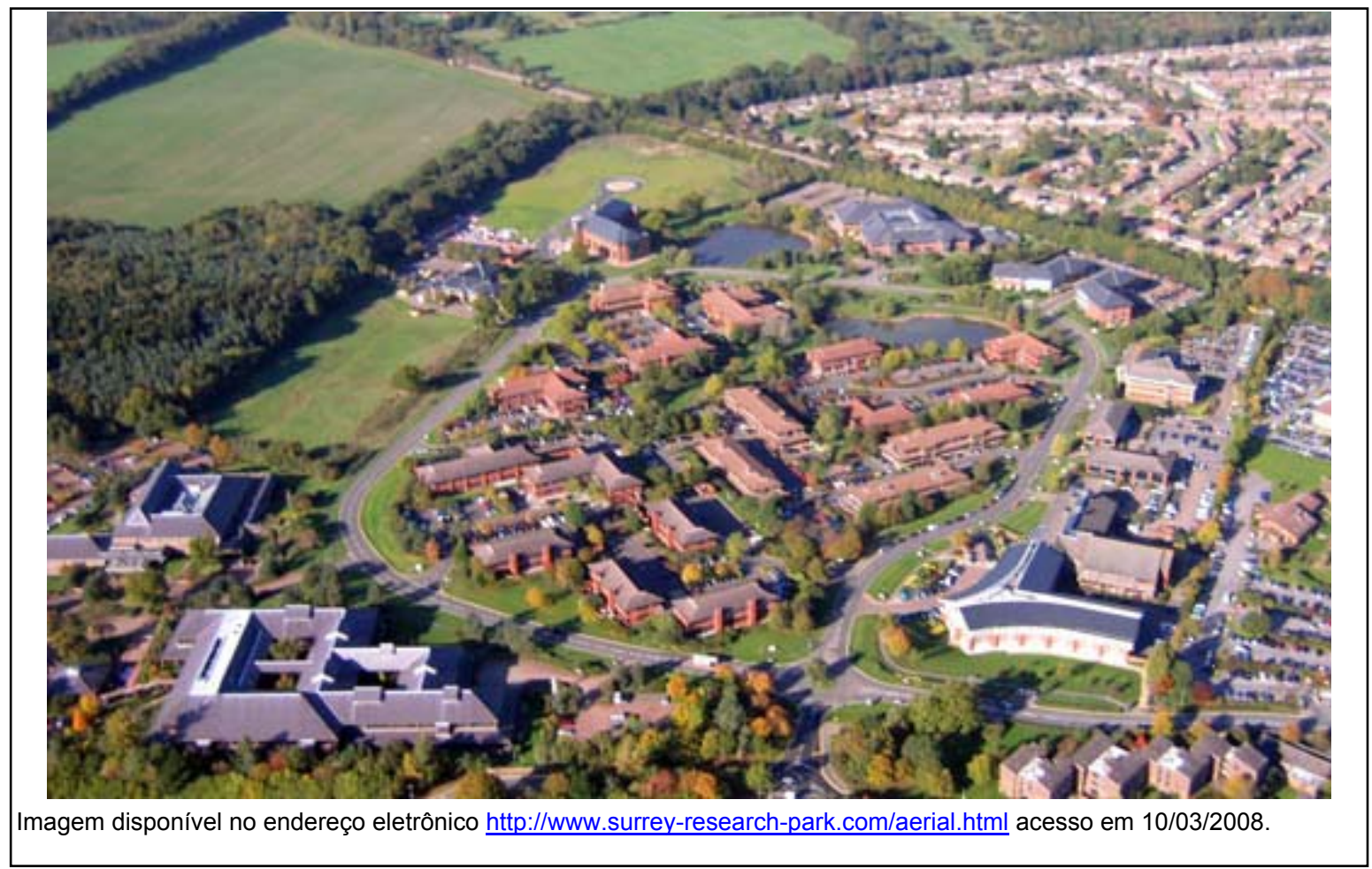

FIGURA 5.29 - Vista aérea do Surrey Research Park

Os serviços comuns oferecidos pelo parque são: segurança 24 horas; serviços de restauração em seu "café"; serviços de comunicação (fibra ótica e conexões fornecidos pelo NTL e pela BTea Cable \& Wireless) com conexão de alta velocidade; lojas de conveniência (Superstore Tesco a 500 metros do parque); hotel de negócios Forte Post House a cinco minutos de caminhada do parque; e serviços de liftshare (transporte compartilhado entre motoristas) ${ }^{215}$.

215 Tradução livre de informações disponíveis no endereço eletrônico http://www.surrey-research-park.com/ common.html acesso em 10/03/2008. 
O Surrey Research Park oferece às empresas interessadas em se instalar no parque espaços de tamanhos variados em seus edifícios por meio de aluguel; por exemplo, nos edifícios disponíveis atualmente (2008) as áreas variam de 320 $\mathrm{m}^{2}$ a $1020 \mathrm{~m}^{2216}$.

A UniS (Universidade de Surrey) também gere o Surrey Technology Centre que oferece espaço com infra-estrutura e serviços necessários para os interessados em estabelecer pequenas empresas de base tecnológica (pesquisa, desenvolvimento e design) em seu edifício; ao mesmo tempo oferece acesso aos diversos recursos disponíveis na Universidade. Os espaços oferecidos pelo Surrey Technology Centre variam de $19 \mathrm{~m}^{2}$ a $82 \mathrm{~m}^{2}$, localizados em dois andares do edifício que dispõe ainda de: uma área central para recepção, salas de reunião, um espaço para seminários e um restaurante bistrô. Uma área de estacionamento também é disponibilizada aos instalados ${ }^{217}$.

\subsubsection{Observações pessoais (resultados da interação com o pessoal dos parques visitados)}

Foram visitados quatro parques tecnológicos, três localizados na Itália (Centúria - RIT, Parco Tecnológico Padano e AREA Science Park) e um na Espanha (Parque Tecnológico de Andalucia).

\section{VISITA AO CENTURIA-RIT (Romagna Innovazione Tecnologia)}

Esta pesquisadora visitou o Centúria-RIT no dia 14/05/2007 no período da manhã. O Parque fica localizado na cidade de Cesena, na via Tortona; e ocupa um andar de um edifício comercial de três andares, numa região movimentada de indústrias e de serviços do setor agro-alimentar. No entorno há muitos galpões industriais de armazenamento e distribuição, frigoríficos, depósitos de frutas, etc... $\mathrm{Na}$ esquina da rua onde fica o parque há uma empresa de logística; bem próximo há um grande parque de exposições e eventos com um hotel ao lado.

Há muita circulação de caminhões, oficinas de serviços para conserto de máquinas e veículos. Atrás do parque há um galpão oficina para serviços de

\footnotetext{
${ }^{216}$ Tradução livre de informações disponíveis no endereço eletrônico http://www.surrey-research-park.com/

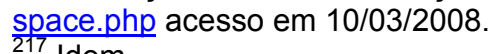

${ }^{17}$ Idem.
} 
recauchutagem de pneus de caminhão. Enfim, as cercanias e o entorno estão relacionadas à cadeia de produtos e serviços do setor agro-industrial.

O Dr. Alessandro Zampagna, Diretor do Centuria-RIT, mostrou o parque e apresentou o Dr. Francesco Beccari, responsável pelos serviços de Transferência de Tecnologia. As instalações do parque são compostas de escritórios e salas de reunião bem equipadas e organizadas, nas paredes dos corredores há cartazes chamativos com fotos e textos relacionados às atividades realizadas pelo Centúria-RIT aos seus clientes associados.

Numa das salas de reunião o Dr. Francesco Beccari entregou material impresso, um CD-ROM com duas apresentações e por duas horas conversou com esta pesquisadora sobre o Centuria-RIT e suas atividades.

Em 1984, os industriais do setor agro-industrial e os representantes de cooperativas solicitaram à municipalidade de Cesena a busca e criação de uma organização, um consórcio de companhias, que pudesse atender as necessidades dos associados. Daí a idealização do parque para o atendimento dessa demanda específica.

O Centuria-RIT possui dois endereços, um em Cesena ${ }^{218}$, e outro em Faenza ${ }^{219}$, em agosto de 2007 o endereço de Cesena mudou, ficando mais próximos da estação ferroviária que é um local mais central da cidade ${ }^{220}$. A Centuria-RIT atua na parte leste da região da Emilia Romanha (vide na Figura 5.2); atendida por três aeroportos num raio de 80 quilômetros, um porto e as três estradas principais. A Figura 5.30 apresenta a região de atuação do Centúria-RIT.

\footnotetext{
${ }^{218}$ Cesena é uma comuna italiana da região da Emília-Romanha, província de Forlì-Cesena.

${ }^{219}$ Faenza é uma comuna italiana da região da Emília-Romanha, província de Ravenna.

220 Desde agosto de 2007 a unidade do Centúria-RIT em Cesena foi transferida para: Via dell'Arrigoni, n.60 frazione Case Gentile.
} 


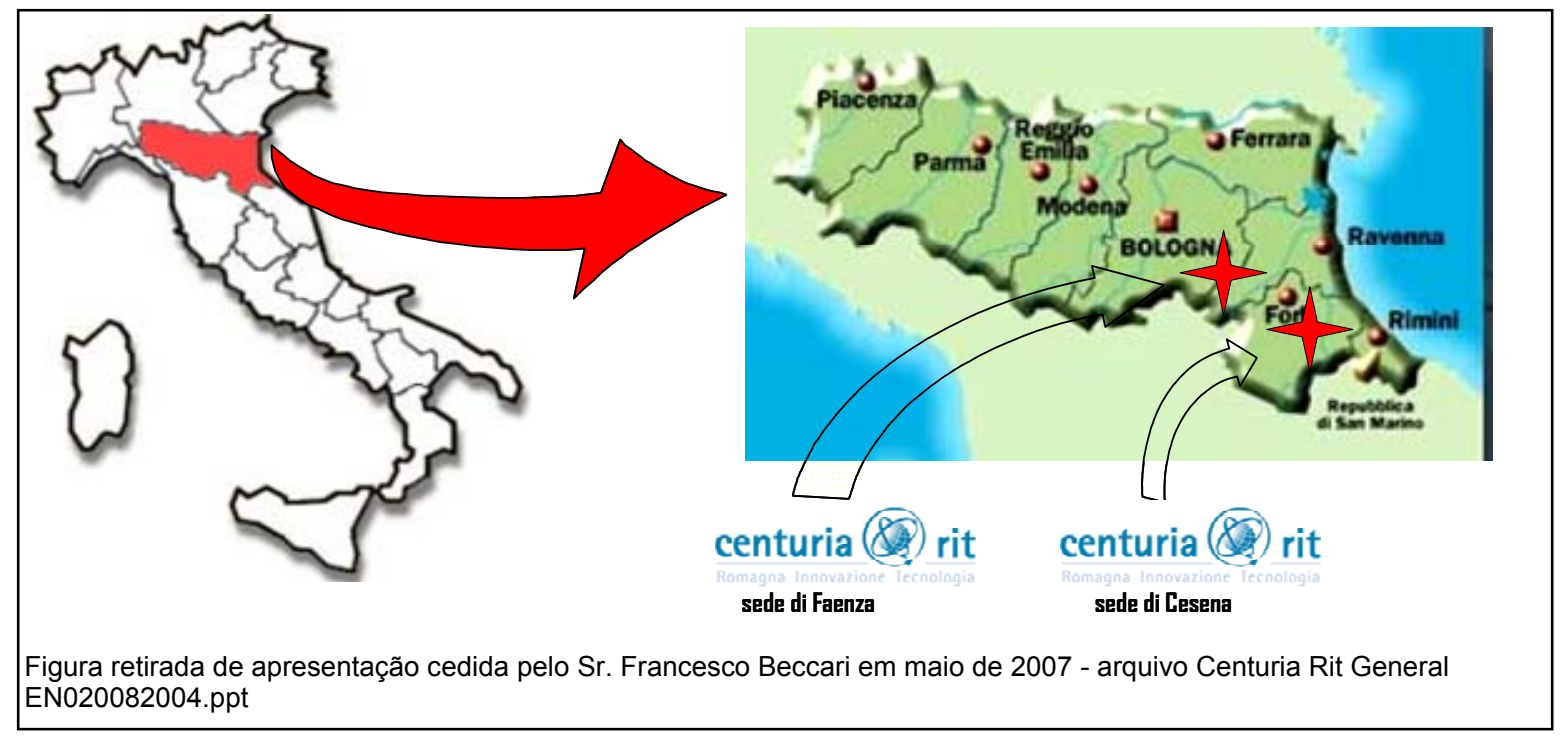

FIGURA 5.30 - Região de atuação do Centúria-RIT

A região atendida pelo parque contém infra-estruturas de inovação ${ }^{221}$, tais como: Universidade de Bolonha ${ }^{222}$ (Polo di Cesena e Polo di Forli), centro de pesquisa ENEA (Ente per Le Nuove Tecnologie, I'Energia e l'Ambiente) da região da Emilia Romanha; CRPA (Centro Ricerche Produzioni Animal), PRINT ${ }^{223}$ (Per una Rinnovata cultura di Impresa Nel Territorio regionale), etc...

O Centuria-RIT executa uma série de atividades a fim de promover a inovação e o desenvolvimento regional, apoiando a competitividade dos seus clientes associados e parceiros. O parque oferece serviços de inovação para todos os associados do parque e aconselhamento especializado para empresas e instituições.

\footnotetext{
221 Informações obtidas a partir do portal de informação ERMES Regione Emilia - Romagna endereço eletrônico http://www.regione.emilia-romagna.it/wcm/ERMES/notizie/news/2007/dic/rete alta tecnologia .htm. Acesso em 23/02/2008.

${ }^{222}$ A universidade de Bologna possui quatro campi: na comuna de Bologna (Universitá di Bologna), de Forli (Universitá di Bologna - Polo Scientifico-Didattico di Forli), de Ravenna (Universitá di Bologna - Polo Scientifico-Didattico di Ravenna), de Rimini (Universitá di Bologna - Polo Scientifico-Didattico di Riminii) e de Cesena (Universitá di Bologna - Polo Scientifico-Didattico di Cesena). Informações disponíveis no endereço eletrônico http://www.unibo.it/Portale/Ateneo/Multicampus/default.htm. Acesso em 20/02/2008.

${ }^{223}$ O PRINT (Per una Rinnovata cultura di Impresa Nel Territorio regionale) é um projeto promovido pelos centros de pesquisa ENEA da Emilia Romanha em colaboração com a província de Bolonha, Projetti di Impresa da província de Bolonha e IPAB Fondazione Bertocchi. O PRINT tem o objetivo duplo de: fornecer às empresas do território romagnolo os instrumentos adequados para inovação de processos e produtos; e criar novas e concretas oportunidades profissionais para pesquisadores, estudantes, doutorandos do Centro ENEA e de outras estruturas de pesquisa regional. Tradução livre de texto disponível no endereço eletrônico http://www.print.enea.it/index.asp?id=1. Acesso em 23/02/2008.
} 
Pode-se dizer que o Centuria-RIT oferece cinco tipos de serviços aos seus clientes: (1) informação \& processamento de dados (Data Mining) e estudos especializados; (2) financiamento de projetos; (3) transferência de tecnologia; (4) desenvolvimento de estratégia e de negócios; e (5) rede de relacionamentos (networking).

Algumas atividades regulares de rede de relacionamentos do Parque são: uma sessão de networking (anual) por cliente, como, por exemplo, uma visita ao cliente; e a edição e envio (bimestral) de um jornal (newsletter) contendo notícias sobre os clientes e parceiros do Centuria-RIT.

Com relação a atividades de prestação de serviços são realizados, por exemplo, pesquisas tecnológicas baseadas em palavras-chave de interesse dos seus clientes, como "mercado" ou "concorrência"; outra atividade é a transferência de tecnologia, tanto de tecnologia já existente no mercado como das desenvolvidas na Universidade ou Centros de Pesquisa; também se buscam oportunidades para obtenção de fundos públicos para projetos, nesse caso, quando e se o projeto for aprovado o Centúria-RIT receberá de $2 \%$ a $3 \%$ do valor obtido.

A circulação da informação interna, externa e dentro da rede é a principal preocupação do Centuria-RIT, para tanto o parque é membro da APSTI (Associazione Parchi Scientifici Technologici Italiani), IASP (International Association of Science Parks), IRC (Innovation Relay Center Network) e outras associações, consideradas partes fundamentais da rede, segundo o Dr. Beccari, fazer parte de uma rede é o fator mais importante para poder encontrar solução para seus clientes.

Atualmente o Centuria-RIT conta com nove profissionais, conforme apresentado na Tabela 5.14. 


\begin{tabular}{|c|c|c|}
\hline \multicolumn{3}{|c|}{ TABELA 5.14 - Quadro de Profissionais do Centúria-RIT ${ }^{224}$} \\
\hline Nome & Atividade / Descrição & Formação / Experiência profissional \\
\hline $\begin{array}{l}\text { Alessandro } \\
\text { Zampagna } \\
\text { (SEDE: } \\
\text { Cesena) }\end{array}$ & Diretor Geral & $\begin{array}{l}\text { Doutor e Mestre em Desenvolvimento Rural pela University } \\
\text { College Dublino, Irlanda } \\
\text { Bacharel em Ciências Agrárias pela Università degli Studi di } \\
\text { Bologna } \\
\text { Diretor Geral do Centúria-RIT desde 2003, Diretor da } \\
\text { Agência Pólo Cerâmico de Faenza desde 2006, } \\
\text { responsável do Projeto do Parque Científico Tecnológico de } \\
\text { tema agroindustrial "Centúria" (1995-2002), responsável do } \\
\text { serviço de planejamento, pesquisa e desenvolvimento da } \\
\text { Centrale Ortofrutticola di Cesena, Centro Servici Avanzati } \\
\text { per l'Agricoltura (1992-1995), serviço voluntário } \\
\text { internacional no Zaire como responsável técnico do setor } \\
\text { agrícola e de alfabetização em um projeto de } \\
\text { desenvolvimento rural com a organização não } \\
\text { governamental Cooperazione Internazionale. }\end{array}$ \\
\hline $\begin{array}{l}\text { Loretta } \\
\text { Antonioli } \\
\text { (SEDE: } \\
\text { Cesena) }\end{array}$ & $\begin{array}{l}\text { Responsável da administração: } \\
\text { gestão, contabilidade, compras } \\
\text { e controle da gestão contábil, } \\
\text { gestão de caixa, relação com o } \\
\text { banco, redação do balanço } \\
\text { social. Gestão operacional de } \\
\text { pessoal: práticas de } \\
\text { contratação, relação com } \\
\text { entidades competentes. } \\
\text { Responsável pela verificação } \\
\text { do Collegio Sindicale: gestão da } \\
\text { verificação trimestral e } \\
\text { assistência durante o Collegio. } \\
\text { Assistência à Direção: } \\
\text { assistência para a preparação } \\
\text { do Conselho de Administração } \\
\text { e da Assembléia de sócios. }\end{array}$ & $\begin{array}{l}\text { Técnica em Administração de Empresas pelo Istituto } \\
\text { Professionale Comercial di Cesena. } \\
\text { Outras experiências de formação e de atualização: } \\
\text { Participação em cursos e seminários - "Gestão de } \\
\text { Recursos Humanos", "Gestão de Empresas", "O Prêmio por } \\
\text { objetivo na indústria alimentar", "Arquivamento ótico de } \\
\text { documentação fiscal e contábil"; "Microsoft Access", Gestão } \\
\text { de Pessoal". } \\
\text { Experiência profissional: } \\
\text { Assistente Fiscal na empresa TEOREMA (Cesena, 2004), } \\
\text { Instrutora Administrativa na Comuna de Cesena } \\
\text { (2003,2004), Operadora técnica central ASL de Cesena } \\
\text { (1992-1998), Atividade comercial (1983-1986). }\end{array}$ \\
\hline $\begin{array}{l}\text { Francesco } \\
\text { Beccari } \\
\text { (SEDE: } \\
\text { Cesena) }\end{array}$ & $\begin{array}{l}\text { Responsável de Transferência } \\
\text { Tecnológica. } \\
\text { Serviço de monitoração, } \\
\text { inserção de oferta/demanda de } \\
\text { tecnologia em bancos de dados } \\
\text { especializados a favor dos } \\
\text { sócios e parceiros externos } \\
\text { para fins de transferência } \\
\text { tecnológica. Assistência } \\
\text { durante a fase de negociação e } \\
\text { transferência tecnológica. } \\
\text { Participação em jornadas de } \\
\text { transferência tecnológica por } \\
\text { conta das empresas } \\
\text { associadas. }\end{array}$ & $\begin{array}{l}\text { Bacharel em Ciência da Formação - especialista do } \\
\text { processo de formação pela Università degli Studi di } \\
\text { Bologna. } \\
\text { Outras experiências de formação e de atualização: } \\
\text { Participação em cursos e seminários: O prêmio por objetivo } \\
\text { na indústria alimentar, A inovação como elemento } \\
\text { estratégico para a competitividade de uma empresa, } \\
\text { Fundamentos em transferência tecnológica, Percurso } \\
\text { Formativo sobre a Inovação, Curso de formação sobre } \\
\text { "Marketing de serviço para a inovação" para operadores de } \\
\text { transferência tecnológica, Percurso Formativo sobre a } \\
\text { inovação, do CAD ao KAD, Curso de facilitadores da } \\
\text { Agenda } 21 \text {. }\end{array}$ \\
\hline
\end{tabular}

224 Informações do quadro disponíveis no endereço eletrônico http://www.centuriarit.com/centuria/ viewnode.do?pagine name=-3529329303360169978+organico acesso em 21/02/2008. 


\begin{tabular}{|c|c|c|}
\hline \multicolumn{3}{|c|}{ TABELA 5.14 Quadro de Profissionais do Centúria-RIT } \\
\hline Nome & Atividade / Descrição & Formação / Experiência profissional \\
\hline $\begin{array}{l}\text { Patrizia } \\
\text { Bernardelli } \\
\text { (SEDE: } \\
\text { Faenza) }\end{array}$ & $\begin{array}{l}\text { Responsável pelo Informativo } \\
\text { periódico (Newsletter) e de } \\
\text { Patentes (Brevetti) } \\
\text { Serviços de monitoramento de } \\
\text { patentes (monitoraggio } \\
\text { brevettuale) a favor dos sócios } \\
\text { e sujeitos externos; } \\
\text { monitoramento periódico em } \\
\text { bancos de dados internacionais } \\
\text { especializados com base em } \\
\text { palavras chaves e } \\
\text { monitoramento específico. } \\
\text { (monitoraggio periodico su } \\
\text { banche dati specializzate } \\
\text { internazionali sulla base di } \\
\text { parole chiave e monitoraggi } \\
\text { specifici). } \\
\text { Consultoria de base em matéria } \\
\text { de propriedade industrial. } \\
\text { Redação de Informativo } \\
\text { periódico de monitoramento } \\
\text { tecnológico sobre patentes } \\
\text { (Newsletter di Monitoraggio } \\
\text { tecnologico-brevettuale) e } \\
\text { Newsletter News e } \\
\text { Approfondimenti. } \\
\text { Responsável pelo conteúdo do } \\
\text { sítio internet. }\end{array}$ & $\begin{array}{l}\text { Bacharel em Ciência Política Internacional pela Università } \\
\text { degli Studi di Bologna. } \\
\text { Outras experiências de formação e de atualização: } \\
\text { - Curso de Formação "Tutela Internacional da Propriedade } \\
\text { Intelectual"; "Método e Inovação", Percurso formativo sobre } \\
\text { a inovação", "Gerir a inovação para desenvolver o negócio", } \\
\text { Curso de formação "valorização do resultado da pesquisa", } \\
\text { Training day "Brevetti e Marchi" }\end{array}$ \\
\hline $\begin{array}{l}\text { Alessandra } \\
\text { Folli } \\
\text { (SEDE: } \\
\text { Cesena) }\end{array}$ & $\begin{array}{l}\text { Responsável de projeto área } \\
\text { (area Progetti). }\end{array}$ & $\begin{array}{l}\text { - Curso de especialização "Desenvolvimento rural e } \\
\text { cooperação internacional com os Países em vias de } \\
\text { desenvolvimento", Università degli Studi di Padova } 1995 . \\
\text { - Certificado de Estudo Superior "Economia rural e } \\
\text { agroalimentar" - ENSA Montpellier (Francia). } \\
\text { - Diploma de especialização "Marketing de produtos } \\
\text { agroalimentares" - IAM - CIHEAM Saragozza (Spagna). } \\
\text { - Bacharel em Ciências Agrárias pela Università degli Studi } \\
\text { di Bologna. } \\
\text { Experiência Profissional: } \\
\text { 2000-2003 - Responsável de Área de Pesquisa da SG } \\
\text { Consulting, empresa de consultoria em marketing } \\
\text { agroalimentar de Bolonha. } \\
\text { 1998-2003 - Consultora por diversas organizações em } \\
\text { matéria de planejamento e Project Management em } \\
\text { programas de financiamento comunitário/nacional/regional. } \\
\text { 1997 - Responsável do Serviço de Planejamento, Pesquisa } \\
\text { e Desenvolvimento da Centrale Ortofrutticola de Cesena, } \\
\text { Centro de Serviço Avançado pela Agricultura. } \\
\text { 1995-1996 - Responsável pelo Centro de Documentação } \\
\text { Agricultura Sustentável do Observatório Agroambiental de } \\
\text { Cesena. }\end{array}$ \\
\hline
\end{tabular}




\begin{tabular}{|c|c|c|}
\hline \multicolumn{3}{|c|}{ TABELA 5.14 Quadro de Profissionais do Centúria-RIT } \\
\hline Nome & Atividade / Descrição & Formação / Experiência profissional \\
\hline $\begin{array}{l}\text { Elena Lotti } \\
\text { (SEDE: } \\
\text { Cesena) }\end{array}$ & $\begin{array}{l}\text { Project Manager Junior } \\
\text { (Progetti area) } \\
\text { Elaboração e gestão de projeto; } \\
\text { identificação e contato de } \\
\text { parceiros; busca de } \\
\text { financiamento; suporte a fase } \\
\text { de identificação e contato de } \\
\text { parceiros; suporte } \\
\text { organizacional para as açães a } \\
\text { organizar (encontros públicos, } \\
\text { eventos). } \\
\text { Colaboração com a província } \\
\text { de Forlì-Cesena - Assessorato } \\
\text { dell'Agricoltura e Spazio Rurale } \\
\text { - para suportar a gestão do } \\
\text { projeto ADRIAFOOD QUALITY } \\
\text { - Promoção de um espaço } \\
\text { inter-Adriatico para a produção } \\
\text { horti-frutícola e zootécnica de } \\
\text { qualidade. }\end{array}$ & $\begin{array}{l}\text { - Diploma de Mestre Universitário de } 2^{\circ} \text { nível em } \\
\text { "Planejamento por Acesso aos Fundos Europeus" pela } \\
\text { Università degli Studi di Perugia } \\
\text { - Bacharel em Ciência Política Internacional pela Università } \\
\text { degli Studi di Bologna. } \\
\text { Outras experiências de formação e de atualização: } \\
\text { - "Método de Inovação" - Treinamento (percorso formativo) } \\
\text { sobre sistema de pesquisa, promoção e gestão de idéias } \\
\text { inovadoras em empresas. } \\
\text { - "A Internacionalização do Mercado" - Curso de formação } \\
\text { no âmbito do projeto Parabola della Provincia di Forli- } \\
\text { Cesena em colaboração com a Techné soc. cons. a r.l. } \\
\text { - "Criação, gestão, valorização e avaliação dos Programas } \\
\text { de Cooperação Internacional" pela Scuola di } \\
\text { Specializzazione CESTAS - Centro di Educazione Sanitaria } \\
\text { e Tecnologie Appropriate Sanitarie. } \\
\text { - "Gestão da Organização não Governamental" Curso } \\
\text { universitário, curso de Bacharel em Economia da Empresa } \\
\text { Cooperativa e de Organização sem fins lucrativos pela } \\
\text { Università di Bologna. } \\
\text { - "Curso Multidisciplinar de Educação para o } \\
\text { Desenvolvimento", curso promovido pela Università di } \\
\text { Bologna em colaboração com o comitê italiano da UNICEF, } \\
\text { na provincia de Forlì-Cesena. }\end{array}$ \\
\hline $\begin{array}{l}\text { Dario } \\
\text { Monti } \\
\text { (SEDE: } \\
\text { Faenza) }\end{array}$ & $\begin{array}{l}\text { Responsável para novos } \\
\text { empreendedores } \\
\text { (neoimpreditoria) e capital } \\
\text { semente. } \\
\text { - Consultoria especializada a } \\
\text { grupos com idéias inovadoras e } \\
\text { empreendedoras (pesquisa de } \\
\text { mercado, redação de plano de } \\
\text { negócios, suporte ao } \\
\text { planejamento econômico } \\
\text { financeiro). } \\
\text { - Pesquisa sobre a } \\
\text { possibilidade de parceria sobre } \\
\text { o plano tecnológico e comercial } \\
\text { (networking tecnológico e } \\
\text { comercial). } \\
\text { - Assistência para o } \\
\text { desenvolvimento de start-up } \\
\text { inovadoras. } \\
\text { Responsável da qualidade } \\
\text { empresarial: } \\
\text { - Verifica a correspondência da } \\
\text { documentação do Sistema da } \\
\text { de Gestão da Qualidade aos } \\
\text { princípios da norma UNI EN } \\
\text { ISO 9001:2000. } \\
\text { - Condução da verificação de } \\
\text { Inspeção Interna. }\end{array}$ & $\begin{array}{l}\text { Bacharel em Economia e Comércio pela Università degli } \\
\text { Studi di Bologna. } \\
\text { Outras experiências de formação e de atualização: } \\
\text { - Curso "Técnico de redação de Plano de Negócios". } \\
\text { - Curso de formação "Sistema de Gestão para a Qualidade" } \\
\text { - "Método e Inovação" - Treinamento (Percorso formativo) } \\
\text { sobre sistema de pesquisa, promoção e gestão de idéias } \\
\text { inovadoras. } \\
\text { - "Percorso Formativo sull'Innovazione" - Ciclo integrado de } \\
\text { seminário de aprofundamento sobre o tema da inovação } \\
\text { empresarial. } \\
\text { - "Gerir a inovação para o desenvolvimento do negócio", } \\
\text { curso compreendido no âmbito do projeto "Competência } \\
\text { para competir" da Confindustria Forli-Cesena, modulo } \\
\text { didático dedicado à gestão das diversas tipologias de } \\
\text { inovação (estratégica, do produto, do processo, tecnológica } \\
\text { e organizativa). } \\
\text { - Curós "A gestão do aspecto financeiro da inovação", } \\
\text { curso" Strumenti di finanza innovativa" organizado pelo IPI } \\
\text { - Istituto per la Promozione Industriale. } \\
\text { - Atividades de formação junto à Cofimp Bologna sobre as } \\
\text { temáticas do project management e planejamento de } \\
\text { negócios } \\
\text { Experiência professional: } \\
\text { 2001 - 2002: responsável do projeto CREA - creazione } \\
\text { imprenditorialità high-tech junto à Agenzia Polo Ceramico } \\
\text { (coordenação e gestão do projeto; apoio na elaboração do }\end{array}$ \\
\hline
\end{tabular}




\begin{tabular}{|c|c|c|}
\hline \multicolumn{3}{|c|}{ Tabela 5.14 Quadro de Profissionais do Centúria-RIT } \\
\hline Nome & Atividade / Descrição & Formação / Experiência profissional \\
\hline & $\begin{array}{l}\text { - Gestão da não conformidade, } \\
\text { da ação corretiva, preventiva e } \\
\text { da melhoria. } \\
\text { - Suporte às diversas áreas } \\
\text { das empresas na atividade de } \\
\text { monitoramento da satisfação do } \\
\text { Cliente e das prestações de } \\
\text { processo da empresa. } \\
\text { Responsável por eventos - } \\
\text { Coordenação de seminários. }\end{array}$ & $\begin{array}{l}\text { plano de negócios). } \\
2000 \text { - 2001: Operador junto à Spinner Point (Consorzio } \\
\text { Spinner) - atividade de pesquisa e especialização sobre o } \\
\text { tema criação de empresa de base tecnológica e de } \\
\text { transferência de tecnologia. }\end{array}$ \\
\hline $\begin{array}{l}\text { Chiara Pari } \\
\text { (SEDE: } \\
\text { Cesena) }\end{array}$ & $\begin{array}{l}\text { Colaboração com a província } \\
\text { de Forli-Cesena, Assessoria à } \\
\text { Agricoltura e Spazio Rurale, } \\
\text { para o projeto BETTER (Biofuel } \\
\text { chain enhancement for } \\
\text { territorial development of } \\
\text { European Regions). } \\
\text { Suporte a área de projetos - } \\
\text { Project Manager Junior. } \\
\text { Elaboração e gestão de } \\
\text { projetos; contato com os } \\
\text { parceiros; suporte } \\
\text { organizacional para as ações a } \\
\text { realizar (encontros públicos, } \\
\text { eventos); tradução de } \\
\text { documentos e cartas em língua } \\
\text { inglesa. Gestão do sítio internet } \\
\text { do projeto BETTER. }\end{array}$ & $\begin{array}{l}\text { Bacharelado em Literatura e Língua Estrangeira pela } \\
\text { Università degli Studi di Bologna. } \\
\text { Outras experiências de formação e de atualização: } \\
\text { - "A inovação como elemento estratégico para a } \\
\text { competitividade de uma empresa"- percorso formativo }\end{array}$ \\
\hline $\begin{array}{l}\text { Francesca } \\
\text { Silvera } \\
\text { (SEDE: } \\
\text { Cesena) }\end{array}$ & $\begin{array}{l}\text { Responsável de Projetos de } \\
\text { Empresas e Project Manager } \\
\text { Senior, com atividade de } \\
\text { planejamento, elaboração e } \\
\text { gestão de projetos e } \\
\text { comercialização. }\end{array}$ & $\begin{array}{l}\text { Formação: } \\
\text { - Mestrado em “Indústria Agro-alimentar e gestão da } \\
\text { Produção" pela Ecole Nationale Superieure en Agronomie } \\
\text { Montpellier (França); } \\
\text { Habilitação profissional de Tecnólogo Alimentar } \\
\text { Bacharelado em Ciência e Tecnologia Alimentar pela } \\
\text { Università degli Studi di Udine } \\
\text { Experiência professional: } \\
\text { Responsável de Transferência de Tecnologia e de } \\
\text { Inovação do Consórcio InAgro (2001), Docente de Gestão } \\
\text { de Projetos, Levantamento de Fundos, Marketing } \\
\text { Alimentar, Marketing da Inovação, Educação Alimentar, } \\
\text { Higiene e Mercadologia do Alimento em curso de formação. }\end{array}$ \\
\hline
\end{tabular}

O Centuria-RIT sobrevive com recursos públicos e privados; $60 \%$ advindos do pagamento de taxas pelos clientes associados e $40 \%$ advindos de instituições públicas. 


\section{Visita ao AREA Science Park}

A visita ao AREA Science Park foi realizada dia 15 de maio de 2007 no período da manhã.

O campus visitado foi o de Padriciano, no entanto o trajeto de ônibus do centro para o parque, tanto na ida quanto no retorno, passa defronte ao campus de Bazovizza, evidenciando a proximidade e facilidade de acesso.

A parada do ônibus circular no parque AREA é dentro do campus, há inclusive uma máquina automática para a venda de bilhetes junto ao ponto de ônibus. O trajeto do ponto aos prédios varia, mas pode ser feito a pé.

Os estacionamentos são amplos. Há áreas para estacionamento de visitantes e, próximo aos prédios, áreas de estacionamento para pessoas que trabalham no parque. Dentro do campus e próximo ao prédio da administração do parque há uma creche que atende os filhos daqueles que trabalham no parque.

A Dra. Laura Citossi, responsável de Marketing e Relações Internacionais, forneceu material impresso sobre o parque, especificamente uma apresentação feita pelo Dr. Gabrielle Gatti.

\section{Visita ao Parco Tecnológico Padano - PTP}

A visita ao Parco Tecnológico Padano foi realizada dia 17 de maio de 2007 no período da manhã.

O acesso ao parque pode ser feito de ônibus circular, táxi ou veículo próprio. Há um acordo entre o parque e os taxistas para que o valor cobrado para o trajeto da estação ferroviária de Lodi e imediações até o PTP seja de oito euros.

O Dr. Davide Ederle responsável de Transferência de Tecnologia foi quem apresentou o parque, em especial o prédio onde fica a administração.

O prédio onde fica a administração do PTP é o mesmo que abriga a instalação "Empreendedores de pesquisa em Agro-biotecnologia". Todos os locais são bem sinalizados por placas indicadoras e o acesso aos departamentos e áreas é controlado por cartão de acesso.

A recepção do prédio fica logo na entrada e nenhuma pessoa é autorizada a entrar sem a devida identificação. No andar térreo fica a sala de conferência, a cafeteria e áreas de descanso. O acesso aos andares superiores é feito por 
elevador e a entrada em qualquer área só é permitida por meio de cartão de acesso.

Há um laboratório de análise no andar térreo onde além das pesquisas são prestados serviços de análise para clientes sob demanda. Os recursos financeiros para manutenção do parque são advindos de receita de prestação de serviços do próprio PTP.

\section{Visita ao Parque Tecnológico de Andalucia - PTA}

O Parque Tecnológico de Andalucia foi visitado no dia 18/05/2007. O acesso ao parque pode ser feito facilmente por transporte público (ônibus); há várias linhas de ônibus intermunicipais com destino ao Parque e imediações.

$\mathrm{Na}$ data da visita uma manifestação ocorrida a poucos quilômetros do parque atrasou a chegada ao local no horário previsto e impossibilitou o encontro que estava marcado para o período da manhã, com a Sra. Sonia Palomo das Neves, responsável de Transferência de Tecnologia do PTA. Segundo a recepcionista do PTA, naquele dia da semana, sexta-feira, os funcionários são dispensados após o meio dia e o parque permanece fechado para visitação.

No entanto, foi possível observar alguns elementos da estrutura do parque e do seu entorno, toda a área e cercanias é muito bem sinalizada, há duas paradas de ônibus circular quase em frente ao PTA, ao lado da entrada do PTA há dois hotéis, alguns restaurantes, um posto de combustível; e a auto-estrada que dá acesso ao aeroporto e ao centro da cidade de Málaga fica a cerca de mil metros do parque e nela se pode observar sinalizações para o PTA. 


\section{6 - ANÁLISE E DISCUSSÃO DOS RESULTADOS}

A análise dos resultados da pesquisa é apresentada em quatro partes, a saber:

6.1 Análise e discussão dos resultados das questões fechadas e abertas;

6.2 Análise e discussão dos resultados das observações in loco;

6.3 Identificação e análise das práticas de sucesso (Best practices ${ }^{1}$ );

6.4 A identificação dos fatores críticos de sucesso relacionados aos serviços do conhecimento.

A análise e discussão dos resultados da pesquisa trazem uma percepção desta pesquisadora quanto às dimensões e subdimensões analisadas, que contribuem para a elaboração dos elementos da proposta de modelo de serviços para PCT, objeto desta pesquisa.

As respostas das questões de abertura do questionário demonstraram que os PCT são provedores de serviços do conhecimento; e que $86 \%$ deles oferece esses serviços às PME diretamente pelo próprio parque e por meio de contratação de serviços de terceiros. Esse resultado é reforçado pela pesquisa recente da IASP que concluiu que a maioria dos PCT provê muitos de seus serviços utilizando terceiros, sendo que apenas $14 \%$ dos PCT provêem todos os serviços internamente 2 .

Sendo assim, a combinação prestação de serviços diretos e por meio de terceiros, parece ser a combinação ideal para prestação de serviços do conhecimento pelos PCT.

Quanto à análise e discussão dos resultados das questões fechadas e abertas, são apresentadas a seguir.

\footnotetext{
${ }^{1}$ Best Practices ou melhores práticas é a melhor maneira de executar um negócio, ou tudo que guiará a empresa para uma performance superior. Definição adotada por Rozenfeld,H. e Amaral, C.S.T. , no artigo "Um ambiente colaborativo de conhecimento aberto visando a criação de modelos de processos de desenvolvimento de produtos", disponível no endereço eletrônico http://www.isssbrasil.usp.br/pdfs2/gso 4.pdf Acesso 20/2/2009.

2 Informações contidas no s itens 10.2 "Provision of services in STPs" do relatório "Facts and Figures of Science and Technology Parks in the World", IASP General Survey, 2006-2007 disponível no endereço eletrônico http://www.rtp.org/files/iasp survey on stps.pdf. Acesso em 31/3/2008.
} 


\subsection{Análise e discussão dos resultados das questões fechadas e abertas}

$\mathrm{Na}$ Tabela 6.1, a análise e discussão dos resultados das questões fechadas e abertas são apresentadas por dimensão e subdimensão a que se relacionaram no contexto desta pesquisa. É importante frisar que na interpretação dos resultados das questões abertas foram considerados os percentuais dos PCT respondentes que, ao responderem as questões, concordaram totalmente com as proposições fornecidas no questionário. ${ }^{3}$

TABELA 6.1 - Análise e discussão dos resultados por dimensão/sub-dimensão da pesquisa

\begin{tabular}{|c|c|c|}
\hline Dimensão & Sub-dimensão & Interpretação \\
\hline $\begin{array}{l}\text { (1) } \\
\text { Serviços } \\
\text { do conheci- } \\
\text { mento }\end{array}$ & $\begin{array}{l}(1.1) \\
\text { Acesso ao } \\
\text { conhecimento }\end{array}$ & $\begin{array}{l}\text { Constatou-se que } 53 \% \text { dos PCT oferecem às PME serviços de apoio } \\
\text { relacionados a oportunidades de cooperação com outras } \\
\text { organizações nacionais e internacionais, resultado semelhante àquele } \\
\text { obtido no relatório recente da IASP; nele os serviços de Internal } \\
\text { Networking são oferecidos por } 64 \% \text { dos PCT e os serviços de External } \\
\text { Networking oferecidos por } 53 \% \text { dos PCT. }{ }^{4} \\
\text { Observa-se que os PCT oferecem serviços de acesso ao } \\
\text { conhecimento relacionados à globalização, variando a } \\
\text { ênfase/intensidade e a forma como ela é oferecida às PME. Nesse } \\
\text { sentido, se observa a preocupação dos PCT com o apoio e a } \\
\text { proposição de oportunidades de parcerias internacionais: } \\
\text { - No Brasil, o parque tecnológico de Campinas, por exemplo, tem } \\
\text { instalado no parque o Núcleo do Softex que apóia e atende essa entre } \\
\text { outras necessidades das empresas de software da região; o parque } \\
\text { da PUCRS atende as PME por meio da incubadora RAIAR, que apóia } \\
\text { a participação em programas específicos do SEBRAE, e da } \\
\text { Assessoria de Assuntos Internacionais e Interinstitucionais (AAII) da } \\
\text { PUCRS que viabiliza convênios internacionais com Universidades, } \\
\text { parques e outras organizações. } \\
\text { - Muitos parques Europeus e de outros países (dos Estados Unidos da } \\
\text { América, Chile, Islândia, Israel, Noruega, Suíça e Turquia) estão } \\
\text { ligados à rede de centros de inovação da Comunidade Européia (IRC } \\
\text { Network); dessa forma, eles apóiam as PME por meio dos IRC que } \\
\text { oferecem uma série de serviços tais como: contato com parceiros; } \\
\text { identificação tecnológica das necessidades dos parceiros; busca de } \\
\text { parceiros europeus; apoio no estabelecimento da parceria; e } \\
\text { assistência nas negociações do contrato de parceria }{ }^{5} \text {. }\end{array}$ \\
\hline
\end{tabular}

\footnotetext{
${ }^{3}$ Escala de Likert utilizada no questionário: $\mathrm{CT}=$ Concordo Totalmente, $\mathrm{CP}=$ Concordo Parcialmente, $\mathrm{N}=$ Neutro, DP = Discordo Parcialmente, DT = Discordo Totalmente.

${ }^{4}$ Informações contidas nos itens 10.2 "Provision of services in STPs" do relatório "Facts and Figures of Science and Technology Parks in the World", IASP General Survey, 2006-2007 disponível no endereço eletrônico http://www.rtp.org/files/iasp survey on stps.pdf. Acesso 31/3/2008.

${ }^{5}$ Tradução livre de informações disponíveis sobre serviços de suporte da rede de centros de inovação (IRC Support Services) no endereço eletrônico http://www.innovationrelay.net/ircnetwork/. Acesso em 25/03/2008.
} 
TABELA 6.1 - Análise e discussão dos resultados por dimensão/sub-dimensão da pesquisa

\begin{tabular}{|c|c|c|}
\hline Dimensão & Sub-dimensão & Interpretação \\
\hline $\begin{array}{l}(1) \\
\text { Serviços } \\
\text { do conheci- } \\
\text { mento }\end{array}$ & $\begin{array}{l}(1.1) \\
\text { Acesso ao } \\
\text { conhecimento }\end{array}$ & 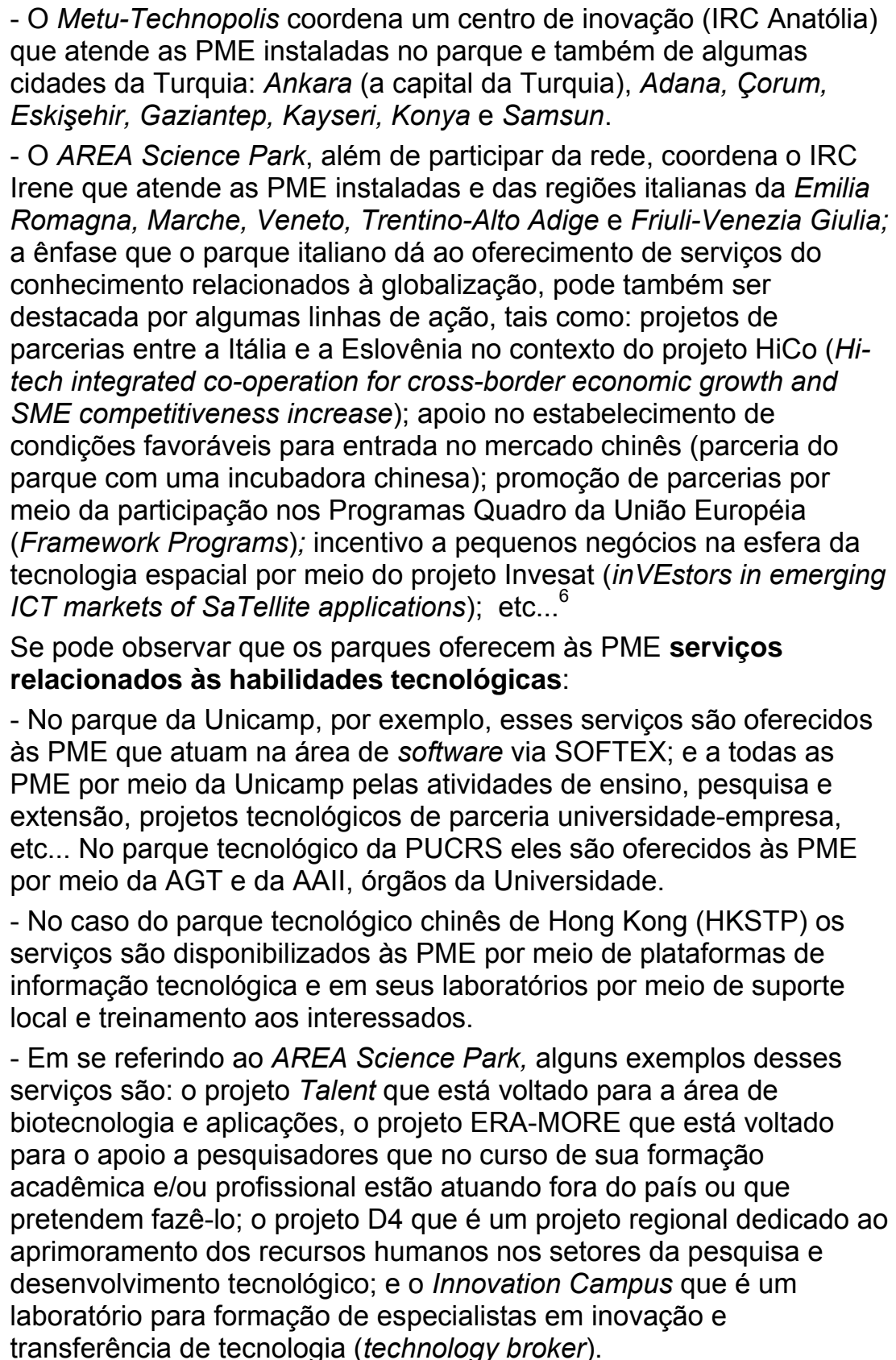 \\
\hline
\end{tabular}

6 Tradução livre de informações disponíveis no endereço eletrônico http://www.area.trieste.it/opencms/ opencms/area/en/attivita en/partenariati reti en/linee azione en.html. Acesso em 25/03/2008. 
TABELA 6.1 - Análise e discussão dos resultados por dimensão/sub-dimensão da pesquisa

\begin{tabular}{|c|c|c|}
\hline Dimensão & Sub-dimensão & Interpretação \\
\hline $\begin{array}{l}\text { (1) } \\
\text { Serviços } \\
\text { do conheci- } \\
\text { mento }\end{array}$ & $\begin{array}{l}(1.2) \\
\text { Compartilha- } \\
\text { mento de } \\
\text { conhecimento }\end{array}$ & 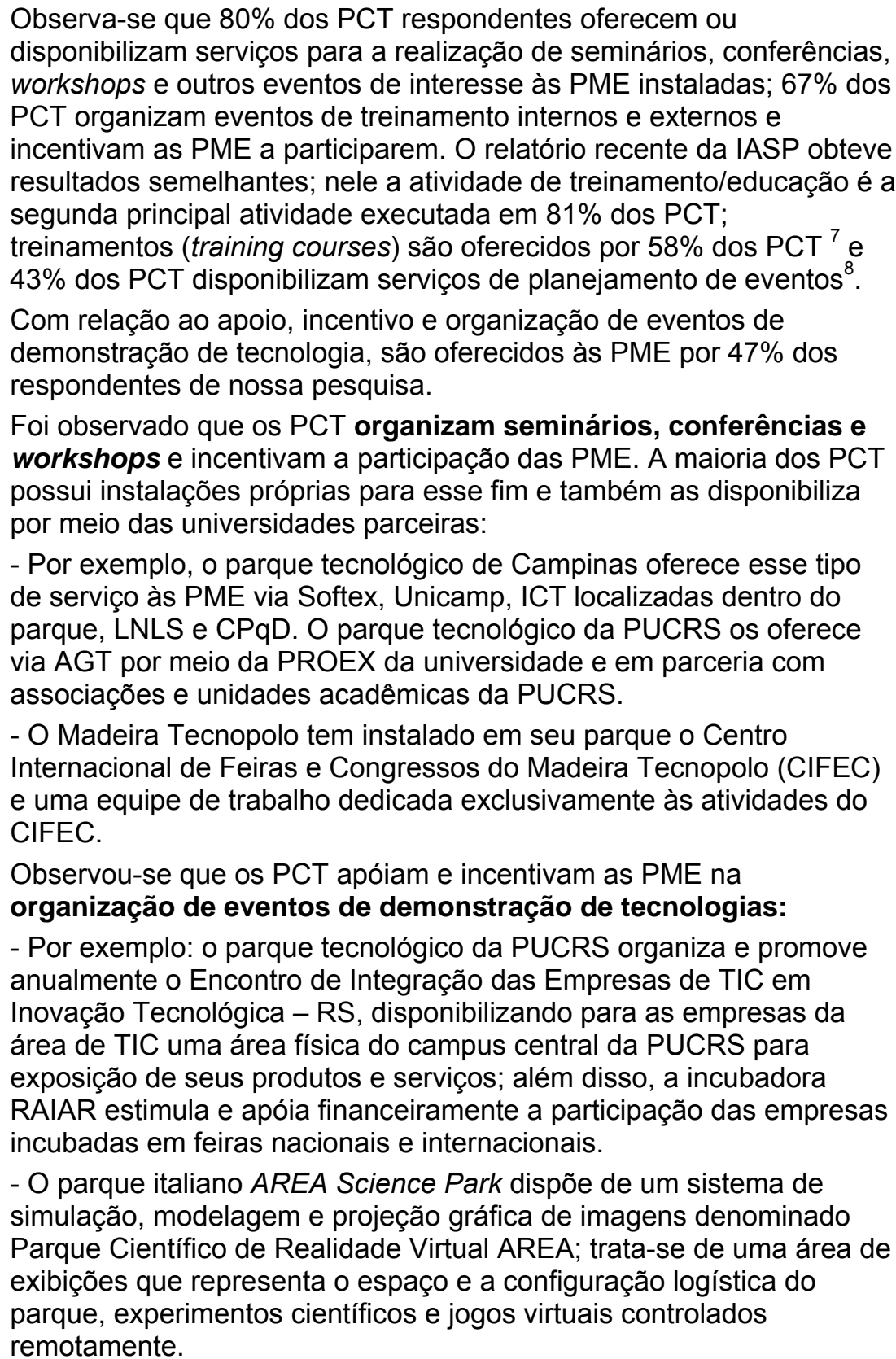 \\
\hline
\end{tabular}

\footnotetext{
7 Informações contidas no item 9.1 "Park activity" e 10.1 "Park Services" do relatório "Facts and Figures of Science and Technology Parks in the World", IASP General Survey, 2006-2007 disponível no endereço eletrônico http://www.rtp.org/files/iasp survey on stps.pdf. Acesso 31/3/2008.

${ }^{8}$ Idem.
} 


\begin{tabular}{|c|c|c|}
\hline \multicolumn{3}{|c|}{ TABELA 6.1 - Interpretação dos resultados por dimensão/sub-dimensão da pesquisa } \\
\hline Dimensão & Sub-dimensão & Interpretação \\
\hline $\begin{array}{l}\ldots(1) \\
\text { Serviços } \\
\text { do conheci- } \\
\text { mento }\end{array}$ & $\begin{array}{l}\text {...(1.2) } \\
\text { Compartilha- } \\
\text { mento de } \\
\text { conhecimento }\end{array}$ & $\begin{array}{l}\text { Os PCT apóiam, organizam e incentivam as PME a participarem de } \\
\text { treinamentos internos e externos: } \\
\text { - O parque italiano AREA Science Park oferece em seu Campus de } \\
\text { Inovação o treinamento vocacional para a formação de Especialista de } \\
\text { Transferência de Tecnologia e Inovação (technology broker). }\end{array}$ \\
\hline $\begin{array}{l}(1) \\
\text { Serviços } \\
\text { do conheci- } \\
\text { mento }\end{array}$ & $\begin{array}{l}(1.3) \\
\text { Propriedade } \\
\text { intelectual e } \\
\text { comercializa- } \\
\text { ção } \\
\text { tecnológica }\end{array}$ & $\begin{array}{l}\text { Quanto à propriedade intelectual, } 53 \% \text { dos PCT respondentes } \\
\text { disponibilizam serviços de consultoria em propriedade intelectual às } \\
\text { PME; ou por meios próprios, ou por meio das universidades ou por } \\
\text { outras instituições. } \\
\text { O relatório recente da IASP reforça esse resultado, a informação, nele } \\
\text { o serviço de consultoria de propriedade intelectual é oferecido por } \\
64 \% \text { dos PCT.9. } \\
\text { Quanto à utilização atual desses serviços pelas PME, apenas } 7 \% \text { dos } \\
\text { PCT indicam que as PMEs de fato utilizam tais serviços; infere-se } \\
\text { portanto uma necessidade dos PCT monitorarem a efetividade de } \\
\text { suas ações junto ao público alvo. } \\
67 \% \text { dos PCT oferecem às PME serviços de consultoria em } \\
\text { Transferência de Tecnologia por meios próprios ou por terceiros. } \\
\text { A efetividade do uso desses serviços pelas PME foi confirmada por } \\
14 \% \text { das PME, indicando esse ser também um serviço que merece } \\
\text { ser monitorado pelo parque. } \\
\text { Dos PCT respondentes, } 36 \% \text { oferecem às PME serviços de } \\
\text { consultoria em comercialização tecnológica por meios próprios ou } \\
\text { terceirizados. } \\
\text { Somente } 14 \% \text { dos PCT confirmam o uso efetivo desses serviços pelas } \\
\text { PME, sendo esse, portanto, mais um serviço que necessita um melhor } \\
\text { monitoramento por parte dos PCTs. } \\
\text { Os PCT oferecem às PME serviços de apoio a propriedade } \\
\text { intelectual; os meios para a prestação desse serviço podem ser: } \\
\text { Escritórios de Transferência de Tecnologia (ETT) das universidades; } \\
\text { escritórios de transferência de tecnologias particulares; advogados de } \\
\text { patentes atuando no parque; consultoria ad hoc com especialistas } \\
\text { legais externos; consulta a Innovation Relay Centre; e departamentos } \\
\text { dedicados à propriedade intelectual e patentes do próprio parque. Tais } \\
\text { meios podem ser disponibilizados em concomitância: } \\
\text { - O parque italiano AREA Science Park possui um centro de } \\
\text { informações PATLIB (Patent Library) que oferece às PME informações } \\
\text { sobre patentes e assistência em assuntos de propriedade intelectual, } \\
\text { a equipe que atua no centro é especializada no tema. } \\
\text { Os PCT oferecem às PME serviços de apoio na comercialização } \\
\text { tecnológica. Os servicos podem ser oferecidos pelos ETT ou AGT }\end{array}$ \\
\hline
\end{tabular}

\footnotetext{
${ }^{9}$ Informações contidas no item 9.1 "Park activity" e 10.1 "Park Services" do relatório "Facts and Figures of Science and Technology Parks in the World", IASP General Survey, 2006-2007 disponível no endereço eletrônico http://www.rtp.org/files/iasp survey on stps.pdf acesso 31/3/2008.
} 


\begin{tabular}{|c|c|c|}
\hline \multicolumn{3}{|c|}{ TABELA 6.1 - Interpretação dos resultados por dimensão/sub-dimensão da pesquisa } \\
\hline Dimensão & Sub-dimensão & Interpretação \\
\hline $\begin{array}{l}\text {...(1) } \\
\text { Serviços } \\
\text { do conheci- } \\
\text { mento }\end{array}$ & $\begin{array}{l}\text {...(1.3) } \\
\text { Propriedade } \\
\text { intelectual e } \\
\text { comercializa- } \\
\text { ção } \\
\text { tecnológica }\end{array}$ & $\begin{array}{l}\text { das universidades; pelo IRC ao que o parque está associado ou tem } \\
\text { instalado; e pelo parque (diretamente ou por contratação de terceiros) } \\
\text { para atendimento de demanda específica: } \\
\text { - No AREA Science Park esse tipo de serviço é disponibilizado pelo } \\
\text { projeto SISTER - Liason Office, criado para apoiar e valorizar os } \\
\text { resultados da pesquisa na região da Friuli Venezia Giulia. } \\
\text { Os serviços de transferência de tecnologia são oferecidos pelos } \\
\text { parques tecnológicos às PME por meio de: Escritório de transferência } \\
\text { de Tecnologia da universidade (exemplo: PUCRS); agência de } \\
\text { inovação da universidade (na Unicamp - somente para tecnologias } \\
\text { geradas por pesquisadores da universidade ou de suas empresas } \\
\text { incubadas); escritórios de licenciamento de tecnologia regionais; e por } \\
\text { meio dos IRC associado ou instalado no parque. }\end{array}$ \\
\hline $\begin{array}{l}(1) \\
\text { Serviços } \\
\text { do conheci- } \\
\text { mento }\end{array}$ & $\begin{array}{l}(1.4) \\
\text { Desenvolvi- } \\
\text { mento } \\
\text { tecnológico }\end{array}$ & $\begin{array}{l}\text { Em se tratando de serviços para desenvolvimento tecnológico, } 43 \% \\
\text { dos PCT acompanha o desenvolvimento das PME e busca atendê-las } \\
\text { inclusive em suas necessidades pontuais de serviços tecnológicos. } \\
64 \% \text { dos PCT respondentes oferecem às PME serviços de apoio ao } \\
\text { estabelecimento de parcerias tecnológicas, incentivando o } \\
\text { desenvolvimento conjunto de produtos e serviços tecnológicos. } \\
\text { A pesquisa recente da IASP reforça esse resultado, nela os serviços } \\
\text { de tenant development são oferecidos por } 53 \% \text { dos PCT e os serviços } \\
\text { de suporte a gestão (management support) por } 73 \% \text { dos PCT }{ }^{10} \text {. } \\
\text { Os PCT acompanham o desenvolvimento das PME nele instaladas: } \\
\text { - o parque tecnológico de Campinas o faz via Observatório Digital do } \\
\text { Programa Softex Nacional; no parque da PUCRS as PME instaladas } \\
\text { são acompanhadas pela gerência da incubadora RAIAR; no parque } \\
\text { tecnológico de Heidelberg essa atividade é realizada pelo Centro de } \\
\text { Inovação para PME que recebe } 50 \text { novas empresas ao ano. } \\
\text { Os PCT oferecem às PME serviços de apoio ao estabelecimento } \\
\text { de parcerias tecnológicas e à prospecção tecnológica: a } \\
\text { proposição desses serviços pode ser realizada por: um departamento } \\
\text { do próprio parque; redes tecnológicas de que participam os parques; } \\
\text { departamentos das universidades (o parque tecnológico de Campinas } \\
\text { o faz via Unicamp, especificamente o Departamento de Política } \\
\text { Científica e Tecnológica do Instituto de Geociências da universidade); } \\
\text { atividades programadas pelos parques (o Parco Tecnologico Padano } \\
\text { realiza reuniões e momentos de reflexão com cientistas e } \\
\text { administradores do parque, entre outras atividades); e estudos } \\
\text { setoriais realizados pelos parques (por exemplo: estudo de } \\
\text { prospecção tecnológica nos setores mecânico e agro-alimentar } \\
\text { realizado pelo PTA; estudos setoriais multi-cliente nos campos de } \\
\text { produtos alimentares, ambiental e madeireiro realizados pelo AREA }\end{array}$ \\
\hline
\end{tabular}

\begin{tabular}{|c|c|c|}
\hline \multicolumn{2}{|c|}{ TABELA 6.1 - Interpretação dos resultados por dimensão/sub-dimensão da pesquisa } \\
\hline Dimensão & Sub-dimensão & Interpretação \\
\hline
\end{tabular}

\footnotetext{
10 Informações contidas no item 9.1 "Park activity" e 10.1 "Park Services" do relatório "Facts and Figures of Science and Technology Parks in the World", IASP General Survey, 2006-2007 disponível no endereço eletrônico http://www.rtp.org/files/iasp survey on stps.pdf acesso 31/3/2008.
} 


\begin{tabular}{|c|c|c|}
\hline $\begin{array}{l}\text { Serviços } \\
\text { do conheci- } \\
\text { mento }\end{array}$ & $\begin{array}{l}\text { Desenvolvi- } \\
\text { Desen } \\
\text { mento } \\
\text { tecnológico }\end{array}$ & $\begin{array}{l}\text { Science Park). O Cyberpark disponibiliza às PME via internet, uma } \\
\text { Plataforma de Sinergia com o objetivo de facilitar a comunicação e a } \\
\text { cooperação entre os parceiros (empresas instaladas, universidades e } \\
\text { estudantes). }\end{array}$ \\
\hline $\begin{array}{l}\text { (2) Provisão } \\
\text { de serviços } \\
\text { de gestão } \\
\text { do negócio }\end{array}$ & $\begin{array}{l}(2.1) \\
\text { Plano de } \\
\text { negócios e } \\
\text { propostas de } \\
\text { investimento }\end{array}$ & $\begin{array}{l}\text { 64\% dos parques oferecem serviços de apoio à elaboração e gestão } \\
\text { do plano de negócios das PME; e } 36 \% \text { dos PCT oferecem serviços de } \\
\text { apoio às PME no acesso a programas de cooperação e a } \\
\text { organizações internacionais, objetivando a adequação do plano de } \\
\text { negócios das empresas aos desafios do mercado globalizado. } \\
\text { A pesquisa recente da IASP apresenta resultados semelhantes; nela } \\
\text { os resultados apontam para que os serviços de tenant development } \\
\text { são oferecidos por } 53 \% \text { dos PCT. }{ }^{11} \text {. } \\
43 \% \text { dos PCT disponibilizam às PME consultoria especializada para a } \\
\text { captação de recursos financeiros por meio de projetos como: capital } \\
\text { de risco, capital semente, etc...; ; e } 36 \% \text { dos PCT oferecem serviços de } \\
\text { apoio às PME para elaboração de planos para atração de capital de } \\
\text { risco e investidores em geral (investment proposals). } \\
\text { A pesquisa recente da IASP reforça esse resultado, nele os serviços } \\
\text { de assistência ao acesso a fundos de capital semente são oferecidos } \\
\text { por } 71 \% \text { dos PCT; e } 31 \% \text { dos PCT disponibilizam serviços de acesso } \\
\text { a fundos próprios de capital semente (own seed capital funds) }{ }^{12} \text {. } \\
\text { Os PCT oferecem às PME serviços de apoio ao acesso } \\
\text { internacional objetivando às empresas fazerem frente aos desafios } \\
\text { do mercado globalizado. Para tanto os parques participam de } \\
\text { associações e redes regionais, nacionais e internacionais (como por } \\
\text { exemplo: Business Innovation Centres - que são centros de } \\
\text { competência especializados em diversas áreas relacionadas à gestão } \\
\text { empresarial }{ }^{13} \text {; EBN - que é uma rede Européia que reúne os BIC e } \\
\text { outras organizações; TII - rede especializada em transferência de } \\
\text { tecnologia, inovação e informação industrial; BC-NET - que é uma } \\
\text { rede européia de apoio à cooperação em negócios; NBIA - } \\
\text { associação especializada incubação de negócios e } \\
\text { empreendedorismo; etc...): } \\
\text { - O parque chinês HKSTP associa a prestação desse serviço a } \\
\text { apresentações itinerantes, exibições e conferências internacionais por } \\
\text { ele oferecidas. } \\
\text { - O parque italiano AREA o associa a atividades de seus programas } \\
\text { ITI (International TEchnology Incubators Programme) - voltado para }\end{array}$ \\
\hline
\end{tabular}

\footnotetext{
${ }^{11}$ Informações contidas no item 9.1 "Park activity" e 10.1 "Park Services" do relatório "Facts and Figures of Science and Technology Parks in the World", IASP General Survey, 2006-2007 disponivel no endereço eletrônico http://www.rtp.org/files/iasp survey on stps.pdf acesso 31/3/2008. ${ }^{12}$ Idem.

${ }^{13}$ Informação sobre BICs (Business Innovation Centres) disponível em apresentação da Associação dos Centros de Empresa e Inovação Portugueses (BICS) no endereço eletrônico http://www.bics.pt/ downloads/ Apres BICS15Mar06.pdf acesso em 27/02/2008.
} 


\begin{tabular}{|c|c|c|}
\hline \multicolumn{3}{|c|}{ TABELA 6.1 - Interpretação dos resultados por dimensão/sub-dimensão da pesquisa } \\
\hline Dimensão & Sub-dimensão & Interpretação \\
\hline $\begin{array}{l}\ldots(2) \\
\text { Provisão de } \\
\text { serviços de } \\
\text { gestão do } \\
\text { negócio }\end{array}$ & $\begin{array}{l}\ldots(2.1) \\
\text { Plano de } \\
\text { negócios e } \\
\text { propostas de } \\
\text { investimento }\end{array}$ & $\begin{array}{l}\text { PME italianas da região do Friuli Venezia Giulia que desenvolvem } \\
\text { tecnologias de ponta; HiCo Project ; Invesat; e o DETECT IT } 2 \text { - que } \\
\text { tem desenvolve uma rede de relacionamentos de clusters } \\
\text { internacionais com o objetivo de estimular a participação das PME em } \\
\text { programas de pesquisa europeus. } \\
\text { - No Ankara Cyberpark da Turquia tais serviços são oferecidos pelo } \\
\text { seu EU-Center - centro dedicado ao atendimento das necessidades } \\
\text { das PME. } \\
\text { Alguns parques disponibilizam serviços de apoio às PME na } \\
\text { elaboração de seus planos de negócios: } \\
\text { - o parque da PUCRS os disponibiliza via incubadora RAIAR. No } \\
\text { Ankara Cyberpark esse serviço é oferecido pelo EU-Center. } \\
\text { A maioria dos parques disponibiliza às PME serviços de apoio para } \\
\text { obtenção de recursos financeiros: } \\
\text { - No Ankara Cyberpark há um serviço dedicado de consultoria } \\
\text { oferecido às PME para acesso a recursos financeiros e bolsas; e um } \\
\text { serviço de consultoria para acesso a capital de risco. No AREA } \\
\text { Science Park serviços de suporte às PME são oferecidos pelo Projeto } \\
\text { Innovation Factory que está iniciando um fundo capital semente. } \\
\text { - No parque da PUCRS, todas as empresas incubadas na RAIAR } \\
\text { receberam apoio financeiros via SEBRAE para implementação de } \\
\text { seus planos de negócios e na atração de investidores. }\end{array}$ \\
\hline $\begin{array}{l}\text { (2) Provisão } \\
\text { de serviços } \\
\text { de gestão } \\
\text { do negócio }\end{array}$ & $\begin{array}{l}(2.2) \\
\text { Melhoria da } \\
\text { gestão do } \\
\text { negócio }\end{array}$ & $\begin{array}{l}50 \% \text { dos PCT estabelecem redes de cooperação e participam de } \\
\text { alianças estratégicas para apoiar o desenvolvimento de novas PME } \\
\text { no ambiente globalizado; e } 43 \% \text { dos PCT oferecem às PME serviços } \\
\text { de apoio ao desenvolvimento e estabelecimento de processos de } \\
\text { gestão de negócios. Dos PCT respondentes, } 29 \% \text { disponibilizam } \\
\text { serviços de consultoria especializada às PME com vistas à inovação } \\
\text { na gestão do negócio das empresas. } \\
\text { A pesquisa recente da IASP reforça esse resultado, nele } 71 \% \text { dos } \\
\text { PCT oferece serviços de suporte à gestão }{ }^{14} \text {. } \\
\text { Dos PCT respondentes, } 50 \% \text { estabelecem redes de cooperação e } \\
\text { participam de alianças estratégicas para apoiar o desenvolvimento de } \\
\text { novas PME no ambiente globalizado; e } 43 \% \text { dos PCT oferecem } \\
\text { serviços de apoio ao desenvolvimento e estabelecimento de } \\
\text { processos de gestão de negócios. } \\
29 \% \text { dos PCT disponibilizam serviços de consultoria especializada às } \\
\text { PME com vistas à inovação na gestão do negócio das empresas (29\% } \\
\text { CT e } 57 \% \text { CP). A pesquisa recente da IASP fortalece esse resultado, } \\
\text { nele } 71 \% \text { dos PCT oferece serviços de suporte à gestão }{ }^{15} \text {. }\end{array}$ \\
\hline
\end{tabular}

\footnotetext{
${ }^{14}$ Informações contidas no item 9.1 "Park activity" e 10.1 "Park Services" do relatório "Facts and Figures of Science and Technology Parks in the World", IASP General Survey, 2006-2007 disponível no endereço eletrônico http://www.rtp.org/files/iasp survey on stps.pdf acesso 31/3/2008.

${ }^{15}$ Idem.
} 


\begin{tabular}{|c|c|c|}
\hline \multicolumn{3}{|c|}{ TABELA 6.1 - Interpretação dos resultados por dimensão/sub-dimensão da pesquisa } \\
\hline Dimensão & Sub-dimensão & Interpretação \\
\hline $\begin{array}{l}\ldots(2) \\
\text { Provisão de } \\
\text { serviços de } \\
\text { gestão do } \\
\text { negócio }\end{array}$ & $\begin{array}{l}\ldots(2.2) \\
\text { Melhoria da } \\
\text { gestão do } \\
\text { negócio }\end{array}$ & 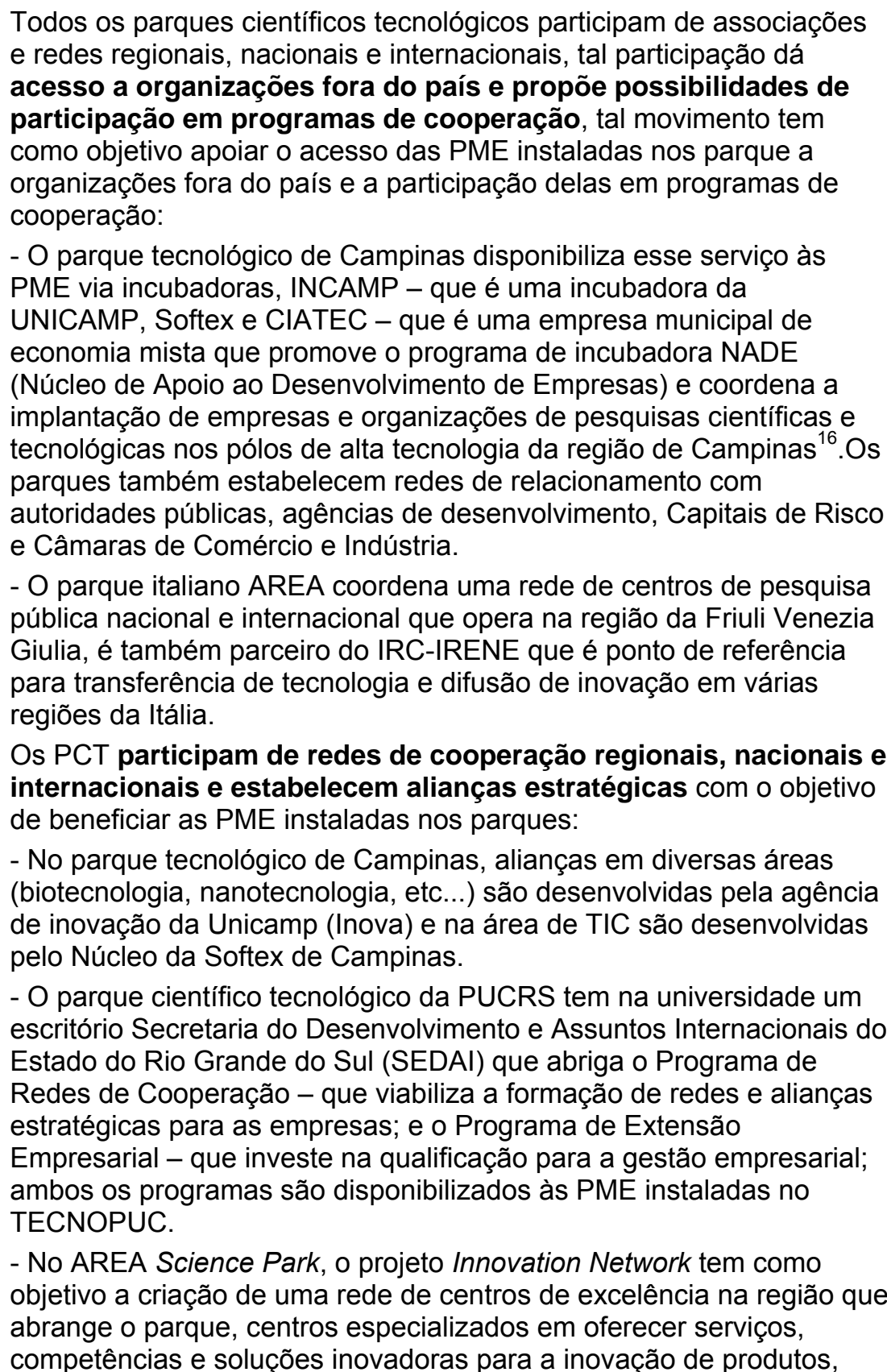 \\
\hline
\end{tabular}

16 Informações sobre o CIATEC disponíveis no endereço eletrônico http://www.ciatec.org.br/modules.php? name=News\&file=article\&sid=1 acesso em 28/03/2008. 


\begin{tabular}{|c|c|c|}
\hline \multicolumn{3}{|c|}{ TABELA 6.1 - Interpretação dos resultados por dimensão/sub-dimensão da pesquisa } \\
\hline Dimensão & Sub-dimensão & Interpretação \\
\hline $\begin{array}{l}\text { Provisão de } \\
\text { serviços de } \\
\text { gestão do } \\
\text { negócio }\end{array}$ & $\begin{array}{l}\text { W. (2.2) } \\
\text { Melhoria da } \\
\text { gestão do } \\
\text { negócio }\end{array}$ & $\begin{array}{l}\text { processos e gestão em diferentes setores de produtos da região da } \\
\text { Friuli Venezia Giulia. } \\
\text { Os PCT disponibilizam às PME serviços de apoio ao } \\
\text { desenvolvimento e estabelecimento de processos de gestão do } \\
\text { negócio: } \\
\text { - Por exemplo, no TECNOPUC esses serviços são disponibilizados } \\
\text { pela sua Incubadora RAIAR por meio do Serviço de Apoio a Gestão } \\
\text { (SAGE). O SAGE foi desenvolvido a partir de um projeto de pesquisa } \\
\text { encaminhado ao CNPq que disponibiliza bolsas para uma equipe de } \\
\text { cinco pessoas para dar suporte às ações institucionais da RAIAR e às } \\
\text { empresas instaladas; dois bolsistas desenvolvem o Plano de } \\
\text { Negócios, o Planejamento Estratégico e o Plano de Comercialização } \\
\text { das empresas que ingressam na RAIAR, além disso, acompanham o } \\
\text { crescimento dos empreendimentos, elaboram relatórios estatísticos e } \\
\text { fazem a manutenção dos dados }{ }^{17} \text {. } \\
\text { - No Parco Tecnológico Padano são oferecidos às PME serviços de } \\
\text { consultoria em marketing, competitividade, ações de } \\
\text { acompanhamento, ferramentas financeiras e gestão. }\end{array}$ \\
\hline $\begin{array}{l}\text { (3) } \\
\text { Provisão de } \\
\text { serviços } \\
\text { comuns }\end{array}$ & $\begin{array}{l}(3.1) \\
\text { Categoria de } \\
\text { serviços } \\
\text { comuns }\end{array}$ & $\begin{array}{l}50 \% \text { dos PCT oferecem serviços comuns que atendem todas as } \\
\text { necessidades das PME, independente do tamanho da empresa e de } \\
\text { suas peculiaridades. } \\
\text { A pesquisa recente da IASP reforça esse dado por meio da lista de } \\
\text { itens de serviços auxiliares propostos pelos } \mathrm{PCT}^{18 .} \\
\text { A infra-estrutura física necessária para o atendimento das } \\
\text { necessidades das PME é oferecida por } 36 \% \text { dos PCT respondentes. }\end{array}$ \\
\hline $\begin{array}{l}\text { (3) } \\
\text { Provisão de } \\
\text { serviços } \\
\text { comuns }\end{array}$ & $\begin{array}{l}(3.2) \\
\text { Acesso aos } \\
\text { serviços } \\
\text { comuns e à } \\
\text { infra-estrutura }\end{array}$ & $\begin{array}{l}57 \% \text { dos PCT oferecem às empresas serviços comuns projetados } \\
\text { para serem acessíveis a todas as PME; em } 50 \% \text { dos PCT o acesso } \\
\text { físico aos serviços comuns é simples e eficiente, atendendo às } \\
\text { necessidade das PME. }\end{array}$ \\
\hline $\begin{array}{l}\text { P. (3) } \\
\text { Provisão de } \\
\text { serviços } \\
\text { comuns }\end{array}$ & $\begin{array}{l}(3.3) \\
\text { Utilização dos } \\
\text { serviços } \\
\text { comuns }\end{array}$ & $\begin{array}{l}36 \% \text { dos PCT tem seus serviços comuns oferecidos às PME utilizados } \\
\text { por elas e atendendo a todas as suas necessidades; e } 43 \% \text { dos PCT } \\
\text { monitoram a utilização dos serviços comuns e garantem o seu bom } \\
\text { aproveitamento e o atendimento das necessidades das PME. }\end{array}$ \\
\hline $\begin{array}{l}\text { (4) } \\
\text { Disponibi- } \\
\text { lidade para } \\
\text { expansão } \\
\text { de área }\end{array}$ & $\begin{array}{l}(4.1) \\
\text { Área para } \\
\text { construção } \\
\text { de prédios }\end{array}$ & $\begin{array}{l}\text { O Plano Diretor de } 57 \% \text { dos PCT prevê a flexibilidade para a } \\
\text { expansão das PME. } \\
\text { Na questão fechada referente ao índice de ocupação das áreas } \\
\text { destinadas às PME, verificou-se que os PCT prevêem a flexibilidade } \\
\text { para a expansão das PME nele instaladas. Alguns PCT estão com }\end{array}$ \\
\hline
\end{tabular}

\footnotetext{
${ }_{17}$ Informações disponíveis no endereço eletrônico http://www.pucrs.br/agt/raiar/infra.php acesso em 28/03/2008.

18 Informações contida na tabela 22 "Ancillary services" do relatório "Facts and Figures of Science and Technology Parks in the World", IASP General Survey, 2006-2007 disponível no endereço eletrônico http://www.rtp.org/files/iasp survey on stps.pdf acesso 31/3/2008.
} 


\begin{tabular}{|c|c|c|}
\hline \multicolumn{3}{|c|}{ TABELA 6.1 - Interpretação dos resultados por dimensão/sub-dimensão da pesquisa } \\
\hline Dimensão & Sub-dimensão & Interpretação \\
\hline $\begin{array}{l}(4) \\
\text { Disponibi- } \\
\text { lidade para } \\
\text { expansão } \\
\text { de área }\end{array}$ & $\begin{array}{l}(4.1) \\
\text { Área para } \\
\text { construção } \\
\text { de prédios }\end{array}$ & $\begin{array}{l}\text { suas áreas destinadas às PME quase totalmente ou totalmente } \\
\text { utilizadas: } \\
\text { - O índice de ocupação da área construída no parque espanhol PTA é } \\
\text { de } 95 \% \text {, no parque chinês HKSTP esse índice é de } 96 \% \text {, no parque } \\
\text { alemão Technologiepark Heildelberg o índice é de } 90 \% \text {, no parque } \\
\text { italiano AREA Science Park é de } 97 \% \text {, nos parques da Turquia } \\
\text { Metutech e Ankara Cyberpark as áreas foram } 100 \% \text { ocupadas e } \\
\text { novas construções para esse fim foram ou estão sendo edificadas e já } \\
\text { estão sendo ocupadas. } \\
\text { - No TECNOPUC o índice também é de } 100 \% \text {. O parque italiano } \\
\text { Parco Tecnológico Padano que é relativamente novo (construído em } \\
\text { outubro de 2004) está com índice de ocupação em } 50 \% \text {. }\end{array}$ \\
\hline $\begin{array}{l}\text {...(4) } \\
\text { Disponibi- } \\
\text { lidade para } \\
\text { expansão } \\
\text { de área }\end{array}$ & $\begin{array}{l}(4.2) \\
\text { Projetos } \\
\text { futuros para } \\
\text { construção de } \\
\text { prédios }\end{array}$ & $\begin{array}{l}79 \% \text { dos PCT têm projetos de construção de prédios previstos no } \\
\text { curto prazo - próximos cinco anos. } \\
79 \% \text { dos PCT têm projetos de construção de prédios, previstos no } \\
\text { médio prazo - próximos } 5 \text { a } 10 \text { anos. } \\
43 \% \text { dos PCT têm projetos de construção de prédios, previstos no } \\
\text { longo prazo - próximos } 10 \text { anos ou mais. } \\
\text { A pesquisa recente realizada pela IASP reforça essa informação, nela } \\
\text { foi observado que } 78 \% \text { dos PCT expandiram suas áreas ou } \\
\text { instalações desde a sua criação; } 67 \% \text { fizeram a expansão uma vez, } \\
18 \% \text { duas vezes e } 15 \% \text { mais de três vezes; e } 78 \% \text { dos PCT têm } \\
\text { planos de expansão num futuro próximo }{ }^{19} \text { : } \\
\text { - Os parques científicos tecnológicos têm planos de expansão ou os } \\
\text { tem em andamento. O PTA espanhol está desenvolvendo } 900.000 \text { m }{ }^{2} \\
\text { adicionais de área aos originais } 1.860 .000 \text { m }{ }^{2} \text { de seu parque. } \\
\text { - No HKSTP chinês, até o ano } 2011 \text {, será finalizado o plano diretor de } \\
\text { construção e expansão do parque, que é composto de três fases e } \\
\text { abrange a construção de } 30 \text { prédios com espaços para escritórios de } \\
\text { P\&D e um total de área construída de } 330.000 m^{2} \text {. A fase } 1 \text { do projeto } \\
\text { foi inaugurada em } 2004 \text { e incluiu a construção de instalações de } \\
\text { classe mundial e laboratórios com serviços de apoio a atividades de } \\
\text { P\&D. A fase } 2 \text { foi inaugurada em } 2007 \text {, é composta da construção de } \\
\text { duas torres energia; dois edifícios dedicados a laboratórios e seis } \\
\text { edifícios de escritórios com áreas para instalaçães laboratoriais, } \\
\text { totalizando } 300.000 \text { m² de áreas para escritórios classe A; um } \\
\text { auditório e áreas de exposição; centros de negócios; áreas de lazer e } \\
\text { um clube; lojas de varejo e de restauração. A conclusão da fase } 3 \text { está } \\
\text { prevista para } 2011, \text { quando serão ocupados mais } 22.000 \text { m². }\end{array}$ \\
\hline
\end{tabular}

\footnotetext{
19 Informações contidas nos itens 1.3 "Expansion of Science Parks"; e 5.5 "STP expansion plans", do relatório "Facts and Figures of Science and Technology Parks in the World", IASP General Survey, 2006-2007 disponivel no endereço eletrônico http://www.rtp.org/files/iasp survey on stps.pdf acesso 31/3/2008.
} 


\begin{tabular}{|c|c|c|}
\hline \multicolumn{3}{|c|}{ TABELA 6.1 - Interpretação dos resultados por dimensão/sub-dimensão da pesquisa } \\
\hline Dimensão & Sub-dimensão & Interpretação \\
\hline $\begin{array}{l}\text {...(4) } \\
\text { Disponibi- } \\
\text { lidade para } \\
\text { expansão } \\
\text { de área }\end{array}$ & $\begin{array}{l}\ldots(4.2) \\
\text { Projetos } \\
\text { futuros para } \\
\text { construção de } \\
\text { prédios }\end{array}$ & $\begin{array}{l}\text { - O Technologiepark Heildelberg está desenvolvendo e agregando } \\
\text { novos } 200.000 \mathrm{~m}^{2} \text { de área aos originais } 1.700 .000 \mathrm{~m}^{2} \text { do parque, } \\
\text { oferecendo às PME a oportunidade de deixar o Centro de Inovação e } \\
\text { se instalarem em outros prédios do parque construídos por } \\
\text { investidores públicos e privados. Em julho de } 2005 \text { foi inaugurada uma } \\
\text { nova área do parque, Parque Tecnológico Ambiental do } \\
\text { Technologiepark Heidelberg; em } 2006 \text { foi inaugurado um novo Centro } \\
\text { de Conferências do parque; em } 2006 \text { foi adquirida nova área para } \\
\text { expansão do bioparque do Technologiepark Heidelberg. O Parco } \\
\text { Tecnológico Padano da Itália tem projetos de expansão de mais } \\
460.000 \mathrm{~m}^{2} \text { para agregar aos atuais } 40.000 \mathrm{~m}^{2} \text {. Dos } 460.000 \mathrm{~m}^{2} \text { do } \\
\text { projeto } 350.000 \mathrm{~m}^{2} \text { serão dedicados ao Business Park e o resto da } \\
\text { área dedicado às novas instalações da Universidade de Ciência, } \\
\text { Agricultura e Veterinária, ao Institute for Livestock healthcare Survey; } \\
\text { e a House of Agricultura Business Associations. } \\
\text { - O parque italiano AREA Science Park tem um projeto de expansão } \\
\text { para a construção e desenvolvimento de aproximadamente } 46.000 \mathrm{~m}^{2} \text {, } \\
\text { o período de execução do plano é de } 2006 \text { a } 2012 \text {. } \\
\text { - O plano de construção e expansão do parque Metutech da Turquia é } \\
\text { composto de quatro estágios de desenvolvimento e será completado } \\
\text { em } 2020 \text {. Desde o início da execução do plano o parque vem } \\
\text { desenvolvendo e agregando novas áreas dedicadas às PME } \\
\text { instaladas no parque e até } 2006 \text { contava com } 65.000 \mathrm{~m}^{2} \text { de área } \\
\text { construída. O Ankara Cyberpark da Turquia também tem projetos de } \\
\text { expansão previstos. } \\
\text { - No TECNOPUC foi concluída a fase II de expansão da área em } 2006 \\
\text { que previu a construção de um edifício com } 18.300 \mathrm{~m}^{2} \text { de área e outro } \\
\text { de sete andares com mais } 2.400 \mathrm{~m}^{2} \text { de área dedicada à incubação de } \\
\text { empresas; e a fase III está prevista para terminar em } 2008 \text {. }\end{array}$ \\
\hline $\begin{array}{l}\text { (5) } \\
\text { Visão geral } \\
\text { do parque }\end{array}$ & $\begin{array}{l}(5.1) \\
\text { Caracterís- } \\
\text { ticas do local } \\
\text { e do entorno }\end{array}$ & $\begin{array}{l}79 \% \text { dos PCT estão instalados em locais estratégicos para o } \\
\text { desenvolvimento dos negócios das PME; e } 57 \% \text { dos PCT } \\
\text { respondentes têm um entorno que contribui para a expansão dos } \\
\text { negócios das PME. } \\
\text { Os PCT estão localizados em locais estratégicos e têm um entorno } \\
\text { que contribui para o desenvolvimento e a expansão dos negócios das } \\
\text { PME. Na questão fechada sobre a influência do entorno do } \\
\text { empreendimento na decisão das empresas em se instalarem nos } \\
\text { PCT, se conclui que, na percepção dos PCT, as PME, ao decidirem } \\
\text { sobre se instalar nos PCT, levam em consideração o local e o entorno } \\
\text { do parque: } \\
\text { - O parque tecnológico de Campinas tem próximo a ele as } \\
\text { universidades Unicamp e PUC de Campinas; instituições de renome } \\
\text { como o Instituto de Zootecnica, o IAC, a CATI, o CENPRA, o ITAL, } \\
\text { entre outras; uma boa infra-estrutura viária e proximidade do } \\
\text { aeroporto de Campinas; várias empresas multinacionais instaladas }\end{array}$ \\
\hline
\end{tabular}




\begin{tabular}{|c|c|c|}
\hline \multicolumn{3}{|c|}{ TABELA 6.1 - Interpretação dos resultados por dimensão/sub-dimensão da pesquisa } \\
\hline Dimensão & Sub-dimensão & Interpretação \\
\hline $\begin{array}{l}\ldots(5) \\
\text { Visão geral } \\
\text { do parque }\end{array}$ & $\begin{array}{l}\ldots(5.1) \\
\text { Caracterís- } \\
\text { ticas do local } \\
\text { e do entorno }\end{array}$ & $\begin{array}{l}\text { como a Lucent, a Motorola, a Sansung, a IBM, entre outras. } \\
\text { - O parque HKSTP chinês está localizado próximo a Universidade } \\
\text { Chinesa de Hong Kong; a centros de pesquisa, como o Centro de } \\
\text { Suporte e Desenvolvimento \& Design Integrado de Circuitos e o } \\
\text { Centro de Suporte de Desenvolvimento em Fotônica; a laboratórios, } \\
\text { como o Laboratório de Análise de Materiais; e o Laboratório de Testes } \\
\text { de Comunicação Sem Fio; e ao Centro de Serviços de Propriedade } \\
\text { Intelectual; está também próximo ao Mercado Chinês, à estação de } \\
\text { trem e está localizado em área de proteção ambiental. } \\
\text { - O parque Português Madeira Tecnopólo está localizado em local } \\
\text { estratégico próximo à capital da ilha Funchal, o aeroporto fica a } 20 \\
\text { minutos do parque, próximo à rede hoteleira; empresas de prestigio na } \\
\text { área de tecnologia estão instaladas no parque. } \\
\text { - O Technologiepark Hildelberg está em local reconhecido como de } \\
\text { ambiente científico; e suas instalações oferecem a conveniência de } \\
\text { curtas distâncias (percursos que podem ser feitos a pé pelos } \\
\text { instalados) entre as instalações e os locais de alimentação, as livrarias } \\
\text { científicas, os institutos universitários e outros institutos de pesquisa. } \\
\text { - O Parco Tecnologico Padano está em local de tradição e vocação } \\
\text { agrícola e suas atividades estão basicamente voltadas para a } \\
\text { biotecnologia aplicada ao setor agro-alimentar; sendo assim, as PME } \\
\text { que se instalam no parque se beneficiam do entorno tanto em termos } \\
\text { das infraestruturas físicas disponíveis como na facilidade de acesso e } \\
\text { relacionamento com os produtores e criadores da região. } \\
\text { - O AREA Science Park é um distrito do conhecimento que conecta a } \\
\text { pesquisa pública e privada na região do Friuli-Venezia Giulia, sua } \\
\text { atuação, localização e entorno, são um atrativo para as PME } \\
\text { inovadoras. } \\
\text { - O Ankara Cyberpark está localizado próximo a três universidades de } \\
\text { prestígio, a Universidade Bilkent, a Universidade de METU e a } \\
\text { Universidade de Hacettepe; e a corporações públicas e privadas que } \\
\text { possuem necessidades de P\&D. }\end{array}$ \\
\hline $\begin{array}{l}\ldots(5) \\
\text { Visão geral } \\
\text { do parque }\end{array}$ & $\begin{array}{l}(5.2) \\
\text { Caracterís- } \\
\text { ticas dos } \\
\text { parceiros }\end{array}$ & $\begin{array}{l}\text { Em } 50 \% \text { dos PCT os parceiros têm participação efetiva na vida do } \\
\text { parque e interagem com regularidade entre si e com as PME. } \\
\text { Em } 14 \% \text { dos PCT os parceiros atuam tanto reativamente as } \\
\text { demandas das PME como pró ativamente nos assuntos relacionados } \\
\text { ao desenvolvimento dos PCT e das PME nele instaladas. } \\
\text { Na questão aberta sobre a influência do envolvimento dos } \\
\text { parceiros, se concluiu haver nos PCT interação dos parceiros com o } \\
\text { parque e/ou com as PME. No que se refere à ação dos parceiros às } \\
\text { demandas das PME, alguns atuam reativamente e/ou pró ativamente } \\
\text { no atendimento de suas necessidades: } \\
\text { No parque tecnológico de Campinas o parceiro mais influente é a } \\
\text { Unicamp; os demais parceiros são o CIATEC, a Prefeitura Municipal }\end{array}$ \\
\hline
\end{tabular}




\begin{tabular}{|c|c|c|}
\hline \multicolumn{3}{|c|}{ TABELA 6.1 - Interpretação dos resultados por dimensão/sub-dimensão da pesquisa } \\
\hline Dimensão & Sub-dimensão & Interpretação \\
\hline $\begin{array}{l}\text {... (5) } \\
\text { Visão geral } \\
\text { do parque }\end{array}$ & $\begin{array}{l}\ldots(5.2) \\
\text { Caracterís- } \\
\text { ticas dos } \\
\text { parceiros }\end{array}$ & $\begin{array}{l}\text { de Campinas e o Governo do Estado de São Paulo. } \\
\text { - No caso do Madeira Tecnopólo os parceiros mais importantes são as } \\
\text { associações empresariais, a Universidade e o Governo Regional. } \\
\text { - No TECNOPUC, que é gerido pela PUCRS, são as empresas e } \\
\text { associações; para estimular o envolvimento desses atores, reuniões } \\
\text { mensais são coordenadas pela AGT e pelo Gestor do TECNOPUC.Na } \\
\text { área de TIC a ASSESPRO é responsável pela triagem e indicação de } \\
\text { PME potenciais para instalação no parque; todas as indicações são } \\
\text { submetidas à Direção da AGT. } \\
\text { - No Technologiepark Bremen há forte interação com a Rhein Neckar } \\
\text { Immobilien (RNI), proprietária dos prédios do parque e que provê } \\
\text { software e hardware para o parque. } \\
\text { - Os parceiros do AREA Science Park são as instituições econômicas } \\
\text { regionais, as câmaras de comércios, as uniões de comércio e as } \\
\text { associações de indústrias, as instituições de pesquisa e as PME, a } \\
\text { região da Friuli Venezia Giulia (que desenvolve políticas de } \\
\text { desenvolvimento baseadas nos clusters de PME) e os programas de } \\
\text { financiamento de P\&D. }\end{array}$ \\
\hline $\begin{array}{l}. .(5) \\
\text { Visão geral } \\
\text { do parque }\end{array}$ & $\begin{array}{l}(5.3) \\
\text { Prestígio do } \\
\text { Parque }\end{array}$ & $\begin{array}{l}\text { 72\% dos PCT estão instalados em um local de prestígio que pode } \\
\text { trazer benefícios às empresas instaladas; e as empresas consideram } \\
\text { o local onde está situado o PCT, um fator determinante na decisão de } \\
\text { se instalarem no parque. } \\
\text { Na questão aberta referente à influência do prestígio do } \\
\text { empreendimento e impactos se concluiu que os PCT estão } \\
\text { instalados em local considerado de prestígio e esse fato é um dos } \\
\text { determinantes que é considerado pelas PME ao decidirem se instalar } \\
\text { num PCT: } \\
\text { - Parte do prestígio do PTA pode ser associada ao fato dele ter em } \\
\text { suas instalações as sedes de importantes instituições representativas } \\
\text { como a IASP, a APTE, o RETA e a IUCN. } \\
\text { - No caso do parque tecnológico de Campinas se pode associar à } \\
\text { proximidade de duas importantes rodovias do Estado de São Paulo } \\
\text { (Campinas Mogi-Mirim e Dom Pedro I), ao lado de condomínios de } \\
\text { luxo, áreas comerciais e de serviços. } \\
\text { - O prestígio do HKSTP pode ser associado também à proximidade do } \\
\text { Mercado Chinês. } \\
\text { - O TECNOPUC foi considerado e premiado como o melhor parque } \\
\text { tecnológico do Brasil pela ANPROTEC/SEBRAE/IEL/CNPq, ele é } \\
\text { modelo no Brasil e na América Latina; este fato entre outros, influi na } \\
\text { decisão das empresas em desejarem se instalar no parque. } \\
\text { - Alguns fatores que estão associados ao prestígio do Parco } \\
\text { Tecnologico Padano são a localização do parque (na porta da Pianura } \\
\text { Padana e ao sul da Europa), a tradição agrícola da região, e o fato do } \\
\text { diretor científico do parque ser um cientista de renome internacional } \\
\text { no campo da genômica (o Dr. Fracesco Salamini foi ex-diretor do }\end{array}$ \\
\hline
\end{tabular}




\begin{tabular}{|c|c|c|}
\hline \multicolumn{3}{|c|}{ TABELA 6.1 - Interpretação dos resultados por dimensão/sub-dimensão da pesquisa } \\
\hline Dimensão & Sub-dimensão & Interpretação \\
\hline$\ldots(5)$ & $\ldots(5.3)$ & Instituto Max Planck). \\
\hline $\begin{array}{l}\text { Visão geral } \\
\text { do parque }\end{array}$ & $\begin{array}{l}\text { Prestígio do } \\
\text { Parque }\end{array}$ & $\begin{array}{l}\text { - O AREA Science Park é conhecido em nível nacional e internacional, } \\
\text { suas instalações são modernas, o local em que está instalado é } \\
\text { privilegiado e a qualidade de vida que a região proporciona é muito } \\
\text { boa. Esses são fatores de prestígio que influenciam a decisão das } \\
\text { PME em se instalar no parque. } \\
\text { - O prestígio do Ankara Cyberpark pode ser associado à sua } \\
\text { localização, em campus de qualidade mundial e na capital da Turquia, } \\
\text { além de oferecer diversas possibilidades de pesquisa científicas e } \\
\text { tecnológicas e oportunidades sociais, culturais, esportivas e de lazer. }\end{array}$ \\
\hline
\end{tabular}

\subsection{Discussão e interpretação dos resultados das observações in loco}

Dos PCT visitados, três estão localizados na Itália em regiões com características de distritos industriais; na visão desta pesquisadora, esse fato interfere positivamente nos resultados dos PCT, já que estão instalados em áreas de setores de atividades já organizados e que possuem uma cultura de parceria nos negócios que favorece o desenvolvimento da inovação.

Da visita ao Centúria-RIT, esta pesquisadora concluiu ser aquele um empreendimento voltado essencialmente à prestação de serviços do conhecimento de interesse do setor agro-industrial local. Para tanto possui uma estrutura leve, organizada e transparente.

Essa estrutura leve é caracterizada por mínimo de investimento em infraestrutura física e quadro de pessoal pequeno e altamente especializado; são nove pessoas distribuídas nos dois endereços do Centúria-RIT, nas cidades de Cezena e Faenza.

Um fato interessante foi o do Centuria-RIT disponibilizar em seu sítio da internet, o currículo de cada profissional da equipe. Na visão desta pesquisadora essa é uma prática que demonstra confiança e dá transparência e às atividades do parque, o contato com essas informações permite verificar a qualificação dos profissionais, seu desenvolvimento contínuo, suas atividades e as responsabilidades a eles atribuídas.

Outro ponto de destaque do Centúria-RIT é a ênfase no estabelecimento e manutenção de rede de relacionamentos; em sua logomarca, networking é o 
elemento que permite o movimento, é o principal serviço e o mais valorizado por eles; a equipe do Centúria-RIT reconhece a circulação da informação interna, externa e dentro da rede, como ação que viabiliza a execução dos demais serviços que ele presta a seus associados.

$\mathrm{Na}$ visão desta pesquisadora, a prática da rede de relacionamentos e a valorização da circulação da informação, é uma prática que deve ser observada e destacada nas atividades dos PCT.

Da visita ao AREA Science Park está pesquisadora observou que se trata de um grande empreendimento público criado nos anos 70 para fomentar o desenvolvimento científico e tecnológico das províncias da região do Friuli-Venezia Giulia, em particular da província de Trieste.

Por se tratar de um empreendimento público incluído nos planos da política regional, o PCT, que ocupa posição de destaque na pesquisa e desenvolvimento do país, recebe apoio e recursos financeiros que viabilizam, sobretudo, o estabelecimento de parcerias para a implantação de novos projetos de serviços.

O AREA Science Park disponibiliza uma grande variedade de serviços do conhecimento, destacados, principalmente, pelos projetos de serviços, muitos deles, idealizados para o atendimento de demandas identificadas.

Da visita ao Parco Tecnológico Padano, esta pesquisadora observou tratar se de um empreendimento promovido por entidades públicas da região da Lombardia em conjunto com a Universidade de Estudos de Milão, voltado para a pesquisa e o desenvolvimento tecnológico da área de biotecnologia agro-alimentar da Lombardia.

Sobretudo pela presença e atuação do CERSA, o PTP é um centro de excelência de referência nacional internacional em sua área de atuação; é um cluster agro-biotecnológico do sul da Europa.

O PTP oferece serviços de P\&D e serviços do conhecimento relacionados a temas tais como: propriedade intelectual, plano de negócios, relações públicas, gestão de projetos. Os recursos financeiros para manutenção do parque são provenientes de fontes públicas e de receitas de serviços de P\&D prestados a empresas privadas, sobretudo de análises laboratoriais. 
Quanto ao Parque Tecnológico de Andalucia, trata se de um empreendimento criado no fim dos anos 80 , com o objetivo de fomentar o desenvolvimento científico e tecnológico da região de Andalucia.

É um PCT de atuação multidisciplinar e que desde sua criação recebeu muitos investimentos financeiros (590 milhões de euro foram investidos no PTA, donde 480 milhões foram advindos da iniciativa privada).

Na visão desta pesquisadora, há que se destacar as várias edificações voltadas para apoiar o modelo de desenvolvimento empresarial contínuo (préincubadoras, incubadoras, escritórios e plantas industriais); o edifício da Universidade de Málaga e os três centros de difusão e transferência de tecnologia.

Outro destaque do PCT é o fato dele ter as sedes da IASP, APTE e do IDEA instalados no PTA.

No tópico a seguir, serão apresentadas e analisadas as melhores práticas ou práticas de sucesso identificadas nos PCT respondentes.

\subsection{Análise das práticas de sucesso}

As práticas de sucesso identificadas nos PCT respondentes e uma descrição em linhas gerais de cada uma delas, estão apresentadas na Tabela 6.2.

\begin{tabular}{|l|l|l|}
\hline \multicolumn{3}{|c|}{ TABELA 6.2 - Identificação das melhores práticas e descrição em linhas gerais } \\
\hline \multicolumn{1}{|c|}{ PCT } & Prática & \multicolumn{1}{c|}{ Descrição da prática (linhas gerais) } \\
\hline $\begin{array}{l}\text { Area } \\
\text { Science } \\
\text { Park }\end{array}$ & $\begin{array}{l}\text { AREA } \\
\text { Science } \\
\text { Park Virtual } \\
\text { Reality }\end{array}$ & $\begin{array}{l}\text { O AREA Science Park Virtual Reality é um espaço para exposições (Show } \\
\text { Room) virtual, ela consiste em um sistema de simulação, modelagem e } \\
\text { projeção gráfica de imagens; essa área de exibições representa de uma } \\
\text { maneira simples e efetiva o território e a configuração logística do Parque } \\
\text { Científico Tecnológico bem como os experimentos científicos e os jogos } \\
\text { virtuais controlados remotamente. O Show Room será estruturado em } \\
\text { quatro partes: teatro virtual, visita virtual, experimentos científicos e jogos } \\
\text { interativos. }\end{array}$ \\
\hline $\begin{array}{l}\text { Area } \\
\text { Science } \\
\text { Park }\end{array}$ & D4 Project & $\begin{array}{l}\text { O AREA Science Park é o líder do projeto D4, que foi fundado pelo } \\
\text { Escritório Central para o Trabalho, Treinamento, Universidades e } \\
\text { Pesquisa na Região Autônoma do Friuli-Venezia Giulia, no âmbito do } \\
\text { Programa Operacional Regional, que é dedicado ao aprimoramento dos } \\
\text { recursos humanos nos setores da pesquisa e desenvolvimento } \\
\text { tecnológico. }\end{array}$ \\
\hline
\end{tabular}




\begin{tabular}{|c|c|c|}
\hline \multicolumn{3}{|c|}{ TABELA 6.2 - Identificação das melhores práticas e descrição em linhas gerais } \\
\hline PCT & Prática & Descrição da prática (linhas gerais) \\
\hline $\begin{array}{l}\text { Area } \\
\text { Science } \\
\text { Park }\end{array}$ & $\begin{array}{l}\ldots \\
\text { D4 Project }\end{array}$ & $\begin{array}{l}\text { O objetivo do projeto D4 é consolidar, em nível regional, a parceria entre } \\
\text { empresas, universidades e centros de pesquisa; promovendo a troca } \\
\text { contínua de habilidades e competências, a mobilidade de idéias e } \\
\text { pesquisadores, a junção e a sinergia que envolve à implantação de } \\
\text { projetos de pesquisa inovadores, e o desenvolvimento e transferência de } \\
\text { tecnologia. } \\
\text { O projeto D4 oferece vários caminhos para a promoção e obtenção } \\
\text { pesquisadores visitantes e de bolsas de pesquisa. O projeto também } \\
\text { realiza análise de desempenho da região do Friuli-Venezia Giulia em } \\
\text { termos de inovação e pesquisa, utilizando ferramentas quantitativas (EIS - } \\
\text { European Innovation Scoreboard) projetadas para oferecer uma visão } \\
\text { geral da situação da inovação. }\end{array}$ \\
\hline $\begin{array}{l}\text { Area } \\
\text { Science } \\
\text { Park }\end{array}$ & $\begin{array}{l}\text { ERA- } \\
\text { MORE }\end{array}$ & $\begin{array}{l}\text { O European Network of Mobility Centres (ERA-MORE) foi criado em } 2004 \\
\text { e é produto de uma iniciativa conjunta da Comunidade Européia e dos } \\
\text { países participantes do FP6 ( } 6^{a} \text { edição do Programa Quadro). A rede é } \\
\text { composta por cerca de } 200 \text { centros de mobilidade distribuídos pela } \\
\text { Europa; e numerosos pontos de contato locais distribuídos por } 32 \text { países, } \\
\text { fornecendo informações sobre tudo o que se relaciona à vida profissional } \\
\text { e às atividades do dia-a-dia dos pesquisadores móveis da Europa e } \\
\text { estrangeiros. } \\
\text { O objetivo da iniciativa é oferecer assistência aos pesquisadores móveis } \\
\text { (em trânsito) e a encorajar a troca de informação e boas práticas em } \\
\text { gestão de mobilidade entre aqueles que já operam o sistema. } \\
\text { O Centro de Mobilidade do AREA Science Park está operando desde } \\
\text { março de } 2005 \text { e oferece aos pesquisadores assistência sobre } \\
\text { procedimentos para entrada e residência na Itália, assim como } \\
\text { informações referentes a oportunidades de pesquisa e de trabalho na } \\
\text { Itália. } \\
\text { Os Centros de Mobilidade oferecem aos pesquisadores móveis uma série } \\
\text { de informações relevantes, por meio da preparação de pacotes de } \\
\text { informação e pela publicação de dados úteis no Portal de Mobilidade } \\
\text { Italiano e no Portal de Mobilidade dos Pesquisadores Europeus. Os } \\
\text { Centros de Mobilidade organizam encontros individuais, bem como } \\
\text { informações e dias de treinamento focados nos melhores caminhos para } \\
\text { encorajar a mobilidade. }\end{array}$ \\
\hline $\begin{array}{l}\text { Area } \\
\text { Science } \\
\text { Park }\end{array}$ & FIRM & $\begin{array}{l}\text { O projeto Formazione per gli Imprenditori Regionali e i Manager - FIRM } \\
\text { (Formação para Empresários e Gestores da Região) tem como objetivo } \\
\text { promover a cultura empresarial na região do Friuli-Venezia Giulia, } \\
\text { provendo serviços de informação, orientação, assistência em treinamento } \\
\text { para proprietários, administradores e líderes de projetos de PME da } \\
\text { região. } \\
\text { O projeto FIRM, é coordenado pela AREA Science Park em parceria com } \\
\text { o Consórcio ARPA; o En.A.I.P. Friuli Venezia Giulia, o IAL Friuli Venezia } \\
\text { Giulia, o IRES - Institute for Economic and Social Research in Friuli } \\
\text { Venezia Giulia; o Centro de Empreendedorismo Boston do MIT; o Skillab } \\
\text { s.r.I. - Human Resource Enhancement centre; o Politecnico di Torino; a }\end{array}$ \\
\hline
\end{tabular}




\begin{tabular}{|c|c|c|}
\hline \multicolumn{3}{|c|}{ TABELA 6.2 - Identificação das melhores práticas e descrição em linhas gerais } \\
\hline PCT & Prática & Descrição da prática (linhas gerais) \\
\hline $\begin{array}{l}\text { Area } \\
\text { Science } \\
\text { Park }\end{array}$ & $\ldots F I R M$ & 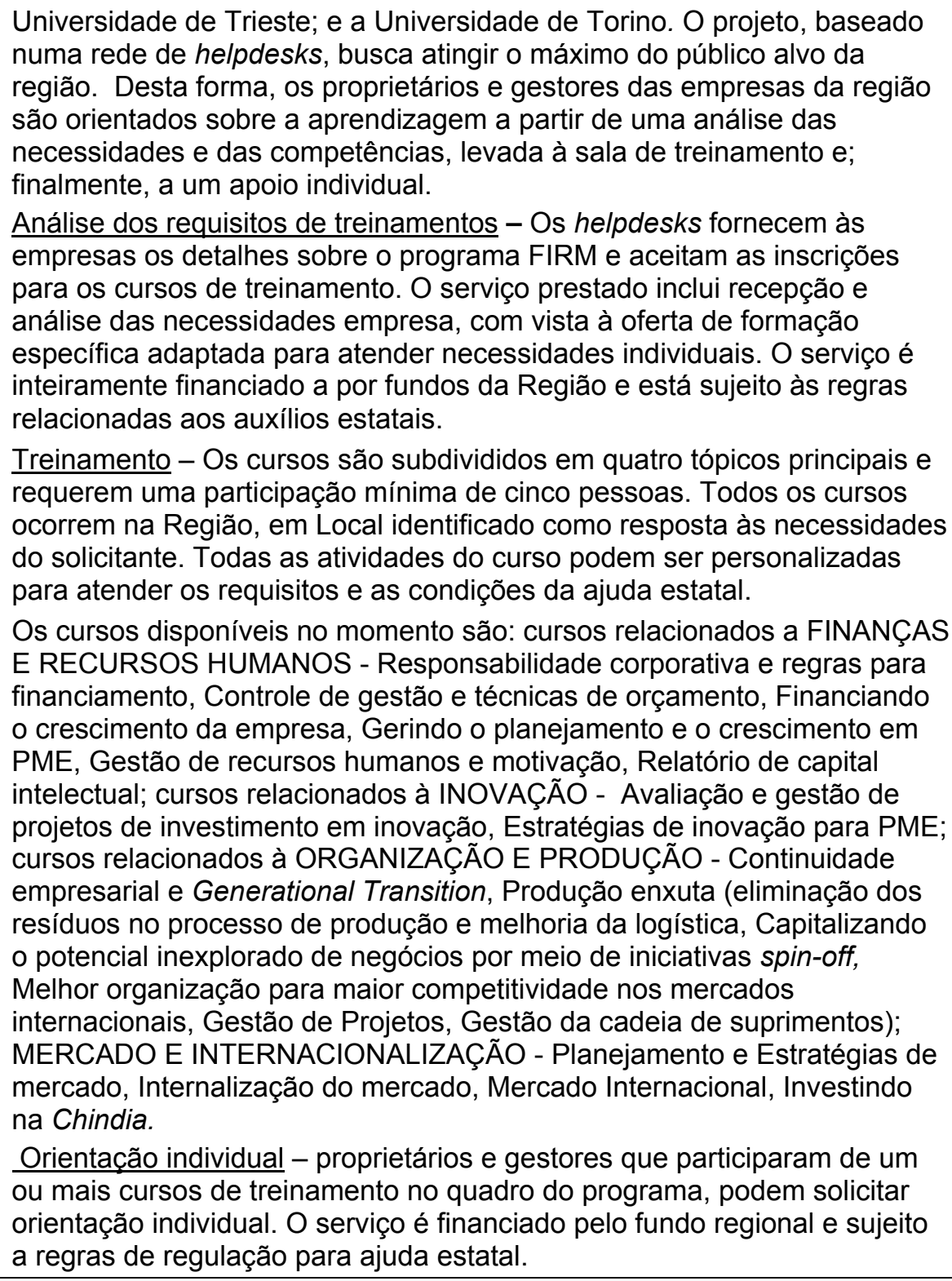 \\
\hline $\begin{array}{l}\text { Area } \\
\text { Science } \\
\text { Park }\end{array}$ & $\begin{array}{l}\text { HiCo (Hi- } \\
\text { tech } \\
\text { Integrated } \\
\text { Cooperation) }\end{array}$ & $\begin{array}{l}\text { O projeto HiCo-Hi-tech integrated Co-operation for cross-border economic } \\
\text { growth and SME competitiveness increase é um projeto voltado para o } \\
\text { desenvolvimento da área fronteiriça do Friuli Venezia Giulia/Eslovênia } \\
\text { (região HiCo) objetivando a criação de grupos industriais (industrial } \\
\text { clusters) e distritos de aprendizado (cognitive districts). } \\
\text { O projeto HiCo tem como objetivos reforçar as habilidades e } \\
\text { especialização tecnológicas, científicas e dos sistemas produtivos na área } \\
\text { do projeto (região HiCo); promover o estabelecimento de parcerias } \\
\text { industriais e científicas; implementar e testar em campo estruturas }\end{array}$ \\
\hline
\end{tabular}




\begin{tabular}{|c|c|c|}
\hline \multicolumn{3}{|c|}{ TABELA 6.2 - Identificação das melhores práticas e descrição em linhas gerais } \\
\hline PCT & Prática & Descrição da prática (linhas gerais) \\
\hline $\begin{array}{l}\text { Area } \\
\text { Science } \\
\text { Park }\end{array}$ & $\begin{array}{l}\ldots \\
\text { HiCo (Hi- } \\
\text { tech } \\
\text { Integrated } \\
\text { Cooperation) }\end{array}$ & $\begin{array}{l}\text { fronteiriças para iniciar atividades orientadas para a tecnologia e a } \\
\text { inovação; criar metodologias, estruturas de promoção e serviços para } \\
\text { atrair investimentos da indústria. } \\
\text { O projeto busca harmonizar e coordenar políticas locais para o } \\
\text { desenvolvimento das áreas fronteiriças, desenvolvendo um competitivo } \\
\text { sistema industrial de fronteiras orientado para a inovação (innovation- } \\
\text { oriented); atraindo investimentos em pesquisa e negócios de tecnologia } \\
\text { intensiva e concentrando o conhecimento (know how) tecnológico em } \\
\text { serviços de inovação alvos (innovation targeted services). } \\
\text { O Projeto HiCo é promovido e coordenado pelo AREA Science Park em } \\
\text { colaboração com os órgãos regionais de desenvolvimento econômico } \\
\text { SVILUPPO ITALIA FVG e EZIT Trieste. A parceria com a Eslovênia é } \\
\text { importante, contanto com mais de } 20 \text { participantes (serviços de P\&D, } \\
\text { agências regionais de desenvolvimento, Centro de Negócios e Inovação, } \\
\text { municipalidades), trabalhando em estreita sinergia com o AREA no âmbito } \\
\text { de iniciativas semelhantes e em curso na Eslovênia. }\end{array}$ \\
\hline $\begin{array}{l}\text { Area } \\
\text { Science } \\
\text { Park }\end{array}$ & Imprenderò & $\begin{array}{l}\text { O projeto, promovido e fundado pela Região Autônoma da Friuli-Venezia } \\
\text { Giulia por meio do Fundo Social Europeu, é administrado por um } \\
\text { consórcio de } 19 \text { parceiros; e tem por objetivo disseminar e promover a } \\
\text { cultura empresarial entre pesquisadores, doutorandos e graduados } \\
\text { interessados em estabelecer negócios ou a colaborar e atuar em } \\
\text { empresas interessadas em promover spin-offs. } \\
\text { Nesse projeto o AREA Science Park: realiza consultorias individuais } \\
\text { provendo informações; orienta e audita habilidades para o } \\
\text { estabelecimento de negócios; assiste a fase de desenvolvimento do plano } \\
\text { de negócios e sua implementação, por meio de suporte e } \\
\text { aconselhamento; cria um sistema integrado de seminários que provêem } \\
\text { informações e treinamento nos principais tópicos relacionados a spin-offs; } \\
\text { realiza no Centro de Conferências do AREA Science Park, uma série de } \\
\text { seminários gratuitos nos tópicos relacionados à cultura empresarial. } \\
\text { Os resultados do projeto até o momento foram os seguintes: } 283 \text { horas de } \\
\text { orientação para negócios; } 35 \text { seminários em tópicos relacionados a } \\
\text { empresas e gestão; } 1.250 \text { horas de assistência técnica individual; } 112 \\
\text { pessoas utilizaram o serviço de assistência técnica individual; e } 24 \\
\text { empresas foram criadas com o apoio do projeto. }\end{array}$ \\
\hline $\begin{array}{l}\text { Area } \\
\text { Science } \\
\text { Park }\end{array}$ & $\begin{array}{l}\text { Innovation } \\
\text { Campus }\end{array}$ & $\begin{array}{l}\text { O campus de inovação (Innovation Campus) foi criado em } 2006 \text { pelo } \\
\text { AREA Science Park, é uma iniciativa que tem por objetivo oferecer } \\
\text { treinamento contínuo e suporte a encontros e workshops para operadores } \\
\text { nacionais e internacionais e agências do setor. O projeto provê cursos de } \\
\text { educação superior, estudos especializados, consultoria em temas } \\
\text { relacionados a projetos e transferência de tecnologia. } \\
\text { O Innovation Campus também funciona como um laboratório para a } \\
\text { modelagem de novas profissões, como é o caso do Especialista em } \\
\text { inovação e transferência de tecnologia ou Mediador de Tecnologia } \\
\text { (Specialist of technology transfer and innovation - technology broker); } \\
\text { uma experiência de treinamento de alto nível com origem na transferência }\end{array}$ \\
\hline
\end{tabular}




\begin{tabular}{|c|c|c|}
\hline \multicolumn{3}{|c|}{ TABELA 6.2 - Identificação das melhores práticas e descrição em linhas gerais } \\
\hline PCT & Prática & Descrição da prática (linhas gerais) \\
\hline $\begin{array}{l}\text { Area } \\
\text { Science } \\
\text { Park }\end{array}$ & $\begin{array}{l}\text { Innovation } \\
\text { Campus }\end{array}$ & $\begin{array}{l}\text { de tecnologia Italiana; nesse caso, o método de ensino foi baseado nas } \\
\text { técnicas do "aprender fazendo" e "assumindo o papel" ("learning by doing" } \\
\text { and "role playing"). } \\
\text { O novo perfil profissional (que é o primeiro curso superior do programa, } \\
\text { visa criar é o technology broker - especializado em transferência de } \\
\text { tecnologia e inovação". } \\
\text { Este novo perfil profissional( que é o primeiro curso superior do campus } \\
\text { de inovação) está fortemente orientado para a demanda por inovação, } \\
\text { com atenção particular ao desenvolvimento de: habilidade de se colocar } \\
\text { apropriadamente ao empreendedor ou gestor da empresa e interpretar } \\
\text { corretamente a demanda de inovação; habilidade em identificar as } \\
\text { melhores oportunidades, mais desejáveis para o negócio, no campo da } \\
\text { pesquisa; habilidade de acompanhar "pesquisa" e "empresa" durante o } \\
\text { desenvolvimento de produtos e processos. } \\
\text { O projeto é gerido pelo AREA Science Park em parceria com o Milan MIP- } \\
\text { Politecnico (Instituto Tecnológico especializado em Gestão e Engenharia } \\
\text { Industrial), o qual transmite sua experiência, obtida por meio do escritório } \\
\text { de transferência de tecnologia (TTO - Technology Transfer Office). } \\
\text { O Innovation Campus é patrocinado pelo Instituto de Promoção Industrial } \\
\text { (IPI) e pela Câmara de Comércio da Itália (UNIONCAMERE). É também } \\
\text { suportada pelo Convegno permanente dei Direttori Amministrativi e } \\
\text { dirigenti delle Università italiane (CODAU); pelo Diffusione Informazioni } \\
\text { Normativa Tecnica (DINTEC); e pela IASP. }\end{array}$ \\
\hline $\begin{array}{l}\text { Area } \\
\text { Science } \\
\text { Park }\end{array}$ & $\begin{array}{l}\text { Innovation } \\
\text { factory }\end{array}$ & $\begin{array}{l}\text { O projeto Fábrica de Inovação (Innovation Factory) é uma iniciativa do } \\
\text { AREA Science Park criado para dar suporte e assistência à criação de } \\
\text { novos negócios inovadores. Esta dirigida a pesquisadores e grupos de } \\
\text { pesquisa que pretendam implementar seus próprios projetos spin-offs; e a } \\
\text { empreendedores interessados em fazer parte na criação de novas } \\
\text { empresas à luz de pesquisas realizadas em colaboração com instituições } \\
\text { de pesquisa do parque. } \\
\text { O Innovation Factory oferece serviços de incubação de negócios com } \\
\text { unidades especialmente equipadas; oferece assistência na avaliação dos } \\
\text { conceitos de empreendimento tecnológico, e posições comercial, jurídica } \\
\text { e econômica; oferece também apoio financeiro com a possibilidade de } \\
\text { financiamento sob a forma de capital semente. } \\
\text { O Innovation Factory oferece ainda: treinamento econômico, financeiro e } \\
\text { gerencial; treinamento específico sob demanda; um business coach para } \\
\text { atuar como tutor empresarial; ajuda na identificação de fontes de } \\
\text { recursos. Consultores e pessoal qualificado são também disponibilizados } \\
\text { para aconselhar em: aplicações e desenvolvimento de produtos; serviços } \\
\text { de proteção de propriedade intelectual; validação de tecnologia e de } \\
\text { desempenho; analise de mercado e controles. }\end{array}$ \\
\hline $\begin{array}{l}\text { Area } \\
\text { Science } \\
\text { Park }\end{array}$ & $\begin{array}{l}\text { Innovation } \\
\text { Network }\end{array}$ & $\begin{array}{l}\text { Trata-se de um projeto do AREA Science Park, apoiado pela Região do } \\
\text { Friuli-Venezia Giulia, que foi estabelecido na região como uma estrutura } \\
\text { de serviços para negócios, dedicado a transferir experiência e tecnologia } \\
\text { obtida no mundo da pesquisa e estimular o estabelecimento de projetos } \\
\text { de inovação. }\end{array}$ \\
\hline
\end{tabular}




\begin{tabular}{|c|c|c|}
\hline \multicolumn{3}{|c|}{ TABELA 6.2 - Identificação das melhores práticas e descrição em linhas gerais } \\
\hline PCT & Prática & Descrição da prática (linhas gerais) \\
\hline $\begin{array}{l}\text { Area } \\
\text { Science } \\
\text { Park }\end{array}$ & $\begin{array}{l}\text {... } \\
\text { Innovation } \\
\text { Network }\end{array}$ & $\begin{array}{l}\text { A estrutura da rede é constituída em torno de Centros de Competência } \\
\text { ativos nas áreas de interesse comum, como meio-ambiente, energia e } \\
\text { eficiência produtiva, ou especializada em setores de produtos típicos da } \\
\text { região do Friuli-Venezia Giulia, como madeira e mobiliário, agroindústria e } \\
\text { construção de barcos para navegação e lazer. Os centros de competência } \\
\text { atualmente em operação são: agroindústria; meio-ambiente; construção } \\
\text { de barcos e navios; madeira e mobiliário; energia; negócios e engenharia; } \\
\text { plásticos e novos materiais; e biomedicina molecular. } \\
\text { Cada link dessa rede de inovação disponibiliza oportunidades de negócios } \\
\text { relacionados a habilidades específicas e serviços necessários para o } \\
\text { desenvolvimento inovador de produtos, processos e gestão. }\end{array}$ \\
\hline $\begin{array}{l}\text { Area } \\
\text { Science } \\
\text { Park }\end{array}$ & $\begin{array}{l}\text { Innovation } \\
\text { Relay } \\
\text { Centre } \\
\text { Network } \\
\text { (IRC) }\end{array}$ & 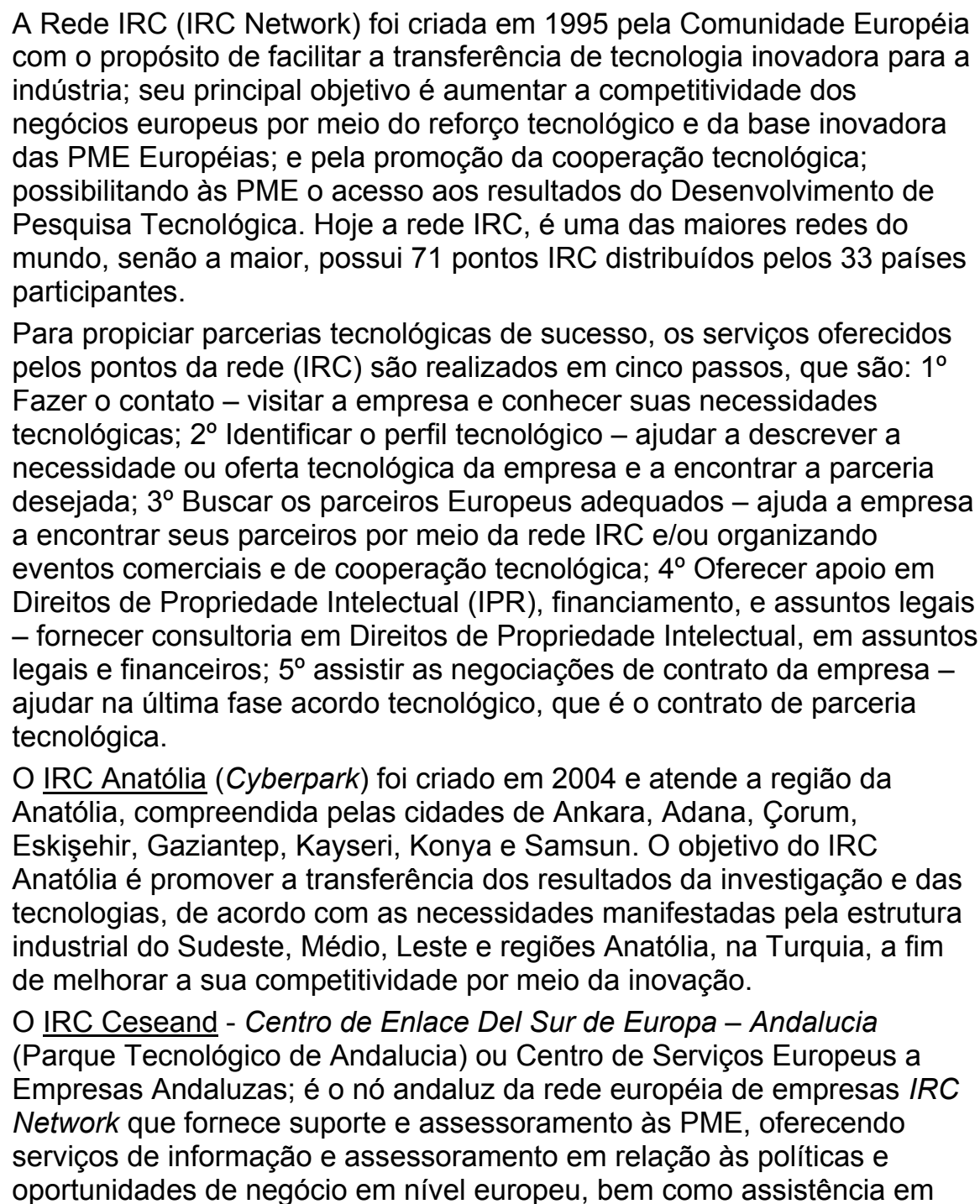 \\
\hline
\end{tabular}




\begin{tabular}{|c|c|c|}
\hline \multicolumn{3}{|c|}{ TABELA 6.2 - Identificação das melhores práticas e descrição em linhas gerais } \\
\hline PCT & Prática & Descrição da prática (linhas gerais) \\
\hline $\begin{array}{l}\text { Area } \\
\text { Science } \\
\text { Park }\end{array}$ & $\begin{array}{l}\text { Innovation } \\
\text { Relay } \\
\text { Centre } \\
\text { Network } \\
\text { (IRC) }\end{array}$ & $\begin{array}{l}\text { processos de transferência tecnológica e acesso a programas europeus } \\
\text { de financiamento de P\&D\&I. } \\
\text { O IRC Irene - Italian Relay Centre for North-East (AREA Science Park) é } \\
\text { um ponto central de transferência tecnológica transnacional e difusão das } \\
\text { habilidades de inovação nas regiões da Emilia Romagna, Marche, Veneto, } \\
\text { Trentino-Alto Adige e Friuli Venezia Giulia. As operações regionais do } \\
\text { AREA no âmbito do projeto IRC Irene incluem: assistência à indústria na } \\
\text { definição de necessidades tecnológicas; promoção de idéias inovadoras } \\
\text { em nível Europeu e por meio da Rede Centros de Inovação (IRC), } \\
\text { identificação de parceiros para a aquisição de tecnologias; promoção da } \\
\text { assinatura de acordos transnacionais de transferência tecnológica; apoio } \\
\text { a projetos de pesquisa e de desenvolvimento tecnológico no âmbito do } \\
\text { quadro dos programas de pesquisa e inovação da União Européia. }\end{array}$ \\
\hline $\begin{array}{l}\text { Area } \\
\text { Science } \\
\text { Park }\end{array}$ & $I T I$ & $\begin{array}{l}\text { O projeto International Technology Incubators (ITI) tem por objetivo } \\
\text { promover e gerir o grupo de PME de alta tecnologia inovadora Italiana que } \\
\text { deseja estabelecer seus negócios no exterior. O projeto é baseado numa } \\
\text { organização conjunta capaz de assistir as PME na alocação em } \\
\text { incubadoras tecnológicas especializadas, promovendo a } \\
\text { internacionalização das empresas Italianas em direção a uma } \\
\text { convergência de crescimento econômico e industrial com o } \\
\text { desenvolvimento de negócios intensivos em conhecimento. } \\
\text { As principais questões do projeto são: reforçar as competências e } \\
\text { conhecimentos dos sistemas científicos e produtivos italianos; promover a } \\
\text { criação de parcerias técnicas e industriais; compartilhar metodologias, } \\
\text { serviços e estruturas. } \\
\text { O ITI oferece serviços profissionais avançados pelo sistema de } \\
\text { subcontratação de profissionais locais e de empresas locais, serviços tais } \\
\text { como: espaços físicos para receber empresas e laboratórios de P\&D; } \\
\text { representação legal e assessorias; consultoria administrativa; } \\
\text { intermediação de marketing; intermediação financeira; rede de } \\
\text { relacionamentos com Universidades e centros de pesquisa; treinamento; } \\
\text { serviços subordinados (ancillary services). }\end{array}$ \\
\hline $\begin{array}{l}\text { Area } \\
\text { Science } \\
\text { Park }\end{array}$ & Novaregio & $\begin{array}{l}\text { Novaregio é um projeto internacional que tem por objetivo tornar o Friuli- } \\
\text { Venezia Giulia uma das Regiões Inovadoras da Europa, por meio de uma } \\
\text { análise comparativa das melhores e mais efetivas políticas e estratégias } \\
\text { regionais e governamentais, direcionadas à inovação em âmbito Europeu. } \\
\text { O projeto indicará os melhores caminhos a seguir para adotar tais práticas } \\
\text { a nível local. } \\
\text { O projeto Novaregio tem oito parceiros de sete países Europeus (Áustria, } \\
\text { Grécia, Itália, Espanha, Eslovênia, Suécia e Hungria), hábeis na } \\
\text { promoção da inovação e nos link-ups com instituições influentes operando } \\
\text { junto com o governo regional e suporte a inovação. O projeto também } \\
\text { atua junto a duas significativas redes Européias: a CEI - Central European } \\
\text { Initiative (com } 17 \text { estados membros) e a CPMR - Conference of Peripheral } \\
\text { Maritime Regions of Europe (representando } 140 \text { áreas periféricas e } \\
\text { marítimas da Europa). Os objetivos do projeto são: elaborar um plano de }\end{array}$ \\
\hline
\end{tabular}




\begin{tabular}{|c|c|c|}
\hline \multicolumn{3}{|c|}{ TABELA 6.2 - Identificação das melhores práticas e descrição em linhas gerais } \\
\hline PCT & Prática & Descrição da prática (linhas gerais) \\
\hline $\begin{array}{l}\text { Area } \\
\text { Science } \\
\text { Park }\end{array}$ & $\begin{array}{l}\text { Novaregio } \\
\text { No }\end{array}$ & $\begin{array}{l}\text { ações para a coordenação de políticas de inovação; criar um centro } \\
\text { Europeu virtual para a publicação online e pooling de conhecimento em } \\
\text { matéria de políticas de inovação; produzir uma análise comparativa das } \\
\text { melhores e mais efetivas políticas e estratégias dos governos regionais, } \\
\text { referentes à inovação em nível Europeu, para que elas possam ser } \\
\text { adotadas em nível local; fazer um manual de benchmarking contendo } \\
\text { exemplos políticas de financiamento da inovação regional e promover a } \\
\text { difusão de } 10 \text { casos de boas práticas na Europa, escolhidas de } 25 \\
\text { exemplos de sucesso; e encorajar organizações regionais a adotarem as } \\
\text { instruções sugeridas no manual. }\end{array}$ \\
\hline $\begin{array}{l}\text { Area } \\
\text { Science } \\
\text { Park }\end{array}$ & $\begin{array}{l}\text { Novimpres } \\
\text { a Project }\end{array}$ & $\begin{array}{l}\text { O projeto Novimpresa foi criado em } 1997 \text { e é uma iniciativa do AREA } \\
\text { Science Park que tem por objetivo promover a difusão da inovação das } \\
\text { PME da região do Friuli-Venezia Giulia. O projeto é resultado da } \\
\text { necessidade de tornar acessível aos negócios da região do Friuli-Venezia } \\
\text { Giulia o acesso ao conhecimento e habilidades desenvolvidas nas áreas } \\
\text { próximas a duas universidades, aos Centros de Excelência científica e ao } \\
\text { AREA Science Park. } \\
\text { O AREA oferece suporte de qualidade aos empreendedores locais e pode } \\
\text { ajudá-los no desenvolvimento de produtos, processos e gestão } \\
\text { inovadores. O projeto Novimpresa está concentrado nas seguintes } \\
\text { estratégias básicas de ação: ação intensiva na região por meio de } \\
\text { pesquisas porta-a-porta; colaboração com os órgãos de pesquisa e } \\
\text { instituições com o objetivo de desenvolver uma rede de competências na } \\
\text { região do Friuli-Venezia Giulia; transferência de habilidades e expertise de } \\
\text { vários setores e contextos; desenvolvimento de colaboração entre } \\
\text { negócios e compartilhamento de necessidades de inovação. O projeto } \\
\text { atua com uma mix de instrumentos inovadores, serviços e expertise } \\
\text { disponível para negócios. Os resultados obtidos pelo projeto até o } \\
\text { momento são os seguintes: contato com } 1071 \text { empreendimentos, visita a } \\
493 \text { deles, } 500 \text { ações efetivas de inovação em } 26 \text { setores. } \\
\text { As atividades do projeto Novimpresa foram co-fundadas pela União } \\
\text { Européia por meio do Fundo de Desenvolvimento Regional Europeu } \\
\text { (FESR), pelo Estado Italiano, pela Região do Friuli-Venezia Giulia e pelo } \\
\text { AREA Science Park. }\end{array}$ \\
\hline $\begin{array}{l}\text { Area } \\
\text { Science } \\
\text { Park }\end{array}$ & $\begin{array}{l}\text { PATLIB } \\
\text { Library }\end{array}$ & $\begin{array}{l}\text { O Centro de Informações PATLIB (PATent LIBrary) do AREA Science } \\
\text { Park foi criado com o objetivo de prover aos usuários o acesso local a } \\
\text { informações sobre patentes e assuntos relacionados. O centro investiu na } \\
\text { qualificação e experiência da equipe (experienced staff), que oferece } \\
\text { assistência prática em assuntos relacionados a direito de Propriedade } \\
\text { Intelectual. A equipe está familiarizada com as necessidades e requisitos } \\
\text { da indústria local, agricultura e comércio, e esta apta a fornecer serviços } \\
\text { de informação valiosos, especialmente às PME, inventores privados e } \\
\text { acadêmicos. }\end{array}$ \\
\hline $\begin{array}{l}\text { Area } \\
\text { Science } \\
\text { Park }\end{array}$ & $\begin{array}{l}\text { Projeto } \\
\text { Talent }\end{array}$ & $\begin{array}{l}\text { - "O AREA Science Park oferece diferentes tipos de consultoria de } \\
\text { serviços às PME. Há um projeto (Talent) o qual está especificamente } \\
\text { devotado a suportar as PME que atuam no campo da biotecnologia } \\
\text { baseada em diagnóstico e sistemas de detecção e aplicações nos setores }\end{array}$ \\
\hline
\end{tabular}




\begin{tabular}{|c|c|c|}
\hline \multicolumn{3}{|c|}{ TABELA 6.2 - Identificação das melhores práticas e descrição em linhas gerais } \\
\hline PCT & Prática & Descrição da prática (linhas gerais) \\
\hline $\begin{array}{l}\text { Area } \\
\text { Science } \\
\text { Park }\end{array}$ & $\begin{array}{l}\ldots \\
\text { Projeto } \\
\text { Talent }\end{array}$ & $\begin{array}{l}\text { Alimentar, de Saúde e Ambiental. Consultores altamente qualificados } \\
\text { desenvolvem um conjunto de ações coordenadas para ir de encontro às } \\
\text { habilidades das PME e necessidades de cientistas, tecnologias de ponta } \\
\text { (leading-edge) e transnacionais, Consórcios de P\&D para suportar as PME } \\
\text { na participação ativa; e para beneficiarem se do processo de inovação } \\
\text { Biotecnológica por meio dos recursos do FP6. } \\
\text { O International Fellowships Programme "Talents" é um programa de } \\
\text { mobilidade regional, promovido pelo AREA Science Park e criado em abril } \\
\text { de } 2005 \text {; ele busca estimular o potencial científico da região por meio do } \\
\text { aumento do capital de recursos humanos qualificados e pela troca de } \\
\text { conhecimento, anunciando periodicamente cooperações de mobilidade } \\
\text { (mobility fellowship) criadas por vários organismos para a seleção de } \\
\text { jovens pesquisadores com alto nível de habilidade científica. } \\
\text { O Talents procura criar uma rede regional de inovação que poderá } \\
\text { aumentar a cooperação entre o mundo da pesquisa e o da indústria. } \\
\text { Também promove a transferência de conhecimentos inovadores } \\
\text { provenientes das pesquisas, dos centros de transferência tecnológica, dos } \\
\text { centros de inovação e das universidades, para o sistema produtivo da } \\
\text { região. As características essenciais das atividades de pesquisa cobertas } \\
\text { pelo projeto são interdisciplinares, multidisciplinares, originais e } \\
\text { inovadoras. Atenção especial é dada às atividades de pesquisa de longo } \\
\text { prazo na região, as quais não devem ser interrompidas durante a } \\
\text { pesquisa fellowship anunciada. Ao mesmo tempo, o projeto considera o } \\
\text { potencial de estabelecer redes de excelência úteis e estáveis em áreas } \\
\text { científicas específicas. }\end{array}$ \\
\hline $\begin{array}{l}\text { Area } \\
\text { Science } \\
\text { Park }\end{array}$ & Scounting & $\begin{array}{l}\text { O projeto Scouting, desenvolvido pelo AREA Science Park em 2006, } \\
\text { pretende fortalecer a competitividade das empresas estimulando novos } \\
\text { projetos baseado em idéias que ainda não tenham sido colocadas em } \\
\text { prática. Ele oferece serviços relacionados a oportunidades de inovação } \\
\text { para empresas, sobretudo às pertencentes à Associação Manufatureira } \\
\text { de Trieste, um parceiro do AREA para o desenvolvimento da inovação. } \\
\text { Em particular, o projeto suporta o estágio inicial mais crítico de cada } \\
\text { projeto estimulando a transferência de tecnologia; prove também } \\
\text { assistência de especialista e de suporte financeiro. Especificamente, o } \\
\text { AREA disponibiliza seu conhecimento e recursos às empresas enquanto a } \\
\text { Câmara de Comércio de Trieste provê os fundos necessários. } \\
\text { Ainda, são oferecidos os seguintes serviços gratuitos: acesso às } \\
\text { necessidades para inovação; definição das estratégias potenciais; coleta } \\
\text { de patentes e de informação documental; identificação das técnicas e } \\
\text { habilidades científicas mais apropriadas; elaboração de planos de projeto. } \\
\text { Um número limitado de projetos de inovação pode receber também } \\
\text { fundos para executar as seguintes atividades: estudo e design de } \\
\text { soluções inovadoras; identificação de habilidades relevantes; contatos e } \\
\text { relações nacionais e/ou internacionais; analise de viabilidade técnica e } \\
\text { econômica; desenvolvimento e teste experimental de protótipos. }\end{array}$ \\
\hline $\begin{array}{l}\text { Area } \\
\text { Science } \\
\text { Park }\end{array}$ & SISTER & $\begin{array}{l}\text { O Escritório de Ligação SISTER (Sister - Liaison Office) é um projeto do } \\
\text { AREA Science Park criado em } 2001 \text { e desenvolvido por peritos do AREA, }\end{array}$ \\
\hline
\end{tabular}




\begin{tabular}{|c|c|c|}
\hline \multicolumn{3}{|c|}{ TABELA 6.2 - Identificação das melhores práticas e descrição em linhas gerais } \\
\hline PCT & Prática & Descrição da prática (linhas gerais) \\
\hline $\begin{array}{l}\text { Area } \\
\text { Science } \\
\text { Park }\end{array}$ & $\begin{array}{l}\ldots \\
\text { SISTER }\end{array}$ & $\begin{array}{l}\text { dedicado a aumentar a pesquisa na região do Friuli-Venezia Giulia. } \\
\text { Graças à colaboração com instituições regionais de pesquisa e de fundos } \\
\text { provenientes da região do Friuli-Venezia Giulia, o AREA implementou um } \\
\text { sistema permanente de transferência de conhecimentos e inovações } \\
\text { existentes e provenientes da pesquisa realizada no sistema regional, para } \\
\text { negócios. } \\
\text { O sistema elaborado e testado pelo Sister - Liaison Office representa um } \\
\text { caminho efetivo para organizar os procedimentos e serviços requeridos } \\
\text { para transferir os resultados da pesquisa para o mercado. Os serviços } \\
\text { oferecidos, tais como, a avaliação do potencial tecnológico de uma idéia, } \\
\text { a aplicabilidade da inovação, a análise de Mercado, a proteção de } \\
\text { propriedade intelectual e o suporte para a criação de novas empresas, } \\
\text { são disponibilizados sem custos a todos os pesquisadores da região do } \\
\text { Friuli-Venezia Giulia. Um das atividades promovidas pelo Sister- Liaison } \\
\text { Office foi a elaboração de um mapa das competências existentes nas } \\
\text { instituições de pesquisa da região que são aplicáveis à indústria, com o } \\
\text { objetivo de incentivar a transferência de tecnologia para os negócios. } \\
\text { O sistema oferece uma vasta seleção de serviços para a transferência de } \\
\text { tecnologias, por exemplo, a avaliação do potencial tecnológico de uma } \\
\text { idéia, a aplicabilidade da inovação, a análise de Mercado, a proteção de } \\
\text { propriedade intelectual e o suporte para a criação de novas empresas. O } \\
\text { ano em que o projeto foi criado foi } 2001 \text {. } \\
\text { Até o momento os resultados obtidos foram os seguintes: } 153 \\
\text { pesquisadores contatados, } 183 \text { resultados de pesquisa identificados, } 322 \\
\text { atividades de aprimoramento iniciadas, } 30 \text { patentes registradas na Itália, } \\
18 \text { patentes registradas no exterior. }\end{array}$ \\
\hline $\begin{array}{l}\text { Area } \\
\text { Science } \\
\text { Park }\end{array}$ & $\begin{array}{l}\text { Support } \\
\text { Project }\end{array}$ & $\begin{array}{l}\text { O AREA Science Park participa no Support Project, fundado pelo } \\
\text { programa Leonardo da Vinci da União Européia. O objetivo do projeto é } \\
\text { criar, checar e difundir programas de treinamento e instrumentos de } \\
\text { incentivo à introdução, em PME, de metodologias e ferramentas que } \\
\text { podem apoiar a adoção de estratégias ecologicamente sustentáveis de } \\
\text { inovação. } \\
\text { O AREA atua definindo estrutura e desenho dos materiais de treinamento } \\
\text { criados no âmbito do projeto. Outros parceiros do projeto são: a } \\
\text { Universidade de Leoben na Austria; a Creax da Bélgica; o Instituto } \\
\text { Fraunhofer da Alemanha; o Joanneum Research da Austria e a } \\
\text { Universidade de Maribor da Eslovênia. }\end{array}$ \\
\hline $\begin{array}{l}\text { Madeira } \\
\text { Tecnopolo }\end{array}$ & $\begin{array}{l}\text { CIFEC } \\
\text { (Madeira } \\
\text { Tecnopolo) }\end{array}$ & $\begin{array}{l}\text { O Centro Internacional de Feiras e Congressos do Madeira Tecnopolo } \\
\text { (CIFEC) está instalado na área do Madeira Tecnopolo, o que confere ao } \\
\text { parque um espaço ideal para eventos. O CIFEC dispõe de grandes } \\
\text { espaços para exposições, múltiplas áreas para congressos e inúmeras } \\
\text { hipóteses de organização de espaço para atender as necessidades de } \\
\text { eventos com características diversas. } \\
\text { O Centro de Exposições possui } 5000 \mathrm{~m} 2 \text { de área de exposição, } \\
\text { distribuídos entre dois pavilhões contíguos e complementares que } \\
\text { possibilitam a montagem de até } 300 \text { módulos de } 9 \text { m2, inclusive utilizando } \\
\text { paredes móveis que conferem grande mobilidade aos espaços. A }\end{array}$ \\
\hline
\end{tabular}




\begin{tabular}{|c|c|c|}
\hline \multicolumn{3}{|c|}{ TABELA 6.2 - Identificação das melhores práticas e descrição em linhas gerais } \\
\hline PCT & Prática & Descrição da prática (linhas gerais) \\
\hline $\begin{array}{l}\text { Madeira } \\
\text { Tecnopolo }\end{array}$ & $\begin{array}{l}\ldots \\
\text { CIFEC } \\
\text { (Madeira } \\
\text { Tecnopolo) }\end{array}$ & $\begin{array}{l}\text { instalação de ligações elétricas, água, esgotos, telecomunicações, } \\
\text { internet, etc..., são facilmente acopladas graças às diversas galerias } \\
\text { técnicas situadas sob os pavilhões. O CIFEC possui também onze salas e } \\
\text { auditórios no seu Centro Congressos; e têm uma equipe de trabalho } \\
\text { formada por quatro organizadores de eventos, dois oficiais administrativos } \\
\text { e três oficiais de manutenção e serviços. }\end{array}$ \\
\hline $\begin{array}{l}\text { Parque } \\
\text { Tecnologic } \\
\text { o de } \\
\text { Andalucia } \\
\text { e AREA }\end{array}$ & $\begin{array}{l}\text { Estudos } \\
\text { prospectivo } \\
\text { s setoriais } \\
\text { realizados } \\
\text { pelos PCT }\end{array}$ & $\begin{array}{l}\text { São estudos sobre tendências tecnológicas em setores de interesse } \\
\text { como: setor de alimentos e setor mecânico (PTA), produtos alimentares, } \\
\text { ambientais e relacionados a indústria madeireira (AREA Science Park). }\end{array}$ \\
\hline $\begin{array}{l}\text { TECNOP } \\
\text { UC }\end{array}$ & $\begin{array}{l}\text { Encontro } \\
\text { de } \\
\text { Integração } \\
\text { de } \\
\text { Empresas } \\
\text { de TIC em } \\
\text { Inovação } \\
\text { Tecnológic } \\
\text { a } \\
\end{array}$ & $\begin{array}{l}\text { Trata-se de um evento promovido anualmente pelo TECNOPUC em } \\
\text { parceria com a AGT (Agência de Gestão Tecnológica) e a ASSESPRO } \\
\text { (Associação Brasileira de Software e Serviços de Informática); os } \\
\text { parceiros organizam e promovem anualmente o Encontro de Integração } \\
\text { das Empresas de TIC em Inovação Tecnológica do Rio Grande do Sul; no } \\
\text { evento é disponibilizado sem custo às empresas da área de TIC, um } \\
\text { espaço do campus central da PUCRS para fins de exposição de produtos } \\
\text { e serviços. }\end{array}$ \\
\hline $\begin{array}{l}\text { TECNOP } \\
\text { UC }\end{array}$ & $\begin{array}{l}\text { SAGE da } \\
\text { Incubadora } \\
\text { RAIAR }\end{array}$ & $\begin{array}{l}\text { O Serviço de Apoio a Gestão (SAGE) foi desenvolvido a partir de um } \\
\text { projeto de pesquisa encaminhado ao CNPq que disponibiliza bolsas para } \\
\text { uma equipe de cinco pessoas para dar suporte às ações institucionais da } \\
\text { Incubadora RAIAR do TECNOPUC e às empresas instaladas; dois } \\
\text { bolsistas desenvolvem o Plano de Negócios, o Planejamento Estratégico } \\
\text { e o Plano de Comercialização das empresas que ingressam na RAIAR, } \\
\text { além disso, acompanham o crescimento dos empreendimentos, elaboram } \\
\text { relatórios estatísticos e fazem a manutenção dos dados. }\end{array}$ \\
\hline
\end{tabular}

\subsection{A identificação dos fatores críticos de sucesso relacionados aos serviços do conhecimento}

A partir da observação dos resultados da pesquisa de campo (e-survey, caracterização dos PCT e entrevistas), são identificados os elementos estratégicos (visão, missão e objetivos) e os Fatores Críticos de Sucesso (FCS) apontados por cada PCT da amostra, e destacados os FCS relacionados aos serviços do conhecimento, objeto desta pesquisa.

$\mathrm{Na}$ Tabela 6.4 são apresentados os elementos estratégicos e os fatores críticos de sucesso destacados por cada PCT da amostra; a primeira coluna identifica o PCT, a segunda coluna indica os elementos estratégicos de cada PCT; e a terceira coluna apresenta os fatores críticos de sucesso, sendo que os FCS relacionados aos serviços do conhecimento aparecem sublinhados. Observa-se 
também que, dentre os FCS apontados na terceira coluna da Tabela, diversos se relacionam à infra-estrutura e à imagem do parque.

\begin{tabular}{|c|c|c|}
\hline PCT & Elementos estratégicos & Fatores críticos de sucesso \\
\hline $\begin{array}{l}\text { Parque } \\
\text { Tecnológico de } \\
\text { Andalucía S.A. } \\
\text { (1) }\end{array}$ & $\begin{array}{l}\text { Ser motor de } \\
\text { desenvolvimento econômico } \\
\text { e tecnológica para a } \\
\text { província de Málaga e para a } \\
\text { Região de Andalucia. } \\
\text { Ser um lugar de alta } \\
\text { qualidade para a instalação } \\
\text { de PME e grandes } \\
\text { empresas, inovadoras e } \\
\text { respeitadoras com o meio } \\
\text { ambiente e que se dedicam } \\
\text { às áreas de: } \\
\text { - produção, serviços } \\
\text { avançados e pesquisa e } \\
\text { desenvolvimento. } \\
\text { - geração de conhecimentos } \\
\text { científicos e tecnológicos; } \\
\text { - implantação de atividades } \\
\text { industriais e de serviços de } \\
\text { alta qualidade; } \\
\text { - estabelecimento de } \\
\text { estruturas de serviços } \\
\text { tecnológicos e de formação } \\
\text { orientados às necessidades } \\
\text { das empresas e instituições. }\end{array}$ & $\begin{array}{ll}\text { o } & \text { Visibilidade internacional do Parque. } \\
\text { o } & \begin{array}{l}\text { Infra-estrutura básica e espaços de } \\
\text { qualidade. }\end{array} \\
\text { o } & \begin{array}{l}\text { Capacidade de criação e } \\
\text { desenvolvimento de PME inovadoras. }\end{array} \\
\text { o } & \begin{array}{l}\text { Apoio aos setores emergentes e } \\
\text { geradores de emprego. }\end{array} \\
\text { o } & \begin{array}{l}\text { Gerência de redes regionais e } \\
\text { internacionais de gestão do }\end{array} \\
\text { conhecimento (IASP, APTE e RETA) } \\
\text { o Estreita conexão com a Universidade } \\
\text { Málaga e com Centros de Pesquisa. } \\
\text { o Serviços de difusão e de transferência de } \\
\text { tecnologia } \\
\text { Apoio dos atores sociais (Junta de } \\
\text { Andalucia, Ayuntamento de Málaga, } \\
\text { sociedade malaguenha) } \\
\text { Oapacidade de adaptação às novas } \\
\text { demandas tecnológicas e sociais que } \\
\text { surgem no decorrer do tempo. } \\
\text { Utilização de um "modelo de } \\
\text { desenvolvimento empresarial contínuo", } \\
\text { composto de: pré-incubadoras (que } \\
\text { oferece espaço e serviços de pré- } \\
\text { incubação e abriga os empreendedores } \\
\text { que tem a idéia de criar uma empresa até } \\
\text { o momento em que ela seja constituída); } \\
\text { incubadoras (que oferece espaço e } \\
\text { serviços empresariais e abriga empresas } \\
\text { que estão começando a se desenvolver); } \\
\text { nidos ou ninhos (que oferece espaços e } \\
\text { serviços em regime de aluguel às } \\
\text { empresas que se instalam no PTA); } \\
\text { contenedores ou contentores (que } \\
\text { oferece espaços de tipos variados, } \\
\text { parcial ou totalmente construídos, } \\
\text { conforme a necessidade das empresas } \\
\text { que se instalam no PTA; e parcelas } \\
\text { (cessão de parcelas de terreno no PTA à } \\
\text { empresas interessadas, áreas de } \\
\text { tamanho variando entre 2500 m² a 50000 } \\
\text { m², nas modalidades de venda ou }\end{array}$ \\
\hline
\end{tabular}




\begin{tabular}{|c|c|c|c|}
\hline PCT & Elementos estratégicos & & Fatores críticos de sucesso \\
\hline $\begin{array}{l}\text {... Parque } \\
\text { Tecnológico de } \\
\text { Andalucía S.A. } \\
\text { (1) }\end{array}$ & & 0 & $\begin{array}{l}\text { concessão de direito de superfície por } 75 \\
\text { anos). } \\
\text { Atuação em redes locais/regionais: na } \\
\text { Red Andalucia Emprende por meio do } \\
\text { CADE (Centro de Apoyo al Desarollo } \\
\text { Empresarial); no BIC Euronova (Centro } \\
\text { Europeo de Empresas e Innovación de } \\
\text { Málaga). } \\
\text { Desenvolvimento de acões de formação } \\
\text { profissional baseadas na demanda } \\
\text { laboral no âmbito do marco empresarial } \\
\text { do PTA. Oferecimento de cursos e } \\
\text { treinamentos para formação de } \\
\text { profissionais. }\end{array}$ \\
\hline Centuria RIT (2) & $\begin{array}{l}\text { Favorecer o } \\
\text { desenvolvimento das } \\
\text { empresas associadas e do } \\
\text { território romagnolo por meio } \\
\text { da inovação tecnológica e da } \\
\text { organização nos setores } \\
\text { manufatureiro e } \\
\text { agroindustrial, encorajando a } \\
\text { troca de idéias, a } \\
\text { transferência tecnológica e a } \\
\text { produção de conhecimento, } \\
\text { e se colocando como ponto } \\
\text { de encontro e de estímulo } \\
\text { entre as instituições, o } \\
\text { empreendedorismo e a } \\
\text { pesquisa. } \\
\text { Aumentar a competitividade } \\
\text { do território e das empresas } \\
\text { locais por meio da inovação } \\
\text { no setor agroindustrial e } \\
\text { manufatureiro. } \\
\text { Desenvolver ações voltadas } \\
\text { para: } \\
\text { - a otimização do fluxo de } \\
\text { informações qualificadas } \\
\text { sobre o tema de inovação, } \\
\text { seja selecionando e } \\
\text { drenando do ambiente } \\
\text { externo ao local, seja } \\
\text { favorecendo o diálogo entre } \\
\text { os diversos atores do } \\
\text { sistema local; }\end{array}$ & 0 & $\begin{array}{l}\text { Atuação como agente de geração, } \\
\text { promoção e difusão da inovação } \\
\text { tecnológica e organizacional, servindo ao } \\
\text { sistema local de produção para ajudar a } \\
\text { manter o elevado padrão qualitativo e } \\
\text { quantitativo. } \\
\text { Atendimento das necessidades de sua } \\
\text { base social constituindo os principais } \\
\text { horizontes estratégicos e operacionais do } \\
\text { Centuria RIT. } \\
\text { Atuação em redes locais/regionais como } \\
\text { ponto de juncão dinâmico entre os } \\
\text { diferentes sistemas de relações; abertura } \\
\text { para as possibilidades qualificadas de } \\
\text { parceria com os agentes que participam } \\
\text { de redes empresariais e de pesquisa. } \\
\text { Atividades de informação e rede de } \\
\text { relacionamentos (networking - Membro } \\
\text { da APSTI e IASP, parceiro do IRC-Irene, } \\
\text { membro representante para a Itália da } \\
\text { rede EUROLINK Partners, parceiro da } \\
\text { INSME; } \\
\text { O fato dos membros do Centúria RIT } \\
\text { estarem em conformidade com os valores } \\
\text { orientadores gerais e os benefícios das } \\
\text { suas iniciativas serem projetados em um } \\
\text { horizonte que abarca a totalidade do } \\
\text { território de referência. } \\
\text { A constante busca da "solução leve" (soft } \\
\text { solution), que favorece os serviços } \\
\text { imateriais, a flexibilidade e a aderência às } \\
\text { exigências do mundo empresarial. }\end{array}$ \\
\hline
\end{tabular}




\begin{tabular}{|c|c|c|c|}
\hline PCT & Elementos estratégicos & & Fatores críticos de sucesso \\
\hline $\begin{array}{l}\text {... Centuria RIT } \\
\text { (2) }\end{array}$ & $\begin{array}{l}\text { - o aumento da capacidade } \\
\text { local de investimento } \\
\text { tecnológico; e } \\
\text { - o estímulo à realização de } \\
\text { sinergia profícua entre os } \\
\text { sujeitos locais em uma ótica } \\
\text { integrada e interdisciplinar. }\end{array}$ & 0 & $\begin{array}{l}\text { As atividades realizadas pelo Centuria } \\
\text { RIT, a saber, divulgação, projetos e } \\
\text { consultoria. }\end{array}$ \\
\hline $\begin{array}{l}\text { Parque } \\
\text { Tecnológico de } \\
\text { Viçosa-PTV } \\
\text { (3) }\end{array}$ & $\begin{array}{l}\text { Incrementar a riqueza da } \\
\text { comunidade circunvizinha, } \\
\text { promovendo a cultura da } \\
\text { inovação e a competitividade } \\
\text { de suas empresas e } \\
\text { instituições geradoras de } \\
\text { saber, desenvolvimento local } \\
\text { e regional, através da } \\
\text { atração e fixação de novos } \\
\text { empreendimentos de base } \\
\text { tecnológica. } \\
\text { Criar condições físicas e } \\
\text { institucionais que facilitem e } \\
\text { promovam a transferência de } \\
\text { informações, experiências e } \\
\text { conhecimentos, gerados na } \\
\text { UFV, para o setor produtivo, } \\
\text { aproximando a universidade } \\
\text { à empresa através da } \\
\text { geração contínua de spin- } \\
\text { offs; } \\
\text { Desmistificar o saber } \\
\text { científico; } \\
\text { Aumentar a consciência da } \\
\text { população a respeito da } \\
\text { importância de se preservar } \\
\text { o meio ambiente; } \\
\text { Oferecer condições para o } \\
\text { desenvolvimento de } \\
\text { atividades relacionadas com } \\
\text { o empreendedorismo social, } \\
\text { em paralelo com as } \\
\text { atividades empresariais. }\end{array}$ & 0 & $\begin{array}{l}\text { Instalações que privilegiam o acesso do } \\
\text { Parque ao público e atividades que } \\
\text { dinamizam as relações internas e } \\
\text { aumentam a interação com a cidade. } \\
\text { Um sistema viário interno que permite } \\
\text { várias conexões com as vias que cruzam } \\
\text { a área, garantindo que os fluxos } \\
\text { existentes permaneçam ativos após a } \\
\text { sua implantação; } \\
\text { implantação de um Centro de Estudos } \\
\text { Ambientais; } \\
\text { implantação do Museu Interativo de } \\
\text { Ciência e Tecnologia; e } \\
\text { Desenvolvimento de projetos sociais que } \\
\text { permitem às empresas instaladas } \\
\text { interagirem com as comunidades de seu } \\
\text { entorno; e suprirem suas carências e } \\
\text { demandas por meio de ações. }\end{array}$ \\
\hline $\begin{array}{l}\text { Parque } \\
\text { Tecnológico de } \\
\text { Campinas (4) }\end{array}$ & $\begin{array}{l}\text { Ser promotor do } \\
\text { desenvolvimento econômico } \\
\text { e da inovação. } \\
\text { Atrair unidades públicas e } \\
\text { privadas de P\&D; } \\
\text { Atrair empresas já } \\
\text { existentes; e oferecer } \\
\text { desenvolvimento de novas }\end{array}$ & 0 & $\begin{array}{l}\text { - Ambiente de ensino e pesquisa que } \\
\text { serve de apoio ao desenvolvimento de } \\
\text { parcerias entre os Institutos de Pesquisa, } \\
\text { as Universidades e as empresas locais e } \\
\text { regionais, caracterizados pela UNICAMP, } \\
\text { Agência de Inovação da Unicamp } \\
\text { (INOVA), PUC-Campinas, LNLS, CPqD, } \\
\text { CenPRA, EMBRAPA, IAC, entre outros. }\end{array}$ \\
\hline
\end{tabular}




\begin{tabular}{|c|c|c|c|}
\hline PCT & Elementos estratégicos & & Fatores críticos de sucesso \\
\hline $\begin{array}{l}\text {... Parque } \\
\text { Tecnológico de } \\
\text { Campinas (4) }\end{array}$ & $\begin{array}{l}\text { empresas de base } \\
\text { tecnológica; espaço para } \\
\text { incubação; e } \\
\text { Criar e reter empregos de } \\
\text { alto valor agregado; } \\
\text { Comercializar novas } \\
\text { tecnologias; } \\
\text { Incubar novas tecnologias } \\
\text { orientadas para negócios; } \\
\text { Promover a competência das } \\
\text { instituições acadêmicas e de } \\
\text { pesquisa de Campinas; e } \\
\text { Promover relações entre a } \\
\text { indústria, o governo e a } \\
\text { academia. }\end{array}$ & 0 & $\begin{array}{l}\text { Ambiente Empresarial de relevo no } \\
\text { cenário nacional e internacional e } \\
\text { ambiente favorável à atração de novas } \\
\text { empresas - segundo maior parque } \\
\text { industrial do Estado de São Paulo e do } \\
\text { Brasil, com várias empresas do setor de } \\
\text { tecnologias da informação, instaladas na } \\
\text { região, como: Algar, Alcatel, Avex, } \\
\text { Compaq, Hewlett Packard, Motorola, } \\
\text { Nextel, Nortel Networks, entre outras. } \\
\text { Infra-estrutura - região que articula } \\
\text { Campinas à Região Metropolitana de São } \\
\text { Paulo, ao principal porto marítimo do país } \\
\text { - Porto de Santos, e ao interior do Estado } \\
\text { de São Paulo. Rede básica de fibra ótica } \\
\text { que interliga as principais instituições de } \\
\text { pesquisa do Estado de São Paulo pelo } \\
\text { sistema de "Internet rápida". } \\
\text { Sistemas de Incubadoras - Na área do } \\
\text { Parque Tecnológico e entorno estão } \\
\text { instaladas três incubadoras: INCAMP; } \\
\text { SOFTEX e NADE do CIATEC. } \\
\text { Agência de Inovação INOVA - que } \\
\text { estimula parcerias e articula atividades da } \\
\text { Unicamp com empresas, setor público, } \\
\text { institutos e fundações; realiza cursos de } \\
\text { extensão e especializacão, projetos de } \\
\text { P\&D cooperativos, consultorias, } \\
\text { pareceres técnicos, licenciamento de } \\
\text { patentes, ensaios e certificação, } \\
\text { contratação de egressos da Unicamp e } \\
\text { oferta de estágios qualificados; entre } \\
\text { outras ações. }\end{array}$ \\
\hline $\begin{array}{l}\text { Hong Kong } \\
\text { Science \& } \\
\text { Technology } \\
\text { Parks } \\
\text { Corporation (5) }\end{array}$ & $\begin{array}{l}\text { Ter papel de liderança em } \\
\text { Hong Kong para se tornar } \\
\text { um importante centro } \\
\text { internacional de inovação e } \\
\text { geração de tecnologia no } \\
\text { desenvolvimento de clusters } \\
\text { específicos; e ser um hub de } \\
\text { alto valor agregado, } \\
\text { manufatura intensiva em } \\
\text { habilidades e aptidão em } \\
\text { serviços industriais. } \\
\text { Proporcionar infra-estrutura } \\
\text { de qualidade e instalações } \\
\text { de apoio à inovação e ao }\end{array}$ & 0 & $\begin{array}{l}\text { Atuação em quatro áreas tecnológicas: } \\
\text { eletrônica, biotecnologia, engenharia de } \\
\text { precisão e tecnologia da informação / } \\
\text { telecomunicação. } \\
\text { Instalações, espaços e equipamentos de } \\
\text { qualidade. } \\
\text { Serviços oferecidos pelo Centro de } \\
\text { Negócios; Salas multipropósito } \\
\text { equipadas; serviços relacionados à à } \\
\text { tecnologia da informação; InnoCentre } \\
\text { (apoio ao desenvolvimento de empresas } \\
\text { na área de design); Design Incubation } \\
\text { Programme; Centro de Apoio ao } \\
\text { Desenvolvimento da Informação e }\end{array}$ \\
\hline
\end{tabular}




\begin{tabular}{|c|c|c|c|}
\hline PCT & Elementos estratégicos & & Fatores críticos de sucesso \\
\hline $\begin{array}{l}\text {... Hong Kong } \\
\text { Science \& } \\
\text { Technology } \\
\text { Parks } \\
\text { Corporation (5) }\end{array}$ & $\begin{array}{l}\text { desenvolvimento tecnológico } \\
\text { a grupos específicos, à } \\
\text { modernização da indústria } \\
\text { manufatureira e às aptidões } \\
\text { da indústria de serviços, a } \\
\text { fim de prover serviços } \\
\text { completos em programas de } \\
\text { incubação para tecnologias } \\
\text { nascentes (technology start- } \\
\text { ups); e } \\
\text { Incrementar a parceria e a } \\
\text { colaboração entre a indústria } \\
\text { e as universidades / } \\
\text { institutos de pesquisa } \\
\text { aplicada, por meio de } \\
\text { consultoria, treinamento e } \\
\text { programas de pesquisa. }\end{array}$ & 0 & $\begin{array}{l}\text { Comunicação; } \text { Incu-Tech } \text { (programas de } \\
\text { incubação e apoio a start-ups e programa } \\
\text { de incubação de negócios); Technology } \\
\text { Support Laboratory; Wireless } \\
\text { Communications Test Laboratory - } \\
\text { WCTL; Programa STEP (Small } \\
\text { Technology/Design Incubation); } \\
\text { atendimento das necessidades } \\
\text { tecnológicas ou habilidades especiais } \\
\text { necessária às empresas; IC Design } \\
\text { Centre; Intellectual Property Servicing } \\
\text { Centre - IPSC; etc... } \\
\text { Instalações -_Centro Internacional de } \\
\text { Feiras e Congressos do Madeira } \\
\text { Tecnopolo (CIFEC); Centro de Empresas } \\
\text { de Inovação da Madeira } \\
\text { (CEIM), Agência Regional de Energia e } \\
\text { Ambiente (AREAM); Núcleo Estratégico } \\
\text { para a Sociedade de Informação (NESI); }\end{array}$ \\
\hline $\begin{array}{l}\text { Pólo Científico } \\
\text { da Madeira (6) }\end{array}$ & $\begin{array}{l}\text { Assumir-se como um centro } \\
\text { de competências, num } \\
\text { espaço físico que está em } \\
\text { constante atualização, } \\
\text { perseguindo o objetivo de } \\
\text { aproveitar e depois transmitir } \\
\text { a s vantagens que advêm } \\
\text { dos relacionamentos } \\
\text { institucionais do Parque no } \\
\text { espaço interno, com a } \\
\text { Região Autônoma do } \\
\text { Madeira e com Entidades } \\
\text { Internacionais. } \\
\text { - Atuar em duas áreas } \\
\text { prioritárias de negócios: } \\
\text { Projetos; e - Centro } \\
\text { Internacional de Feiras e } \\
\text { Congressos. } \\
\text { - Ter como áreas estratégias } \\
\text { de intervenção, as seguintes: } \\
\text { Inovação; Novas } \\
\text { Tecnologias de Informação e } \\
\text { Comunicação -NTIC; } \\
\text { Desenvolvimento } \\
\text { Sustentável; Ambiente; } \\
\text { Educação / Formação } \\
\text { avançada / e-Learning; e } \\
\text { Sociedade de Informação. }\end{array}$ & 0 & $\begin{array}{l}\text { Associação Portuguesa de Parques de } \\
\text { Ciência e Tecnologia (TecParques) - } \\
\text { sediada no Madeira Tecnopólo, a } \\
\text { TecParques promove a valorização dos } \\
\text { PCT e de sua interação com outras } \\
\text { organizações nacionais e internacionais, } \\
\text { visando a modernização do tecido } \\
\text { impresarial pela via da inovação } \\
\text { tecnológica de base e da transferência de } \\
\text { conhecimento. } \\
\text { Serviços oferecidos pelo CIFEC - Centro } \\
\text { Internacional de Feiras e Comgressos } \\
\text { As ações do Programa Regional de } \\
\text { Ações Inovadoras - PRAM, a saber: } \\
\text { ações nas áreas de Desenvolvimento } \\
\text { Sustentável; Sociedade do Conhecimento } \\
\text { (programa InTrack); e Turismo (Centro de } \\
\text { Investigação Aplicada de Turismo - } \\
\text { CIAT, Idea Travel, ISNOVA, } \\
\text { Tr@velSmarT card, TourlSt, NeTur, } \\
\text { Nitoura, Toureg-Research Driven Cluster } \\
\text { for Tourism Sector, Competitiveness and } \\
\text { Knowledge). }\end{array}$ \\
\hline
\end{tabular}




\begin{tabular}{|c|c|c|c|}
\hline PCT & Elementos estratégicos & & Fatores críticos de sucesso \\
\hline $\begin{array}{l}\text { Parque } \\
\text { Científico e } \\
\text { Tecnológico da } \\
\text { PUCRS - } \\
\text { TECNOPUC (7) }\end{array}$ & $\begin{array}{l}\text { - Desenvolvimento de } \\
\text { Inserir a PUCRS diretamente } \\
\text { no processo de } \\
\text { desenvolvimento tecno- } \\
\text { econômico-social da região e } \\
\text { do país. } \\
\text { Atrair empresas de pesquisa } \\
\text { e desenvolvimento (P\&D) } \\
\text { para trabalhar em parceria } \\
\text { com a Universidade; } \\
\text { Promover a criação e o } \\
\text { desenvolvimento de novas } \\
\text { empresas de base } \\
\text { tecnológica; } \\
\text { Atrair projetos de pesquisa e } \\
\text { desenvolvimento tecnológico } \\
\text { em geral; } \\
\text { Estimular a inovação e a } \\
\text { interação empresas- } \\
\text { Universidade; } \\
\text { Gerar uma sinergia positiva } \\
\text { entre o meio acadêmico e o } \\
\text { empresarial; e } \\
\text { Atuar de forma coordenada } \\
\text { com as esferas } \\
\text { governamentais, } \\
\text { particularmente no âmbito do } \\
\text { Projeto Porto Alegre } \\
\text { Tecnópole. }\end{array}$ & 0 & $\begin{array}{l}\text { Serviços oferecidos pela da Incubadora } \\
\text { Raiar (em particular os serviços do SAGE } \\
\text { - Serviço de Apoio a Gestão) da PUCRS } \\
\text { Localização em região de grande } \\
\text { potencial e infra-estrutura de ciência e } \\
\text { tecnologia (localizado no campus central } \\
\text { da PUCRS, posição geográfica } \\
\text { privilegiada em relação ao MERCOSUL). } \\
\text { Atuação em três áreas: Tecnologia da } \\
\text { Informação e Comunicação; Energia e } \\
\text { Física Aplicada; e Ciências Biológicas, da } \\
\text { Saúde e Biotecnologia. } \\
\text { Serviços oferecidos pelo ETT - Escritório } \\
\text { de Transferência de Tecnologia da } \\
\text { PUCRS, tais como: apoio a P\&D, registro } \\
\text { de propriedade intelectual, transferência } \\
\text { de tecnologia e capacitação de recursos } \\
\text { humanos. } \\
\text { Serviços oferecidos pela AGT da PUCRS } \\
\text { - Agência de Gestão Tecnológica e } \\
\text { Propriedade Intelectual da PUCRS, tais } \\
\text { como: apoio a projetos de P\&D } \\
\text { cooperados com empresas, serviços } \\
\text { relacionados à propriedade intelectual e } \\
\text { ações de fomento ao empreendedorismo. } \\
\text { Acesso aos serviços e instalações da } \\
\text { PUCRS - Laboratório Especializado em } \\
\text { Eletro-Eletrônica - LABELO; Centro de } \\
\text { Microscopia e Microanálises; CEPUC } \\
\text { (Centro de Eventos da PUCRS); } \\
\text { Biblioteca Central; Hospital São Lucas da } \\
\text { PUCRS; Instituto de Pesquisas } \\
\text { Biomédicas; EDIPUCRS; Museu de } \\
\text { Ciências e Tecnologia da PUCRS; } \\
\text { PUCRS Virtual Educação a Distância; e } \\
\text { Projeto GENOMA. }\end{array}$ \\
\hline $\begin{array}{l}\text { Technologiepark } \\
\text { Bremen (8) }\end{array}$ & $\begin{array}{l}\text { Ser um dos centros líderes } \\
\text { de alta tecnologia na } \\
\text { Alemanha. } \\
\text { Desenvolver-se e crescer } \\
\text { continuamente. }\end{array}$ & o & $\begin{array}{l}\text { Atuação da BIG Bremen - Economic } \\
\text { Development (agência central da cidade } \\
\text { de Bremen em matérias relacionadas ao } \\
\text { desenvolvimento de negócios na região). } \\
\text { Arquitetura que facilita a fertilização } \\
\text { cruzada e a comunicação } \\
\text { Sinergia gerada pela proximidade dos } \\
\text { negócios e da academia - já que no } \\
\text { espaço do parque estão juntos institutos } \\
\text { de pesquisa de classe mundial, empresas } \\
\text { de alta performance e mão de obra } \\
\text { qualificada. }\end{array}$ \\
\hline
\end{tabular}




\begin{tabular}{|c|c|c|c|}
\hline \multicolumn{4}{|c|}{ TABELA 6.4 - Planejamento Estratégico dos PCT da amostra selecionada } \\
\hline PCT & Elementos estratégicos & & Fatores críticos de sucesso \\
\hline $\begin{array}{l}\text { Technologiepark } \\
\text { Bremen (8) }\end{array}$ & & 0 & $\begin{array}{l}\text { Instalação de empresas de porte no } \\
\text { parque (ex. Siemens) como âncoras e } \\
\text { atração de outras empresas das cadeias } \\
\text { e instalação de institutos de pesquisa de } \\
\text { classe mundial (ex. Max-Planck e } \\
\text { Fraunhofer) } \\
\text { Ênfase no oferecimento contínuo de } \\
\text { espaços para instalação e expansão. }\end{array}$ \\
\hline $\begin{array}{l}\text { Polo } \\
\text { Tecnológico de } \\
\text { Pando (9) }\end{array}$ & $\begin{array}{l}\text { Promover a incorporação de } \\
\text { conhecimento e a produção } \\
\text { de bens e serviços, } \\
\text { originando a geração de } \\
\text { empregos e uma melhor } \\
\text { qualidade de vida aos } \\
\text { uruguaios. } \\
\text { Ser um Centro de referência } \\
\text { na América Latina dedicado } \\
\text { a P\&D, nas áreas de } \\
\text { Química e Biotecnologia, } \\
\text { fortemente vinculado aos } \\
\text { Setores farmacêutico, } \\
\text { alimentar e ambiental, } \\
\text { preferencialmente sob a } \\
\text { forma de associações de } \\
\text { risco e benefícios } \\
\text { compartilhados com as } \\
\text { empresas usuárias. } \\
\text { Ter como valores a } \\
\text { inovação; a responsabilidade } \\
\text { social; a integridade moral e } \\
\text { ética; e a excelência. } \\
\text { Atuar em contato direto com } \\
\text { as empresas e instituições } \\
\text { que potencialmente possam } \\
\text { demandar conhecimento, } \\
\text { organizando equipes de } \\
\text { trabalho por unidades } \\
\text { estratégicas, integradas por } \\
\text { um Chefe de Projetos e seu } \\
\text { correspondente grupo de } \\
\text { Pesquisadores e } \\
\text { Tecnólogos. }\end{array}$ & 0 & $\begin{array}{l}\text { Localização - na cidade de Pando, a } 37 \\
\text { km de Montevideo, } 15 \text { km do Aeroporto } \\
\text { Internacional de Carrasco. } \\
\text { Instalações - edifício principal de } 4000 \\
\mathrm{~m}^{2}, 15 \text { laboratórios que ocupam uma } \\
\text { área de } 1200 \mathrm{~m}^{2}, \text { área destinada às } \\
\text { plantas pilotos, locais onde funcionam os } \\
\text { projetos de empresas em incubação e um } \\
\text { parque de aproximadamente } 70000 \mathrm{~m}^{2} \text {. } \\
\text { Muitas plataformas tecnológicas } \\
\text { disponíveis, como: Química Analítica/ } \\
\text { estrutural, Análises Fisicoquímicas, } \\
\text { Ensaios Biofarmacêuticos, Purificação e } \\
\text { caracterização de proteínas, Síntese e } \\
\text { caracterização de peptídeos, Produção e } \\
\text { caracterização de anticorpos poli e } \\
\text { monoclonais, etc... } \\
\text { Atuação como provedor permanente de } \\
\text { P\&D e Serviços Tecnológicos utilizando o } \\
\text { sistema de pesquisa por contrato; } \\
\text { Atuação como incubadora de } \\
\text { departamentos de P\&D; } \\
\text { Serviços oferecidos aos } \\
\text { empreendimentos incubados: provisão do } \\
\text { local, acesso aos laboratórios de } \\
\text { pesquisa e às plantas piloto, apoio } \\
\text { científico e dos pesquisadores, } \\
\text { capacitação em negócios e apoio por } \\
\text { meio de organizações parceiras } \\
\text { (Fundasol e Incubadora Ingenio). } \\
\text { Serviços tecnológicos oferecidos - } \\
\text { Atividades de P\&D em parceria e por } \\
\text { contrato, serviços analíticos de alta } \\
\text { tecnologia, capacitação de pessoal } \\
\text { adaptado às necessidades das } \\
\text { empresas, Assessoramento integral em } \\
\text { temas de propriedade intelectual, } \\
\text { Assessoramento em Inteligência } \\
\text { Competitiva. }\end{array}$ \\
\hline
\end{tabular}

TABELA 6.4 - Planejamento Estratégico dos PCT da amostra selecionada 


\begin{tabular}{|c|c|c|c|}
\hline PCT & Elementos estratégicos & & Fatores críticos de sucesso \\
\hline $\begin{array}{l}\text { Technologiepark } \\
\text { Heildelberg (10) }\end{array}$ & $\begin{array}{l}\text { Ser o cluster biotecnológico } \\
\text { da região do Rhein-Neckar, } \\
\text { considerado um dos mais } \\
\text { importantes parques na área } \\
\text { de biotecnologia da } \\
\text { Alemanha e do mundo. } \\
\text { Atuar na área de } \\
\text { biotecnologia, área médica, } \\
\text { informação, comunicação e } \\
\text { tecnologias ambientais, bem } \\
\text { como em ambiente de } \\
\text { negócios. }\end{array}$ & 0 & $\begin{array}{l}\text { Vínculo com a Universidade de Ruprecht- } \\
\text { Karls e Universidade de Heidelberg. } \\
\text { Instalação de Institutos de pesquisa de } \\
\text { renome (EMBL, DKFZ, ZMBH, BZH Max } \\
\text { Planck Institute for Medical Research and } \\
\text { Cell Biology). } \\
\text { Instalação de vários campi situados na } \\
\text { cidade de Heidelberg e divididos por } \\
\text { áreas de especialidade (Heidelberg } \\
\text { Technology Park BioPark I, Heidelberg } \\
\text { Technology Park BioPark II, Heidelberg } \\
\text { Technology Park UmweltPark e Start-up } \\
\text { center for female entrepreneurs, } \\
\text { Localização dos campi e a arquitetura } \\
\text { dos espaços que privilegia a proximidade } \\
\text { de empresas e institutos de pesquisa. } \\
\text { Serviços de apoio abrangentes e atuação } \\
\text { em estreita colaboração com empresas e } \\
\text { institutos de pesquisa; } \\
\text { Base de dados completa em várias áreas } \\
\text { do conhecimento } \\
\text { Programas internacionais de treinamento } \\
\text { sob medida } \\
\text { Fórum de discussão e eventos (cursos de } \\
\text { treinamento, seminários e conferências) } \\
\text { sobre assuntos de interesse (negócios, } \\
\text { educação, pesquisa e desenvolvimento, } \\
\text { programas de apoio) } \\
\text { Participação em programas de apoio } \\
\text { regionais, nacionais e internacionais. }\end{array}$ \\
\hline $\begin{array}{l}\text { Parco } \\
\text { Tecnologico } \\
\text { Padano (11) }\end{array}$ & $\begin{array}{l}\text { Ser líder no desenvolvimento } \\
\text { regional e principal cluster } \\
\text { biotecnológico do Sul da } \\
\text { Europa. } \\
\text { Construir uma rede sócio- } \\
\text { política e financeira de } \\
\text { pesquisa com o objetivo de } \\
\text { - lidar com as necessidades } \\
\text { regionais; } \\
\text { - realizar pesquisas } \\
\text { altamente eficazes para } \\
\text { apoiar o desenvolvimento } \\
\text { regional; e } \\
\text { - criar start-ups e spin-offs } \\
\text { por meio do oferecimento } \\
\text { know-how, incubadora, } \\
\text { instalações e serviços. }\end{array}$ & 0 & $\begin{array}{l}\text { Vínculos com a região da Lombardia, } \\
\text { com a cidade de Lodi, com a } \\
\text { Universidade de Milão, e instituições } \\
\text { locais. } \\
\text { Atuação como articulador do Cluster } \\
\text { Biotecnológico de Lodi } \\
\text { Instalações - Prédio do PTP, Parque de } \\
\text { Negócios, Incubadora do parque, } \\
\text { CERSA, Casa da Agricultura e Instituto } \\
\text { Zooprofilattico Sperimentale. } \\
\text { Serviços tecnológicos: PTP Genomics } \\
\text { Plataform e Project Proposal Genomic } \\
\text { Analyses. } \\
\text { Atividades de pesquisa conduzidas pelo } \\
\text { CERSA - Agro-food Research Center, } \\
\text { que tem por missão efetuar pesquisa } \\
\text { inovadora no campo da genômica e } \\
\text { diversidade genética. }\end{array}$ \\
\hline
\end{tabular}




\begin{tabular}{|c|c|c|c|}
\hline PCT & Elementos estratégicos & & Fatores críticos de sucesso \\
\hline $\begin{array}{l}\text {... Parco } \\
\text { Tecnologico } \\
\text { Padano (11) }\end{array}$ & & 0 & $\begin{array}{l}\text { Desenvolvimento de startups e spin-offs, } \\
\text { por meio do oferecimento de } \\
\text { conhecimento, instalações e serviços às } \\
\text { empresas. }\end{array}$ \\
\hline $\begin{array}{l}\text { Metu- } \\
\text { Technopolis } \\
\text { (12) }\end{array}$ & $\begin{array}{l}\text { Ser apoio à formação e ao } \\
\text { desenvolvimento de alta } \\
\text { tecnologia para empresas } \\
\text { produtoras e utilizadores. } \\
\text { Aumentar a colaboração } \\
\text { internacional e os contatos } \\
\text { para estabelecimento de } \\
\text { parcerias; } \\
\text { Apoiar o empreendedorismo } \\
\text { e a inovação; } \\
\text { Apoiar a pesquisa e o } \\
\text { desenvolvimento regional; } \\
\text { Instigar e manter a } \\
\text { colaboração universidade- } \\
\text { empresa; } \\
\text { Apoiar a transformação da } \\
\text { infra-estrutura de pesquisa } \\
\text { universitária e a acumulação } \\
\text { de informações em valor } \\
\text { econômico por meio de spin- } \\
\text { offs; } \\
\text { Preparar o ambiente } \\
\text { adequado para a } \\
\text { transferência tecnológica e } \\
\text { para o investimento } \\
\text { estrangeiro direto; } \\
\text { Criar empregos para } \\
\text { recursos humanos } \\
\text { qualificados; e promover a } \\
\text { universidade baseada em } \\
\text { start-ups e spin-offs. }\end{array}$ & $\begin{array}{l}0 \\
0\end{array}$ & $\begin{array}{l}\text { Vínculo com a Universidade METU. } \\
\text { Instalações disponibilizadas (Metu-Smido } \\
\text { Technology Development Centre; Metu- } \\
\text { Halycy Software House; Metu-Twins } \\
\text { Building; Metu-Silver Blocks; Silicon } \\
\text { Blocks; Gallium Buiding; Centro de } \\
\text { incubação Metutech Middle East Industry } \\
\text { and Commerce Center (OSTIM); Centro } \\
\text { de Incubação do Metutech. } \\
\text { Serviços de transferência de Tecnologia } \\
\text { (IRC Anatólia) } \\
\text { Serviços relacionados ao } \\
\text { Empreendedorismo ("New Ideas New } \\
\text { Businesses”, Metutech-BAN - rede de } \\
\text { business angels da Turquia, Pre- } \\
\text { incubation Center e Technology Transfer } \\
\text { Office- TTO) } \\
\text { Serviços de assistência e } \\
\text { aconselhamento a empresas (três } \\
\text { categorias de serviços: programas de } \\
\text { treinamento, serviços de consultoria e } \\
\text { serviços de valor agregado. Serviços de } \\
\text { gerenciamento local - instalações de } \\
\text { gestão, serviços de telecomunicações, } \\
\text { segurança, manutenção de áreas, } \\
\text { serviços de gestão. } \\
\text { Serviços relacionados à obtenção de } \\
\text { recursos financeiros. } \\
\text { Serviços de apoio - Atividades sociais e } \\
\text { culturais, bancos, shopping centers, } \\
\text { restaurantes, centro de cultura e } \\
\text { convenções, livraria, piscinas, lavanderia, } \\
\text { ginásio de esportes, etc. }\end{array}$ \\
\hline $\begin{array}{l}\text { AREA Science } \\
\text { Park (13) }\end{array}$ & $\begin{array}{l}\text { Ser um dos mais importantes } \\
\text { centros de excelência da } \\
\text { Europa. } \\
\text { Favorecer o } \\
\text { desenvolvimento territorial e } \\
\text { regional. } \\
\text { Apoiar a criação e o } \\
\text { crescimento de novas } \\
\text { iniciativas empreendedoras }\end{array}$ & $\begin{array}{l}\text { Locali } \\
\text { campl } \\
\text { dois c } \\
\text { de pe } \\
\text { institu } \\
\text { oferec } \\
-\underline{\text { trans }} \\
-\underline{\text { apc }} \\
-\underline{p a} \\
-p e\end{array}$ & $\begin{array}{l}\text { ação - em área de } 558.000 \mathrm{~m}^{2} \text { a oeste do } \\
\text { da Universidade Bilkent - Instalações - } \\
\text { mpi (Padriciano e Basovizza); } 84 \text { centros } \\
\text { qquisa instalados; e várias empresas e } \\
\text { s que atuam com P\&D. Serviços } \\
\text { dos por meio de execução de projetos de: } \\
\text { erência de tecnologia; } \\
\text { o à pesquisa; } \\
\text { intes; } \\
\text { quisa e inovação; }\end{array}$ \\
\hline
\end{tabular}




\begin{tabular}{|c|c|c|}
\hline \multicolumn{3}{|c|}{ TABELA 6.4 - Planejamento Estratégico dos PCT da amostra selecionada } \\
\hline PCT & Elementos estratégicos & Fatores críticos de sucesso \\
\hline $\begin{array}{l}\ldots \text { AREA } \\
\text { Science Park } \\
\text { (13) }\end{array}$ & $\begin{array}{l}\text { com alto conteúdo de } \\
\text { conhecimentos; } \\
\text { Oferecer às empresas, } \\
\text { institutos de pesquisa e } \\
\text { universidades, as condições } \\
\text { ideais para atuarem em } \\
\text { conjunto e de maneira } \\
\text { cooperativa; } \\
\text { Elevar o nível de } \\
\text { conhecimentos técnicos e } \\
\text { científicos, desenvolvendo a } \\
\text { pesquisa fundamental e } \\
\text { aplicada e definindo novas } \\
\text { tecnologias, produtos e } \\
\text { processos; e } \\
\text { Transferir Tecnologia e } \\
\text { atividades de gestão da } \\
\text { inovação no território. }\end{array}$ & $\begin{array}{l}\text { - parcerias internacionais e redes de } \\
\text { relacionamento (networks); } \\
\text { - } \text { treinamento; } \\
\text { - } \text { mobilidade; } \\
\text { - } \text { disseminação científica; e } \\
\text { - estudos setoriais }\end{array}$ \\
\hline $\begin{array}{l}\text { Ankara } \\
\text { Cyberpark (14) }\end{array}$ & $\begin{array}{l}\text { Ser reconhecido como um } \\
\text { centro de excelência para o } \\
\text { desenvolvimento científico e } \\
\text { tecnológico e tornar se uma } \\
\text { Cybercity que atenderá toda } \\
\text { a metrópole de Ankara. } \\
\text { Criar novos recursos e } \\
\text { melhorar a utilização dos } \\
\text { recursos existentes no } \\
\text { âmbito de seus parceiros } \\
\text { (parceiros, instalados, } \\
\text { estudantes, pesquisadores, } \\
\text { governos, municipalidade de } \\
\text { Ankara, etc...); } \\
\text { Prover aos instalados uma } \\
\text { atmosfera geradora de } \\
\text { sinergia e a melhor relação } \\
\text { custo-benefício em seus } \\
\text { serviços; } \\
\text { Proporcionar um novo } \\
\text { modelo de interação entre as } \\
\text { universidades e as empresas } \\
\text { do parque, com o maior } \\
\text { envolvimento dos } \\
\text { acadêmicos, estudantes e } \\
\text { pessoal de pesquisa; } \\
\text { Criar um cluster de } \\
\text { empresas nacionais e } \\
\text { internacionais de tecnologias }\end{array}$ & $\begin{array}{l}\text { O Vínculo com a Universidade privada } \\
\text { Bilkent do grupo Bilkent (composto por } \\
\text { várias empresas de software e de P\&D). } \\
\text { Serviço de provisão de espaços } \\
\text { apropriados (infra-estrutura de qualidade) } \\
\text { para instalação de escritórios, indústrias } \\
\text { e áreas de armazenamento às empresas } \\
\text { instaladas no parque. } \\
\text { Oerviços qualificados oferecidos aos } \\
\text { instalados: } \\
\text { - Fornecimento de infra-estrutura, serviços de } \\
\text { limpeza, serviços de manutenção, reparo e } \\
\text { jardinagem, brigada de incêndio, cuidados } \\
\text { médicos, correio, seguros, } \\
\text { - aconselhamento e treinamento, } \\
\text { - serviços de tecnologia da informação, } \\
\text { - } \text { serviços financeiros, } \\
\text { - serviços de propriedade intelectual, - agências } \\
\text { de viagens, restaurantes, centros comerciais, etc. } \\
\text { Instalações dedicadas à prestação de } \\
\text { serviços qualificados às empresas } \\
\text { instaladas: Incubation Center (espaços, } \\
\text { equipamentos, consultoria, treinamento, } \\
\text { etc...); Unidade de consultoria para } \\
\text { acesso a recursos financeiros e bolsas; } \\
\text { EU Center (aconselhamento e serviços } \\
\text { de treinamento para pessoas ou PME } \\
\text { que podem desenvolver projetos capazes }\end{array}$ \\
\hline
\end{tabular}




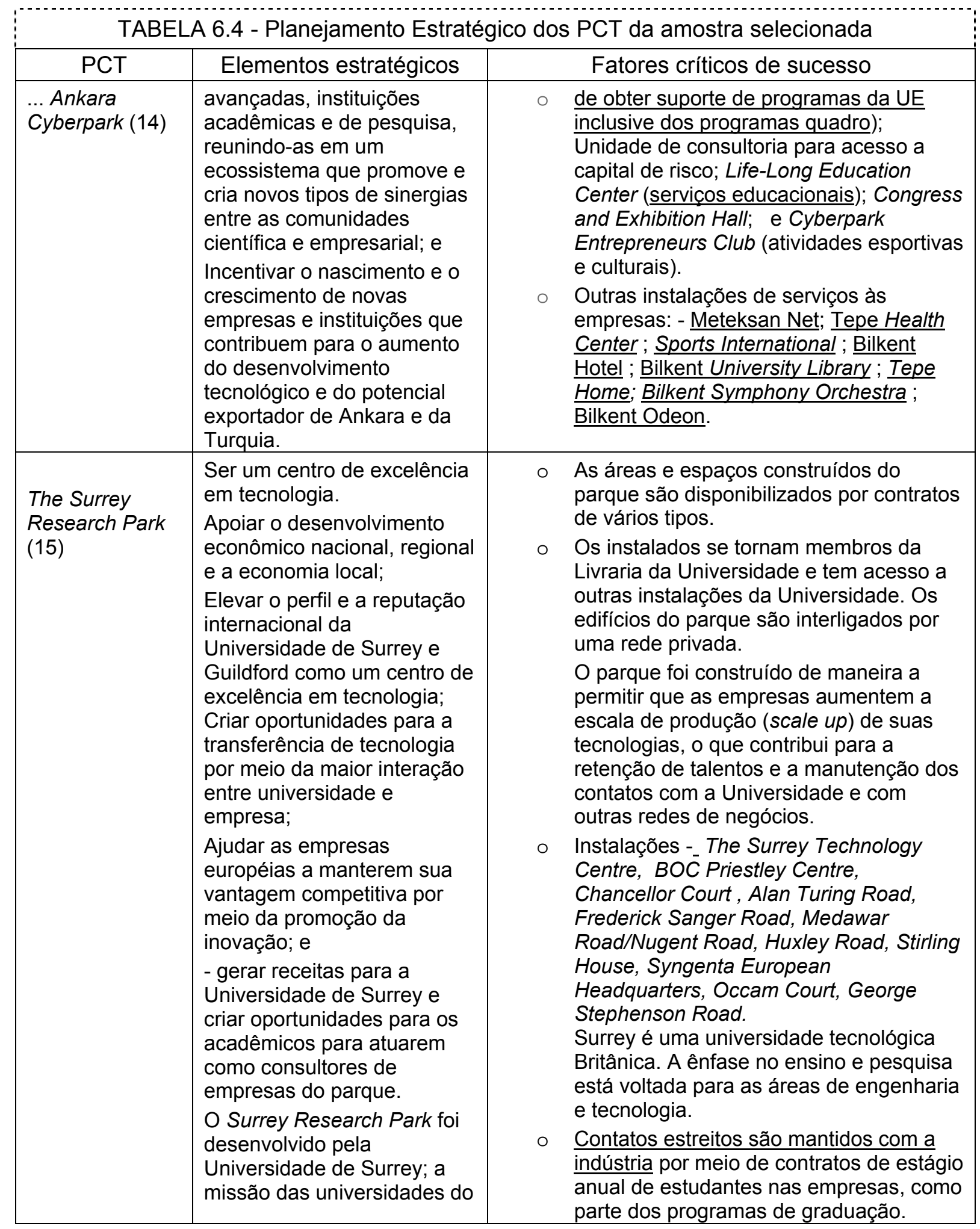


TABELA 6.4 - Planejamento Estratégico dos PCT da amostra selecionada

\begin{tabular}{|c|c|c|c|}
\hline PCT & Elementos estratégicos & & Fatores críticos de sucesso \\
\hline $\begin{array}{l}\text {.. The Surrey } \\
\text { Research Park } \\
\text { (15) }\end{array}$ & $\begin{array}{l}\text { Reino Unido é equilibrar três } \\
\text { elementos fundamentais: (1) } \\
\text { Geração de novos } \\
\text { conhecimentos; (2) Repasse } \\
\text { desse conhecimento para as } \\
\text { gerações futuras, e (3) } \\
\text { atender as necessidades das } \\
\text { empresas e da comunidade. }\end{array}$ & 0 & $\begin{array}{l}\text { A Universidade é bem sucedida em atrair } \\
\text { investimentos da indústria para fins de } \\
\text { pesquisa. } \\
\text { O contato com as empresas instaladas } \\
\text { no parque inclui participação ativa em } \\
\text { contratos de pesquisa, consultoria e } \\
\text { intercâmbio de pessoal, incluindo: projeto } \\
\text { de trabalho com estudantes, } \\
\text { "sanduíches" ou programas de } \\
\text { cooperação para estudantes alocados } \\
\text { nas empresas instaladas, contratação de } \\
\text { graduados e retenção do capital humano } \\
\text { no mercado de trabalho, treinamento e } \\
\text { intercâmbio de empregados entre } \\
\text { empresas do parque }\end{array}$ \\
\hline
\end{tabular}

Uma observação deve ser feita sobre o PCT (3) da amostra: se trata de um parque em fase de implantação, com planejamento estratégico inicial definido, considerando os serviços do conhecimento como fundamentais, conforme foi observado nas respostas do questionário, porém não experimentaram a realidade do parque em funcionamento e ainda não têm definidos todos os serviços do conhecimento que serão disponibilizados pelo parque.

Sendo assim, os levantamentos e análise realizados levam esta pesquisadora a concluir que os fatores críticos de sucesso dos PCT da amostra, no que se refere aos serviços do conhecimento que apóiam as PME de base tecnológica e contribuem para otimizar a relação empresa - universidade e centros de pesquisa, são os seis FCS a seguir:

(1) apoio à criação e o desenvolvimento das PME inovadoras;

(2) rede de relacionamentos internos e externos (networking) do parque;

(3) informações e treinamentos que beneficiem as PME inovadoras;

(4) apoio às PME inovadoras no que tange aos assuntos relacionados à transferência tecnológica dos produtos e serviços por elas realizados;

(5) apoio ao desenvolvimento de produtos e serviços tecnológicos das PME; e

(6) apoio à melhoria da gestão dos negócios das PME inovadoras.

Tais fatores críticos de sucesso (FCS) estão relacionados às dimensões 1 e 2 e respectivas sub-dimensões utilizadas na pesquisa; as melhores práticas 
identificadas na pesquisa confirmam a validade dessa afirmativa, conforme apresentado na Figura 6.4. 

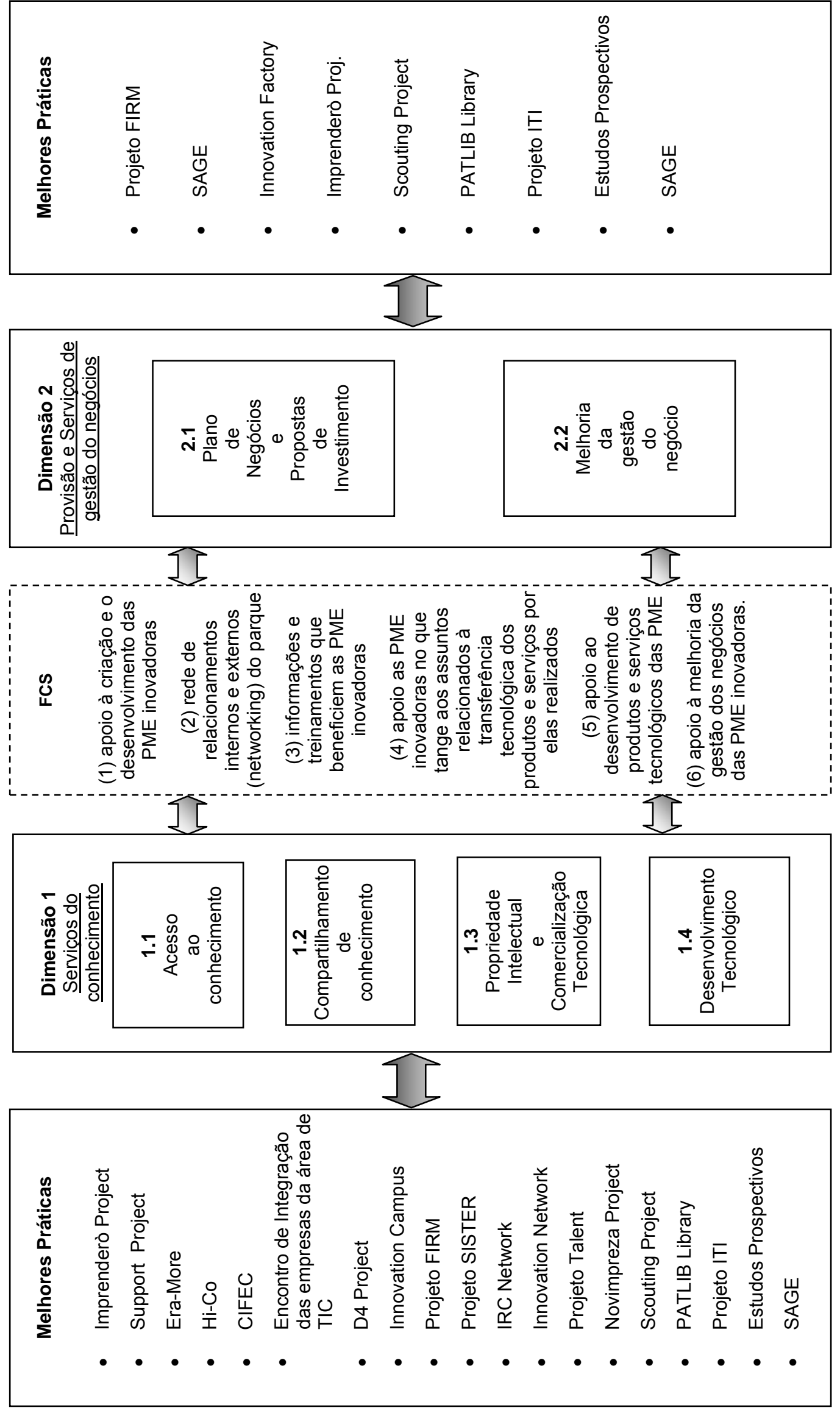

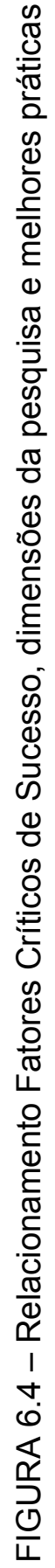




\section{FORMULAÇÃO DO MODELO CONCEITUAL}

Neste capítulo são abordados os aspectos relacionados à proposta do modelo de estrutura de serviços do conhecimento para Parques Científicos e Tecnológicos (PCT), em acordo com as práticas, os resultados e as análises dos resultados da pesquisa realizada.

A partir das experiências estudadas, sobretudo nas entrevistas presenciais, são selecionados grupos de serviços do conhecimento em cada experiência, que permitem a esta pesquisadora considerar alguns desses serviços como estruturados num "núcleo" e que poderiam ser adotados por diversos tipos de experiências (sem a eles se restringir).

Na Figura 7.1 são apresentadas as dimensões e sub-dimensões relacionadas aos serviços do conhecimento e os grupos e subgrupos de serviços do conhecimento correspondentes.

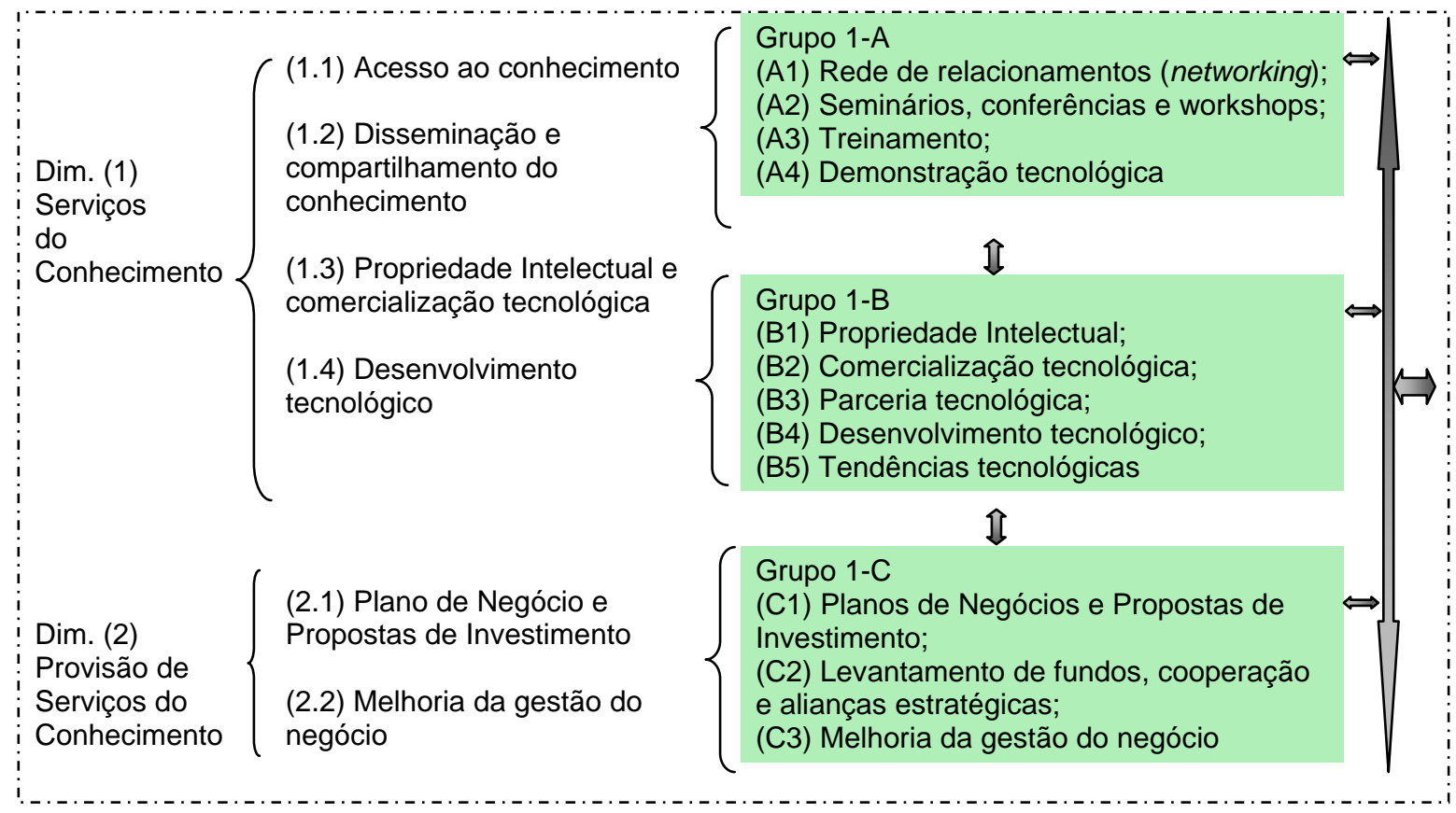

FIGURA 7.1 - Estrutura dos serviços do conhecimento para PCT 
Na Figura 7.2 são apresentas as dimensões e sub-dimensões relacionadas à infra-estrutura e à imagem ou visibilidade, do parque, e os grupos e subgrupos de serviços correspondentes.

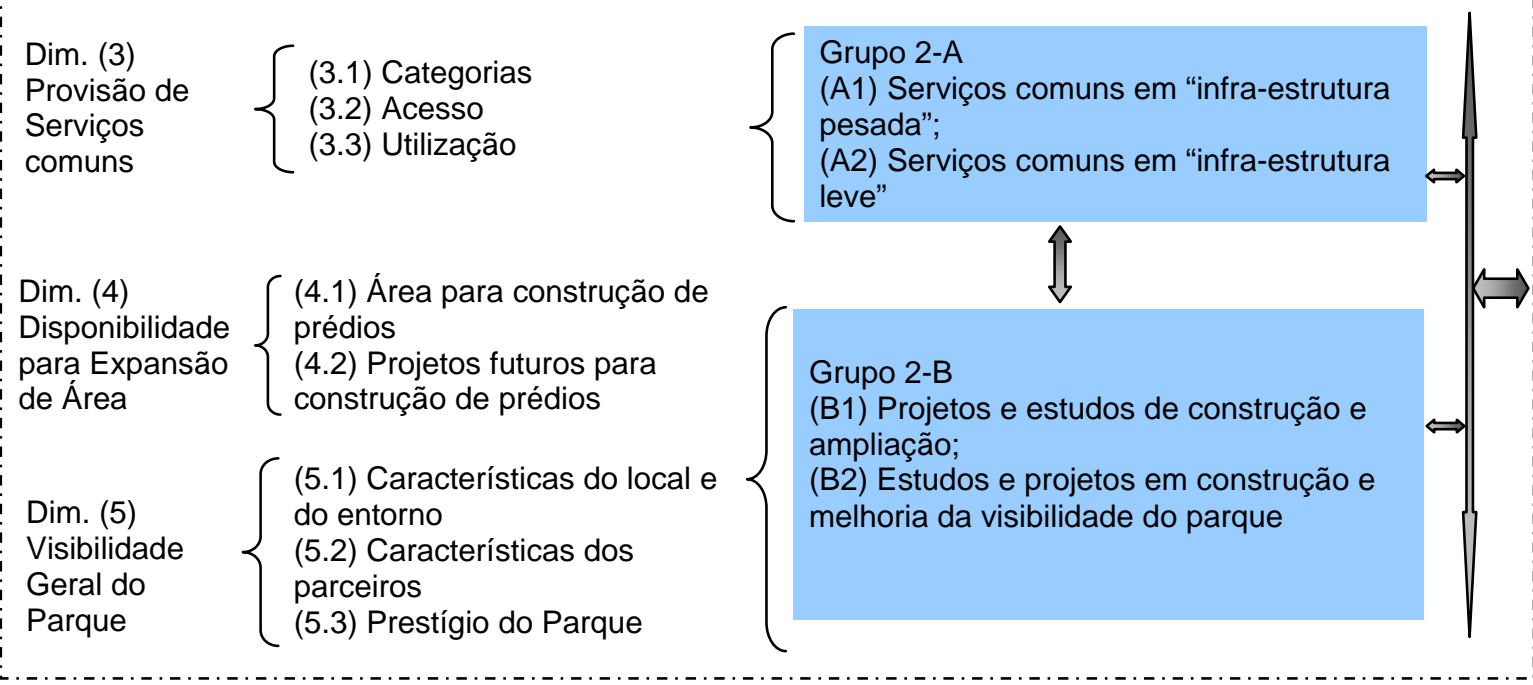

FIGURA 7.2 - Estrutura de serviços de infra-estrutura e visibilidade dos PCT

Na Figura 7.3 é apresentado o Modelo de Estrutura de Serviços de Inovação para PCT, que é o acoplamento da Estrutura de serviços do conhecimento apresentada na Figura 7.1, com a Estrutura de serviços de infra-estrutura e visibilidade (Figura 7.2).

Este acoplamento se deve ao fato de que, em certo grau, a prestação de serviços do conhecimento depende da infra-estrutura disponibilizada pelo PCT, ao mesmo tempo em que a infra-estrutura disponibilizada e a sua melhoria, dependem, dos serviços do conhecimento que o parque disponibiliza às PME; portanto, há uma interdependência entre esses serviços e uma necessidade de diálogo e troca constante de informações. De certa maneira, se pode dizer o mesmo quanto à visibilidade do parque, que é tanto influenciada pelos serviços do conhecimento prestados pelo PCT às PME, como pela infra-estrutura disponibilizada pelo parque. 


\section{G1-A}

(A1) Rede de relacionamentos

(networking);

(A2) Seminários, conferências e workshops;

(A3) Treinamento;

(A4) Demonstração tecnológica

D G1-B

(B1) Propriedade Intelectual;

(B2) Comercialização tecnológica;

(B3) Parceria tecnológica;

(B4) Desenvolvimento tecnológico;

(B5) Tendências tecnológicas

\section{II}

\section{G1-C}

(C1) Planos de Negócios e Propostas de Investimento;

(C2) Levantamento de fundos, cooperação

e alianças estratégicas;

(C3) Melhoria da gestão do negócio
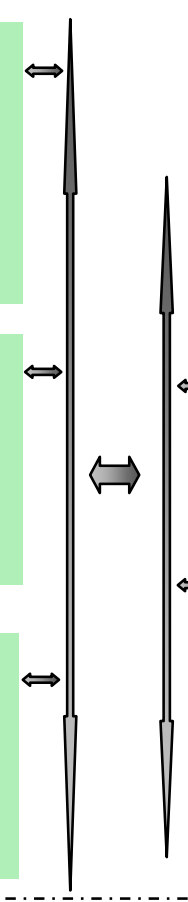

G2-A

(A1) Serviços comuns em "infraestrutura pesada";

(A2) Serviços comuns em "infraestrutura leve"

$\Leftrightarrow$

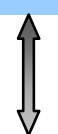

G2-B

(B1) Projetos e estudos de construção e ampliação;

(B2) Estudos e projetos em construção e melhoria da visibilidade do parque

FIGURA 7.3 - Estrutura de Serviços de Inovação para PCT

A pesquisa realizada, os resultados obtidos e a análise dos dados, trouxeram a esta pesquisadora a percepção da importância dos serviços relacionados à infraestrutura e da visibilidade (ou prestígio) do parque como elementos indispensáveis para a execução dos serviços do conhecimento e fundamentais para o sucesso de um PCT.

Para que o PCT possa propor e realizar os serviços do conhecimento às PME e aprimorar a interação empresa - universidade - centros de pesquisa, além de propor serviços que agregam valor às PME, é necessário atrair as empresas a se instalarem no parque; isso se faz por meio do oferecimento de infra-estrutura de qualidade e de outros itens, dentre os quais se destacam a visibilidade ou prestígio (overall image of the site) e a possibilidade de expansão dos espaços para os negócios estabelecidos, que segundo KIRK \& CATTS (2004) são os atributos que as empresas mais valorizam quando da escolha de se estabelecer num PCT. Afirmação que é confirmada tanto pelos resultados obtidos nesta pesquisa como pela recente pesquisa da IASP.

Além disso, pudemos observar no levantamento e na definição dos seis fatores críticos de sucesso (FCS) relacionados aos serviços do conhecimento dos 
PCT da amostra (Tabela 6.4) que são considerados críticos por todos os PCT da amostra, a infra-estrutura, os serviços comuns e o crescimento contínuo (expansão do parque), dentre outros.

Como esta pesquisa foi conduzida do ponto de vista dos representantes dos PCT que responderam aos questionários e foram entrevistados, o olhar dos clientes não foi abordado, ou seja, as PME não foram ouvidas nesse processo, o que constitui uma oportunidade para pesquisa posterior.

Ainda sobre clientes, ALLINGTON \& PIGDEN (2006) em seu artigo "Entregando o que está na lata" (Delivering what says on the tin - IASP Bookstore, código P23_Pa1jp, e-article, IASP, 2006) destacam a importância de compreender e estar próximo ao cliente, para a gestão eficaz num PCT; segundo eles, para obter sucesso, os PCT devem atuar orientados aos clientes (customer-driven) oferecendo infra-estrutura e solução de serviços flexíveis, centrando-se nas necessidades clientes.

O exemplo de PCT de sucesso que atua orientado aos clientes apresentado por ALLINGTON \& PIDGEN (2006) foi o Langstone Technology Park (LTP); trata-se de um PCT localizado em Havant, Hampshire, no Reino Unido, que atendia exclusivamente à IBM e que com a saída da empresa, se tornou um parque multisetorial. O LTP se beneficiou da 'imagem e da presença' adquirida na região e na comunidade local, para atrair empresas; sua estratégia foi baseada na identificação da marca (LTP) junto aos clientes e a proposição de 'produtos' e serviços sob medida, de maneira a garantir que os custos de ocupação das áreas, manutenção dos prédios e serviços prestados fossem competitivos comparados ao mercado tradicional.

A análise dos resultados desta pesquisa, sobretudo os dados resultantes da dimensão 3, que se refere à provisão de serviços comuns - categoria, acesso e utilização, indicaram haver um certo desconhecimento quanto à utilização pelos clientes dos serviços oferecidos pelo parque. De fato, estar próximo ao cliente e compreender suas necessidades é fundamental, afinal a razão de existir de qualquer organização é atender a demanda dos clientes. Para os PCT uma alternativa é possuir um serviço de interface com os clientes, para atendê-los, compreender as 
suas necessidades e monitorar a utilização dos serviços oferecidos. Na Figura 7.5 é representado o modelo proposto de Estruturas de Serviços de Inovação para PCT com a inserção desse serviço de interface com os clientes.

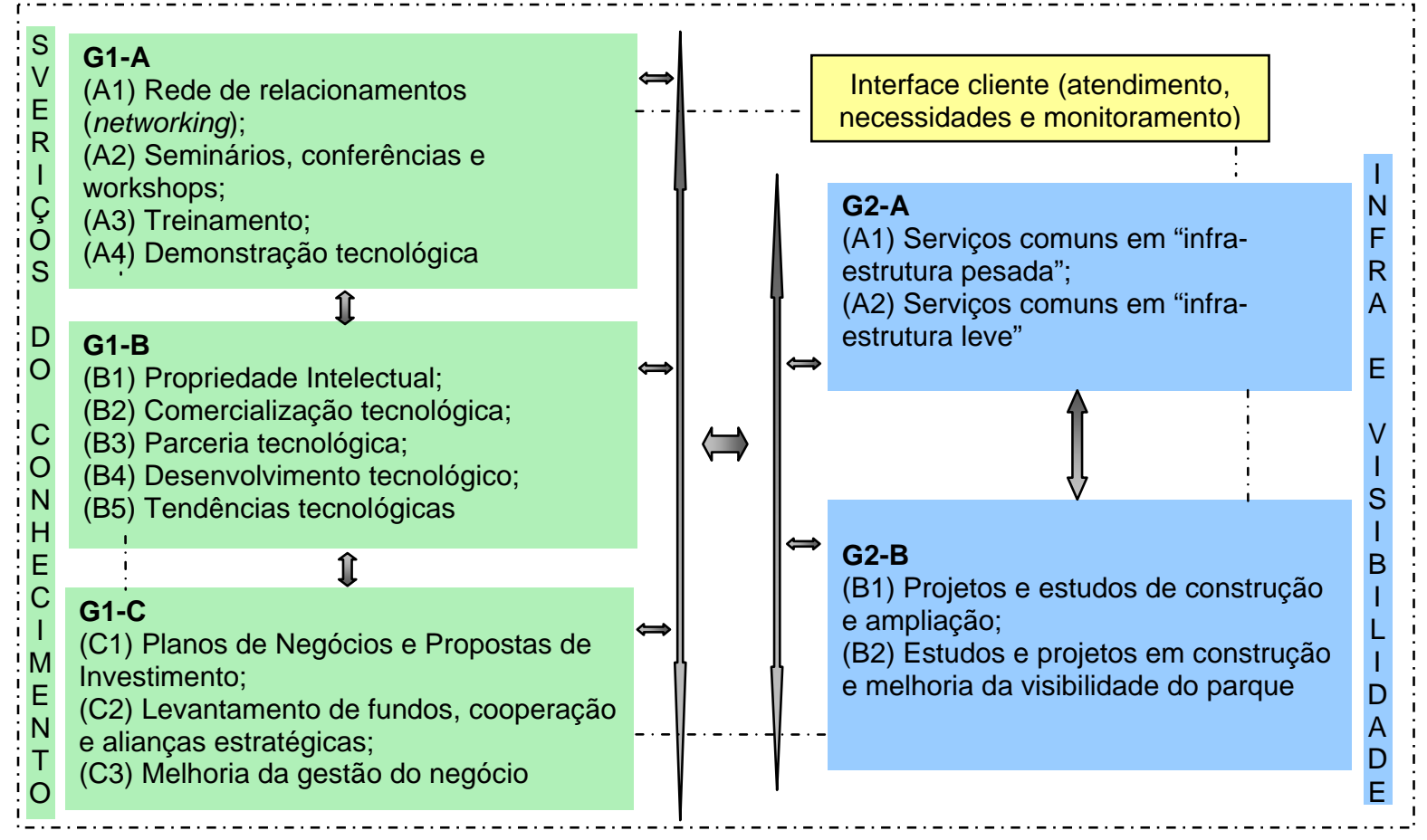

FIGURA 7.5 - Modelo de Estrutura de Serviços de Inovação para PCT

\subsection{Detalhamento dos grupos de serviços e dos serviços propostos no modelo}

Grupo de serviços do conhecimento A (G1-A): é o grupo de serviços do conhecimento relacionados ao acesso, disseminação e compartilhamento do conhecimento.

- (G1-A1) Rede de relacionamentos (networking) - os PCT devem estabelecer uma rede de relacionamentos de qualidade, estabelecendo de forma sistemática e contínua a troca de informações junto às PME e os principais parceiros, para garantir a qualidade do serviço. A rede deve ter dois focos, interno e externo. Do ponto de vista interno, a rede deve proporcionar o contato entre as PME instaladas e os parceiros do parque (Estado, Prefeitura, Universidade, Centros de Pesquisa, Agentes de Apoio, etc...). Do ponto de vista externo, os PCT devem estabelecer novas parcerias de interesse, tanto em nível nacional (inclusive Estados, Municípios e Regiões) como 
internacional (outros PCT, organizações representativas, etc...) e disponibilizálas às PMEs.

- (G1-A2) Seminários, conferências e workshops - os PCT devem promover e divulgar seus serviços e atividades; e realizar seminários, conferências e workshops (que podem ser realizados em parceria com outras organizações) sobre temáticas relacionadas com: inovação, gestão, tecnologia, estabelecimento e fortalecimento da rede de relacionamento, e que apresentem oportunidades para o desenvolvimento do negócio das PME.

- (G1-A3) Treinamento - o PCT deve promover e realizar treinamentos (que podem ser desenvolvidos em parceria com outras organizações). Para tanto o PCT deverá realizar de forma sistemática o levantamento das necessidades de treinamento junto às incubadoras e às PME instaladas no parque.

- (G1-A4) Demonstração Tecnológica - o PCT deve promover eventos de demonstração tecnológica (que podem ser desenvolvidos em parceria com outras organizações). Para tanto o PCT deverá realizar de forma sistemática o levantamento das necessidades de demonstração tecnológica junto às incubadoras e às PME instaladas no parque.

Grupo de serviços do conhecimento B (G1-B): é o grupo de serviços do conhecimento relacionados à Propriedade Intelectual, Desenvolvimento Tecnológico das PME; e correlatos; cabe ressaltar que esse grupo de serviços é baseado na confiança e confidencialidade, que deve ser estabelecida e mantida entre as partes envolvidas (o PCT, a PME e os parceiros).

- (G1-B1) Propriedade Intelectual - os PCT devem atender as demandas relacionadas a Direito de Propriedade Intelectual das PME; este serviço pode ser realizado em colaboração com organizações parceiras. O serviço compreende o apoio e a disponibilidade de acesso local, às informações sobre patentes e assuntos relacionados; e disponibilidade de assistência jurídica sobre o tema.

- (G1-B2) Comercialização tecnológica - os PCT devem atender as demandas de apoio à transferência tecnológica das PME, o serviço compreende tanto a busca de parceria(s) para a transferência de tecnologia, quanto o apoio à 
transferência de tecnologia a parceiro já identificado pela PME. As etapas compreendidas deste serviço são as seguintes: $1^{\circ}$ visitar a PME demandante do serviço e identificar a tecnologia a ser transferida; $2^{\circ}$ descrever, em parceria com a PME, a tecnologia a ser transferida e identificar a parceria adequada; $3^{\circ}$ ajudar a empresa a buscar o parceiro comercial (nacional ou internacional), inclusive organizando encontros comerciais; $4^{\circ}$ apoiar a PME nos assuntos jurídicos, financeiros e de Propriedade Intelectual; $5^{\circ}$ assistência e apoio nas negociações do contrato de transferência tecnológica até a sua assinatura.

- (G1-B3) Parceria tecnológica - os PCT devem responder às demandas de formação de parcerias tecnológicas das PME, o serviço é realizado em cinco etapas: $1^{\circ}$ visitar a PME demandante de parceria e conhecer suas necessidades tecnológicas; $2^{\circ}$ descrever, em parceria com a PME, a sua necessidade tecnológica e identificar a parceria adequada; $3^{\circ}$ ajudar a empresa a buscar o(s) parceiro(s) nacionais ou internacionais, inclusive organizando encontros de cooperação tecnológica; $4^{\circ}$ apoiar a PME nos assuntos legais, financeiros e de Direito de Propriedade Intelectual; e $5^{\circ}$ assistir e apoiar as negociações do contrato de parceria tecnológica da empresa, até a assinatura do contrato.

- (G1-B4) Desenvolvimento tecnológico - os PCT devem apoiar o desenvolvimento tecnológico das PME, buscando soluções que atendam suas necessidades pontuais durante o processo de desenvolvimento tecnológico do produto ou serviço da empresa.

- (G1-B5) Tendências tecnológicas - os PCT devem atender as demandas de prospecção tecnológica das PME. Esse serviço compreende tanto a realização de estudos prospectivos, como a indicação de trabalhos de prospecção já realizados. É aconselhável que os PCT mantenham um banco de informações atualizado sobre estudos prospectivos nos temas relacionados às áreas de atuação das PME. 
Grupo de serviços do conhecimento C (G1-C): é o grupo de serviços relacionados ao plano de negócios, às propostas de investimento; e à melhoria da gestão dos negócios das PME.

- (G1-C1) Planos de Negócios e Propostas de Investimento - os PCT devem atender as PME nas suas necessidades de desenvolvimento do Plano de Negócios e das Propostas de Investimento. Esses serviços podem ser realizados em parceria com outras organizações (incubadoras, unidades das Universidades, etc...).

- (G1-C2) Levantamento de fundos, cooperação e alianças estratégicas - os PCT devem atender as PME nas suas necessidades de levantamento de fundos financeiros (capital semente, capital de risco, financiamento junto a órgãos financiadores); e de cooperação e estabelecimento de alianças estratégicas com outras organizações nacionais e/ou internacionais, visando inclusive a internacionalização da PME. Esse serviço pode ser realizado em parceria com outras organizações (incubadoras, unidades da Universidade, agências de Inovação, organizações internacionais tais como outros PCT e/ou outras incubadoras, etc ...).

- (G1-C3) Melhoria da gestão do negócio - os PCT devem atender as PME em suas necessidades de melhoria dos processos relacionados à gestão do negócio. Esse serviço pode ser realizado em parceria com outras organizações (incubadoras, unidades da Universidade, órgãos como o Sebrae,...).

Grupo de serviços de infra-estrutura e visibilidade A (G2-A): é o grupo de serviços relacionados à provisão, manutenção e controle dos serviços comuns em infraestrutura "leve" e infra-estrutura "pesada".

A infra-estrutura "leve" corresponde às "funcionalidades básicas" e necessárias às PME para o seu bom funcionamento no PCT; são serviços tais como: limpeza, segurança, estacionamento, secretaria geral, correspondência, alimentação, internet , utilização das salas de reunião, das áreas para apresentação, etc...

Quanto à infra-estrutura "pesada", corresponde à infra-estrutura física do PCT; tais como: edificações, instalações elétricas, rede de águas, vias de acesso, etc... 
- (G2-A1) Serviços comuns em "infra-estrutura pesada" - os PCT devem executar os serviços comuns de provisão, manutenção e controle das instalações físicas do parque. Tais serviços podem ser executados em parceria.

- (G2-A2) Serviços comuns em "infra-estrutura leve" - os PCT devem executar os serviços comuns de provisão, manutenção e controle da "infra-estrutura leve" do parque; ou seja, prover os serviços que atendem as "funcionalidades básicas" para o bom funcionamento das PME instaladas no PCT. Tais serviços podem ser executados em parceria.

Grupo de serviços de infra-estrutura e visibilidade B (G2-B): é o grupo de serviços relacionado à área para expansão do PCT e para a melhoria da "visibilidade" do parque.

- (G2-B1) Projetos e estudos de construção e ampliação (das instalações físicas do parque) - este serviço corresponde à elaboração de estudos e projetos para construção de novas edificações e ampliação do PCT. O serviço toma como base o Plano Diretor do parque, sua evolução em termos de ocupação das áreas/edificações do parque; e as tendências nacionais e internacionais no que se refere à infra-estrutura física dos PCT. Este serviço pode ser executado em parceria com outras organizações (unidades da Universidade, órgãos da Prefeitura e Municípios, etc...).

- (G2-B2) Estudos e projetos em construção e melhoria da visibilidade (imagem) do parque - este serviço corresponde aos estudos e projetos relacionados à construção e à melhoria da visibilidade do PCT junto à comunidade (empresarial, local, regional, nacional e internacional). Pode ser realizado em parceria com outras organizações (unidades da Universidade, outros PCT, etc...).

Interface cliente (atendimento, necessidades e monitoramento) ${ }^{\underline{1}}$ - esta atividade de interface cliente tem como objetivo a melhoria da satisfação dos clientes (PME); e

\footnotetext{
${ }^{1}$ Esta pesquisadora utilizou como parte da base para a descrição da atividade "interface cliente", elementos descritos na apresentação "Satisfação do Cliente" disponível no endereço eletrônico http://www.prdu.unicamp.br/projetos/plano de acao satisfacao cliente.pdf, Acesso em 05/03/2009.
} 
tem como premissas básicas que os serviços prestados pelo PCT devem ter credibilidade, serem acessíveis, confiáveis, excelentes, e flexíveis às PME, atendendo as necessidades dos clientes. Cabe ressaltar que a disseminação e incorporação da cultura de satisfação do cliente junto às equipes do PCT é condição fundamental não somente para esta atividade como para o sucesso do PCT.

A interface cliente executa as seguintes atividades: elabora, em conjunto com as áreas de execução de serviços do PCT, os indicadores de prestação de serviços; coleta e controla periodicamente, os indicadores junto às áreas de execução dos serviços; elabora, com base nos indicadores construídos, um questionário de satisfação dos clientes (pesquisa), aplicando-o periodicamente junto às PME; tabula os resultados da pesquisa de satisfação dos clientes, expõe os resultados às áreas de serviço do PCT e à comunidade do parque (funcionários, clientes e parceiros); e propõe, em conjunto com as áreas de serviço, do PCT ações de melhoria, inclusive visita aos clientes. 


\section{8 - DISCUSSÃO E LIMITAÇÕES DO MODELO CONCEITUAL}

A discussão e as limitações do modelo conceitual desenvolvido neste trabalho serão apresentadas em dois tópicos: o primeiro apresenta uma comparação/discussão com o estudo recente da IASP versus os resultados desta pesquisa; o segundo tópico apresenta um questionamento do modelo na opinião da especialista que o analisou, Dra. Conceição Vedovello.

\subsection{IASP General Survey 2006/2007 versus Magalhães e-survey}

É interessante observar que os resultados obtidos neste estudo apresentaram semelhanças/proximidade com os resultados divulgados pela IASP em 2007, contidos no relatório IASP General Survey 2006-2007 - Facts and Figures of Science and Technology Parks in the World ${ }^{1}$, como se pode observar na Tabela 6.1 do capítulo de Resultados (à página 149).

A pesquisa da IASP foi realizada por meio do levantamento informações junto a 77 (de um universo de 268) Parques Científicos e Tecnológicos, de 65 países e membros da IASP; o instrumento de pesquisa utilizado foi um questionário online.

Cabe salientar que um dos avaliadores de nosso instrumento de pesquisa foi o mesmo profissional que contribuiu com a elaboração do questionário da IASP, o Dr. Selwyn Seymour da University of Edinburgh School of Managemente \& Economics, a quem a IASP direciona agradecimentos especiais logo no início do relatório.

De acordo com os resultados apresentados pelo relatório da IASP, a escala utilizada no questionário de múltipla escolha online foi de tipo semelhante à adotada por esta pesquisadora, ou seja, escalas de Likert.

Em se referindo a como os PCT provêm serviços aos instalados, o resultado obtido pela IASP e pelo e-survey Magalhães foram os mesmos, qual seja, $86 \%$ utilizam ajuda externa (outsourced) e14\% o fazem por meio do time de gestão do parque (in-house). Na Tabela 8.1 são apresentados alguns resultados do relatório da

\footnotetext{
${ }^{1}$ Disponível no endereço eletrônico http://www.rtp.org/files/iasp survey on stps.pdf Acesso em 10/01/2008.
} 
IASP referente, entre outros, ao levantamento dos serviços prestados pelos PCT em contraposição aos resultados oriundos do e-survey de Magalhães; a terceira coluna da tabela contém comentários relacionados aos grupos de serviços propostos no modelo conceitual desenvolvido por Magalhães.

\begin{tabular}{|c|c|c|}
\hline IASP General Survey 2006-2007 & e-survey Magalhães ${ }^{2}$ & Comentários \\
\hline $\begin{array}{l}\text { Serviços de Networking internal } \\
\text { são oferecidos por } 64 \% \text { dos } \\
\text { PCT; e } \\
\text { serviços de Networking external } \\
\text { oferecidos por } 53 \% \text { dos PCTs. }\end{array}$ & $\begin{array}{l}53 \% \text { dos PCT oferecem às PME } \\
\text { serviços de apoio relacionados a } \\
\text { oportunidades de cooperação } \\
\text { com outras organizações } \\
\text { nacionais e internacionais }\end{array}$ & $\begin{array}{l}\text { Os resultados obtidos por } \\
\text { ambas as pesquisas } \\
\text { evidenciam a importância dos } \\
\text { serviços networking. } \\
\text { Serviço proposto no modelo: } \\
\text { (G1-A1) Rede de } \\
\text { relacionamentos (networking) } \\
\text { 3. }\end{array}$ \\
\hline $\begin{array}{l}\text { Atividades de treinamento são a } \\
\text { segunda principal atividade em } \\
81 \% \text { dos PCT; } \\
\text { Training courses são oferecidos } \\
\text { por } 60 \% \text { dos PCT; e } \\
43 \% \text { dos PCT disponibilizam } \\
\text { serviços de planejamento de } \\
\text { eventos. }\end{array}$ & $\begin{array}{l}80 \% \text { dos PCT oferecem ou } \\
\text { disponibilizam serviços para a } \\
\text { realização de seminários, confe- } \\
\text { rências, workshops e outros } \\
\text { eventos de interesse às PME } \\
\text { instaladas; } \\
67 \% \text { dos PCT organizam } \\
\text { eventos de treinamento internos } \\
\text { e externos e incentivam as PME } \\
\text { a participarem. } \\
47 \% \text { dos PCT oferecem às PME } \\
\text { serviços de apoio, incentivo e } \\
\text { organização de eventos de } \\
\text { demonstração de tecnologia. }\end{array}$ & $\begin{array}{l}\text { Os resultados obtidos por } \\
\text { ambas as pesquisas } \\
\text { evidenciam a importância dos } \\
\text { serviços relacionados a cursos } \\
\text { e treinamentos. } \\
\text { Serviços propostos no modelo: } \\
\text { (G1-A2) Seminários, } \\
\text { conferências e workshops; e } \\
\text { (G1-A3) Treinamento }{ }^{4} \text {. }\end{array}$ \\
\hline $\begin{array}{l}64 \% \text { dos PCT oferecem serviços } \\
\text { de consultoria em Propriedade } \\
\text { Intelectual. }\end{array}$ & $\begin{array}{l}53 \% \text { dos PCT disponibilizam } \\
\text { serviços de consultoria em } \\
\text { propriedade intelectual às PME; } \\
\text { ou por meios próprios, ou por } \\
\text { meio das universidades ou por } \\
\text { outras instituições. }\end{array}$ & $\begin{array}{l}\text { Os resultados obtidos por } \\
\text { ambas as pesquisas } \\
\text { evidenciam a importância dos } \\
\text { serviços relacionados à } \\
\text { Propriedade Intelectual. } \\
\text { Serviços propostos no modelo: }\end{array}$ \\
\hline $\begin{array}{l}53 \% \text { dos PCT oferecem serviços } \\
\text { de desenvolvimento de PME } \\
\text { instaladas (tenant development); } \\
56 \% \text { dos PCT oferecem } \\
\text { instalações de laboratórios (lab } \\
\text { facilities) aos instalados }\end{array}$ & $\begin{array}{l}\text { Em se tratando de serviços para } \\
\text { desenvolvimento tecnológico, } \\
43 \% \text { dos PCT acompanha o } \\
\text { desenvolvimento das PME e } \\
\text { busca atendê-las inclusive em } \\
\text { suas necessidades pontuais de } \\
\text { serviços tecnológicos. }\end{array}$ & $\begin{array}{l}\text { (G1-B1) Propriedade } \\
\text { Intelectual; (G1-B2) } \\
\text { Comercialização Tecnológica; } \\
\text { (G1-B3) Parceria Tecnológica, } \\
\text { (G1-B4) Desenvolvimento } \\
\text { Tecnológico; e (G1-B5) } \\
\text { Tendências Tecnológicas } 5\end{array}$ \\
\hline $\begin{array}{l}73 \% \text { dos PCT oferecem serviços } \\
\text { de suporte à gestão } \\
\text { (management support services) }\end{array}$ & $\begin{array}{l}64 \% \text { dos PCT respondentes } \\
\text { oferecem às PME serviços de } \\
\text { apoio ao estabelecimento de } \\
\text { parcerias tecnológicas, }\end{array}$ & \\
\hline
\end{tabular}

\footnotetext{
${ }^{2}$ Vide Tabela 6.1 do Capítulo 6 - Resultados

${ }^{3}$ Vide Figura 7.1 Estrutura dos serviços do Conhecimento para PCT, no Capítulo 7

${ }^{4}$ Idem.

5 Idem.
} 


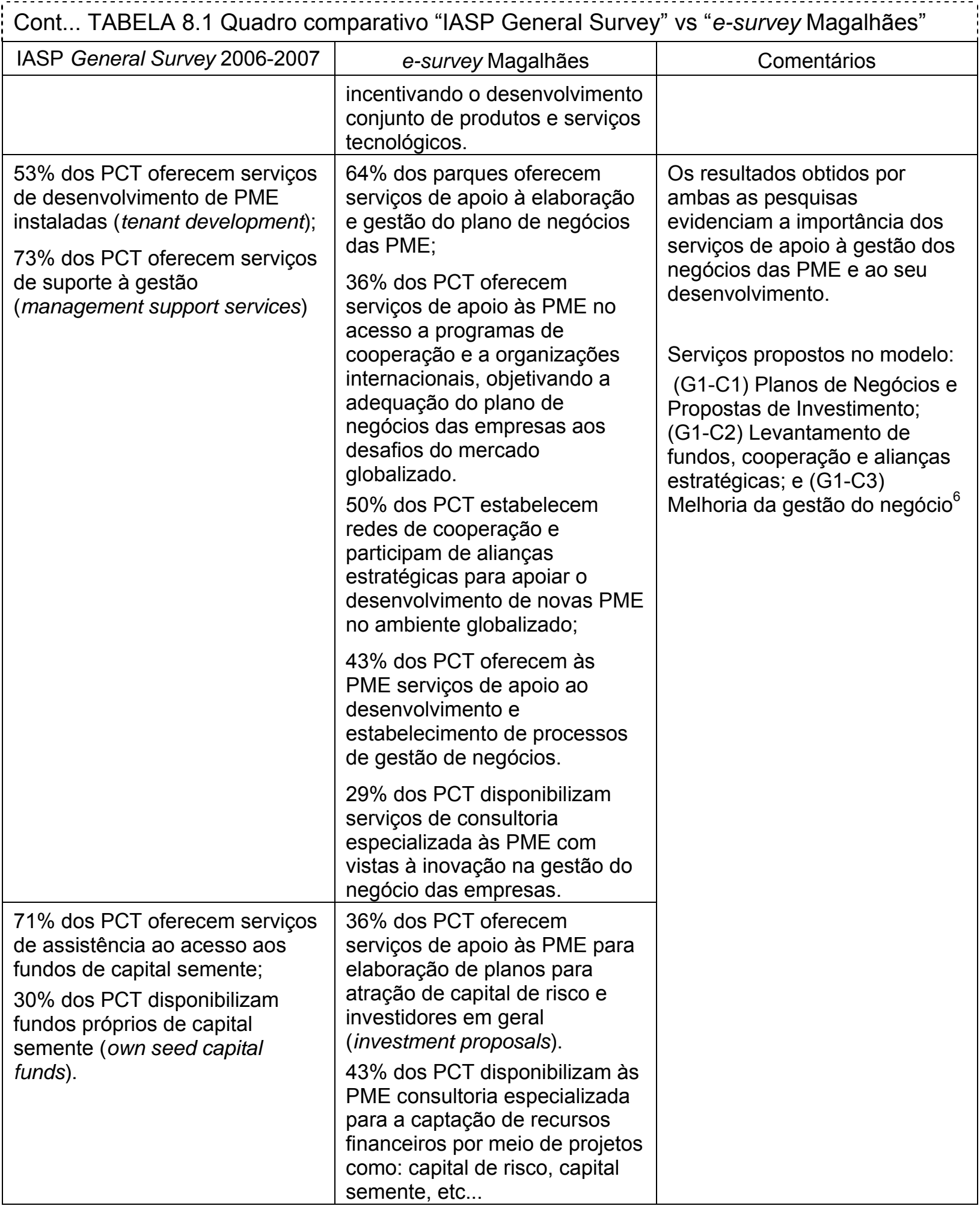

\footnotetext{
${ }^{6}$ Vide Figura 7.1 Estrutura dos serviços do Conhecimento para PCT, no Capítulo 7.
} 
Cont... TABELA 8.1 Quadro comparativo "IASP General Survey" vs "e-survey Magalhães"

\begin{tabular}{|l|l|}
\hline IASP General Survey 2006-2007 & \multicolumn{1}{|c|}{ e-survey Magalhães } \\
\hline Itens da lista de serviços & $50 \%$ dos PCT oferecem \\
auxiliares propostos pelos PCT: & $\begin{array}{l}\text { serviços comuns que atendem } \\
\text { sala de reunião (87\%), cafeteria } \\
\text { todas as necessidades das }\end{array}$ \\
rências (79\%), alimentaçação & PME, independente do \\
(75\%), vigilância 24 horas (71\%), & tamanho da empresa e de suas \\
\hline
\end{tabular}
transporte público $(62 \%)$, restaurantes $(56 \%)$, segurança individual $(55 \%)$, sala de vídeo conferência $(52 \%)$, segurança comum $(48 \%)$, secretaria $(44 \%)$, planejamento de eventos $(43 \%)$, relações públicas $(39 \%)$, instalações esportivas $(38 \%)$, etc...

A infra-estrutura física necessária para o atendimento das necessidades das PME é oferecida por $36 \%$ dos PCT respondentes. Comentários

Os resultados obtidos por ambas as pesquisas evidenciam a importância da proposição de serviços de serviços comuns relacionados à infra-estrutura.

Serviços propostos no modelo: (G2-A1) Serviços comuns em "infra-estrutura pesada"; e (G2B2) Serviços comuns em "infraestrutura leve" ${ }^{\prime 7}$.

Desde a sua criação, $67 \%$ dos PCT fizeram a expansão uma vez, $18 \%$ duas vezes e $15 \%$ mais de três vezes

$50 \%$ dos PCTs estão quase no limite de sua capacidade instalada, com uma taxa de ocupação entre $81 \%$ e $100 \%$ de sua capacidade total.

O Plano Diretor de $57 \%$ dos PCT prevê a flexibilidade para a expansão das PME.

Na questão fechada referente ao índice de ocupação das áreas destinadas às PME, verificou se que os PCT prevêem a flexibilidade para a expansão das PME nele instaladas. Alguns PCT estão com suas áreas destinadas às PME quase totalmente ou totalmente utilizadas.

O índice de ocupação da área construída em diversos PCT é quase de $100 \%$ (PTA - 95\%; HKSTP - 96\%; Technologiepark Heildelberg - 90\%; AREA Science Park - 97\%; Metutech e Ankara Cyberpark - 100\%; TECNOPUC - 100\%).

$78 \%$ dos PCT têm planos para expandir sua capacidade num futuro próximo; e
$79 \%$ dos PCT têm projetos de construção de prédios previstos no curto prazo ( $\leq 5$ anos); $79 \%$ dos PCT têm projetos de construção de prédios, previstos no médio prazo $(5 \leq 10)$; $43 \%$ dos PCT têm projetos de construção de prédios, previstos no longo prazo ( $\geq 10$ anos).

\footnotetext{
${ }^{7}$ Vide Figura 7.2 - Estrutura de serviços de infra-estrutura e visibilidade dos PCT, do Capítulo 7.

${ }^{8}$ Idem.
}

Os resultados obtidos por ambas pesquisas evidenciam a importância da disponibilidade para expansão de área e construção de edificações. Serviço proposto no modelo: (G2-B1) Projetos e estudos de construção e ampliação ${ }^{8}$. 
Cont... TABELA 8.1 Quadro comparativo "IASP General Survey" vs "e-survey Magalhães"

\begin{tabular}{|l|l|}
\hline IASP General Survey 2006-2007 & \multicolumn{1}{|c|}{ e-survey Magalhães } \\
\hline $\begin{array}{l}\text { 65\% dos PCT tendem a se } \\
\text { localizar próximos a clusters de } \\
\text { negócios; }\end{array}$ & $\begin{array}{l}79 \% \text { dos PCT estão instalados } \\
\text { em locais estratégicos para o } \\
\text { desenvolvimento dos negócios } \\
\text { das PME; e }\end{array}$ \\
$\begin{array}{l}\text { clusters próximos se } \\
\text { especializam nos mesmos } \\
\text { setores tecnológicos, mas em } \\
21 \% \text { dos casos focam em } \\
\text { diferentes tecnologias. }\end{array}$ & $\begin{array}{l}57 \% \text { dos PCT respondentes } \\
\text { têm um entorno que contribui } \\
\text { para a expansão dos negócios } \\
\text { das PME. }\end{array}$ \\
\hline
\end{tabular}

Sobre a importância das instituições parceiras para os PCT, $75 \%$ indicaram que a influencia da universidade é a mais importante e que está cumpre um papel chave no seu desenvolvimento;

$43 \%$ dos PCT indicaram que as empresas de capital de risco e capital semente são instituições que, junto com as universidades, são as mais importantes para os PCT.

Empresas de serviços advocatícios (legal services firms) também contribuem direta ou indiretamente ao desenvolvimento dos PCT, na opinião de $49 \%$ dos PCT, a influência dessas instituições é moderadamente importante.

Imagem/prestígio é considerado muito importante para $62 \%$ dos PCT;

Localização é muito importante para 53\% dos PCT;

Ligações com Universidades é o terceiro fator de sucesso mais importante com $52 \%$ dos PCT considerando muito importante.
Em $50 \%$ dos PCTs os parceiros têm participação efetiva na vida do parque e interagem com regularidade entre si e com as PMEs; e

em $14 \%$ dos PCT os parceiros atuam tanto reativamente as demandas das PME como pró ativamente nos assuntos relacionados ao desenvolvimento dos PCT e das PME nele instaladas.

Comentários

Se pode dizer que os resultados da IASP são coerentes com os obtidos nesta pesquisa.

Os resultados obtidos por ambas as pesquisas evidenciam a importância da dimensão de Visibilidade Geral do Parque que considera como elementos principais - subdimensões - as características do local e do

Entorno; as características dos parceiros; e o "prestígio" do parque.

Serviço proposto no modelo: (G2-B2) Estudos e projetos em construção e melhoria da visibilidade do parque.
$72 \%$ dos PCT estão instalados em um local de prestígio que pode trazer benefícios às empresas instaladas; e as empresas consideram o local onde está situado o PCT, um fator determinante na decisão de se instalarem no parque.

Cabe ressaltar que todos os PCT informaram ter ligação formal e/ou informal com Universidades.

$\mathrm{Na}$ pesquisa da IASP, a importância do atendimento ao cliente pode ser evidenciada pela importância atribuída pelos PCT ao item "serviço ao cliente" 
(quantidade e qualidade dos serviços providos aos instalados), considerado um elemento base da competitividade do PCT, que está em segundo lugar (precedido da qualidade das empresas incubadas). Esse dado corrobora a importância de se conhecer as necessidades e a satisfação do cliente com relação a cada serviço prestado pelo PCT; este elemento compõe o Modelo de Estrutura de Serviços de Inovação para PCT, qual seja, a "Interface cliente (atendimento, necessidades e monitoramento)" 9

Por fim, tendo em vista o exposto neste tópico, esta pesquisadora conclui que o fato de a pesquisa da IASP apresentar resultados semelhantes àqueles obtidos no e-survey de Magalhães, esta comparação valida os resultados desta pesquisa.

\subsection{Questionamento do modelo desenvolvido na opinião de Vedovello}

O modelo desenvolvido por esta pesquisadora, conforme apresentado no capítulo 7, foi submetido à avaliação da pesquisadora Dra. Conceição Vedovello, economista e doutorada na área de Estudos em Política de Ciência e Tecnologia pela Universidade de Sussex (Grã-Bretanha), atualmente ocupando o cargo de Diretora da Área de Engenharia e Ciências Exatas da Fundação de Amparo a Pesquisa do Estado de São Paulo (FAPESP), atuante nos temas de inovação tecnológica, interação universidade-indústria, ciência e tecnologia, observatório e desenvolvimento tecnológico; e tendo participado recentemente da equipe de projeto que desenvolveu o Estudo sobre Parques Tecnológicos no Brasil - Estudo, Análise e Proposições, publicado em 2008 pela ANPROTEC.

Em sua análise, Vedovello considerou o modelo satisfatório ("OK”); e acrescentou os questionamentos e comentários a seguir.

\section{Questionamentos}

Com relação aos serviços propostos no modelo: em (G1-A2) Seminários, conferências e workshops - "valeria a pena acrescentar 'feiras'?"; em (G1-B5) Tendências tecnológicas - "poderia ser substituído por 'prospecção tecnológica' ?”; e em (G1-C) - "poderia ser acrescentado no grupo de serviços 1-C o item '(C4) Aconselhamento legal' ?"

\footnotetext{
${ }^{9}$ Vide Figura 7.5 - Modelo de Estrutura de Serviços de Inovação para PCT, do Capítulo 7.
} 


\section{Comentários}

"É positivo o fato de que seu trabalho corrobora os resultados da IASP (2007), mas, dois pontos: 1) Seria importante você dar detalhes sobre esse estudo (o que investigaram, como investigaram e o que alcançaram; e 2) Se há algum diferencial que o teu trabalho evidencia e que não foi evidenciado pelo trabalho da IASP."

Com relação aos questionamentos feitos por Vedovello, esta pesquisadora argumenta o seguinte:

Sobre a inclusão da atividade 'feiras' no serviço proposto (G1-A2), se argumenta que o termo 'feiras' foi citado por PCT respondentes desta pesquisa, como exemplo de evento de demonstração tecnológica; de fato, alguns espaços identificados como 'feiras' apresentam produtos e/ou serviços e suas aplicações. Nesse caso, a atividade 'feiras' estaria contemplada no modelo pelo serviço (G1-A4) Demonstração tecnológica.

Quanto à troca do nome do serviço proposto (G1-B5) 'Tendências tecnológicas' por 'Prospecção tecnológica', apesar da prospecção tecnológica ser o exercício de busca e determinação de tendências tecnológicas, acredito que não há impedimento para que a atividade de prospecção esteja contida num serviço denominado 'tendências'. A escolha do termo se deve inclusive à reflexão de que uma PME pode necessitar conhecer as tendências de uma determinada tecnologia que demande esforços diferenciados por parte do PCT; é possível que em alguns casos o esforço seja apenas o de indicar um estudo de prospecção realizado por outra organização, em outros pode ser necessário realizar o próprio estudo de prospecção tecnológica.

Em se tratando da possibilidade de se acrescentar no grupo de serviços 1-C o serviço de 'aconselhamento legal' como item (C4), esta pesquisadora considera o seguinte:

De fato, os assuntos legais permeiam parte significativa das atividades das PME e a proposição de serviço de apoio voltado para essas questões, pode ser considerada importante de ser oferecida pelos PCT às PME; no entanto, questões legais não se restringem ao grupo de serviços $1-C$ do modelo. 
No capítulo de resultados foi possível observar nas respostas das questões abertas que alguns PCT respondentes disponibilizam alguns tipos de serviços de consultoria legal nos assuntos em que esta se faz necessária, por exemplo: propriedade intelectual, comercialização tecnológica, parceria tecnológica, propostas de investimento, alianças estratégicas, etc...

No âmbito dos serviços do modelo proposto, se entende que, nos assuntos em que houver a necessidade de aconselhamento legal, os PCT apoiarão as PME oferecendo o apoio adequado, não havendo a necessidade de incluir no modelo esse serviço específico, pois não contempla apenas um grupo de serviços.

Com relação aos comentários feitos por Vedovello, esta pesquisadora argumenta o seguinte:

Em se referindo ao detalhamento do estudo da $\mathrm{IASP}^{10}$ cujos resultados corroboram os alcançados por esta pesquisa, conforme apresentado no item 8.1 deste capítulo, se observa o seguinte:

O estudo da IASP investigou doze aspectos relacionados às características dos Parques Científicos e Tecnológicos no mundo, a saber: criação; localização; relação com as universidades; contexto dos PCT; infra-estrutura; orçamento e financiamento; propriedade, governança e gestão; macro ambiente; setores de especialização; serviços; empresas instaladas e geração de emprego; e fatores de sucesso.

Foi elaborado um questionário online (com a assistência do Dr. Selwyn Seymour) que foi respondido por uma amostra compreendida por 77 PCT que representaram 29\% do universo da pesquisa (268 PCT membros da IASP em 65 países). A pesquisa foi conduzida, analisada e revisada por funcionários da IASP e a equipe de trabalho envolveu ao todo seis funcionários - dois diretores, um coordenador e três analistas. Maiores detalhes sobre a metodologia utilizada na pesquisa não foram disponibilizados. Em se tratando dos resultados obtidos pela IASP, as informações que se relacionam diretamente aos tópicos de interesse desta pesquisa foram expostas na Tabela 8.1 deste capítulo.

${ }^{10}$ IASP General Survey 2006-2007, IASP, Madri, 2007 
Finalmente, com relação ao diferencial que o trabalho de Magalhães evidencia e que não tenha sido evidenciado pelo trabalho da IASP, creio que o levantamento dos fatores críticos de sucesso no que se refere aos serviços do conhecimento ${ }^{11}$ definidos neste trabalho, alinhados à estrutura dos serviços do conhecimento para $\mathrm{PCT}^{12}$ que compõe o modelo de estrutura de serviços de inovação para $\mathrm{PCT}^{13}$ proposto nesta tese, pode ser considerado um diferencial e uma contribuição interessante para compor a lacuna existente sobre os serviços do conhecimento em PCT.

\footnotetext{
${ }^{11}$ Vide Figura 6.4 do capítulo 6.

${ }^{12}$ Vide Figura 7.1 - Estrutura dos serviços do conhecimento para PCTs, capítulo 7.

${ }^{13}$ Vide Figura 7.5 - Modelo de Estrutura de Serviços de Inovação para PCTs, no capítulo 7.
} 


\section{CONCLUSÕES E RECOMENDAÇÕES}

Esta pesquisa teve por objeto o estudo da estrutura de serviços prestados por parques científicos e tecnológicos (PCT), especialmente os serviços do conhecimento prestados por eles às micro, pequenas e médias empresas de base tecnológica, visando contribuir para o preenchimento da lacuna no conhecimento, visto que não estão disponíveis trabalhos acadêmicos que modelem as estruturas de serviços de apoio à relação empresa - universidade - centros de pesquisa em PCT.

$\mathrm{Na}$ fundamentação teórica foi possível verificar que o processo de intensificação da globalização apresenta, como características, o movimento de liberalização e desregulação dos mercados, assim como o advento das Tecnologias de Informação e Comunicação (TIC), que teve como principais conseqüências o estabelecimento de uma nova dinâmica tecnológica e econômica em nível internacional, onde o conhecimento configura-se como elemento básico de incremento da competitividade, ao mesmo tempo em que emergem novas formas de organização e interação entre empresas e rápidas mudanças na estrutura de pesquisa, produção e comercialização. Nesse contexto destaca-se o papel da cooperação como um dos elementos fundamentais de estratégia das organizações e do desenvolvimento institucional, que pode ser considerado o "eixo estruturante para a sustentabilidade contemporânea, como contraponto à competição" (PLONSKY, 1999).

Foi igualmente exposto, que as redes de inovação, tem como mecanismos utilizados os sistemas e formas de cooperação que oferecem respostas às novas demandas e desafios para a promoção, geração e difusão do conhecimento, como base para a competitividade empresarial e o crescimento econômico. No contexto da economia global, destaca-se a atuação dos protagonistas menores, como as micro, pequenas e médias empresas, cuja importância é confirmada em nível global e regional, principalmente considerando os aspectos sócioeconômicos de desenvolvimento, tendo o conhecimento como combustível para da inovação e chave para a competitividade. 
As micro, pequenas e médias empresas de base tecnológica (PME) instaladas em Parques Científicos e Tecnológicos (PCT) buscam esses ambientes de inovação em função da proximidade com o geradores de conhecimento - acesso às Universidades e/ou Centros de Pesquisa - a fim de para obterem vantagens no desenvolvimento do seu produto ou serviço inovador (considerando esta uma vantagem competitiva). Da concepção e do desenvolvimento do produto ou serviço inovador à introdução no mercado, existe um 'mar' a navegar e o trajeto dessa navegação está relacionado ao conhecimento, que pode ser apoiado por políticas públicas direcionadas a esse fim e por ações diretas do PCT e/ou conjugadas com os parceiros envolvidos. O diálogo da PME com a universidade e/ou com os centros de pesquisa é fundamental e complexo; daí a necessidade de se estabelecer um modelo de estrutura de serviços do conhecimento a ser oferecida pelos PCT em apoio às PME visando otimizar a relação empresa - universidade - centros de pesquisa.

Sobre os PCT foi exposto que surgem nas décadas de 60 e 70 com o objetivo de desenvolver negócios inovadores, evitar a evasão de cérebros, apoiar o desenvolvimento regional, entre outras ações de caráter econômico e imobiliário; os primórdios do movimento têm como melhor referência a experiência da Universidade de Stanford conhecida como "Vale do Silício", caso que influenciou uma série de modelos mundiais de criação de espaços privilegiados e estimulantes ao desenvolvimento da relação entre universidades, centros de pesquisa e empresas privadas. Considerando-se a necessidade de se utilizar mais as infra-estruturas científico-tecnológicas e apoiar o desenvolvimento econômico regional, entre outros, o movimento dos PCT vem se expandindo mundialmente, tendo sido acelerado na década de 90 nas economias denominadas em desenvolvimento ou emergentes.

Quanto às definições de PCT, as mais utilizadas são aquelas veiculadas por três associações internacionais de parques científicos, que são a International Association of Science Parks (IASP), Association of University Research Parks (AURP) e a United Kingdom Science Park Association (UKSPA) e em nível nacional pela Associação Nacional de Entidades Promotoras de Empreendimentos de Tecnologias Avançadas (ANPROTEC), sendo a IASP a mais representativa Associação agregando os PCT e outros modelos de inovação no mundo, contando, atualmente, com 356 membros, mais de 200.000 empresas 
inseridas no contexto de seus associados e estando em 71 países (segundo dados da IASP de 2008). Nesta pesquisa, assume-se a definição de PCT veiculada pela IASP como referência; de toda forma, a definição de PCT pode mudar ao longo do tempo, pois os modelos continuam a evoluir e se modificar como entidades físicas e organizacionais e como instrumento de desenvolvimento econômico sustentável, apoiando à formação de negócios empresariais saudáveis. Suas funções apresentam um desafio pois não há dois similares; suas metas e objetivos variam de acordo com os parceiros envolvidos, com a balança de poder e a influência entre eles e o ambiente econômico local/regional; ainda assim, há um objetivo que parece comum a todos os PCT, qual seja, atrair e manter agrupadas novas empresas de base tecnológica e reforçar a base econômica local e regional.

Em seguida, foram apresentados alguns estudos recentes sobre a evolução dos modelos de parques tecnológicos que apontam para uma "terceira geração" de PCT. As características dos PCT de terceira geração, segundo o estudo produzido pelo Manchester Science Park (MSP), são: está conectado e envolvido na aplicação de políticas de inovação regionais e nacionais; tem estratégias de gestão de alta qualidade; emprega chefes executivos de primeira linha (top-quality) com qualidades de liderança e habilidade de se relacionar de forma positiva com todos os setores que interagem regularmente com o parque; é financeiramente sustentável, tendo proporção crescente de investimentos do setor privado; compreende a estrutura física e o ambiente do parque como uma construção de apoio ao processo de inovação, interação e criatividade - não como um fim em si mesmo; tem um relacionamento ativo, efetivo e diverso com a universidade; está conectado e atua em rede em todos os níveis (networking); e preocupa-se e desenvolve ações e serviços para as PME instaladas, adicionando valor aos negócios, interpretando oportunidades e conseqüências para os negócios, apoiando o crescimento dos negócios das empresas e sua atratividade para investidores potenciais, mantendo um relacionamento de proximidade, entendimento e confiança. Os principais desafios dos PCT no século XXI são: a superação de barreiras culturais entre a academia e as empresas e a facilitação de parcerias profícuas; o financiamento e apoio à comercialização/licenciamento da propriedade intelectual; a atração e retenção de talentos; a especulação e a "onda" de desenvolvimento de espaços - a questão dos negócios imobiliários; a 
colaboração entre empresas e com outros parceiros; a segurança nos negócios; a continuidade do apoio financeiro; a inserção no planejamento e revitalização urbana; o desempenho e a responsabilidade; e os serviços de valor agregado às PME instaladas.

Um levantamento foi elaborado e apresentado na forma da Tabela 3.3.1 (à página 22), indicando a infra-estrutura e os serviços do conhecimento disponibilizados por alguns PCT. A partir desses estudos observa-se que os PCT bem sucedidos reconhecem como principal deficiência das PME a falta do entendimento e das habilidades comerciais necessárias para a gestão bem sucedida do negócio, principalmente por parte do empreendedor; para atendê-las, os PCT oferecem uma série de suportes e aconselhamento como, por exemplo, capacitação e treinamento sob o tema de comercialização de produtos ou serviços tecnológicos.

Em nível nacional, o recente estudo da ANPROTEC realizado em parceria com a Agência Brasileira de Desenvolvimento Industrial (ABDI) apresentou uma proposta de taxonomia para a área de parques científicos e tecnológicos no Brasil e indica alguns elementos de políticas públicas em apoio aos PCT brasileiros. No seu Portfólio Executivo, a ANPROTEC apresenta uma série de informações relacionadas aos 74 parques científicos e tecnológicos existentes hoje do Brasil, sendo que 25 deles estão operantes, 17 em fase de implantação e 32 em fase de projeto. No Estado de São Paulo há quatro parques em operação, dois em fase de implantação e dez em fase de projeto, sendo o Parque Tecnológico de São Paulo um deles.

É possível constatar que nos últimos anos vem ocorrendo um movimento de apoio à implantação e desenvolvimento de parques tecnológicos no Estado de São Paulo o que pode ser exemplificado por iniciativas tais como: a criação do Sistema Paulista de Parques Tecnológicos - SPTec; o Programa de Apoio aos Parques Tecnológicos - Pró-Parques; o protocolo de intenções da Prefeitura de São Paulo para a criação e implantação do Parque Tecnológico de São Paulo na Zona Oeste de São Paulo, no bairro do Jaguaré e de outro na Zona leste da cidade; e o objetivo do Estado de São Paulo de ter dez parques tecnológicos implantados até 2010. A importância da disposição dos serviços do conhecimento pelos PCT direcionadas às PME visando otimizar a relação empresa universidade - centros de pesquisa, evidenciada pela fundamentação teórica 
apresentada e a provável implantação do Parque Tecnológico de São Paulo nos próximos anos, são elementos concordantes com a proposição da estrutura de serviços direcionada para o Parque Tecnológico de São Paulo, oferecida nesta tese.

A questão desta pesquisa é: como devem ser estruturados os serviços de apoio a empresas de base tecnológica que possam otimizar a relação universidade - centros de pesquisas - empresas em parques científicos e tecnológicos?

A pesquisa conduzida foi de caráter exploratório, sobretudo devido à inovação do tema (serviços baseados no conhecimento que podem ser prestados pelos Parques Tecnológicos às Micro Pequenas e Médias Empresas de base tecnológica) e ao limitado conjunto de informações de caráter científico sobre o tema disponíveis na literatura.

Com base nos estudos exploratórios foram definidas cinco dimensões, representadas na Figura 4.1 (à página 35), utilizadas no desenvolvimento do instrumento de pesquisa (Anexo 1) e na pesquisa de campo. O questionário foi elaborado em inglês e português, avaliado por três avaliadores e enviado por email aos membros cadastrados na IASP; e das respostas recebidas foram consideradas completas e com qualidade suficiente para a realização deste estudo, as experiências apresentadas na Tabela 5.1 (à página 37); a pesquisa de campo foi realizada por meio de visita a quatro PCT Europeus.

$\mathrm{Na}$ consolidação dos resultados foram apresentadas as respostas dos PCT respondentes (Tabelas 5.2 e 5.3), sua caracterização e as observações pessoais desta pesquisadora referente à pesquisa de campo (entrevistas presenciais nos parques); em seguida foi apresentada a análise e discussão dos resultados, a identificação das melhores práticas identificadas nos PCT analisados; e a identificação dos fatores críticos de sucesso relacionados aos serviços do conhecimento, respondendo ao objetivo desta pesquisa (identificar e compreender os fatores críticos de sucesso em iniciativas nacionais e internacionais caracterizadas como parques científicos e tecnológicos no que tange as suas estruturas de serviços do conhecimento em apoio às micro, pequenas e médias empresas de base tecnológica, visando otimizar a relação empresa - universidade - centros de pesquisa, no contexto desses ambientes de inovação), representados na parte central da Figura 6.4 (à página 187). 
Na seqüência foi formulado o modelo conceitual que tem por base os resultados obtidos na pesquisa; e sua análise e discussão. A Estrutura de Serviços do Conhecimento para PCT foi representada na Figura 7.1 (à página 188); a Estrutura de Serviços de Infra-estrutura e Visibilidade dos PCT foi representada na Figura 7.2 (à página 189); e o acoplamento das duas estruturas representado na Figura 7.3 (à página 190) da Estrutura de Serviços de Inovação para PCT. Após considerações sobre a necessidade de inclusão de uma 'interface cliente' no modelo proposto por este trabalho, a Estrutura de Serviços de Inovação para PCT foi representada na Figura 7.5 (à página 195); na continuidade foi exposto o detalhamento dos grupos de serviços dos serviços propostos no modelo proposto.

Finalmente, foi apresentada a discussão sobre o modelo conceitual e suas limitações em dois tópicos; o primeiro apresentou uma comparação e discussão dos resultados da pesquisa geral realizada pela IASP em 2006/2007 em paralelo com os dados obtidos por esta pesquisa, representada na Tabela 8.1 (à página 202); e o segundo elencou as considerações e questionamentos da pesquisadora e avaliadora Dra. Conceição Vedovello, que foram refletidos e respondidos por esta pesquisadora.

Tendo em vista o exposto nesta tese, esta pesquisadora conclui que a pesquisa atendeu os seus propósitos, visto que propôs um Modelo de Estrutura de Serviços do Conhecimento para PCT, aliado a um Modelo de Estrutura de Serviços de Infra-estrutura e Visibilidade, na forma de um Modelo de Estrutura de Serviços de Inovação para PCT, que pode ser utilizado em experiências nacionais e internacionais, entre elas a do Núcleo do Parque Tecnológico de São Paulo, suportado na forma do modelo proposto por ZOUAIN (2003), como por outros PCT.

Esta pesquisadora vê como oportunidade de pesquisas futura, explorar os serviços do conhecimento do ponto de vista dos clientes (PME) dos PCT como também customizá-lo para o caso dos parques tecnológicos de São Paulo.

Como considerações finais desta pesquisadora no que se refere aos resultados desta pesquisa, destaca se que, a forma como o modelo conceitual foi concebido (estruturas que se complementam - tais como as apresentadas na Figura 7.1, 7.2 e 7.5), permite aos PCT, independente de seu tamanho, optarem tanto pela utilização parcial como total do modelo, dependendo de suas necessidades e objetivos. 
Finalmente, é sobretudo na proposição da estrutura dos serviços do conhecimento (Figura 7.1) que se pode identificar quais são os serviços disponibilizados pelos PCT que propiciam às PME o diferencial competitivo, necessário para o sucesso de seus empreendimentos; serviços que estimulam e imprimem o diálogo contínuo entre as PME e seus parceiros, otimizando a relação empresa-universidade-centros de pesquisa. 
APÊNDICE A -Instrumento de pesquisa 
DOCUMENTO RESTRITO

Pesquisa sobre Parques Científico Tecnológicos - tópico: SERVI çOS DE I NOVAÇÃO

Pesquisadora: Adriana Magalhães, Aluna de Doutorado do IPEN - USP -SP

Cidade Universitária - São Paulo - SP - BRASIL

(e_mail principal): abmagalh@ipen.br (e_mail alternativo): 4amaga@uol.com.br

(telefone comercial): + +551138169151 (telefone móvel): + 551196277796

\section{DENTI FI CAÇÃO DO RESPONDENTE}

Nome do respondente:

Cargo do respondente:

E-mail de contato:

Nome do Parque:

Endereço do site do Parque:

Esta pesquisa está dividida em cinco partes e seus desdobramentos. As questões estão relacionadas aos aspectos dos desdobramentos das partes, conforme apresentado abaixo:

\begin{tabular}{|l|l|}
\hline PARTE UM - Serviços do conhecimento & \\
\hline 1.1 Acesso ao conhecimento & 01 \\
\hline 1.2 Compartilhamento de conhecimento & 02 \\
\hline 1.3 Propriedade Intelectual e Comercialização de Tecnologia & 03 \\
\hline 1.4 Desenvolvimento Tecnológico & 04 \\
\hline PARTE DOI S - Provisão de serviços de gestão do negócio & \\
\hline 2.1 Plano de Negócios e Propostas de Investimento & 06 \\
\hline 2.2 Melhoria da gestão do negócio & \\
\hline PARTE TRÊS - Provisão de serviços comuns & 08 \\
\hline 3.1 Serviços comuns & 08 \\
\hline 3.2 Acesso aos serviços comuns e à infra-estrutura & \\
\hline 3.3 Utilização dos serviços comuns & 08 \\
\hline PARTE QUATRO - Disponibilidade para expansão de área & \\
\hline 4.1 Área para construção de prédios & 10 \\
\hline 4.2 Projetos futuros para construção de prédios & 10 \\
\hline PARTE CI NCO - Visão geral do Parque & 12 \\
\hline 5.1 Características do local e do entorno & \\
\hline 5.2 Características dos parceiros & \\
\hline 5.3 Prestígio & \\
\hline GLOSSÁRIO DE TERMOS E SIGLAS & \\
\hline
\end{tabular}

Agradeço a gentileza do tempo despendido para responder as perguntas dessa pesquisa.

TODAS AS RESPOSTAS SERÃO TRATADAS COM A MAIS ESTRITA CONFI DENCI ALI DADE E NENHUMA I NFORMAÇÃO SERÁ DI VULGADA SEM O EXPRESSO CONSENTI MENTO DO(A) GESTOR(A) DO EMPREENDI MENTO. 


\section{PARTE UM - SERVI ÇOS DO CONHECI MENTO}

O Parque oferece serviços do conhecimento às PMEs ? Sim ( ) Não ( )

Se sim, como o Parque oferece os serviços do conhecimento às PMEs:

(a) Internamente (diretamente, do Parque para as PMEs)

(b) Terceirizando (indiretamente, por consultores às PMEs)

(c) Uma mistura de ambos (internamente e terceirizando)

\subsection{Acesso ao Conhecimento (globalização e habilidades tecnológicas)}

GLOBALIZAÇÃo - Globalização é um processo no qual a distância geográfica se torna um fator menor no estabelecimento e sustentabilidade das fronteiras, distâncias econômicas, políticas e relações sócio culturais. As pessoas tornam-se conscientes e temerosas deste fato. Consequentemente, redes de relações e dependências, potencialmente, atravessam cruzam as fronteiras físicas e atravessam o mundo todo. Esta internacionalização potencial de relações e dependências causam medo, resistências, ações e reações.- tradução livre de definição disponível em abril/2006 no site

http://www.iasp.ws/information/definitions.php?ce $=$

HABILIDADES TECNOLÓGICAS - Nesse contexto habilidades tecnológicas são os recursos humanos especializados que contribuem com a atividade de pesquisa e o desenvolvimento. tradução livre de definição disponível em 20/05/2006 no site

http://www.rsnz.org/policy/i3 response.php

\begin{tabular}{|c|c|c|c|c|c|}
\hline & $\begin{array}{c}\text { Discordo } \\
\text { totalmente }\end{array}$ & \begin{tabular}{|c|} 
Discordo \\
parcialmente
\end{tabular} & Neutro & \begin{tabular}{|c|} 
Concordo \\
Parcialmente
\end{tabular} & $\begin{array}{c}\text { Concordo } \\
\text { totalmente }\end{array}$ \\
\hline $\begin{array}{l}\text { GLOBALI ZAÇÃO - O Parque } \\
\text { Tecnológico oferece às PMEs } \\
\text { serviços de apoio relacionados à } \\
\text { oportunidades de cooperação } \\
\text { internacional. }\end{array}$ & & & & & \\
\hline $\begin{array}{l}\text { HABI LI DADES TECNOLÓGI CAS - } \\
\text { O Parque oferece às PMEs } \\
\text { consultoria especializada em } \\
\text { cooperação com outras organizações } \\
\text { (empresas, institutos de pesquisa ou } \\
\text { universidades) envolvendo C\&T e } \\
\text { desenvolvimento em P\&D\&I, por } \\
\text { meio de projetos. }\end{array}$ & & & & & \\
\hline
\end{tabular}

Por favor, comente a respeito das categorias dos serviços de consultoria oferecidos pelo Parque às PMEs, em particular aqueles relacionados a globalização.

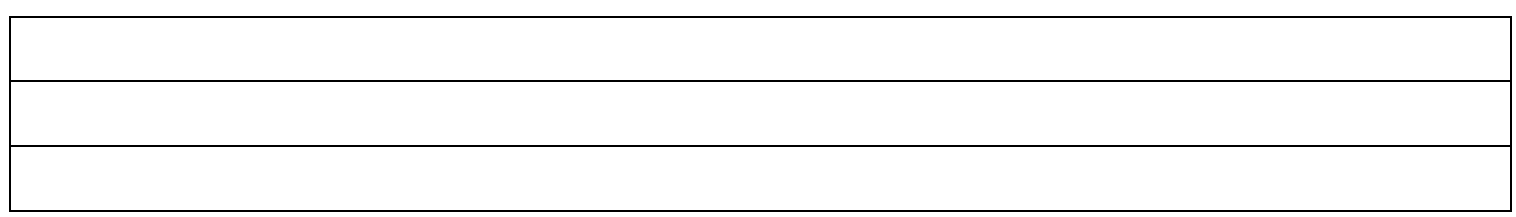

Por favor, comente a respeito das categorias dos serviços de consultoria oferecidos pelo Parque às PMEs, em particular aqueles relacionados a habilidades tecnológicas. 
DOCUMENTO RESTRITO

1.2 Compartilhamento e Disseminação do Conhecimento

\begin{tabular}{|c|c|c|c|c|c|}
\hline & $\begin{array}{l}\text { Discordo } \\
\text { totalmente }\end{array}$ & $\begin{array}{c}\text { Discordo } \\
\text { parcialmente }\end{array}$ & Neutro & $\begin{array}{c}\text { Concordo } \\
\text { Parcialmente }\end{array}$ & $\begin{array}{l}\text { Concordo } \\
\text { totalmente }\end{array}$ \\
\hline $\begin{array}{l}\text { SEMI NÁRI OS E } \\
\text { CONFERÊNCI AS: O Parque apoia } \\
\text { e incentiva as PMEs, organizando } \\
\text { seminários, conferências, } \\
\text { workshops e outros eventos de } \\
\text { interesse das empresas. }\end{array}$ & & & & & \\
\hline $\begin{array}{l}\text { DEMONSTRAÇÃO DE } \\
\text { TECNOLOGI A: O Parque apoia e } \\
\text { incentiva a participação de PMEs, } \\
\text { organizando eventos de } \\
\text { demonstração de tecnologia } \\
\text { desenvolvida nas empresas e } \\
\text { outras de interesse específico. }\end{array}$ & & & & & \\
\hline $\begin{array}{l}\text { TREI NAMENTO - O Parque apoia } \\
\text { e incentiva as PMEs, organizando } \\
\text { eventos de treinamento, } \\
\text { divulgando eventos internos e } \\
\text { externos e incentivando a } \\
\text { participação das empresas. }\end{array}$ & & & & & \\
\hline
\end{tabular}

Por favor, comente sobre os serviços de organização de seminários, conferências, workshops e outros eventos correlatos, oferecidos pelo Parque às PMEs.

\begin{tabular}{|l|}
\hline \\
\hline
\end{tabular}

Comente sobre os eventos de demonstração de tecnologia organizados / promovidos pelo Parque em benefício das PMEs.

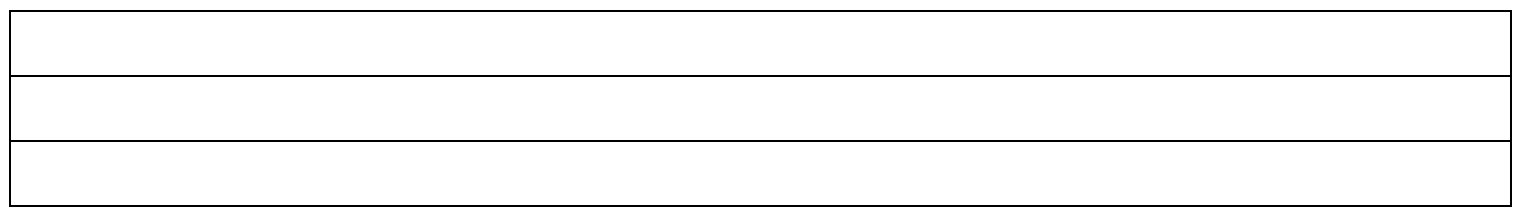

Por favor, comente sobre os serviços de organização de treinamentos e eventos correlatos, oferecidos pelo Parque às PMEs.

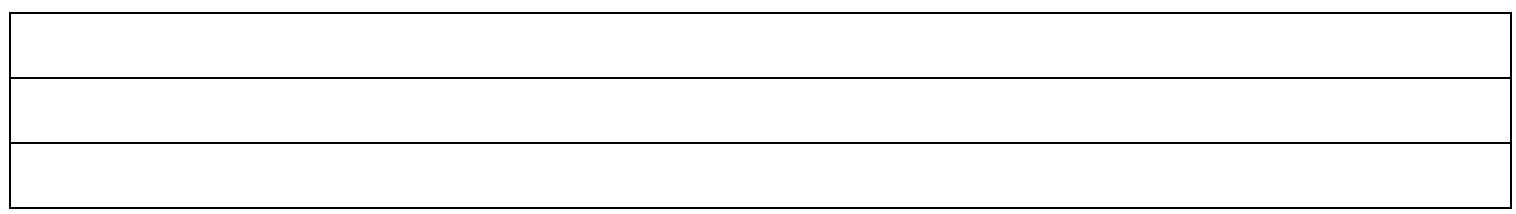

\subsection{Propriedade Intelectual e Comercialização de Tecnologia}

COMERCIALIZAÇÃO TECNOLÓGICA: Direito de utilização de know how ou de conhecimento tecnológico efetivado através de compra e venda ou pagamento de royalties pelo uso de processos ou produtos patenteados. - definição retirada do "Glossário dinâmico de termos na área de Tecnópolis, Parques Tecnológicos e Incubadoras de Empresas" - ANPROTEC 2002 disponível no site www.anprotec.br/glossario em abril/2006.

TRANSFERÊNCIA DE TECNOLOGIA - Intercâmbio de conhecimento e habilidades tecnológicas entre instituições de ensino superior e/ou centros de pesquisa e empresas. Faz.se na forma de contratos de pesquisa e desenvolvimento, serviços de consultoria, formação profissional, inicial e continuada, venda de patentes, marcas e processos industriais, publicação na mídia científica, apresentação em congressos, migração de especialistas, programas de assistência técnica, espionagem industrial e atuação de empresas multinacionais. - definição retirada do 


\section{DOCUMENTO RESTRI TO}

"Glossário dinâmico de termos na área de Tecnópolis, Parques Tecnológicos e Incubadoras de Empresas" - ANPROTEC 2002 - disponível no site www.anprotec.br/glossario em abril/2006.

\begin{tabular}{|c|c|c|c|c|c|}
\hline \multirow[b]{2}{*}{$\begin{array}{l}\text { PROPRI EDADE I NTELECTUAL - } \\
\text { O Parque oferece às PMEs } \\
\text { serviços de consultoria, por meios } \\
\text { próprios ou terceirizados (por } \\
\text { Universidades ou outros } \\
\text { organismos), em Propriedade } \\
\text { Intelectual. }\end{array}$} & $\begin{array}{c}\text { Discordo } \\
\text { totalmente }\end{array}$ & $\begin{array}{c}\text { Discordo } \\
\text { parcialmente }\end{array}$ & Neutro & $\begin{array}{c}\text { Concordo } \\
\text { Parcialmente }\end{array}$ & \begin{tabular}{|c|} 
Concordo \\
totalmente \\
\end{tabular} \\
\hline & & & & & \\
\hline $\begin{array}{l}\text { UTI LI ZAÇÃO ATUAL - } \\
\text { Se sim, a maioria das PMEs } \\
\text { instaladas no Parque ( } \geq 50 \%) \\
\text { utiliza um ou mais serviços de } \\
\text { consultoria em Propriedade } \\
\text { Intelectual, oferecidos pelo } \\
\text { Parque. }\end{array}$ & & & & & \\
\hline $\begin{array}{l}\text { COMERCI ALI ZAÇÃO DE } \\
\text { TECNOLOGI A: O Parque } \\
\text { disponibiliza às PMEs serviços de } \\
\text { consultoria em Comercialização } \\
\text { Tecnológica, por meios próprios } \\
\text { ou terceirizados (por } \\
\text { Universidades ou outros } \\
\text { organismos). }\end{array}$ & & & & & \\
\hline $\begin{array}{l}\text { UTI LI ZAÇÃ́ ATUAL - } \\
\text { Se sim, a maioria das PMEs } \\
\text { instaladas no Parque ( } \geq 50 \%) \\
\text { utiliza um ou mais serviços de } \\
\text { consultoria em Comercialização } \\
\text { Tecnológica, oferecidos pelo } \\
\text { Parque. }\end{array}$ & & & & & \\
\hline $\begin{array}{l}\text { TRANSFERÊNCI A DE } \\
\text { TECNOLOGI A: O Parque oferece } \\
\text { às PMEs serviços de consultoria, } \\
\text { por meios próprios ou } \\
\text { terceirizados (por Universidades } \\
\text { ou outros organismos), em } \\
\text { Transferência de Tecnologia. }\end{array}$ & & & & & \\
\hline $\begin{array}{l}\text { UTI LI ZAÇÃO ATUAL - } \\
\text { Se sim, a maioria das PMEs } \\
\text { instaladas no Parque }(\geq 50 \%) \\
\text { utiliza um ou mais serviços de } \\
\text { consultoria em Transferência de } \\
\text { Tecnologia, oferecidos pelo } \\
\text { Parque. }\end{array}$ & & & & & \\
\hline
\end{tabular}


No que se refere aos serviços de Propriedade Intelectual oferecidos pelo parque, informe se são prestados por escritórios das Universidades parceiras ou por outros organismos. Explique como se dá a gestão desta relação.

No que se refere aos serviços de Comercialização Tecnológica oferecidos pelo parque, informe se são prestados por escritórios das Universidades parceiras ou por outros organismos. Explique como se dá a gestão desta relação.

No que se refere aos serviços de Transferência de Tecnologia oferecidos pelo parque, informe se são prestados por escritórios das Universidades parceiras ou por outros organismos. Explique como se dá a gestão desta relação.

\subsection{Desenvolvimento Tecnológico}

TECNOLOGIA - (a) Método para transformar inputs em outputs; (b) aplicação dos resultados de pesquisa científica à produção de bens e serviços; (c) tipo específico de conhecimento, processo ou técnica exigido para fins práticos.- definição retirada do "Glossário dinâmico de termos na área de Tecnópolis, Parques Tecnológicos e Incubadoras de Empresas" ANPROTEC 2002 - disponível no site www.anprotec.br/glossario em abril/2006.

SERVIÇOS PARA DESENVOLVIMENTO TECNOLÓGICO - Serviços de apoio 'as PME para acesso aos meios de desenvolvimento tecnológico das Universidades e Institutos de Pesquisa.

PROSPECÇÃO TECNOLÓGICA - (a) Tentativas sistemáticas para observar, no longo prazo, o futuro da ciência, da tecnologia, da economia e da sociedade, com o propósito de identificar tecnologias emergentes que possam produzir benefícios econômicos e/ou sociais; (b) . Estudos sobre tendências tecnológicas em setores industriais específicos, utilizando principalmente informações contidas em documentos de patentes nacionais ou estrangeiros. - definição retirada do "Glossário dinâmico de termos na área de Tecnópolis, Parques Tecnológicos e Incubadoras de Empresas" - ANPROTEC 2002 - disponível no site www.anprotec.br/glossario em abril/2006.

\begin{tabular}{|c|c|c|c|c|c|}
\hline & $\begin{array}{l}\text { Discordo } \\
\text { totalmente }\end{array}$ & $\begin{array}{c}\text { Discordo } \\
\text { parcialmente }\end{array}$ & Neutro & $\begin{array}{c}\text { Concordo } \\
\text { Parcialmente }\end{array}$ & $\begin{array}{l}\text { Concordo } \\
\text { totalmente }\end{array}$ \\
\hline $\begin{array}{l}\text { SERVI CCOS PARA } \\
\text { DESENVOLVI MENTO } \\
\text { TECNOLÓGI CO - O Parque } \\
\text { acompanha o desenvolvimento } \\
\text { das PMEs, buscando atendê-las } \\
\text { inclusive em suas necessidades } \\
\text { pontuais de serviços } \\
\text { tecnológicos. }\end{array}$ & & & & & \\
\hline $\begin{array}{l}\text { PARCERI AS TECNOLÓGI CAS } \\
\text { - O Parque oferece as PMEs } \\
\text { serviços de apoio ao } \\
\text { estabelecimento de parcerias; } \\
\text { incentivando o desenvolvimento }\end{array}$ & & & & & \\
\hline
\end{tabular}


DOCUMENTO RESTRITO

\begin{tabular}{|l|l|l|l|l|}
\hline conjunto de produtos e serviços & & & & \\
tecnológicos. & & & & \\
\hline TENDÊNCI A TECNOLÓGI CA - & & & & \\
O Parque oferece serviços de & & & & \\
apoio às PMEs para atualização & & & \\
das tendências tecnologicas, & & & \\
por meio de prospecção & & & \\
tecnológica, eventos de & & & & \\
informação e assistência às das & & & & \\
PMEs. & & & & \\
\hline
\end{tabular}

Como o Parque acompanha o desenvolvimentos das PMEs ? Como o Parque realiza prospecção tecnológica e apóia o estabelecimento de parcerias para as PMEs? E quantas parcerias são estabelecidas por ano e para quantas PMEs?

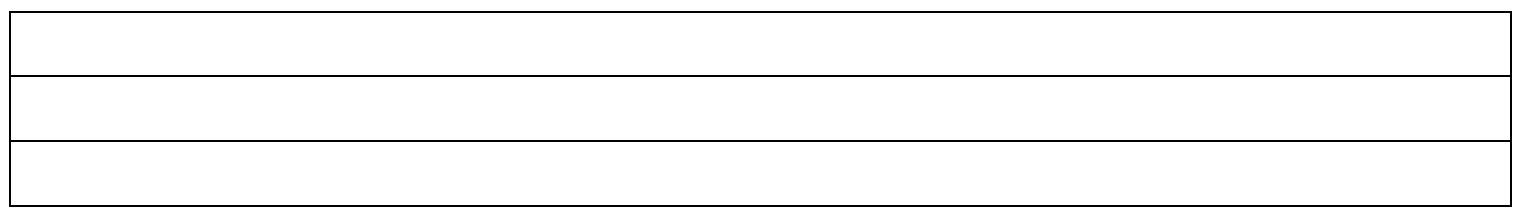

Com relação à prospecção de tendências tecnológicas, indique possíveis resultados e/ou metodologias para o acompanhamento dos impactos dessa ação. 


\section{PARTE DOIS: $\quad$ SERVI ÇOS PARA DESENVOLVI MENTO DO NEGÓCIO}

PLANO DE NEGÓCIOS - Documento preparado pela administração da empresa, contendo descrição detalhada do passado, presente e futuro da organização. É geralmente utilizado para atrair investimentos, conseguir empréstimos ou financiamentos, promover controle interno de integração e envolvimento do pessoal. - definição retirada do "Glossário dinâmico de termos na área de Tecnópolis, Parques Tecnológicos e Incubadoras de Empresas" ANPROTEC 2002 - disponível no site www.anprotec.br/glossario em abril/2006

\section{$2.1 \quad$ Plano de Negócios}

\begin{tabular}{|c|c|c|c|c|c|}
\hline & $\begin{array}{l}\text { Discordo } \\
\text { totalmente }\end{array}$ & $\begin{array}{c}\text { Discordo } \\
\text { parcialmente }\end{array}$ & Neutro & $\begin{array}{c}\text { Concordo } \\
\text { Parcialmente }\end{array}$ & $\begin{array}{l}\text { Concordo } \\
\text { totalmente }\end{array}$ \\
\hline $\begin{array}{l}\text { ACESSO A ORGANI ZAÇÕES } \\
\text { I NTERNACI ONAI S: } \\
\text { Serviços para apoiar as PMEs no } \\
\text { acesso a organizações } \\
\text { internacionais e programas de } \\
\text { cooperação, com vistas a } \\
\text { adequar os seus planos de } \\
\text { negócios aos desafios do } \\
\text { mercado globalizado. }\end{array}$ & & & & & \\
\hline $\begin{array}{l}\text { PLANO DE NEGÓCI OS - O } \\
\text { Parque Tecnológico oferece } \\
\text { serviços de apoio à elaboração e } \\
\text { gestão do Plano de Negócios } \\
\text { das MPEs. }\end{array}$ & & & & & \\
\hline $\begin{array}{l}\text { RECURSOS FI NANCEI ROS - O } \\
\text { parque disponibiliza às PMEs } \\
\text { consultoria especializada para a } \\
\text { captação de recursos financeiros } \\
\text { por meio de projetos (tais } \\
\text { como:venture capital, angels, } \\
\text { seed money,...). }\end{array}$ & & & & & \\
\hline $\begin{array}{l}\text { PLANO DE ATRAÇÃO DE } \\
\text { CAPI TAL - serviços para apoiar } \\
\text { as PMEs na elaboração de planos } \\
\text { para atração de capital de risco e } \\
\text { investidores em geral. }\end{array}$ & & & & & \\
\hline
\end{tabular}

Por favor, comente sobre quantos planos de negócios foram elaborados com o apoio do Parque, e quantas PMEs foram impactadas com esse serviço.

Por favor, comente sobre quantas PMEs obtiveram recursos financeiros com o apoio do Parque. 


\subsection{Melhoria da Gestão do Negócio}

COOPERAÇÃO INTERNACIONAL - Estímulo, através de programas/ações formalmente constituídos, ou não, à cooperação entre MPEs e organizações internacionais (outras empresas localizadas no Parque, empresas localizadas fora do parque, institutos de pesquisa ou universidades)

MELHORIA DA GESTÃO DO NEGÓCIO: Serviços de apoio que tem como objetivo assistir as PMEs e apoiá-las no desenvolvimento e melhoria de seus negócios de maneira a aumentar as suas chances de sucesso, por meio de respostas efetivas aos desafios do negócio, desafios sociais e do ambiente. Esta explicação foi baseada na definição de Business Support Services baixada do site http://www.iasp.ws/information/definitions.php?ce em 20/04/2006.

\begin{tabular}{|c|c|c|c|c|c|}
\hline & $\begin{array}{c}\text { Discordo } \\
\text { totalmente }\end{array}$ & $\begin{array}{c}\text { Discordo } \\
\text { parcialmente }\end{array}$ & Neutro & $\begin{array}{c}\text { Concordo } \\
\text { Parcialmente }\end{array}$ & $\begin{array}{l}\text { Concordo } \\
\text { totalmente }\end{array}$ \\
\hline $\begin{array}{l}\text { COOPERAÇÃO E } \\
\text { PARTI CI PAÇÃO EM REDES E } \\
\text { ALI ANÇAS ESTRATÉGI CAS } \\
\text { O parque estabelece redes de } \\
\text { cooperação e de participação em } \\
\text { alianças estratégicas para apoiar } \\
\text { o desenvolvimento das novas } \\
\text { PMEs no ambiente globalizado. }\end{array}$ & & & & & \\
\hline $\begin{array}{l}\text { GESTÃO DO NEGÓCI O: } \\
\text { O Parque oferece às PMEs } \\
\text { serviços de apoio ao } \\
\text { desenvolvimento e } \\
\text { estabelecimento de processos } \\
\text { de gestão do negócio. }\end{array}$ & & & & & \\
\hline $\begin{array}{l}\text { SERVI ÇOS DE APOI O A } \\
\text { GESTÃO DE NEGÓCI OS - O } \\
\text { Parque proporciona serviços de } \\
\text { consultoria especializada às } \\
\text { PMEs com vistas à inovação na } \\
\text { Gestão do Negócio das } \\
\text { empresas. }\end{array}$ & & & & & \\
\hline
\end{tabular}

Por favor, comente sobre o como o Parque disponibiliza às PMEs o acesso a organizações fora do país e programas de cooperação.

\begin{tabular}{|l|}
\hline \\
\hline
\end{tabular}

Por favor, comente sobre o desenvolvimento de Alianças Estratégias e Redes de Cooperação, e como isto apoia as PMEs.

\begin{tabular}{|l|}
\hline \\
\hline
\end{tabular}

Por favor, comente sobre os serviços que o Parque oferece às PMEs, em apoio ao desenvolvimento e estabelecimento de processos de gestão negócio, e quantas empresas já foram impactadas com esse serviço. 


\section{PARTE TRÊS: PROVISÃO LOCAL DE SERVI ÇOS COMUNS}

\subsection{Serviços Comuns Disponíveis}

INFRA-ESTRUTURA FÍSICA (Hard infrastructure) é o conjunto de instalações físicas do Parque (por exemplo: vias de acesso, edifícios, serviços de luz, rede de águas, etc...). Tradução livre de definição extraída de KIRK \& CATTS (2004, pg. 43).

SERVIÇOS COMUNS (Soft infraestruture) - há uma lista considerável de serviços que podem ser oferecidos pelo Parques às empresas instaladas. A extensão dos serviços oferecidos dependem do tipo de Parque Científico Tecnológico e de seus objetivos. Alguns serviços poderão ser oferecidos pelo próprio Parque, mas outros poderão ser disponibilizados por meio de acordos com outras organizações locais. Tradução livre de definição extraída de KIRK \& CATTS (2004, pg. 45).

\begin{tabular}{|c|c|c|c|c|c|}
\hline & $\begin{array}{l}\text { Discordo } \\
\text { totalmente }\end{array}$ & $\begin{array}{c}\text { Discordo } \\
\text { parcialmente }\end{array}$ & Neutro & $\begin{array}{c}\text { Concordo } \\
\text { Parcialmente }\end{array}$ & $\begin{array}{l}\text { Concordo } \\
\text { totalmente }\end{array}$ \\
\hline $\begin{array}{l}\text { Os serviços comuns } \\
\text { oferecidos pelo Parque } \\
\text { atendem a todas as } \\
\text { necessidades das PMEs, } \\
\text { independente do tamanho da } \\
\text { empresa e de suas } \\
\text { peculiaridades. }\end{array}$ & & & & & \\
\hline $\begin{array}{l}\text { A infra-estrutura física } \\
\text { oferecida pelo Parque atende } \\
\text { todas as necessidades das } \\
\text { PMEs, independente do } \\
\text { tamanho da empresa e de suas } \\
\text { peculiaridades. }\end{array}$ & & & & & \\
\hline
\end{tabular}

\subsection{Acessibilidade aos serviços comuns e infra-estrutura}

\begin{tabular}{|c|c|c|c|c|c|}
\hline & $\begin{array}{l}\text { Discordo } \\
\text { totalmente }\end{array}$ & $\begin{array}{c}\text { Discordo } \\
\text { parcialmente }\end{array}$ & Neutro & $\begin{array}{c}\text { Concordo } \\
\text { Parcialmente }\end{array}$ & $\begin{array}{l}\text { Concordo } \\
\text { totalmente }\end{array}$ \\
\hline $\begin{array}{l}\text { Todos os serviços comuns } \\
\text { oferecidos pelo Parque foram } \\
\text { projetados para serem } \\
\text { acessíveis a todas as PMEs, } \\
\text { independente do seu tamanho } \\
\text { ou de suas peculiaridades. }\end{array}$ & & & & & \\
\hline $\begin{array}{l}\text { O acesso físico aos serviços } \\
\text { comuns oferecidos pelo } \\
\text { Parque é simples e eficiente e } \\
\text { atendem as necessidades de } \\
\text { todas as PMEs, independente } \\
\text { do seu tamanho ou de suas } \\
\text { peculiaridades. }\end{array}$ & & & & & \\
\hline
\end{tabular}

\subsection{Utilização dos serviços comuns}

\begin{tabular}{|c|c|c|c|c|c|}
\hline & $\begin{array}{l}\text { Discordo } \\
\text { totalmente }\end{array}$ & $\begin{array}{c}\text { Discordo } \\
\text { parcialmente }\end{array}$ & Neutro & $\begin{array}{c}\text { Concordo } \\
\text { Parcialmente }\end{array}$ & $\begin{array}{l}\text { Concordo } \\
\text { totalmente }\end{array}$ \\
\hline $\begin{array}{l}\text { Os serviços comuns são } \\
\text { utilizados por todas as PMEs e } \\
\text { atendem a todas as suas } \\
\text { necessidades. }\end{array}$ & & & & & \\
\hline $\begin{array}{l}\text { A utilização dos serviços } \\
\text { comuns é monitorada pelo } \\
\text { Parque, que garante seu } \\
\text { melhor aproveitamento e o } \\
\text { atendimento de todas as } \\
\text { necessidades das PMEs, } \\
\text { independente do seu tamanho } \\
\text { e de suas peculiaridades. }\end{array}$ & & & & & \\
\hline
\end{tabular}


DOCUMENTO RESTRITO

\section{PARTE QUATRO: $\quad$ DI SPONI BI LI DADE DE EXPANSÃO DAS SALAS}

\section{1 Área prevista para construção de prédios}

PLANO DIRETOR (Master Plan) - Um plano guia, inteligível e diretivo, utilizado como guia para o desenvolvimento físico de longo prazo de uma determinada área. - Tradução livre de definição apresentada no site http://www.4554.com/Glossary/MASTER PLAN.html em abril/2006

\begin{tabular}{|c|c|c|c|c|c|}
\hline & $\begin{array}{c}\text { Discordo } \\
\text { totalmente }\end{array}$ & $\begin{array}{c}\text { Discordo } \\
\text { parcialmente }\end{array}$ & Neutro & $\begin{array}{c}\text { Concordo } \\
\text { Parcialmente }\end{array}$ & $\begin{array}{l}\text { Concordo } \\
\text { totalmente }\end{array}$ \\
\hline $\begin{array}{l}\text { O Plano Diretor do Parque } \\
\text { prevê a flexibilidade para } \\
\text { expansão das PMEs. }\end{array}$ & & & & & \\
\hline
\end{tabular}

Comente sobre o índice de ocupação (em percentagem) das áreas destinadas às PMEs no Parque Tecnológico.

4.2 Projetos futuros de construção de prédios (impacto do crescimento do Parque Tecnológico)

\begin{tabular}{|c|c|c|c|c|c|}
\hline & $\begin{array}{l}\text { Discordo } \\
\text { totalmente }\end{array}$ & $\begin{array}{c}\text { Discordo } \\
\text { parcialmente }\end{array}$ & Neutro & $\begin{array}{c}\text { Concordo } \\
\text { Parcialmente }\end{array}$ & $\begin{array}{l}\text { Concordo } \\
\text { totalmente }\end{array}$ \\
\hline $\begin{array}{l}\text { CURTO PRAZO - Há projeto } \\
\text { para construção de prédios no } \\
\text { Parque nos próximos } 5 \text { anos. }\end{array}$ & & & & & \\
\hline $\begin{array}{l}\text { MÉDI O PRAZO - Há projeto } \\
\text { para construção de prédios no } \\
\text { Parque nos próximos } 5 \text { a } 10 \\
\text { anos. }\end{array}$ & & & & & \\
\hline $\begin{array}{l}\text { LONGO PRAZO - Há projeto } \\
\text { para construção de prédios no } \\
\text { Parque nos próximos } 10 \text { anos } \\
\text { ou mais. }\end{array}$ & & & & & \\
\hline
\end{tabular}

Comente sobre os planos de expansão para o Parque Tecnológico. 


\section{PARTE CI NCO: $\quad$ ELEMENTOS DA I MAGEM DO EMPREENDI MENTO}

\subsection{Características do local e do entorno}

LOCALIZAÇÃO FÍSICA - se está dentro ou fora do campi - Tradução livre de informação disponível no endereço eletrônico

http://www.ukspa.org.uk/downloads/ANGLE UKSPA Evaluation Executive Summary.pdf em 20/04/2006

ENTORNO - se refere à circunvizinhança do Parque, definida aqui definida como Economia do Conhecimento da Sub Região (Sub Regional Knowledge Economy) tradução livre, disponível no endereço eletrônico

http://www.ukspa.org.uk/downloads/ANGLE UKSPA Evaluation Executive Summary.pdf em 20/04/2006

\begin{tabular}{|c|c|c|c|c|c|}
\hline & $\begin{array}{l}\text { Discordo } \\
\text { totalmente }\end{array}$ & $\begin{array}{c}\text { Discordo } \\
\text { parcialmente }\end{array}$ & Neutro & $\begin{array}{c}\text { Concordo } \\
\text { Parcialmente }\end{array}$ & $\begin{array}{l}\text { Concordo } \\
\text { totalmente }\end{array}$ \\
\hline $\begin{array}{l}\text { O Parque está localizado em um } \\
\text { local estratégico para o } \\
\text { desenvolvimento dos } \\
\text { negócios das PMEs. }\end{array}$ & & & & & \\
\hline $\begin{array}{l}\text { O entorno do empreendimento } \\
\text { é excelente e contribui } \\
\text { enormemente para a expansão } \\
\text { dos negócios das PMEs. }\end{array}$ & & & & & \\
\hline
\end{tabular}

Por favor, comente sobre a influência do entorno do empreendimento na decisão das empresas em se instalarem no parque/empreendimento.

\subsection{Características dos parceiros}

\begin{tabular}{|c|c|c|c|c|c|}
\hline & $\begin{array}{l}\text { Discordo } \\
\text { totalmente }\end{array}$ & $\begin{array}{c}\text { Discordo } \\
\text { parcialmente }\end{array}$ & Neutro & $\begin{array}{c}\text { Concordo } \\
\text { Parcialmente }\end{array}$ & $\begin{array}{l}\text { Concordo } \\
\text { totalmente }\end{array}$ \\
\hline $\begin{array}{l}\text { Os parceiros do } \\
\text { empreendimento têm uma } \\
\text { participação efetiva na vida } \\
\text { do parque e interagem } \\
\text { regularmente entre si e com as } \\
\text { PMEs. }\end{array}$ & & & & & \\
\hline $\begin{array}{l}\text { Os parceiros do } \\
\text { empreendimento, além de } \\
\text { atenderem reativamente as } \\
\text { demandas das PMEs, atuam } \\
\text { pró ativamente com relação ao } \\
\text { desenvolvimento do parque e } \\
\text { sobretudo das PMEs que estão } \\
\text { instaladas no Parque. }\end{array}$ & & & & & \\
\hline
\end{tabular}

Por favor, comente a respeito da influência do envolvimento dos parceiros do parque, sobre a escolha, por parte das empresas, que se instalaram no parque. 
DOCUMENTO RESTRITO 
DOCUMENTO RESTRITO

\subsection{PRESTÍ GI O DO PARQUE}

PRESTÍGIO - se relaciona ao estágio de maturidade do Parque Científico Tecnológico, definido por quatro fases, Início, Crescimento, Maturidade e Diversificação, cada um com suas características específicas. tradução livre, extraído de

http://www.ukspa.org.uk/downloads/ANGLE UKSPA Evaluation Executive Summary.pdf pg. II - em abril/2006

BENEFÍCIOS - se relaciona ao estágio de maturidade da economia do conhecimento na subregião que circunda o Parque Científico Tecnológico (entorno) tradução livre, extraído de http://www.ukspa.org.uk/downloads/ANGLE UKSPA Evaluation Executive Summary.pdf pg. II - em abril/2006

\begin{tabular}{|c|c|c|c|c|c|}
\hline & $\begin{array}{l}\text { Discordo } \\
\text { totalmente }\end{array}$ & $\begin{array}{c}\text { Discordo } \\
\text { parcialmente }\end{array}$ & Neutro & $\begin{array}{c}\text { Concordo } \\
\text { Parcialmente }\end{array}$ & $\begin{array}{l}\text { Concordo } \\
\text { totalmente }\end{array}$ \\
\hline $\begin{array}{l}\text { O parque esta instalado em } \\
\text { um local de prestígio, que } \\
\text { pode trazer grandes benefícios } \\
\text { para a imagem das empresas ali } \\
\text { presentes. O local é um fator } \\
\text { determinante na decisão das } \\
\text { empresas que se instalaram no } \\
\text { Parque. }\end{array}$ & & & & & \\
\hline
\end{tabular}

Por favor, comente a respeito da influência do prestígio do empreendimento e quais seus impactos sobre a decisão das empresas, ao se instalarem no parque. 


\section{GLOSSÁRIO DE TERMOS E SIGLAS}

BENEFÍCIOS - se relaciona ao estágio de maturidade da economia do conhecimento na sub- região que circunda o Parque Científico Tecnológico (entorno) tradução livre, extraído de

http://www.ukspa.org.uk/downloads/ANGLE UKSPA Evaluation Executive Summa ry.pdf pg. II - em abril/2006

COMERCIALIZAÇÃO TECNOLÓGICA: Direito de utilização de know how ou de conhecimento tecnológico efetivado através de compra e venda ou pagamento de royalties pelo uso de processos ou produtos patenteados. - definição retirada do "Glossário dinâmico de termos na área de Tecnópolis, Parques Tecnológicos e Incubadoras de Empresas" - ANPROTEC 2002 - disponível no site www.anprotec.br/glossario em abril/2006.

COOPERAÇÃO INTERNACIONAL - Estímulo, através de programas/ações formalmente constituídos, ou não, à cooperação entre MPEs e organizações internacionais (outras empresas localizadas no Parque, empresas localizadas fora do parque, institutos de pesquisa ou universidades)

ENTORNO - se refere à circunvizinhança do Parque, definida aqui definida como Economia do Conhecimento da Sub Região (Sub Regional Knowledge Economy) tradução livre, extraído de

http://www.ukspa.org.uk/downloads/ANGLE UKSPA Evaluation Executive Summa ry.pdf pg. II - em abril/2006

GLOBALIZAÇÃO - Globalização é um processo no qual a distância geográfica se torna um fator menor no estabelecimento e sustentabilidade das fronteiras, distâncias econômicas, políticas e relações sócio culturais. As pessoas tornam-se conscientes e temerosas deste fato. Consequentemente, redes de relações e dependências, potencialmente, atravessam cruzam as fronteiras físicas e atravessam o mundo todo. Esta internacionalização potencial de relações e dependências causam medo, resistências, ações e reações.- tradução livre de definição disponível em abril/2006 no site

http://www.iasp.ws/information/definitions.php?ce=

HABILIDADES TECNOLÓGICAS - Nesse contexto habilidades tecnológicas são os recursos humanos especializados que contribuem com a atividade de pesquisa e 0 desenvolvimento. tradução livre de definição disponível em 20/05/2006 no site http://www.rsnz.org/policy/i3 response.php

INFRA-ESTRUTURA FÍSICA (Hard infrastructure) é o conjunto de instalações físicas do Parque (por exemplo: vias de acesso, edifícios, serviços de luz, rede de águas, etc...). - Tradução livre de definição extraída de KIRK \& CATTS (2004, pg. 43).

MELHORIA DA GESTÃO DO NEGÓCIO: Serviços de apoio que tem como objetivo assistir as PMEs e apoiá-las no desenvolvimento e melhoria de seus negócios de maneira a aumentar as suas chances de sucesso, por meio de respostas efetivas aos desafios do negócio, desafios sociais e do ambiente. Esta explicação foi baseada na definição de Business Support Services baixada do site http://www.iasp.ws/information/definitions.php?ce em 20/04/2006.

PLANO DE NEGÓCIOS - Documento preparado pela administração da empresa, contendo descrição detalhada do passado, presente e futuro da organização. É geralmente utilizado para atrair investimentos, conseguir empréstimos ou financiamentos, promover controle interno de integração e envolvimento do pessoal. - definição retirada do "Glossário dinâmico de termos na área de Tecnópolis, Parques Tecnológicos e Incubadoras de Empresas" - ANPROTEC 2002 - 


\section{DOCUMENTO RESTRITO}

disponível no site www.anprotec.br/glossario em abril/2006.

PLANO DIRETOR (Master Plan) - Um plano guia, inteligível e diretivo, utilizado como guia para o desenvolvimento físico de longo prazo de uma determinada área. - Tradução livre de definição apresentada no site http://www.4554.com/Glossary/MASTER PLAN.html em abril/2006

PRESTÍGIO - se relaciona ao estágio de maturidade do Parque Científico Tecnológico, definido por quatro fases, Início, Crescimento, Maturidade e Diversificação, cada um com suas características específicas. tradução livre, extraído de

http://www.ukspa.org.uk/downloads/ANGLE UKSPA Evaluation Executive Summa ry.pdf pg. II - em abril/2006

PROSPECÇÃO TECNOLÓGICA - (a) Tentativas sistemáticas para observar, no longo prazo, o futuro da ciência, da tecnologia, da economia e da sociedade, com o propósito de identificar tecnologias emergentes que possam produzir benefícios econômicos e/ou sociais; (b). Estudos sobre tendências tecnológicas em setores industriais específicos, utilizando principalmente informações contidas em documentos de patentes nacionais ou estrangeiros. - definição retirada do "Glossário dinâmico de termos na área de Tecnópolis, Parques Tecnológicos e Incubadoras de Empresas" - ANPROTEC 2002 - disponível no site www.anprotec.br/glossario em abril/2006.

SERVIÇOS COMUNS (Soft infraestruture) - há uma lista considerável de serviços que podem ser oferecidos pelo Parques às empresas instaladas. A extensão dos serviços oferecidos dependem do tipo de Parque Científico Tecnológico e de seus objetivos. Alguns serviços poderão ser oferecidos pelo próprio Parque, mas outros poderão ser disponibilizados por meio de acordos com outras organizações locais. Tradução livre de definição extraída de KIRK \& CATTS (2004, pg. 45).

SERVIÇOS PARA DESENVOLVIMENTO TECNOLÓGICO - Serviços de apoio 'as PME para acesso aos meios de desenvolvimento tecnológico das Universidades e Institutos de Pesquisa.

TECNOLOGIA - (a) Método para transformar inputs em outputs; (b) aplicação dos resultados de pesquisa científica à produção de bens e serviços; (c) tipo específico de conhecimento, processo ou técnica exigido para fins práticos.- definição retirada do "Glossário dinâmico de termos na área de Tecnópolis, Parques Tecnológicos e Incubadoras de Empresas" - ANPROTEC 2002 - disponível no site www.anprotec.br/glossario em abril/2006.

TRANSFERÊNCIA DE TECNOLOGIA - Intercâmbio de conhecimento e habilidades tecnológicas entre instituições de ensino superior e/ou centros de pesquisa e empresas. Faz.se na forma de contratos de pesquisa e desenvolvimento, serviços de consultoria, formação profissional, inicial e continuada, venda de patentes, marcas e processos industriais, publicação na mídia científica, apresentação em congressos, migração de especialistas, programas de assistência técnica, espionagem industrial e atuação de empresas multinacionais. - definição retirada do "Glossário dinâmico de termos na área de Tecnópolis, Parques Tecnológicos e Incubadoras de Empresas" - ANPROTEC 2002 - disponível no site www.anprotec.br/glossario em abril/2006. 
APÊNDICE B - Siglário 
Siglário

A

AAll - Assessoria de Assuntos Internacionais e Interinstitucionais da PUCRS

ABO - Applicazione Biotechnologie in Oncologia

AGT - Agência de Gestão Tecnológica

AGT-TECNOPUC - Agência de Gestão Tecnológica e Propriedade Intelectual da Pontifícia Universidade Católica do Rio Grande do Sul ANPROTEC - Associação Nacional das Entidades Promotoras de Empreendimentos Inovadores

APRE - Agency for the Promotion of European Research

APSTI - Associazione Parchi Scientifici Technologici Italiani

APTE - Associación de Parques Científicos y Tecnológicos de Espanã

AREAM - Agência Regional de Energia e Ambiente

ASIT - Asociación al Servicio de la Investigación y la Tecnología

ASSESPRO - Associação das Empresas Brasileiras de Tecnologia da Informação, Software e Internet

B

BAN - Business Angel Network

BC-NET - Business Cooperation Network

BIG - Bremer Investitions-Gesellschaft $\mathrm{mbH}$

BINASP - Bio-Nanotechnology European Infrastructure in AREA Science Park

BZH - University of Heidelberg's Biochemistry Center

C

CADE - Centro Andaluz de Emprendedores

CADE - Centro de Apoio al Desarrollo Empresarial

CATI - Coordenadoria de Assistência Técnica Integral

CBM - Scarl - Consortium for Molecular Biomedicine

CBM - Centro de Biomedicina Molecolare

CEI - Central European Initiative

CEIM - Centro de Empresas e Inovação da Madeira 
CenPRA - Centro de Pesquisa Renato Archer

CEPUC - Centro de Eventos da PUCRS

CERSA - Centro Ricerche e Studi Agroalimentari

CESEAND - IRC - Centro de Enlace de Andalucía

CESTI - Consorcio de Estrategía Tecnológica e Innovación

CIFEC - Centro Internacional de Feiras e Congressos do Madeira

Tecnopolo.

CITIC - Centro Andaluz de Innovación y Tecnologias de La Información

CODAU - Convegno permanente dei Direttori Amministrativi e dirigenti delle Università italiane

CPqD - Centro de Pesquisa e Desenvolvimento em

Telecomunicações

CPMR - Conference of Peripheral Maritime Regions of Europe

CRPA - Centro Ricerche Produzioni Animal

CSF - Centre for the Study of Liver Diseases of the Fund for Liver

Diseases

C\&T - Ciência e Tecnologia

D

D4 Project - Projeto de longo prazo criado pelo Escritório Central para o Trabalho, Treinamento, Universidades e Pesquisa na região autônoma da Friuli Venezia Giulia, junto ao Programa Operacional, objetivo 3, 2000-2006, Prioridade D, Medida D4, dedicado ao aprimoramento dos recursos humanos nos setores da pesquisa e desenvolvimento tecnológico.

DKFZ - German Cancer Research Center

DAP - Empresa Pública para el Desarrollo Agrario y Pesquero de Andalucía

DEPTEQ - Departamento Tecnológica da Faculdade de Química

DINTEC - Diffusione Informazioni Normativa Tecnica

DPCT - Departamento de Política Científica e Tecnológica

E

EADS - European Aeronautic Defence and Space Company

EBN - European Business and Innovation Network 
EBAN - European Business Angel Network

EIS - European Innovation Scoreboard

EMBL - European Molecular Biology Laboratory

EMBRAPA - Empresa Brasileira de Pesquisa Agropecuária

ENEA - Ente per Le Nuove Tecnologie, I'Energia e l'Ambiente

ENFAP - Ente Nazionale Formazione Addestramento Professionale

ERA-MORE - European Network of Mobility Centres

ESAV - Escola Superior de Agricultura e Veterinária

ETT - Escritório de Transferência de Tecnologia

EU - Europe Union

EURADA - European Association of Development Agencies

EXTECAMP - Escola de Extensão da Unicamp

$\mathbf{F}$

FAPEMIG - Fundação de Amparo a Pesquisa do Estado de Minas Gerais

FESR - European Fund for Regional Development

FINEP - Financiadora de Estudos e Projetos

FIRB - Fund for investing in fundamental research

FIRM - Formazione per gli Imprenditori Regionali e i Manager

FORMAN - Centro de Formación en Comunicaciones y Tecnologías de la Información

FP - Framework Programme

FP6 - 6a edição do Framework Programme

FP7 - $7^{\text {a }}$ edição do Framework Programme

FUNDAQUIM - Fundação sem fins lucrativos da Faculdade de

Química da Universidade da República do Uruguai

$\mathbf{H}$

HiCo project - HiCo-Hi-tech integrated Co-operation for cross-border economic growth and SME competitiveness increase HKSTP - Hong Kong Science \& Technology Parks Corporation

\section{I}

IAC - Instituto Agronômico de Campinas

IASP - International Association of Science Parks 
IAT - Instituto Andaluz de Tecnologia

ICGEB - International Center for Genetic Engineering and

Biotecnology

ICS - International Center of Science

ICT - Instituição Científico Tecnológica

IDEA -Investigation y Desarrollo en Andalucia

IDT - Investigação e Desenvolvimento Tecnológico

IEL - Instituto Euvaldo Lodi

IFA - Instituto de Fomento de Andalucia

ifex - Initiative for Start-ups and Business Transfer

INDYCEE, S.L. - Instituto de Investigatión, Desarrollo y Control de Calidad em La Edificación

INOVA - Agência de Inovação da UNICAMP

INSME - International Network for Small and Medium Enterprises

Invesat - Investors in emerging ICT markets of Satellite applications

IPs - Integrated Projects

IPI - Institute for Industrial Promotion

IPR - Intellectual Property Rights

IRC Anatólia - Innovation Relay Centre Anatolia

IRC CESEAND - Centro de Enlace Del Sur de Europa -Andalucía

IRC IRENE - Italian Relay Centre North East

IRC Network - Innovation Relay Centre Network

IRES - Institute for Economic and Social Research in Friuli Venezia Giulia

ITAL - Instituto de Tecnologia de Alimentos

ITI -International Technology Incubators programme

IUCN - International Union for Conservation of Natural Resources

$\mathbf{L}$

LABELO - Laboratório Especializado em Eletro-Eletrônica

LNLS - Laboratório Nacional de Luz Síncroton

M

MAE - Ministero degli Afare Esteri 
MBA - Master of Business Administration

MIUR - Ministero dell'Università e de la Ricerca

$\mathbf{N}$

NANOLAB - Nanosized Cancer Polymarker Biochip

NBIA - National Business Incubation Association

NESI - Núcleo Estratégico para a Sociedade de Informação

NoEs - Networks of Excellence

O

OTRI - Oficina de Transferência de Resultados de Investigatión

$\mathbf{P}$

PAT - Projeto Porto Alegre Tecnópole

PATLIB - Patent Library

PCTs - Parques Científicos Tecnológicos

PGP - Piattaforma Genomica del PTP

PIB - Produto Interno Bruto

PMEs - Pequenas e Médias Empresas

PMI - Project Management Institute

PRINT - Per una Rinnovata cultura di Impresa Nel Territorio regionale

PROAF - Pró-Reitor de Administração e Finanças

PROEX - Pró-reitoria de Extensão

PROJUR - Procuradoria Jurídica

PRPPG - Pró-Reitor de Pesquisa e Pós-Graduação

PTA - Parque Tecnológico de Andalucia (Espanha)

PTP - Parco Tecnologico Padano (Itália)

PTV - Parque Tecnológico de Viçosa

PUCRS - Pontifícia Universidade Católica do Rio Grande do Sul

P\&D - Pesquisa e Desenvolvimento

P\&D\&I - Pesquisa, Desenvolvimento e Inovação

$\mathbf{R}$

RETA - Red de Espacios Tecnológicos de Andalucia

REPOTs - Regiões de Potencial Tecnológico da RMPA 
RIPA - Rede de Inovação e Prospecção Tecnológica para Agronegócio

RMPA - Região Metropolitana de Porto Alegre

$\mathrm{RNI}$-Rhein Neckar Immobilien

$\mathrm{S}$

SEBRAE - Serviço Brasileiro de Apoio às Micro e Pequenas Empresas

SEDAI - Secretaria do Desenvolvimento e Assuntos Internacionais SMIDO - Small and Medium Size Industry Development Organization

SOFTSUL - Associação Sul-riograndense de Apoio ao Desenvolvimento de Software

SOFTEX - Sociedade Brasileira para Promoção da Exportação de Software

STEP - Small Technology/Design Incubation Programme

$\mathbf{T}$

TECNOPUC - Parque Tecnológico da PUCRS

TecParques - Associação Portuguesa de Parques de Ciência e Tecnologia

TEKMER - Teknoloji Geliştirme Merkezi

TIDEB - Teknoloji İzleme ve Değerlendirme Başkanlığı

TI\&C - Tecnologias da Informação e Comunicação

TII - European Association for Technology Transfer Innovation and Industrial Information

TPCC - Technologiepark Heildelberg Conference Center

TRIZ - Teoriya Resheniya Izobretatelskikh Zadatch

TT - Transferência de Tecnologia

TTGF - Türkiye Teknoloji Geliştirme Vakfı (Turkish Technology Development Foundation)

TTO - Technology Transfer Office

U

UE - União Européia

UNICAMP - Universidade Estadual de Campinas

UNIONCAMERE - Camere di Commercio d'Italia 
UniS - University of Surrey

UFV - Universidade Federal de Viçosa

Urutec - Uruguay Tecnológico

W

WCTL - Wireless Comunication Test Laboratory

Z

ZARM - Center of Applied Space Technology and Microgravity 


\section{REFERÊNCIAS BIBLIOGRÁFICAS}

1. ASSOCIAÇÃO NACIONAL DE ENTIDADES PROMOTORAS DE EMPREENDIMENTOS DE TECNOLOGIAS AVANÇADAS (ANPROTEC) Parques Tecnológicos Brasileiros - Estudo, Análise e Proposições, versão impressa pela para distribuição no XVIII Seminário Nacional de Parques Tecnológicos e Incubadoras de Empresas, realizado de 22 a 26 de setembro Aracaju, Sergipe, 2008.

2. ASSOCIAÇÃO NACIONAL DE ENTIDADES PROMOTORAS DE EMPREENDIMENTOS DE TECNOLOGIAS AVANÇADAS (ANPROTEC), Glossário dinâmico de termos na área de Tecnópolis, Parques Tecnológicos e Incubadoras de Empresas, SEBRAE, Brasília, 2002.

3. ASSOCIAÇÃO NACIONAL DE ENTIDADES PROMOTORAS DE EMPREENDIMENTOS DE TECNOLOGIAS AVANÇADAS (ANPROTEC), Portfolio de Parques Tecnológicos no Brasil, ANPROTEC/ABDI, Brasília, 2008.

4. ASSOCIAÇÃO NACIONAL DE ENTIDADES PROMOTORAS DE EMPREENDIMENTOS DE TECNOLOGIAS AVANÇADAS (ANPROTEC), Panorama 2003 - ANPROTEC - panorama de incubadoras e parques tecnológicos, UNB, Brasília, 2004.

5. ASSOCIAÇÃO NACIONAL DE ENTIDADES PROMOTORAS DE EMPREENDIMENTOS DE TECNOLOGIAS AVANÇADAS (ANPROTEC), XIII Seminário Nacional de Parques Tecnológicos e Incubadoras de Empresas e XI Workshop ANPROTEC - Sessão 3. UNB, Brasília, 2004.

6. ASSOCIAÇÃO NACIONAL DE ENTIDADES PROMOTORAS DE EMPREENDIMENTOS DE TECNOLOGIAS AVANÇADAS (ANPROTEC), XVI Seminário Nacional de Parques Tecnológicos e Incubadoras de Empresas e XIV Workshop ANPROTEC - Agosto, 21 a 25 de agosto, Salvador, Bahia, Compact Disk dos Anais, 2006.

7. ASSOCIAÇÃO NACIONAL DE ENTIDADES PROMOTORAS DE EMPREENDIMENTOS DE TECNOLOGIAS AVANÇADAS (ANPROTEC), Caminhos para o sucesso em Incubadoras e Parques Tecnológicos - UM GUIA DE BOAS PRÁTICAS, ANPROTEC \& SEBRAE, Brasília, 2006

8. ASSOCIAÇÃO NACIONAL DE PESQUISA, DESENVOLVIMENTO DE ENGENHARIA DAS EMPRESAS INOVADORAS (ANPEI), MOVIMENTO BRASIL COMPETITIVO (MBC), Manual de Inovação Tecnológica. Brasília, 2004. Disponível em http://www.inovar.org.br/biblioteca/detalhe arquivo.asp?idArquivo=9\&m= acesso em 08/11/2005.

9. Battelle Technology Partnership Practice e Association of University Research Parks. Characteristics and Trends in North American Research Parks - 21 century directions, outubro de 2007, Disponível em http://www.aurp.net/more/ FinalBattelle.pdf Acesso em 10/12/2008.

10. CAMPODALL'ORTO,S. Evolução dos Distritos Industriais na Itália Desenvolvimento, Fatores críticos e Oportunidades, Politecnico Innovazione, Rio 
de Janeiro, 2005, disponível no endereço eletrônico http://portal.crie.coppe.ufri.br/portal/data/documents/storedDocuments/\%7B93787 CAE-E94C-45C7-992B-9403F6F40836\%7D/\%7BA2893148-FC13-48D6-BC3B2D2814CF5B73\%7D/Evolucao Distritos.pdf Acesso em 12/3/2009.

11. CASSIOLATO J.E.; LASTRES, H. M. M. Globalização \& Inovação Localizada Experiências de Sistemas Locais no Mercosul. Brasília, Distrito Federal. IBICT, 1999.

12. CASSIOLATO J.E.; LASTRES, H. M. M. Tecnoglobalismo e o papel dos esforços de $P, D \& I$ de multinacionais no mundo e no Brasil. Seminários temáticos para a $3^{\mathrm{a}}$ Conferência Nacional de C\&T\&l, p. 1225-1245, Parcerias Estratégicas, n.20, jun. 2005.

13. CRUZ, C. H. B. A A universidade, a empresa e a Pesquisa. Revista

Humanidades, v. 45 pg. 15-29, UNB, 1999. (nota: este artigo foi preparado para o seminário 'Brasil em Desenvolvimento', organizado pelo Instituto de Economia da UFRJ).

14. CRUZ, C. H. B. A Universidade, a Empresa e a Pesquisa que o país precisa. Parcerias Estratégicas, v. 8, n. 16, p. 5-30, 2000.

15. CRUZ, C. H.de B. A verdadeira riqueza das nações. Gazeta Mercantil, São Paulo, 16, ago. 2001 Disponível em < http://www1.investnews.com.br/inn/gmo noticia.asp?integra=1\&id=2068718\&ling $>$ Acesso em 05/4/2004.

16. CRUZ, C. H. B. O Investimento Nacional em Ciência e Tecnologia: uma Análise Comparativa. Apresentação da conferência regional de C\&T\&I, 2001.

Disponível em < http://www.ifi.unicamp.br/ brito/artigos/desafios-estrat-19092001h.pdf $>$ Acesso em 20/09/2005.

17. CRUZ, C. H. B. Uma nova mentalidade em ação - Sistema tripartide para C\&T Avança. Revista Pesquisa Fapesp, Ed. 85, São Paulo, março de 2003. Disponível em < http://revistapesquisa.fapesp.br:2222/transform.php?xml=7/0/20030307/20030385/ pt/SEC5 6.xml\&xsl=xsl/pt/opinion.xsl\&transf=normal\&id=SEC5 6\&lang=pt\&issue= 20030385 Acesso em 01/11/2005.

18. CRUZ, C. H. B. Universidade pública e desenvolvimento. Folha de São Paulo, 21/06/2001. Disponível em < http://www.ifi.unicamp.br/ -brito/artigos/fsp2106200109.pdf > Acesso em $01 / 11 / 2005$

19. CRUZ, C. H. B. Universidade e Institutos como parceiros tecnológicos para empresas. V Conferência da ANPEI - Cadeias Sinérgicas de Inovação Florianópolis, maio, 10 a 13, 2005. Disponível no site da ANPEI, arquivo 2005-05carlos_brito_cruz_fapesp1-VConfANPEI. Acesso em set., 2005.

20. EUROPEAN COMISSION (CE) within the Fifth Framework Programme for Research and Development. Regional Innovation Strategy for Prague Region" - Bohemian Regional Innovation Strategy - BRIS. ISBN 8086794-15-6. Prague, 2004. 
21. GIL, A. C. Métodos e Técnicas de Pesquisa Social. São Paulo. 5. ed. Ed. Atlas, 1999.

22. IGAMI, M.P.Z.; ZARPELON, L.M.C. (Org). Guia para a elaboração de dissertações e teses: preparado para orientação dos alunos de Pósgraduação do IPEN. São Paulo: IPEN, Divisão de Informação e Documentação Científicas, 2002. Disponível em $<$ http://www.ipen.br/biblioteca/apresentacao guia.htm>. Acesso em: $10 / 01 / 2008$

23. INTERNATIONAL ASSOCIATION OF SCIENCE PARKS (IASP) Facts and Figures of Science and Technology Parks in the World - IASP General Survey 2007, IASP, 2008. Disponível em http://www.rtp.org/files/iasp survey on stps.pdf Acesso 12/3/2009.

24. ITALIAN NATIONAL INSTITUT OF STATISTICS (ISTAT) Italy in Figures - 2007, CRS, Roma, 2008, disponível em http://www.istat.it/dati/catalogo/20070517 00/Italy2007Ing.pdf Acesso em 12/3/2009.

25. KIRK, C. M., CATTS B. C. Science and Technology Park Scoping Study. New Zealand Trade and Entreprise (NZTE). New Zealand, 28, jan., 2004, disponível no endereço eletrônico http://www.nzte.govt.nz/common/files/ science-tech-scoping.pdf. Acesso em 01/7/2008.

26. LASTRES, H. M. M. Gestão da Inovação e Sistemas Nacionais de Inovação a Experiência Japonesa. $1^{\mathrm{a}}$. ed. Brasília, DF: SEBRAE, 1996 (nota: elaborado para utilização no Curso de Especialização em Agentes de Difusão Tecnológica).

27. LIMA, E.O. As Definições de Micro, Pequena e Média Empresas Brasileiras como Base para Formulação de Políticas Públicas, Londrina, PR, novembro, 2001, disponível no endereço eletrônico http://home.furb.br/edmilsonlima/EDMILSONEgepe2001-definicoes-MPME.pdf Acesso 12/3/2009.

28. MONTGOMERY, C. A., PORTER M. E. A busca da Vantagem Competitiva. Tradução autorizada do idioma inglês publicada pela HBS Press. Copyright 1979 a 1991 by Harvard College, 6. ed., Rio de Janeiro, Ed. Campus, 1998. Título original: Strategy ISBN 0-87548-243-7 - Harvard Business School Publishing Division.

29. NACIONAL GOVERNORS ASSOCIATION (NGA). Cluster-Based Strategies for Growing State Economies. Council on Competitiveness. NGA Center for Best Practices, Washington, 2007, disponível no endereço http://www.nga.org/portal/site/nga/menuitem.9123e83a1f6786440ddcbeeb501010 a0/?vgnextoid=1a5f496c350f0110VgnVCM1000001a01010aRCRD Acesso $12 / 3 / 2009$.

30. NAISBITT, J., Paradoxo Global. Tradução de Ivo Koritowski. 11. ed. Rio de Janeiro. Ed. Campus, 1994. Título original: Global Paradox.

31. OHMAE, K., O Fim do Estado Nação - A ascensão das economias regionais. Tradução de Ivo Korytowski ed. 3 Rio de Janeiro, Ed. Campus, 1996. Título original: The End of the Nation State. 
32. ORGANISATION DE CO-OPÉRATION ET DE DEVELOPPEMENT

ECONOMIQUES (OCDE). La Charte de Bologne - sur les politiques a l'égard des

PME. 2004. Conference de Bologne, Italy, 2004. Site www.oecd.org/sti/smes.

33. ORGANISATION DE CO-OPÉRATION ET DE DEVELOPPEMENT

ECONOMIQUES (OCDE). Promouvoir l'entreprenariat et lês PME innovantes dans une économie mondialisée - vers une mondialisation plus responsible et mieux partagée. Note de synthèse des rapports de référence. La deuxiéme conference $d$ l'OCDE des Ministres em Carge des petites et moyènnes emtreprises (PME). Istanbul, Turquie, 3-5 juin/2004. Les editions de I'OCDE, Paris, 2004 n. 82676. Disponível em www.oecd.org/sti/smes et www.oecd.org/sti/smes .

34. ORGANIZAÇÃO DAS NAÇÕES UNIDAS PARA O DESENVOLVIMENTO INDUSTRIAL (ONUDI) Guide Opérationnel pour La Gestion des Pépinières de Parcs Technologiques: Un modèle pour la Tunisie - avec l'assistance du Pole de Elgazala des Technologies de la Communication, Tunis. Disponível em http://www.unido.org/fileadmin/import/48990 Manuel des Procedures.pdf Acesso em 12/3/2009.

35. PINHEIRO, I. A., PAULA, E. A. W. O Pólo de Informática de São Leopoldo, Rio Grande do Sul, Brasil - três anos após a pedra fundamental. Revista Eletrônica de Administração - REAd - Edição 22 Vol. 7 No. 4, jul-ago, Porto Alegre-RS, 2001.

36. PLONSKY, G. A. Cooperação Empresa-Universidade no Brasil: Um Novo Balanço Prospectivo, In: Interação Universidade-Empresa, Brasília, Distrito Federal, 1998. IBICTI/IEL, p. 9-23.

37. PORTER, M. E. Estratégia Competitiva - Técnicas para Análise de Indústrias e da Concorrência. Tradução de Elizabeth Maria de Pinho Braga - Revisão técnica de Jorge Garcia Gomez, Rio de Janeiro, Ed. Campus, 1986. Título original Competitive Strategy (1980).

38. PORTER, M. E. Vantagem Competitiva - Criando e sustentando um desempenho superior. Tradução de Elizabeth Maria de Pinho Braga - Revisão técnica de Jorge Garcia Gomez, 29 ed., Rio de Janeiro, Ed. Elsevier, 1989. Título original Competitive Advantage (1985).

39. PORTER, M. E. A Vantagem Competitiva das Nações. Tradução de Waltensir Dutra. 11. ed. Rio de Janeiro, Ed. Campus, 1989. Título original: The Competitive Advantage of Nations.

40. Porter, M.E. "On competition", Harvard Business Review Book, 1998

41. RESEARCH TRIANGLE PARK Competiting in the Global Economy, setembro, 2007. Disponível em http://www.rtp.org/files/Fact\%20Sheets/over view presentation.pdf; e no sítio do Research Triangle Park, endereço eletrônico http://www.rtp.org/main/ index.php?pid=183\&sec=1. Acesso em 20/12/2008.

42. ROMERA, F. El Modelo de Desarrollo Del PTA - Jornada INNOVACIÓN, UN DESAFÍO PERMANENTE, outubro, 2008. Disponível em http://www.coiiaoc.com/cuenta2/jornadas/innovacion/mesa2/romera.pdf Acesso 13/2/2009. 
43. ROZENFELD, H., AMARAL, C.S.T. Um ambiente colaborativo de conhecimento aberto visando a criação de modelos de processo de desenvolvimento de produtos, 2008. Disponível em http://www.isssbrasil.usp.br/pdfs2/gso 4.pdf Acesso 13/2/2009.

44. SANZ, L. Innovation and Human Resources in the Knowledge Economy - The role of Science Parks, abril, 2005. Disponível em http://www.nvf.cz/archiv/cei2005/sanz 1.pdf Acesso 12/3/2009.

45. SEBRAE, ABIPTI, CNPq, Gestão da Inovação e Sistemas Nacionais de Inovação: a Experiência Japonesa. Tecnologia, SEBRAE, Brasília, 2003.

46. SECRETARIA EXECUTIVA DO PORTO ALEGRE TÉCNOLOPE (PAT). Termo de Cooperação do PAT - 2000-2001. - Integrantes do Porto Alegre Tecnópole (CUTRS, FEDERASUL, FIERGS-IEL, SEBRAE, Governo do Rio Grande do SulSecretaria de C\&T [SCT] - Secretaria de Desenvolvimento e Assuntos Internacionais [SEDAI], Prefeitura de Porto Alegre - Secretaria de Produção e Comércio [SMIC] - Equipe Técnica da SDTec.

47. SECRETARIA EXECUTIVA DO PORTO ALEGRE TÉCNOLOPE (PAT). Termo de Referência do PAT - 1995. - Integrantes do Porto Alegre Tecnópole (CUT-RS, FEDERASUL, FIERGS-IEL, SEBRAE, Governo do Rio Grande do Sul-Secretaria de C\&T [SCT] - Secretaria de Desenvolvimento e Assuntos Internacionais [SEDAI], Prefeitura de Porto Alegre - Secretaria de Produção e Comércio [SMIC] - Equipe Técnica da SDTec.

48. STIGLITZ, J. E., A Globalização e seus malefícios - A promessa não-cumprida de benefícios globais. Tradução de Bazan Tecnologia e Lingüística. 3. ed. São Paulo, Ed. Futura, 2002. Título original: Globalization and its discontents.

49. TERRA, B. A Transferência de Tecnologia em Universidades

Empreendedoras - Um Caminho para a Inovação Tecnológica. Rio de Janeiro, Ed. Qualitymark, 2001.

50. TERRA, J. C. C., Gestão do Conhecimento - O grande desafio empresarial Uma abordagem no aprendizado e na Criatividade. São Paulo, Negócio Editora Ltda., 2000.

51. VEDOVELLO, C. Apresentação sobre a FINEP. In: I ENCONTRO PAULISTA DE PARQUES CIENTÍFICOS E TECNOLÓGICOS EM ÁREAS URBANAS: CONSTRUINDO ESPAÇOS PARA O DESENVOLVIMENTO DE REGIÕES. 16 e 17 de agosto, 2004, São Paulo, SP. Disponível em http://sistecparq.cietec.org.br/SistecParqFiles/CONNIE.PPS Acesso em 03/11/2005.

52. WILIAMS, R. The epistemology of knowledge and the knowkedge process cycle: beyound the "objectivist" vs "interpretivist, JOURNAL OF KNOWLEDGE MANAGEMENT, Vol. 12, no. 4, 2008, pp. 72-85, Q Emerald Group Publishing Limited.

53. ZOUAIN, D. M. Parques Tecnológicos Propondo um Modelo Conceitual para Regiões Urbanas O Parque Tecnológico de São Paulo, 2003. Tese (Doutorado) - Instituto de Pesquisas Energéticas e Nucleares, São Paulo. 
54. ZOUAIN, D. M. Sobre o Parque Tecnológico de São Paulo. In: I ENCONTRO PAULISTA DE PARQUES CIENTÍFICOS E TECNOLÓGICOS EM ÁREAS URBANAS: CONSTRUINDO ESPAÇOS PARA O DESENVOLVIMENTO DE REGIÕES, 16 e 17 de agosto, 2004, São Paulo, SP. Disponível em: < http://sistecparq.cietec.org.br/SistecParqFiles/DRA.\%20DESIREE.PPS > Acesso em 03/11/2005.

55. ZOUAIN, D.M., MARTINS, E. O. F. Transformação Tecnológica e Estratégia Competitiva: um estudo multicaso. Revista Eletrônica de Administração - REAd Edição 37, Vol. 10 nº 1. jan-fev, Porto Alegre - RS, 2004.

56. ZOUAIN,D.M., PLONSKY, G.A. Parques Tecnológicos - Planejamento e Gestão. Brasília, ANPROTEC, 2007

\section{BIBLIOGRAFIA RECOMENDADA}

1. ACWORTH, E.B., GHOSE S. Knowledge Integration Communities (KICs): A Case Study of an Innovative University-Industry Knowledge Exchange Programme. In: $5^{\circ}$ TRIPLE HELIX CONFERENCE, 18 a 21 de maio, Turin, Itália, paper id: PA270, Compact Disk dos Anais, 2005.

2. ADMADE M. T., ROMERO E. The Invisibility of Local Innovative Networks: A methodological problem non solved. In: 50 TRIPLE HELIX CONFERENCE, 18 a 21 de maio, Turin, Itália, paper id: PA337, Compact Disk dos Anais, 2005.

3. ALLEN, D. Da descoberta à comercialização Revista Pesquisa Fapesp, Ed. 50, São Paulo, jan. 2001 Disponível em < http://revistapesquisa.fapesp.br:2222/transform.php?xml=1/0/20011001/20000150/ pt/SEC15 2.xml\&xsl=xsl/pt/article.xsl\&transf=normal\&id=SEC15 2\&lang=pt\&issue $=20000150>$ Acesso em 31/10/2005.

4. ALMEIDA, M. L. P. A Apropriação do conhecimento Público pelo Setor Privado na Relação Universidade-Empresa: um estudo a partir do caso da UNICAMP, 2001. Tese (Doutorado) - Depto. De História e Filosofia da Educação da Faculdade de Educação da Universidade de Campinas, Campinas.

5. ANDRADE, V. Planejamento Tecnológico na CVRD. V Conferência da ANPEI Cadeias Sinérgicas de Inovação - Florianópolis, Maio, 11 a 13, 2005.

Disponível no site da ANPEI, arquivo 2005-04-vania andrade cvrd-VConfANPEI. Acesso em set., 2005.

6. ANDRADE, F. L. Industrialização do Resultado de PD\&E: a materialização da inovação para o mercado - caso Tigre. V Conferência da ANPEI - Cadeias Sinérgicas de Inovação - Florianópolis, Maio, 11 a 13, 2005. Disponível no site da ANPEI, arquivo 2005-19-04-fernando_lete_tigre-VConfANPEI. Acesso em set., 2005.

7. ARAGONES, A. Industrialização do Resultado de P\&D: A materialização da inovação para o mercado. V Conferência da ANPEI - Cadeias Sinérgicas de Inovação - Florianópolis, Maio, 11 a 13, 2005. - Florianópolis, May, 10, 2005. Disponível no site da ANPEI, arquivo 2005-18-aragones bioinnovationVConfANPEl. Acesso em set., 2005. 
8. AURANEN O. Social Capital in Mode 1 and Mode 2 Knowledge Production: a finish case study. In: $5^{\circ}$ TRIPLE HELIX CONFERENCE, 18 a 21 de maio, Turin, Itália, paper id: PA065, Compact Disk dos Anais, 2005.

9. BALESTRIN, A., VARGAS M., FAYARD, P. Ampliação Interorganizacional do Conhecimento: o caso das redes de cooperação. Revista Eletrônica de Administração - REAd- Ed. 43 Vol. 11 No. 1, jan-fev Porto Alegre/RS, 2005.

10. BALESTRIN, A., VARGAS M., FAYARD, P. O efeito rede em pólos de inovação: um estudo comparativo. Revista de Administração - USP - v.40, n. 2, p. 159171, abr/mai/jun, São Paulo, 2005.

11. BANCO MUNDIAL (World Bank-WB). Pobreza Mundial Reduzida pela Metade desde 1981, mas avanços são desiguais porque o crescimento econômico não alcançou muitos países. Comunicado à imprensa No.2004/309/S.

12. BARBOSA, L. C. Demanda das MPEs para os Institutos Tecnológicos. In: CONGRESSO DA ABIPTI 2004, 28-30, abril, 2004, Belo Horizonte - MG. Arquivo 2004-luis_carlos_barboza-sebrae-congresso abipti, Compact Disk dos Anais, 2004.

13. BARBOSA, L. C. A Tecnologia no Incremento da Competitividade e Sustentabilidade das Micro e Pequenas Empresas (SEBRAE-NA). V Conferência da ANPEI - Cadeias Sinérgicas de Inovação - Florianópolis, Maio, 11 a 13, 2005. Disponível no site da ANPEI, arquivo 2005-08-

luiz_carlos_barbosa_sebrae-VConfANPEI. Acesso em set., 2005.

14. BARRA, E., SILVA R. Proposta: demonstrar um caso real de desenvolvimento eficaz de inovação, pela sinergia e comprometimento da cadeia produtiva no lançamento de um novo conceito de produto. V Conferência da ANPEI Cadeias Sinérgicas de Inovação - Florianópolis, Maio, 11 a 13, 2005. Florianópolis, May, 10, 2005. Disponível no site da ANPEI, arquivo 2005-15mario_barra_multibras-VConfANPEI. Acesso em set., 2005.

15. BASAK, C. Metutech: An Analysis of the Middle East Technical University Science Park from the Perspectives of the Triple Helix Model and the National Systems of Innovation Framework. In: 50 TRIPLE HELIX CONFERENCE, 18 a 21 de maio, Turin, Itália, paper id: PA183, Compact Disk dos Anais, 2005.

16. BELKHODJA O., LANDRY, R. The Triple Helix collaboration: Why do researchers collaborate with industry and the government? What are the factors influencing the perceived barriers? In: $5^{\circ}$ TRIPLE HELIX CONFERENCE, 18 a 21 de maio, Turin, Itália, paper id: PA296, Compact Disk dos Anais, 2005.

17. BETANCOURT, R. Parques C\&T Privados e visão imobiliária Publicação. In: I ENCONTRO PAULISTA DE PARQUES CIENTÍFICOS E TECNOLÓGICOS EM ÁREAS URBANAS: CONSTRUINDO ESPAÇOS PARA O DESENVOLVIMENTO DE REGIÕES, 16 e 17 de agosto, 2004, São Paulo, SP. Disponível em < http://sistecparq.cietec.org.br/SistecParqFiles/BETANCOURT.PPS $>$ Acesso em 03/11/2005.

18. BILICH M. G., BILICH F. Analysis of World Scientific and Technological Productivity. In: $5^{\circ}$ TRIPLE HELIX CONFERENCE, 18 a 21 de maio, Turin, Itália, paper id: PA161, Compact Disk dos Anais, 2005. 
19. BULLA, R. PD\&E na Oxiteno. V Conferência da ANPEI - Cadeias Sinérgicas de Inovação - Florianópolis, Maio, 11 a 13, 2005. Disponível no site da ANPEI, arquivo 2005-13-romeo_bulla_oxiteno-VConfANPEI. Acesso em set., 2005.

20. CABRAL, J. E. O. Technological Regimes and Patterns of Innovation in the Brazilian Food Industry. Revista Eletrônica de Administração - REAd - Special Issues 42 Vol. 10 No. 6, December, 2004.

21. CAMERINI, C. Petrobras - visão 2030. V Conferência da ANPEI - Cadeias Sinérgicas de Inovação - Florianópolis, Maio, 11 a 13, 2005. " Florianópolis, May, 10, 2005. Disponível no site da ANPEI, arquivo 2005-26Camerini-Petrobras-VConfANPEI. Acesso em 10/2005.

22. CAMPBELL E. G., KOSKI G., ZINNER D. E., BLUMENTHAL D. Managing the Triple Helix in the Life Sciences. Issues in Science and Technology, winter, 2005 Disponível em <http://www.issues.org/issues/21.2/campbell.html > Acesso em 05/05/2005.

23. CAPELLO R., MORRISON A. An Evaluation of the Effectiveness of Science Parks in Local Knowledge Creation: a Territorial Perspect. In: 5० TRIPLE HELIX CONFERENCE, 18 a 21 de maio, Turin, Itália, paper id: PA145, Compact Disk dos Anais, 2005.

24. CARVALHAL, E. Gargalos da competitividade. Conjuntura Econômica, FGV, pg. 58, julho, 2004.

25. CASAS, R. Knowledge based social capital for local development. In: $5^{\circ}$ TRIPLE HELIX CONFERENCE, 18 a 21 de maio, Turin, Itália, paper id: PA017, Compact Disk dos Anais, 2005.

26. CERVANTES, M. Background Report: an analysis of S\&T labour markets in OECD countries. Science and Technology Policy Division, OECD, 1999. Id. DSTI/STP/TIP(99)2/FINAL. Disponível em < http://www.oecd.org/document/16/0,2340,en $264934293 \quad 1894608111111,00$. $\underline{\mathrm{html}}>$ acesso em 12/11/2005.

27. CHAMBRE DE COMMERCE ET D'INDUSTRIE DE PARIS. Raport D'Activités 2004. Paris Développement - L'agence de développement économique de Paris, 2005. Disponível em http://www.parisdeveloppement.com acesso em outubro/2005.

28. CHIARELLO, M. D. As Plataformas Tecnológicas e a Promoção de Parcerias para a Inovação. Parcerias Estratégicas, v. 8, n. 17, p. 93-102, 2000.

29. COUNCIL OF COMPETITIVINESS. National Innovation Initiative Report thriving in a world of challenge and change. ISBN 1-889866-20-2. USA, 2004. Disponível em http://www.compete.org Acesso em março/2005.

30. CRAWLEY, E., GREENWALD S. Creating a ten-year Science \& Innovation Framework for the UK: A perspective based on us experience. In: $5^{\circ}$ TRIPLE HELIX CONFERENCE, 18 a 21 de maio, Turin, Itália, paper id: PA078, Compact Disk dos Anais, 2005. 
31. CUNHA, S. K., CUNHA J. C. Clusters: New Routes to Regional Development. In: $5^{\circ}$ TRIPLE HELIX CONFERENCE, 18 a 21 de maio, Turin, Itália, paper id: PA255, Compact Disk dos Anais, 2005.

32. D'ESTE P., PATEL P. University - Industry linkages in the UK: what are the factors determining the variety of interactions with industry? In: $5^{\circ}$ TRIPLE HELIX CONFERENCE, 18 a 21 de maio, Turin, Itália, paper id: PA104, Compact Disk dos Anais, 2005.

33. DORNELAS, J. C. A., Empreendedorismo Corporativo - Como ser empreendedor, inovar e se diferenciar em organizações estabelecidas. 2. ed. Rio de Janeiro, Ed. Campus, 2003.

34. DORNELAS, J. C. A., Empreendedorismo - Transformando Idéias em Negócios. 11. ed. Rio de Janeiro, Ed. Campus, 2001.

35. DORNELAS, J. C. A., Planejando Incubadoras de Empresas - como desenvolver um plano de negócios. 11. ed. Rio de Janeiro, Ed. Campus, 2002.

36. DUDZIAK E. A., PLONSKY G. A. Core competencies assessment in public research university groups: a case study of three laboratories at University of São Paulo Engineering School. . In: 50 TRIPLE HELIX CONFERENCE, 18 a 21 de maio, Turin, Itália, paper id: PA294, Compact Disk dos Anais, 2005.

37. EDUARDO, J. Agência Brasileira de Desenvolvimento Industrial (ABDI). A política industrial e tecnológica do governo e o desenvolvimento econômico e social sustentável. V Conferência da ANPEI - Cadeias Sinérgicas de Inovação Florianópolis, maio, 11 a 13, 2005. Disponível no site da ANPEI, arquivo 2005-19jose_eduardo_abdi-VConfANPEI. Acesso em 10/2005.

38. ELIAS, A. Programa de Inovação Braskem - PIB. V Conferência da ANPEI Cadeias Sinérgicas de Inovação - Florianópolis, Maio, 10 a 13, 2005. Disponível no site da ANPEI, arquivo 2005-10-alexandre_elias_braskemVConfANPEI. Acesso em 10/2005.

39. ELIAS A. A., CAVANA R. Y., JACKSON L. S. Stakeholder analysis for R\&D project management. R\&D Management, 32, 4, 2002.

40. FALCO G. D., BRUSSONI M., CRUGNOLA P., VECCHI V. Pit Agora: A Systemic Skills Empowerment Action for Fostering Local Development. In: $5^{\circ}$ TRIPLE HELIX CONFERENCE, 18 a 21 de maio, Turin, Itália, paper id: PA132, Compact Disk dos Anais, 2005.

41. FIATES, J. E. Apresentação sobre a Anprotec. In: I Encontro Paulista de Parques Científicos e Tecnológicos em Áreas Urbanas: construindo espaços para o desenvolvimento de regiões, 16 e 17 de agosto, 2004, São Paulo, SP. Disponível em < http://sistecparq.cietec.org.br/SistecParqFiles/FIATES.PPS > Acesso em 03/11/2005.

42. FIGUEIREDO, P. N., Gestão da Estratégia Industrial. Conjuntura Econômica, FGV, pg. 24, novembro, 2004.

43. FINANCIADORA DE ESTUDOS E PROJETOS (FINEP). C\&T: Fator decisivo para riqueza atual - Programa de Reestruturação dos Institutos Tecnológicos. In: CONGRESSO DA ABIPTI 2004, 28-30, abril, 2004, Belo Horizonte - MG. Arquivo 
2004-prog_de_reest_instit_tecnol-congresso abipti, Compact Disk dos Anais, 2004.

44. FINANCIADORA DE ESTUDOS E PROJETOS (FINEP)., Manual de Oslo Proposta de Diretrizes para Coleta e Interpretação de Dados sobre Inovação, Brasília, 2004 Disponível em < http://www.finep.gov.br/imprensa/sala imprensa/manual de oslo.pdf $>$ Acesso em 21/06/2004. (Nota: Manual base para Mensuração das Atividades Científicas e Tecnológicas - Traduzido em 2004 sob responsabilidade da FINEP - das edições em inglês e francês publicadas sob os títulos: The Measurement of Scientific and Technological Activities - Proposed Guidelines for Collecting and Interpreting Technological Innovation Data: Oslo Manual / La mesure des donnés sur I'innovation technologique: Manuel d'Oslo. Copyright OECD, 1997)

45. FRECHET, M. Prévenir les conflits dans les partenariats d'innovation. ISBN 2 71176969 0, Collection éditée avec la Fondation nationale pour l'einseingment de la gestio des empreprises (FNGE), Librairie Vuibert, Paris, 2004.

46. GANEM, C. FINEP - Agência Brasileira de Inovação. V Conferência da ANPEI Cadeias Sinérgicas de Inovação - Florianópolis, Maio, 10 a 13, 2005. Disponível no site da ANPEI, arquivo 2005-22-carlos_ganem_finep-VConfANPEI. Acesso em set., 2005.

47. GARGIONE, L. Apresentação do Parque Tecnológico da Universidade do Vale da Paraíba (UNIVAP). In: I Encontro Paulista de Parques Científicos e Tecnológicos em Áreas Urbanas: construindo espaços para o desenvolvimento de regiões, 16 e 17 de agosto, 2004, São Paulo, SP. Disponível em: < http://sistecparq.cietec.org.br/SistecParqFiles/GARGIONE.PPS >Acesso em 03/11/2005.

48. GATTI, G. Cluster Policies for Innovation: Science and Technology Parks as Regional Innovation Systems. In: I Encontro Paulista de Parques Científicos e Tecnológicos em Áreas Urbanas: construindo espaços para o desenvolvimento de regiões, 16 e 17 de agosto, 2004, São Paulo, SP. Disponível em: < http://sistecparq.cietec.org.br/SistecParqFiles/GABRIELLE\%20GATTI.PPS > Acesso em 03/11/2005.

49. Gerolamo, M., Carpinetti, L., Fleschutz, T; Seliger G.; Clusters e redes de cooperação de pequenas e médias empresas: observatório europeu, caso alemão e contribuições ao caso brasileiro, Gest. Prod. vol.15 no.2 São Carlos Maio/Agosto, 2008.

50. GODIN, B. The Linear Model of Innovation; The Construction of an Analytical Framework. In: $5^{\circ}$ TRIPLE HELIX CONFERENCE, 18 a 21 de maio, Turin, Itália, paper id: PA039, Compact Disk dos Anais, 2005.

51. GOKTEPE, D. Towards an Assisted Linear Model of Innovation: An Exploratory Study of Technology Transfer Offices In the USA. In: $5^{\circ}$ TRIPLE HELIX CONFERENCE, 18 a 21 de maio, Turin, Itália, paper id: PA183, Compact Disk dos Anais, 2005.

52. GOMES, E.J. A relação Universidade-Empresa no Brasil: testando hipóteses a partir do caso da UNICAMP. 2001. Tese (Doutorado) - Instituto de Geociências da Universidade de Campinas, Campinas, São Paulo. 
53. GOSSELIN, P. M. Between Conflicts and Interests: A Socio-Historical Perspective. In: $5^{\circ}$ Triple Helix Conference, 18 a 21 de maio, Turin, Itália, paper id: PA203, Compact Disk dos Anais, 2005.

54. GRANDINETTI R., CAMUFFO A. A theoretical model of knowledge transfer and combination within industrial districts. In: $5^{\circ}$ TRIPLE HELIX CONFERENCE, 18 a 21 de maio, Turin, Itália, paper id: PA286, Compact Disk dos Anais, 2005.

55. GUEDES, M. Os Parques Tecnológicos na América Latina - perspectivas. In: I ENCONTRO PAULISTA DE PARQUES CIENTÍFICOS E TECNOLÓGICOS EM ÁREAS URBANAS: CONSTRUINDO ESPAÇOS PARA O DESENVOLVIMENTO DE REGIÕES, 16 e 17 de agosto, 2004, São Paulo, SP. Disponível em < http://sistecparq.cietec.org.br/SistecParqFiles/MAURICIO\%20GUEDES.PPS > Acesso em 03/11/2005.

56. GUIMARÃES, F. C. M. S.; A Política de Incentivo e acesso à Inovação Inovação, Desenvolvimento Econômico e Política Tecnológica. Parcerias Estratégicas, v. 9, p. 121-128, 2000.

57. GUIMARÃES, R. R. R. Transferência de Tecnologia de Instituições de P\&D para o Setor Produtivo: O Papel das Estruturas de Interface. 2002. Tese (Doutorado) - Escola Politécnica da Universidade de São Paulo, São Paulo.

58. HANSSON, F. Science parks as knowledge organizations - The 'ba' in action? (WP 15/2004) Publicação: MPP Working Paper No. 15/2004 - December 2004 ISBN: 87-91181-86-0, ISSN: 1396-2817, Copenhagen N, Denmark, 2004. www.mpp.cbs.dk

59. HAUSER, G., ZEN, A. (organizadoras) Parques Tecnológicos: Um Debate Aberto - Porto Alegre Tecnópole. Editora Nova Prova. Porto Alegre, RS, 2003

60. HAUSER, G. PAT-Porto Alegre Tecnópole-Potencializando sinergias para o desenvolvimento da Região. In: I ENCONTRO PAULISTA DE PARQUES CIENTÍFICOS E TECNOLÓGICOS EM ÁREAS URBANAS: CONSTRUINDO ESPAÇOS PARA O DESENVOLVIMENTO DE REGIÕES, 16 e 17 de agosto, 2004, São Paulo, SP. Disponível em <" http://sistecparq.cietec.org.br/SistecParqFiles/GUISSIA.PPS > Acesso em 03/11/2005.

61. HENRIQUEZ C., VERHEUL I., KNAAP I., BISCHOFF C. Determinants of entrepreneurship in france: policies, institutions and culture. ISSN 01-4 - The Institute for Development Strategies - Indiana University, USA, ago. 2001.

62. HONAKA I., TAKEUCHI H. , Criação de Conhecimento na Empresa - Como as Empresas Japonesas Geram a Dinâmica da Inovação. Tradução de Ana BeaJtriz Rodriguez e Priscilla Martins Celeste. 12. ed. Rio de Janeiro, Ed. CamKpus, 1997. Título original: The Knowledge-Creating Company.

63. IKEDA, A. A., OLIVEIRA T. M. V. O Conceito de Valor para o Cliente: definições e implicações gerenciais em marketing. Revista Eletrônica de Administração REAd - Ed. 44 Vol. 11 No. 2, mar-abr, Porto Alegre-RS, 2005.

64. INSTITUTO BRASILEIRO DE GEOGRAFIA E ESTATÍSTICA (IBGE), FINEP, MCT, MPO. Pesquisa Industrial de Inovação Tecnológica (PINTEC)- 2003. IBGE, Rio de Janeiro, RJ, 2005. 
65. INSTITUTO DE ESTUDOS PARA O DESENVOLVIMENTO INDUSTRIAL (IEDI), Indicadores de Ciência, Tecnologia e Inovação nos Países da OCDE: Tendências dos Investimentos em P\&D e Reflexos nos Padrões de Comércio. São Paulo, 2003. Disponível em http://www.iedi.org.br Acesso em set., 2005.

66. IZARRA, M. Desafios para concorrer num mercado mundial altamente competitivo num habitat hostil para a inovação (Brapenta). V Conferência da ANPEI Cadeias Sinérgicas de Inovação - Florianópolis, Maio, 10 a 13, 2005. Disponível no site da ANPEI, arquivo 2005-11-martin_izarra1-VConfANPEI. Acesso em set., 2005.

67. JINDRA, B. The Role of Subsidiary Strategy as Determinant for Direct Technology Transfer - Empirical Evidence From Five New EU-Member Countries. In: $5^{\circ}$ TRIPLE HELIX CONFERENCE, 18 a 21 de maio, Turin, Itália, paper id: PA353, Compact Disk dos Anais, 2005.

68. JONASH, R.S.; SOMMERLATTE, T. O Valor da Inovação - Como as empresas mais avançadas atingem alto desempenho e lucratividade. Tradução de Flávia Beatriz Rossler. Rio de Janeiro. Ed. Campus, 2001. Título original: The Innovation Premium.

69. JONASH, R.S. - Ronald Jonash proporá um novo conceito de inovação no $23^{\circ}$ Simpósio, INOVA Gestão e Tecnologia - Boletim do Núcleo de Política e Gestão Tecnológica da USP, ano XI - nº 39 julho/agosto/setembro de 2004. http://www.fia.com.br/pgtusp/ Acesso em 15/07/2004.

70. KELLY, M. J. Knowledge Exchange at more Effective Academic-Industrial Interfaces. In: $5^{\circ}$ TRIPLE HELIX CONFERENCE, 18 a 21 de maio, Turin, Itália, paper id: PA074, Compact Disk dos Anais, 2005.

71. KIM W. C., MAUBORGNE, R. Inovação de valor: a lógica estratégica do alto crescimento. Harvard Business Review (HBR) p. 98 a 106, Boston-Estados Unidos, 1997.

72. KITAGAWA, F. Regionalising the Governance of Science and Innovation: Triple Helix and New Innovation Systems in East Asia. In: $5^{\circ}$ TRIPLE HELIX CONFERENCE, 18 a 21 de maio, Turin, Itália, paper id: PA138, Compact Disk dos Anais, 2005.

73. KRUGLIANSKAS, I. Pesquisa e Desenvolvimento: A função Central do Processo de Inovação. V Conferência da ANPEI - Cadeias Sinérgicas de Inovação Florianópolis, Maio, 10 a 13, 2005. Disponível no site da ANPEI, arquivo 2005-12isak_kruglianskas_fia-VConfANPEI. Acesso em set., 2005.

74. KUNZ, I. Relação Universidade-Empresa: Uma Analise a partir da Interação Unicamp-Empresas no Período 1996-2001, 2003. Dissertação (Mestrado) Universidade de Campinas, São Paulo.

75. LAHORGUE M. A., SANTOS M. E. R., MELLO J. M. C. Economic Development Mission in Brazilian Universities. . In: $5^{\circ}$ TRIPLE HELIX CONFERENCE, 18 a 21 de maio, Turin, Itália, paper id: PA136, Compact Disk dos Anais, 2005.

76. LOBO A. J. A. Conceptualizing The New Emerging Enterprise imbricates to the Local Development Paradigm: The Mesoenterprise. In: 5 TRIPLE HELIX 
CONFERENCE, 18 a 21 de maio, Turin, Itália, paper id: PA117, Compact Disk dos Anais, 2005.

77. LOOY B. V., DEBACKERE K., ANDRIES, P. Policies to stimulate regional innovation capabilities via university-industry collaboration: an analysis and an assessment. R\&D Management, 33, 2, 2003.

78. LOTUFO, R. Apresentação da INCAMP-INOVA (UNICAMP). In: I Encontro Paulista de Parques Científicos e Tecnológicos em Áreas Urbanas: construindo espaços para o desenvolvimento de regiões, 16 e 17 de agosto, 2004, São Paulo, SP. Disponível em http://sistecparq.cietec.org.br/SistecParqFiles/FIATES.PPS Acesso em 03/11/2005.

79. LUNA, M., VELASCO, J. L. Bridging the Gap between Business Firms and Academic Institutions: Translation and Trust. In: $5^{\circ}$ TRIPLE HELIX CONFERENCE, 18 a 21 de maio, Turin, Itália, paper id: PA041, Compact Disk dos Anais, 2005.

80. MALMGREN C.Project SMER - A Development Model for Successful Participation in EU's Framework Programme for Research and Development. In: 5० TRIPLE HELIX CONFERENCE, 18 a 21 de maio, Turin, Itália, paper id: PA211, Compact Disk dos Anais, 2005.

81. MARCHANDEE, N. Apresentação do Sophia Antopolis (Nice - França). In: I Encontro Paulista de Parques Científicos e Tecnológicos em Áreas Urbanas: construindo espaços para o desenvolvimento de regiões, 16 e 17 de agosto, 2004, São Paulo, SP. Disponível em < http://sistecparq.cietec.org.br/SistecParqFiles/NADINE.PPS Acesso em $\underline{03 / 11 / 2005 .}$

82. MARIN, M. Managing University-Industry Relations: a study of institutional practices from 12 different coutries. IIEP International Institute for Education Planning/UNESCO Working document in the series: Improving the managerial effectiveness of higher education institutions. Paris, 2000. A paper copy may be obtained on request from: information@iiep.unesco.org Web site: http://www.unesco.org/iiep.

83. MARIN, M. P., ARACIL A. G. Excellence in research groups in a region with lowlevel absorptive capacity: A typology of their research performance. . In: $5^{\circ}$ TRIPLE HELIX CONFERENCE, 18 a 21 de maio, Turin, Itália, paper id: PA001, Compact Disk dos Anais, 2005.

84. MASSAMBANI, O. Agência USP de Inovação. In: I Encontro Paulista de Parques Científicos e Tecnológicos em Áreas Urbanas: construindo espaços para o desenvolvimento de regiões, 16 e 17 de agosto, 2004, São Paulo, SP. Disponível em < http://sistecparq.cietec.org.br/SistecParqFiles/MASSAMBANI.PPS > Acesso em 03/11/2005.

85. MATOS, E A.; KOVALESKY, J.L. Transferência de tecnologia e gestão de negócios. In: XXI SIMPOSIO DE GESTAO DA INOVAÇÃO TECNOLÓGICA, São Paulo 7-10 novembro, 1998, São Paulo 2000. Anais...São Paulo, 2000.

86. MAYKOT, R. Planejamento Tecnológico - O Fator Essencial para a Estratégia da Inovação na Empresa (Embraco). V Conferência da ANPEI - Cadeias Sinérgicas de Inovação - Florianópolis, Maio, 10 a 13, 2005. Disponível no site 
da ANPEI, arquivo 2005-03-reinaldo_maykot_embraco-VConfANPEI. Acesso em set., 2005.

87. MELARA C., ARCELUS M. The Role of Industry for Promoting Research-Based Spin-outs from University and other Research Institutions. In: $5^{\circ}$ TRIPLE HELIX CONFERENCE ,18 a 21 de maio, Turin, Itália, paper id: PA001, Compact Disk dos Anais, 2005.

88. MENDES, A. P. S., ROCHA K. C. Contribuições da teoria de agência ao estudo dos processos de cooperação tecnológica universidade-empresa. Revista de Administração SP - v.40, n. 2, p. 172-183, São Paulo, abr/mai/jun.2005.

89. MENEZES, H. R. G. APLs, Tecnologia e Inclusão Social. In: CONGRESSO DA ABIPTI 2004, 28-30, abril, 2004, Belo Horizonte - MG. Arquivo 2004-

heloisa_menezes_apls-congresso abipti, Compact Disk dos Anais, 2004.

90. METCALFE A. S. Towards a Theory of Intermediating Organizations: Agency between the Academy, Industry, and Government. In: $5^{\circ}$ TRIPLE HELIX CONFERENCE, 18 a 21 de maio, Turin, Itália, paper id: PA049, Compact Disk dos Anais, 2005.

91. MOUTINHO, P. S. F., FONTES M., GODINHO M. M. The influence of scientists' attitudes and perceptions on university patenting. In: $5^{\circ}$ TRIPLE HELIX CONFERENCE, 18 a 21 de maio, Turin, Itália, paper id: PA314, Compact Disk dos Anais, 2005.

92. MOREL, L., BOLY, V. Mastering Innovativeness Potential: The Results of An Expert Consultation. Revista Eletrônica de Administração - REAd-Special Issue 42 Vol. 10 No. 6, December, Porto Alegre-Rs, 2004.

93. MUSA, F. Planejamento Tecnológico (Monitor Group). V Conferência da ANPEI Cadeias Sinérgicas de Inovação - Florianópolis, Maio, 10 a 13, 2005.

Disponível no site da ANPEI, arquivo 2005-02-fernando_musa_monitorgroup1. Acesso em set., 2005.

94. NAKANO, Y. A dinâmica da economia mundial e a estratégia de desenvolvimento. Conjuntura Econômica, FGV, pg. 13, novembro, 2004.

95. NOGUEIRA, S. L. MAYKOT, Programa de Especialização em Engenharia - PEE (Embraer). V Conferência da ANPEI - Cadeias Sinérgicas de Inovação Florianópolis, Maio, 10 a 13, 2005. Disponível no site da ANPEI, arquivo 2005-06sidney_lage_embraer-VConfANPEI. Acesso em set., 2005.

96. OLIVEIRA, M. Benefícios de uma parceria - Projetos entre o mundo acadêmico e o empresarial tem bons resultados. Revista Pesquisa Fapesp, Ed. 58, São Paulo, out. 2000. Disponível em < http://revistapesquisa.fapesp.br:2222/transform.php?xml=8/2/20010828/20001058/ pt/SEC7 2.xml\&xsl=xsl/pt/article.xsl\&transf=normal\&id=SEC7 2\&lang=pt\&issue=2 $\underline{0001058}>$ Acesso em 01/11/2005.

97. ORGANIZACIÓN PARA LA COOPERACIÓN Y DESARROLLO ECONÔMICOS (OCDE). Manual de Frascati - Propuesta de Norma Práctica para Encuestas de Investigación y Desarrollo Experimental. FECYT - Fundación Española Ciência y Tecnologia., Publicado originalmente por la OCDE em inglês y francês. 
Para la edición Espanõla FECYT, publicado por acuerdo com la OCDE, Paris. ISBN 84-688-2888-2, Espanha, 2003. Disponível em www.SourceOECD.org

98. PACHECO, C. A. Sistema de Parques SCTDET - Seminário SP. In: I ENCONTRO PAULISTA DE PARQUES CIENTÍFICOS E TECNOLÓGICOS EM ÁREAS URBANAS: CONSTRUINDO ESPAÇOS PARA O DESENVOLVIMENTO DE REGIÕES. 16 e 17 de agosto, 2004, São Paulo, SP. Disponível em: < http://sistecparq.cietec.org.br/SistecParqFiles/RUI\%20ALBUQUERQUE.PPS > Acesso em 03/11/2005.

99. PALMA, M. A. M. A capacidade de inovação como formadora de valor: análise dos vetores de valor em empresas brasileiras de biotecnologia. 2004. Tese (Doutorado) - Faculdade de Economia e Administração da Universidade de São Paulo, São Paulo.

100. PATEL, H., FERNANDES, V. "Staying Competitive Trough Innovation: To Lead or to Follow" V Conferência da ANPEI - Cadeias Sinérgicas de Inovação" Florianópolis, Maio, 10 a 13, 2005. Disponível no site da ANPEI, arquivo 2005-01hitendra_patel_conferencia_magna1. Acesso em set., 2005.

101. PEREZ, J. F. Apresentação sobre a FAPESP e seus programas. In: I ENCONTRO PAULISTA DE PARQUES CIENTÍFICOS E TECNOLÓGICOS EM ÁREAS URBANAS: CONSTRUINDO ESPAÇOS PARA O DESENVOLVIMENTO DE REGIÕES. 16 e 17 de agosto, 2004, São Paulo, SP. Disponível em: http://sistecparq.cietec.org.br/SistecParqFiles/PEREZ.PPS Acesso em 03/11/2005.

102. PERUSSI, S. Uma avaliação da contribuição das cooperações universidade-empresa e inter-industriais do pólo tecnológico de São Carlos. 2001. Tese (Mestrado) - Escola de Engenharia de São Carlos da Universidade de São Paulo, São Carlos.

103. PIEKARSKI, A. E. T., TORKOMIAN L. V. How R\&D Public Financing incites the Academy-Industry Cooperation: an assessment of the effects of a public policy in Brazil. In: 5० TRIPLE HELIX CONFERENCE, 18 a 21 de maio, 2005, Turin, Itália, paper id: PA298, Compact Disk dos Anais, 2005.

104. PIER, C. Apresentação sobre o PORTO DIGITAL em Recife. . In: I ENCONTRO PAULISTA DE PARQUES CIENTÍFICOS E TECNOLÓGICOS EM ÁREAS URBANAS: CONSTRUINDO ESPAÇOS PARA O DESENVOLVIMENTO DE REGIÕES. 16 e 17 de agosto, 2004, São Paulo, SP. Disponível em: http://sistecparq.cietec.org.br/SistecParqFiles/PIER\%20CARLO.PPS Acesso em 03/11/2005.

105. PINELLI D. The Scientific and Technological Parks in Piemonte. In: $5^{\circ}$ TRIPLE HELIX CONFERENCE, 18 a 21 de maio, 2005, Turin, Itália, paper id: PA126, Compact Disk dos Anais, 2005.

106. PINHEIRO, I. A., PAULA, E. A. W. O Pólo de Informática de São Leopoldo, Rio Grande do Sul, Brasil - três anos após a pedra fundamental. Revista Eletrônica de Administração - REAd - Edição 22 Vol. 7 No. 4, jul-ago, Porto Alegre-RS, 2001.

107. PROGRAMME DEVELOPMENT AND TECHNICAL COOPERATION DIVISION (PTC), INDUSTRIAL PROMOTION TECHNOLOGY BRANCH (IPT). IPT'S integrated institutional capacity building services and programmes for Technology 
Centres and Parks. Unites Nations Industrial Development Organization (UNIDO), VIENNA, 2004. Disponível em http://www.unido.org/filestorage/download/?file id=30233 . Acesso em 07/11/2005.

108. PORTO, G. S. A. Decisão Empresarial de Desenvolvimento Tecnológico por meio da Cooperação Empresa-Universidade, 2000. Tese (Doutorado) Faculdade de Economia e Administração da Universidade de São Paulo, São Paulo.

109. ROCHA, E. M. P. ; FERREIRA, M. A. T. Análise dos indicadores de inovação tecnológica no Brasil: comparação entre um grupo de empresas privatizadas e o grupo geral de empresas, Ciência da informação. v. 30, n. 2, p. 64-69, IBICT, Brasília, 2001.

110. SÁEZ, C. B., MARCO, T. G., ARRIBAS, E. H. Collaboration in R\&D with universities and research centres: an empírical study of Spanish firms. $R \& D$ Management v. 32, p.4 - Ed. Blackwell Publishers Ltda., Estados Unidos da América, 2002.

111. SÁENS, T. W., CAPOTE, E. G. Ciência, Inovação e Gestão Tecnológica, Brasília, CNI/IEL/SENAI, ABIPTI, 2002.

112. SAXENIAN, A. Regional Advantage-Culture and Competition in Silicon Valley and route 128. Harvard University Press, fourth printing, ISBN 0-67475339-9 (alk. Paper) ISBN 0-674-75340-2 (pbk) Cambridge, Massachussets, and London, England, 1996

113. SCHNEIDER, C. A. Processo de Inovação Tecnológica - Questão: viabilidade econômica - a gestão de risco no processo de inovação. V Conferência da ANPEI - Cadeias Sinérgicas de Inovação - Florianópolis, Maio, 10 a 13, 2005. Disponível no site da ANPEI, arquivo 2005-09-schneider_certi-VConfANPEI. Acesso em set., 2005.

114. SCHOLZE S.; CHAMAS, C. Instituições públicas de pesquisa e o setor empresarial: o papel da inovação e da propriedade intelectual. Parcerias Estratégicas v. 8, n. 17, p. 85-92, 2000.

115. SEGATTO, A.P. M. Teoria de Agência Aplicada à Análise de Relações entre os participantes dos Processos de Cooperação Tecnológica Universidade Empresa. 2001. Tese (Doutorado) - Faculdade de Economia e Administração da Universidade de São Paulo, São Paulo.

116. SEGATTO, A.P. M.; SBRAGIA, R. O Processo de Cooperação UniversidadeEmpresa em Universidades Brasileiras. Revista de Administração. v. 37, n. 4, p. 58-71, São Paulo, 2002.

117. SILVA, E. A. El uso de la inteligência empresarial y la prospectiva tecnológica para la toma de decisiones em instituciones de ciência y tecnologia. In: CONGRESSO DA ABIPTI 2004, 28-30, abril, 2004, Belo Horizonte - MG. Arquivo 2004-eduardo_orozco-congresso abipti, Compact Disk dos Anais, 2004.

118. SOBOLL, R. Parceria UFPE-CIn / Motorola na Residência de Software. V Conferência da ANPEI - Cadeias Sinérgicas de Inovação - Florianópolis, 
Maio, 10 a 13, 2005. Disponível no site da ANPEI, arquivo 2005-07roberto_soboll_motorola-VConfANPEI. Acesso em set., 2005.

119. SOLLEIRO, J. L., CASTAÑON, R. Intellectual Capital Management in Mexican R\&D Centers. Revista Eletrônica de Administração - REAd - Special Issue 42 , Vol. 10 No. 6, December, Porto Alegre - RS, 2004.

120. TEIXEIRA F., FORTUNA R. An analysis of the potential and risks associated with regional industry cluster based policies: a case study from a less developed economy . In: 50 TRIPLE HELIX CONFERENCE, 18 a 21 de maio, 2005, Turin, Itália, paper id: A096, Compact Disk dos Anais, 2005.

121. TOlEDO, G., QUELOPANA, E. M., POLLERO, A. C. Competitive Strategies for Internationalization of Companies. Case Study: company leader in research, development and innovation. Revista Eletrônica de Administração - REAd Special Issue 42 Vol. 10 No. 6, December, Porto Alegre - RS, 2004.

122. TORNATZKY, L. G., WAUGAMAN, P. G., GRAY, D. O. Innovation U. - New University Roles in a Knowledge Economy. Southern, Growth Policies Board, ISBN 0-927364-25-5, USA, 2002.

123. UNIDADE ORGANIZACIONAL DE INOVAÇÃO E ACESSO A TECNOLOGIA SEBRAE/SP. Parques Tecnológicos-CIETEC_Sebrae. In: I ENCONTRO PAULISTA DE PARQUES CIENTÍFICOS E TËCNOLÓGICOS EM ÁREAS URBANAS: CONSTRUINDO ESPAÇOS PARA O DESENVOLVIMENTO DE REGIÕES. 16 e 17 de agosto, 2004, São Paulo, SP. Disponível em: http://sistecparq.cietec.org.br/SistecParqFiles/MARCELO\%20DINI.PPS Acesso em 03/11/2005.

124. VAN LOOY, Bart, DEBACKERE, Koenraad, ANDRIES, Petra. Policies to stimulate regional innovation capabilities via university-industry collaboration: an analysis and an assessment. R\&D Management 33, 2, 2003, p. 209-226 Blackwell Publishing Ltd., Oxford, UK, 2003.

125. VARGAS, M. I. R. The Capitalization of Knowledge as a result of the Triple Helix Model and Foreign Direct Investment: The case of electronics cluster in Mexican's Silicon Valley. In: 50 TRIPLE HELIX CONFERENCE, 18 a 21 de maio, 2005, Turin, Itália, paper id: PA348, Compact Disk dos Anais, 2005.

126. VASCONCELOS, M. C. R. L., MILAGRES R., NASCIMENTO E. Sharing Knowledge and innovation in the productive chain: an analysis in the brasilian industrial sector. In: 50 TRIPLE HELIX CONFERENCE, 18 a 21 de maio, 2005, Turin, Itália, paper id: PA160, Compact Disk dos Anais, 2005.

127. VESTERGAARD J. Mobilising Universities Barriers to University Entrepreneurship And How to Overcome Them. In: $5^{\circ}$ TRIPLE HELIX CONFERENCE, 18 a 21 de maio, 2005, Turin, Itália, paper id: PA182, Compact Disk dos Anais, 2005.

128. ZAWISLAK, P. A. From the Dream of Oportunities to the Nirvana of Trust: issues for a framework on cooperative agreement stability. Revista Eletrônica de Administração - REAd - Special Issue 42 Vol. 10 No. 6, December, Porto Alegre - RS, 2004. 